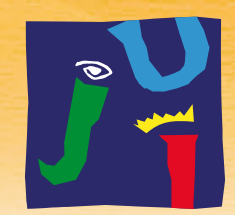

UNIVERSITAT

JAUME·

Facultad de Ciencias de la Salud

Departamento de Psicología Básica, Clínica y Psicobiología

\title{
Afectación emocional asociada al ingreso en una Unidad de Cuidados Intensivos
}

Tesis doctoral

Presentada por: Beatriz Gil Juliá Dirigida por: Dr. Rafael Ballester Arnal

Dr. Ricardo Abizanda Campos 

Afectación emocional asociada al ingreso en una Unidad de Cuidados Intensivos 

Esta tesis doctoral se ha desarrollado gracias a la Beca para la formación de Personal Investigador de carácter Predoctoral (BFPI/2008/129) de la Generalitat Valenciana y a los Proyectos de la Conselleria de Sanitat, Ref. AP-040/08 y Ministerio de Educación y Ciencia (PSI 2008- 01642/PSIC). 



\section{AGRADECIMIENTOS}

Transmitir en pocas líneas toda la gratitud y el aprecio que siento no es tarea sencilla sobre todo teniendo en cuenta el gran privilegio que supone sentirse acompañada tanto en lo personal como en lo profesional.

Mis primeras palabras de agradecimiento van dirigidas de forma especial a Rafael Ballester por la entrega, el cariño, la sabiduría y el esfuerzo dedicado a esta investigación. Por permitirnos seguir aprendiendo y crecer a su lado, a todos y cada uno de los que tenemos la suerte de trabajar con él.

Asimismo quisiera agradecer a Ricardo Abizanda, uno de los pilares de esta investigación junto con Rafael, la oportunidad que brindó a nuestro equipo de poder investigar en un entorno tan complejo como son las Unidades de Cuidados Intensivos. Sin él este trabajo no hubiera sido posible.

De igual forma quisiera agradecer a $\mathrm{M}^{\mathrm{a}}$ Carmen, Maite y $\mathrm{M}^{\mathrm{a}}$ Pilar la labor desempeñada en este proyecto, facilitando de manera importante nuestra andadura en el mismo. Y cómo no agradecer a Sandra por compartir conmigo su tiempo, esfuerzo y sueños en este trabajo.

También a Loli, Cristina, Estefanía, Pedro, Jesús y Ángel por los diferentes momentos compartidos, por siempre "estar ahí", convirtiéndose de una u otra forma en una parte importante a lo largo de este proceso.

Por supuesto quisiera agradecer a mi familia y sobre todo a mis padres su cariño, comprensión y grandes enseñanzas. Y de manera especial a Raül, por su apoyo incondicional mimando cada uno de mis sueños y proyectos, por comprender mejor que nadie mis ausencias y contribuir a que cada día fuera especial y si cabe mejor que el anterior.

No quisiera terminar estas líneas sin agradecer la colaboración de los profesionales sanitarios de UCI. Asimismo, mi más sincero agradecimiento a los enfermos y familiares que han participado en este estudio. A todos, les agradezco el habernos dado la oportunidad de acompañarles en momentos tan difíciles y especiales, permitiéndonos comprender un poco mejor la realidad que estaban viviendo. Con la esperanza de que este estudio pueda contribuir de alguna manera a aliviar el sufrimiento y mejorar la calidad de vida de estas personas. 



\section{ÍNDICE}

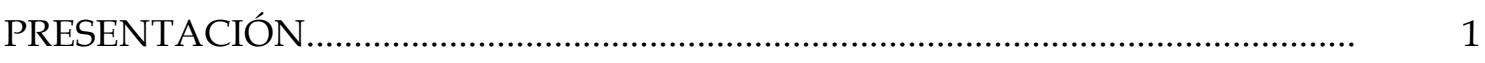

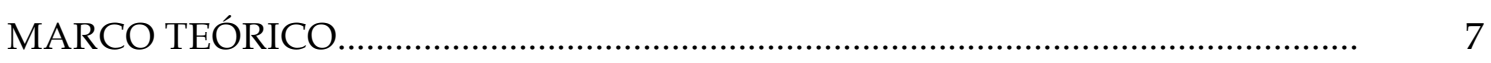

CAPÍTULO 1. LAS UNIDADES DE CUIDADOS INTENSIVOS 9

1.1. EVOLUCIÓN HISTÓRICA DE LOS CUIDADOS INTENSIVOS.................. 12

1.2. CARACTERÍSTICAS DE LAS UNIDADES DE CUIDADOS INTENSIVOS.

1.3. REQUERIMIENTOS MÍNIMOS EN LAS LAS UNIDADES DE CUIDADOS INTENSIVOS......

1.4. CUIDADOS CRÍTICOS Y CUIDADOS PALIATIVOS EN UCI..................... 24

1.5. RECOMENDACIONES AL FINAL DE LA VIDA EN LAS UNIDADES DE CUIDADOS INTENSIVOS................................................................. 29

CAPÍTULO 2. AFECTACIÓN EMOCIONAL DE LOS PACIENTES 37 INGRESADOS EN UNA UNIDAD DE CUIDADOS INTENSIVOS

2.1. LA ADAPTACIÓN AL ENTORO DE UNA UNIDAD DE CUIDADOS INTENSIVOS.

2.1.1. Estresores en una UCI.................................................................................. 40

2.1.2. Necesidades psicosociales de los pacientes en una UCI....................... 46

2.2. PRINCIPALES SÍNTOMAS PSICOLÓGICOS EN PACIENTES INGRESADOS EN UNA UCI

CAPÍTULO 3. AFECTACIÓN EMOCIONAL EN LOS FAMILIARES DE

PACIENTES INGRESADOS EN UNA UNIDAD DE CUIDADOS INTENSIVOS

3.1. EL INGRESO DE UN SER QUERIDO EN UNA UNIDAD DE CUIDADOS INTENSIVOS...

3.1.1. Principales estresores percibidos por los familiares.

3.1.2. Necesidades percibidas por la família durante el ingreso en una Unidad de Cuidados Intensivos

3.2. PRINCIPALES SÍNTOMAS PSICOLÓGICOS EXPERIMENTADOS POR LOS FAMILIARES DE PACIENTES CRÍTICOS.. 
CAPÍTULO 4. OBJETIVOS E HIPÓTESIS................................................................ 113

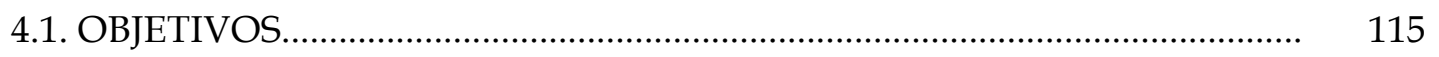

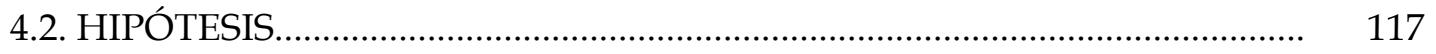

$\begin{array}{ll}\text { CAPÍTULO 5. MÉTODO } & 123\end{array}$

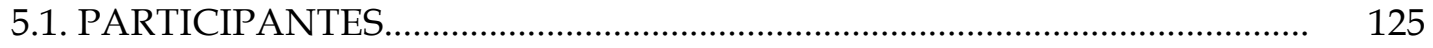

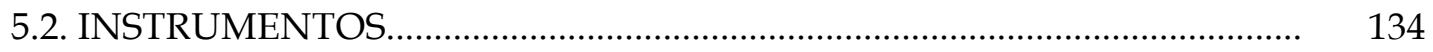

5.2.1. Hoja de registro de datos sociodemográficos............................................ 134

5.2.2. Instrumentos de evaluación de aspectos clínicos.................................... 134

5.2.2.1. Escala de Ansiedad y Depresión (HAD).......................................... 134

5.2.2.2. Cuestionario de ansiedad estado-rasgo (STAI).............................. 135

5.2.2.3. Inventario de Depresión de Beck (BDI)............................................. 136

5.2.2.4. Escala de Estado de Ánimo.................................................................... 136

5.2.2.5. Cuestionario de Valoración de la estancia en UCI............................ 136

5.2.2.6. Escala sobre Factores Estresantes en UCI: Adaptación de la Escala de Estresores Hospitalarios..................................................... 137

5.2.2.7. Cuestionario de Ayuda a Morir en Paz.............................................. 138

5.2.2.8. Cuestionario de Valoración del Proceso de Información y Toma de Decisiones en el ámbito hospitalario............................................. 138

5.2.2.9. Cuestionario de Calidad de Vida relacionada con la salud: Adaptación del EuroQol-5D............................................................... 139

5.2.2.10. Escala de Inadaptación......................................................................... 140

5.2.2.11. Cuestionario de Necesidades de los familiares de pacientes de Cuidados Intensivos (CCFNI): versión breve................................. 140

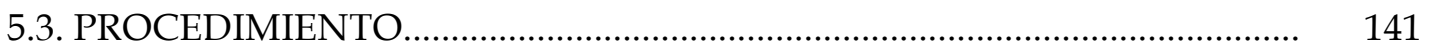

5.4. ANÁLISIS ESTADÍSTICOS......................................................................... 144 
6.1. RESULTADOS DE LA MUESTRA DE PACIENTES......................................... 150

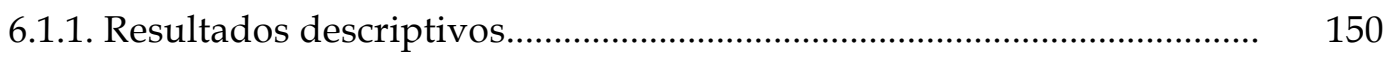

6.1.1.1. Síntomas de ansiedad y depresión............................ 150

6.1.1.2. Percepción subjetiva del malestar emocional...................... 152

6.1.1.3. Valoración de la estancia en la Unidad de Cuidados Intensivos... 153

6.1.1.4. Percepción de estrés en UCI desde el punto de vista de los pacientes.................................................... 156

6.1.1.5. Calidad de vida.............................................. 161

6.1.1.6. Valoración sobre el proceso de morir................................ 164

6.1.1.7. Valoración del Proceso de Información y Toma de decisiones..... 166

6.1.2. Resultados diferenciales dentro del grupo de pacientes.............. 169

6.1.2.1. Análisis diferenciales en función del género.................... 169

6.1.2.2. Análisis diferenciales en función del estado civil................. 175

6.1.2.3. Análisis diferenciales en función de si los pacientes tienen hijos o no.

6.1.2.4. Análisis diferenciales en función de la patología de ingreso.......

6.1.2.5. Relación entre las variables evaluadas y la edad.................. 204

6.1.2.6. Relación entre las variables evaluadas y el nivel de estudios...... 208

6.1.3. Análisis de regresión en la muestra de pacientes.................... 212

6.2. RESULTADOS DE LA MUESTRA DE FAMILIARES...................... 216

6.2.1. Resultados descriptivos......................................... 216

6.2.1.1. Síntomas de ansiedad y depresión............................ 216

6.2.1.2. Percepción subjetiva del malestar emocional..................... 218

6.2.1.3. Valoración de la estancia en la Unidad de Cuidados Intensivos... 219

6.2.1.4. Percepción de estrés en UCI desde el punto de vista de los familiares................................................... 222

6.2.1.5. Adaptación al ingreso de un ser querido en UCI.................. 227 
6.2.1.6. Necesidades de los familiares en UCI........................... 228

6.2.1.7. Valoración sobre el proceso de morir........................... 230

6.2.1.8. Valoración del Proceso de Información y Toma de decisiones.... 233

6.2.2. Resultados diferenciales dentro del grupo de familiares.............. 235

6.2.2.1. Análisis diferenciales en función del género...................... 236

6.2.2.2. Análisis diferenciales en función del estado civil................. 243

6.2.2.3. Análisis diferenciales en función de si los familiares tienen hijos o no.

6.2.2.4. Análisis diferenciales en función del grado de parentesco con el paciente.

6.2.2.5. Análisis diferenciales en función del lugar de residencia.......... 275

6.2.2.6. Relación entre las variables evaluadas y la edad.................. 283

6.2.2.7. Relación entre las variables evaluadas y el nivel de estudios..... 289

6.2.3. Análisis de regresión en la muestra de familiares..................... 295

6.3. ANÁLISIS DIFERENCIALES ENTRE PACIENTES Y FAMILIARES....... 297

CAPÍTULO 7. DISCUSIÓN Y CONCLUSIONES 303

7.1. AFECTACIÓN EMOCIONAL DE PACIENTES......................... 306

7.1.1. Ansiedad y depresión.......................................... 306

7.1.2. Valoración de la estancia en la Unidad de Cuidados Intensivos......... 311

7.1.3. Percepción de estrés en UCI desde el punto de vista de los pacientes. 313

7.1.4. Calidad de vida............................................. 316

7.1.5. Valoración sobre el proceso de morir............................ 318

7.1.6. Valoración del proceso de Información y Toma de Decisiones........ 321

7.1.7. Principales variables predictoras de la afectación psicológica de los pacientes.................................................... 324

7.2. AFECTACIÓN EMOCIONAL DE FAMILIARES........................ 325

7.2.1. Ansiedad y depresión.......................................... 325

7.2.2. Valoración de la estancia en la Unidad de Cuidados Intensivos......... 333 
7.2.3. Percepción de estrés en UCI desde el punto de vista de los familiares

7.2.4. Adaptación al ingreso de un ser querido en UCI..................... 339

7.2.5. Necesidades de los familiares en UCI.............................. 341

7.2.6. Valoración sobre el proceso de morir................................ 344

7.2.7. Valoración del proceso de Información y Toma de Decisiones......... 347

7.2.8. Principales variables predictoras de la afectación psicológica de los familiares........................................................ 350

7.3. COMPARACIÓN ENTRE PACIENTES Y FAMILIARES.................... 352

CAPÍTULO 8. PRINCIPALES CONCLUSIONES 357

8.1. PACIENTES........................................................ 359

8.2. FAMILIARES........................................................ 361

8.3. COMPARACIÓN ENTRE PACIENTES Y FAMILIARES.................... 363

CAPÍTULO 9. REFERENCIAS BIBLIOGRÁFICAS............................... 365

ANEXOS.................................................................... 401 



\section{ÍNDICE DE TABLAS}

Tabla 1. Niveles de asistencia....

Tabla 2. Resumen de las principales características sociodemográficas de la muestra.

Tabla 3. Análisis de las distintas variables sociodemográficas en función del grupo pacientes-familiares

Tabla 4. Puntuaciones medias de los ítems del Cuestionario de Valoración de la estancia en UCI según los pacientes....

Tabla 5. Porcentajes en las distintas opciones de respuesta de los ítems del Cuestionario de Valoración de la estancia en UCI según los pacientes....

Tabla 6. Medias de los factores estresantes en pacientes ingresados en UCI......... 159

Tabla 7. Porcentajes de los principales estresores en pacientes de UCI. 160

Tabla 8. Medias en calidad de vida antes y después del ingreso en UCI 161

Tabla 9. Porcentajes de los distintos factores del Cuestionario de Ayuda a Morir en Paz (CAMP) (pacientes)

Tabla 10. Porcentajes obtenidos en la satisfacción ante la información, preferencias en el estilo del médico a la hora de informar y participación en la toma de decisiones (TD) desde el punto de vista de los pacientes.

Tabla 11. Análisis diferencial en función del género de la ansiedad, depresión y percepción subjetiva de estado de ánimo (pacientes).

Tabla 12. Análisis diferencial en función del género de la Valoración de la estancia en UCI (pacientes)

Tabla 13. Análisis diferencial en función del género de los Factores estresantes en UCI (pacientes)

Tabla 14. Análisis diferencial en función del género en la calidad de vida de los pacientes

Tabla 15. Análisis diferencial en función del género de los distintos factores del Cuestionario de Ayuda a Morir en Paz (CAMP) (pacientes).

Tabla 16. Valoración diferencial en función del género del proceso de información y toma de decisiones (TD) (pacientes).

Tabla 17. Análisis diferencial en función del estado civil de la ansiedad, depresión y estado de ánimo de los pacientes.

Tabla 18. Análisis diferencial en función del estado civil de la valoración de la estancia en UCI (pacientes) 
Tabla 19. Análisis diferencial en función del estado civil de los Factores estresantes en UCI (pacientes)

Tabla 20. Análisis diferencial en función del estado civil en la calidad de vida (CV) de los pacientes.

Tabla 21. Análisis diferencial en función del estado civil de los distintos factores del Cuestionario de Ayuda a Morir en Paz (CAMP) (pacientes).

Tabla 22. Análisis diferencial en función del estado civil del proceso de información y toma de decisiones (pacientes)

Tabla 23. Análisis diferencial en función del número de hijos de la ansiedad, depresión y estado de ánimo (pacientes)

Tabla 24. Análisis diferencial en función del número de hijos de la valoración dela estancia en UCI (pacientes)

Tabla 25. Análisis diferencial en función del número de hijos de los Factores estresantes en UCI (pacientes)

Tabla 26. Análisis diferencial en función del número de hijos en la calidad de vida $(\mathrm{CV})$ de los pacientes.

Tabla 27. Análisis diferencial en función del número de hijos de los distintos factores del Cuestionario de Ayuda a Morir en Paz (CAMP) (pacientes)

Tabla 28. Análisis diferencial en función del número de hijos del proceso de información y toma de decisiones de los pacientes

Tabla 29. Análisis diferencial en función de la patología de la ansiedad, depresión y percepción de estado de ánimo (pacientes)

Tabla 30. Análisis diferencial en función de la patología de la valoración de la estancia en UCI (pacientes)

Tabla 31. Análisis diferencial en función de la patología de los distintos Factores estresantes de UCI (pacientes)

Tabla 32. Análisis diferencial en función de la patología de la calidad de vida (CV) de los pacientes

Tabla 33. Análisis diferencial en función de la patología de los distintos factores del Cuestionario de Ayuda a Morir en Paz (CAMP) (pacientes)...........

Tabla 34. Análisis diferencial en función de la patología de la valoración del proceso de información y toma de decisiones en los pacientes....

Tabla 35. Correlaciones de Pearson entre la edad y los síntomas de ansiedaddepresión y percepción subjetiva de malestar (pacientes)

Tabla 36. Correlaciones de Pearson entre la edad y la Valoración de la estancia en UCI (pacientes) 
Tabla 37. Correlaciones de Pearson entre la edad y los Factores estresantes en UCI (pacientes) ....................................................... 206

Tabla 38. Correlaciones de Pearson entre la edad y la calidad de vida de los pacientes

Tabla 39. Correlaciones de Pearson entre la edad y los factores del CAMP (pacientes)

Tabla 40. Correlaciones de Pearson entre la edad y la Valoración del proceso de información y toma de decisiones(pacientes)

Tabla 41. Correlaciones de Spearman entre el nivel de estudios y los síntomas de ansiedad-depresión y percepción subjetiva de estado de ánimo (pacientes)

Tabla 42. Correlaciones de Spearman entre el nivel de estudios y la Valoración de la estancia en UCI (pacientes)

Tabla 43. Correlaciones de Spearman entre el nivel de estudios y los Factores estresantes (pacientes).

Tabla 44. Correlaciones de Spearman entre el nivel de estudios y la calidad de vida de los pacientes

Tabla 45. Correlaciones de Spearman entre el nivel de estudios y los factores del CAMP (pacientes)

Tabla 46. Correlaciones de Spearman entre el nivel de estudios y la Valoración del proceso de información y toma de decisiones (pacientes).

Tabla 47. Análisis de regresión (pacientes)

Tabla 48. Puntuaciones medias de los ítems del Cuestionario de Valoración de la estancia en UCI según los familiares....

Tabla 49. Porcentajes en las distintas opciones de respuesta de los ítems del Cuestionario de Valoración de la estancia en UCI según los familiares...

Tabla 50. Medias de los factores estresantes en familiares de pacientes ingresados en UCI....

Tabla 51. Porcentajes de los principales estresores en familiares de pacientes de UCI.

Tabla 52. Grado de interferencia en las distintas esferas de la vida de los familiares de UCI.

Tabla 53. Medias en el Cuestionario de las necesidades de los familiares en UCI..

Tabla 54. Porcentaje de las necesidades de los familiares de UCI.

Tabla 55. Porcentajes de los distintos factores del Cuestionario de Ayuda a Morir en Paz (CAMP) (familiares). 
Tabla 56. Porcentajes obtenidos en la satisfacción de la información, preferencias en el estilo del médico a la hora de informar y participación en la toma de decisiones (TD) desde el punto de vista de los familiares

Tabla 57. Análisis diferencial en función del género de la ansiedad, depresión y percepción subjetiva de estado de ánimo (familiares).

Tabla 58. Análisis diferencial en función del género de la Valoración de la estancia en UCI (familiares)

Tabla 59. Análisis diferencial en función del género de los Factores estresantes en UCI (familiares)

Tabla 60. Análisis diferencial en función del género del Grado de interferencia en las distintas esferas de la vida de los familiares de UCI.................

Tabla 61. Análisis diferencial en función del género de las Necesidades de los familiares en UCI.

Tabla 62. Análisis diferencial en función del género de los distintos factores del Cuestionario de Ayuda a Morir en Paz (CAMP) (familiares)..............

Tabla 63. Valoración diferencial en función del género del proceso de información y toma de decisiones (TD) en los familiares.

Tabla 64. Análisis diferencial en función del estado civil de la ansiedad, depresión y estado de ánimo (familiares).

Tabla 65. Análisis diferencial en función del estado civil de la valoración de la estancia en UCI (familiares)

Tabla 66. Análisis diferencial en función del estado civil de los Factores estresantes en UCI (familiares)....

Tabla 67. Análisis diferencial en función del estado civil del Grado de interferencia en las distintas esferas de la vida de los familiares de UCI

Tabla 68. Análisis diferencial en función del estado civil de las Necesidades de los familiares en UCI.

Tabla 69. Análisis diferencial en función del estado civil de los distintos factores del Cuestionario de Ayuda a Morir en Paz (CAMP) (familiares)..........

Tabla 70. Valoración diferencial en función del estado civil del proceso de información y toma de decisiones (TD) en los familiares.

Tabla 71. Análisis diferencial en función del número de hijos de la ansiedad, depresión y percepción de estado de ánimo (familiares)...................

Tabla 72. Análisis diferencial en función del número de hijos de la valoración de la estancia en UCI (familiares).

Tabla 73. Análisis diferencial en función del número de hijos de los Factores estresantes en UCI (familiares). 
Tabla 74. Análisis diferencial en función del número de hijos sobre el Grado de interferencia en las distintas esferas de la vida de los familiares de UCI..

Tabla 75. Análisis diferencial en función del número de hijos sobre las

Necesidades de los familiares en UCI.....................................

Tabla 76. Análisis diferencial en función del número de hijos de los distintos factores del Cuestionario de Ayuda a Morir en Paz (CAMP) (familiares)

Tabla 77. Valoración diferencial en función del número de hijos del proceso de información y toma de decisiones (TD) en los familiares....

Tabla 78. Análisis diferencial en función del parentesco de la ansiedad, depresión y percepción de estado de ánimo (familiares)

Tabla 79. Análisis diferencial en función del parentesco sobre la valoración de la estancia en UCI (familiares)

Tabla 80. Análisis diferencial en función del parentesco de los distintos Factores estresantes de UCI (familiares)

Tabla 81. Análisis diferencial en función del parentesco sobre el Grado de interferencia en las distintas esferas de la vida de los familiares de UCI..

Tabla 82. Análisis diferencial en función del parentesco de las necesidades de los familiares de UCI.

Tabla 83. Análisis diferencial en función del parentesco de los distintos factores del Cuestionario de Ayuda a Morir en Paz (CAMP) (familiares)...........

Tabla 84. Valoración diferencial en función del parentesco del proceso de información y toma de decisiones (TD) en familiares...

Tabla 85. Análisis diferencial en función del lugar de residencia de la ansiedad, depresión y percepción de estado de ánimo (familiares)

Tabla 86. Análisis diferencial en función del lugar de residencia sobre la valoración de la estancia en UCI (familiares)....

Tabla 87. Análisis diferencial en función del lugar de residencia de los distintos Factores estresantes de UCI (familiares).

Tabla 88. Análisis diferencial en función del lugar de residencia del Grado de interferencia en las distintas esferas de la vida de los familiares de UCI..

Tabla 89. Análisis diferencial en función del lugar de residencia de las necesidades de los familiares de UCI

Tabla 90. Análisis diferencial en función del lugar de residencia de los distintos factores del Cuestionario de Ayuda a Morir en Paz (CAMP) (familiares)

Tabla 91. Valoración diferencial en función del lugar de residencia del proceso de información y toma de decisiones (TD) en familiares 
Tabla 92. Correlaciones de Pearson entre la edad y los síntomas de ansiedaddepresión y percepción de estado de ánimo (familiares)...................

Tabla 93. Correlaciones de Pearson entre la edad y la Valoración de la estancia en UCI (familiares)

Tabla 94. Correlaciones de Pearson entre la edad y los Factores estresantes en UCI (familiares)

Tabla 95. Correlaciones de Pearson entre la edad y la adaptación de la familia al ingreso en UCI.

Tabla 96. Correlaciones de Pearson entre la edad y las necesidades de los familiares en UCI.

Tabla 97. Correlaciones de Pearson entre la edad y los factores del CAMP (familiares)

Tabla 98. Correlaciones de Pearson entre la edad y la Valoración del proceso de información y toma de decisiones (familiares)

Tabla 99. Correlaciones de Spearman entre el nivel de estudios y los síntomas de ansiedad-depresión y percepción de estado de ánimo (familiares).

Tabla 100. Correlaciones de Spearman entre el nivel de estudios y la Valoración de la estancia en UCI (familiares)

Tabla 101. Correlaciones de Spearman entre el nivel de estudios y los Factores estresantes en UCI (familiares)

Tabla 102. Correlaciones de Spearman entre el nivel de estudios y la adaptación de la familia al ingreso en UCI.

Tabla 103. Correlaciones de Spearman entre el nivel de estudios y las necesidades de los familiares de UCI

Tabla 104. Correlaciones de Spearman entre el nivel de estudios y los factores del CAMP (familiares)

Tabla 105. Correlaciones de Spearman entre el nivel de estudios y la Valoración del proceso de información y toma de decisiones (familiares)...........

Tabla 106. Análisis de regresión en familiares consideradas las variables individualmente.

Tabla 107. Puntuaciones medias en ansiedad, depresión, percepción subjetiva de estado de ánimo y estrés en pacientes y familiares.

Tabla 108. Puntuaciones medias dela Valoración de la estancia en UCI en pacientes y familiares.

Tabla 109. Puntuaciones medias de los factores que ayudarían en el proceso de morir (CAMP) en pacientes y familiares. 
Tabla 110. Puntuaciones medias en la valoración del proceso de información y toma de decisiones en pacientes y familiares...

\section{ÍNDICE DE CUADROS RESUMEN}

Cuadro 1. Principales estresores en una Unidad de Cuidados Intensivos............

Cuadro 2. Principales Necesidades de los Familiares de pacientes críticos agrupadas por categorías................................................

Cuadro 3. Principales Necesidades de los familiares de UCI según diferentes estudios cualitativos.

Cuadro 4. Instrumentos utilizados para la evaluación de pacientes y familiares...

\section{ÍNDICE DE FIGURAS}

Figura 1. Modelo de las necesidades psicosociales de los pacientes de UCI (Hupcey, 2000)....

Figura 2. Proceso de desarrollo del Síndrome de Cuidados Intensivos (tomado de Granberg et al., 1996) 62

Figura 3. Muestra final de pacientes y familiares. 176 


\section{ÍNDICE DE GRÁFICAS}

Gráfica 1. Distribución de la muestra de pacientes según el género.............. 128

Gráfica 2. Distribución de la muestra de pacientes según nivel de estudios........ 128

Gráfica 3. Distribución de la muestra de pacientes según estado civil............ 128

Gráfica 4. Distribución de la muestra de pacientes en función del número de hijos........................................................

Gráfica 5. Distribución de la muestra de pacientes según grupo de diagnóstico al ingreso......

Gráfica 6. Distribución de la muestra de familiares según el género.

Gráfica 7. Distribución de la muestra de familiares según el lugar de residencia.. $\quad 130$

Gráfica 8. Distribución de la muestra de familiares según nivel de estudios....... 130

Gráfica 9. Distribución de la muestra de familiares según estado civil............ 131

Gráfica 10. Distribución de la muestra de familiares en función del número de hijos....

Gráfica 11. Distribución de la muestra de familiares en función del parentesco con el paciente.

Gráfica 12. Distribución de las puntuaciones en Ansiedad según el baremo de la escala HADS (pacientes)

Gráfica 13. Distribución de las puntuaciones en Depresión según el baremo de la escala HADS (pacientes)

Gráfica 14. Distribución de las puntuaciones en Depresión según el baremo del cuestionario BDI (pacientes).

Gráfica 15. Medias de las puntuaciones totales en ansiedad y depresión en pacientes críticos evaluadas mediante distintos cuestionarios.

Gráfica 16. Medias de las puntuaciones totales de malestar subjetivo en pacientes (Escala 0-10)

Gráfica 17. Puntuaciones medias de los ítems del Cuestionario de Valoración de la estancia en UCI según los familiares.

Gráfico 18. Nivel general de estrés en pacientes de UCI

Gráfica 19. Principales factores estresantes en pacientes de UCI.

Gráfica 20. Medias en las dimensiones de calidad de vida antes y después del ingreso en UCI

Gráfica 21. Porcentajes de las diferentes dimensiones en calidad de vida antes y tras el ingreso en UCI. 
Gráfica 22. Percepción de Estado de salud actual en comparación con el previo al ingreso.

Gráfica 23. Medias de las puntuaciones en los factores del Cuestionario de Ayuda a Morir en Paz (CAMP) (pacientes) .....

Gráfica 24. Priorización de los dos factores (CAMP) que más ayudarían a morir en paz.

Gráfica 25. Proporción de respuestas sobre la importancia de los agentes implicados en el proceso de información y toma de decisiones desde el punto de vista de los pacientes....

Gráfica 26. Distribución de las puntuaciones en Ansiedad según el baremo de la escala HADS (familiares).....

Gráfica 27. Distribución de las puntuaciones en Depresión según el baremo de la escala HADS (familiares)

Gráfica 28. Distribución de las puntuaciones en Depresión según el baremo del cuestionario BDI (familiares).

Gráfica 29. Medias de las puntuaciones totales en ansiedad y depresión en familiares evaluadas mediante distintos cuestionarios.

Gráfica 30. Medias de las puntuaciones totales de malestar subjetivo en familiares (Escala 0-10)

Gráfica 31. Puntuaciones medias de los ítems del Cuestionario de Valoración de la estancia en UCI según los familiares.

Gráfica 32. Nivel general de estrés en Familiares de UCI

Gráfica 33. Principales factores estresantes en familiares de UCI.

Gráfica 34. Medias de las puntuaciones en los factores del Cuestionario de Ayuda a Morir en Paz (CAMP) (familiares).

Gráfica 35. Priorización de los dos factores (CAMP) que más ayudarían a morir en paz según los familiares (\%)

Gráfica 36. Proporción de respuestas sobre la importancia de los agentes implicados en el proceso de información y toma de decisiones desde el punto de vista de los familiares 



\section{PRESENTACIÓN}



Los avances científico-técnicos acontecidos durante las últimas décadas han dado lugar a una medicina altamente especializada cuya máxima expresión se encuentra en las unidades de cuidados intensivos (UCIs), donde tecnología y eficacia se unen para intentar salvar la vida de pacientes gravemente enfermos. Si bien es cierto que éste ha sido uno de los principales objetivos de la medicina intensiva (Ferdinande, 1997) también lo es que este proceso, incluso en el mejor de los casos, no está exento de gran malestar y sufrimiento.

En este sentido, si el ambiente hospitalario en sí mismo se considera extraño e intimidante, cuánto más puede serlo una unidad de cuidados intensivos en la que además de la gravedad médica del paciente, con todo lo que esto conlleva, convergen diferentes aspectos característicos de estas unidades que pueden afectar de manera particular a los pacientes y sus familias. Tal es el caso de la alta tecnología, el constante ir y venir de los profesionales sanitarios tanto de día como de noche, el ruido de máquinas y alarmas, gran cantidad de tubos y cables que limitan la movilidad y posibilidades de comunicación en la persona enferma, el aislamiento de la familia y la ruptura con la vida cotidiana, viéndose alterado el normal funcionamiento del círculo familiar en su conjunto (Hewitt, 2002; Llubià \& Canet, 2000). De esta manera, el ingreso en UCI puede constituir una experiencia realmente estresante y disruptiva tanto para el paciente como para sus familiares, pudiendo dar a lugar a un grado variable de afectación emocional.

Todo esto pone de relieve la importancia de entender a la persona como un ser biopsicosocial, ofreciéndole una atención integral, en la que además de las dolencias físicas, de vital importancia en estos momentos, se atiendan sus necesidades psicológicas, sociales y espirituales, con la finalidad de disminuir el impacto del ingreso en UCI y facilitar un mejor afrontamiento, tanto en los pacientes como en sus familiares y allegados. 
Partiendo de la premisa de que es necesario conocer una realidad para poder mejorarla, la presente tesis doctoral se centra en el análisis del grado de afectación psicológica de pacientes y familiares de UCI, valorando el posible papel modulador de distintos factores en dicha afectación. De esta manera se pretende mejorar el bienestar y calidad de vida de las personas que, por diversas circunstancias, se ven sometidas al impacto de la experiencia del ingreso en una Unidad de Cuidados Intensivos, bien como pacientes bien como familiares.

Para este propósito, hemos estructurado la presente tesis doctoral en dos partes claramente diferenciadas. La primera parte, de carácter teórico, está compuesta por tres capítulos. El capítulo 1 ofrece una visión general del marco de actuación de los cuidados intensivos desde su origen hasta la actualidad, revisando las principales características de las Unidades de Cuidados Intensivos y teniendo en consideración cuestiones relativas al final de la vida en este contexto. El capítulo 2 trata sobre la propia experiencia del paciente ingresado en una $\mathrm{UCI}$, analizando los diferentes factores que en la literatura se han asociado a un aumento en la fragilidad y vulnerabilidad de la persona enferma, derivando en diversas alteraciones psicológicas que pueden contribuir a aumentar su sufrimiento. En el capítulo 3 se aborda el impacto emocional que puede tener en la familia el ingreso de un ser querido en $\mathrm{UCI}$, teniendo en cuenta los principales aspectos generadores de malestar vinculados a esta situación que pueden interferir en el afrontamiento adaptativo a la misma.

En la segunda parte de la tesis doctoral, de carácter empírico, se plantean los objetivos e hipótesis de la investigación realizada (capítulo 4). Asimismo, se analiza el perfil de la muestra según sus principales características sociodemográficas y se describen los instrumentos de evaluación utilizados y el procedimiento seguido para poder llevarla a cabo (capítulo 5). Dentro del marco empírico también se presentan los principales resultados estructurados en tres bloques para facilitar su comprensión. Así se ofrece un apartado para los resultados correspondientes a la muestra de pacientes y otro para la muestra de familiares, mostrándose en ambos grupos resultados descriptivos, resultados de análisis diferenciales en función de variables 
sociodemográficas y clínicas así como los resultados del análisis de regresión. Un último bloque de resultados será el relativo al análisis diferencial entre la muestra de pacientes y la de familiares (capítulo 6). A partir de la discusión de los resultados obtenidos y de la revisión de la literatura existente sobre el tema se presentan las principales conclusiones derivadas de nuestra investigación, teniendo en consideración las limitaciones encontradas así como posibles líneas futuras de investigación (capítulo 7 y 8). Finalmente, se presenta un listado de las fuentes bibliográfias consultadas (capítulo 9), cuya reflexión ha facilitado la elaboración de este trabajo. Asimismo, al capítulo de referencias bibliográficas sigue un apartado de anexos que contiene los instrumentos de evaluación utilizados en el estudio experimental.

En definitiva, con este estudio en el que analizamos la experiencia psicológica del ingreso en UCI desde el punto de vista del paciente y su familia, pretendemos conocer con el mayor grado posible de detalle esta realidad asociada a gran sufrimiento y malestar emocional, pues éste será el primer eslabón que justifique la necesidad de adoptar una serie de medidas que permitan aliviar el sufrimiento y mejorar la calidad de vida de los pacientes críticos y sus familiares. 

MARCO TEÓRICO 

CAPÍTULO 1

LAS UNIDADES DE CUIDADOS

INTENSIVOS 



\section{LAS UNIDADES DE CUIDADOS INTENSIVOS}

La Medicina Intensiva (MI) es definida por la Comisión Nacional de Medicina Intensiva (1993) como aquella parte de la medicina que se ocupa de los pacientes con disfunción actual o potencial de uno o varios órganos que representan una amenaza para su vida y son susceptibles de recuperación. La MI conlleva el manejo continuo de los pacientes incluyendo la monitorización, el diagnóstico y el soporte de las funciones vitales afectadas, así como el tratamiento de las enfermedades que provocan dicho fracaso, constituyendo el escalón más avanzado del esquema gradual de atención a los pacientes gravemente enfermos (Esteban, De la Cal \& Gómez-Rubí, 1993).

Su ámbito de actuación son los Servicios de Medicina Intensiva, cuya actividad asistencial se lleva a cabo fundamentalmente en las unidades de cuidados intensivos (UCI), tanto en las polivalentes como las dedicadas a una sola especialidad, médica o quirúrgica, y en otras áreas del Sistema Sanitario donde existan enfermos críticos que requieran una atención integral, tales como las áreas de Urgencias y Emergencias, Unidades de Intermedios, el ámbito extrahospitalario, el transporte del paciente grave o la atención sanitaria en las situaciones de catástrofes (González \& García, 2008; Sociedad Española de Medicina Intensiva, Crítica y Unidades Coronarias, 2011).

En este contexto, la situación médica de los pacientes es considerada realmente grave. Y el enfermo crítico podría definirse como aquel que reúne al menos dos de las tres condiciones siguientes (Couceiro, 2003):

a) La afectación que padece representa una amenaza grave para su vida y es potencialmente recuperable.

b) Necesita una monitorización continua de sus funciones vitales.

c) Necesita medidas de soporte vital para ganar tiempo en espera de que evolucione hacia la curación, bien por la recuperación espontánea, o por el efecto de alguna de las medidas terapéuticas instauradas.

A partir de la definición de medicina intensiva y enfermo crítico, se deduce que los cuidados en este contexto asocian la inestabilidad fisiológica con la probabilidad de supervivencia, lo que sin duda alguna nos remite al objetivo inicial de los cuidados críticos, esto es, conseguir la supervivencia de los pacientes (Ferdinande, 1997). No obstante, es necesario tener en consideración que incluso con los mejores avances 
científico-técnicos, la recuperación de los pacientes no siempre es posible y éstos muchas veces fallecen o llegan a sobrevivir con graves secuelas, realidad que no podemos obviar si pretendemos mejorar la asistencia global ofrecida en las unidades de cuidados intensivos.

\subsection{EVOLUCIÓN HISTÓRICA DE LOS CUIDADOS INTENSIVOS}

En el origen de la Medicina Intensiva, una de las especialidades más jóvenes de la medicina, han influido distintas circunstancias históricas marcadas por la necesidad de agrupar y de tratar a enfermos graves de forma diferenciada y más eficaz.

En este sentido, las raíces de los cuidados intensivos suelen situarse en la Guerra de Crimea (1853-1856) de la mano de Florence Nightingale (1820-1910), enfermera nacida en el seno de una familia de origen británico. Las noticias llegadas a Gran Bretaña sobre las pésimas condiciones en las que se encontraban los heridos hicieron que Nightingale y otras 38 enfermeras voluntarias entrenadas por ella, se trasladaran a Scutari, actual distrito de Üsküdar (Estambul, Turquía). A su llegada, encontraron escasos recursos médicos junto con pésimas condiciones higiénicas, siendo todo ello causa de infecciones importantes que en la mayoría de los casos tenían consecuencias fatales. Concretamente, el número de soldados que morían por enfermedad era siete veces mayor que los que morían en el campo de batalla (Gill \& Gill, 2005; Stinnett, 1990). Nightingale, también conocida como "la dama de la lámpara" por sus largas rondas de noche atendiendo a los heridos de guerra, reconoció que algunos enfermos requerían cuidados más frecuentes y especializados que otros por lo que empezó a agrupar a los pacientes más graves junto al puesto de enfermería (Weil \& Shoemaker, 2004). De esta manera, Florence había allanado el camino de la medicina crítica escribiendo unos años más tarde en su libro "Notes on hospitals" (1863) sobre las ventajas de disponer de áreas separadas en el hospital para aquellos pacientes que están recuperándose de una cirugía.

Un nuevo avance para la medicina intensiva tuvo lugar en 1923. Walter E. Dandy, considerado uno de los padres de la neurocirugía, organizó una unidad de terapia intensiva para el cuidado de los pacientes neuroquirúrgicos recién operados (Long, 1989). En esta unidad del hospital Johns Hopkins (Baltimore), los pacientes eran atendidos por enfermeras especializadas, convirtiéndose de esta manera en las primeras profesionales especializadas en prestar cuidados intensivos, concretamente 
bajo las órdenes de neurocirujanos. Esta unidad inicial de cuidados intensivos sirvió de modelo para unidades de recuperación postquirúrgica posteriores como las habilitadas en la Segunda Guerra Mundial (1939-1945), la Guerra de Corea (1950-1953) y la Guerra de Vietnam (1964-1975), en las que se intentó agrupar a los pacientes después de ser operados en una sala de recuperación que garantizara un cuidado especial a los mismos. Estas salas, especialmente las unidades de postoperatorios de la Segunda Guerra Mundial, pueden considerarse como las precursoras de las unidades de medicina intensiva modernas.

Otro hecho histórico relevante que contribuyó al nacimiento de los cuidados críticos está relacionado con la epidemia de poliomielitis. Entre los años veinte y cincuenta tuvo lugar un brote importante de esta enfermedad en los países del norte de Europa y América. La poliomielitis es una enfermedad infecciosa producida por un virus que ataca las neuronas responsables de los movimientos de los músculos esqueléticos produciendo su parálisis, de manera que cuando las neuronas afectadas son las que controlaban los músculos respiratorios se produciría la muerte por asfixia. Además este virus se contagia por contacto directo de persona a persona, lo que favorecería la propagación de la enfermedad (Lassen, 1954).

En los inicios de la pandemia prácticamente no había medios para tratarla. Fue en 1928 cuando Drinker y McKhann introdujeron un respirador artificial al que llamaron "pulmón de acero" que permitía la ventilación pulmonar en periodos prolongados a las personas con parálisis respiratoria, gracias a la presión negativa que favorecía el desplazamiento de la caja torácica (Drinker \& McKhann, 1929). Este procedimiento redujo la mortalidad de manera considerable, habilitándose salas para el cuidado especial de estos pacientes que requerían pulmones de acero (Medina, 2002).

En 1952, Bjørn Ibsen, anestesista danés, participó en el brote de poliomielitis que tuvo lugar en Dinamarca. Conocía el uso de los respiradores de presión negativa externa disponibles, pero estos dispositivos, aunque útiles, eran limitados y no protegían contra la aspiración de secreciones. En este contexto otros especialistas como Lassen que también trataban pacientes afectados de poliomielitis, pidieron opinión a Ibsen respecto a casos particulares en los que no había mejoría y este anestesista mostró el modo de proporcionar suficiente ventilación sin la ayuda del respirador, sustituyendo de esta manera los pulmones de acero por la ventilación prolongada manual, de presión positiva, a través de la intubación endotraqueal (Ibsen, 1954; 
Lassen, 1954). Aunque en un principio esta bomba era de activación manual requiriendo el trabajo continuo, en este caso llevado a cabo por estudiantes de medicina, pronto empezaron a utilizarse los primeros ventiladores de volumen controlado y de presión positiva, desarrollados por Carl-Gunnar Engström (Engström, 1954). De esta manera y gracias a la intervención de Ibsen, la mortalidad descendió notablemente, pasó del 90\% a alrededor del 25\% (Ocampo, 2009; West, 2005).

En 1953, después de que el brote de poliomielitis disminuyera, Ibsen obtuvo un puesto de trabajo en el Hospital Municipal de Copenhage para supervisar la recuperación de los pacientes quirúrgicos. Y en ese mismo año, convirtió esta sala de observación y recuperación en una unidad donde todo tipo de pacientes podían recibir cuidados críticos. Así, Ibsen puso en marcha lo que se ha considerado la primera Unidad de Cuidados Intensivos (Berthelsen \& Cronqvist, 2003; Pincok, 2007).

Posteriormente, con los tratamientos descritos y la aparición de las vacunas antipoliomielíticas en los años 1955 y 1957 (Sabin et al., 1984; Salk, 1983) empezó a extinguirse la epidemia de poliomielitis. Las áreas en las que se venían atendiendo estos pacientes concentraban recursos humanos y técnicos importantes por lo que resultaron útiles para atender otras formas de fracaso respiratorio y poco a poco pasaron a atender a todo tipo de pacientes críticos.

Otra figura relevante en el origen de los actuales cuidados intensivos fue Peter Safar (1924-2003). A finales de los años cincuenta y siendo jefe del departamento de anestesiología del Hospital Baltimore City (EE.UU) sentó las bases de la resucitación cardiopulmonar moderna (CPR). En este contexto y teniendo presente el trabajo de Ibsen en Dinamarca, Safar centra su atención en aplicar el soporte de ventilación en pacientes críticos que pudieran presentar lesiones graves. Así, Safar fundó en Baltimore (1958) la primera unidad de cuidados intensivos médico-quirúrgica de Estados Unidos (Baskett, 2003; Oransky, 2003). En 1961 Safar se trasladó a Pittsburgh, ciudad en la que funda de nuevo una unidad de cuidados intensivos y donde desarrollará el resto de su carrera profesional. Casi de forma simultánea, la medicina intensiva empieza a instalarse por todo el mundo apareciendo unidades de cuidados intensivos en Auckland, Toronto, Boston, Southhampton, California City, Glasgow, Kansas City, Denver, Rochester (Minnesota), Londres, Birmingham, Viena, Munich y otras tantas ciudades (Perdomo, 1992; Ruiz \& Martín, 2006). 
Avanzando un poco más en el desarrollo de los cuidados críticos cabe señalar un hecho traumático en la vida de Peter Safar. En 1966 fallece su hija de 12 años como consecuencia de un paro cardíaco, lo cual aumentó si cabe aún más el interés de Safar por seguir investigando en el campo de los cuidados intensivos y la reanimación cerebral, estableciendo el diagnóstico de muerte cerebral y fomentando la donación de órganos (Baskett, 2002, 2003).

Fruto del creciente interés en mejorar el cuidado de aquellos pacientes en los que sus vidas se ven seriamente amenazadas, en la década de los 70, aparecen distintas sociedades relacionadas con la medicina intensiva. La primera de ellas aparece en 1970 cuando un grupo de 28 médicos, provenientes de distintas especialidades (medicina interna, cardiología, cirugía, anestesiología y pediatría ) y entre los que destacaban nombres como Weil, Safar y Shoemaker, proponen la creación de una organización multidisciplinar en este campo, convirtiéndose en la Society of Critical Care Medicine (SCCM) (Weil, 1973). Un año más tarde, en 1971, se crea la American Association of Critical Care Nurses (AACN) (Fairman \& Lynaugh, 1998). Posteriormente, (1979) aparece la Federación Panamericana e Ibérica de Medicina Crítica y Cuidados Intensivos (Celis-Rodríguez \& Rubiano, 2007), formada por todos los países de América, España y Portugal. Y poco a poco, la formación de este tipo de sociedades va llegando a otros países aunque en algunos casos como la India, hay que esperar hasta 1992, año en el que se crea la Indian Society of Critical Care Medicine (Prayag, 2002).

Si centramos nuestra atención en el origen de la medicina intensiva en España es necesario hacer referencia al profesor Jiménez Díaz, considerado como principal impulsor de esta especialidad en nuestra geografía, inaugurando en 1965 la primera unidad de vigilancia intensiva en la Clínica de la Concepción de Madrid. Esta clínica se convirtió durante los años siguientes en la más productiva cantera de especialistas en la materia. Un poco más tarde se implantan en Barcelona y después en las principales ciudades españolas (Perdomo, 1992).

Los médicos que trabajaban en estas primeras unidades en nuestro país provenían de distintas especialidades, fundamentalmente de la medicina interna, cardiología, anestesiología y en menor medida neumología y cirugía (Esteban, De la Cal \& Gómez-Rubí, 1993). Esta primera generación de intensivistas tuvo que adaptar los conocimientos de sus respectivas especialidades de origen a las peculiaridades del enfermo critico. 
Con el interés de mejorar la atención y cuidados de los pacientes críticamente enfermos nace en 1974 la Sociedad Española de Medicina Intensiva y Unidades Coronarias (SEMIUC) que posteriormente cambió el nombre por el de Sociedad Española de Medicina Intensiva, Crítica y Unidades Coronarias (SEMICYUC) que es como se conoce en la actualidad. La necesidad de una atención específica y continuada de estos enfermos críticos supuso el nacimiento de la especialidad denominada Medicina Intensiva en 1978, año en el que se reguló legalmente la formación de médicos especialistas (MIR: Médicos Internos y Residentes), y entre las especialidades médicas reconocidas figuraba la Medicina Intensiva (Sociedad Española de Medicina Intensiva, Crítica y Unidades Coronarias, 2011). Así, en 1979 la primera generación de MIR inicia su formación especializada en Medicina Intensiva, recibiendo su titulación oficial en el año 1984. De la misma forma, en 1986, la Junta Americana de Especialidades médicas aprobó una certificación especial de competencia en cuidados intensivos para cuatro especialidades: anestesiología, medicina interna, pediatría y cirugía (American Board of Medical Specialties, 2006-2011).

Desde la primera unidad de cuidados intensivos fundada en España en torno a la década de los 70, se ha experimentado un incremento importantísimo en el número de estas unidades y actualmente las encontramos en prácticamente todos los hospitales y centros privados de España tanto de ámbito general como comarcal. Concretamente, según la Estadística de Establecimientos Sanitarios con Régimen de Internado, en el año 2009 se disponía en España, entre hospitales públicos y privados, de un total de 4100 camas dedicadas a cuidados intensivos en las que fueron atendidos 981.438 pacientes (Ministerio de Sanidad y Política Social, 2011).

Desde sus orígenes, la Medicina Intensiva ha recorrido un largo camino en el que han tenido lugar importantes avances científico-técnicos contribuyendo de manera notable al desarrollo de una medicina altamente especializada. Si bien es cierto que los grandes logros tecnológicos han permitido restablecer en numerosas ocasiones el estado de salud de pacientes gravemente enfermos e incluso tratar enfermedades hasta ese momento incurables, no podemos obviar que esa fascinación por la tecnología podría convertirse en un arma de doble filo, conduciéndonos de manera casi inadvertida hacia una cierta deshumanización de la medicina (Gómez, 1998). 


\subsection{CARACTERISTICAS DE LAS UNIDADES DE CUIDADOS INTENSIVOS}

Las unidades de cuidados intensivos constituyen el último escalón de un esquema de atención médica que intenta ajustar las necesidades de los pacientes a los esfuerzos y los medios disponibles. Suelen poseer una ubicación física determinada en la que se concentran recursos humanos, distintas competencias profesionales, equipamiento técnico especializado y el espacio necesario para poder llevar a cabo las diferentes funciones asignadas a estas unidades.

Estas unidades presentan características comunes que vienen determinadas por una serie de recomendaciones (a las que nos referiremos en el apartado 1.3.) elaboradas en 1997 por un grupo de expertos, la Task Force de la Sociedad Europea de Medicina Intensiva, junto con otras instituciones. A partir de estas recomendaciones mínimas, cada UCI elaborará sus propias directrices de actuación y gestión, estableciendo los protocolos pertinentes.

En líneas generales, se considera que las unidades de cuidados críticos presentan características que las hace diferentes de otros servicios ubicados en el mismo hospital, tanto en lo referente al entorno físico de estas unidades como a los distintos agentes implicados en las mismas, es decir, pacientes, familiares y profesionales sanitarios.

En cuanto al entorno físico de la UCI cabe señalar algunas características relativas a su ubicación dentro del hospital, las cuales están condicionadas fundamentalmente por su función. Así, estas unidades deben localizarse en una zona diferenciada y con acceso controlado a la vez que han de estar relacionadas con la práctica totalidad de unidades y servicios del hospital, especialmente los servicios de cirugía y de urgencias con los que además es recomendable mantener cierta proximidad física/topográfica.

Igualmente, cuando hablamos de las características de estas unidades de atención a pacientes en estado crítico, es inevitable hacer referencia a la alta tecnología que se utiliza para la vigilancia y cuidado de los mismos, resultando ser un ambiente en el que constantemente asaltan estímulos sensoriales extraños, donde además las visitas de los familiares son restringidas no pudiendo permanecer todo el tiempo al lado del enfermo, junto con una presión asistencial considerable tanto por el tipo de paciente atendido como por la carga de trabajo (Llubià \& Canet, 2000).

Asimismo, los pacientes ingresados en estas unidades y sus familiares también presentan características diferenciales. En el caso de los pacientes destacarían la 
gravedad de su situación médica, muchos miedos y temores en torno al sufrimiento y la muerte, los sentimientos de soledad, el aislamiento, la falta de autonomía, la falta de intimidad, la preocupación por los familiares, gran incertidumbre y la dificultad que pueden presentar para expresar todas estas emociones (Hewitt, 2002; Llubià \& Canet, 2000). En cuanto a los familiares, en este contexto suelen tener mayor protagonismo que en otros servicios del hospital dada la especial situación clínica del paciente. A menudo el enfermo crítico se encuentra en estado de abolición de la consciencia, bien por la propia enfermedad o por la sedación tan frecuente en una UCI, lo cual le impide participar en la toma de decisiones relevantes, siendo la familia en dichas circunstancias la que tiene que hacerlo en su lugar, con toda la carga emocional que ello conlleva. Los familiares también refieren sentirse poco preparados anímicamente para afrontar el ingreso en estas unidades ya que la mayoría de veces ocurre de forma inesperada y sin olvidar que frecuentemente la vida de su ser querido se ve seriamente amenazada, dando lugar todo ello a respuestas de negación de la realidad, shock e incredulidad, sobre todo inicialmente. Además, en este contexto la familia presenta un estrés adicional por cuestiones prácticas de organización así como por verse alterada su dinámica habitual. De esta manera, la familia en el contexto de UCI es propicia a presentar un importante cansancio o agotamiento físico y emocional el cual se hace más evidente a medida que pasan los días de ingreso en la unidad (Kleiber et al., 1994; Llubià \& Canet, 2000).

Finalmente, los profesionales sanitarios que desempeñan su labor en una unidad de cuidados intensivos, también están sometidos a gran impacto emocional. A diario conviven con el sufrimiento y la muerte, enfrentándose por tanto a situaciones de tensión tanto por la atención y cuidado de pacientes gravemente enfermos en los que la cercanía de la muerte suele ser una realidad, como por el trato directo con los familiares a quienes informan la mayoría de veces sobre pronósticos nada favorables, con las consiguientes reacciones emocionales que tal circunstancia puede desencadenar. Así, las unidades de cuidados intensivos, junto a las de paliativos y servicios de urgencias suelen ser contextos con una mayor prevalencia de burnout entre los profesionales sanitarios (Casado, Muñoz, Ortega \& Castellanos, 2005). 


\subsection{REQUERIMIENTOS MÍNIMOS EN LAS UNIDADES DE CUIDADOS INTENSIVOS}

El adecuado funcionamiento de las unidades de cuidados intensivos está garantizado a partir del seguimiento de unas recomendaciones sobre requerimientos mínimos en base a los cuales se organizan las distintas unidades. Estas recomendaciones mínimas se han establecido por consenso de especialistas en el ámbito de los cuidados intensivos, miembros de distintos grupos de trabajo (Task Forces) de la Sociedad Europea de Medicina Intensiva en cooperación con otras sociedades nacionales e internacionales (por ejemplo, Société de Réanimation de Langue Française, American Thoracic Society, Society of Critical Care Medicine and the American College of Chest Physicians) (Ferdinande, 1997).

En estas directrices se contemplan los principales objetivos de los servicios de medicina intensiva, incidiendo en la monitorización y el soporte a las funciones vitales de pacientes gravemente enfermos para de esta manera poder llevar a cabo procedimientos diagnósticos adecuados y terapias médico-quirúrgicas que en definitiva mejoren los resultados. Así, el éxito de los cuidados intensivos dependerá de una adecuada interacción entre los distintos recursos disponibles tanto humanos como tecnológicos y espaciales, que a su vez se distribuirán en función de las necesidades particulares de cada unidad.

Con la finalidad de facilitar la comprensión de las recomendaciones sobre requerimientos mínimos en las UCI, nos gustaría señalar que éstas presentarán una gradación en cuanto a su importancia, valorándose como "esenciales" (E), "deseables" (D), “opcionales" (O) o "no necesarias" (-). Esta valoración estará en función de los niveles de atención que proporcione cada unidad y de la gravedad de los pacientes atendidos, las cargas de trabajo que generen y las actividades que los profesionales realicen fuera de la unidad. Para establecer medidas idénticas de cuidados que permitan calcular la necesidad de recursos humanos, tecnológicos y espaciales, los miembros del grupo de expertos identificaron tres niveles distintos de asistencia (véase Tabla 1) en base a los que se plantearán los distintos requerimientos mínimos (véase Anexo 1) (Ferdinande, 1997). 
Tabla 1. Niveles de asistencia

\begin{tabular}{ccc}
\hline Niveles de Cuidado & Ratio enfermera/paciente & Ratio médico/paciente \\
\hline III & $1 / 1$ & $5 / 6-8$ \\
\hline
\end{tabular}

(nivel más alto de cuidados)

\begin{tabular}{ccc}
\hline II & $1 / 1,6$ & $4 / 6-8$ \\
\hline I & $1 / 3$ & $3 / 6-8$ \\
(nivel más bajo de cuidados) & & \\
\hline
\end{tabular}

(La ratio representa la media anual y podría ser necesario ajustarla en cada país)

En líneas generales las principales recomendaciones a considerar en una unidad de cuidados intensivos, propuestas por la Sociedad Europea de Medicina Intensiva (Ferdinande, 1998), incluyen aspectos relacionados con la descripción de lo que se considera un servicio de medicina intensiva (SMI) (objetivos, ubicación y tamaño), el personal que interviene, así como criterios de actividad y recomendaciones generales en el diseño de estos servicios. A continuación, pasaremos a resumir estas recomendaciones, actualmente también contempladas en el informe sobre estándares y recomendaciones de las UCIs elaborado por el Ministerio de Sanidad y Política Social (2011).

\section{Descripción del Servicio de Medicina Intensiva (SMI)}

El servicio es definido como una organización de profesionales sanitarios que ofrece asistencia multidisciplinar en un espacio físico específico del hospital que cumple unos requisitos funcionales, estructurales y organizativos, de forma que garantiza las condiciones de seguridad, calidad y eficiencia adecuadas para atender a los pacientes críticos. Se trata de un servicio médico bien definido que dispondrá como mínimo de seis camas y que funcionará de forma independiente a otros servicios del hospital. En esta área se centralizarán todos los medios tanto humanos como tecnológicos necesarios para poder atender los objetivos de la medicina intensiva, que tal como hemos comentado unas líneas más arriba fundamentalmente se basan en la vigilancia y soporte de las funciones vitales afectadas en pacientes cuya vida se halla en peligro. 


\section{Equipo de profesionales del SMI}

En UCI es necesario un equipo de profesionales que garantice la cobertura médica las 24 horas del día. Así, sería deseable que el grupo de profesionales estuviese formado por un equipo médico, personal de enfermería y otros profesionales necesarios para el correcto funcionamiento de la unidad.

- En relación con el equipo médico cabe señalar que éste debería estar integrado por un jefe de servicio y por un número variable de médicos en función de las necesidades de cada unidad, pero siempre garantizando la continuidad en los cuidados intensivos. Concretamente se recomienda la presencia de al menos cuatro médicos especialistas por cada 6-8 camas.

El jefe de servicio será especialista en anestesiología, medicina interna, cirugía o pediatría y habrá tenido la formación y entrenamiento en cuidados intensivos indicados en las directrices de la Sociedad Europea de Medicina Intensiva. Se dedicará a los cuidados intensivos a tiempo completo o al menos en su mayor parte (75\%). A su vez, compartirá responsabilidad en términos médicos con el resto del equipo. No obstante, será el responsable último sobre la calidad, la seguridad y el buen hacer de la unidad, siendo necesaria su disponibilidad las 24 horas del día, los sietes días de la semana para atender los problemas que pudieran surgir.

El resto de médicos del equipo también serán especialistas en Medicina Intensiva. Se considera importante la formación continua de los médicos, siendo responsable de la misma el jefe de servicio. Igualmente, desde estas recomendaciones se contempla como tarea importante del personal médico, el supervisar y enseñar a los médicos todavía en periodo de formación.

Y este mismo equipo médico será quien definirá los criterios de admisión y alta de la unidad, responsabilizándose de los protocolos de actuación establecidos en cada servicio.

- Por lo que respecta al personal de enfermería en este contexto, su labor es sumamente importante y trabajarán en constante cooperación con el equipo de médicos siendo necesario un sistema de comunicación eficiente entre ambos.

El personal de enfermería estará dirigido por un jefe o supervisor con formación específica y amplia experiencia en los cuidados intensivos (más de cinco años) que le proporcionarán la competencia necesaria para el desarrollo de su actividad en la 
UCI. Será responsable del funcionamiento y de la calidad de los cuidados que proporcione enfermería. De la misma forma, el supervisor debe garantizar la continua formación de enfermeros/as en medicina intensiva y de emergencia así como él mismo estará preparado para participar en la formación del personal de la unidad y en actividades de investigación. Por tanto, el equipo de enfermería también es necesario que esté especialmente formado en medicina intensiva. Y en relación con el número de profesionales recomendado, éste variará entre 1y 3 por paciente dependiendo del nivel de asistencia ofrecido por la unidad

- Asimismo, se recomienda que el SMI tenga acceso las veinticuatro horas del día a un equipo médico multidisciplinar, es decir, que otros profesionales sanitarios ajenos a la unidad estén disponibles para intervenir en caso de que sea necesario. Algunos de estos especialistas pueden ser cirujanos, anestesistas, cardiólogos, radiólogos, traumatólogos, etc.

Dentro del equipo de profesionales del SMI también se incluirá la figura del fisioterapeuta (un fisioterapeuta cada 12 camas), técnicos en radiología (disponibles todo el día), dietistas (en las horas habituales de trabajo) y un/a secretario/a (aproximadamente uno cada 12 camas). Además, para el adecuado funcionamiento de estos servicios se requiere de profesionales de otros ámbitos como puedan ser los técnicos de mantenimiento, calibración y reparación del equipamiento disponible así como personal de limpieza familiarizado con el protocolo de prevención de infecciones y riesgos del equipamiento médico.

\section{Criterios de actividad}

Las recomendaciones sobre los criterios de actividad, en principio hacen referencia tanto a las características de los pacientes críticos (algunas de las cuales ya se han citado a lo largo del texto) como al tamaño proporcional de la UCI respecto al hospital en el que se encuentra.

En cuanto a los pacientes críticos, se considera que serán dos tipos de enfermos los que a priori podrían beneficiarse del ingreso en UCI:

- Pacientes que requieren monitorización y tratamiento al verse amenazadas una o más de la funciones vitales por una enfermedad aguda o por las secuelas de una intervención quirúrgica u otros tratamientos intensivos. 
- Pacientes que ya presentan fallos de una de las funciones vitales (cardiovascular, respiratoria, renal, metabólica, cerebral).

En este sentido, los pacientes de UCI serían aquellos que siendo susceptibles de recuperación precisen soporte respiratorio o requieran soporte respiratorio básico junto con soporte de al menos otros dos órganos o sistemas, así como todos los pacientes que presenten fallo multiorgánico.

Igualmente, la UCI puede atender pacientes que requieran de un menor nivel de cuidado pero cuya situación clínica aconseje una vigilancia intensiva. Y respecto a los pacientes en estadio final de enfermedad, en principio y cuando sea posible, no serían ingresados en estas unidades.

Respecto al tamaño de la UCI, estos criterios incluyen datos orientativos sobre el número de camas destinadas a los cuidados intensivos que variará en función de distintos factores como el tipo de hospital, categorías específicas de enfermedades, localización geográfica, etc. Así, estas cifras oscilarán entre el $4 \%$ de camas en hospitales comunitarios y el 10\% en hospitales universitarios.

\section{Recomendaciones de diseño}

Dentro de los requerimientos mínimos en una UCI se contempla otro grupo de recomendaciones, las cuales hacen referencia al diseño de estas unidades. En este apartado se incluyen normas arquitectónicas para el funcionamiento de los SMI al más alto nivel de cuidados intensivos. Estas directrices contienen información relativa a diferentes aspectos como por ejemplo:

- Quién ha de integrar el equipo de planificación del nuevo SMI.

- Vías de conexión entre UCI y otros servicios como emergencias y quirófanos.

- Acceso de visitas y público en general al servicio.

- Área destinada a los pacientes.

- Puesto central de enfermería.

- Otras instalaciones: almacén, sala de limpieza, salas para personal sanitario, sala de espera para familiares, etc.

- Seguridad contra incendios.

- Suministro de oxígeno, aire comprimido y otros gases médicos.

- Instalaciones centrales de luz, agua, calefacción, etc. 
Como podemos ver, en estas recomendaciones se incluye una amplia variedad de temas. No obstante, creemos oportuno centrarnos en aquellas cuestiones del diseño del área de los pacientes que pueden repercutir más directamente en su bienestar emocional dada la especial relevancia para el tema que nos ocupa. En este sentido las recomendaciones subrayarían los siguientes aspectos:

- Distribuir los espacios de manera que los pacientes que están conscientes no se angustien o aflijan por los problemas agudos de otros pacientes.

- Asegurar el debido respeto a la privacidad de los pacientes.

- Visualizar en todo momento al paciente para facilitar la detección de cambios en su estado y poder mejorar la aplicación de acciones terapéuticas.

- Orientarles de modo que éstos puedan ver a la enfermera/o pero no puedan ver a los otros pacientes.

- Todas las habitaciones de los pacientes deben tener fuente de luz del día.

Tras revisar las principales recomendaciones previstas en el diseño y organización de una UCI con la finalidad de optimizar su funcionamiento, se evidencia la complejidad que las caracteriza. Igualmente, llama la atención que entre los objetivos propuestos en estas directrices no se haga referencia a los cuidados al final de la vida en una unidad de cuidados intensivos así como tampoco a la importancia de incluir como parte del equipo multidisciplinar a un profesional de la salud mental, como un psicólogo, para la atención de los aspectos emocionales necesariamente afectados en los pacientes y familiares que se encuentran en estas unidades y en muchas ocasiones también en los propios profesionales sanitarios.

\subsection{CUIDADOS CRÍTICOS Y CUIDADOS PALIATIVOS EN UCI}

Hacer referencia a los cuidados que pueden recibir los pacientes de alguna manera lleva implícito tener en consideración los objetivos de la medicina. Tradicionalmente el objetivo de la medicina ha sido intentar prevenir y curar las enfermedades. Sin embargo, aunque los avances en esta área han permitido mejorar la capacidad de curación de ciertas enfermedades antes incurables, es importante ser conscientes de que el poder de la medicina no es absoluto. De ahí que los fines de la medicina deberían ser algo más que la curación de la enfermedad y el alargamiento de la vida. En este sentido, Callahan, filósofo y experto en bioética plantea que el objetivo 
de la medicina del S.XXI, debería ser doble: no sólo intentar prevenir y curar las enfermedades, sino también y al mismo nivel, proporcionar los mejores cuidados al final de la vida (Callahan, 2000).

En esta misma línea, el prestigioso centro de investigación en bioética, The Hastings Center de Nueva York, reunió a un equipo de investigadores internacionales con el objetivo de emprender un ambicioso estudio sobre los fines de la medicina obteniéndose como resultado el conocido Informe Hastings (2005). Según este informe, los fines de la medicina de nuestro siglo serían cuatro: a) la prevención de enfermedades y lesiones, y la promoción y conservación de la salud; b) el alivio del dolor y el sufrimiento; c) la atención y curación de los enfermos y la prestación de cuidados a los incurables, y d) evitar la muerte prematura y buscar una buena muerte. De esta manera, podemos considerar que las aportaciones de Callahan y el Informe Hastings hicieron culminar lo que ya en 1982 apuntaba Cassel sobre los objetivos de la medicina en su trabajo "The nature of suffering and the goals of medicine".

Si desde la medicina general se contemplan los citados objetivos dándoles la misma entidad a todos ellos, parece natural pensar que éstos tengan que tenerse en cuenta en un contexto médico especial como son las unidades de cuidados intensivos, puesto que aunque en principio ingresen pacientes potencialmente recuperables, se trata de un contexto en el que a diario se convive con el dolor, el sufrimiento e incluso la muerte. Así, por más avances tecnológicos y por más que se intente negar existe una gran realidad y es que los pacientes críticos no siempre evolucionan hacia la curación o la recuperación sino que en ocasiones fallecen presentando estas unidades una tasa de mortalidad considerable. Concretamente, un estudio llevado a cabo en EE.UU sugiere que el $20 \%$ de todas las muertes de este país tienen lugar en una UCI, lo que se traduce en aproximadamente 540.000 fallecidos al año (Angus et al., 2004). Igualmente, otra investigación realizada en Europa muestra que de los 31.417 pacientes ingresados en UCI durante dieciocho meses consecutivos, 4.248 mueren o tienen limitación del esfuerzo terapéutico, lo que equivale al 13,5\% de los pacientes (Sprung et al., 2003). Y en España, la tasa de mortalidad en UCI durante el año 2.005 ascendió al 10,6\% (Ministerio de Sanidad y Política Social, 2011). Resultados similares se han obtenido en un estudio llevado a cabo en el SMI del Hospital Universitario Asociado General de Castellón, en el que hemos realizado nuestra investigación, con una mortalidad intra SMI del 15,77\% (Heras et al., 2007). 
Estos datos reflejan la importancia de contemplar desde la medicina intensiva un objetivo más allá de mejorar la supervivencia de los pacientes en el que el alivio del dolor y el sufrimiento sean una prioridad. En estas unidades no se tratará de alargar la vida de las personas a cualquier precio, sino que en aquellas situaciones en las que se hayan agotado las opciones terapéuticas disponibles o no haya posibilidades de recuperación, se intentará aliviar en la medida de lo posible el sufrimiento de la persona y conservar aquella vida que a juicio del enfermo merezca ser vivida (Bayés, 2006a). En este sentido, podemos señalar que ya en el año 1997, en un documento de la American Thoracic Society sobre la asignación de recursos en UCI, destacaban entre los principales objetivos de la unidad de cuidados intensivos el "preservar la vida humana con significado desde el punto de vista del paciente" y "proporcionar cuidados compasivos a los moribundos y sus familiares, asegurando el alivio del sufrimiento de los pacientes en sus horas finales".

De esta manera, se evidenciaría el hecho de que en ocasiones en el contexto de una UCI los cuidados críticos coexisten con los paliativos. Tradicionalmente se han intentado delimitar por separado los cuidados intensivos y los cuidados paliativos. Los primeros dedicados a enfermos críticos cuya vida estaba amenazada pero que tenían posibilidades razonables de recuperación y los segundos a pacientes terminales para los que la ciencia sólo podía ofrecer el alivio de las manifestaciones de un proceso incurable. No obstante, la realidad es bastante más compleja y a pesar del esfuerzo por delimitar dos tipos de cuidados con perfiles y características bien diferenciados, en la evolución de ambos se encuentran puntos de conexión y sinergia llegando incluso a fundirse (Levy \& Carlet, 2001; Palomeque, 2005) sobre todo si tenemos en cuenta los siguientes hechos (Gómez, 2002):

a) Un porcentaje importante de pacientes críticos ingresados en la UCI acaban falleciendo.

b) Casi todos los enfermos que fallecen en la UCI, lo hacen después de que ellos o sus médicos hayan renunciado a algunas de las posibilidades que ofrecen las modernas tecnologías por alargar la vida (es decir, después de algún gesto de limitación del esfuerzo terapéutico). 
c) Tan importante como conocer las posibilidades de la medicina actual es ser consciente de sus limitaciones, y tan primordial como el intento de curar es evitar el sufrimiento innecesario.

Además, en este contexto a menudo resulta difícil identificar a tiempo aquellos pacientes que no van a recuperarse con la finalidad de cambiar la orientación de los cuidados de curativos a paliativos. Dado que el riesgo de muerte de pacientes en UCI es considerable, así como el grado de distrés y malestar, parece obvio pensar que lo más apropiado sería ofrecer una propuesta alternativa que atienda las necesidades de pacientes y familiares, tanto de aquellos que luchan por alargar la vida como de los que se están enfrentando al final de sus días. Así, el modelo tradicional que distingue claramente entre pacientes terminales y críticos cedería paso a un nuevo modelo, un modelo integral (Nelson \& Danis, 2001; Nelson \& Meier, 1999a; Nelson \& Meier, 1999b) en el que los cuidados paliativos se incluyeran en los cuidados críticos pudiéndose beneficiar de ellos todos los pacientes críticamente enfermos y sus familias. Por tanto, los tratamientos curativos y los paliativos estarían presentes en mayor o menor grado en una UCI dependiendo de la situación clínica particular y siempre intentando maximizar la humanidad y la eficacia de los tratamientos que se proporcionan en este contexto. De hecho parece existir consenso sobre la idea de que los cuidados paliativos pertenezcan al núcleo del currículo de los cuidados críticos (Nelson \& Meier, 1999a).

Igualmente, es necesario tener en consideración que ciertos pacientes dependen al final de sus días de la tecnología que ofrece una unidad de cuidados intensivos no siendo posible su traslado a una unidad de cuidados paliativos. Por otra parte, el traslado a otra unidad de los pacientes que se espera que sobrevivan poco tiempo una vez retirados los tratamientos de soporte vital, podría añadir estresores en esta etapa final. Entre ellos podríamos citar el esfuerzo requerido por adaptarse a un ambiente desconocido con nuevos cuidadores, lo que sin duda alguna repercutiría negativamente en el paciente, pudiendo interferir en el afrontamiento adaptativo de la muerte. No obstante, sería aconsejable valorar costes y beneficios sobre el posible traslado a otras unidades en cada caso particular, primando siempre los deseos y bienestar del paciente con independencia de la unidad en la que se encuentre.

Por ello, a lo largo del ingreso de un paciente en UCI se deberían contemplar planes paralelos de cuidados (intensivos y paliativos) lo que a su vez plantearía la necesidad de que el profesional sanitario que atiende a pacientes críticos tuviera mayor 
experiencia y formación en cuidados paliativos (Mularski, 2006; Nelson \& Meier, 1999a). Así, los médicos de intensivos deberían estar tan preparados y formados en lo relacionado a la renuncia de tratamientos de soporte vital como lo están en proporcionar cuidados dirigidos a curar (Truog et al., 2001). En este sentido, en el contexto de una UCI sería aconsejable profundizar también en el estudio de aquellos aspectos que permitieran poder llevar a cabo cuidados de calidad al final de la vida.

Según Rubenfeld y Curtis (2001) un posible punto de partida para mejorar la atención al final de la vida en UCI podría ser clarificar de antemano los principales objetivos de cuidado así como evitar el ingreso en UCI cuando éste no se desee o cuando sea improbable satisfacer los propósitos del paciente. Igualmente, en esa misma línea, sería importante conocer cuál es la realidad presente para poder encontrar soluciones alternativas, es decir, identificar aquellos aspectos que potencialmente impedirían u obstaculizarían cuidados de calidad al final de la vida en UCI para intentar subsanarlos. Así, Nelson y Meier (1999a) plantean como posibles obstáculos a los cuidados paliativos en este contexto los siguientes:

- La especialidad de medicina intensiva se desarrolló para evitar que los pacientes murieran, incluso pacientes en situaciones avanzadas de enfermedad.

- Falta de reconocimiento de que una muerte en paz y digna constituye un objetivo legítimo o un logro profesional valioso.

- El enfoque tecnológico resta valor a los problemas que no pueden cuantificarse (muchas cuestiones que se plantean en paliativos son de este tipo).

- El curso de las enfermedades críticas es impredecible, y no siempre es evidente antes de la propia muerte el que se vaya a morir.

- Los pacientes a menudo incapacitados no pueden tomar decisiones autónomas.

- El equipo que proporciona cuidados de salud está fragmentado (desacuerdo entre profesionales puesto que cada uno tiene su propio sistema de valores y creencias).

- La comunicación es particularmente difícil debido a que las relaciones son a corto plazo y se da en situaciones críticas especialmente delicadas.

- Los seguimientos son limitados.

- Inadecuado conocimiento y habilidades del profesional en medicina paliativa.

- Información inadecuada sobre los cuidados paliativos de los pacientes críticamente enfermos. 
- Presiones económicas.

A pesar del esfuerzo dedicado durante los últimos años por incluir los cuidados paliativos en las unidades de cuidados intensivos, estudios recientes muestran que los cuidados al final de la vida en pacientes críticos siguen siendo poco adecuados. En este sentido se considera que es esencial comprender cómo se están llevando a cabo los actuales cuidados al final de la vida en las UCI, identificando aquellos aspectos que impiden alcanzar cuidados óptimos al final de la vida para poder conseguir posibles soluciones al respecto (Nelson et al., 2006).

\subsection{RECOMENDACIONES AL FINAL DE LA VIDA EN LAS UNIDADES DE CUIDADOS INTENSIVOS}

En este contexto en el que se plantea que los cuidados paliativos e intensivos no son opciones excluyentes sino que deben coexistir, desde el Comité ético de la Society of Critical Care Medicine (Truog et al., 2001; Truog et al., 2008) así como desde el Grupo de trabajo de Bioética de la SEMICYUC (Monzón et al., 2008) se proponen una serie de recomendaciones para mejorar los cuidados al final de la vida en una unidad de cuidados intensivos. Estas recomendaciones sobre todo estarán relacionadas con la preparación de los diferentes agentes implicados en una UCI, el confort del paciente, la comunicación con la familia y otros aspectos más médicos (retirada de tratamientos de soporte vital, extubación terminal, pautas de actuación en lo referente a la sedación en el final de la vida, etc.), que no pasaremos a comentar por alejarse del objetivo del trabajo que nos ocupa. A continuación se resumirán las principales recomendaciones.

\section{Preparación del paciente, la familia y el equipo clínico}

Ante la decisión de renunciar a los tratamientos de soporte vital es necesario preparar tanto a la familia como al equipo clínico para lo que supuestamente les espera en esta situación. Se trata de un acontecimiento singular en la vida del paciente y en el que posiblemente la familia no tenga experiencia, pudiendo experimentar gran malestar asociado sobre todo a sintomatología ansiosa, la cual podría aliviarse con explicaciones claras y explícitas por parte de los médicos que a su vez ayudarían a reorientar las expectativas de la familia. 
Por todo ello, desde estas recomendaciones se plantea como fundamental atender las necesidades particulares de los diferentes agentes implicados.

- Necesidades de los pacientes

Los pacientes presentan necesidades a distintos niveles, es decir, tanto a nivel físico, como emocional, social y espiritual, las cuales será esencial tener en consideración (Hastings Center, 2005). En esta línea, autores como Singer, Martin y Kelner (1999) identifican como parte de una buena práctica clínica al final de la vida la atención de cinco áreas concretas, como son el adecuado control de los síntomas de dolor, evitar alargar innecesariamente la vida, facilitar el sentido de control, aliviar o mitigar posibles cargas y estrechar relaciones con los seres queridos. Todas ellas en mayor o menor medida serán relevantes en este contexto adquiriendo si cabe mayor protagonismo el control de los síntomas de malestar y dolor. En este sentido el equipo sanitario deberá dar la certeza al paciente de que sus necesidades serán atendidas en función de sus preferencias particulares.

Igualmente es necesario asegurar que serán tratados con total respeto y dignidad tanto durante el proceso de morir como después, permitiendo la presencia continua de los familiares y amigos junto al paciente en los casos en que así se desee, puesto que es de suma importancia para los pacientes con capacidad de relacionarse tener la oportunidad de poder decir adiós. No obstante, cabe tener en consideración que puede haber diferencias de unos pacientes a otros.

Asimismo, en estas circunstancias los pacientes tendrán la certeza de que sus creencias culturales serán comprendidas y respetadas así como también que se intentará satisfacer sus necesidades espirituales y religiosas.

Estas recomendaciones ponen de relieve que la obligación de los profesionales sanitarios será proporcionar cuidados que alivien el sufrimiento no sólo físico sino también emocional, social y espiritual.

- Necesidades de la familia

Cada vez se es más consciente del valioso papel de la familia al final de la vida sobre todo en contextos como una unidad de cuidados intensivos, donde frecuentemente son los familiares y/o allegados quienes tienen que participar en decisiones relevantes referidas al paciente ya que a éste en numerosas ocasiones le 
resulta imposible poder hacerlo, debido a la propia gravedad de la enfermedad o por encontrarse bajo sedación. De ahí la importancia creciente de fomentar un enfoque centrado en la familia (Azoulay, 2005).

Es aconsejable que los familiares del paciente reciban información si se produce un cambio clínico importante y en el caso de que el paciente se esté muriendo necesitarán estar informados sobre todo lo relacionado con el proceso de morir. No obstante, la comunicación entre los médicos y las familias en este contexto no es tarea sencilla, tal como señalan distintas investigaciones (Abbott, Sago, Breen, Abernethy \& Tulsky, 2001; Azoulay et al., 2000; Deep, Griffith \& Wilson, 2008).

Asimismo, se garantizará cierta flexibilidad horaria ante la imposibilidad por parte de la familia para acudir tanto a la hora prevista de información como a las visitas. Además la familia necesita tener la oportunidad de estar junto al paciente el mayor tiempo posible en un momento tan delicado, sin olvidarnos de las ventajas que esta mayor flexibilidad puede tener tanto para la familia como para el paciente (Whitton \& Pittiglio, 2011). Aunque no siempre sea viable, disponer de una habitación individual sería lo más apropiado para tener intimidad tanto física como emocional y debería considerarse como un objetivo importante para proporcionar cuidados excelentes al final de la vida. Igualmente, cuando las circunstancias lo permitan y dentro de lo razonable, la retirada del soporte vital debería ser programada facilitando la llegada de aquellos familiares que tengan que desplazarse largas distancias hasta el hospital. Sin embargo, cabe destacar que no todas las familias quieren estar junto a la cama en el momento de la muerte del paciente, lo cual también es necesario respetar.

De la misma forma, tener en consideración ciertos detalles podría contribuir a la sensación de bienestar y tranquilidad de la familia, como por ejemplo conocer de forma clara la identidad del médico que les atiende, tener la seguridad de que los médicos se centran en el confort del paciente, que éste no estará solo aun cuando ellos no puedan estar a su lado, saber que la responsabilidad de sus decisiones será compartida con el equipo sanitario así como sentirse útiles participando en el cuidado del paciente en la medida de lo posible.

Y finalmente, respecto a la necesidades de la familia cabe señalar que la responsabilidad de los cuidados intensivos no finaliza cuando muere el paciente, sino que desde estas recomendaciones se hace referencia a que en la medida de lo posible será pertinente facilitar apoyo a los familiares en duelo. En este sentido Fauri, Ettner y 
Kovacs (2000) señalan que facilitar un seguimiento del duelo en estas circunstancias facilitaría sin duda alguna la adaptación de la familia.

- Necesidades del equipo clínico

El equipo de profesionales sanitarios como ya hemos comentado anteriormente ha de ser multidisciplinar y estar comprometido a cooperar y a que la comunicación entre todos los miembros sea clara, lo que exigirá desarrollar un mayor consenso entre los distintos profesionales en relación con los objetivos y estrategias para proporcionar cuidados al final de la vida en UCI (Curtis \& Vincent, 2010).

Por su parte los profesionales de UCI a diario se enfrentan al sufrimiento de los pacientes y sus familias, acompañado de una gran dosis de incertidumbre respecto al resultado de los tratamientos. Adquirir las habilidades necesarias en el manejo de estas circunstancias requiere mejorar la formación teórica y práctica incluyendo cuestiones relacionadas con los cuidados al final de la vida, dando la oportunidad a todos los profesionales de adquirir conocimientos sobre cuidados intensivos-paliativos (Danis et al., 1999). Al mismo tiempo es necesario que reciban suficiente apoyo administrativo para de esta manera aliviar la gran carga de trabajo a la que se ven sometidos, así como también apoyo institucional y de otros compañeros.

Por último hay que tener en cuenta que los profesionales también pueden estar en duelo y/o experimentar malestar tras la atención de determinados pacientes dado el vínculo que ha podido establecerse entre ellos durante la estancia en UCI (Ballester, Gil \& Bernat, 2009). A este respecto podría ser beneficioso para los sanitarios recibir formación específica sobre los problemas asociados a la muerte y el duelo, mantener sesiones regulares programadas donde puedan compartir sus pensamientos y experiencias, establecer sistemas de comunicación e información efectivos entre los miembros del equipo así como entre el equipo y los usuarios, fomentar la formación en habilidades para el afrontamiento de estas situaciones, así como establecer sistemas de apoyo intergrupales para la protección de las personas más vulnerables. Todo ello con la finalidad de preservar la integridad y bienestar de los profesionales sanitarios.

\section{Asegurar el confort de los pacientes}

Tradicionalmente la medicina intensiva se ha basado en el modelo curativo, por lo que los médicos suelen tener dificultades para adoptar un modelo centrado en los síntomas. Llegado este momento el alivio de los síntomas generadores de malestar, el 
alivio del sufrimiento es básico. Una diferencia importante entre el modelo curativo y el modelo paliativo es el criterio utilizado para determinar si ciertos procedimientos terapéuticos o diagnósticos son indicados dada la situación del paciente.

En ocasiones, al final de la vida los pacientes pueden recibir combinaciones de tratamientos incompatibles, algunos dirigidos a proporcionar confort y otros a la curación. En dichas situaciones, una solución posible sería reformular completamente el plan de cuidado del paciente, como si fuera ingresado de nuevo en UCI.

En este sentido algunos procedimientos terapéuticos considerados propios de la UCI pueden no contribuir positivamente al confort del paciente en cuyo caso deberían ser excluidos. En cambio, otros procedimientos típicos de UCI producen malestar ligero a cambio de proporcionar gran beneficio al paciente, en cuyas circunstancias sería razonable mantener estas terapias incluso en pacientes terminales que no reciben otros tratamientos que prolonguen la vida. Es necesario tener en cuenta que los médicos han de interpretar los objetivos del tratamiento siempre desde la perspectiva del paciente (Mosenthal, Lee \& Huffman, 2002).

\section{Comunicación con la familia en torno a la muerte}

Dar malas noticias es una de las tareas más difíciles a la que se enfrentan los médicos pero es una necesidad en la práctica de la medicina crítica. A pesar de la importancia que tienen las habilidades de comunicación en el ejercicio de la profesión, la formación específica en este ámbito es más bien escasa tal como revela la literatura revisada sobre el tema (Bascuñan, Roizblatt \& Roizblatt, 2007; Vandekieft, 2001). En esta línea, se considera que las siguientes recomendaciones podrían ser de ayuda (Campbell \& Sanson-Fisher, 1998; Ptacek \& Eberhardt, 1996 ):

a. Las malas noticias se darán siempre que se pueda en persona, preferiblemente en una habitación privada con asiento disponible para todos.

b. Los médicos deberán cuidar su apariencia sobre todo después de llevar a cabo ciertas maniobras en UCI como la resucitación.

c. Los médicos deberán aprender cómo demostrar compasión y empatía, empezando con palabras de condolencia, manteniendo el contacto ocular y un pequeño contacto físico reconfortante siempre y cuando sea apropiado.

d. Evitar frases hechas que aun siendo bien intencionadas a menudo no son bien recibidas e incluso pueden llegar a ofender. 
e. Utilizar un vocabulario claro que los familiares puedan entender fácilmente.

f. No tener miedo de utilizar las palabras "morir" y "muerte".

g. Cuando el paciente se declara muerto neurológicamente, es decir, "muerte cerebral" (la hora del fallecimiento que aparecerá en el certificado de defunción), los médicos han de ser especialmente cuidadosos para no confundir a la familia. Deben tener cuidado en proporcionarles mensajes precisos y coherentes y enfatizar que las funciones cerebrales se mantienen artificialmente y cesarán tan pronto como se paren las máquinas.

En estas circunstancias, además de la notificación del fallecimiento del paciente, los profesionales sanitarios también necesitan informar a la familia sobre otras cuestiones como por ejemplo la posibilidad de realizar una autopsia o la donación de órganos.

En referencia a la primera, en ocasiones los médicos tienen la oportunidad de abordarlo antes del fallecimiento, particularmente en aquellas situaciones en las que la muerte es esperada y el paciente o la familia han podido manifestar sus deseos de antemano. Sin embargo, en la mayoría de casos las discusiones sobre la autopsia tienen lugar en un periodo corto de tiempo después de la muerte del paciente. Dado que los familiares se encuentran abatidos por el dolor de haber perdido a un ser querido, muchas familias no están en disposición de tomar decisiones de este calibre, lo cual merece total respeto y comprensión por parte de los profesionales sanitarios. Por lo que respecta a la discusión en torno a la posible donación de órganos, se recomienda que ésta se haga por separado a la notificación de la muerte del paciente y además por un profesional especialmente entrenado (Williams et al., 2003).

Finalmente, cabe señalar que en las recomendaciones sobre el final de la vida en una UCI, tanto en relación con lo que acabamos de citar como en lo relativo a la retirada de soporte vital es necesario tener en cuenta las prioridades del propio paciente y actuar de acuerdo con su sistema de valores y creencias, asegurando en la medida de lo posible la satisfacción de sus necesidades.

Estas recomendaciones en cuidados al final de la vida propuestas desde la Society of Critical Care Medicine y la Sociedad Española de Medicina Intensiva, Crítica y Unidades Coronarias, reflejan las principales consideraciones vigentes en estos 
momentos respecto al final de la vida en una UCI y en las que se basarán la mayoría de protocolos de actuación de las diferentes unidades de cuidados intensivos.

En resumen, como hemos visto a lo largo del capítulo las unidades de cuidados intensivos constituyen un entorno complejo cuyo principal objetivo será por un lado intentar salvar la vida del paciente crítico mediante la vigilancia y soporte continuo de las funciones vitales afectadas y en los casos en que fracasen las medidas terapéuticas disponibles, ayudar a que el paciente muera lo más dignamente posible.

Estas unidades se caracterizan por contar con la más moderna tecnología a disposición de los pacientes, contribuyendo a hacer de éste un ambiente poco familiar en el que constantemente irrumpen estímulos sensoriales extraños. Si además tenemos en cuenta la gran cantidad de temores que conlleva el ingreso en UCI (miedo al dolor, al sufrimiento y a la propia muerte), es fácil comprender la afectación emocional de los pacientes y sus familiares como consecuencia de esta experiencia. Por tanto, será necesario considerar una atención integral del paciente crítico y su familia más allá de los cuidados físicos, llevada a cabo por un equipo multidisciplinar en el que además de médicos, enfermeras y auxiliares se incluyan profesionales de la salud mental, como los psicólogos. 

CAPÍTULO 2

\section{AFECTACIÓN EMOCIONAL DE LOS PACIENTES INGRESADOS EN UNA UNIDAD DE CUIDADOS INTENSIVOS}





\section{AFECTACIÓN EMOCIONAL DE LOS PACIENTES INGRESADOS EN UNA UNIDAD DE CUIDADOS INTENSIVOS}

El ingreso en una Unidad de Cuidados Intensivos (UCI) lleva asociado además del estrés de ingresar en un hospital (Koenig, George, Stangl \& Tweed, 1995) el hecho de que se trata de una unidad específica con ciertas características que la diferencian de otros servicios del hospital, como la alta tecnología que se utiliza para la vigilancia y cuidado de los pacientes, la limitación de la autonomía de los enfermos y la gravedad médica de los mismos con los razonables miedos al sufrimiento y a la muerte. Se trata de un ambiente en el que constantemente asaltan estímulos sensoriales extraños (Moser et al., 2003), con todas las implicaciones que esto conlleva. Además, el ingreso en UCI exige un reajuste importante en la vida de estas personas al verse alterada su dinámica habitual, pues abandonan temporalmente los roles que venían desempeñando en su entorno, teniendo que adaptarse a esta nueva situación la mayoría de veces inesperada (Lange, 2001).

De esta manera, los pacientes de UCI se enfrentan a una situación realmente estresante y disruptiva, que requiere de un proceso de adaptación a lo largo del cual pueden experimentar diversas alteraciones emocionales.

\subsection{LA ADAPTACIÓN AL ENTORNO DE UNA UNIDAD DE CUIDADOS INTENSIVOS}

El rápido progreso de la medicina crítica lleva asociados avances importantes en la tecnología convirtiendo estas unidades específicas del hospital en los entornos más sofisticados a nivel tecnológico (Lindahl, 2005; Wikström, 2003) que pueden resultar un tanto extraños e incluso hostiles para los pacientes, especialmente la primera vez que ingresan en una unidad de estas características.

Por su propia naturaleza, las unidades de cuidados intensivos se consideran en general entornos estresantes. En este sentido, parece obvio que el hecho de atender aquellos factores que contribuyan al estrés de los pacientes críticos así como satisfacer las necesidades originadas tras su ingreso en UCI, podría contribuir en la mejora de la calidad de los cuidados proporcionados en este contexto. 


\subsubsection{ESTRESORES EN UNA UCI}

Ciertas características propias del entorno de una unidad de cuidados intensivos pueden constituir una fuente importante de estrés. Entre los aspectos más investigados frecuentemente se incluyen el ruido, la privación de sueño, el aislamiento social y los problemas de comunicación (Alasad \& Ahmad, 2005; Granberg-Axèll, 2001), que junto con otros posibles estresores asociados a este contexto podrían repercutir de manera notable en la salud de los enfermos, tanto a nivel físico como psicológico, influyendo en el proceso de recuperación de su enfermedad.

Antes de centrarnos en el estudio de los estresores asociados a una UCI sería pertinente hacer un breve repaso sobre el concepto de estrés, el cual ha resultado ser un tanto controvertido. La primera definición del término viene de la mano de Selye (1936, citado en Ballard, 1981) quien consideró al estrés como un conjunto de respuestas fisiológicas no específicas a estímulos físicos externos o internos (estresores) que implicaba una activación del eje hipotalámico-hipofísico-suprarrenal y del sistema nervioso autónomo. A este proceso lo llamó "Síndrome de Adaptación General", que describió en tres etapas claramente diferenciadas: alarma, resistencia y agotamiento. Aunque inicialmente Selye postuló una respuesta no específica, general a cualquier estresor, ignorando diferencias cualitativas, unos años más tarde (1974) estableció la diferencia entre eustrés y distrés. El primero sería el llamado "estrés bueno" ya que suele asociarse con sentimientos positivos y estados corporales saludables. Mientras que el segundo sería el "estrés malo", asociado con sentimientos negativos y estados corporales alterados.

A diferencia del estrés fisiológico investigado por Selye, el estrés que solemos experimentar es siempre el resultado de una mediación cognitiva (Lazarus 1966, 1974) aspecto que no contempla Selye. De la misma forma, este autor tampoco tuvo en cuenta el papel de los mecanismos de afrontamiento como importantes mediadores de la relación entre el estrés y sus resultados. Sin embargo, estos dos aspectos son centrales desde el punto de vista de las teorías psicológicas del estrés.

Si bien es cierto que la teoría de Selye ha sido muy útil, también lo es que en ella no se explican las diferencias individuales en las respuestas de estrés observadas en distintos sujetos ante los mismos acontecimientos estresantes. En este contexto, surge la teoría del estrés de Lazarus, que tras haber sufrido distintas revisiones (Lazarus, 1991; Lazarus \& Folkman, 1984) considera al estrés como un concepto relacional, es decir, el 
estrés no es definido ni como un tipo específico de estimulación externa, ni como un patrón específico de reacciones fisiológicas, comportamentales o subjetivas sino como una relación (transacción) entre los individuos y su medio ambiente. Así, la "Teoría transaccional del estrés" de Lazarus y Folkman (1984), plantea que la persona y el ambiente mantienen una relación dinámica, mutuamente recíproca y bidireccional. Por ello el estrés es considerado como un proceso que incluye las transacciones entre el individuo y su medio ambiente durante el cual la percepción de amenaza y/o daño ocasiona reacciones físicas y psicológicas. Esta concepción del estrés lleva implícito también el concepto de significado personal ya que según Lazarus (1993) lo que causa las reacciones de estrés no será el estresor ambiental por sí solo sino la evaluación que lleva a cabo la persona sobre su significado.

Así, es necesario tener en cuenta que las personas pueden percibir de forma diferente las situaciones estresantes a la vez que también emplearán diferentes habilidades, capacidades y recursos, tanto personales como sociales (familia, amigos, etc.), para hacerles frente (Lazarus \& Folkman, 1984; Sandín, 1999, 2003) y el contexto de una unidad de cuidados intensivos no será una excepción.

Con la finalidad de identificar los principales aspectos susceptibles de producir estrés en una UCI así como su impacto en los pacientes críticos se han llevado a cabo diferentes estudios.

Un estudio pionero en esta área fue el llevado a cabo en 1967 por De Meyer, quien pensaba que la percepción que el paciente tenía de su entorno y de los cuidados recibidos en él jugaban al menos en parte un papel importante en su proceso de recuperación. En este estudio el autor describió cómo los pacientes de UCI se sentían atados, referían quejas sobre el ruido y falta de tranquilidad, pérdida de la noción del tiempo y también se quejaban de no ser incluidos en las conversaciones que tenían lugar a su alrededor. Otro autor importante en este contexto, Ballard (1981), en un estudio con pacientes de UCI postquirúrgicos encontró que los pacientes reconocían como principales estresores la restricción de movimientos y la presencia de tubos por la nariz y la boca. También fueron valorados como estresantes en orden decreciente el tener dolor y sed, el estar aislados de sus familiares, tener dificultades para dormir y la pérdida de orientación -por ejemplo, no saber la hora que era-.

Unos años más tarde en otra investigación llevada a cabo en una UCI general (Novaes, Aronovich, Ferraz \& Knobel, 1997) se obtuvo que los principales estresores 
físicos eran el dolor y no poder dormir debido al ruido y a los tubos que llevaban los pacientes en nariz y/o boca. Igualmente mostraron como principales estresores psicológicos, la pérdida de control (estado de dependencia de los demás) y la falta de explicaciones sobre el tratamiento y los procedimientos médicos.

Posteriormente, se llevó a cabo un estudio (Novaes et al., 1999) en el que se intentaba comparar la percepción de los principales estresores para los pacientes desde el punto de vista del propio paciente, sus familiares y profesionales sanitarios. Los resultados obtenidos mostraron que los factores estresantes más importantes para los tres grupos fueron: tener dolor, dificultades para dormir y la presencia de tubos en nariz y/o boca. No obstante, se encontraron diferencias entre los grupos en relación con otros factores como por ejemplo, "no tener a la familia al lado" aspecto que fue valorado como más estresante desde el punto de vista de la familia, mientras que al paciente le preocuparían más aquellas cuestiones relacionadas con su enfermedad y posible recuperación.

Hay que tener en cuenta que en el caso de la intubación de los pacientes, además de las molestias o incomodidades físicas que puede provocar, ésta también limita las posibilidades de comunicarse y comer, y en general añade estrés a todas las demás restricciones de UCI. Por otra parte, la pérdida de independencia puede generar angustia y sensación de impotencia, causa importante de inestabilidad psicológica en este contexto.

En una investigación posterior Granja et al. (2005) obtuvieron como principales experiencias generadoras de estrés en los pacientes las siguientes: aspiración del tubo traqueal, tubos por la nariz, preocupación por la familia, dolor, inmovilización en la cama y miedo a morir/incertidumbre sobre el futuro.

Un año más tarde, los resultados de un estudio piloto llevado a cabo por Ballester et al. (2006) detectaron como principales estresores en los pacientes de UCI el tener dolor, permanecer acostados/sentados todo el día, utilizar la cuña, la posibilidad de experimentar dolor por la realización de pruebas, el miedo a que no le dieran medicación para el dolor cuando lo necesitara, tener que ser ayudado para hacer sus necesidades, no tener la compañía de familiares y amigos a lo largo de todo el día, no saber cómo quedaría tras la operación, no sentir alivio del dolor a pesar de la medicación y no entender en qué consistía la enfermedad. 
Más tarde, Ayllón, Álvarez y González (2007) encontraron que los diez factores considerados como más estresantes por los pacientes eran en orden decreciente los siguientes: tener sed, dificultad/imposibilidad para dormir, presencia de tubos en nariz o boca, no saber qué hora es, tener pesadillas, no poder hablar, tener limitada la movilidad por la presencia de tubos, la mascarilla de oxígeno, ausencia de un familiar cercano y que el horario de visitas sea limitado.

Y más recientemente, otros investigadores (Meriläinen, Kyngäs \& Ala-Kokko, 2010) tras entrevistar a pacientes de UCI han observado que ciertos factores como el ruido, las luces intensas, la falta de intimidad, el estar aislados de sus seres queridos, la falta de información y el escuchar voces y ruidos mientras los sanitarios atendían a otros pacientes en la unidad podían ser causa de estrés y malestar en los pacientes.

Como se puede apreciar, a lo largo de los años se han llevado a cabo diferentes estudios con el objetivo de identificar los principales estresores desde el punto de vista de los pacientes ingresados en una UCI. A pesar de que estas investigaciones se han realizado en centros diferentes, de ciudades también distintas y en contextos socioculturales que han ido variando con el paso de los años, el contenido de los estresores descritos es bastante similar. De entre los aspectos físicos predomina el tener dolor, no poder dormir, estar intubados y con la movilidad restringida, mientras que otros factores como la pérdida de control (dependencia de los demás), la pérdida de orientación (sobre todo temporal) y la falta de explicaciones sobre el tratamiento y procedimientos constituyen potentes estresores psicológicos en los pacientes (véase Cuadro 1). 
Cuadro 1. Principales estresores en una Unidad de Cuidados Intensivos

\begin{tabular}{|c|c|c|c|c|c|c|}
\hline $\begin{array}{c}\text { De Meyer } \\
\text { (1967) }\end{array}$ & $\begin{array}{l}\text { Ballard } \\
\text { (1981) }\end{array}$ & $\begin{array}{c}\text { Novaes, } \\
\text { Aronovich, } \\
\text { Ferraz \& Knobel } \\
\text { (1997) }\end{array}$ & $\begin{array}{c}\text { Granja et al. } \\
\text { (2005) }\end{array}$ & $\begin{array}{c}\text { Ballester et al. } \\
\text { (2006) }\end{array}$ & $\begin{array}{l}\text { Ayllón, Álvarez } \\
\text { \& González } \\
\text { (2007) }\end{array}$ & $\begin{array}{l}\text { Meriläinen } \\
\text { et al. (2010) }\end{array}$ \\
\hline & (3) Dolor & (1) Dolor & (4) Dolor & $\begin{array}{l}\text { (1) (4) (5) (9) } \\
\text { Dolor }\end{array}$ & & \\
\hline \multirow[t]{8}{*}{$\begin{array}{l}\text { Sentirse } \\
\text { atados }\end{array}$} & $\begin{array}{l}\text { (1) } \\
\text { Restricción } \\
\text { de } \\
\text { movimientos }\end{array}$ & $\begin{array}{l}\text { (5) Sentirse } \\
\text { atados por los } \\
\text { tubos }\end{array}$ & $\begin{array}{l}\text { (5) } \\
\text { Inmovilización } \\
\text { en la cama }\end{array}$ & & $\begin{array}{l}\text { (7) Restricción de } \\
\text { movimientos por } \\
\text { los tubos }\end{array}$ & \\
\hline & & & & $\begin{array}{l}\text { (2) } \\
\text { Acostado/sentado } \\
\text { todo el día }\end{array}$ & & \\
\hline & $\begin{array}{l}\text { (2) Tubos en } \\
\text { nariz y boca }\end{array}$ & $\begin{array}{l}\text { (3) Tubos en } \\
\text { nariz y boca }\end{array}$ & $\begin{array}{l}\text { (2) Tubos por } \\
\text { nariz } \\
\text { (1) Tubo } \\
\text { traqueal }\end{array}$ & & $\begin{array}{l}\text { (3) Tubos en } \\
\text { nariz o boca }\end{array}$ & \\
\hline & $\begin{array}{l}\text { (6) } \\
\text { Dificultades } \\
\text { para dormir }\end{array}$ & $\begin{array}{l}\text { (2) Dificultades } \\
\text { para dormir }\end{array}$ & & & $\begin{array}{l}\text { (2) } \\
\text { Dificultad/imposi } \\
\text { bilidad para } \\
\text { dormir }\end{array}$ & \\
\hline & & & & & $\begin{array}{ll}\text { (5) } & \text { Tener } \\
\text { pesadillas } & \end{array}$ & \\
\hline & $\begin{array}{l}\text { (5) Aislados } \\
\text { de la familia }\end{array}$ & & $\begin{array}{l}\text { (3) } \\
\text { Preocupación } \\
\text { por familia }\end{array}$ & $\begin{array}{l}\text { (7) No tener a } \\
\text { familiares y } \\
\text { amigos todo el día }\end{array}$ & $\begin{array}{l}\text { (9) Ausencia de } \\
\text { un familiar } \\
\text { cercano }\end{array}$ & $\begin{array}{l}\text { Aislados de } \\
\text { seres } \\
\text { queridos }\end{array}$ \\
\hline & & & $\begin{array}{l}\text { (6) Miedo a } \\
\text { morir/ } \\
\text { incertidumbre } \\
\text { sobre el } \\
\text { futuro }\end{array}$ & $\begin{array}{l}\text { (8) No saber } \\
\text { cómo quedará } \\
\text { tras la operación }\end{array}$ & & \\
\hline & & $\begin{array}{l}\text { (6) No recibir } \\
\text { explicaciones } \\
\text { tratamientos }\end{array}$ & & $\begin{array}{l}\text { (10) No entender } \\
\text { en qué consiste la } \\
\text { enfermedad }\end{array}$ & & $\begin{array}{l}\text { Falta de } \\
\text { información }\end{array}$ \\
\hline \multirow[t]{2}{*}{$\begin{array}{l}\text { Pérdida de } \\
\text { noción del } \\
\text { tiempo }\end{array}$} & $\begin{array}{l}\text { (7) Pérdida } \\
\text { de } \\
\text { orientación } \\
\text { (no saber la } \\
\text { hora que } \\
\text { era) }\end{array}$ & $\begin{array}{l}\text { (4) No tener } \\
\text { control de sí } \\
\text { mismos }\end{array}$ & & & $\begin{array}{l}\text { (4) No saber qué } \\
\text { hora es }\end{array}$ & \\
\hline & & & $\begin{array}{l}\text { (8) } \\
\text { Dificultades } \\
\text { comunicación }\end{array}$ & & $\begin{array}{l}\text { (6) No poder } \\
\text { hablar }\end{array}$ & \\
\hline
\end{tabular}


(Continuación Cuadro 1)

\begin{tabular}{|c|c|c|c|c|c|c|}
\hline $\begin{array}{l}\text { De Meyer } \\
\text { (1967) }\end{array}$ & $\begin{array}{l}\text { Ballard } \\
\text { (1981) }\end{array}$ & $\begin{array}{l}\text { Novaes, } \\
\text { Aronovich, } \\
\text { Ferraz \& Knobel } \\
\text { (1997) }\end{array}$ & $\begin{array}{l}\text { Granja et al. } \\
(2005)\end{array}$ & $\begin{array}{l}\text { Ballester et al. } \\
(2006)\end{array}$ & $\begin{array}{l}\text { Ayllón, Álvarez } \\
\& \quad \text { González } \\
\text { (2007) }\end{array}$ & $\begin{array}{l}\text { Meriläinen } \\
\text { et al. (2010) }\end{array}$ \\
\hline & & $\begin{array}{l}\text { (7) Recibir } \\
\text { pinchazos con } \\
\text { agujas }\end{array}$ & $\begin{array}{l}\text { (7) Pinchazos } \\
\text { con agujas } \\
\text { diarios }\end{array}$ & & & \\
\hline & & & $\begin{array}{l}\text { (9) } \\
\text { Ventilación } \\
\text { mecánica }\end{array}$ & & $\begin{array}{l}\text { (8) Mascarilla de } \\
\text { oxígeno }\end{array}$ & \\
\hline & & $\begin{array}{l}\text { (10) Visitas } \\
\text { restringidas de } \\
\text { familia y amigos }\end{array}$ & & & $\begin{array}{l}\text { (10) Horario de } \\
\text { visitas limitado }\end{array}$ & \\
\hline & (4) Sed & (8) Sed & & & (1) Sed & \\
\hline $\begin{array}{l}\text { Ruido-falta de } \\
\text { tranquilidad }\end{array}$ & & & & & & $\begin{array}{l}\text { Ruido/ } \\
\text { Escuchar } \\
\text { ruidos-voces } \\
\text { de otros } \\
\text { pacientes }\end{array}$ \\
\hline & & $\begin{array}{l}\text { (9) Luces } \\
\text { constantemente } \\
\text { encendidas }\end{array}$ & & & & $\begin{array}{l}\text { Luces } \\
\text { intensas }\end{array}$ \\
\hline \multicolumn{7}{|l|}{$\begin{array}{l}\text { Excluidos de } \\
\text { las } \\
\text { conversaciones }\end{array}$} \\
\hline & & & & $\begin{array}{l}\text { (6) Ayudado para } \\
\text { hacer sus } \\
\text { necesidades }\end{array}$ & & \\
\hline & & & & (3) Utilizar la cuña & & \\
\hline & & & & & & $\begin{array}{l}\text { Falta de } \\
\text { intimidad }\end{array}$ \\
\hline & & & $\begin{array}{l}\text { (10) Malestar } \\
\text { general }\end{array}$ & & & \\
\hline
\end{tabular}

Todo lo comentado evidenciaría que el paso de un paciente por UCI constituye una experiencia difícil que puede agravarse por los citados factores que progresivamente estresan a la persona enferma viéndose de esta manera afectada parcial o totalmente su capacidad para descansar. De ahí que con el adecuado manejo del estrés se facilitarían mejores condiciones físicas y psicológicas para la recuperación del paciente, intentando que el ambiente en estas unidades fuera siempre lo más humano posible. 


\subsubsection{NECESIDADES PSICOSOCIALES DE LOS PACIENTES EN UNA UCI}

La estancia en UCI puede tener un gran impacto emocional en los pacientes, puesto que a la gravedad de su enfermedad se suman toda una serie de factores, que aun no estando relacionados directamente con la patología médica que motivó su ingreso en la unidad, en cierto modo pueden influir en la evolución de la misma, no sólo en términos de alargar la estancia en estas unidades sino también de la calidad de vida de los pacientes tanto a corto como a largo plazo.

Así una parte importante del malestar de los pacientes no proviene directamente de la enfermedad sino de la experiencia subjetiva de la misma (Cassell, 1982). Por ello además de las necesidades físicas o biológicas estrictamente relacionadas con la patología, atendidas y satisfechas en la medida de lo posible, será preciso explorar necesidades a otros niveles que podrán afectar negativamente en el afrontamiento que el paciente hace de su ingreso en UCI y en definitiva en su bienestar.

Son numerosos los estudios que reflejan que los pacientes de UCI tienen necesidades concretas que atender pero en general dichas investigaciones no detallan el contenido de esas necesidades. En este sentido destaca la importancia de una investigación llevada a cabo por Hupcey (2000) con pacientes ingresados en UCI una vez que éstos se encontraban médicamente estables o inmediatamente después de su traslado a planta. La autora a partir de los datos recogidos en las entrevistas realizadas a 45 pacientes críticos desarrolló un modelo sobre las necesidades psicosociales de los pacientes de UCI (véase Figura 1). En el núcleo de este modelo y habiendo sido identificada por todos los pacientes como una necesidad fundamental se encuentra la seguridad, es decir, la sensación de sentirse seguros. Esta necesidad central a su vez estará influida por otras cuatro, como son la necesidad de saber, tener control, esperanza y confianza, que en la medida en que sean satisfechas reportarán seguridad a los pacientes. A continuación describiremos estas cuatro categorías de necesidades. 
Figura 1. Modelo de las necesidades psicosociales de los pacientes de UCI (Hupcey, 2000)

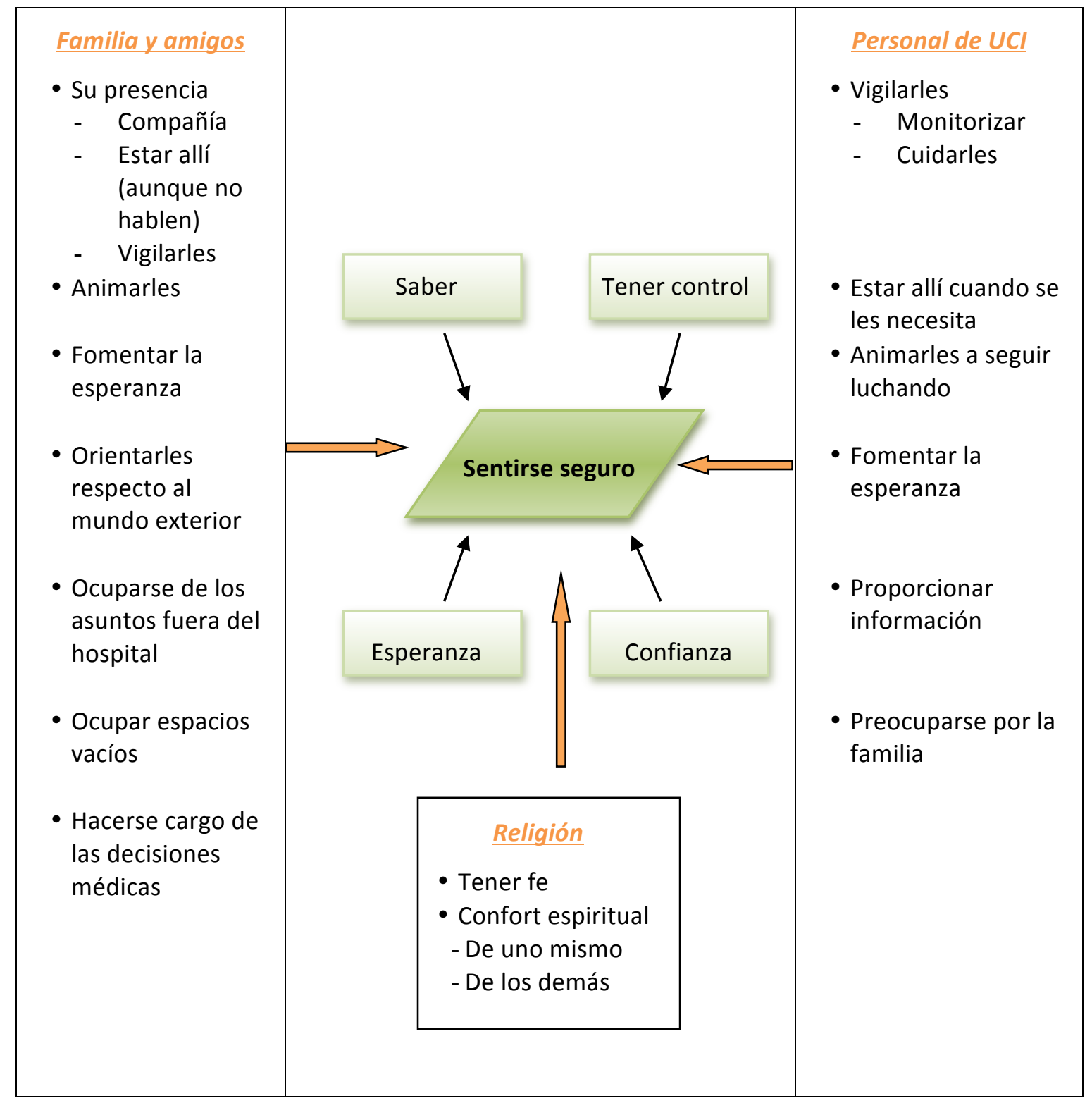

\section{- Necesidad de saber}

Cuando los pacientes están conscientes tienen la necesidad y el derecho de saber qué les ocurre. El hecho de saberlo les proporciona tranquilidad y serenidad lo que en cierto modo les ayudará a lo largo de todo este proceso. Sin embargo, la falta de información, bien porque no se les haya explicado bien porque no la hayan entendido, puede afectar al paciente de diferentes formas (Hofhuis et al., 2008). Por ejemplo, puede generar miedo, hacer que rechacen determinados tratamientos a veces agresivos por no entender el motivo por el que se requieren o incluso puede llevarles a intentos 
desesperados de obtener información a partir de las conversaciones que tienen lugar entre los mismos profesionales, lo cual en numerosas ocasiones proporciona información errónea y confusa, pues en el mejor de los casos sólo escuchan una parte de la conversación sin tener la certeza de que los datos pertenezcan al propio paciente y no a otro enfermo ingresado en la misma unidad. Todo ello exige por parte del paciente un desgaste de energía innecesario unido a miedo, incertidumbre, dudas y en definitiva ansiedad y gran malestar.

\section{- Necesidad de control}

La percepción de control sobre lo que sucede a nuestro alrededor es importante incluso en las situaciones más triviales, adquiriendo ésta un papel fundamental en aquellos entornos que implican cambio y/o amenaza, como puede ser una UCI. Inicialmente, muchos pacientes ingresados en unidades de cuidados intensivos refieren tener una pérdida total de control, pasando a ser sujetos pasivos y dependientes de los demás.

Si bien es cierto que en determinadas circunstancias es inevitable que el paciente sea una persona dependiente de los demás debido a la gravedad de su situación médica o como consecuencia de intervenciones terapéuticas que pueden comprometer su competencia (Abizanda et al., 2008) sería aconsejable considerar la importancia que tiene para el paciente poder satisfacer esta necesidad siempre que sea viable (Frediksen \& Ringsberg, 2007). Y en la medida de lo posible facilitar que retome el control de la situación aunque de momento esto sólo fuera viable con pequeños detalles, que aunque pudieran parecer insignificantes desde el punto de vista de una persona sana puede que no lo fueran tanto desde la óptica del paciente crítico.

- Necesidad de mantener la esperanza

Mantener la esperanza es sumamente importante en todo proceso de recuperación. No se trata de crear falsas expectativas sino una esperanza real ajustada a la realidad del día a día, pues de esta manera se genera la expectativa de que no todo está perdido, incluso en aquellas situaciones en las que el pronóstico no sea nada favorable, repercutiendo de manera positiva en el estado de ánimo del paciente (Penson et al., 2007). 
De manera especial esta necesidad puede verse influida por el continuado apoyo y ánimo de los familiares, amigos, personal sanitario e incluso las propias creencias religiosas o existenciales (Löf, Berggrena \& Ahlström, 2008).

\section{- Necesidad de confianza}

La confianza del paciente en el personal sanitario que le atiende es esencial para fomentar la sensación de seguridad en el contexto de una UCI. De manera general la confianza en el médico y personal de enfermería suele estar implícita pues tal y como refieren los propios pacientes "ellos (profesionales sanitarios) son los expertos en este ámbito; ellos saben lo que tienen que hacer". Así, basándose en esta confianza, los pacientes no dudarán acerca de la idoneidad de los tratamientos recibidos y de que en cada momento se intenta atender las principales necesidades de la persona enferma, estando siempre bajo el atento cuidado del personal sanitario. Por el contrario, los pacientes que desconfían de los profesionales que les atienden se muestran hipervigilantes en cuanto a los cuidados recibidos y preocupados sobre la competencia profesional del personal. Por ello estos pacientes no se sentirán seguros estando siempre en alerta, lo que también repercutirá en su estado de salud.

Una vez revisadas estas cuatro categorías de necesidades que a su vez influirán en la necesidad que tienen los pacientes de sentirse seguros, desde el modelo de necesidades psicosociales descrito por Hupcey (2000) se contempla que en el logro de esta necesidad central también influirán de manera notable la familia y amigos, los profesionales sanitarios y asimismo para algunos pacientes la religión.

Concretamente los familiares y amigos en este contexto, salvo excepciones, constituyen una fuente muy importante de apoyo para los pacientes, animándoles a seguir luchando e infundiéndoles esperanza (Almerud, Alapack, Fridlund \& Ekebergh, 2007; Wåhlin, Ek \& Idvall, 2006) lo que contribuirá a crear una atmósfera de seguridad. De la misma manera, los profesionales de UCI con sus continuos cuidados y vigilancia también fomentan la esperanza en los pacientes a la vez que les hacen sentirse más seguros (Wåhlin et al., 2006). Respecto a las creencias religiosas, algunos pacientes comentan que el hecho de sentirse vigilados por una Autoridad Superior (Dios) les proporciona seguridad. Igualmente, rezar cuando tienen miedo así como saber que otros están rezando por ellos les resulta reconfortante. Desde el modelo de Hupcey (2000) observamos pues cómo la religión puede contribuir a satisfacer la necesidad de 
seguridad. En este sentido, la autora parece hacer referencia sólo a aquella parte de la espiritualidad que las propias creencias religiosas llevan implícita.

Sin embargo, profundizado un poco más, en este contexto de atención integral de los pacientes cada vez adquiere más importancia otro conjunto de necesidades con entidad propia, las necesidades espirituales (Bayés \& Borràs, 2005).

- Necesidades espirituales

$\mathrm{Al}$ analizar las posibles relaciones entre espiritualidad y salud, la espiritualidad se confirma como un factor protector (Koenig, Larson \& Weaver, 1998). Actualmente, desde el ámbito de la medicina se reconoce que los factores espirituales son elementos susceptibles de contribuir a la serenidad o padecimiento de los pacientes (Payás et al., 2008), por lo que de manera especial este grupo de necesidades tendrá gran valor en el contexto de una UCI en el que muchos enfermos viven bajo la incertidumbre del curso de su enfermedad y la amenaza de poder morir.

Pero ¿qué se entiende por necesidades espirituales? Delimitar el concepto de espiritualidad no ha sido ni es una tarea sencilla. Tradicionalmente, los términos espiritualidad y religión han sido prácticamente inseparables pero poco a poco la definición religiosa de espiritualidad ha ido sustituyéndose por otra más amplia y relacionada con la búsqueda personal y psicológica de significado (Daaleman \& VandeCreek, 2000). Así una persona puede ser religiosa y espiritual al mismo tiempo, pero el primero no es requisito indispensable para el segundo, es decir, un individuo puede ser espiritual sin ser religioso (Rowe \& Allen, 2004).

En este contexto encontraremos pacientes que podrán expresar explícitamente este tipo de necesidades pero otros en cambio no estarán en disposición de poder o saber reconocerlas, de ahí la importancia de que los profesionales sanitarios sean conscientes del amplio abanico de necesidades que pueden presentar los pacientes para poder ayudar a satisfacerlas.

De esta forma quedarían reflejadas las principales necesidades de los pacientes ingresados en una UCI. No obstante, hay que tener en cuenta que habrá variabilidad interpersonal, esto es, diferencias individuales de unos pacientes a otros, así como variabilidad temporal en un mismo enfermo, es decir, a lo largo del tiempo en que el paciente esté ingresado serán más manifiestas unas necesidades u otras. Por ello será imprescindible explorar de manera individual las necesidades particulares de cada 
paciente en cada momento desde una perspectiva del proceso de adaptación a un entorno amenazante.

La atención de estas necesidades enfatiza la importancia de llevar a cabo un cuidado multidisciplinar de los pacientes ingresados en UCI, que atienda de manera integral al paciente explorando las necesidades a diferentes niveles y ayudándoles a identificar aquellas otras que por sí solos no son capaces de reconocer y que subyacen al sufrimiento y malestar emocional experimentado. De esta manera, el ambiente de una UCI en principio hostil y amenazador podría convertirse en un entorno en el que el paciente se siente arropado, protegido y seguro, lo que se traduciría en una disminución del malestar emocional y mejora en la calidad de vida de estos pacientes.

Así, el hecho de que los pacientes vieran satisfechas sus necesidades repercutiría positivamente no sólo a nivel psicológico mejorando su estado de ánimo y la percepción subjetiva de bienestar, sino que además ese bienestar emocional a través fundamentalmente de su influencia en el sistema inmunitario tendría efectos beneficiosos en la evolución de la enfermedad e incluso en la propia supervivencia de los enfermos (Caine, 2003; Ulla, 2003).

\subsection{PRINCIPALES SÍNTOMAS PSICOLÓGICOS EN PACIENTES INGRESADOS EN UNA UCI}

Durante mucho tiempo referirse a los grandes logros de los cuidados intensivos suponía centrarse en aspectos puramente clínicos que se traducían en cifras de supervivencia de los pacientes ingresados en estas unidades. Si bien es cierto que disminuir la mortalidad en UCI es un aspecto muy importante, no podemos obviar el impacto en términos de sufrimiento y afectación emocional que puede tener el paso de un paciente por una unidad de estas características, tanto a corto como a largo plazo (Curtis, 2003; Lloyd, 1993).

Los factores estresantes asociados al ingreso en una UCI así como las diferentes necesidades no satisfechas de los pacientes descritas en el apartado anterior, pueden desencadenar toda una serie de alteraciones emocionales que podrían continuar siendo causa de malestar incluso varios meses después del alta del hospital. De hecho, tras el alta algunos pacientes informan de peor calidad de vida en lo que se refiere a aspectos de malestar, ansiedad y depresión que en lo referido a problemas físicos, los cuales 
suelen desaparecer con anterioridad a los emocionales (García, Peres, De Cubber \& Vincent, 2003).

En líneas generales, los pacientes ingresados en UCI suelen presentar sintomatología variada destacando los síntomas de miedo, ansiedad, depresión, psicosis leve/grave con alucinaciones y alteraciones del sueño (Gómez-Carretero, Monsalve, Soriano \& De Andrés, 2007; Hewitt, 2002; McKinley, Nagy, Stein-Parbury, Bramwell \& Hudson, 2002). Sin embargo, esto no implica que todos los pacientes ingresados en UCI experimenten necesariamente estos síntomas, sino que habrá diferencias individuales que abarcarán todo un continuo de posibilidades, desde los pacientes que no experimenten sintomatología o los casos en que ésta sea muy leve por diferentes motivos, como por ejemplo que no se trate del primer ingreso en la Unidad, hasta los pacientes en los que coexistan síntomas diversos de intensidad medio-alta.

Además cabe destacar que la presencia de determinada sintomatología psicológica no necesariamente implicaría psicopatología, es decir, puede tratarse de síntomas totalmente adaptativos que formarán parte de un proceso necesario que permita afrontar esta nueva situación de manera satisfactoria.

A continuación revisaremos las alteraciones psicológicas más comunes en pacientes ingresados en UCI, entre las que se encuentran la ansiedad y la depresión. Igualmente, describiremos el "síndrome de UCI" en el que confluyen además de la ansiedad y la depresión otras alteraciones emocionales.

\section{- Ansiedad}

Al revisar la literatura existente sobre alteraciones emocionales asociadas a la hospitalización en general, en cualquier servicio de un hospital, se observa que los pacientes presentan diversos síntomas entre los que destaca la ansiedad, obteniéndose prevalencias entre el 16\% y el 30\% (Grau, Suñer, Abulí \& Comas, 2003).

Si tenemos en cuenta que las UCIs son entornos desconocidos y poco familiares para los pacientes y que su ingreso en estas unidades está asociado a gravedad y riesgo de morir, es esperable que los enfermos en este contexto presenten con mayor motivo sintomatología ansiosa (Chew, 1986). 
Si bien es cierto que el término "ansiedad" es ampliamente conocido en el ámbito hospitalario, revisar de manera breve su conceptualización puede ayudarnos a comprender mejor su aparición en una unidad de cuidados intensivos. Así, el término ansiedad (del lat. anxiětas, -ātis), hace referencia a un "estado de agitación, inquietud o zozobra del ánimo" (Real Academia Española, XXII Edición). Igualmente, puede ser definido como una respuesta emocional o patrón de respuestas que engloba aspectos cognitivos displacenteros, de tensión y aprensión; aspectos fisiológicos caracterizados por un alto grado de activación del sistema nervioso autónomo; y aspectos motores que suelen implicar comportamientos poco ajustados y escasamente adaptativos. En este sentido la respuesta de ansiedad puede ser provocada tanto por estímulos o acontecimientos externos como por estímulos internos al sujeto, como por ejemplo pensamientos, creencias, imágenes, etc. que son percibidos por el individuo como peligrosos y amenazantes. En general entendemos la ansiedad como una reacción emocional ante la percepción de un peligro o amenaza, manifestándose mediante un conjunto de respuestas que se agrupan en tres sistemas: cognitivo, fisiológico y motor, pudiendo actuar con cierta independencia.

Entre los aspectos que pueden estar relacionados con la aparición de respuestas de ansiedad en una UCI, estarían por una parte aquellos factores generadores de estrés inherentes a estas unidades y por otra parte aquellos aspectos más relacionados con el propio paciente y su percepción de amenaza respecto a la situación que está viviendo.

En relación con los factores propios de estas unidades podemos referirnos por un lado al entorno físico de la unidad, subrayando la presencia de equipamientos altamente tecnológicos, con luces intensas y prácticamente todo el día encendidas, ruidos, ritmo de trabajo, etc. Por otro lado, podemos considerar el entono más social o relacional dentro de UCI, donde destacaría el aislamiento de los pacientes de sus seres queridos y del resto del mundo, la posibilidad de observar a otros pacientes gravemente enfermos y las dificultades para comunicarse que la mayoría de pacientes presentan. Finalmente, la gravedad médica de los pacientes en este contexto conlleva síntomas físicos de malestar derivados de la misma enfermedad así como efectos colaterales de determinados procedimientos terapéuticos propios de una UCI, por ejemplo, la ventilación mecánica, las intubaciones, las traqueotomías, etc., los cuales favorecerían la restricción de movimientos, la sensación de estar atado, las dificultades para hablar, etc. 
Si nos centramos en la persona enferma, ésta además de verse privada de su entorno habitual y sometida a estimulación sensorial nueva, se enfrenta prácticamente en solitario a múltiples dudas e incertidumbres, que pueden ir desde no saber qué pruebas le van a hacer esa misma mañana o si va a ser intervenido quirúrgicamente, hasta cuestiones de gran trascendencia relacionadas con el pronóstico de su enfermedad y la propia muerte. Incluso en el mejor de los casos, cuando el paciente ya no se encuentra en estado crítico y es posible su traslado de UCI a planta algunos pacientes suelen angustiarse y sentirse inseguros por no saber lo que les espera en este nuevo contexto (McKinney \& Deeny, 2002). A todo esto hay que añadir la frecuente ausencia de control así como la falta de significado que percibe el paciente sobre la situación que vive (Frediksen \& Ringsberg, 2007; McKinley et al., 2002; Moser et al., 2003; Scott, 2004; Stein-Parbury \& McKinley, 2000). Todo esto unido a la percepción de amenaza que tenga el paciente sobre su ingreso en la Unidad influirá en la aparición de diversas manifestaciones de ansiedad que tendrán lugar a diferentes niveles.

Como es sabido, en la década de los años sesenta se formuló la teoría tridimensional de la ansiedad, según la cual, la ansiedad se podía manifestar a través de reacciones agrupadas en tres categorías: cognitiva, fisiológica y conductual (Lang, 1968). En este sentido la evaluación de los principales síntomas de ansiedad suele tener en cuenta indicadores a estos tres niveles. No obstante, en una investigación en la que se intentaban identificar los síntomas de ansiedad más importantes en pacientes de UCI (Moser et al., 2003), además de manejar indicadores de ansiedad a nivel cognitivo (alteraciones cognitivas, manifestación explícita de ansiedad por parte del paciente y pensamientos negativos), físico (dolor y síntomas relacionados con el sistema cardiovascular, respiratorio, gastrointestinal y sistema nervioso autónomo) y conductual (agitación/tensión, falta de cooperación en los cuidados y cambios en la verbalización), también utilizaron indicadores sociales como la búsqueda de seguridad, necesidad de atención o compasión, interacciones reducidas, etc. Moser et al. (2003) aunque en principio plantearon que los síntomas de ansiedad pueden manifestarse a estos cuatro niveles, muestran en su estudio la dificultad de llegar a un consenso en cuanto a los síntomas de ansiedad característicos en los pacientes críticos, ya que éstos pueden manifestarse de muy diferentes formas, estando sujetos a grandes diferencias individuales. Por ello afirman que resulta necesario explorar de manera particular las manifestaciones de cada paciente puesto que en cada persona puede predominar la activación de un sistema u otro. 
Finalmente, al hablar de ansiedad parece casi inevitable referirnos a otro término, el miedo, pues en muchos contextos y de manera especial en el de una unidad de cuidados intensivos, ambos suelen ir asociados. De hecho, en la mayoría de la literatura sobre la sintomatología que presentan los pacientes de UCI, ansiedad y miedo suelen aparecer juntos. En este contexto es frecuente el miedo al sufrimiento y a la muerte, acompañado de todo un listado de incertidumbres entre las que priman aspectos relacionados con el pronóstico y evolución de la enfermedad.

Si bien es cierto que los dos términos se caracterizan por su cercanía, presentando manifestaciones parecidas, también hay ciertas diferencias entre ellos. Básicamente, mientras que el miedo suele aparecer ante estímulos presentes, la ansiedad se relaciona con la anticipación de peligros futuros, indefinibles e imprevisibles (Marks, 1986). Así, una característica básica de la ansiedad es su carácter anticipatorio, es decir, permite prever o señalar el peligro y/o amenaza para el propio individuo, por lo que adquiere un valor funcional importante (Sandín \& Chorot, 1995). Tanto el miedo como la ansiedad poseen valor biológico de supervivencia de la especie, siempre y cuando éstos no sean excesivos o desproporcionados a la situación de amenaza, en cuyo caso serían respuestas desadaptadas que dificultarían un buen afrontamiento al ingreso en UCI.

A pesar de que se reconoce que la ansiedad es una alteración frecuente en los pacientes de $\mathrm{UCI}$, hay pocos estudios que refieran cifras de prevalencia en pacientes ingresados en estas unidades, dada la gran dificultad que se encuentra a la hora de evaluar a los enfermos críticos. Uno de los pocos estudios llevado a cabo con pacientes dentro de UCI ha sido el de Rincon et al. (2001) a partir de la evaluación de 95 enfermos críticos ingresados en tres unidades de cuidados intensivos de adultos de Colombia. Estos pacientes fueron evaluados durante el primer día de ingreso en la Unidad obteniéndose mediante The Hospital Anxiety and Depression Scale (HADS) una prevalencia para la ansiedad del $24 \%(\mathrm{HADS} \geq 10)$, cifra que se ha visto superada en algunos estudios referidos a alteraciones emocionales de los pacientes tras el alta de UCI (Rattray, Johnston \& Wildsmith, 2005). No obstante, cabe señalar que la prevalencia de ansiedad en las investigaciones realizadas con pacientes después de haber sido dados de alta de la Unidad presenta una importante variabilidad, cuyos valores oscilan entre el $5 \%$ y el $48 \%$ en función del estudio, observándose además que 
estos datos no corresponden en todos los casos al mismo rango de puntuaciones del HADS (Eddleston, White \& Guthrie, 2000; Hatchett, Langley \& Schmollgruber, 2010; Rattray et al., 2005; Samuelson, Lundberg \& Fridlund, 2007; Scragg, Jones \& Fauvel, 2001; Sukantarat, Greer, Brett \& Williamson, 2007; Young et al., 2005).

En este sentido, cuatro de los citados estudios ofrecen datos de prevalencia en ansiedad correspondientes a las puntuaciones de probable problema clínico (HADS>11) cuyo punto de corte se acercaría más a la presencia real de un problema clínico (Crawford, Henry, Crombie \& Taylor, 2001). Así, uno de estos estudios ha sido el llevado a cabo por Rattray et al. (2005) en Escocia (Reino Unido) obteniéndose mediante la evaluación de 80 pacientes tras el alta de UCI, justo antes de ser dados de alta del hospital, una prevalencia del $37 \%$ que disminuye en las evaluaciones realizadas a los seis meses (22\%) y 12 meses (18\%). Asimismo, Samuelson et al. (2007) en una investigación llevada a cabo en Suecia han obtenido una prevalencia en ansiedad del 4,9\% al evaluar a 226 pacientes dos meses después de haber sido dados de alta de UCI. Por su parte, Sukantarat et al. (2007) en Reino Unido han obtenido una prevalencia del $24 \%$ tanto a los tres meses como a los nueve meses después del alta de UCI con una muestra de 51 y 45 pacientes respectivamente. Y otro estudio (Young et al., 2005) también llevado a cabo en Reino Unido, ha contado con la participación de 20 pacientes críticos evaluados mediante el HADS como parte de un seguimiento rutinario a los tres meses del alta de UCI. Los autores han obtenido una prevalencia del $5 \%$ para el rango de probable problema clínico (11-21 puntos), valor que aumentará hasta el $25 \%$ al incluir en los resultados las puntuaciones que indicarían posible problema clínico (rango 8-10) y probable problema clínico (rango 11-21).

Otras investigaciones que contribuyen a mostrar la variación en los datos de prevalencia en ansiedad tras el alta de UCI son los siguientes.

Eddleston et al. (2000) en Reino Unido, tras evaluar a 143 pacientes tres meses después de ser dados de alta de UCI, han obtenido una prevalencia en ansiedad del $11,9 \%$, porcentaje que según la baremación del HADS incluiría las puntuaciones correspondientes a las categorías de posible y probable problema clínico (puntuaciones 28). Otra investigación realizada por Scragg et al. (2001) (Reino Unido) tras evaluar por correo postal a 80 pacientes que previamente habían sido atendidos en una UCI de adultos, muestra una prevalencia en ansiedad del $43 \%$ (puntuaciones $\geq 8$ ). Y prevalencias similares (48\%) se han obtenido en un estudio llevado a cabo en Sudáfrica 
por Hatchett et al., (2010) en el que se han evaluado 98 pacientes en la primera visita a consultas externas después del alta de UCI.

En esta línea, continuando con la ansiedad, cabe señalar uno de los pocos estudios realizados sobre la percepción subjetiva de síntomas de ansiedad llevado a cabo por Li y Puntillo (2006) en San Francisco (USA) con 15 pacientes ingresados en una UCI quienes se encontraban intubados en el momento de la evaluación. Estos pacientes mostraron en una escala que evalúa esta sintomatología de 0 (nada) a 10 (muchísimo/máximo) una puntuación media en percepción de ansiedad de 4,5 puntos.

\section{- Depresión}

Junto con la ansiedad, la depresión es otra de las alteraciones psicológicas más frecuentes en los pacientes hospitalizados en general, con prevalencias que oscilan entre el 16\% y el 43\% (Grau et al., 2003).

Al igual que hemos comentado al respecto de la ansiedad, si el hecho general de ingresar en un hospital está asociado a determinadas alteraciones emocionales, es fácil comprender que éstas sean más manifiestas en el contexto de una UCI donde confluyen diferentes estresores así como ciertas necesidades no siempre atendidas que pueden contribuir a que los pacientes experimenten entre otros, síntomas depresivos.

El término depresión (del lat. depressǐo, -ōnis) hace referencia a la "acción y efecto de deprimir o deprimirse" y al "síndrome caracterizado por una tristeza profunda y por la inhibición de las funciones psíquicas, a veces con trastornos neurovegetativos" (Real Academia Española, XXII Edición). No obstante, la definición de depresión es mucho más compleja, habiendo sido descrita por distintos autores desde diferentes perspectivas.

Un modelo integrador y multifactorial fue el descrito por Lewinsohn, Hoberman, Teri y Hautzinger (1985), según el cual la ocurrencia de la depresión se consideraría como un producto de factores tanto ambientales como disposicionales. De esta manera la depresión se conceptualiza como el resultado final de cambios iniciados por el ambiente sobre la conducta, el afecto y las cogniciones. Desde este modelo los factores situacionales serían importantes como "desencadenantes" mientras que los cognitivos lo serían como "moderadores" de los efectos del ambiente. Igualmente, según estos autores, las características de personalidad podrían moderar el impacto de los 
acontecimientos antecedentes tanto para iniciar el ciclo de la depresión como para mantenerla una vez que empieza.

En este contexto y con la finalidad de simplificar, utilizaremos indistintamente los términos depresión y síntomas depresivos para referirnos a aquel estado de ánimo en el que predominen estos síntomas, con independencia de que se cumplan o no los criterios mínimos para poder hacer el diagnóstico clínico de trastorno depresivo.

Así, en el entorno de una unidad de cuidados intensivos encontramos ciertos factores ambientales que además de producir síntomas de ansiedad también pueden contribuir a la aparición de síntomas depresivos en los pacientes, entre los que destacarán la deprivación sensorial, las variaciones en los estímulos habituales, el aislamiento físico y social, las restricciones de movimientos y la imposibilidad o dificultades para comunicarse. Además, el presentar dolor, dificultades para dormir, sentimiento de pérdida de autonomía, falta de privacidad, falta de control sobre la situación y la sensación de falta de seguridad pueden acentuar los síntomas de depresión (Hewitt, 2002; Novaes et al., 1997; Sandiumenge, Torrado \& Anglés, 2009). Sin embargo, no todos los enfermos ingresados en estas unidades presentarán los mismos síntomas depresivos, sino que habrá variabilidad en su manifestación tanto en términos cualitativos como cuantitativos, la cual estará influida por la interpretación que hace la propia persona sobre dicha experiencia así como por variables de personalidad.

Entre los principales síntomas de depresión que pueden presentar los pacientes de UCI destacarían la tristeza, pena, desesperanza, apatía y pérdida de interés hacia aspectos que antes les resultaban interesantes.

Al igual que ocurre con la ansiedad, los estudios sobre la incidencia de depresión en pacientes intra-UCI son más bien escasos, así como aquellos que evalúan la percepción del estado de ánimo deprimido. Los datos disponibles informan por un lado de puntuaciones medias (2,6 puntos) en percepción de síntomas de depresión en un rango de 0 (nada) a 10 (muchísimo/máximo) (Li \& Puntillo, 2006) y por otro lado de prevalencias en torno al 13,7\% según el estudio realizado por Rincon et al. (2001) con 95 pacientes críticos en Colombia. Cabe recordar, tal como comentamos en relación con los síntomas de ansiedad, que esta cifra corresponde a la categoría de probable problema clínico según la baremación del HADS. 
Igualmente, la mayoría de investigaciones sobre prevalencia de depresión en pacientes de UCI presentan cifras post-alta siendo éstas heterogéneas. Se estima que la prevalencia de depresión en pacientes críticos tras el alta de UCI oscila entre $8 \%$ y 57\% (Davydow, Gifford, Desai, Bienvenu \& Needham, 2009). Distintos estudios confirman esta variabilidad, observándose además que las cifras de prevalencia basadas en la evaluación realizada mediante el HADS, al igual que ocurría en los síntomas de ansiedad, no consideran la misma puntuación de corte para determinar la presencia de sintomatología depresiva.

Así, algunos estudios para determinar la prevalencia en depresión se basan en las puntuaciones correspondientes a la categoría de "probable problema clínico" según la baremación del HADS. Tal es el caso del estudio de Rattray et al. (2005) llevado a cabo en Reino Unido, en el que la evaluación de 80 pacientes tras el alta de UCI y previamente al alta del hospital, muestra una prevalencia del $25 \%$ que disminuye al $7 \%$ a los seis meses. Otro estudio que utiliza la misma puntuación de corte ha sido el realizado en Suecia por Samuelson et al. (2007) obteniéndose una prevalencia en depresión del 7,5\% al evaluar a 226 pacientes dos meses después de haber sido dados de alta de UCI. Y finalmente, en la investigación de Young et al. (2005) tras evaluar a 20 pacientes a los tres meses del alta de UCI han obtenido una prevalencia del $5 \%$ para el rango de "probable problema clínico", aumentando hasta el 15\% cuando se consideran conjuntamente las puntuaciones que indicarían "posible problema clínico" (10\%) y “probable problema clínico" (5\%).

Mientas que los resultados de otros estudios de prevalencia han utilizado una puntuación de corte menor $(\geq 8)$, la cual de acuerdo a la baremación del HADS, incluiría tanto la presencia de "posible" como "probable" problema clínico. En este sentido, Eddleston et al. (2000) en Reino Unido, a los tres meses del alta de UCI ( $n=143$ ) han obtenido una prevalencia en depresión del 9,8\%. Otra investigación realizada por Scragg et al. (2001) (Reino Unido) tras evaluar por correo postal a 80 pacientes previamente atendidos en UCI, muestra una prevalencia del $30 \%$. Y otro estudio llevado a cabo en Sudáfrica por Hatchett et al., (2010) a partir de la evaluación de 98 pacientes han obtenido una prevalencia en depresión post-UCI del $28 \%$.

Parece por tanto manifiesto que la depresión es una alteración frecuente entre los pacientes críticos. 
Al intentar describir las principales alteraciones emocionales detectadas en los pacientes de UCI, nos hemos centrado en aquellos factores circunscritos al ingreso en la unidad. No obstante, es fundamental tener en cuenta que en la manifestación de determinados síntomas influirá la historia previa de alteraciones emocionales, la presencia de otras enfermedades médicas (por ejemplo, hipotiroidismo en el caso de síntomas depresivos e hipertiroidismo para los síntomas de ansiedad), el efecto de algunos fármacos que pueden simular o precipitar sintomatología ansiosa y/o depresiva e incluso las variables de personalidad.

Además tras revisar la literatura relacionada con las alteraciones emocionales en pacientes críticos hemos podido comprobar que éstas pueden continuar manifestándose incluso varios meses después del alta, repercutiendo de manera negativa sobre la calidad de vida de los pacientes (Davydow et al., 2009). En este sentido, aunque hay estudios (Granja, Teixeira-Pinto \& Costa-Pereira, 2002; Wehler et al., 2003) que puedan indicar una tendencia a la mejoría en la calidad de vida tras el alta de UCI influido por diferentes factores como el motivo de ingreso (Badia et al., 2001; Badía, Trujillano, Serviá, March \& Rodríguez, 2008), cabe destacar que en general la calidad de vida de los pacientes que sobreviven al ingreso en UCI es peor que su calidad de vida previa, evaluada en diferentes dimensiones entre las que se incluyen la ansiedad y la depresión (Badía et al., 2008; Cuthbertson, Scott, Strachan, Kilonzo \& Vale, 2005; Cuthbertson, Roughton, Jenkinson, MacLennan \& Vale, 2010).

De esta manera, se enfatiza la importancia de profundizar en el estudio de las alteraciones emocionales en los pacientes críticos, intentando detectar posibles factores que pueden contribuir a la aparición y perpetuación de estos síntomas. En un intento por hallar posibles predictores o factores de riesgo para presentar ansiedad y depresión en este contexto, se han obtenido resultados contradictorios.

Algunos estudios muestran relación entre la presencia de síntomas ansiosodepresivos y la experiencia de haber estado sometido a cuidados intensivos, esta última valorada tanto de forma objetiva (en términos de la duración de la estancia en UCI) como subjetiva, en función de las características personales de cada enfermo (Ratrray et al., 2005). Sin embargo, respecto a la duración de la estancia en UCI otros autores como Sukantarat et al. (2007), no parecen encontrar relación alguna entre ésta y los síntomas de ansiedad y depresión. 
En esta misma línea, otras investigaciones al analizar posibles variables que pudieran influir en la aparición de malestar emocional, han encontrado relación entre la presencia de recuerdos desagradables, aterradores o delirantes durante la estancia en UCI y la aparición de alteraciones emocionales como los síntomas de ansiedad y depresión (Rattray, Crocker, Jones \& Connaghan, 2010; Ringdal, Kaety, Dag, Lotta \& Ingegerd, 2009).

Finalmente, parece haber consenso en cuanto a la ausencia de relación entre estas alteraciones y la gravedad de la enfermedad médica (Ratrray et al., 2005; Sukantarat et al., 2007).

Por todo lo expuesto parece necesario hacer una adecuada evaluación de los pacientes en el contexto de UCI para obtener diagnósticos fiables que nos permitan poner en marcha recursos que mejoren el estado de ánimo de los pacientes. Esto será sumamente importante en la evolución de la enfermedad durante el ingreso en UCI así como en la facilitación de su posterior recuperación e incorporación a la vida cotidiana, influyendo de manera notable en la calidad de vida de estas personas a más largo plazo.

\section{- "Síndrome de cuidados intensivos"}

Al hablar de alteraciones psicológicas en el contexto de una unidad de cuidados intensivos, merece especial atención el "síndrome de UCI", el cual fue acuñado por McKegney en 1966. A lo largo de los años ha recibido distintas denominaciones como "la nueva enfermedad del progreso médico" y "delirio de UCI".

A pesar de haber despertado el interés de muchos investigadores sigue siendo un tema controvertido y de total actualidad debido a la falta de acuerdo sobre su definición, la descripción de los síntomas que incluye así como cuáles son los principales factores de riesgo para desarrollar este síndrome. Todo esto se refleja en la amplia variabilidad de su prevalencia, la cual según algunos estudios oscila entre $9 \%$ y 31\% (Dubois, Bergeron, Dumont, Dial \& Skrobik, 2001; Forsgren \& Eriksson, 2010; Lin et al., 2008; Ouimet, Kavanagh, Gottfried \& Skrobik, 2007) mientras que otros ofrecen cifras que pueden llegar incluso al 80-85\% (Ely et al., 2001; Ely et al., 2004; Kuehn, 2010). 
Según muestran distintas investigaciones, el desarrollo del síndrome/delirio de cuidados intensivos parece ser resultado de una compleja interacción entre diferentes factores (Granberg, Bergbom-Engberg \& Lundberg, 1996; Granberg-Axèll, Malmros, Bergbom \& Lundberg, 2002), a saber: los problemas psicológicos previos del paciente, el trauma psicológico causado por la enfermedad, el estrés inducido por el ambiente y el tratamiento y cuidados proporcionados en la UCI. Además ciertos aspectos fisiológicos así como el uso de determinados fármacos parecen ser importantes en el desarrollo del síndrome.

En este sentido, el síndrome de cuidados intensivos podría entenderse como un proceso gradual en el que la enfermedad médica o el trauma junto a los tratamientos y cuidados recibidos, incrementarían la tensión interna y el miedo, lo que podría resultar en una situación grave de agotamiento con resignación, apatía y desesperanza, en caso de no interrumpirse o prevenirse de alguna forma (Granberg et al., 1996) (véase Figura 2).

Figura 2. Proceso de desarrollo del Síndrome de Cuidados Intensivos (tomado de Granberg et al., 1996)

Factores psicológicos predisposicionales/ precipitantes

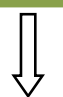

Emergencia aguda con estrés que incluye

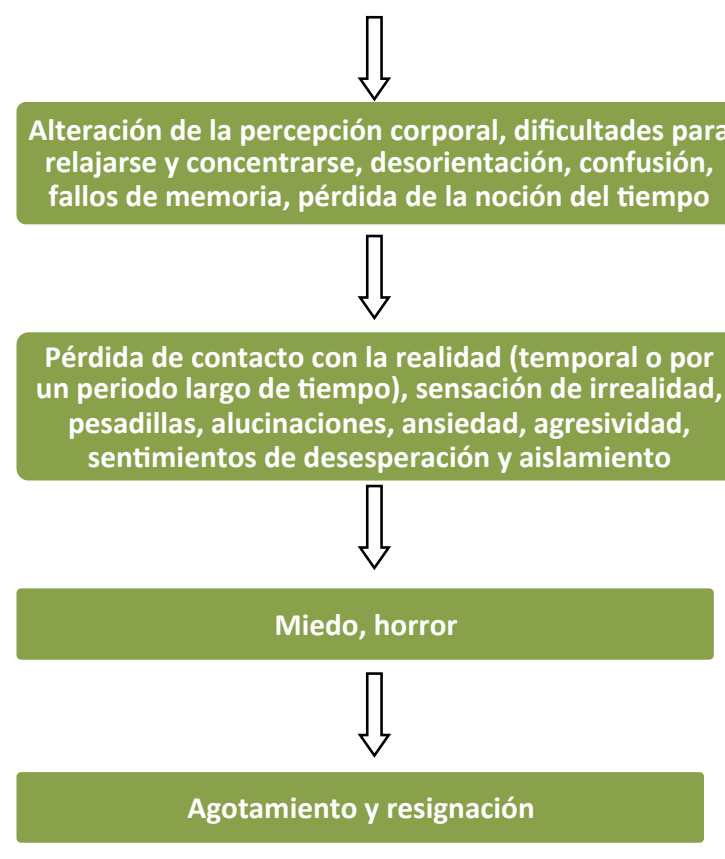


En relación con este síndrome se plantean dos cuestiones básicas: ¿se trata de un síndrome en sí mismo que puede llevar a intensificar el uso de opioides y sedantes, lo que a su vez prolongará la ventilación mecánica y la estancia en UCI? O ¿es más bien secundario a la utilización de drogas activas a nivel del sistema nervioso central? A pesar de la polémica generada por estas cuestiones, un estudio llevado a cabo por Granberg-Axèll y colaboradores (2002) parece apoyar la primera hipótesis, es decir, se trataría de un fenómeno primario asociado a la gravedad de la enfermedad, si bien no excluyen totalmente que pudiera haber algún tipo de relación con determinadas drogas psicoactivas.

Además estos autores plantean tres posibles categorías en función de la gravedad de los síntomas experimentados por los pacientes:

\section{- $\quad$ Síndrome severo}

Se caracteriza por presentar los siguientes síntomas tan pronto como los pacientes recuperan la conciencia: comportamiento agitado; experiencias irreales, perturbadoras, extrañas, y pavorosas; sentimientos de caos; alteración del sueño; pérdida de control. Además la estancia en UCI de estos enfermos es considerablemente mayor así como la duración de la ventilación mecánica.

- $\quad$ Síndrome moderado

Suelen presentar pocas experiencias irreales pero reiteradas en los días posteriores a la extubación. Los pacientes parecen estar normales la mayor parte del tiempo aunque muestran pequeños estallidos de inquietud con discurso incoherente. También experimentan cierto nivel de miedo y malestar.

- Ausencia de síndrome

Los pacientes de este grupo o bien no presentan síntomas o bien muestran signos ligeros de confusión así como desorientación espacial y temporal.

A pesar de esta descripción, el síndrome de UCI parece ser mucho más que la presentación de los síntomas expuestos en estas tres categorías, los cuales podrían complementarse con datos de otros estudios. 
En esta línea, Hewitt (2002) intenta profundizar en el análisis de las características clínicas que se presentan en el síndrome de UCI y los estresores que pueden favorecer su aparición. A continuación pasaremos a resumirlas en dos apartados diferenciados:

\section{A. Aspectos psicológicos}

\section{- $\quad$ Alteraciones de la percepción}

En relación con las alteraciones perceptivas se han descrito psicosis funcionales en las que se informa de ilusiones, alucinaciones táctiles y visuales con delirios y desorientación (Granberg, Bergbom-Engberg \& Lundberg, 1999). A su vez estas alteraciones pueden llevar asociados miedos y desconfianza en el equipo de UCI. Concretamente la desorientación es el principal indicio clínico de que se está desarrollando el síndrome de UCI o de que el paciente ya lo padece (Granberg-Axèll, Bergbom \& Lundberg, 2001).

A pesar de la gravedad de estas alteraciones, no suelen identificarse fácilmente por parte del personal sanitario, lo cual puede ser debido a la incapacidad de los enfermos para comunicarse verbalmente y a la falta de experiencia de los profesionales en el reconocimiento de signos psicóticos no verbales.

\section{- Trastornos afectivos}

La ansiedad, el estrés y la desesperación son componentes importantes de este síndrome. Muchos pacientes refieren haber tenido episodios importantes de confusión y ansiedad cuando empiezan a despertar, después de un periodo de sedación.

Son frecuentes los sentimientos de inseguridad, miedo, pánico e insomnio muy relacionados con la ansiedad. De la misma forma otros pacientes refieren apatía o pasividad que serían signos más silenciosos del síndrome (Granberg-Axèll et al., 2001).

\section{- Estados confusionales}

Los pacientes ingresados en UCI suelen presentar estados confusionales, siendo el síntoma más frecuente la desorientación temporo-espacial (Rodríguez et al., 2001). Los estados de confusión generan gran malestar en los pacientes; de hecho suelen 
recordar episodios de mucho miedo asociados a esta confusión y suelen ser descritos como intensos o insoportables (Granberg et al., 1999).

\section{B. Estresores}

Los estresores asociados a una unidad de cuidados intensivos parecen tener un papel importante en el desarrollo del síndrome de UCI. Los principales factores a tener en cuenta serán los que presentamos a continuación.

\section{- Estimulación sensorial}

Determinadas características de la estimulación sensorial pueden afectar de forma negativa a los pacientes de UCI. En este sentido se han descrito cinco grupos de variaciones en la estimulación recibida por los pacientes que podrían llevar a comportamientos anormales (Gelling, 1999): la reducción absoluta en cantidad y variedad de estimulación; pequeña variación en la estimulación; ruido excesivo; aislamiento físico y social; y la restricción de movimientos.

Hay autores que incluso llegan a considerar que los pacientes de UCI están sometidos a "tortura psicológica" debido a los niveles anormales de estimulación sensorial, tanto por exceso como por defecto, que contribuirían a generar sentimientos de miedo (Dyer, 1996) y otras alteraciones emocionales en la persona enferma.

\section{- $\quad \underline{\text { Ruido }}$}

El ruido aun siendo parte de la estimulación sensorial, merece especial atención por su importancia en este contexto. Así, el ruido y el ritmo de trabajo de los profesionales en una UCI constituyen potentes estresores para los pacientes.

De acuerdo con la Organización Mundial de la Salud (2002) el nivel de ruido recomendado en un hospital y por extensión en una UCI no debe superar los $40 \mathrm{~dB}$ durante el día y los $35 \mathrm{~dB}$ durante la noche. Sin embargo, estos niveles suelen superarse con creces en las UCIs, llegando durante el día a valores de 70-80 dB y en algunos casos a 50-65 dB por la noche (Balogh, Kittinger, Benzer \& Hackl, 1993; Bentley, Murphy \& Dundley, 1977; Dyer, 1996; Meriläinen et al., 2010).

Entre los factores que pueden contribuir a este ruido estarían las alarmas, los equipos de aspiración dejados en funcionamiento después de su uso y los teléfonos. 
Además las conversaciones del personal sanitario a pie de cama también constituyen una fuente importante de ruido, a la vez que añaden confusión en los pacientes sobre todo cuando éstos se encuentran semiconscientes, pues pueden malinterpretar o no entender en su totalidad la conversación que tiene lugar entre los mismos profesionales, lo que derivará en un aumento de miedo y ansiedad, generando malestar en los pacientes.

Por otra parte, la falta de ciertos ruidos familiares para los pacientes, como por ejemplo, la televisión, la radio, el tráfico, conversaciones de amigos, etc. también pueden identificarse como causa de estrés.

\section{- Dolor}

Los pacientes de UCI consideran que el dolor es uno de los mayores estresores que pueden experimentar en estas unidades (Todres, Fulbrook \& Albarran, 2000). De hecho, ciertas prácticas terapéuticas que se asocian a dolor son valoradas como las más altamente estresantes. Tal es el caso de la aspiración traqueal, la obtención de muestra de sangre arterial, etc. No obstante, en estos contextos el malestar no sólo se experimenta por la frecuencia real del dolor en determinados procedimientos terapéuticos sino también por el miedo y las expectativas de sentir dolor (Dyer, 1995).

Así, Hewitt (2002) señala que mientras no se confirme lo contrario debe asumirse que el paciente ingresado en una UCI puede estar sintiendo dolor, sobre todo en los casos en los que no hay posibilidad de comunicarse. Por ello, ante la duda conviene poner en marcha todas las medidas que aseguren que el paciente no tiene dolor, administrando los analgésicos y anestésicos oportunos especialmente cuando se lleven a cabo procedimientos invasivos.

\section{- Comunicación}

Mantener una adecuada comunicación es esencial en toda relación humana adquiriendo la misma un valor esencial en una UCI donde la falta de información o los posibles malentendidos no harán más que añadir sufrimiento y malestar.

La comunicación en una UCI presenta matices diferentes sobre todo en el caso de los pacientes, ya que muchas veces no pueden comunicarse debido a la gravedad de su situación médica así como a los diferentes procedimientos terapéuticos utilizados, que o bien imposibilitan a los enfermos para poder comunicarse (por ejemplo, sedoanalgesia de profundidad e intensidad variable) o dificultan una comunicación 
adecuada (intubación endotraqueal, traqueostomía, etc.) (Abizanda, Gil \& Gómez, 2009).

De esta manera se pone de relieve que la comunicación verbal en UCI a menudo es imposible. Igualmente, los intentos por mantener una comunicación no verbal (leer los labios o escribir), tampoco suelen tener éxito convirtiéndose en fuente de frustración, despersonalización e inseguridad en los enfermos (Todres et al., 2000).

A pesar de estas limitaciones, el estado de ánimo de los pacientes suele mejorar cuando de nuevo pueden comunicarse verbalmente, lo que pone de manifiesto la importancia de la comunicación verbal para la salud mental. En este sentido y siempre que sea posible es esencial explicar a los pacientes los principales aspectos relativos a su condición médica, procedimientos terapéuticos así como el equipamiento técnico utilizado (Hewitt, 2002), respetando también el deseo por parte del paciente de no querer saber más. $\mathrm{Y}$ en los casos en que sea posible, es decir, en los ingresos programados, debería establecerse una adecuada comunicación antes del mismo ingreso en la unidad informando sobre diversos aspectos relativos a las características y funcionamiento de UCI, lo que disminuiría la ansiedad de los pacientes.

\section{- $\quad$ Factores fisiológicos}

En relación con los factores fisiológicos, distintos autores consideran que el síndrome de UCI no es diferente al delirio producido por otras causas físicas y que además es causado exclusivamente por estresores orgánicos sobre el sistema nervioso central (McGuire, Basten, Ryan \& Gallagher, 2000). Esta postura excluiría la influencia de los factores psicológicos y ambientales en el desarrollo del síndrome de UCI lo que resultaría simplista en extremo, de la misma forma que lo son aquellos enfoques que niegan el impacto que tiene la interacción de los individuos con su entorno sobre la salud mental. Este punto de vista sería reflejo del sesgo fisiológico relacionado con la salud que puede existir en un entorno de excelencia tecnológica como las UCIs (Hewitt, 2002).

\section{- $\quad$ Privación de sueño}

El sueño es esencial para el mantenimiento de la salud de las personas y de manera particular, en el contexto de UCI cobrará un papel fundamental en la curación y supervivencia de los pacientes (Richardson, Crow, Coghill \& Turnock, 2007). Por el contrario, la privación de sueño puede repercutir de forma negativa tanto a nivel físico 
como psicológico y conductual, pudiendo retrasar en muchas ocasiones el proceso de recuperación de la enfermedad (Topf, Bookman \& Arand, 1996) e incluso contribuir a un empeoramiento (Calvete, García, Uriel, Fernández \& Medín, 2000). Además la privación de sueño es citada por los pacientes, junto con el dolor, como uno de los factores físicos generadores de estrés y ansiedad más importantes (Novaes et al., 1997).

Entre los posibles factores que podrían alterar el sueño en las UCIs se encuentran por un lado, aquellos relacionados con la propia estructura de la mayoría de estas unidades, en las que el entorno está alterado por un nivel de ruido considerable y por luces ambientales que dificultan la orientación entre el día y la noche, dando lugar a cambios en el ritmo circadiano; por otro lado, los pacientes también refieren tener dificultad para dormir en estas unidades por las interrupciones frecuentes del sueño, debidas a la atención continua que reciben por parte del personal sanitario, así como por aspectos relacionados con la propia enfermedad y su tratamiento (incomodidad, dolor, formas de ventilación y drogas utilizadas) (Friese, 2008; Kass, 2008; Nicolás et al., 2002).

Así, las causas de la privación del sueño suelen ser de naturaleza multifactorial y afectarán prácticamente a todos los sistemas del organismo provocando gran variedad de sintomatología (Tembo \& Parker, 2009) que en definitiva puede llevar a un empeoramiento en el estado de salud del enfermo crítico.

A partir de esta descripción del síndrome de UCI se refleja su complejidad, pues intervienen en él múltiples factores aunque no está del todo claro el papel desempeñado por cada uno de ellos ya que no es el resultado de la suma de diferentes factores sino que se trata más bien de una compleja interacción entre los mismos. Por ello, será necesario seguir profundizando en el estudio de este síndrome.

En resumen, a lo largo de este capítulo se pone de manifiesto que la UCI es un contexto particular en el que además de la gravedad de la enfermedad concurren diversos factores que pueden contribuir a hacer esta experiencia realmente amenazante y hostil. Todo ello favorece la presencia de determinadas alteraciones emocionales en los pacientes ingresados, entre las que predominan los síntomas de ansiedad y depresión, que pueden interferir sensiblemente en la recuperación de la enfermedad a 
la vez que repercuten en el bienestar y calidad de vida de los pacientes. Igualmente al hablar de afectación emocional en pacientes críticos son frecuentes las referencias al síndrome de UCI, en el que confluyen diferentes factores dando lugar a síntomas también variados, aunque no se ha encontrado consenso generalizado sobre su conceptualización.

Por todo lo comentado será fundamental proporcionar una atención integral al enfermo crítico, entendido éste como un ser biopsicosocial. Además de los aspectos físicos de la enfermedad será necesario atender todos aquellos aspectos que pueden influir en el bienestar del paciente tanto a nivel físico como emocional, pues esto reportara mejoras en la calidad de la asistencia ofrecida. 



\title{
CAPÍTULO 3
}

\author{
AFECTACIÓN EMOCIONAL EN \\ LOS FAMILIARES DE PACIENTES \\ INGRESADOS EN UNA UNIDAD \\ DE CUIDADOS INTENSIVOS
}





\section{AFECTACIÓN EMOCIONAL EN LOS FAMILIARES DE PACIENTES INGRESADOS EN UNA UNIDAD DE CUIDADOS INTENSIVOS}

Tradicionalmente cuando un paciente era hospitalizado, la atención se centraba mayoritariamente en la enfermedad y no tanto en el enfermo y su entorno, quedando la familia relegada a un segundo plano. Sin embargo, con el paso de los años cada vez se es más consciente del valor que ésta desempeña en la recuperación de la persona enferma en general y de manera particular en el paciente ingresado en una unidad de cuidados intensivos (UCI) (Bernat, López \& Fontseca, 2000; Hidalgo, Vélez \& Pueyo, 2007).

Este cambio se ha producido al hilo de la evolución general en la concepción de los cuidados proporcionados en una UCI. Inicialmente, la atención del paciente se centraba en los aspectos más fisiológicos, es decir, en aquellos que permitían restablecer las constantes vitales para poder salvar su vida dejando de lado otros aspectos de carácter psicológico y social. Si bien es cierto que intentar recuperar el estado de salud de la persona enferma ha sido y sigue siendo uno de los objetivos prioritarios de los cuidados críticos, poco a poco observamos un cambio en la orientación de los cuidados hacia una concepción más humanitaria, desde la que además de atender los aspectos físicos se tiene en cuenta el impacto que la enfermedad y el necesario ingreso en UCI puede tener en términos de sufrimiento y afectación emocional, siendo necesario atender de manera global a la persona (Castledine, 2001).

Avanzando un poco más en este largo camino, la concepción holística de los cuidados incluye a la familia como parte de los mismos (Henneman \& Cardin, 2002), lo cual es especialmente relevante en el contexto de una UCI tanto por el hecho de que los familiares son parte afectada en este proceso desde el mismo momento en que reciben la noticia de que su ser querido requiere cuidados intensivos (Jamerson et al., 1996) como por el valioso papel que éstos pueden desempeñar en el cuidado y recuperación del paciente (Azoulay et al., 2003; Nelms \& Eggenberger, 2010; Williams, 2005).

Así, en el contexto de una UCI los cuidados del paciente y los cuidados de los familiares aparecen entrelazados (Pryzby, 2005). A este respecto, Beeby (2000) señala que "cuidar a la familia es un componente del cuidado del paciente y se consigue apoyando a la familia e implicándola en los cuidados". En la medida en que el paciente pertenece a una unidad familiar, las necesidades o problemas de salud de uno de sus 
miembros no sólo le afectarán a él, sino a toda la familia como grupo (Díaz \& Díaz, 2004).

En este sentido, podría sugerirse que la crisis fisiológica en el paciente, es decir, la gravedad de su situación clínica, puede dar lugar a un periodo de crisis en la familia (Caine, 1989) alterándose su sistema de equilibrio de forma tan severa que la inmovilice e incapacite al menos temporalmente (Boss, 2002). No obstante, aun afectando a toda la familia habrá diferencias individuales en cómo experimente la crisis cada miembro de la unidad (O'Hagan, 1984). De hecho, mientras que unos familiares pueden sentirse devastados desde el mismo momento del ingreso en UCI, en otros casos la situación de crisis no se desencadenará hasta ser confirmado un empeoramiento o incluso una muerte inminente del paciente.

Por tanto, el grado de afectación en cada uno de los familiares puede ser variable y dependerá en buena medida de la interpretación de la situación que están viviendo y de la percepción de amenaza. A su vez, estas interpretaciones pueden estar mediadas por otros aspectos más directamente relacionados con las características del ingreso y la enfermedad (ingreso esperado o inesperado, gravedad médica, etapa del proceso en que se encuentren, etc.) así como por otros factores más personales, relativos al propio familiar (experiencias pasadas en las que se ha visto sometido a gran estrés, experiencia de ingresos previos en UCI, características de personalidad, el contexto general en ese momento de su vida, etc.). Inevitablemente estas variables influirán en el modo en cómo los familiares utilizan los distintos recursos y capacidades durante el ingreso en UCI para afrontar de forma adaptativa esta nueva situación (Söderström, Saveman, Hagberg \& Benzein, 2009).

Todo esto pone de relieve que no todas las familias vivenciarán de igual forma el ingreso de un ser querido en UCI. Si bien es cierto que en general todos se ven sometidos a un importante impacto emocional, éste tendrá matices diferentes en cada caso particular encontrando diferencias individuales que será necesario atender. 


\subsection{EL INGRESO DE UN SER QUERIDO EN UNA UNIDAD DE CUIDADOS INTENSIVOS}

En general, el término "cuidados intensivos" parece evocar cierta reacción emocional en aquellas personas que están familiarizadas con las implicaciones que tiene el hecho de ingresar en esta área específica del hospital. La gravedad médica de la situación exige que el paciente sea atendido en una UCI generando gran impacto emocional en toda la familia (Vandall-Walker \& Clark, 2011; Vandall-Walker, Jensen \& Oberle, 2007), tanto en el propio paciente aunque éste no siempre presenta recuerdos vívidos de la experiencia en UCI como en sus familiares más cercanos quienes sí parecen vivenciar la situación al completo (Paul \& Rattray, 2008).

Es importante tener en cuenta que el ingreso en estas unidades suele ocurrir de forma inesperada, sin previo aviso. Familiares y allegados no han tenido la oportunidad de prepararse emocionalmente y suelen disponer de poco tiempo para asimilar una situación nueva y desconocida en la mayoría de casos dada la escasa o nula familiaridad con este tipo de circunstancias. Además, el ingreso suscita múltiples dudas e incertidumbre en relación con cuestiones tan significativas como la posible supervivencia del paciente y/o el grado de discapacidad en caso de sobrevivir (Johansson, Fridlund \& Hildingh, 2005; Mitchell, Courtney \& Coyer, 2003) así como cierta sensación de irrealidad (Coulter, 1989). De esta manera, las vivencias que experimenta la familia dentro del contexto de UCI sin duda alguna afectarán a su equilibrio previo, lo cual puede verse agravado por otras circunstancias paralelas derivadas del propio ingreso. En este sentido puede verse alterada la dinámica familiar habitual teniendo que adaptarse en ámbitos muy diferentes, lo que exigirá de entrada una redistribución de los roles familiares asumiendo en ocasiones algunos de los miembros más responsabilidades en el entorno familiar, por ejemplo con cuestiones relacionadas con la economía doméstica, el cuidado de los hijos, etc. (Hupcey \& Penrod, 2000; Van Horn \& Tesh, 2000).

Así, la familia tras el ingreso del paciente en UCI, se ve sometida a gran cantidad de estresores que pueden desencadenar toda una serie de sintomatología emocional que afectará a su propio bienestar y de manera indirecta al bienestar del paciente, al no poder proporcionarle todo el apoyo necesario dada la afectación experimentada por el propio familiar. Por tanto, en este contexto y dentro de la atención integral de los pacientes críticos, será primordial analizar aquellos factores generadores de estrés en 
los familiares, así como sus principales necesidades ante una situación tan delicada como lo es el tener a un ser querido gravemente enfermo y en riesgo de morir.

\subsubsection{PRINCIPALES ESTRESORES PERCIBIDOS POR LOS FAMILIARES}

Desde el momento en que ingresa en UCI un paciente, sus familiares pasan a ser parte de este proceso. Son mucho más que meros espectadores que acuden a visitar a los enfermos en el horario establecido. Familiares y allegados interactúan directamente con el entorno de la UCI pudiendo tener el resultado de dicha interacción tanto efectos positivos como negativos en el proceso de adaptación del familiar al ingreso en UCI (Davidson, 2009).

Asimismo, dicha experiencia será vivenciada de forma particular por cada familiar (Blanchard \& Alavi, 2008), afectándole más unos aspectos que otros de un entorno tecnológico altamente estresante que separa a la familia de su ser querido, un ambiente desconocido en el que ven a su familiar rodeado de múltiples aparatos con alarmas que emiten continuamente sonidos, y personal sanitario moviéndose rápidamente de un lugar a otro de la unidad (Simpson, 1997). Todo esto además en un contexto en el que se presupone la gravedad médica del paciente acompañado de gran cantidad de dudas e incertidumbres sobre todo en relación con el pronóstico de la enfermedad, posibilidades de sobrevivir, secuelas que puedan quedarle unido a la continua preocupación y miedo de que pueda empeorar en cualquier momento.

Así, el entorno de UCI presenta numerosos y variados estresores para la familia del paciente crítico (Astedt-Kurki, Paavilainen, Tammentie \& Paunonen-Ilmonen, 2001; Williams, 2005). Hacer frente a una situación estresante única y aislada será diferente en costes de repercusión a nivel físico y emocional que enfrentarse a una experiencia en la que converjan múltiples factores generadores de estrés y además de manera continua como ocurre en una UCI, en cuyo caso los recursos de afrontamiento personales y sociales de que dispone el individuo pueden resultar insuficientes o verse sobrepasados (Hughes, Bryan \& Robbins, 2005) dificultando notablemente el afrontamiento adaptativo.

Si bien es cierto que el contexto de una UCI se considera estresante tanto para los pacientes como para los familiares, tras revisar la literatura disponible sobre este tema se observa que la mayoría de estudios se centran en cómo afectan los factores 
estresores de UCI a los pacientes, tanto valorados por el propio enfermo (Novaes et al., 1997; Granja et al., 2005; Ayllón et al., 2007), como por su familia (Novaes et al., 1999), siendo escasas las investigaciones que analizan los factores generadores de estrés en los propios familiares y allegados. En este sentido cabe señalar un estudio realizado recientemente por Da Costa et al. (2010) en una UCI polivalente de un hospital público de Brasil. Los autores tras evaluar a 53 familiares de pacientes críticos encontraron que los factores que más estrés generaban eran aquellos relacionados con el paciente y su sufrimiento, concretamente y en orden decreciente los principales estresores fueron el motivo y el tiempo de ingreso, el hecho de que el paciente estuviera en coma, el que no pudiera hablar y no poder estar acompañando al paciente.

A pesar de la escasez de estudios que exploran los factores reconocidos como estresores por los familiares de UCI, se han identificado a partir de la literatura revisada diferentes aspectos inherentes a una unidad de cuidados intensivos que de manera especial pueden generar estrés en la familia. Entre los mismos, destacarían la falta de privacidad, las visitas restringidas, los tiempos de espera y la incertidumbre, aspectos que pasaremos a comentar a continuación.

\section{- Falta de privacidad}

La privacidad o intimidad es un aspecto muy importante a tener en cuenta cuando se pretenden ofrecer los mejores cuidados en una UCI (Faber-Langendoen \& Lanken, 2000; Troug et al., 2001; Zafortea et al., 2010).

El ingreso de un ser querido en UCI y si además éste es inesperado genera un importante shock en la familia, la cual suele experimentar un cambio en sus prioridades. Deja en un segundo plano todos aquellos aspectos materiales que casi de manera inadvertida habían tomado el timón de sus vidas, para dar paso a algo tan esencial como es el poder compartir miles de detalles significativos con las personas queridas, para lo cual requieren de un espacio mínimamente privado.

Dado el grado de impacto inicial al que se ve sometida la familia inmediatamente después del ingreso, es posible que en las primeras visitas al paciente la importancia de esa privacidad sea relativa, adquiriendo la misma un valor cada vez mayor en los días sucesivos al ingreso (Freichels, 1991; Fridh, Forsberg \& Bergbom, 2007), permitiendo a los miembros de la familia poder manifestarse algo tan necesario y humano como el 
cariño, el amor, la comprensión, el perdón, los temores compartidos, las preocupaciones, etc.

La falta de ese espacio privado en el que poder expresar y compartir con su ser querido diferentes sentimientos y emociones es considerado como una pérdida añadida en este proceso, convirtiéndose en un factor generador de estrés que contribuirá al malestar de la familia en estas difíciles circunstancias (Plakas, Cant \& Taket, 2009).

A pesar de la reconocida importancia que tiene proporcionar privacidad en este contexto, no siempre ésta es tenida en cuenta, lo que genera gran malestar en toda la familia. En un estudio llevado a cabo por Fridh et al. (2007) en 79 UCIs de Suecia, las autoras obtienen que tan sólo en un $11 \%$ de los casos los pacientes que se enfrentaban al final de sus días lo hicieron en habitaciones individuales, lo cual demuestra la falta de intimidad de la familia y del propio paciente incluso en situaciones tan extremas. En otra investigación de corte cualitativo llevada a cabo en las UCIs de tres hospitales públicos de Grecia (Plakas et al., 2009), los familiares identificaron la falta de intimidad en este contexto como un aspecto importante de sus vivencias en la unidad.

Estos estudios junto a otros (Amorós, Arévalo, Maqueda \& Pérez, 2008; Street, Love \& Blackford, 2005) ponen de relieve que la infraestructura de diferentes UCIs no es la más adecuada para facilitar la intimidad. Si bien es cierto que el no disponer de salas individuales en UCI es un obstáculo para conseguir privacidad, ésta podría ser siempre mejorada de alguna manera, si los profesionales sanitarios fueran conscientes de su importancia y de las consecuencias que puede tener en la familia la falta de intimidad ante una situación tan delicada como lo es tener a un familiar críticamente enfermo e incluso en ocasiones enfrentarse al posible fallecimiento del mismo.

\section{- Visitas restringidas}

En la literatura revisada parece existir consenso en que las visitas de los familiares en UCI son beneficiosas tanto para el paciente como para la familia (Vandijck et al., 2010). No obstante, los procedimientos de visita varían de unos países a otros e incluso dentro de un mismo país entre diferentes unidades (Latour, 2005), siendo poco flexibles y no estando permitida en ningún caso la entrada libre de familiares. Así, en la mayor parte de las UCIs existe un horario de visitas restringido en cuanto al número de visitas al día, duración de cada visita y número de personas que 
pueden entrar (Berti, Ferdinande \& Moons, 2007; González, Carroll, Elliott, Fitzgerald \& Vallent, 2004; Marco \& Bermejillo, 2000; Quinio et al., 2002).

El hecho de no poder permanecer junto al paciente en un momento tan delicado genera gran malestar en la mayoría de familiares. Pueden percibir que le han dejado solo y desatendido, sin colaborar en sus cuidados fomentando de esta manera sentimientos de inutilidad y dependencia prácticamente total del personal sanitario, lo que a su vez contribuye a que perciban ausencia de control sobre la situación. Además, el no estar con el paciente en estas circunstancias de vital gravedad, el no poder ver con sus propios ojos cómo está, hace que la familia se plantee muchas preguntas por ejemplo sobre cómo ha podido evolucionar en el tiempo que transcurre entre las visitas (tendrá dolor, molestias, fiebre, etc.). Y más veces de las deseables salen con mucho miedo de la visita pues temen que pueda empeorar y no estar allí junto a él en ese momento. Todo esto incrementaría el grado de estrés inicial generado por el propio ingreso en UCI de su ser querido, contribuyendo a la aparición de más alteraciones emocionales.

Flexibilizar los horarios de visita en UCI así como facilitar que éstas se produzcan con las mejores garantías, repercutiría de manera positiva tanto en la familia como en el paciente (Eriksson, Lindahl \& Bergbom, 2010). Por una parte, la familia vería disminuido su malestar al poder permanecer más tiempo con su ser querido, mientras que a su vez el paciente también podría beneficiarse de pasar más tiempo con sus familiares. Diferentes estudios muestran lo importante que es para el propio paciente tener a su lado a la familia, motivándole continuamente para seguir luchando, para mantener la esperanza, etc. lo que puede favorecer su recuperación (Bergbom \& Askvall, 2000; Engström \& Söderberg, 2007; Storli, Lindseth \& Asplund, 2008; Williams, 2005).

No obstante, hay que decir que a pesar del beneficio asociado a flexibilizar los horarios de visita, este tema resulta un tanto controvertido. Por un lado, el poder estar con el paciente puede aliviar tanto a éste como a su familia, tal como demuestran los estudios que acabamos de citar. Mientras que por otro lado, tener numerosas horas de visita puede generar malestar en determinados familiares. Concretamente puede crear cierta dependencia del familiar hacia el hospital en el sentido de que éste se pueda sentir obligado a acudir a todas las visitas, generando a su vez sentimientos de culpa en caso de no poder hacerlo. Igualmente, acudir a casi o todos los horarios de visitas supone para la familia desatender otras áreas de su vida no menos importantes. Dado 
que se trata de una cuestión fundamental el hecho de no añadir cargas innecesarias e intentar rentabilizar los recursos de cada familia en estas circunstancias, será necesario tener en cuenta lo que para cada caso particular suponen las visitas al paciente en UCI.

\section{- Tiempos de espera}

Los tiempos de espera probablemente constituirán una de las situaciones generadoras de malestar que con mayor frecuencia aparecerán en el ámbito hospitalario. Pueden darse ante distintas circunstancias, por ejemplo, cuando se espera los resultados de alguna prueba, un diagnóstico, que el paciente salga de quirófano, la espera de recibir distintas opciones terapéuticas que mejoren el bienestar, etc. Cuanto más importante y más incierto es lo que se espera más probable será que el malestar se traduzca en sufrimiento (Bayés, 2006b).

Así, en el contexto de una UCI los tiempos de espera pueden convertirse en una fuente de estrés muy importante, sobre todo para la familia. Por una parte, dada la urgencia de la situación que motivó el ingreso del paciente, cuando el médico informa por primera vez a la familia suele informar sobre datos todavía provisionales a la espera de que las pruebas pertinentes confirmen el diagnóstico; continuamente se somete al paciente a diferentes procedimientos diagnósticos y terapéuticos cuyos resultados también espera ansiosamente la familia; igualmente los familiares pasan el día esperando a que llegue la hora de las diferentes visitas, así como la ansiada hora de la información, pues los médicos suelen informar sólo una vez al día (Eggenberger \& Nelms, 2007).

Esto pone de manifiesto que la familia prácticamente está siempre esperando, lo cual se ve agravado por la importancia de lo que esperan así como por la gran incertidumbre asociada a este entorno, percibiéndose la espera como interminable y sujeta a gran malestar (Bayés, 2000, 2006b). A pesar de que este aspecto puede contribuir notablemente al malestar experimentado por la familia en el contexto de UCI sigue siendo un ámbito poco investigado.

\section{- Incertidumbre}

Tras el ingreso del paciente en UCI los familiares se ven sometidos a una situación de gran estrés donde prima la incertidumbre sobre todo en relación con las 
posibilidades de supervivencia del paciente, las posibles secuelas en el futuro y el miedo a que pueda empeorar (Curtis, 1983; Johansson et al., 2005).

Mishel (1988), que ha investigado ampliamente el concepto de incertidumbre asociado a la enfermedad, define la misma como "la falta de habilidad para encontrar significado a los acontecimientos relacionados con la enfermedad. Se trata del estado cognitivo creado cuando la persona no puede categorizar o estructurar adecuadamente un acontecimiento por la falta de indicaciones o claves suficientes para poder hacerlo". Así, la incertidumbre podría considerarse uno de los principales estresores psicológicos en aquellas enfermedades en las que la vida se ve amenazada, dando lugar a alteraciones psicológicas cuando las respuestas de afrontamiento son insuficientes para resolver la incertidumbre o para manejar las reacciones emocionales negativas en caso de no poder resolverla (Mishel, 1988; Stewart, Mishel, Lynn \& Terhorst, 2010).

Hacer frente a la incertidumbre se convierte en un reto continuo, pues ésta les acompañará a lo largo de prácticamente toda la estancia en UCI, en lo relativo a la propia situación del paciente pero también en todo lo impredecible de su experiencia particular en un entorno desconocido, no sabiendo muchas veces ni tan siquiera qué pasos han de seguir y qué es lo que tienen que hacer. Algunos familiares refieren que los altos niveles de incertidumbre que viven en la UCI es lo más duro y difícil de afrontar (Engström \& Söderberg, 2004).

La familia busca desesperadamente respuesta a múltiples cuestiones, algunas de las cuales podrán resolverse proporcionando información adecuada de forma consistente, contribuyendo a disminuir un poco la incertidumbre y el malestar (Mishel \& Braden, 1988; Mitchell et al., 2003). Sin embargo, la información honesta no siempre aliviará la ansiedad de los familiares cuando buscan la certeza sobre el pronóstico de la enfermedad de su ser querido, pues ni todo tiene respuesta ni en ocasiones ésta es la esperada (Agard \& Harder, 2007).

La incertidumbre mantenida a lo largo del tiempo puede constituir sin duda alguna una de las principales fuentes de malestar en la familia del paciente crítico dificultando el proceso de adaptación (Mitchell et al., 2003).

Todos los estudios señalados muestran el gran estrés que supone la experiencia de tener a un ser querido en situación crítica, puesto que al hecho aislado del ingreso con sus connotaciones de gravedad, se añaden toda una serie de factores como por ejemplo el horario de visitas, la falta de privacidad, los tiempos de espera y la 
incertidumbre, que pueden convertirse en potentes estresores contribuyendo a generar gran malestar emocional. De ahí la importancia de tener en cuenta todos estos aspectos cuando se proporcionen cuidados a la familia dentro del marco de atención integral en los cuidados intensivos.

\subsubsection{NECESIDADES PERCIBIDAS POR LA FAMILIA DURANTE EL INGRESO EN UNA UNIDAD DE CUIDADOS INTENSIVOS}

\section{- Necesidades de los familiares: Marco general}

Los primeros estudios sobre las necesidades particulares de los familiares datan de la década de los años setenta. En 1975 Hampe llevó a cabo un estudio con 27 esposas de pacientes terminales en el que intentaba analizar sus principales necesidades y en qué medida éstas eran satisfechas. Se identificaron un total de ocho necesidades básicas que en caso de ser satisfechas facilitarían el proceso de adaptación de la familia. Estas necesidades se dividieron en dos grupos. En el primero, se incluyeron las necesidades relativas a la relación con el paciente: acompañar a la persona moribunda, ser útil al enfermo y tener seguridad de que éste va a estar bien atendido. Mientras que en el segundo grupo se encontraban las necesidades personales de los familiares: necesidad de estar informado tanto de la condición del enfermo como de la inminencia de la muerte, poder ventilar emociones, recibir confort y apoyo de otros miembros de la familia y recibir apoyo y confort del equipo asistencial que les atiende. El estudio de Hampe (1975) influyó de manera importante en las investigaciones posteriores realizadas sobre las necesidades de los familiares de pacientes críticos.

Unos años más tarde, Molter (1979) a partir del estudio anterior y de su propia experiencia clínica consideró importante identificar aquellos aspectos que los familiares percibían como necesidades durante el periodo de crisis que supone el ingreso de un ser querido en UCI y de esta manera poder atenderlas como parte del cuidado global del paciente. Así, la autora elaboró una escala con 46 ítems ayudada de una exhaustiva revisión de la literatura y de las encuestas realizadas a estudiantes de enfermería sobre las necesidades que según su experiencia podían requerir los familiares del paciente en estado critico. Este instrumento inicial fue modificado ligeramente y pasó a denominarse más tarde "The Critical Care Family Needs Inventory" 
(CCFNI) (Molter \& Leske, 1983). El CCFNI tanto en su versión original como en posteriores adaptaciones ha sido utilizado en la mayoría de trabajos realizados sobre este tema en los últimos años.

En el estudio inicial de Molter (1979), los 46 ítems fueron valorados por los familiares subrayando como más importantes y en orden decreciente las siguientes necesidades: sentir esperanza (S), recibir información adecuada y honesta (S), sentir que el personal del hospital se preocupa por el paciente (S), tener una sala de espera cerca del paciente $(\mathrm{P})$, ser llamado a casa ante cambios en la condición del paciente $(\mathrm{P})$, conocer el pronóstico (S), conocer hechos específicos sobre el pronóstico del paciente (I), recibir información sobre el paciente una vez al día (I), recibir explicaciones fáciles de entender (S) y poder visitar al paciente con frecuencia (P). Molter (1979) en su estudio original no agrupó las necesidades en categorías, puesto que el análisis de las propiedades psicométricas del cuestionario fue llevado a cabo con posterioridad por Leske (1991) obteniendo cinco dimensiones:

- $\operatorname{Apoyo}(\mathrm{A})$

- $\operatorname{Confort}(\mathrm{C})$

- Información (I)

- Proximidad $(\mathrm{P})$

- $\quad$ Seguridad $(S)$

De acuerdo con los resultados de esta factorización podemos observar que los ítems sobre las necesidades más valoradas por la familia en el primer estudio de Molter (1979) pertenecerían a las categorías de seguridad, proximidad e información, recibiendo los de confort y apoyo puntuaciones más bajas (véase Cuadro 2).

Por otra parte, cabe destacar que en este estudio todas las necesidades fueron elegidas como muy valiosas al menos por un familiar, lo que nos muestra la importancia de atender de forma individual las necesidades de cada persona.

Si bien es cierto que el CCFNI creado por Molter y Leske (1983) ha sido ampliamente utilizado en las investigaciones realizadas en todo el mundo sobre las necesidades de los familiares de UCI, también lo es que este instrumento presenta algunas limitaciones. Entre ellas se encuentra el hecho de que ha sido desarrollado por una investigadora formada en enfermería junto con estudiantes de enfermería, y por tanto las necesidades incluidas serán importantes desde el punto de vista de la 
profesión de enfermería. Igualmente, el cuestionario sólo recoge información sobre las necesidades incluidas a priori en el mismo. Y aunque al final del cuestionario hay una pregunta abierta para que los familiares puedan aportar otras necesidades no recogidas en él, las respuestas a la misma no suelen aparecer en los estudios publicados.

A pesar de las limitaciones, no podemos obviar la importancia de este estudio, habiendo sido considerado como referente en el ámbito de los cuidados intensivos, al contemplar al paciente como parte de una unidad familiar cuyas necesidades será fundamental atender desde una concepción holística de los cuidados.

Con posterioridad a los estudios de Molter, diferentes autores intentaron replicar los resultados obtenidos. Así, en un estudio llevado a cabo por Mendonca y Warren (1998), también en EE.UU., los familiares respondieron el CCFNI concediendo las puntuaciones más altas a las necesidades de seguridad, proximidad e información, mientras que las de apoyo y confort fueron de nuevo menos valoradas (véase Cuadro 2).

En otro trabajo realizado en Bélgica (Bijttebier, Vanoost, Delva, Ferdinande \& Frans, 2001), los familiares de pacientes ingresados en una UCI quirúrgica valoraron las diferentes subescalas del cuestionario CCFNI de Molter en el siguiente orden: información, seguridad, proximidad, apoyo y confort (véase Cuadro 2). Asimismo en este estudio los autores compararon la percepción que tenían los familiares sobre sus propias necesidades con la percepción que tenían los profesionales sanitarios sobre las necesidades de la familia, encontrando que la valoración general de las necesidades fue bastante parecida en los dos grupos. No obstante, refieren haber obtenido diferencias significativas sobre todo en relación con las necesidades de información y proximidad, subestimadas tanto por el personal de enfermería como por los médicos, y en menor medida las necesidades de seguridad también fueron subestimadas por los médicos.

Un año después algunos de estos autores junto con otros (Delva, Vanoost, Bijttebier, Lauwers \& Wilmer, 2002) ofrecen resultados similares, en este caso con familiares de pacientes ingresados en una UCI general, ordenando las necesidades según su importancia del siguiente modo: necesidad de información seguida por la de seguridad y reducción del miedo, accesibilidad, apoyo y por último la necesidad de confort (véase Cuadro 2).

En otro estudio más reciente llevado a cabo en EE.UU. por Maxwell, Stuenkel y Saylor (2007) mediante una versión reducida a 30 ítems del CCFNI (Norris \& Grove, 
1986), los familiares de UCI identificaron las siguientes necesidades según su importancia en orden decreciente: que las preguntas sean contestadas honestamente (S), conocer el pronóstico (S), hablar con la enfermera cada día (I), conocer cómo está siendo tratado el paciente (I), conocer el motivo por el que se le hacen las cosas al paciente (I), ser llamado a casa ante un cambio significativo en las condiciones del paciente $(\mathrm{P})$, recibir información sobre el paciente una vez al día $(\mathrm{I})$, tener la certeza de que se están dando los mejores cuidados al paciente (S), recibir explicaciones fáciles de entender (S) y sentir que hay esperanza (S).

Estos autores no presentan los resultados de las necesidades agrupados por categorías. No obstante, y con la finalidad de facilitar la comprensión, si agrupamos estas necesidades en función de los factores obtenidos por Leske (1991) en el análisis de las propiedades psicométricas del CCFNI original, podemos observar que los factores más importantes para la familia en el estudio de Maxwell et al. (2007) son la seguridad, la información y la proximidad, dando menos importancia al confort y apoyo (véase Cuadro 2). Igualmente, en este estudio se comparó la percepción sobre las necesidades de los familiares por parte de las enfermeras y los propios familiares. En este sentido, los resultados indican que familiares y enfermeras sólo coinciden en 5 de las 12 necesidades más importantes para la familia, siendo significativas las diferencias encontradas en la percepción de las necesidades.

\section{- Necesidades de los familiares: estudios realizados en España}

En España uno de los primeros estudios donde se evaluaron las necesidades de los familiares de pacientes críticos fue llevado a cabo en la Clínica Universitaria de Navarra por Margall et al. (1993), utilizando una adaptación al español del CCFNI, "Cuestionario de Necesidades de Familiares de pacientes ingresados en UCI", realizada por los mismos autores. Así, el instrumento de los cuarenta y cinco ítems originales quedó reducido a treinta y cuatro, al agrupar ítems de contenido similar en un único enunciado, que también se distribuirían aunque de manera diferente en cinco categorías de necesidades:

- Información (I)

- Confort del entorno (C)

- Seguridad (S)

- Estar cerca del paciente (CP)

- Apoyo-ayuda (AA) 
Los resultados de este estudio indican que casi tres cuartas partes $(73 \%)$ de las necesidades fueron valoradas como importantes o muy importantes, perteneciendo a las categorías de seguridad e información (véase Cuadro 2), coincidiendo con los resultados obtenidos por otros autores (Delva et al., 2002; Gómez-Calcerrada, 2004; Molter, 1979). Concretamente, las dos necesidades más valoradas por los familiares fueron "estar seguro de que se está dando al paciente el mejor cuidado posible" y "sentir que el personal del hospital se preocupa por el paciente" seguido por "sentir que hay esperanza", encontrándose esta última necesidad entre las más importantes en prácticamente todos los estudios revisados. En el estudio de Margall et al. (1993) las necesidades de apoyo-ayuda y estar cerca del paciente obtuvieron puntuaciones intermedias, mientras que las necesidades de confort del entorno fueron las menos valoradas.

Otro trabajo sobre las necesidades de los familiares en UCI en nuestra geografía, fue llevado a cabo en el Hospital General Universitario de Alicante (GómezCalcerrada, 2004). Como instrumento de evaluación utilizaron la versión modificada del Cuestionario de Necesidades de Familiares de pacientes ingresados en UCI de Molter (adaptado por Margall et al., 1993). Los resultados mostraron que las necesidades más valoradas por los familiares pertenecían a las siguientes categorías en orden decreciente: información, seguridad, estar cerca del paciente, apoyo-ayuda y confort con el entorno (véase Cuadro 2).

Más recientemente, en otro trabajo realizado en Girona (Hidalgo et al., 2007) a partir de una versión del CCFNI (Molter \& Leske, 1983) modificada y adaptada al catalán, se han obtenido como principales necesidades aquellas relacionadas con la seguridad y el apoyo, seguido por las de información, proximidad y en último lugar las relativas a la comodidad (véase Cuadro 2). 


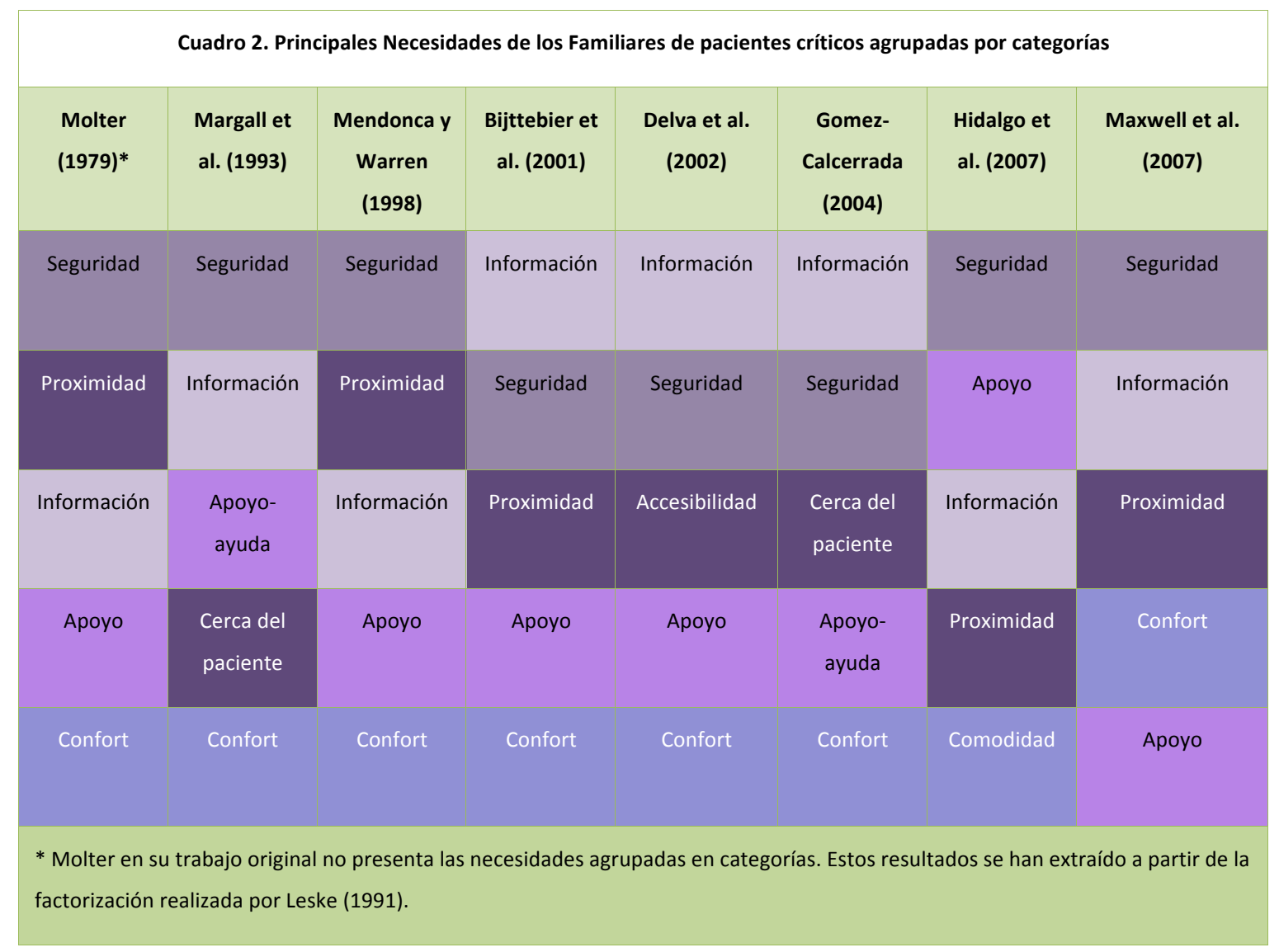

Tal como hemos podido comprobar a partir de la literatura revisada, los resultados de diferentes estudios cuantitativos coinciden en señalar las necesidades relacionadas con el apoyo y el confort como las menos importantes. Mientras que los familiares consideran las necesidades de información, seguridad y proximidad como prioritarias, aplazando las necesidades personales de apoyo y confort incluso en los casos en los que la estancia en UCI es prolongada (Gómez-Calcerrada, 2004; Hickey, 1990; Koller, 1991; Margall et al., 1993; Mendonca \& Warren, 1998).

\section{- Necesidades de los familiares: estudios cualitativos}

La mayoría de estudios sobre las necesidades de la familia realizados en el contexto de una unidad de cuidados intensivos han sido cuantitativos, basándose sobre todo en el cuestionario de Molter y Leske (1983). Sin embargo, estos estudios han sido criticados por no atender aquellas necesidades más subjetivas informadas por los propios familiares. 
Con la finalidad de profundizar en el estudio de las necesidades de los familiares de UCI otros autores han realizado trabajos a partir de un enfoque más cualitativo. En estos estudios se evalúa de manera particular las posibles necesidades de cada familiar, teniendo en cuenta que éstas pueden estar influidas por su propia historia personal y asociadas a un contexto sociocultural determinado. De esta manera, se espera conseguir mayor flexibilidad y riqueza en los resultados.

Entre los principales trabajos cualitativos destaca el de Coulter (1989) en Inglaterra quien a través de diferentes entrevistas mantenidas con los familiares de enfermos críticos y después de analizar los datos minuciosamente obtuvo que las necesidades se distribuían en seis posibles categorías relacionadas con:

- Shock en el momento del ingreso en UCI y la obtención de conocimientos sobre la enfermedad crítica.

- Búsqueda de formas de afrontar la situación.

- Necesidad de información.

- Necesidad de apoyo social.

- Satisfacción de las necesidades personales.

- Mantener la esperanza.

Otro estudio cualitativo fue el realizado unos años más tarde también en Inglaterra por Wilkinson (1995), cuyos resultados ofrecen las principales necesidades distribuidas igualmente en seis categorías:

- Shock ante el ingreso en UCI y llegar a comprender la enfermedad crítica.

- Necesidad de acceso y proximidad.

- Necesidad de un ambiente positivo.

- Necesidad de apoyo social.

- Necesidad de información.

- Necesidad de esperanza.

Atendiendo a estos dos estudios, podemos observar que las categorías obtenidas en el estudio de Wilkinson (1995) fueron similares a las de Coulter (1989). No obstante, la muestra de ambos estudios fue muy reducida: seis familiares en el estudio de Wilkinson (1995) y once en el de Coulter (1989), por lo que hay que ser cautelosos a la hora de generalizar los resultados. 
Unos años más tarde y con la intención de complementar los resultados obtenidos hasta la fecha con estudios cuantitativos, Burr (1998) llevó a cabo un estudio más completo en Australia, analizando las necesidades de los familiares tanto desde un enfoque cuantitativo, utilizando el CCFNI de Molter y Leske (1983), como cualitativo, a partir de una entrevista semi-estructurada. Así, la autora ofreció resultados sobre las necesidades de los familiares a nivel cualitativo, señalando al mismo tiempo en qué medida coincidían con los datos cuantitativos obtenidos mediante el CCFNI.

De esta manera, las principales necesidades encontradas en este estudio fueron las siguientes:

- Necesidad de estar cerca del paciente, la cual coincide con los resultados obtenidos mediante el CCFNI ya que entre las 10 primeras necesidades se encuentran aquellas relacionadas con la proximidad del paciente.

- Necesidad de saber que en caso de no estar los familiares en el hospital, el personal sanitario contactaría con ellos ante un cambio significativo en el estado del paciente. Este aspecto también se encuentra entre los más valorados en el CCFNI.

- Necesidad de esperanza. También considerada entre las más importantes en el estudio cuantitativo.

- Necesidad de saber, necesitan tener información por dolorosa que ésta sea. Estos datos coinciden con la necesidad de información obtenida en el CCFNI, en el que necesidades como la de tener respuestas honestas a sus preguntas se encuentran entre las más valoradas por los familiares.

- Necesidad de sentirse cómodo en la sala de espera. No obstante, esta necesidad fue bien tolerada pues lo que más les importaba era todo lo relativo al paciente. Este dato coincide con los resultados obtenidos mediante el CCFNI (a nivel cuantitativo) ya que la necesidad de mobiliario cómodo en la sala de espera se encontraba entre las menos valoradas.

Por su parte, Burr (1998) a nivel cualitativo identificó dos necesidades nuevas:

- Necesidad de proporcionar seguridad y apoyo al paciente (incluye respuestas como poder tocarle, hablarle, apoyarle simplemente con su presencia, es decir, sentir que de alguna manera contribuyen a su bienestar). 
- Necesidad de proteger tanto al paciente como a otros miembros de la familia. Los familiares entrevistados refieren la necesidad de adoptar un amplio papel protector, lo cual coincide con el estudio de Titler, Cohen y Craft (1991) en el que los padres se preocupaban por no contar información que pudiera preocupar o generar malestar en sus hijos.

Más recientemente, en otro estudio cualitativo llevado a cabo en EE.UU (Bond, Draeger, Mandleco \& Donnelly, 2003) se entrevistaron individualmente siete familiares de pacientes con daño cerebral severo para explorar sus necesidades durante la estancia en UCI. Los resultados de este trabajo mostraron cuatro necesidades primarias: necesidad de saber; necesidad de recibir información consistente; necesidad de implicarse en el cuidado del paciente; y la necesidad de encontrar sentido a la experiencia. Las necesidades encontradas en este trabajo presentan similitudes con las de estudios anteriores, sobre todo en relación con la necesidad de recibir información. No obstante, cabe señalar que la necesidad de "encontrar sentido a la experiencia" no se cita en otras investigaciones llevadas a cabo con familiares lo cual puede ser debido a las características de los pacientes de este estudio, pues se trata de enfermos con lesiones cerebrales traumáticas graves cuya probabilidad de fallecer es relativamente alta.

Con el interés de seguir explorando cuáles son las necesidades de los familiares en este contexto, se han llevado a cabo nuevos estudios cualitativos. En 2004, Engström y Söderberg realizaron un estudio en Suecia, en el que se entrevistaron a las parejas de siete pacientes críticos. En este estudio las autoras encontraron que lo más importante para la familia era "estar cerca del paciente", "el respeto al paciente por parte del personal de UCI", "tener cerca a otros familiares o amigos para recibir apoyo", "sentir esperanza y seguridad", "saber qué está pasando" y "tener momentos en los que pudieran estar solos para pensar tranquilamente o desahogarse emocionalmente".

Y más recientemente, una investigación a nivel cualitativo sobre las necesidades de los familiares de pacientes críticamente enfermos que ha constituido el estudio central de una tesis doctoral (Sheaffer, 2010) realizada en EE.UU., muestra que las principales necesidades han sido la necesidad de "comunicación e información", "estar presente en el hospital" y sentir "seguridad" y "esperanza realista". En este estudio las 
necesidades de apoyo emocional y confort quedan relegadas a un segundo plano, es decir, no fueron prácticamente consideradas por los familiares al igual que se ha obtenido en otros estudios previos (Bijttebier et al., 2001; Delva et al., 2002; GómezCalcerrada, 2004; Mendonca \& Warren, 1998; Molter, 1979).

A continuación, presentaremos un cuadro resumen con los principales estudios cualitativos realizados en los últimos años y las necesidades encontradas en los mismos (véase Cuadro 3).

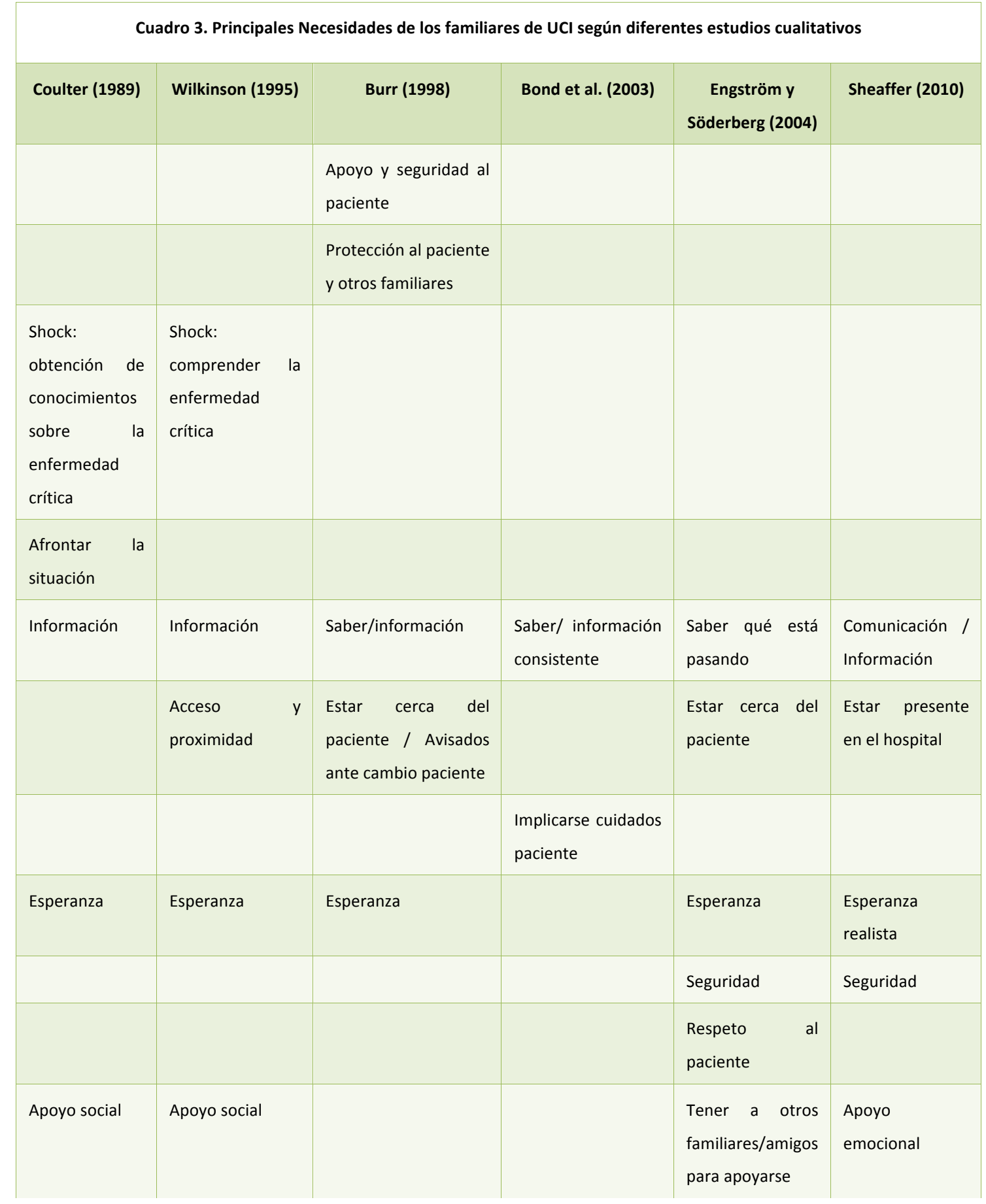


(Continuación Cuadro 3)

\begin{tabular}{|l|l|l|l|l|}
\hline Coulter (1989) & Wilkinson (1995) & Burr (1998) & Bond et al. (2003) & Engström y \\
\hline $\begin{array}{l}\text { Necesidades } \\
\text { personales }\end{array}$ & & & Sheaffer (2010) \\
\hline & & $\begin{array}{l}\text { Encontrar sentido a } \\
\text { la experiencia }\end{array}$ & \\
\hline & & & Confort \\
\hline
\end{tabular}

A partir de la literatura revisada se han identificado como relevantes una serie de necesidades en los familiares de UCI que a modo de resumen describiremos seguidamente:

\section{- Necesidad de Información}

La familia en una UCI tiene gran necesidad de saber. Esta necesidad ha sido identificada por los familiares como una de las más importantes en numerosos estudios (Auerbach et al., 2005; Bijttebier et al., 2001; Delva et al., 2002; GómezCalcerrada, 2004; Leske, 1991; Margall et al., 1993; Maxwell et al., 2007; Molter, 1979; Quinn, Redmon \& Begley, 1996; Verhaeghe, Defloor, Van Zuuren, Duijnstee \& Grypdonck, 2005) y de manera especial esta información adquirirá gran protagonismo sobre todo en los primeros días tras el ingreso del paciente (Freichels, 1991).

En este contexto, la familia se plantea un sinfín de cuestiones cuyo contenido variará a lo largo del periodo de estancia en UCI. Por ejemplo, en los primeros momentos las preguntas van más dirigidas a saber qué ha pasado, por qué han ingresado a su familiar, cómo se encuentra, en qué condiciones ha llegado al hospital, cuán grave es la situación, etc. Mientras que a medida que pasan los días se plantean cuestiones más relacionadas con la evolución del paciente, los procedimientos diagnósticos y terapéuticos que recibe, el pronóstico, etc.

Durante las primeras horas de la estancia en UCI, la cantidad de información que pueden ofrecer los sanitarios a la familia es más bien escasa, lo cual irá asociado a ese grado de incertidumbre tan característico en estas unidades (Mitchell et al., 2003). No obstante, lo más importante en estos momentos puede que no sea tanto la cantidad sino la calidad de la información que se les proporcione. 
Es necesario tener en cuenta el incuestionable valor que tiene para los familiares, sometidos a gran impacto emocional, el hecho de que el médico responsable les dedique unos minutos tras el ingreso, escuchándoles y ofreciéndoles la información disponible hasta ese momento. Y además que esta información sea clara y honesta, exenta de incongruencias (Burr, 1998; Maxwell et al., 2007; Molter, 1979) pues sólo de esta manera disminuirá su malestar (Bond et al., 2003).

- Necesidad de seguridad y esperanza

Junto a la necesidad de información y habiendo sido identificada como prioritaria por los familiares se encuentra la necesidad de seguridad (Bijttebier et al., 2001; Delva et al., 2002; Gómez-Calcerrada, 2004; Hidalgo et al., 2007; Margall et al., 1993; Maxwell et al., 2007; Mendonca \& Warren, 1998; Molter, 1979).

De manera especial la familia necesita tener la seguridad de que los profesionales sanitarios se preocupan por el paciente, dándole los mejores cuidados posibles a todos los niveles. Esta confianza en el profesional sanitario contribuye a favorecer el bienestar en la familia, sobre todo si partimos de la generalizada sensación de dependencia que tienen los familiares de los sanitarios, pues por una parte éstos son los expertos en atender a pacientes críticos pero además son los que más tiempo pasan con el paciente, ya que las visitas de la familia en UCI suelen estar restringidas.

En este contexto, otra necesidad sumamente importante y que en la literatura encontramos íntimamente asociada con la necesidad de seguridad es la necesidad de mantener la esperanza incluida en diferentes estudios como el de Molter (1979) así como en otros de corte más cualitativo (Bond et al., 2003; Coulter, 1989; Engström \& Söderberg, 2004; Sheaffer, 2010; Wilkinson, 1995). La esperanza en una UCI puede ser entendida como "tener en mente la posibilidad de resultados positivos en una situación de gran incertidumbre, incluso sabiendo que es poco probable que este resultado ocurra" (Verhaeghe, Van Zuuren, Defloor, Duijnstee \& Grypdonck, 2007). Así, los familiares de UCI tendrán la necesidad de lo que Leske y Pasquale (2007) denominan "esperanza realista", es decir, optimismo sin olvidar o ignorar la situación y posibilidades reales de recuperación del paciente.

Respecto a esta necesidad, Margall et al. (1993) señalaron en su estudio que la esperanza estaba relacionada con la naturaleza de la enfermedad, su pronóstico y si la 
misma era aguda o crónica, ya que en pacientes con ingresos repetidos o desahuciados encontraron que la necesidad de sentir esperanza iba perdiendo valor. Sin embargo, este dato difiere en parte de los resultados obtenidos en otros estudios (Burr, 1998) en los que se señala que los familiares tienen la necesidad de sentir que hay esperanza tanto cuando el paciente tiene posibilidades de sobrevivir como cuando éstas se han agotado y se enfrentan a la muerte. Por tanto, mantener una esperanza ajustada a la realidad por difícil y dolorosa que ésta sea, puede ser muy valioso, contribuyendo a fomentar la seguridad y favoreciendo el adecuado afrontamiento de la familia ante una situación tan difícil de manejar (Dufault \& Martocchio, 1985).

\section{- Necesidad de proximidad}

La necesidad de estar cerca del paciente en el estudio original de Molter (1979) es considerada la segunda más importante y de forma consistente, en estudios posteriores aparece entre las más importantes junto con la necesidad de información y seguridad, siendo más valorada que las de apoyo o confort (Lam \& Beaulieu, 2004). No obstante, en algunos estudios (Hidalgo et al., 2007; Margall et al., 1993) puede que la necesidad de proximidad no esté considerada entre las primeras, lo cual no significaría que no sea importante para la familia estar cerca de su ser querido. Posiblemente tan sólo estaría indicándonos que en caso de que a la familia se le pida que valore de entre un grupo de necesidades habría otras que ocuparían posiciones más privilegiadas sobre todo si nos encontramos en los primeros estadios del ingreso en UCI.

Así, dos aspectos significativos para la familia y relacionados con la proximidad serían el poder estar junto al paciente y poder visitarle regularmente tal y como señalan diferentes estudios (Bijttebier at al., 2001; Delva et al., 2002; Mendonca \& Warren, 1998).

Esta necesidad si cabe tendrá más importancia en aquellas unidades en las que las visitas a UCI son restringidas, convirtiéndose este aspecto en un potente agente generador de malestar sobre todo en los contextos con escasa flexibilidad horaria bien por la propia política del servicio o por la situación médica particular del paciente.

- Necesidad de apoyo

Los familiares tienden a minusvalorar las necesidades relacionadas con el apoyo personal que ellos mismos reciban al considerar prioritario todo lo relativo a los 
cuidados y bienestar del paciente. Pero esto no implica que el apoyo social y emocional que puedan recibir de los profesionales sanitarios así como de otros profesionales como los psicólogos u otros miembros de la familia y amigos no sea importante. De hecho, el ser humano se desenvuelve en un contexto social que puede constituir una fuente importante de apoyo sobre todo en circunstancias de gran estrés y malestar (Cassel, 1976). En este sentido, parece lógico pensar que muchos familiares pudieran tener dificultades para entender la situación de crisis que sigue al ingreso del paciente en UCI sin la presencia de fuentes de apoyo (Burr, 1998).

Por otro lado, si bien es cierto que al principio del ingreso estas necesidades quedan en un segundo plano, siendo más importantes otras como la seguridad y la información, a medida que el paciente se recupera van adquiriendo más protagonismo (Gómez-Calcerrada, 2004; Margall et al., 1993; Mendoca \& Warren, 1998).

De la misma manera que atender estas necesidades puede convertirse en un factor protector, en aquellos casos en los que la familia no disponga de suficiente apoyo a diferentes niveles, puede convertirse en fuente de malestar favoreciendo la aparición de alteraciones emocionales.

- Necesidad de confort

De entrada las necesidades relacionadas con la comodidad y confort de la familia también se consideran secundarias (Bijttebier et al. 2001; Delva et al., 2002; GómezCalcerrada, 2004; Hickey, 1990; Koller, 1991; Margall et al., 1993; Mendonca \& Warren, 1998).

Si bien es cierto que la familia suele reconocer que algunos aspectos relativos a su confort no son atendidos, como por ejemplo la comodidad de sala de espera, estas necesidades quedan relegadas a un segundo plano, primando sobre todo lo relativo al paciente (Burr, 1998). Sin embargo, a medida que avanza el tiempo de estancia en UCI, el malestar en la familia puede ir en aumento debido al sufrimiento que conlleva la propia situación médica del paciente y al evidente cansancio y agotamiento que van acumulando día tras día. Por ello, aunque estas necesidades no sean reconocidas de primer orden por la familia, no cabe ninguna duda de que cuanto más y mejor sea el confort proporcionado a los familiares más probabilidad tendrán de afrontar el paso 
por estas unidades de manera adaptativa y al menor coste de sufrimiento y malestar posible.

Así será fundamental atender todos aquellos aspectos tanto materiales como no materiales (Verhaeghe et al., 2005) que puedan contribuir a un mejor afrontamiento de la estancia en UCI por parte de la familia.

Tal y como confirman los estudios revisados ciertas necesidades en la familia parecen ser consideradas universales como por ejemplo la seguridad, estar cerca del paciente, la información, el confort y el apoyo (Leske \& Pasquale, 2007). Mientras que otras en cambio apenas se mencionan en las conclusiones de los trabajos, como por ejemplo las necesidades espirituales. El hecho de que éstas no hubieran sido reconocidas como importantes por un amplio porcentaje de familiares (Molter, 1979; Margall et al., 1993), no significa que no pudieran ser de vital importancia para una persona o un grupo de familiares en particular, ayudándoles notablemente en su proceso de adaptación. De hecho, tal como hemos comentado anteriormente, entre las necesidades identificadas por los familiares en el estudio de Bond et al. (2003), se encontraba la necesidad de "encontrar sentido" a una experiencia de gran sufrimiento emocional, dadas las características de los pacientes ingresados, los cuales tenían una alta probabilidad de fallecer. Esta necesidad podría incluirse dentro de las necesidades espirituales de la familia.

Bien es sabido que en la atención global del paciente cada vez cobra mayor protagonismo la atención de sus necesidades espirituales, sobre todo cuando se enfrentan a situaciones de pérdida o incluso a la propia muerte (Benito, Barbero \& Payás, 2008). Sin embargo, en el caso de los familiares estas necesidades han sido poco estudiadas a pesar de que su atención podría desempeñar un valioso papel en determinadas circunstancias vividas en el entorno de una UCI.

Por tanto, será primordial atender a las diferencias individuales, así como también tener en cuenta que la valoración de las necesidades de los familiares estará sujeta a diferencias socioculturales importantes (Høye \& Severinsson, 2010; Robb, 1998), pudiendo variar dicha valoración de una unidad a otra dentro de un mismo país y por supuesto entre países con notables diferencias en los sistemas de salud y de creencias, lo que exigirá ser cuidadosos a la hora de generalizar resultados de un contexto a otro (Holden, Harrison \& Johnson, 2002). 
Considerando estas diferencias podremos garantizar que la atención ofrecida a cada familiar le ayudará a satisfacer sus propias necesidades, lo que tendrá un gran valor en la promoción del bienestar no sólo de los familiares sino también del paciente ingresado en UCI.

\section{- La satisfacción de las necesidades de los familiares}

Identificar las necesidades de los familiares de pacientes críticos así como analizar en qué medida éstas son atendidas constituyen cuestiones relevantes en el ámbito de los cuidados intensivos.

Al hablar de la satisfacción de las necesidades de los familiares, en ocasiones el término "satisfacción" se presta a confusión ya que por un lado puede referirse al hecho de que las necesidades hayan sido atendidas o satisfechas y por otro lado puede hacer referencia al grado de satisfacción que tienen los familiares en general o respecto a determinadas necesidades atendidas.

Es importante tener en consideración que el hecho de que las necesidades hayan sido o no atendidas, no correlaciona necesariamente con la satisfacción o insatisfacción del familiar (Lederer, Goode \& Dowling, 2005). En diferentes trabajos se observa gran satisfacción general sin haberse satisfecho algunas necesidades al igual que cuando las necesidades han sido atendidas no siempre se garantiza la satisfacción del familiar (Heyland et al., 2002; Stricker et al., 2009).

Así en la literatura revisada sobre la satisfacción de las necesidades de los familiares de entrada vemos reflejada esta misma duda en cuanto a qué se está analizando bajo el nombre de satisfacción aunque es mucho mayor el número de estudios que analizan las necesidades satisfechas que aquellos que pudieran utilizar escalas específicas sobre satisfacción de los familiares.

En nuestro contexto, uno de los primeros estudios sobre la satisfacción de las necesidades de los familiares de pacientes ingresados en UCI se realizó en Pamplona (Zazpe, Margall, Otano, Perochena \& Asiain, 1997). El instrumento utilizado en este trabajo fue una adaptación del CCFNI (Molter \& Leske, 1983) con el que se evaluaron 85 familiares. Una vez identificadas las necesidades, los familiares tenían que decir en qué medida habían sido satisfechas. En este trabajo los autores encontraron que de manera global todas las necesidades identificadas por los familiares fueron satisfechas 
en el 94\% de los casos, estando relacionadas la mayoría de ellas con la información y la confianza. A pesar del gran porcentaje de necesidades satisfechas, cabe señalar que aquellas en las que los familiares se mostraron insatisfechos fueron "recibir explicaciones sobre el entorno de UCI antes de entrar la primera vez" (14\%) y "ser informados sobre servicios religiosos" (21\%).

El primer estudio prospectivo multicéntrico sobre la satisfacción de las necesidades de los familiares de pacientes ingresados en UCI se llevó a cabo en Francia (Azoulay et al., 2001). En este estudio los autores evaluaron a 920 familiares de 120 UCIs distintas mediante una versión modificada del CCFNI (Molter \& Leske, 1983) y validada por Johnson et al. (1998). Los resultados del estudio indicaron que las necesidades satisfechas casi todas las veces según los familiares estaban relacionaban con "haber recibido información honesta sobre la condición del paciente" (87,5\%), "ser llamados a casa ante un cambio significativo en el estado del paciente" (83,5\%), "el que los miembros del equipo hubieran sido atentos con el propio familiar" (78\%), "sentir que se estaban dando los mejores cuidados al paciente" (76,5\%) y "sentir que el personal del hospital cuidaba del paciente" (75,5\%). En cambio estos porcentajes disminuyeron considerablemente, siendo indicadores de menor satisfacción, respecto a la comodidad durante las visitas al paciente (30\%) y la comodidad de la sala de espera $(20,5 \%)$.

Asimismo, en este estudio (Azoulay et al., 2001) se identificaron posibles factores predictores de satisfacción en la familia, dependiendo en su mayoría de la actuación de los profesionales sanitarios:

- No percibir contradicciones en la información recibida

- Información proporcionada por un médico joven

- Ratio personal de enfermería-paciente menor o igual a tres

- Conocer el papel específico de cada cuidador

- Ser ayudados por el médico habitual de la familia

- Disponer de tiempo suficiente a la hora de la información

El hecho de que la satisfacción de los familiares dependiera en gran medida de los profesionales sanitarios, arroja cierto grado de optimismo puesto que modificando estos factores sería posible mejorar la satisfacción de la familia durante la estancia en UCI. 
En otro estudio multicéntrico realizado en Canadá (Heyland et al., 2002) con la participación de 624 familiares de 6 UCIs diferentes, y utilizando un cuestionario que mide específicamente la satisfacción con los cuidados en UCI (Heyland \& Tranmer, 2001), los autores llegaron a la conclusión de que los familiares estaban muy satisfechos con los cuidados que habían recibido tanto ellos como el paciente. Las áreas que proporcionaron mayor satisfacción en orden decreciente fueron las habilidades y competencia del personal de enfermería, la compasión y respeto mostrado al paciente, y el manejo del dolor. Sin embargo, se mostraron menos satisfechos con la frecuencia de la comunicación con los médicos y el ambiente en la sala de espera.

Igualmente, los resultados de esta investigación (Heyland et al., 2002) señalan ciertas variables asociadas de manera más significativa con la satisfacción global de los familiares:

- La información total recibida

- El respeto y la compasión mostrada tanto hacia el paciente como hacia los familiares

- La cantidad de cuidados de salud que han recibido

Estos resultados son confirmados en parte por Auerbach et al. (2005) tras obtener que la principal causa de insatisfacción de la familia está relacionada con la falta y/o escasa claridad de la información recibida respecto a la condición del paciente y el porqué de recibir diferentes procedimientos terapéuticos.

Como puede verse, estos estudios muestran la importancia que tiene recibir información adecuada para una mayor satisfacción global manifestada por los familiares.

Más tarde, en otro estudio realizado en EE.UU. (Maxwell $t$ al., 2007) fueron evaluados 20 familiares mediante una adaptación del "Needs Met Inventory" (NMI) (Warren, 1993) el cual está formado por los mismos ítems del CCFNI (Molter \& Leske, 1983), aunque en este caso mide las necesidades que han sido satisfechas durante su estancia en UCI. Los resultados indicaron que las principales necesidades satisfechas habían sido: "ver al paciente frecuentemente", "hablar con la enfermera cada día", "tener un teléfono en la sala de espera", "poder cambiar las horas de visita o las 
restricciones en condiciones especiales" y "recibir información sobre el paciente una vez al día". Mientras que las dos menos satisfechas habían sido "hablar de sus sentimientos" y "hablar sobre el posible fallecimiento del paciente". Cabe señalar que las necesidades más satisfechas en UCI desde el punto de vista de los familiares no coincidía con las principales necesidades identificadas mediante el CCFNI (Molter \& Leske, 1983) en el mismo grupo de familiares.

Recientemente, nuestro grupo de investigación ha llevado a cabo un estudio sobre las necesidades de los familiares de UCI utilizando la versión breve de 14 ítems del CCFNI (Harvey, 1993) traducida y adaptada a nuestro contexto (Gómez, Ballester \& Gil, 2011). Los resultados, extraídos a partir de 55 familiares muestran que prácticamente todas las necesidades evaluadas han sido atendidas casi todas las veces o la mayoría de veces. Así las necesidades más satisfechas corresponden a aspectos relacionados con los cuidados médicos y la comunicación. Sin embargo, dos necesidades, a saber, "haber recibido explicaciones sobre el equipamiento utilizado" y "haber mostrado algún miembro del equipo interés en cómo se encuentra el propio familiar" han obtenido puntuaciones que indican que se han atendido sólo en ocasiones.

Podemos comprobar que la mayoría de los estudios descritos sobre la satisfacción en UCI, se centran en analizar en qué medida han sido satisfechas las necesidades de los familiares siendo variados los resultados obtenidos. No obstante, algunos de ellos coinciden en señalar como necesidades más satisfechas aquellas relacionadas con los cuidados del paciente y la información o comunicación (Azoulay et al., 2001; Gómez et al., 2011; Maxwell et al., 2007; Zazpe et al., 1997) mientras que citan como menos satisfechas las necesidades relativas a la atención personal del propio familiar (Gómez et al., 2011; Maxwell et al., 2007).

Es importante tener en cuenta que una de las principales utilidades de los estudios sobre la satisfacción de la familia en UCI será identificar aquellos aspectos en los que están más satisfechos para seguir reforzándolos así como aquellos otros en los que los familiares refieren tener carencias, con la finalidad de poner en marcha diferentes estrategias que posibiliten mejorar su satisfacción. De alguna manera la satisfacción de las principales necesidades contribuirá a disminuir el malestar de los familiares y de forma indirecta también el de los pacientes si tenemos en cuenta el 
apoyo tan importante que puede ser la familia para su ser querido (Lam \& Beaulieu, 2004; Nelms \& Eggenberger, 2010).

Asimismo, sería conveniente que cada unidad llevara a cabo su propio estudio en relación con la satisfacción de las principales necesidades ya que éstas pueden variar significativamente entre diferentes unidades (Heyland et al., 2002), no siendo siempre adecuada la generalización de resultados de una UCI a otra.

\subsection{PRINCIPALES SÍNTOMAS PSICOLÓGICOS EXPERIMENTADOS POR LOS FAMILIARES DE PACIENTES CRÍTICOS}

La experiencia particular que supone la hospitalización en UCI de un ser querido, unido a las necesidades de la familia, posibles estresores, problemas de adaptación y de afrontamiento al estrés, así como diversos problemas psicosociales derivados de la misma situación (Hammond, 1995; Holden et al., 2002) pueden dar lugar a la aparición de síntomas psicológicos concretos, los cuales pueden llegar a ser más intensos en la familia que en el propio paciente (Abizanda et al., 2006; Groom, Shaw, O'Connor, Howard \& Pickens, 1998).

Esta sintomatología será variada y reflejará grandes diferencias individuales en la manera de afrontar la situación. Así, los familiares podrán experimentar shock, confusión, negación, ira, desesperación, impotencia, culpa, frustración y miedo ante la posible pérdida de la persona querida, acompañado todo ello de síntomas de ansiedad, depresión, alteraciones del sueño, del apetito, etc. (Hughes et al., 2005; Kleiber et al., 1994; Verhaeghe et al., 2005; McAdam \& Puntillo, 2009). Asimismo, cabe señalar que esa variabilidad individual tiene que ver con otros factores como por ejemplo el estado de la enfermedad del paciente, el equilibrio entre los recursos internos y externos y la evaluación cognitiva del acontecimiento (Halm et al., 1993).

Al analizar la literatura relacionada con la afectación de los familiares de UCI, la mayoría de trabajos se centran en alteraciones emocionales, a las que nos referiremos más adelante en este mismo epígrafe. Sin embargo, al hablar de la afectación de la familia en UCI es necesario tener en consideración que la vida del familiar se verá afectada como un todo, experimentando junto con las alteraciones emocionales toda una serie de cambios físicos y conductuales, que a su vez evolucionarán con el tiempo. 
Así, desde este marco, hemos considerado relevante citar uno de los pocos estudios (Halm et al., 1993) que se ha centrado en las respuestas de los familiares a nivel comportamental y cómo éstas podían variar a lo largo del curso de la hospitalización del paciente. Tal y como era de esperar, los resultados de este estudio mostraron que los familiares experimentaban cambios en sus hábitos diarios viéndose reflejados de manera particular en una menor cantidad y/o calidad del sueño y en la menor ingesta de alimentos, lo que a su vez tendría repercusiones sobre la salud a nivel físico y emocional. Igualmente se vieron afectadas otras áreas de la vida de estas personas disminuyendo el tiempo dedicado a determinadas actividades habituales a favor de pasar más tiempo hablando y visitando al enfermo. Los autores también señalaron que había variabilidad en el nivel de estrés a lo largo de las semanas de estancia en la unidad siendo máximo en el momento del ingreso en UCI, estabilizándose en torno al sexto día para volver a aumentar en torno al mes.

Respecto a este aumento del estrés aproximadamente al mes del ingreso en UCI, es importante subrayar que éste podría coincidir con lo que otros investigadores han convenido en llamar "ansiedad por traslado" (McKinney \& Melby, 2002; Streater et al., 2001). Si bien es cierto que el alta de UCI es motivo de alegría y satisfacción pues suele estar asociada a mejoría de la situación clínica del paciente, al mismo tiempo genera estrés y ansiedad tanto en el paciente como en sus familiares debido a los cambios que se van a producir al ser trasladado a otro servicio del hospital (Mitchell \& Courtney, 2004; Mitchell et al., 2003). En este sentido, Streater et al. (2001) identificaron cinco aspectos relativos al traslado que podían afectar a los familiares, a saber: cambios en las relaciones interpersonales, cambios en el ambiente, la cantidad de información proporcionada, cambios en el nivel de cuidado y la naturaleza del traslado en sí mismo. Todos estos aspectos pueden disminuir la seguridad percibida por los familiares volviéndolos más vulnerables (Chaboyer, Kendall, Kendall, \& Foster, 2005).

Siguiendo con el estudio de la afectación emocional de los familiares en UCI, a continuación describiremos las principales alteraciones psicológicas según la literatura científica sobre el tema: ansiedad, depresión y síntomas relacionados con el trastorno de estrés agudo. 


\section{- Ansiedad}

Tras revisar la literatura existente sobre afectación emocional en familiares de pacientes críticos, parece existir consenso en que los síntomas de ansiedad se encuentran entre los principales síntomas responsables del malestar experimentado por la familia tras el ingreso del paciente en $\mathrm{UCI}$, pues se trata de una situación excepcionalmente estresante (Abizanda et al., 2006; Myhren, Ekeberg, Langen \& Stokland, 2004; Paparrigopoulos et al., 2006).

Recordemos que la ansiedad desde el punto de vista de respuesta emocional puede concebirse no como un patrón de respuesta unitario, sino como un triple sistema en el que interactuarán las respuestas cognitivas, fisiológicas y motoras, respuestas que a su vez no siempre muestran una alta correlación entre ellas (Lang, 1968).

En este sentido, en una unidad de cuidados intensivos convergen diferentes factores generadores de estrés que unidos a la percepción de amenaza que vive la familia, darán lugar a la aparición de respuestas de ansiedad que podrán variar de unos familiares a otros: taquicardia, sudoración, dificultades para respirar, síntomas gastrointestinales, agitación/tensión, cambios en la verbalización, alteraciones cognitivas, pensamientos negativos, etc.

En este contexto, la familia no sólo tendrá que hacer frente de manera aislada a una situación inesperada en la que está en peligro la vida de un ser querido, con todas las connotaciones que esto conlleva, sino que además tendrá que enfrentarse a un ambiente desconocido y altamente tecnológico, en el que se encuentra su familiar rodeado de aparatos y tubos que le impiden comunicarse y sobre los que en general nadie suele haberles dado la más mínima explicación (Gómez et al., 2011).

Otro factor importante que también contribuye a aumentar la ansiedad e inseguridad en la familia será la percepción de falta de control sobre la situación (Quinn et al., 1996) así como la percepción de que dependen del esfuerzo y dedicación de los profesionales sanitarios (sentimiento de dependencia). Y por si fuera poco, bajo estas condiciones de tremendo impacto emocional, se les pide que participen en la toma de decisiones relevantes sobre distintos aspectos relacionados con los cuidados del paciente puesto que éste no suele estar en disposición de hacerlo (Hickman, Daly, Douglas \& Clochesy, 2010). 
Con todo lo expuesto, no resulta extraño entender que la ansiedad sea uno de los principales síntomas manifestados por los familiares (Bailey, Sabbagh, Loiselle, Boileau \& McVey, 2010; Delva et al., 2002; McAdam \& Puntillo, 2009).

Diferentes estudios muestran que la prevalencia de síntomas de ansiedad en familiares de pacientes ingresados en UCI es considerable, con valores comprendidos entre el 42\% y el 73,4\% (Anderson, Arnold, Angus \& Bryce, 2009; Fumis \& Deheinzelin, 2009; Pochard et al., 2001; Pochard et al., 2005) e incluso llegando al 80,3\% en el caso de que el familiar sea la esposa o pareja de la persona ingresada (Pochard et al., 2005). Además, estos síntomas no sólo se limitarán al periodo de estancia en la UCI sino que podrán continuar varios meses después del alta del paciente, obteniéndose cifras de prevalencia variables que oscilarán entre el 28\% y el 49\% (Azoulay et al., 2005; Jones et al., 2000; Jones et al., 2004; Young et al., 2005).

Por otra parte, también se han realizado investigaciones con la finalidad de identificar posibles factores de riesgo asociados a un aumento en los síntomas de ansiedad, entre los que se encuentran: ser "esposa/pareja" del paciente, ser "mujer", "ingreso en UCI no planificado" y "bajo nivel educativo" (Delva et al., 2002; Paparrigopoulos et al., 2006; Pochard et al., 2001; Pochard et al., 2005). No obstante, pueden encontrarse diferencias de unos estudios a otros en base a las características de las muestras estudiadas. En este sentido, nos queda un largo camino por recorrer siendo necesario llevar a cabo más estudios que profundicen en el análisis de los factores implicados.

Todos estos datos ponen de relieve la importancia de detectar estos síntomas en fases iniciales del ingreso con la finalidad de atender aquellos factores responsables de su aparición y mantenimiento. De esta manera se obtendrían mejoras en el bienestar de la familia tanto a corto como a medio y largo plazo, repercutiendo favorablemente en la recuperación del paciente. Si por el contrario los síntomas de ansiedad no disminuyen, esto podría traducirse en desconfianza hacia el personal del hospital, falta de cumplimiento de las pautas establecidas, ira o enfado, insatisfacción con los cuidados e incluso demandas judiciales (Leske, 2002).

Cabe recordar que la respuesta de ansiedad en sí misma no es patológica, sino que puede ser una respuesta completamente normal cuya función será activadora y por tanto mejorará la capacidad de respuesta del individuo, facilitando un proceso totalmente adaptativo, aunque no exento de cierto grado de malestar. No obstante, en 
el caso de que la respuesta fuera excesiva en intensidad, frecuencia o duración, o apareciera asociada a estímulos que no representaran una amenaza real para el organismo, se consideraría una manifestación patológica (Vila, 1984).

Si bien es cierto que los síntomas de ansiedad son frecuentes entre los familiares de UCI, hay que tener en cuenta que éstos están sujetos a grandes diferencias individuales que será necesario analizar si se pretende ofrecer una atención de calidad y con las mejores garantías.

\section{- Depresión}

El entorno de UCI presenta unas características determinadas que pueden convertirse en potentes estresores para la familia lo cual añadido a todo un conjunto de necesidades no satisfechas puede desencadenar una gran afectación emocional también marcada por los síntomas depresivos (Abizanda et al., 2006), aunque a partir de la literatura revisada podemos observar que la prevalencia en depresión suele ser menor que en ansiedad (Pochard et al., 2005).

Atendiendo a los síntomas de depresión, diferentes trabajos ofrecen datos sobre su prevalencia en familiares de UCI la cual oscilará entre el 15\% y el 35,4\% (Anderson et al., 2009; Pochard et al., 2001; Pochard et al., 2005; Young et al., 2005), llegando a valores cercanos al 50\% en aquellos casos en los que los pacientes ingresados se encuentran gravemente traumatizados, con cáncer o próximos a morir (Fumis \& Deheinzelin, 2009; Pérez-San Gregorio et al., 1992; Pochard et al., 2005).

Al igual que ocurre con los síntomas de ansiedad, los familiares pueden continuar presentando síntomas depresivos después de que el paciente haya sido dado de alta. Azoulay et al. (2005) tras evaluar a familiares de UCI transcurridos noventa días del alta obtiene cifras de depresión en torno al 20\%.

Cabe recordar tal y como mencionamos en relación con la ansiedad, que en este contexto, en principio los síntomas depresivos no serán necesariamente patológicos sino que pueden ser reacciones adaptativas que faciliten el afrontamiento de tener a un familiar ingresado en UCI. En este sentido, el estado de ánimo deprimido y la tristeza pueden ser respuestas emocionales que manifiesten los familiares ante circunstancias que conllevan pérdidas a diferentes niveles (por ejemplo, no poder compartir emociones y sentimientos con su ser querido por estar éste sedado, no poder estar 
acompañándole todo el tiempo por estar restringidas las visitas, etc.), unido a la falta de control sobre la situación y desesperanza. Pero de manera especial, los síntomas depresivos adquieren protagonismo ante la posibilidad de que el paciente pueda fallecer o no se recupere completamente.

Esta sintomatología igualmente será variada encontrándose diferencias de unos familiares a otros en función por ejemplo de variables de personalidad, la historia personal de cada sujeto y en definitiva por la interpretación que haga el familiar sobre la situación que está viviendo. Y puede manifestarse tanto a nivel cognitivo/subjetivo (tristeza, apatía, disminución del interés en aspectos que antes le resultaban interesantes, sentimientos de inutilidad, culpa, dificultades para concentrarse, etc.), como físico (pérdida de peso, insomnio, fatiga, etc.) y conductual (disminución de la actividad en general, aislamiento, lentitud/inquietud motora, llanto, etc.).

Entre los principales factores asociados a la aparición de síntomas de depresión se encuentran el ser "esposa/pareja" del paciente ingresado en UCI, "mujer", "información inconsistente" sobre la condición del paciente y "proximidad de la muerte del paciente" (Paparrigopoulos et al., 2006; Pochard et al., 2001; Pochard et al., 2005). Sin embargo, en algunos estudios podemos encontrar resultados contradictorios, dado que las muestras de familiares utilizadas son diferentes variando entre otros aspectos aquellos relacionados con la gravedad de los pacientes, duración de la estancia en UCI, etc. En este sentido sería necesario ser prudentes a la hora de generalizar resultados.

\section{- Síntomas relacionados con el trastorno de estrés agudo}

Tal y como venimos reflejando en epígrafes anteriores, los familiares de UCI se ven sometidos a elevados niveles de estrés durante su estancia en estas unidades. Este hecho motivó el que diferentes investigadores analizaran la presencia de sintomatología relacionada con haber vivido el ingreso en UCI como un acontecimiento traumático. Si bien es cierto que estas alteraciones forman parte de los trastornos de ansiedad, estimamos conveniente dedicarles atención aparte dada su relevancia.

En relación con estas posibles alteraciones, hay un predominio de los trabajos centrados en el estudio del trastorno por estrés postraumático (TEPT). Distintos 
estudios ofrecen datos sobre prevalencia de síntomas de estrés postrauma en familiares entre el 33\% y el 60\% al alta de UCI (Azoulay et al., 2005; Jones et al., 2004) y entre el $37 \%$ y el $49 \%$ a los seis meses (Jones et al., 2000; Jones et al., 2004). No obstante, si principalmente atendemos a la afectación emocional durante el ingreso en UCI y teniendo en cuenta que este periodo de tiempo suele ser relativamente corto, creemos oportuno centrarnos en el análisis de los síntomas relacionados con el trastorno de estrés agudo (TEA) dado que para hablar de estrés postraumático con propiedad deberíamos estar refiriéndonos a síntomas que permanecen al menos un mes después del contacto con el estresor.

El TEA es considerado como una forma aguda del trastorno por estrés postraumático que ocurre casi inmediatamente después de haberse expuesto a un acontecimiento traumático cuyos síntomas duran entre dos días y cuatro semanas. Entre los principales síntomas asociados al TEA se encuentran la desesperación y la desesperanza; sentimientos de culpa; síntomas disociativos; reexperimentación del acontecimiento traumático mediante sueños, imágenes, pensamientos, episodios de flashback recurrentes, etc.; malestar ante las situaciones que puedan recordar el acontecimiento traumático así como evitación de lo que les pueda recordar el trauma; síntomas de ansiedad o aumento de la activación; etc. (American Psychiatric Association, 2003).

Tras revisar la literatura sobre el TEA en cuidados intensivos, podemos observar que no es extraño encontrar síntomas relacionados con este trastorno en UCI, lo cual no significa que necesariamente se cumplan todos los criterios para poder ser diagnosticado como trastorno.

En un estudio realizado por Auerbach et al. (2005) los autores señalan que tras el ingreso de un ser querido en UCI, los familiares experimentaron síntomas característicos del TEA a niveles moderados-altos, equivalentes a los que presentaban los pacientes ingresados en una unidad psiquiátrica por TEPT. Los síntomas experimentados por la familia que alcanzaron puntuaciones más elevadas fueron la reexperiementación (recuerdos continuos y sueños/pesadillas relacionadas con el acontecimiento traumático) y el aumento del arousal (dificultades para dormir, temblores, sudoración, taquicardia, etc.).

En relación con los posibles factores de riesgo asociados concretamente a la aparición de síntomas de estrés agudo hay pocos datos. En cambio, sí disponemos de 
estos datos en referencia a las respuestas de estrés postrauma, que indicarán que su aparición parece ser más frecuentes entre los familiares que percibían como incompleta la información sobre la condición del paciente, quienes participaron en la toma de decisiones, especialmente las relativas al final de la vida y en aquellos familiares cuyo paciente falleció (Azoulay et al., 2005).

Finalmente, cabe resaltar que las respuestas de estrés agudo son elevadas al inicio, lo cual mostraría indicios a favor de un posible trauma (Auerbach et al., 2005). No obstante, en la literatura se observan resultados contradictorios en relación con la evolución de estos síntomas. Por una parte, diferentes estudios señalan que la naturaleza de estos síntomas es transitoria (Auerbach et al., 2005; Halm et al., 1993; Paparrigopoulos et al., 2006; Van Horn \& Tesh, 2000), disminuyendo considerablemente al alta de UCI, lo que haría poco probable el desarrollo de un TEPT como resultado de la experiencia de tener a un familiar en UCI. Mientras que otros trabajos informan de prevalencias altas de síntomas de estrés postrauma tras el alta de UCI (Azoulay et al., 2005; Jones et al., 2000; Jones et al., 2004).

Estos datos ponen de manifiesto la dificultad de evaluar la afectación psicológica en el contexto de una unidad de cuidados intensivos así como la necesidad de seguir profundizando en el estudio de las alteraciones emocionales en UCI, incluidas aquellas relacionadas con los trastornos de estrés agudo y postrauma.

Con todo lo comentado es evidente que el ingreso de un familiar en UCI constituye una experiencia realmente estresante que conlleva un elevado grado de malestar y sufrimiento que podrán manifestarse mediante sintomatología muy variada. En este sentido, cabe remarcar que los familiares no presentarán todas las alteraciones descritas ni lo harán con la misma intensidad, encontrando notables diferencias individuales. Por ello será fundamental llevar a cabo evaluaciones que atiendan las necesidades particulares de cada familiar identificando aquellos aspectos que pueden dificultar un afrontamiento adecuado de tan impactante experiencia.

De la misma forma, la manifestación de estas reacciones no necesariamente implicará psicopatología sino que podrían ser manifestaciones adaptativas que ayuden a afrontar esta situación de manera satisfactoria. No obstante, es necesario que un equipo multidisciplinar atienda a la familia desde los primeros momentos del ingreso del paciente para que el paso por una unidad de estas características tenga el menor 
coste emocional posible, facilitándoles en todo momento un proceso adaptativo, lo que también repercutirá positivamente en el paciente. 



\section{ESTUDIO EMPÍRICO}





\section{CAPÍTULO 4}

\section{OBJETIVOS E HIPÓTESIS}





\section{OBJETIVOS E HIPÓTESIS}

La presente tesis doctoral forma parte de un estudio más amplio en el que se pretende analizar la afectación psicológica tanto de pacientes y familiares como de los profesionales sanitarios implicados en las Unidades de Cuidados Intensivos.

Esta línea de investigación, iniciada en el año 2005, pretende fundamentalmente analizar aquellos aspectos susceptibles de mejora en el funcionamiento de una UCI, en lo que respecta a la atención integral de pacientes y familiares, tanto si hay posibilidades de supervivencia como si el paciente se enfrenta al final de sus días, sin excluir la necesaria preparación psicológica del personal sanitario en este contexto. Todo ello, desde el marco de la necesaria humanización de la asistencia sanitaria, intentando mejorar siempre que sea posible la calidad de los cuidados proporcionados en una UCI y en definitiva el bienestar de las personas implicadas.

\subsection{OBJETIVOS}

Los objetivos propuestos en la realización de esta tesis doctoral centrada en la población de pacientes y familiares de UCI se detallan a continuación.

El objetivo general de esta investigación ha sido analizar la realidad subjetiva asociada al ingreso en una Unidad de Cuidados Intensivos valorando el grado de afectación psicológica de los pacientes críticos y de sus familiares así como el posible papel modulador de distintos factores en dicha afectación.

Dada la amplitud de este objetivo, para facilitar su comprensión y logro se han propuesto los siguientes objetivos específicos:

\section{Pacientes:}

- Analizar la afectación psicológica de los pacientes en términos de ansiedad y depresión así como la percepción subjetiva de su estado de ánimo.

- Evaluar la valoración que los pacientes hacen de su estancia en UCI.

- Detectar los principales factores estresantes identificados por el paciente ingresado en UCI. 
- Analizar la calidad de vida de los pacientes en relación con la que tenían antes del ingreso en UCI.

- Explorar los factores que podrían facilitar una muerte digna desde el punto de vista del propio paciente.

- Conocer la valoración de los pacientes sobre distintas cuestiones relacionadas con el proceso de información y la toma de decisiones.

- Analizar las diferencias existentes en las principales variables incluidas en la investigación relacionadas con el estado emocional del paciente en función de otras variables sociodemográficas como el género, la edad, el estado civil, el número de hijos y nivel de estudios y en función de variables clínicas como la patología motivadora del ingreso.

- Conocer en qué grado determinadas variables podrían explicar la afectación emocional de los pacientes críticos.

\section{Familiares:}

- Analizar la afectación psicológica de los familiares de UCI en términos de ansiedad y depresión así como la percepción subjetiva de su estado de ánimo.

- Evaluar la valoración de la estancia del paciente en UCI desde el punto de vista de los familiares.

- Detectar los principales factores estresantes identificados por la familia en este contexto.

- Analizar la posible interferencia que provoca el ingreso en UCI en distintas áreas de la vida de los familiares.

- Evaluar distintas necesidades de la familia en el contexto de UCI.

- Explorar los factores que podrían facilitar una muerte digna desde el punto de vista de los familiares.

- Conocer la valoración que hacen los familiares sobre distintas cuestiones relacionadas con el proceso de información y la toma de decisiones. 
- Analizar las diferencias existentes en las principales variables indicadas anteriormente en función de otras variables sociodemográficas como el género, la edad, el estado civil, el número de hijos, el nivel de estudios, el grado de parentesco con el paciente y el lugar de residencia.

- Conocer en qué grado determinadas variables podrían explicar la afectación emocional de los familiares que tienen a un ser querido ingresado en UCI.

\section{Pacientes y familiares:}

- Igualmente otro de los objetivos específicos de nuestra investigación ha sido explorar las diferencias entre el grupo de pacientes y familiares en aquellas variables comunes en la evaluación de ambos grupos como los síntomas de ansiedad y depresión, la percepción subjetiva de estado de ánimo, la valoración de la estancia, el estrés general experimentado en UCI, la valoración del proceso de morir así como la valoración del proceso de información y de la toma de decisiones.

\subsection{HIPÓTESIS}

A partir de la revisión de la literatura sobre la vulnerabilidad en pacientes y familiares de UCI a presentar determinadas alteraciones emocionales, así como teniendo en cuenta resultados de estudios preliminares nos planteamos las siguientes hipótesis:

\section{Pacientes:}

- Los pacientes de UCI presentarán una importante afectación psicológica manifestada mediante sintomatología ansiosa y depresiva, así como percepción de malestar subjetivo.

- Respecto a los síntomas de ansiedad y depresión esperamos obtener diferencias en función del género, la edad, el estado civil, el número de hijos y la patología de ingreso, siendo probablemente mayor la afectación en las mujeres, de edades más jóvenes, con pareja e hijos, y con una patología más grave. En cambio no esperamos encontrar tales diferencias en función del nivel de estudios. 
- La valoración global de la estancia en UCI será negativa identificando aspectos susceptibles de mejora.

- Respecto a la valoración de la estancia en UCI esperamos encontrar diferencias en función de distintas variables sociodemográficas como el género, siendo las mujeres quienes valoren más aspectos de carácter emocional (por ejemplo, el apoyo por parte de los sanitarios).

- La experiencia de UCI resultará estresante para los pacientes, identificando como más estresantes aquellos aspectos relacionados con el propio estado médico.

- En cuanto a la percepción de estrés, esperamos obtener diferencias según el género, la edad, el estado civil, el número de hijos, el nivel de estudios y la patología de ingreso, siendo probablemente mayor el grado de estrés general en las mujeres, de edades más jóvenes, con hijos y que presentan un menor nivel de estudios.

- La calidad de vida de los pacientes se verá seriamente afectada en relación con su situación previa al ingreso en UCI.

- Respecto a la calidad de vida de los pacientes esperamos obtener diferencias en función del diagnóstico de ingreso.

- Ante una hipotética situación de enfrentarse al final de la vida los pacientes valorarán más los factores relacionados con el control de los síntomas físicos de malestar y sufrimiento.

- Respecto a la valoración de los aspectos que podrían facilitar una muerte en paz esperamos encontrar sobre todo diferencias en función del género de manera que las mujeres darán más importancia a aspectos existenciales así como a otros más relacionales (por ejemplo, poder estar cerca de las personas queridas). Asimismo esperamos obtener diferencias en función de otras variables sociodemográficas y clínicas.

- Respecto al proceso de información y la toma de decisiones, los pacientes concederán más importancia al rol que debe desempeñar el propio paciente percibiendo la participación en la toma de decisiones como un privilegio más que como una carga. 
- Respecto al proceso de información y la toma de decisiones esperamos obtener diferencias en función de variables sociodemográficas como la edad.

- Respecto a la afectación psicológica de los pacientes esperamos identificar variables sociodemográficas y clínicas moduladoras o explicativas de dicha afectación.

\section{Familiares:}

- Los familiares de UCI presentarán una importante afectación psicológica manifestada mediante sintomatología ansiosa y depresiva, y una elevada percepción de malestar subjetivo.

- Respecto a los síntomas de ansiedad y depresión esperamos obtener diferencias según el género, la edad, el estado civil, el número de hijos, el grado de parentesco y el lugar de residencia, siendo probablemente mayor la afectación en las mujeres, de edades más jóvenes, con pareja e hijos, que viven más lejos del hospital y que son madres del paciente ingresado en UCI. Sin embargo, no esperamos obtener diferencias tan claras en función del nivel de estudios.

- La valoración global de la estancia del paciente en UCI desde el punto de vista de los familiares será negativa identificando aspectos susceptibles de mejora.

- Respecto a la valoración de la estancia en UCI no habrá diferencias significativas en función de las distintas variables sociodemográficas (género, edad, estado civil, número de hijos, grado de parentesco, lugar de residencia y nivel de estudios).

- La experiencia de UCI resultará muy estresante para la familia, identificando como más estresantes aquellos aspectos relacionados con la gravedad del paciente y con el hecho de no poder estar junto a él.

- En cuanto a la percepción de estrés, esperamos obtener diferencias según el género, la edad, el estado civil, el número de hijos, el grado de parentesco, el lugar de residencia y el nivel de estudios, siendo 
probablemente mayor el grado de estrés general en las mujeres, de edades más jóvenes, con pareja e hijos, que viven más lejos del hospital, que son madres del paciente ingresado en UCI y que presentan un menor nivel de estudios.

- El ingreso de un ser querido en UCI interferirá notablemente en distintos ámbitos de funcionamiento de la vida de sus familiares.

- Respecto a la adaptación de la familia al ingreso en UCI esperamos obtener diferencias en función del grado de parentesco con el paciente.

- Los familiares presentarán diferentes necesidades no satisfechas en UCI.

- En cuanto a las necesidades de los familiares esperamos encontrar diferencias en función de distintas variables sociodemográficas.

- Ante la hipotética situación de que tuviesen que enfrentarse al final de la vida los familiares darán más importancia a aspectos relacionales como poder estar más tiempo junto a sus seres queridos.

- Respecto a la valoración de los aspectos que podrían facilitar una muerte en paz esperamos encontrar diferencias en función del género y el nivel de estudios. Así, las mujeres darán más importancia a aspectos existenciales así como a otros más relacionales como poder estar cerca de las personas queridas. Mientras que en función del nivel de estudios esperamos diferencias respecto a creer en otra vida después de la muerte siendo este aspecto más importante para los familiares de menos estudios.

- Respecto al proceso de información y la toma de decisiones, para los familiares el papel más importante en este proceso lo tendrá la familia percibiendo la participación en la toma de decisiones más como una carga que como un privilegio.

- En cuanto a la valoración del proceso de información y la toma de decisiones esperamos obtener diferencias significativas en función de algunas variables sociodemográficas. 
- Respecto a la afectación psicológica de los familiares esperamos identificar variables sociodemográficas y clínicas moduladoras de dicha afectación.

\section{Pacientes y familiares:}

- Respecto a las diferencias entre el grupo de pacientes y familiares esperamos obtener una mayor afectación psicológica en términos de ansiedad, depresión y percepción subjetiva de malestar en los familiares. Asimismo, la familia valorará de forma más negativa la estancia en UCI de su ser querido, experimentará mayor grado de estrés, dará más importancia llegado el momento de la muerte a poder estar con su ser querido y estrechar vínculos afectivos. En cuanto al proceso de información y la toma de decisiones, el papel de la familia en el proceso será más valorado por los familiares mientras que los pacientes darán más importancia al propio enfermo. Y finalmente, en referencia a la participación en decisiones médicas los pacientes se sentirán más capacitados y percibirán dicha participación menos como una carga dura de soportar que los familiares. 

CAPÍTULO 5

MÉTODO 



\section{MÉTODO}

\subsection{PARTICIPANTES}

Los participantes de este estudio sobre la afectación emocional en el contexto de una UCI, han sido pacientes y familiares del Servicio de Medicina Intensiva del Hospital General Universitario de Castellón.

La muestra total ha estado formada por 160 participantes de los cuales el $44,4 \%$ eran pacientes ingresados en la unidad y el 55,6\% restante eran familiares de estos pacientes.

Para la obtención de la muestra nuestro propósito fue incluir los diferentes ingresos consecutivos en la UCI durante el año 2009 y parte del 2010 (enero-julio), tanto a los pacientes como a sus familiares teniendo en cuenta distintos criterios de exclusión.

Los criterios de exclusión para la muestra de pacientes fueron los siguientes:

- Ser menor de 18 años. En esta unidad no todos los pacientes que ingresan son mayores de edad, ya que la edad mínima de ingreso es de 16 años.

- Situación médica que prevea una corta estancia en UCI o alta probabilidad de resultados médicos favorables, lo que supone excluir los ingresos para control postoperatorio después de intervenciones programadas de alto riesgo, con estancias medias que no alcanzan las 48 horas.

- Pacientes que se encuentran en situación de coma, sedoanalgesiados o presentan una situación médica que impide la comunicación sobre todo verbal, como los casos de intubación o alteración cognitiva. Asimismo, fue un criterio de exclusión presentar dificultades con el idioma que impidieran la clara comprensión de las preguntas.

- Cumplir criterios médicos que en un momento dado desaconsejen la intervención con el paciente.

- Haber sido diagnosticados recientemente de algún trastorno psicológico que pudiera interferir en la evaluación, enmascarando la posible afectación psicológica derivada del ingreso en la unidad.

Respecto a los familiares y allegados, los principales criterios de exclusión fueron: 
- Ser menor de edad.

- Ser familiar de un paciente cuya situación médica fuera alguna de las que se ha establecido anteriormente.

- Presentar deterioro cognitivo aparente que les impidiese responder adecuadamente a las preguntas del estudio.

- Presentar dificultades con el idioma.

- Haber sido diagnosticado recientemente de algún trastorno psicológico que pudiera interferir en la evaluación.

A partir de los ingresos consecutivos durante el periodo en que se llevó a cabo la investigación y teniendo en cuenta distintos factores (por ejemplo, el índice de mortalidad, el acceso a los familiares, la voluntariedad, etc.) así como los criterios de exclusión descritos, en el estudio se incluyeron un total de 160 sujetos, concretamente 71 pacientes y 89 familiares, tal como queda reflejado en la Figura 3. 


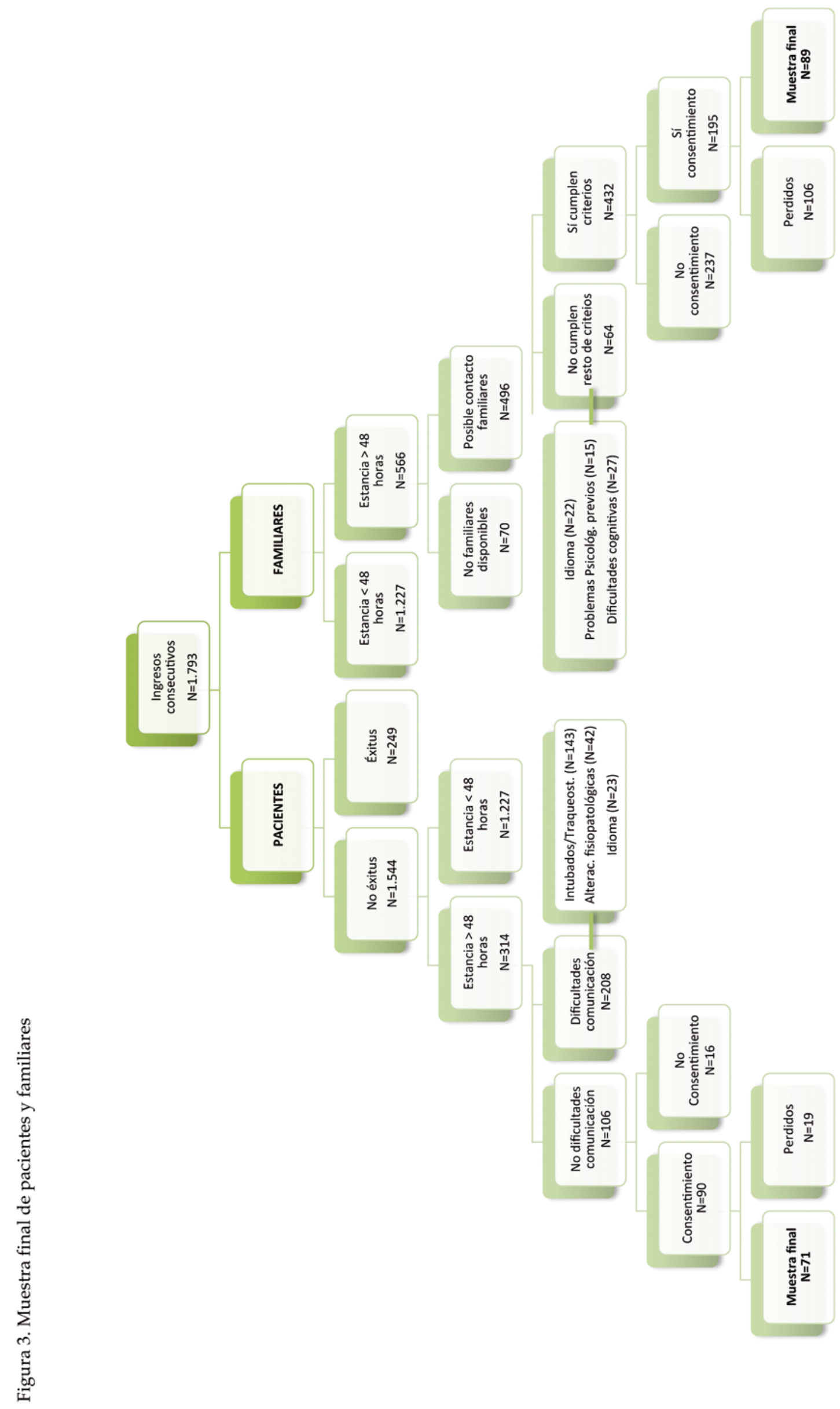


Respecto a la muestra de pacientes, cabe señalar que éstos presentan una edad media de 54,07 años (DT=17,31) siendo el rango de edad de 18 a 83 años. En función del género, el 73,2\% eran hombres y el 26,8\% restante mujeres (véase Gráfica 1).

Gráfica 1. Distribución de la muestra de pacientes según el género

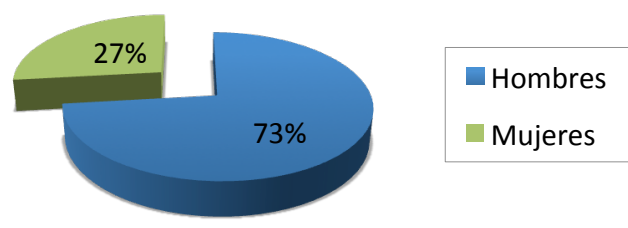

Atendiendo a la distribución de los pacientes en función del nivel cultural, la mayoría tiene estudios primarios $(67,3 \%)$ y en menor medida estudios secundarios $(19,2 \%)$, siendo mínimos los porcentajes de pacientes sin estudios $(7,7 \%)$ o estudios universitarios $(5,7 \%)$ (véase Gráfica 2).

Gráfica 2. Distribución de la muestra de pacientes según nivel de estudios

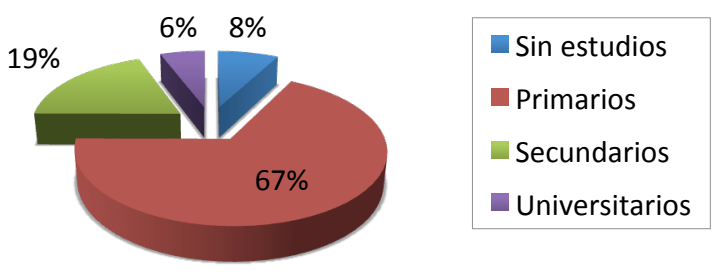

Otro dato a considerar ha sido el estado civil de los participantes correspondiendo el mayor porcentaje a los pacientes casados o con pareja $(70,6 \%)$, mientras que el $29,4 \%$ restante no tenían pareja en la actualidad (15,7\% eran solteros, $9,8 \%$ divorciados y $3,9 \%$ viudos) (véase Gráfica 3 ).

Gráfica 3. Distribución de la muestra de pacientes según estado civil

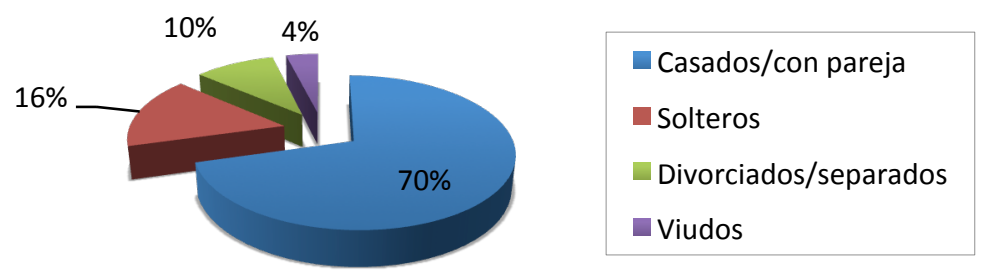


En cuanto al número de hijos, observamos que el $15,8 \%$ de los pacientes ingresados en la unidad referían no tener hijos. Y dentro del $84,2 \%$ restante de participantes que contestaron de forma afirmativa, la mayoría tenía dos hijos (50\%) o más $(38,9 \%)$ (véase Gráfica 4$)$.

Gráfica 4. Distribución de la muestra de pacientes en función del número de hijos

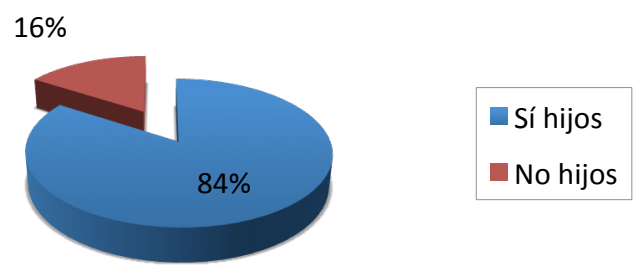

Además de analizar la distribución de la muestra de pacientes en función de los datos sociodemográficos descritos también se incluyó en el estudio otra variable de corte más clínico importante en este contexto, como es la patología que motivó el ingreso del paciente en la UCI. En este sentido, la mayoría de los ingresos han sido debidos a problemas coronarios $(39,7 \%)$ y a problemas derivados de enfermedades médicas que ya padecía el paciente $(20,6 \%)$. En menor medida los pacientes presentaban problemas respiratorios $(10,3 \%)$, traumatismos no operados sin afectación del SNC $(10,3 \%)$ y sepsis $(10,3 \%)$. Mientras que los motivos de ingreso menos representados en nuestra muestra han sido los traumatismos no operados con afectación del SNC (5,9\%) y los pacientes neuroquirúrgicos (2,9\%) (véase Gráfica 5).

Gráfica 5. Distribución de la muestra de pacientes según grupo de diagnóstico al ingreso
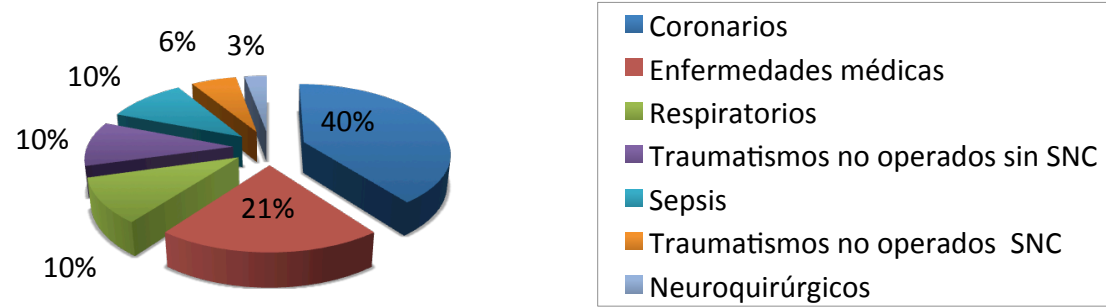

Analizando las principales características sociodemográficas de la muestra de familiares observamos que la edad media de los mismos es de 46,31 años (DT=15,29) dentro de un rango de 19 a 93 años, siendo en su mayoría mujeres (73\%) (véase Gráfica 6). 
Gráfica 6. Distribución de la muestra de familiares según el género

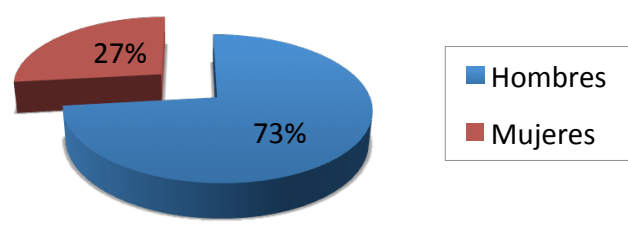

La mayor parte de los familiares que han participado en el estudio residen en la ciudad de Castellón (55,7\%) o en localidades de la misma provincia $(38,6 \%)$. El resto de la muestra de familiares procede de otras regiones de España $(4,3 \%)$ u otros países $(1,4 \%)$ (véase Gráfica 7$)$.

Gráfica 7. Distribución de la muestra de familiares según el lugar de residencia

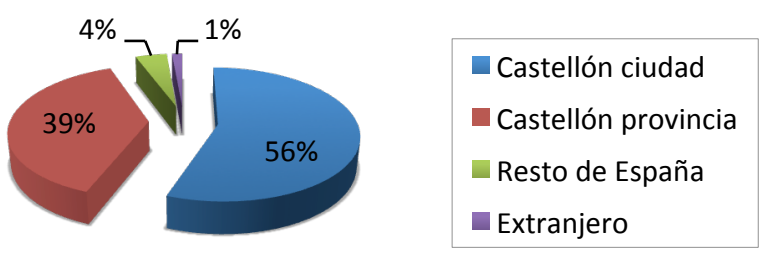

En función del nivel cultural, más de la mitad de los familiares han cursado estudios primarios $(52,4 \%)$, seguido este porcentaje por el de estudios universitarios $(29,5 \%)$ y estudios secundarios $(24,4 \%)$. Mientras que un 3,7\% refiere no tener estudios (véase Gráfica 8).

Gráfica 8. Distribución de la muestra de familiares según nivel de estudios

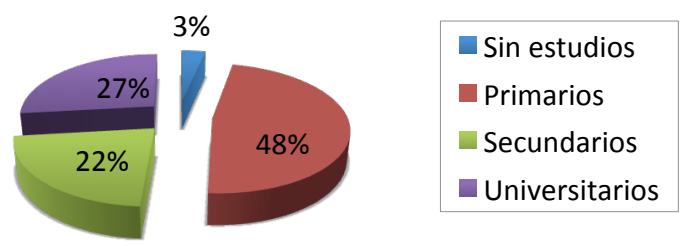

En referencia al estado civil de los familiares podemos observar que un porcentaje considerable de los mismos están casados o con pareja $(72,6 \%)$. En menor medida, los familiares refieren estar solteros $(19 \%)$, viudos $(4,8 \%)$ o divorciados $(3,6 \%)$ (véase Gráfica 9). 
Gráfica 9. Distribución de la muestra de familiares según estado civil

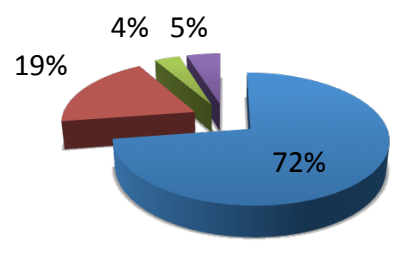

- Casados/con pareja

- Solteros

Divorciados/separados

- Viudos

Otro dato también contemplado para esta muestra ha sido el tener o no hijos. El $24,6 \%$ de los familiares informa no tener hijos frente al 75,4\% restante que afirma tenerlos. De entre los familiares que sí tienen hijos, un 27,7\% sólo tienen uno, mientras que casi la mitad de esta muestra (47,6\%) tienen más de dos (véase Gráfica 10).

Gráfica 10. Distribución de la muestra de familiares en función del número de hijos

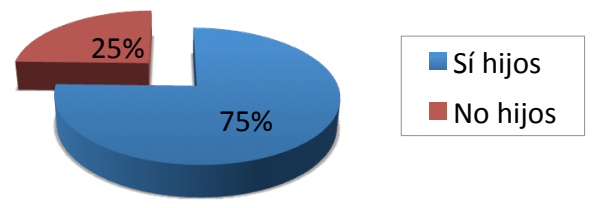

Igualmente, se ha analizado la distribución de la muestra en función del parentesco que tienen con el paciente ingresado en UCI. En este sentido, la mayoría de los familiares son pareja $(40 \%)$ o hijos $(37,6 \%)$ de la persona enferma. Y en menor medida padres $(13 \%)$, hermanos $(5,9 \%)$ u otros familiares (3,5\%) (véase Gráfica 11$)$.

Gráfica 11. Distribución de la muestra de familiares en función del parentesco con el paciente

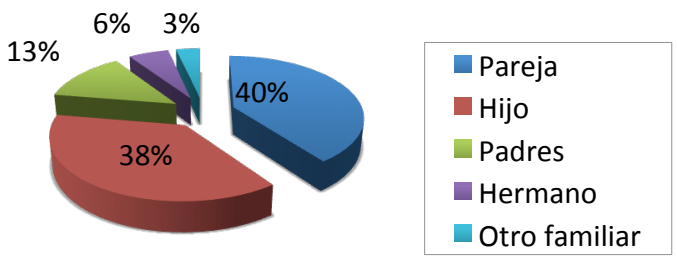

A continuación, en la Tabla 2 se presentan las principales características sociodemográficas de la muestra de pacientes y familiares. 
Tabla 2. Resumen de las principales características sociodemográficas de la muestra

\begin{tabular}{|c|c|c|c|c|c|c|}
\hline \multirow{2}{*}{$\begin{array}{l}\text { DATOS } \\
\text { SOCIODEMOGRÁFICOS }\end{array}$} & \multicolumn{3}{|c|}{ PACIENTES ( $\mathrm{N}=71)$} & \multicolumn{3}{|c|}{ FAMILIARES ( $N=89)$} \\
\hline & & $\bar{X}$ & DT & & $\bar{X}$ & DT \\
\hline \multirow[t]{2}{*}{ Edad } & & 54,07 & 17,31 & & 46,31 & 15,29 \\
\hline & & $\mathbf{N}$ & $\%$ & & $\mathbf{N}$ & $\%$ \\
\hline \multirow[t]{2}{*}{ Género } & Hombres & 52 & 73,2 & Hombres & 24 & 27 \\
\hline & Mujeres & 19 & 26,8 & Mujeres & 65 & 73 \\
\hline \multirow[t]{4}{*}{ Nivel cultural } & Sin estudios & 4 & 7,7 & Sin estudios & 3 & 3,7 \\
\hline & Primarios & 35 & 67,3 & Primarios & 43 & 52,4 \\
\hline & Secundarios & 10 & 19,2 & Secundarios & 20 & 24,4 \\
\hline & Universitarios & 3 & 5,7 & Universitarios & 16 & 29,5 \\
\hline \multirow[t]{2}{*}{ Estado civil } & Casados/pareja & 36 & 70,6 & Casados/pareja & 61 & 72,6 \\
\hline & Sin pareja & 15 & 29,4 & Sin pareja & 23 & 27,4 \\
\hline \multirow[t]{2}{*}{ Hijos } & Sí & 32 & 84,2 & Sí & 49 & 75,4 \\
\hline & No & 6 & 15,8 & No & 16 & 24,6 \\
\hline \multirow[t]{7}{*}{ Patología ingreso } & Coronario & 27 & 39,7 & & & \\
\hline & Enfermedad médica & 14 & 20,6 & & & \\
\hline & Séptico & 7 & 10,3 & & & \\
\hline & Respiratorio & 7 & 10,3 & & & \\
\hline & $\begin{array}{l}\text { Traumatismo no } \\
\text { operado ( } \sin \mathrm{SNC})\end{array}$ & 7 & 10,3 & & & \\
\hline & $\begin{array}{l}\text { Traumatismo no } \\
\text { operado (SNC) }\end{array}$ & 4 & 5,9 & & & \\
\hline & Neuroquirúrgico & 2 & 2,9 & & & \\
\hline \multirow[t]{5}{*}{ Parentesco } & & & & Pareja & 34 & 40 \\
\hline & & & & $\mathrm{Hijo/a}$ & 32 & 37,6 \\
\hline & & & & Hermano/a & 5 & 5,9 \\
\hline & & & & Padre/madre & 11 & 13 \\
\hline & & & & Otro familiar & 3 & 3,5 \\
\hline \multirow[t]{4}{*}{ Lugar residencia } & & & & Castellón ciudad & 39 & 55,7 \\
\hline & & & & Castelló provincia & 27 & 38,6 \\
\hline & & & & España & 3 & 4,3 \\
\hline & & & & Extranjero & 1 & 1,4 \\
\hline
\end{tabular}


Con la finalidad de profundizar en el estudio de las características de la muestra de cara a análisis posteriores que se expondrán en el apartado de Resultados se han llevado a cabo análisis diferenciales entre el grupo de pacientes y el de familiares en función de las variables sociodemográficas consideradas.

Tal como podemos observar en la Tabla 3, se han obtenido diferencias significativas a nivel estadístico entre pacientes y familiares en función de dos variables, el género (Chi-cuadrado=33,91; $p=, 000)$ y la edad $(t=2,97 ; p=, 003)$. Estas diferencias según el género, indican que la mayoría de los pacientes son hombres $(68,4 \%)$ mientras que en los familiares, alrededor de las tres cuartas partes son mujeres $(77,4 \%)$. En cuanto a la edad, los resultados muestran que la edad de los pacientes es significativamente superior a la de los familiares $(t=2,97 ; p=, 003)$.

En el resto de variables sociodemográficas analizadas no se han encontrado diferencias significativas entre el grupo de pacientes y el de familiares (véase Tabla 3). Tal es el caso del estado civil (Chi-cuadrado=2,35; $p=, 503$ ), el tener o no hijos (Chicuadrado=1,11; $\mathrm{p}=, 292$ ) y el nivel de estudios (Chi-cuadrado=6,82; $\mathrm{p}=, 078$ ) aunque en este último caso las diferencias rozan la significación estadística. En esta última variable la tendencia apunta hacia un mayor nivel de estudios en los familiares que en los pacientes.

Tabla 3. Análisis de las distintas variables sociodemográficas en función del grupo pacientes-familiares

\begin{tabular}{|c|c|c|c|c|c|}
\hline $\begin{array}{l}\text { Datos } \\
\text { sociodemográficos }\end{array}$ & & Pacientes (\%) & Familiares (\%) & $\mathrm{Chi}^{2}$ & Sig. $(p \leq, 005)$ \\
\hline \multirow{2}{*}{ Género } & Hombre & 68,4 & 31,6 & 33,91 & , 000 \\
\hline & Mujer & 22,6 & 77,4 & & \\
\hline \multirow{4}{*}{ Nivel estudios } & Sin estudios & 7,7 & 3,7 & 6,82 & , 078 \\
\hline & Primarios & 67,3 & 52,4 & & \\
\hline & Secundarios & 19,2 & 24,4 & & \\
\hline & Universitarios & 5,8 & 19,5 & & \\
\hline \multirow{4}{*}{ Estado civil } & Soltero & 15,7 & 19 & 2,35 & ,503 \\
\hline & Casado/pareja & 70,6 & 72,6 & & \\
\hline & Divorciado & 9,8 & 3,6 & & \\
\hline & Viudo & 3,9 & 4,8 & & \\
\hline \multirow{2}{*}{ Tener hijos } & $\mathrm{Si}$ & 84,2 & 75,4 & 1,11 & ,292 \\
\hline & No & 15,8 & 24,6 & & \\
\hline \multirow[t]{2}{*}{$\begin{array}{l}\text { Datos } \\
\text { sociodemográficos }\end{array}$} & & Pacientes & Familiares & $\mathbf{t}$ & Sig. $(p \leq, 005)$ \\
\hline & & $\bar{X}$ (D.T.) & $\bar{X}$ (D.T.) & & \\
\hline Edad & & $54,07(17,31)$ & $46,31(15,29)$ & 2,97 & ,003 \\
\hline
\end{tabular}




\subsection{INSTRUMENTOS}

Para poder alcanzar los objetivos del presente estudio se han recogido datos sociodemográficos con la correspondiente hoja de registro diseñada para tal propósito así como también se ha utilizado una batería de evaluación formada por diferentes instrumentos que detallaremos más abajo. Cabe señalar que antes de proceder a la evaluación de los distintos participantes obtuvimos el prescriptivo consentimiento informado (véase Anexo II).

\subsubsection{HOJA DE REGISTRO DE DATOS SOCIODEMOGRÁFICOS}

En la primera fase de la entrevista se recogía información sobre variables sociodemográficas tales como la edad, el sexo, el estado civil, el número de hijos, el nivel de estudios, la patología de ingreso, el grado de parentesco con el paciente y el lugar de residencia, cuyos resultados han sido mostrados en el apartado de “participantes" (véase Anexo III-A y Anexo III-B).

Además esta entrevista nos permitía comprobar si los participantes cumplían los criterios de exclusión, descritos anteriormente.

\subsubsection{INSTRUMENTOS DE EVALUACIÓN DE ASPECTOS CLÍNICOS}

Con la finalidad de obtener información precisa sobre la afectación psicológica de pacientes y familiares de UCI se han utilizado diferentes instrumentos que pasaremos a describir a continuación (véase Cuadro 4).

\subsubsection{Escala de Ansiedad y Depresión (HADS)}

Zigmond y Snaith (1983), diseñaron una escala para detectar estados de depresión y ansiedad, en pacientes de servicios hospitalarios no psiquiátricos. Esta escala, adaptada y validada al español por Tejero, Guimera, Farré y Peri (1986) presenta adecuados índices de fiabilidad test-retest, consistencia interna y validez para la población española (Herrero et al., 2003; Quintana et al., 2003; Tejero et al., 1986; Terol et al., 2007). Concretamente presenta una fiabilidad test-retest con coeficientes de correlación por encima de 0,85; un alfa de Cronbach que oscila entre 0,81 y 0,86 para la ansiedad y entre 0,82 y 0,86 para la depresión; y una alta validez concurrente con el STAI $(0,68)$ (Cuestionario de Ansiedad Estado-Rasgo) y con el BDI $(0,71)$ (Inventario de Depresión de Beck). 
Se trata de un cuestionario de 14 ítems, compuesto por dos subescalas de 7 ítems cada una, una de ansiedad (ítems impares) y otra de depresión (ítems pares). Los ítems evalúan la intensidad y frecuencia de ansiedad y depresión en una escala tipo Likert de cuatro alternativas de respuesta (rango 0-3) (véase Anexo IV). El marco temporal, aun cuando las preguntas están formuladas en presente, se refiere a la situación durante la última semana y en nuestro caso particular a los primeros días de ingreso en la unidad de cuidados intensivos.

La puntuación total en cada subescala va de 0 a 21, considerándose los siguientes puntos de corte: 0-7 Normal/Ausencia de ansiedad-depresión; 8-10 Dudoso/posible problema clínico y >10 Probable problema clínico.

Los ítems de este instrumento, ideado para ser administrado a sujetos con enfermedades de tipo médico, aluden sobre todo a respuestas cognitivas, emocionales, y comportamentales de la ansiedad y la depresión obviando en su mayor parte el componente somático, el cual podría ser confundido por el paciente con sintomatología propia de su enfermedad. Este hecho junto con otras características como su brevedad, fácil aplicación y buena capacidad de screening lo convierten en un instrumento especialmente útil en el contexto de una UCI.

\subsubsection{Cuestionario de Ansiedad Estado-Rasgo (STAI)}

Este cuestionario descrito por Spielberger, Gorsuch y Lushene (1983) fue adaptado a población española por TEA (Seisdedos, 1988) mostrando buenos índices de fiabilidad y validez.

El STAI consta de dos escalas, la ansiedad estado (A-E) y la ansiedad rasgo (A-R), formadas por 20 ítems cada una. La principal diferencia entre las dos escalas es que la ansiedad estado mide síntomas ansiosos en el momento actual mientras que la ansiedad rasgo mide estos síntomas en general (véase Anexo V).

Las respuestas se valoran siguiendo una escala tipo Likert de cuatro opciones de respuesta. Las categorías de respuesta para la escala A-R son: casi nunca, a veces, a menudo y casi siempre. Y para la escala A-E: nada, algo, bastante y mucho. El rango de las puntuaciones varía de 0 a 60 en cada escala donde mayor puntuación indica mayor sintomatología. El punto de corte en la población femenina es de 31 para la A-E y de 32 para la A-R, mientras que en los hombres la puntuación de corte es de 28 en la A-E y de 25 en la A-R. El coeficiente alfa de los estudios originales oscila entre 0,83 y 0,92 
(Spielberger et al., 1983). En la muestra española los índices KR20 para A-E oscilan entre 0,90 y 0,93 y en el caso de la A-R entre 0,84 y 0,87 .

\subsubsection{Inventario de Depresión de Beck (BDI)}

Este instrumento, publicado por Beck, Ward, Mendelson, Mock y Erbaugh en 1961 y adaptado y validado a población española por Sanz y Vázquez en 1998, es uno de los más utilizados para evaluar la presencia de sintomatología depresiva.

Consta de 21 ítems con cuatro alternativas de respuesta ordenadas de menor (0) a mayor intensidad (3) que miden aspectos cognitivos, fisiológicos y conductuales del estado de ánimo deprimido (véase Anexo VI). La puntuación total puede oscilar entre 0 y 63, estableciéndose diferentes puntuaciones de corte (Beck, Steer \& Garbin, 1988): 09 ausencia de depresión; 10-18 depresión leve; 19-29 depresión moderada y >30 depresión grave.

El instrumento presenta propiedades psicométricas adecuadas tanto en su versión original como en la versión española (Beck et al., 1988; Lasa, Ayuso-Mateos, Vázquez-Barquero, Díez-Manrique \& Dowrick, 2000; Sanz \& Vázquez, 1998).

\subsubsection{Escala de Estado de Ánimo}

La Escala de Estado de Ánimo de Ballester et al. (2005) ha sido elaborada con la finalidad de poder evaluar la percepción subjetiva del estado de ánimo de forma sencilla. Esta escala consta de tres ítems que se responden mediante una escala analógica visual que va de 0 (nada) a 10 (muchísimo), los cuales valoran el malestar psicológico general, el nerviosismo y el estado de ánimo deprimido que perciben los participantes (véase Anexo VII).

\subsubsection{Cuestionario de Valoración de la estancia en UCI}

Este cuestionario diseñado por Ballester et al. (2005) pretende evaluar la percepción subjetiva de la calidad asistencial ofrecida en una UCI desde el punto de vista del propio paciente y de sus familiares.

El instrumento presenta dos escalas. En la primera de ellas formada por un solo ítem se valora de forma más global cuán desagradable o aversiva está siendo la estancia en UCI con independencia de la situación médica del paciente. La segunda escala consta de quince ítems los cuales proporcionan información útil acerca de la valoración de los pacientes y familiares sobre distintos aspectos propios de una UCI así 
como de los cuidados y atenciones de los distintos agentes implicados en la unidad. Este cuestionario nos ofrece la posibilidad de identificar potenciales estresores directamente asociados con la estancia en UCI.

Todos los ítems se responden siguiendo una escala tipo Likert de cinco puntos. Las opciones de respuesta variarán desde "muy desagradable" (0) a "muy agradable"(5) en la primera escala del instrumento, con una puntuación máxima posible de 5 puntos. En la segunda escala, las opciones de respuesta variarán de "muy mal" (0) a "muy bien" (5) (véase Anexo VIII).

El Cuestionario de Valoración de la estancia en UCI presenta una fiabilidad evaluada a través de la consistencia interna (alfa de Cronbach) de 0,85.

\subsubsection{Escala sobre Factores Estresantes en UCI: Adaptación de la Escala de Estresores Hospitalarios}

Este instrumento es una adaptación al contexto de UCI (Ballester et al., 2005) de la Escala de Estresores Hospitalarios elaborada por Richart, Cabrero y Reig (1993) diseñada originalmente para evaluar el grado de malestar asociado a diferentes estresores durante la hospitalización en pacientes médicos y quirúrgicos.

En esta adaptación se han incluido ítems de la escala original (Richart et al., 1993) así como otros nuevos obtenidos a partir de la literatura revisada (López, Pastor, Rodríguez, Sánchez \& Belmonte, 1990; Volicer \& Bohanon, 1975) y de las entrevistas clínicas realizadas, con la finalidad de evaluar el grado de estrés que pueden generar distintos factores asociados al ingreso en una Unidad de Cuidados Intensivos.

Así, el cuestionario sobre factores estresantes en UCI consta de tres versiones dirigidas a evaluar el grado de estrés que generan distintos factores en los agentes implicados en estas unidades (sanitarios, pacientes y familiares). A continuación, nos centraremos en las dos versiones utilizadas en el presente estudio, es decir, en la versión para pacientes (véase Anexo IX-A) y en la versión para familiares (véase Anexo IX-B). Cada una de las versiones está formada por cuarenta ítems referentes tanto al estrés que pueden generar ciertos aspectos de una UCI como a otras cuestiones más relacionadas con el hecho de estar enfermos. Igualmente, hay un ítem que evalúa el grado de estrés general que ha generado el ingreso en UCI. Las respuestas se puntuan siguiendo una escala tipo Likert con cinco opciones de respuesta: nada (0), algo (1), bastante (2), mucho (3) y muchísimo (4). 
La escala sobre factores estresantes en UCI presenta una fiabilidad evaluada a través de la consistencia interna (alfa de Cronbach) de 0,96 en la versión de pacientes y de 0,91 en la versión de familiares.

\subsubsection{Cuestionario de Ayuda a Morir en Paz (CAMP)}

Este cuestionario fue elaborado por Bayés, Limonero, Romero y Arranz (2000) basándose en los resultados del trabajo de Singer et al. (1999) y en la literatura científica sobre los cuidados paliativos.

Consta de dos partes (véase Anexo X). La primera, evalúa qué aspectos podrían ayudar a las personas a morir en paz a través de la valoración de once enunciados a los que se responde siguiendo una escala Likert con cinco opciones de respuesta (nada, algo, bastante, mucho y muchísimo). A continuación, una vez analizadas las once posibilidades que se ofrecen, en la segunda parte se solicita al participante que priorice de entre los once, aquellos dos aspectos que en su caso más le ayudarían en el proceso de morir.

La consistencia interna de este cuestionario, evaluada mediante alfa de Cronbach para una muestra de pacientes, familiares y profesionales sanitarios de UCI ha sido de 0,62 .

\subsubsection{Cuestionario de Valoración del Proceso de Información y Toma de Decisiones en el ámbito hospitalario (CITD)}

Este cuestionario elaborado por Ballester et al. (2010) valora el proceso de información y toma de decisiones en el ámbito hospitalario. Consta de dos versiones, una para pacientes y familiares y otra para profesionales sanitarios.

Está compuesto por 26 ítems que se responden siguiendo una escala tipo Likert con cuatro opciones de respuesta que valoran el grado de acuerdo con los distintos enunciados: nada, algo, bastante y totalmente. El contenido de los ítems está relacionado con el grado de implicación que la persona evaluada cree que deberían tener los pacientes, los familiares, los médicos y los psicólogos en el proceso de información y toma de decisiones, así como la valoración que hacen sobre la posibilidad de participar en una toma de decisiones (¿es considerada como una carga o un privilegio?), el grado en que creen que la información recibida es adecuada y las preferencias en cuanto al estilo del médico a la hora de informar (véase Anexo XI). 
Este cuestionario ha sido validado provisionalmente por nuestro grupo de investigación en una muestra de 17 profesionales de la salud, obteniéndose un alfa de Cronbach de 0,83 (Bernat, 2010).

\subsubsection{Cuestionario de Calidad de Vida relacionada con la salud: Adaptación del EuroQol-5D}

El cuestionario original EuroQol-5D (EQ-5D, 2000) es un instrumento de medida de la calidad de vida relacionada con la salud y ha sido desarrollado por un grupo internacional y multidisciplinario de investigadores de siete centros con sedes en Inglaterra, Finlandia, Países Bajos, Noruega, Suecia, España y Alemania. Ofrece un método simple para obtener una descripción por dimensiones de la propia calidad de vida relacionada con la salud, referida al momento actual. Las cinco dimensiones que evalúa son: movilidad, cuidado personal/autonomía, actividades cotidianas, dolor/malestar y ansiedad/depresión. Cada dimensión comprende tres niveles que reflejan grados crecientes de gravedad: nivel 1, sin problemas; nivel 2, algunos o moderados problemas y nivel 3, muchos problemas.

En la versión adaptada del EuroQol-5D (García et al., 2003), aun manteniendo esta primera parte de la versión original, en cada una de las dimensiones evaluadas se solicita información sobre la calidad de vida, no sólo referente al momento actual sino también en relación con su estado un mes antes del ingreso en el hospital.

Además de las puntuaciones por dimensión, en esta adaptación se obtendrá una puntuación total correspondiente a la calidad de vida general antes del ingreso y otra relativa a la calidad de vida actual, que podrán oscilar entre 1-15 puntos, siendo la calidad de vida peor a mayores puntuaciones.

Igualmente, se le pide al paciente que valore su estado de salud actual en comparación con el nivel de salud general (previo al ingreso) mediante tres opciones de respuesta: mejor, igual o peor. Otra novedad será incluir una segunda parte dentro de esta adaptación que permita obtener información sobre la situación laboral del paciente actual y previa al ingreso en la Unidad de Cuidados Intensivos: retirado/incapacitado permanentemente, temporalmente incapacitado o trabajador en activo (véase Anexo XII). 


\subsubsection{Escala de Inadaptación}

La escala de Inadaptación adaptada de Echeburúa y Corral (1987) valora el grado en que la situación actual, en este caso el ingreso de un ser querido en la Unidad de Cuidados Intensivos, está afectando a las distintas áreas de su vida cotidiana: trabajo o estudios, vida social, tiempo libre, relación de pareja, vida familiar y una subescala global que refleja el funcionamiento general en la vida cotidiana dada la situación que están viviendo actualmente. Está compuesto por 6 ítems que se responden mediante una escala Likert que va de "ninguna interferencia" (0) a "muchísima interferencia" (5) (véase Anexo XIII). El punto de corte establecido es de 12 en la puntuación total (obtenida sumando los distintos ítems) y de 2 en cada uno de ellos, con una puntuación tanto mayor cuanto mayor es la inadaptación.

Esta escala ha demostrado unas propiedades psicométricas adecuadas (Echeburúa, Corral \& Fernández-Montalvo, 2000) con un alfa de Cronbach de 0,83 en la evaluación de su consistencia interna.

\subsubsection{Cuestionario de necesidades de los familiares de pacientes de Cuidados Intensivos (CCFNI) versión breve}

Este instrumento en su versión original (Harvey, 1993) pretendía medir la capacidad de los profesionales para satisfacer las necesidades de los familiares del paciente de UCI a través de 14 ítems. Posteriormente, Johnson et al. (1998) llevaron a cabo la validación de esta versión breve, descartando dos ítems por mala formulación. Y finalmente, en nuestro estudio se utilizó esta misma versión adaptada y validada a población española por miembros de nuestro equipo de investigación (Gómez et al., 2011) mostrando propiedades psicométricas adecuadas (alfa de Cronbach de 0,65).

La versión utilizada consta de 11 ítems que evalúan necesidades de los familiares de UCI relacionadas con la atención médica al paciente, la información o la comunicación, la atención al familiar y posibles mejoras percibidas (véase Anexo XIV).

Los diferentes ítems se responden siguiendo una escala tipo Likert con cuatro opciones de respuesta: casi todas las veces (1), la mayoría de las veces (2), sólo algunas veces (3) y nunca (4).

En el Cuadro 4 exponemos a modo de resumen todos los instrumentos utilizados para la evaluación tanto de pacientes como de familiares. 


\begin{tabular}{|c|c|c|}
\hline Instrumentos & Pacientes & Familiares \\
\hline -Escala de Ansiedad y Depresión (HADS) de Zigmond y Snaith (1983). & $\mathbf{x}$ & $\mathbf{x}$ \\
\hline -Inventario de ansiedad estado-rasgo (STAI) de Spielberger et al. (1971). & $\mathbf{x}$ & $\mathbf{x}$ \\
\hline -Inventario de Depresión de Beck (BDI) (Beck et al., 1961). & $\mathbf{x}$ & $\mathbf{x}$ \\
\hline -Escala de Estado de Ánimo (Ballester et al., 2005). & $\mathbf{x}$ & $\mathbf{x}$ \\
\hline -Cuestionario de Valoración de la estancia en UCI (Ballester et al., 2005). & $\mathbf{x}$ & $\mathbf{x}$ \\
\hline -Escala sobre factores estresantes en UCI (Ballester et al., 2005). & $\mathbf{x}$ & $\mathbf{x}$ \\
\hline -Cuestionario de Ayuda a Morir en Paz (CAMP) de Bayés et al. (2000). & $\mathbf{x}$ & $\mathbf{x}$ \\
\hline $\begin{array}{l}\text {-Cuestionario de Valoración del Proceso de Información y Toma de Decisiones en el } \\
\text { ámbito hospitalario (CITD) de Ballester et al. (2010) }\end{array}$ & $\mathbf{x}$ & $\mathbf{x}$ \\
\hline -Euro-Qol-5D (Adaptado por García et al., 2003). & $\mathbf{x}$ & \\
\hline -Escala de Inadaptación (Echeburúa y De Corral, 1987). & & $\mathbf{x}$ \\
\hline $\begin{array}{l}\text {-Cuestionario de necesidades de los familiares de pacientes de cuidados intensivos } \\
\text { (CCFNI) versión breve (Adaptada y validada por Gómez et al., 2011). }\end{array}$ & & $\mathbf{x}$ \\
\hline
\end{tabular}

\subsection{PROCEDIMIENTO}

Este estudio, como hemos comentado anteriormente, forma parte de una investigación más amplia sobre la afectación emocional de los diferentes agentes implicados en una Unidad de Cuidados Intensivos que comenzó en el año 2005 y que tras algunas interrupciones temporales ha continuado hasta la actualidad gracias en parte a las ayudas recibidas de la Generalitat Valenciana (Conselleria de Sanitat: Ref. AP-040/08; BFPI/2008/129) y del Ministerio de Educación y Ciencia (PSI 200801642/PSIC). 
Durante el periodo inicial en el que colaboramos con los profesionales de la UCI se elaboraron y pusieron a prueba diferentes materiales de evaluación con la finalidad de adecuar la batería de instrumentos a la muestra a evaluar teniendo en cuenta las características particulares de los participantes, en especial la gravedad médica de los pacientes.

Con la batería de cuestionarios definida, a partir del año 2009 se procedió a llevar a cabo la evaluación pertinente de pacientes y familiares de UCI por parte del equipo de psicólogos. Para este propósito un psicólogo del equipo de investigación se desplazaba a la Unidad de Cuidados Intensivos del Hospital General de Castellón varios días a la semana (de dos a cinco días en función del periodo).

Con el fin de identificar aquellos pacientes ingresados en UCI susceptibles de participar en el estudio, una de las tareas ha sido asistir a las sesiones clínicas que a diario se llevan a cabo en la unidad, donde los médicos comentan las principales características de la situación clínica y evolución de cada enfermo, facilitando a priori la identificación de posibles participantes de la investigación.

A continuación, el psicólogo se ponía en contacto con cada uno de los pacientes informándoles de los objetivos y características del estudio así como también de la voluntariedad, anonimato y confidencialidad de los datos, siendo necesaria la obtención del consentimiento informado para poder evaluarles.

En general, el tiempo estimado para llevar a cabo la evaluación con los instrumentos detallados en el apartado anterior (véase Cuadro 4) podía variar de sesenta a noventa minutos. No obstante, el delicado estado de salud de los pacientes no siempre permitía poder realizar la evaluación completa en una sola sesión siendo necesario un segundo tiempo para completarla, intentando que entre las dos sesiones pasara el menor tiempo posible.

En cuanto a la obtención de la muestra de familiares, el momento elegido para establecer el contacto con ellos era el de la información y / o visita a los pacientes. En este sentido, cabe señalar la labor de los profesionales sanitarios y del equipo de voluntarias de la unidad quienes en la medida de lo posible facilitaban dicho contacto. Igualmente, los psicólogos aprovechaban las horas de visita de los familiares para presentarse y dar a conocer la labor que llevaban a cabo en la unidad. Todo esto se veía reforzado por los carteles informativos sobre la disponibilidad de un servicio de 
atención psicológica en la unidad, colocados en la sala de espera y zonas de paso de los familiares.

A través de todas estas vías se facilitó el contacto de los familiares con el equipo de psicólogos. Al igual que a los pacientes, también se les informaba de las características y objetivos de la investigación, siendo requisito para participar aceptar las condiciones de la misma y no cumplir los criterios de exclusión descritos anteriormente.

Una vez firmado el consentimiento informado se procedía a evaluar a los familiares mediante la batería de cuestionarios prevista (véase Cuadro 4) aproximadamente durante una hora o noventa minutos en función de la situación particular de cada familiar.

Es necesario tener en cuenta que la consecución de muestra en la unidad de cuidados intensivos para este estudio ha resultado muy dificultosa. Por un lado, la gravedad médica de los pacientes imposibilita muchas veces su evaluación al no poder establecer una adecuada comunicación por encontrarse en situación de coma, sedoanalgesiados, intubados, con deterioro cognitivo, etc., lo cual de entrada reduce considerablemente el posible número de participantes. Por otro lado, la situación crítica de los pacientes ingresados requiere la atención continua del personal sanitario, viéndose limitado el tiempo disponible para llevar a cabo la evaluación. En los casos en que es posible evaluar, no siempre se puede hacer en una sola sesión por el delicado estado de salud del paciente, y más veces de las deseables nos hemos visto obligados a interrumpir la evaluación debido a un empeoramiento en el curso de la enfermedad.

De la misma forma cabe señalar que la obtención de la muestra de familiares en UCI también resulta compleja. En numerosas ocasiones los familiares se ven en la necesidad de adoptar nuevos roles y responsabilidades durante el periodo de ingreso del paciente en la unidad, lo cual disminuye considerablemente su tiempo. Así, los familiares suelen llegar al hospital con el tiempo justo para visitar al enfermo. Dado que las visitas en UCI son restringidas, pudiendo acompañar al paciente muy poco tiempo al día, los familiares cuando están en el hospital sólo desean pasar el mayor tiempo posible con su ser querido, reduciéndose de entrada el número de posibles participantes.

Por otro lado, hemos podido comprobar cómo los familiares priorizan el tiempo dedicado a atender todas las cuestiones relacionadas con el paciente dejando en un 
segundo plano sus propias necesidades físicas y emocionales. Este hecho puede influir a dos niveles. En el mejor de los casos, el tiempo que reservan para la entrevista con el psicólogo será breve, lo cual dificultará el poder llevar a cabo la evaluación completa. Mientras que en otros casos, acudirán al psicólogo de la unidad sólo cuando se ven desbordados por el impacto de las circunstancias que están viviendo. Y dada la gravedad de su estado emocional no siempre será pertinente proceder a la evaluación del familiar o ésta tendrá que verse retrasada, lo cual obviamente interferirá en la recogida de datos.

\subsection{ANÁLISIS ESTADÍSTICOS}

Los datos han sido analizados con el paquete estadístico SPSS 19, llevándose a cabo distintos análisis en función de las variables analizadas.

Con la finalidad de describir las características fundamentales de la muestra se han realizado análisis descriptivos y de frecuencias, incluyéndose en estos análisis tanto variables sociodemográficas como otras más relacionadas con la afectación emocional y valoración de distintos aspectos vinculados a una UCI.

Del mismo modo y profundizando en el estudio de la muestra de pacientes y familiares, se han realizado diferentes tipos de análisis diferenciales.

Por un lado, se han llevado a cabo análisis diferenciales de las puntuaciones obtenidas en los distintos cuestionarios en función de variables sociodemográficas y otras de carácter más clínico como es el caso de la patología de ingreso en UCI. En este sentido, se ha utilizado la Prueba $t$ de Student con el fin de comparar las medias de dos muestras independientes y el análisis ANOVA de un factor para comparar las medias de $\mathrm{K}$ muestras independientes. Cuando los resultados del ANOVA han resultado significativos también se ha calculado la Prueba de Scheffé con el objetivo de conocer entre qué grupos se daban las diferencias significativas.

Por otro lado, para analizar las diferencias entre muestras independientes ante la naturaleza nominal de algunos datos, se ha realizado la prueba Chi-cuadrado. Por ejemplo, para ver las diferencias entre pacientes y familiares en cuanto a distintas variables sociodemográficas como el sexo, el nivel cultural o el estado civil. 
Asimismo, con el fin de examinar la relación existente entre variables cuantitativas se han realizado correlaciones bivariadas. Concretamente se ha utilizado el coeficiente de correlación de Pearson y el de Spearman, para conocer la relación entre las puntuaciones obtenidas en los distintos instrumentos y la edad y el nivel de estudios respectivamente.

Y finalmente, se han realizado ecuaciones de regresión múltiple para poder analizar qué variables de entre todas las evaluadas ejercen mayor influencia en el malestar emocional de los pacientes y los familiares de UCI. 

CAPÍTULO 6

RESULTADOS 



\section{RESULTADOS}

A lo largo de este capítulo presentaremos los resultados obtenidos en la presente tesis doctoral centrada en la afectación emocional de pacientes y familiares de UCI, incluyendo datos específicos de afectación psicológica así como de otras variables íntimamente asociadas a este contexto.

Con la finalidad de agilizar su lectura y posterior interpretación, los resultados se agruparán en tres grandes bloques.

En un primer bloque se presentarán los resultados relativos a la afectación psicológica de los pacientes. Por un lado se mostrarán los resultados descriptivos de las siguientes variables: ansiedad, depresión, percepción subjetiva de malestar, valoración de la estancia, factores estresantes, calidad de vida, percepción del proceso de morir y valoración del proceso de información y toma de decisiones. Por otro lado y profundizando un poco más en su estudio se abordarán los resultados referentes a análisis diferenciales en función de variables sociodemográficas y clínicas dentro del grupo de pacientes. En la última parte de este bloque se presentarán los resultados de los análisis de regresión múltiple llevados a cabo con la intención de poder identificar qué variables independientes podrían predecir una mayor afectación psicológica o malestar en los pacientes críticos.

En el segundo bloque y de forma similar a como hemos estructurado los resultados en los pacientes, se presentarán los datos referentes a la afectación psicológica de los familiares. Concretamente, se presentarán los resultados descriptivos de determinadas variables como son: ansiedad, depresión, percepción subjetiva de malestar, valoración de la estancia, factores estresantes, grado de interferencia producida por el ingreso, necesidades percibidas en UCI, percepción del proceso de morir y valoración del proceso de información y toma de decisiones. Asimismo se mostrarán los resultados de los análisis diferenciales en función de distintas variables sociodemográficas dentro del grupo de los familiares. Y finalmente, se presentarán los resultados de los análisis de regresión múltiple que nos permitirán identificar qué variables independientes podrían predecir una mayor afectación psicológica o malestar en los familiares de UCI.

En el tercer y último bloque se mostrarán los resultados de los análisis diferenciales entre pacientes y familiares respecto a las variables que han sido evaluadas en ambos grupos. 
Cabe señalar que los resultados descriptivos correspondientes a los datos sociodemográficos se han presentado en el capítulo anterior, concretamente en el apartado relativo a la descripción de las principales características de los participantes en este estudio.

\subsection{RESULTADOS DE LA MUESTRA DE PACIENTES}

\subsubsection{RESULTADOS DESCRIPTIVOS}

\subsubsection{Síntomas de ansiedad y depresión}

En este apartado se presentarán los síntomas de ansiedad y depresión en el grupo de pacientes, evaluados mediante tres instrumentos diferentes, a saber, HADS, STAI y BDI, descritos en el capítulo anterior (véase Cuadro 4).

Los resultados relacionados con la ansiedad, obtenidos a partir de la evaluación realizada con el cuestionario HADS, muestran una media de la puntuación total de 7,09 (DT=5,29) en una escala cuya puntuación máxima es de 21 puntos. Estos valores, según el baremo del cuestionario, indicarían que la mayoría de la muestra se encuentra casi dentro de lo que se consideran puntuaciones normales. No obstante, tal y como demuestra la desviación típica, en algunos pacientes las puntuaciones obtenidas indicarían dudoso o posible problema clínico (8-10) e incluso probable problema clínico (>10) (véase Gráfica 15). Atendiendo a la distribución de las puntuaciones obtenidas en la subescala de ansiedad del HADS vemos que el $60 \%$ de los pacientes ha obtenido puntuaciones que se situarían dentro de la normalidad, mientras que un $20 \%$ presentaría posible problema clínico y el 20\% restante, probable problema clínico (véase Gráfica 12).

Gráfica 12. Distribución de las puntuaciones en Ansiedad según el baremo de la escala HADS (pacientes)

$\%$

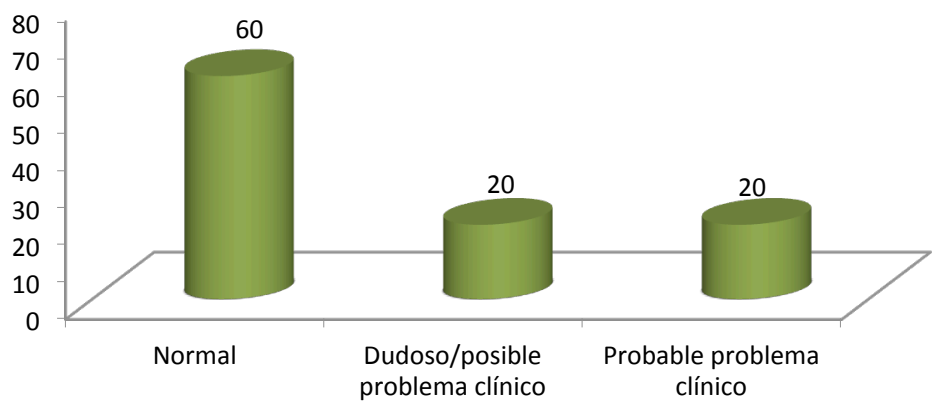


Respecto a los síntomas de ansiedad evaluados mediante el cuestionario STAI, los resultados muestran en la escala de ansiedad-estado una puntuación media de 17,08 (DT=11,37). Siguiendo las indicaciones del baremo del instrumento, esta puntuación en el caso de los hombres equivaldría al percentil 42 y en el caso de las mujeres al percentil 35. En cuanto a la ansiedad-rasgo, la puntuación media es de 13,77 $(\mathrm{DT}=9,97)$, la cual se correspondería con el percentil 22 en el caso de los hombres y con el percentil 13 en las mujeres (véase Gráfica 15). Cabe recordar que el rango de puntuaciones del STAI, tanto en ansiedad-estado como en ansiedad-rasgo, varía entre 0 y 60, situándose el punto de corte en el percentil 75 .

En cuanto a los síntomas de depresión, los resultados obtenidos mediante el cuestionario HADS muestran una puntuación media de 7,22 (DT=5,86) sobre una puntuación total de 21, lo cual atendiendo al baremo del cuestionario indicaría que la mayoría de la muestra se encuentra en el límite de lo que se considera ausencia de depresión o dudoso problema clínico. Si tenemos en cuenta el valor de la desviación típica, podemos observar también en el caso de la depresión, que algunos pacientes presentarían puntuaciones indicativas de dudoso problema clínico (8-10 puntos) y de probable problema clínico (>10 puntos) (véase Gráfica 15). De esta manera, si analizamos la distribución de las puntuaciones obtenidas en esta subescala del HADS podemos observar que el $60 \%$ de los pacientes presentaría puntuaciones normales en depresión, mientras que un $12,9 \%$ de los pacientes presentaría posible problema clínico y el $27,1 \%$ restante presentaría puntuaciones correspondientes a la presencia de probable problema clínico (véase Gráfica 13).

Gráfica 13. Distribución de las puntuaciones en Depresión según el baremo de la escala HADS (pacientes)

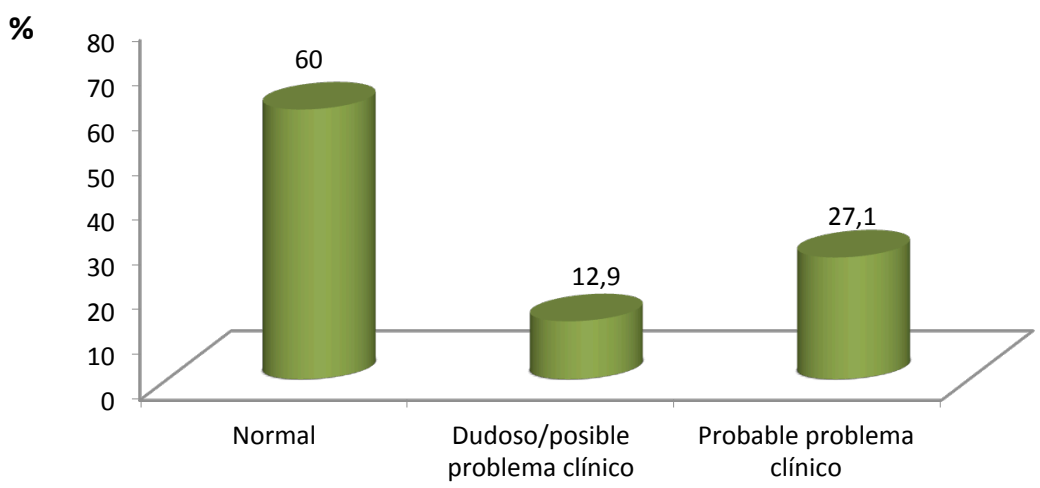

Atendiendo a los síntomas de depresión evaluados mediante el cuestionario BDI, la puntuación media obtenida es de 12,94 (DT=9,68) sobre una puntuación total posible 
de 63 puntos. En este caso, la puntuación se correspondería con lo que se considera depresión leve (10-18 puntos) (véase Gráfica 15). Y analizando la distribución de las puntuaciones obtenidas mediante el BDI observamos que éstas indican ausencia de depresión en el 43,8\% de los pacientes, mientras que el 33,3\% presenta un grado de depresión leve, el 18,8\% depresión moderada y el 4,2\% restante depresión grave (véase Gráfica 14).

Gráfica 14. Distribución de las puntuaciones en Depresión según el baremo del cuestionario BDI (pacientes)

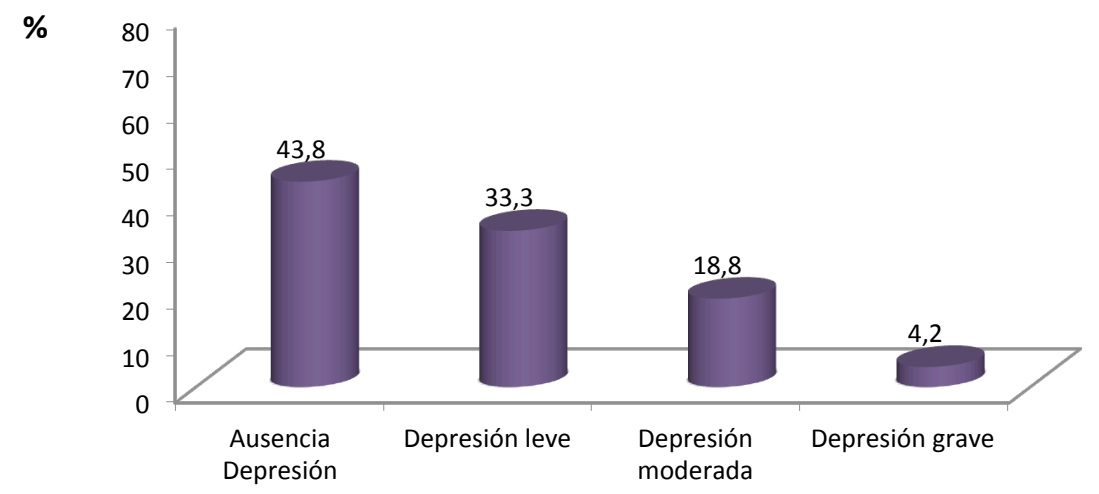

Gráfica 15. Medias de las puntuaciones totales en ansiedad y depresión en pacientes críticos evaluadas mediante distintos cuestionarios

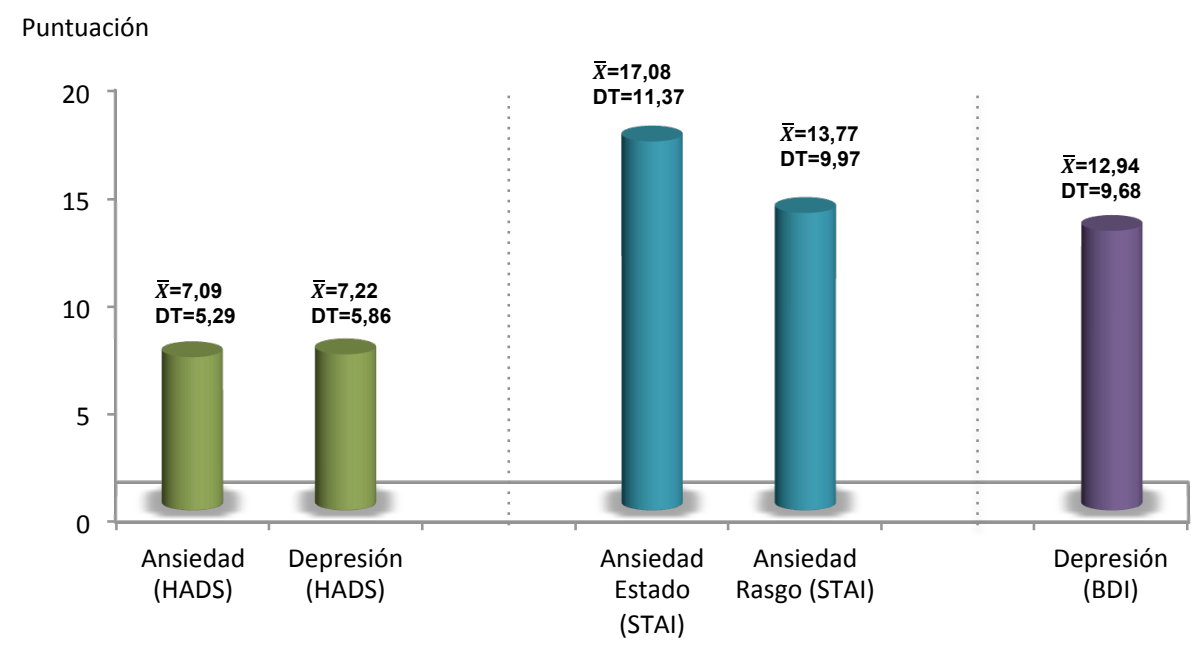

\subsubsection{Percepción subjetiva del malestar emocional}

Otro aspecto que consideramos relevante evaluar fue la percepción subjetiva de malestar de los pacientes, quienes valoraron en una escala de 0 a 10 el nivel de malestar general, ansiedad y estado de ánimo deprimido que ellos mismos percibían. 
En este sentido y tal como se aprecia en la Gráfica 16, los resultados muestran una percepción media de malestar general de 4,37 ( $\mathrm{DT}=2,98)$, siendo menores las puntuaciones en la percepción del grado de ansiedad o nerviosismo $(\bar{X}=2,89 ; \mathrm{DT}=3,03)$ y de estado de ánimo deprimido $(\bar{X}=2,26 ; \mathrm{DT}=2,92)$.

Gráfica 16. Medias de las puntuaciones totales de malestar subjetivo en pacientes (Escala 0-10)

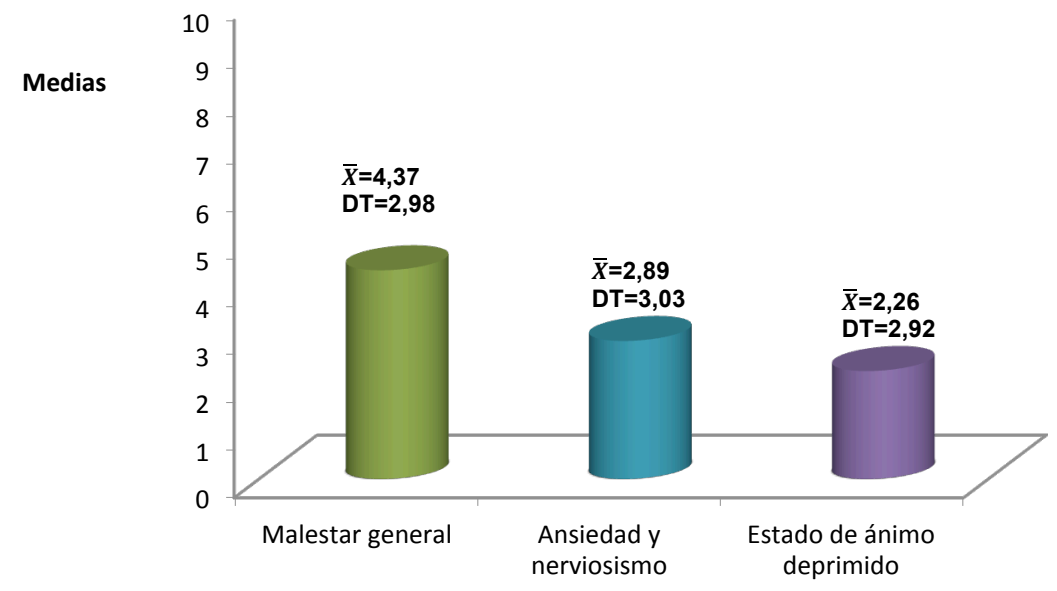

\subsubsection{Valoración de la estancia en la Unidad de Cuidados Intensivos}

Conocer la realidad del entorno de UCI desde el punto de vista de las personas implicadas es un aspecto realmente importante cuando se intentan implementar mejoras en ese contexto. Así, estimamos conveniente analizar cómo valoran los pacientes que está siendo su estancia en la unidad, tanto de manera general como en relación con cuestiones particulares inherentes a estas unidades (véase Tabla 4 y Gráfica 17).

Respecto a la valoración global de la estancia en UCI, sin considerar los problemas derivados de su situación médica, los pacientes presentan una puntuación media de $4,06(\mathrm{DT}=1,25)$ en una escala de 0 (muy desagradable) a 5 (muy agradable). Concretamente, el $80,7 \%$ de los pacientes han valorado su estancia en UCI como bastante/muy agradable, mientras que para el $6,4 \%$ ha sido bastante/muy desagradable (véase Tabla 5).

En cuanto a la valoración de aspectos concretos de la UCI, en una escala de 0 (muy mal) a 5 (muy bien) los resultados muestran que la mayoría de ítems (excepto tres) han sido valorados de forma positiva con puntuaciones superiores a los cuatro 
puntos. En este sentido, las puntuaciones medias más altas $(\bar{X}=4,73)$ corresponden a la atención recibida por los profesionales sanitarios, tanto médicos $(\mathrm{DT}=0,52)$ como personal de enfermería $(\mathrm{DT}=0,68)$, y al trato por parte del personal de enfermería $(\mathrm{DT}=0,52)$. Igualmente, han sido valorados de forma notablemente positiva los cuidados médicos $(\bar{X}=4,68 ; \mathrm{DT}=0,50)$, la atención a los familiares $(\bar{X}=4,67 ; \mathrm{DT}=0,54)$ y la atención de las necesidades psicológicas de pacientes y familiares $(\bar{X}=4,62 ; \mathrm{DT}=0,64)$. En cambio, podemos observar que los aspectos menos valorados o valorados de forma más negativa por los pacientes han sido las posibilidades de distraerse $(\bar{X}=2,41$; $\mathrm{DT}=1,38)$, el silencio en la sala $(\bar{X}=3,15 ; \mathrm{DT}=, 19)$ y el régimen de visitas $(\bar{X}=3,66$; $\mathrm{DT}=1,04)$ (véase Tabla 4 y Gráfica 17).

En términos de frecuencias, estos resultados muestran que entre el 75,8\% y el 80,6\% de los pacientes valoran "muy bien" la atención recibida de los distintos profesionales sanitarios. De la misma forma, otros aspectos muy bien valorados por un 70,5\% de los pacientes han sido la atención a los familiares, seguido de cerca (alrededor del 69\%) por las valoraciones de los cuidados médicos y la atención de las necesidades psicológicas de pacientes y familiares (véase Tabla 5).

Atendiendo a los resultados obtenidos en las categorías de respuesta más negativas (muy mal-bastante mal) encontramos porcentajes reducidos. En este sentido, observamos que los aspectos con peor valoración han sido las posibilidades de distraerse y el silencio o tranquilidad en la sala, valorados como muy/bastante mal por el $24,1 \%$ y $8,2 \%$ de los pacientes respectivamente, si bien estos porcentajes aumentan considerablemente al incluir la categoría "algo mal" (53,4\% y 32,8\%). 
Tabla 4. Puntuaciones medias de los ítems del Cuestionario de Valoración de la estancia en UCI según los pacientes

\begin{tabular}{|c|c|c|c|}
\hline \multicolumn{2}{|c|}{ Ítem } & $\bar{X}$ & DT \\
\hline \multicolumn{2}{|r|}{$\begin{array}{l}\text { - En qué grado está siendo agradable/desagradable su estancia en UCI sin considerar los } \\
\text { problemas médicos }\end{array}$} & 4,06 & 1,25 \\
\hline \multicolumn{2}{|c|}{ Valoración de los siguientes aspectos } & $\bar{X}$ & DT \\
\hline & Cuidados médicos & 4,68 & 0,50 \\
\hline 2. & Atención de los médicos & 4,73 & 0,52 \\
\hline 3. & Atención de las/os enfermeras/os & 4,73 & 0,68 \\
\hline 4. & Atención de las/os auxiliares de enfermería & 4,73 & 0,68 \\
\hline 5. & Claridad de la información recibida & 4,41 & 0,88 \\
\hline 6. & Cantidad de la información recibida & 4,29 & 0,96 \\
\hline 7. & Trato por parte del personal de enfermería & 4,73 & 0,52 \\
\hline 8. & Afecto/apoyo emocional del personal de enfermería & 4,53 & 0,84 \\
\hline 9. & Respeto a la intimidad & 4,47 & 0,74 \\
\hline 10. & Atención a los familiares & 4,67 & 0,54 \\
\hline 11. & Atención de necesidades psicológicas en paciente y familia & 4,62 & 0,64 \\
\hline 12. & Calidad de las instalaciones (comodidad, higiene...) & 4,37 & 0,75 \\
\hline & Posibilidades de distraerse & 2,41 & 1,38 \\
\hline & Silencio o tranquilidad en la sala & 3,15 & 1,19 \\
\hline 15. & Régimen de visitas & 3,66 & 1,04 \\
\hline
\end{tabular}

Gráfica 17. Puntuaciones medias de los ítems del Cuestionario de Valoración de la estancia en UCI según los familiares

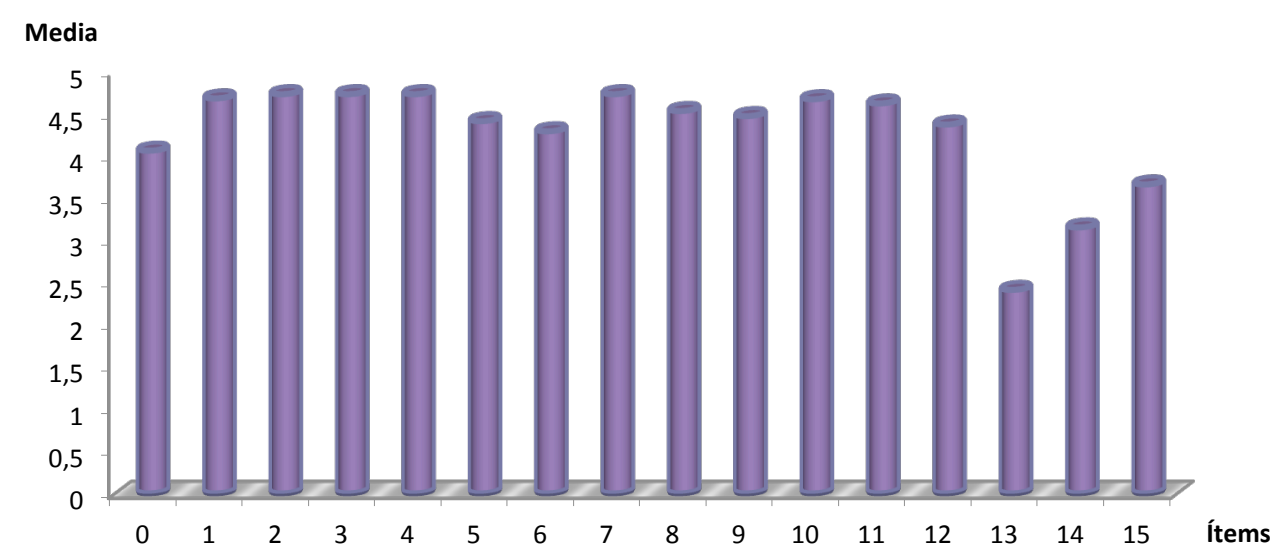
0 . En qué grado la estancia en UCI ha sido agradable o desagradable, sin considerar problemas médicos.
8. Afecto/apoyo emocional recibido por enfermería.
1. Cuidados médicos.
9. Respeto a la intimidad
2. Atención de los médicos.
3. Atención de los enfermeros/as.
4. Atención de los auxiliares de enfermería.
5. Claridad de la información recibida.
6. Cantidad de la información recibida.
10. Atención a los familiares.
11. Atención a necesidades psicológicas de pacientes y familiares.
12. Calidad de las instalaciones.
13. Posibilidades de distraerse.
14. Silencio y tranquilidad en la sala.
7. Trato por parte del personal de enfermería.
15. Régimen de visitas. 
Tabla 5. Porcentajes en las distintas opciones de respuesta de los ítems del Cuestionario de Valoración de la estancia en UCI según los pacientes

\begin{tabular}{|c|c|c|c|c|c|c|}
\hline Ítem & $\begin{array}{c}\text { Muy } \\
\text { desagradable }\end{array}$ & $\begin{array}{c}\text { Bastante } \\
\text { desagradable }\end{array}$ & $\begin{array}{c}\text { Algo } \\
\text { desagradable }\end{array}$ & $\begin{array}{c}\text { Algo } \\
\text { agradable }\end{array}$ & $\begin{array}{l}\text { Bastante } \\
\text { agradable }\end{array}$ & $\begin{array}{c}\text { Muy } \\
\text { agradable }\end{array}$ \\
\hline $\begin{array}{l}\text { - En qué grado está siendo } \\
\text { agradable/desagradable su } \\
\text { estancia en UCI sin considerar } \\
\text { los problemas médicos }\end{array}$ & 3,2 & 3,2 & 4,8 & 8,1 & 33,9 & 46,8 \\
\hline $\begin{array}{l}\text { Valoración de los siguientes } \\
\text { aspectos }\end{array}$ & Muy mal & Bastante mal & Algo mal & Algo bien & $\begin{array}{l}\text { Bastante } \\
\text { bien }\end{array}$ & Muy bien \\
\hline 1. Cuidados médicos & 0 & 0 & 0 & 1,6 & 29 & 69,4 \\
\hline 2. Atención de los médicos & 0 & 0 & 0 & 3,2 & 21 & 75,8 \\
\hline $\begin{array}{l}\text { 3. Atención de las/os } \\
\text { enfermeras/os }\end{array}$ & 0 & 1,6 & 0 & 3,2 & 14,5 & 80,6 \\
\hline $\begin{array}{l}\text { 4. Atención de las/os } \\
\text { auxiliares de enfermería }\end{array}$ & 0 & 1,6 & 0 & 3,2 & 14,5 & 80,6 \\
\hline $\begin{array}{l}\text { 5. Claridad de la información } \\
\text { recibida }\end{array}$ & 0 & 1,6 & 1,6 & 11,5 & 24,6 & 60,7 \\
\hline $\begin{array}{l}\text { 6. Cantidad de la información } \\
\text { recibida }\end{array}$ & 0 & 1,6 & 3,3 & 14,8 & 24,6 & 55,7 \\
\hline $\begin{array}{l}\text { 7. Trato por parte del personal } \\
\text { de enfermería }\end{array}$ & 0 & 0 & 0 & 3,2 & 21 & 75,8 \\
\hline $\begin{array}{l}\text { 8. Afecto/apoyo emocional } \\
\text { del personal de enfermería }\end{array}$ & 1,6 & 0 & 0 & 6,5 & 25,8 & 66,1 \\
\hline 9. Respeto a la intimidad & 0 & 0 & 3,2 & 4,8 & 33,9 & 58,1 \\
\hline 10. Atención a los familiares & 0 & 0 & 0 & 3,3 & 26,2 & 70,5 \\
\hline $\begin{array}{l}\text { 11. Atención de necesidades } \\
\text { psicológicas en paciente y } \\
\text { familia }\end{array}$ & 0 & 0 & 1,7 & 3,4 & 25,9 & 69 \\
\hline $\begin{array}{l}\text { 12. Calidad de las instalaciones } \\
\text { (comodidad, higiene...) }\end{array}$ & 0 & 1,6 & 0 & 6,5 & 43,5 & 48,4 \\
\hline 13. Posibilidades de distraerse & 10,3 & 13,8 & 29,3 & 24,1 & 15,5 & 6,9 \\
\hline $\begin{array}{l}\text { 14. Silencio o tranquilidad en la } \\
\text { sala }\end{array}$ & 1,6 & 6,6 & 24,6 & 19,7 & 37,7 & 9,8 \\
\hline 15. Régimen de visitas & 1,6 & 1,6 & 8,1 & 25,8 & 43,5 & 19,4 \\
\hline
\end{tabular}

\subsubsection{Percepción de estrés en UCI desde el punto de vista de los pacientes}

Consideramos relevante analizar el grado de estrés que perciben los pacientes durante su ingreso en la UCI, tanto a nivel general como en relación con aspectos más concretos de estas unidades y que podrían entenderse como posibles factores estresantes para los propios pacientes. 
Tal como se aprecia en la Tabla 6, la puntuación media de nivel de estrés general obtenida ha sido de 1,72 (DT=1,24) en un rango de 0 a 4 . El mayor porcentaje de sujetos $(57,4 \%)$ manifiestan un grado de estrés general intermedio, es decir, comprendido entre las opciones de respuesta de algo y bastante estresante, frente a un 15\% para el cual el ingreso no ha sido nada estresante y un $28 \%$ que indica que ha sido mucho-muchísimo estresante (véase Gráfica 18).

Gráfica 18. Nivel general de estrés en pacientes de UCI
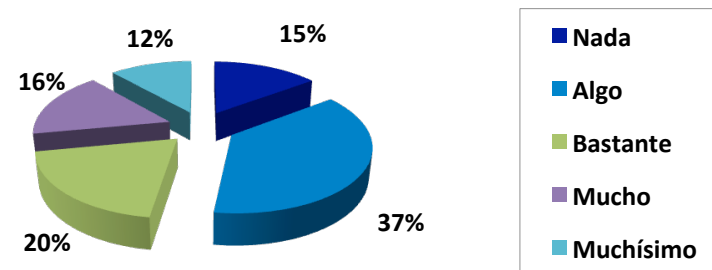

En cuanto a los posibles factores estresantes asociados al contexto de UCI, podemos observar que en una escala de 0 a 4 , los ítems que han obtenido mayores puntuaciones (puntuación media superior a 2) y que por tanto generan más estrés en los pacientes son el ítem 20 "tener dolor" ( $\bar{X}=2,70 ; \mathrm{DT}=1,37)$, el ítem 2 "estar encamado o sentado en el sillón todo el día" $(\bar{X}=2,33 ; \mathrm{DT}=1,43)$, el ítem 32 "no obtener alivio para el dolor aun tomando medicamentos" ( $\bar{X}=2,29 ; \mathrm{DT}=1,52)$, el ítem 5 "tener que utilizar la cuña de cama" $(\bar{X}=2,24 ; \mathrm{DT}=1,62)$ y el ítem 36 "que no le den la medicación para el dolor cuando lo necesita" ( $\bar{X}=2,05 ; \mathrm{DT}=1,47)$. Otro factor cuya puntuación media es de casi 2 puntos corresponde al ítem 26 "estar separado de los familiares más cercanos" $(\bar{X}=1,98 ; \mathrm{DT}=1,41)$. Por el contrario, los factores que menos estrés les generan corresponden a los ítems 11 "estar al cuidado de sanitarios desconocidos" $(\bar{X}=0,21$; $\mathrm{DT}=0,61)$, ítem 38 "sentir olores extraños en el hospital" $(\bar{X}=0,48 ; \mathrm{DT}=0,97)$, ítem 39 “comer a horas diferentes a las habituales" $(\bar{X}=0,49 ; \mathrm{DT}=0,97)$, ítem 12 "tener demasiadas visitas" $(\bar{X}=0,52 ; \mathrm{DT}=1,06)$, seguido por el ítem 37 "pensar en la posible pérdida de dinero a causa de la enfermedad" $(\bar{X}=0,56$; DT=1,02) y el ítem 7 "dormir junto a otros enfermos" $(\bar{X}=0,56 ; \mathrm{DT}=1,01)$.

Igualmente, consideramos que analizar los resultados en términos de frecuencias puede proporcionar información relevante a nivel clínico. En este sentido, podemos apreciar en la Tabla 7 que a un porcentaje considerable de pacientes les resulta de 
"mucho a muchísimo" estresante "tener dolor" (58,5\%), "utilizar la cuña (50\%)" y "estar encamado o sentado en el sillón todo el día" (49,2\%). En porcentajes un poco menores pero no por ello menos importantes observamos que también les genera mucho estrés el "no obtener alivio para el dolor aún tomando medicamentos" (41,5\%) seguido de cerca por "pensar que le pueda ocurrir algo grave" (37,5\%) y "no entender en qué consiste la enfermedad" (37,5\%).

Siguiendo con el análisis de los porcentajes de respuesta en aquellos factores menos estresantes para los pacientes, los resultados indican que determinados aspectos no generan "nada" de estrés para porcentajes considerables de participantes (véase Tabla 7). Tal es el caso del ítem 11 "estar al cuidado de sanitarios desconocidos" $(86,9 \%)$, ítem 38 "sentir olores extraños en el hospital" (73,3\%), ítem 12 "tener demasiadas visitas" $(73,2 \%)$, ítem 37 "pensar en la posible pérdida de dinero a causa de la enfermedad" (72,2\%) e ítem 39 "comer a horas diferentes a las habituales" (71,2\%). A estos porcentajes siguen de cerca los relativos al ítem 7 "dormir junto a otros enfermos" $(68,9 \%)$, ítem 33 "ver que el personal del hospital tiene prisa" (68,3\%), ítem 19 "estar aislado por prescripción médica" (64,5\%) e ítem 10 "estar ingresado en la unidad junto a otros enfermos graves" (60\%). Aun así, cabe señalar que tales aspectos son motivo de estrés para un nada despreciable $13 \%$ a $40 \%$ de los pacientes.

Por otra parte, como se aprecia en las Tablas 6 y 7 existen otros muchos factores que aunque no son comentados aquí por ocupar posiciones intermedias dentro del listado de estresores, resultan causa de estrés para muchos pacientes como puede ser "estar desnudo, únicamente cubierto con una sábana", "dormir en una cama que no es la suya", "escuchar ruidos" y "tener las luces todo el día encendidas".

Con la finalidad de simplificar la información relativa a los estresores en pacientes de UCI en la Gráfica 19 sólo representaremos los diez factores que han obtenido mayores puntuaciones medias. 
Gráfica 19. Principales factores estresantes en pacientes de UCI



Tabla 6. Medias de los factores estresantes en pacientes ingresados en UCI

1. No disponer de baño en el box

2. Tener que estar en la cama/sillón todo el día

3. Estar hospitalizado lejos de casa

4. Dormir en una cama que no es la suya

5. Utilizar la cuña de cama

6. Que no respondan al timbre de aviso

7. Dormir junto a otros enfermos en la unidad

8. Tener que ser ayudado para ir al baño

9. Tener que comer en la cama en una postura incómoda

10. Estar ingresado en la unidad junto a otras personas gravemente enfermas

11. Estar al cuidado de sanitarios desconocidos

12. Tener demasiadas visitas

13. Tener que estar todo el tiempo desnudo, únicamente cubierto con una sábana

14. Necesitar ayuda para comer

15. No poder ver la TV/escuchar la radio/leer el periódico cuando uno quiere

16. Escuchar ruidos de máquinas o gente hablar constantemente

17. Estar las luces todo el día encendidas

18. No tener a los familiares y amigos acompañándole a lo largo del día

19. Estar aislado en la habitación por prescripción médica

20. Tener dolor

21. No saber con seguridad o no entender en qué consiste la enfermedad

22. Pensar que le puede ocurrir algo grave

23. Pensar si podrá volver a su vida normal después de salir del hospital

24. No poder ocuparse de la familia como hasta ahora venía haciendo

25. No saber con seguridad cómo se quedará después de la operación

26. Estar separado de sus familiares más cercanos

27. No saber cuándo le darán el alta de la unidad de cuidados intensivos

28. Haber sido hospitalizado de repente, sin esperarlo

29. No saber los resultados/razones de los tratamientos/pruebas que le hacen 
(Continuación Tabla 6)

Ítem

30. Pensar que puede tener dolor a causa de la operación/análisis/pruebas

31. No saber cuándo van a hacerle cosas a uno

32. No obtener alivio para el dolor aún tomando medicación

33. Ver que el personal del hospital tiene prisa

34. Que sanitarios hablen deprisa o usen palabras que no pueden entender

35. Que el personal sanitario no conteste a sus preguntas

36. Que no le den la medicación para el dolor cuando lo necesita

37. Pensar en la posible pérdida de dinero a causa de la enfermedad

38. Sentir olores extraños en el hospital

39. Tener que comer a horas diferentes a las habituales

40. Nivel de estrés en general

Ítem N Nada Algo Bastante Mucho Muchísimo

1. No disponer de baño en el box

2. Tener que estar en la cama/sillón todo el día

3. Estar hospitalizado lejos de casa

4. Dormir en una cama que no es la suya

5. Utilizar la cuña de cama

6. Que no respondan al timbre de aviso

7. Dormir junto a otros enfermos en la unidad

8. Tener que ser ayudado para ir al baño

9. Tener que comer en la cama en una postura incómoda

10. Estar ingresado junto a otras personas gravemente enfermas

11. Estar al cuidado de sanitarios desconocidos

12. Tener demasiadas visitas

13. Tener que estar desnudo, únicamente cubierto con una sábana

14. Necesitar ayuda para comer

15. No poder ver la TV/escuchar la radio/... cuando uno quiere

16. Escuchar ruidos de máquinas o gente hablar constantemente

17. Estar las luces todo el día encendidas

18. No tener a familiares/amigos a lo largo del día

19. Estar aislado en la habitación por prescripción médica

20. Tener dolor

21. No saber/no entender en qué consiste la enfermedad

22. Pensar que le puede ocurrir algo grave

23. Pensar si podrá volver a su vida normal después del hospital

24. No poder ocuparse de la familia como hasta ahora

25. No saber con seguridad cómo quedará tras la operación

26. Estar separado de sus familiares más cercanos

27. No saber cuándo le darán el alta de UCI

28. Haber sido hospitalizado de repente, sin esperarlo

29. No saber los resultados/razones de los tratamientos...

30. Pensar que puede tener dolor a causa de la operación//pruebas

31. No saber cuándo van a hacerle cosas a uno

32. No obtener alivio para el dolor aún tomando medicación

33. Ver que el personal del hospital tiene prisa

34. Que sanitarios hablen deprisa/usen palabras que no entiendan

35. Que el personal sanitario no conteste a sus preguntas

36. Que no le den la medicación para el dolor cuando lo necesita

37. Pensar en posible pérdida de dinero por la enfermedad

38. Sentir olores extraños en el hospital

39. Tener que comer a horas diferentes a las habituales

40. Nivel de estrés en general
42,6

14,8

59,3

54,2

22,4

40,6

68,9

28,6

41,7

60

86,9

73,2

50

39,3

46,4

52,5

54,2

26,7

64,5

9,4

31,4

32,1

42,4

32,8

38,5

14,8

38,3

42,6

32,1

24

42,6

17,1

68,3

55,1

26,5

13,2

72,2

73,3

71,2

14,8

\section{1,5}

16,4

14,8

11,9

17,2

12,5

18

18,4

21,7

21,7

6,6

14,3

21,7

28,61

26,8

21,3

10,2

20

19,4

11,3

17,6

14,3

20,3

26, 2

23,1

29,5

18,3

14,8

37,7

20

24,1

14,6

13,3

14,3

14,7

34,2

9,3

15

18,6

37,7

$\begin{array}{lll}13,1 & 9,8 & 23\end{array}$

$19,7 \quad 19,7 \quad 29,5$

$9,3 \quad 3,7$

$8,5 \quad 10,2$

$10,3 \quad 13,8$

$15,6 \quad 18,8$

$3,3 \quad 8,2$

$16,3 \quad 12,2$

$15 \quad 13,3$

$10 \quad 1,7$

$4,9 \quad 1,6$

$5,4 \quad 1,8$

$10 \quad 6,7$

$19,6 \quad 8,9$

$14,3 \quad 8,9$

$9,8 \quad 4,9$

$20,3 \quad 3,4$

$23,3 \quad 8,3$

$3,2 \quad 6,5$

$20,8 \quad 17$

$13,7 \quad 15,7$

$16,1 \quad 14,3$

$20,3 \quad 8,5$

$16,4 \quad 19,7$

$12,8 \quad 12,8$

$23 \quad 8,2$

$15 \quad 16,7$

$9,3 \quad 20,4$

$7,5 \quad 17$

$18 \quad 20$

$13 \quad 16,7$

$26,8 \quad 4,9$

$3,3 \quad 10$

$18,4 \quad 8,2$

$29,4 \quad 11,8$

$15,8 \quad 7,9$

$11,1 \quad 5,6$

53,3

$3,4 \quad 3,4$

$19,7 \quad 16,4$
23
29,5

13

15,3

36,2

12,5

1,6

24,5

8,3

6,7

0

5,4

11,7

3,6

3,6

11,5

11,9

21,7

6,5

41,5

21,6

23,2

8,5

4,9

12,8

24,6

11,7

13

5,7

18

3,7

36,6

5

4,1

17,6

28,9

1,9

3,3

3,4

11,5 


\subsubsection{Calidad de vida}

Otro de los objetivos planteados ha sido analizar diferentes cuestiones relacionadas con la calidad de vida $(\mathrm{CV})$ de los pacientes sobre todo en comparación con la calidad de vida previa al ingreso en UCI.

En este sentido analizando los resultados obtenidos mediante una adaptación del cuestionario EuroQol-5D, podemos observar que la puntuación total media en calidad de vida después del ingreso en UCI es de 11,52 (DT=2,16) sobre un total posible de 15 puntos (a mayor puntuación peor calidad de vida), siendo además este valor muy superior al de la puntuación total media antes del ingreso $(\bar{X}=6,51 ; \mathrm{DT}=1,96)$ (véase Tabla 8).

En cuanto a la calidad de vida en función de las diferentes dimensiones consideradas en el cuestionario, los resultados muestran en todas ellas puntuaciones medias mayores (peor CV) tras el ingreso en UCI (véase Tabla 8 y Gráfica 20), destacando las medias de las dimensiones correspondientes a "actividades habituales" $(\bar{X}=2,74 ; \mathrm{DT}=0,54)$, "movilidad" $(\bar{X}=2,72 ; \mathrm{DT}=0,66)$ y "grado de autonomía" $(\bar{X}=2,61$; $\mathrm{DT}=0,69)$. A este respecto cabe señalar que el $83,6 \%$ de los pacientes están encamados, el $78,7 \%$ refiere no tener posibilidades de llevar a cabo las actividades habituales y el $72,1 \%$ no puede lavarse ni vestirse por sí mismo (véase Gráfica 21).

En relación con las diferencias encontradas al evaluar la calidad de vida antes y después del ingreso en UCI, la realización de la prueba t de Student confirma que estas diferencias son estadísticamente significativas tanto a nivel global como en cada una de las dimensiones analizadas (véase Tabla 8).

Tabla 8. Medias en calidad de vida antes y después del ingreso en UCI

\begin{tabular}{|c|c|c|c|c|c|c|c|}
\hline & & \multicolumn{2}{|c|}{ Antes ingreso } & \multicolumn{2}{|c|}{ Después ingreso } & & \multirow{2}{*}{$\begin{array}{c}\text { Sig. } \\
p \leq, 050\end{array}$} \\
\hline \multicolumn{2}{|c|}{ Ítem } & $\bar{X}$ & DT & $\bar{X}$ & DT & t & \\
\hline 1. & Grado de movilidad & 1,25 & 0,43 & 2,72 & 0,66 & $-16,51$ & ,000 \\
\hline 2. & Grado de autonomía & 1,15 & 0,40 & 2,61 & 0,69 & $-15,33$ & ,000 \\
\hline 3. & Posibilidad de actividades habituales & 1,29 & 0,53 & 2,74 & 0,54 & $-15,66$ & ,000 \\
\hline 4. & Grado de dolor/malestar & 1,46 & 0,62 & 1,88 & 0,68 & $-3,48$ & ,001 \\
\hline 5. & Grado de ansiedad/depresión & 1,36 & 0,61 & 1,57 & 0,56 & $-2,20$ & ,031 \\
\hline 6. & Puntuación total & 6,51 & 1,96 & 11,52 & 2,16 & $-13,45$ & 000 \\
\hline
\end{tabular}


Gráfica 20. Medias en las dimensiones de calidad de vida antes y después del ingreso en UCI

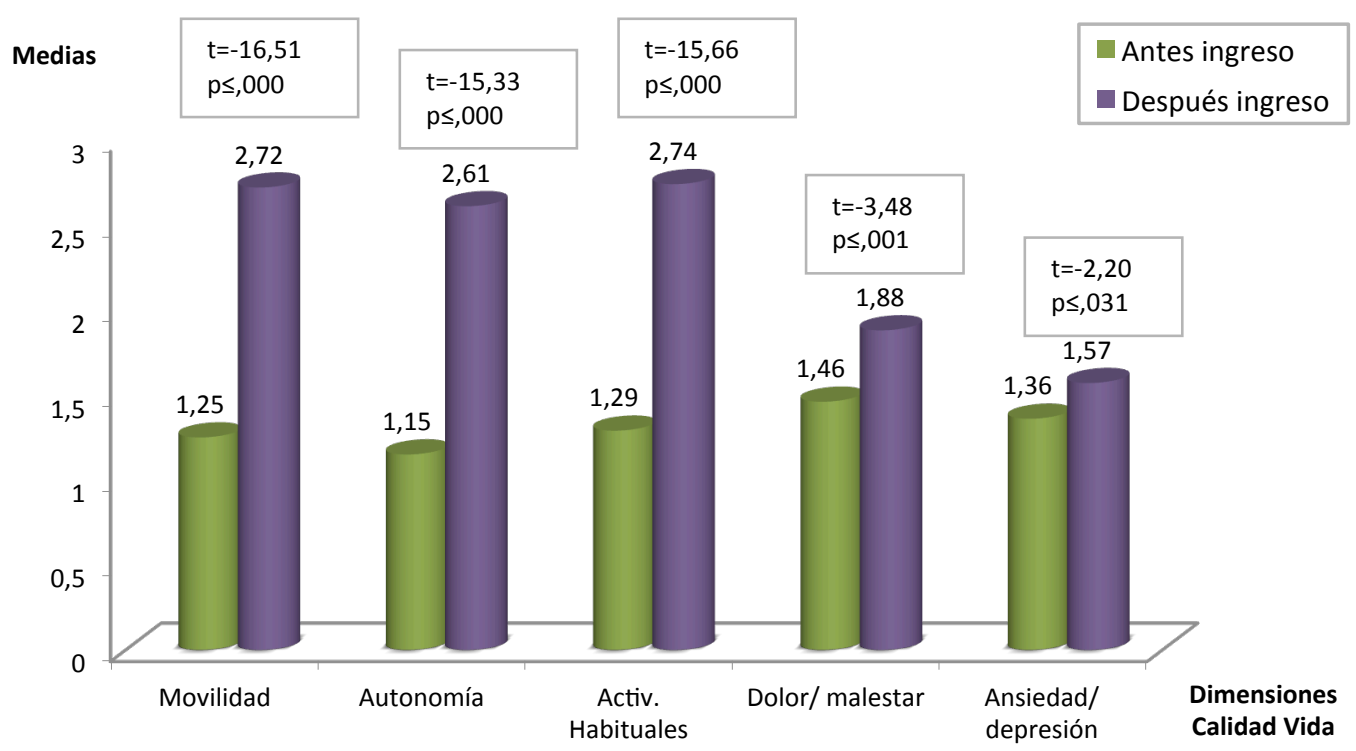

Gráfica 21. Porcentajes de las diferentes dimensiones en calidad de vida antes y tras el ingreso en UCI

\section{Grado de movilidad}

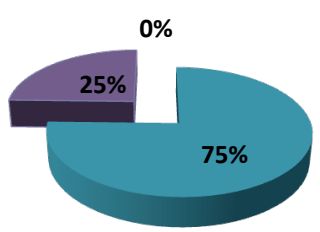

Antes del ingreso

No tengo problemas para
caminar
Tengo algunos problemas para
caminar
Estoy encamado

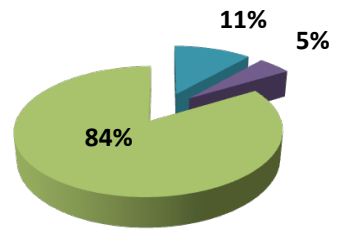

Después del ingreso

Grado de autonomía

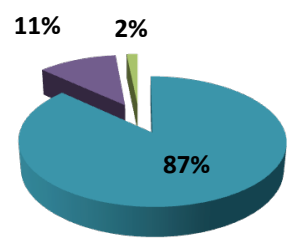

Antes del ingreso
No tengo problemas para mis cuidados

- Tengo problemas para lavarme/vestirme por mí mismo

No puedo lavarme ni vestirme por mí mismo
$12 \%$

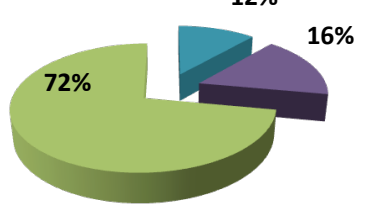

Después del ingreso 


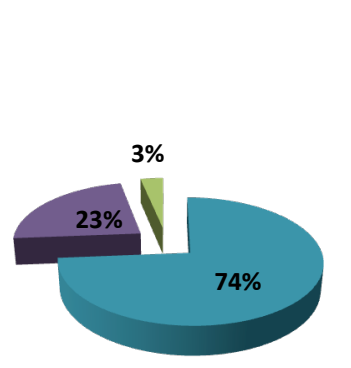

Antes del ingreso

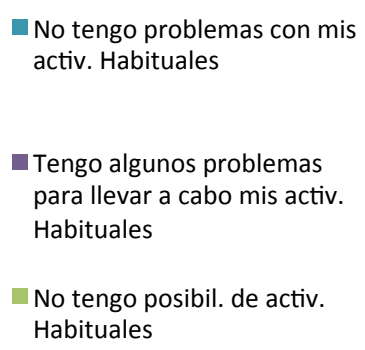

- Tengo algunos problemas para llevar a cabo mis activ. Habituales

No tengo posibil. de activ. Habituales

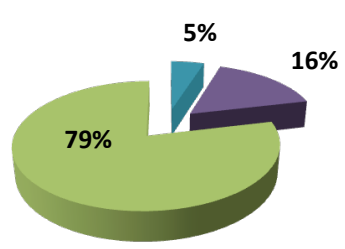

Después del ingreso

Grado de dolor/malestar

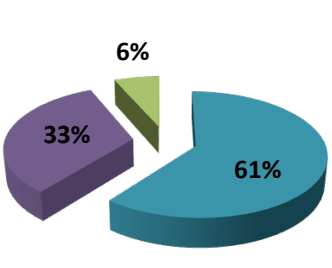

Antes del ingreso

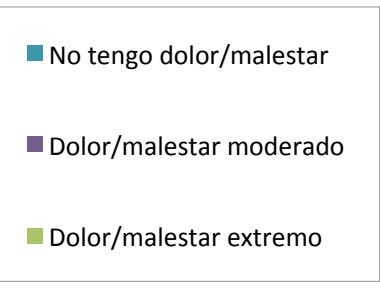

Dolor/malestar extremo

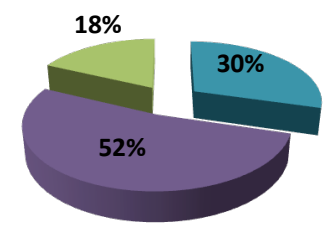

Después del ingreso

Grado de ansiedad/depresión

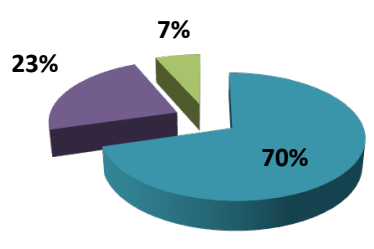

Antes del ingreso

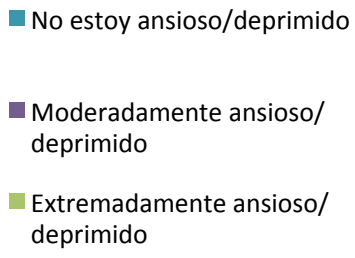

No estoy ansioso/deprimido

- Moderadamente ansioso/ deprimido

Extremadamente ansioso/ deprimido

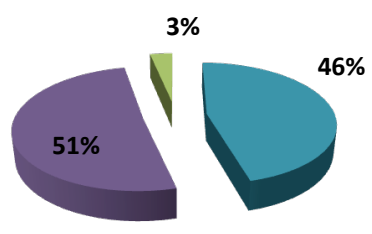

Después del ingreso

Por otro lado también se ha evaluado la percepción de calidad de vida del paciente durante la estancia en UCI en comparación con su estado de salud general un mes antes a la hospitalización. En esta línea cabe señalar que el 49,2\% de los pacientes refieren que su estado de salud actual es peor, mientras que para el $37,7 \%$ es mejor (véase Gráfica 22). Probablemente estos resultados cobren toda su significación cuando realicemos los estudios diferenciales en función de la patología de ingreso, ya que por ejemplo en casos de accidentes parece lógico pensar que en UCI se esté mucho peor que antes pero en cambio en el caso de enfermos que ya estaban graves y que ven que 
ahora se está dando una solución a su problema parece lógico que se encuentren mejor, tal como les sucede a ese casi $38 \%$.

Gráfica 22. Percepción de Estado de salud actual en comparación con el previo al ingreso

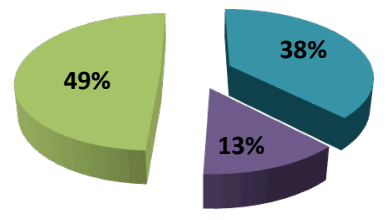

Mejor

Igual

Peor

\subsubsection{Valoración sobre el proceso de morir}

Dada la importancia que adquiere en el contexto de una UCI todo lo relacionado con el proceso de morir, estimamos conveniente analizar aquellos aspectos que podrían facilitar una muerte digna según los pacientes. Para este propósito utilizamos el Cuestionario de Ayuda a Morir en Paz (CAMP) que evalúa distintos factores en una escala de 0 a 4 .

Los resultados de la valoración de los diferentes ítems del cuestionario (véase Gráfica 23) muestran que en el caso de que llegara el momento de la muerte para los pacientes serían más importantes aquellos aspectos relacionados con el control del dolor y los síntomas de malestar $(\bar{X}=3,50 ; \mathrm{DT}=0,89)$, acortar el proceso de morir en caso de sufrimiento $(\bar{X}=3,50$; DT $=0,81)$ y la posibilidad de disponer de ayuda para morir con rapidez $(\bar{X}=3,02 ; \mathrm{DT}=1,31)$. Además, las puntuaciones medias obtenidas en los ítems relacionados con aspectos más emocionales, aun siendo un poco menores, indican que para los pacientes también es importante sentirse cerca de sus seres queridos $(\bar{X}=2,92$; $\mathrm{DT}=1,26)$ y que su muerte no suponga una carga insoportable para los mismos $(\bar{X}=2,87$; $\mathrm{DT}=1,35)$. Los pacientes también consideran relevantes, aunque en menor medida, aspectos existenciales como pensar que su vida haya tenido algún sentido $(\bar{X}=2,82$; $\mathrm{DT}=1)$. En cambio, los factores a los que se les da menos importancia son pensar que pudieran morir en casa $(\bar{X}=1,24 ; \mathrm{DT}=1,52)$ o creer en otra vida después de la muerte $(\bar{X}=1,59 ; \mathrm{DT}=1,59)$.

En términos de frecuencias, tal como se observa en la Tabla 9, los resultados muestran que los pacientes dan "muchísima" importancia al hecho de controlar el dolor y acortar el proceso de morir (66\%), así como disponer de ayuda para morir con 
rapidez (53,1\%). Mientras que estos porcentajes son mucho menores para los ítems relacionados con poder morir en casa $(10,2 \%)$ o creer en otra vida después de la muerte $(19,1 \%)$. No obstante, cabe señalar que aun siendo bajos los porcentajes relativos a estos dos factores, no podemos obviar que siguen siendo importantes para un reducido aunque nada despreciable número de pacientes.

Gráfica 23. Medias de las puntuaciones en los factores del Cuestionario de Ayuda a Morir en Paz (CAMP) (pacientes)

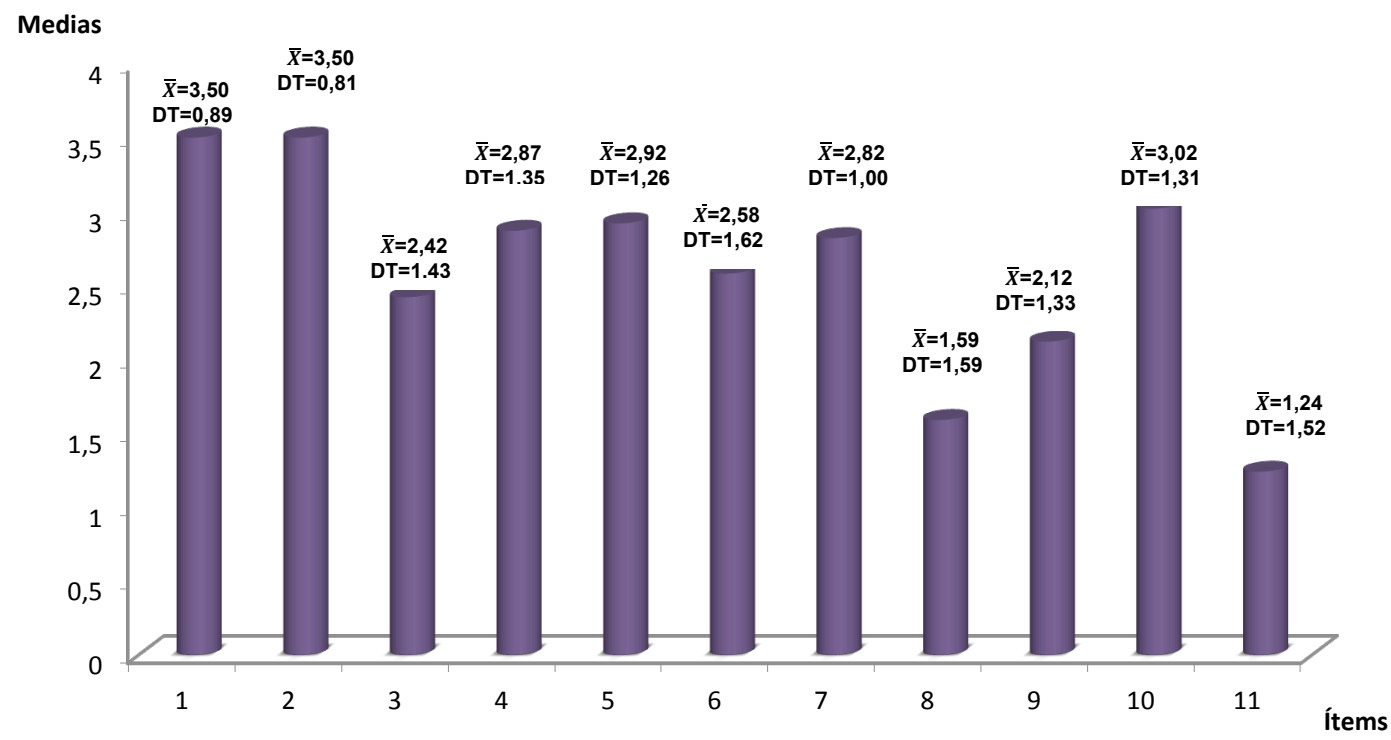
1. Pensar que los médicos puedan controlar mi dolor y otros síntomas de malestar
2. Pensar que mi proceso de morir, si me produce sufrimiento, será corto
3. Pensar que podré controlar hasta el final mis pensamientos y funciones fisiológicas
4. Pensar que mi muerte/desaparición no supondrán una carga insoportable para mis seres queridos
5. Poder sentirme cerca, comunicarme y estrechar vínculos afectivos con mis personas queridas
6. Pensar que si no tengo esperanza real de recuperación, no se alargará artificialmente mi vida en UCI
7. Pensar que mi vida ha tenido algún sentido
8. Creer en otra vida después de la muerte
9. No sentirse culpable por conflictos personales del pasado
10. Pensar que si la situación se me hace insoportable podré disponer de ayuda para morir con rapidez
11. Pensar que podré morir en mi casa

Tabla 9. Porcentajes de los distintos factores del Cuestionario de Ayuda a Morir en Paz (CAMP) (pacientes)

\begin{tabular}{|c|c|c|c|c|c|}
\hline Ítem & Nada & Poco & Bastante & Mucho & Muchísimo \\
\hline 2. Mi proceso de morir, si produce sufrimiento, será corto & 0 & 4 & 8 & 22 & 66 \\
\hline 3.Controlar hasta el final pensamientos y funciones fisiológicas & 16 & 10 & 20 & 24 & 30 \\
\hline $\begin{array}{l}\text { 4. Mi muerte no supondrá una carga insoportable para mis seres } \\
\text { queridos }\end{array}$ & 8,3 & 10,4 & 14,6 & 18,8 & 47,9 \\
\hline $\begin{array}{l}\text { 5. Poder sentirme cerca, comunicarme y estrechar vínculos afectivos con } \\
\text { mis personas queridas }\end{array}$ & 6 & 14 & 4 & 34 & 42 \\
\hline $\begin{array}{l}\text { 6. Sin esperanza real de recuperación, no se alargará artificialmente mi } \\
\text { vida en } \mathrm{UCl}\end{array}$ & 22 & 6 & 8 & 20 & 44 \\
\hline
\end{tabular}


(Continuación Tabla 9)

8. Creer en otra vida después de la muerte

9.No sentirse culpable por conflictos personales del pasado

10. Si la situación se me hace insoportable disponer de ayuda para morir

$40,4 \quad 12,8 \quad 12,8$

20 con rapidez

11. Poder morir en mi casa

$53,1 \quad 10,2 \quad 6,1 \quad 20,4$

19,1

14

53,1

$\begin{array}{ccc}26 & 32 & 14 \\ 10,2 & 20,4 & 53,1\end{array}$

10,2

Profundizando un poco más en el análisis del proceso de morir se les pide a los pacientes que elijan de entre los once factores aquellos dos que más les ayudarían a tener una muerte en paz, mostrando los resultados que priorizan en este sentido el pensar que el proceso de morir si hay sufrimiento sea corto $(50 \%)$ y poder controlar el dolor y otros síntomas de malestar hasta el final (40\%) (véase Gráfica 24).

Gráfica 24. Priorización de los dos factores (CAMP) que más ayudarían a morir en paz

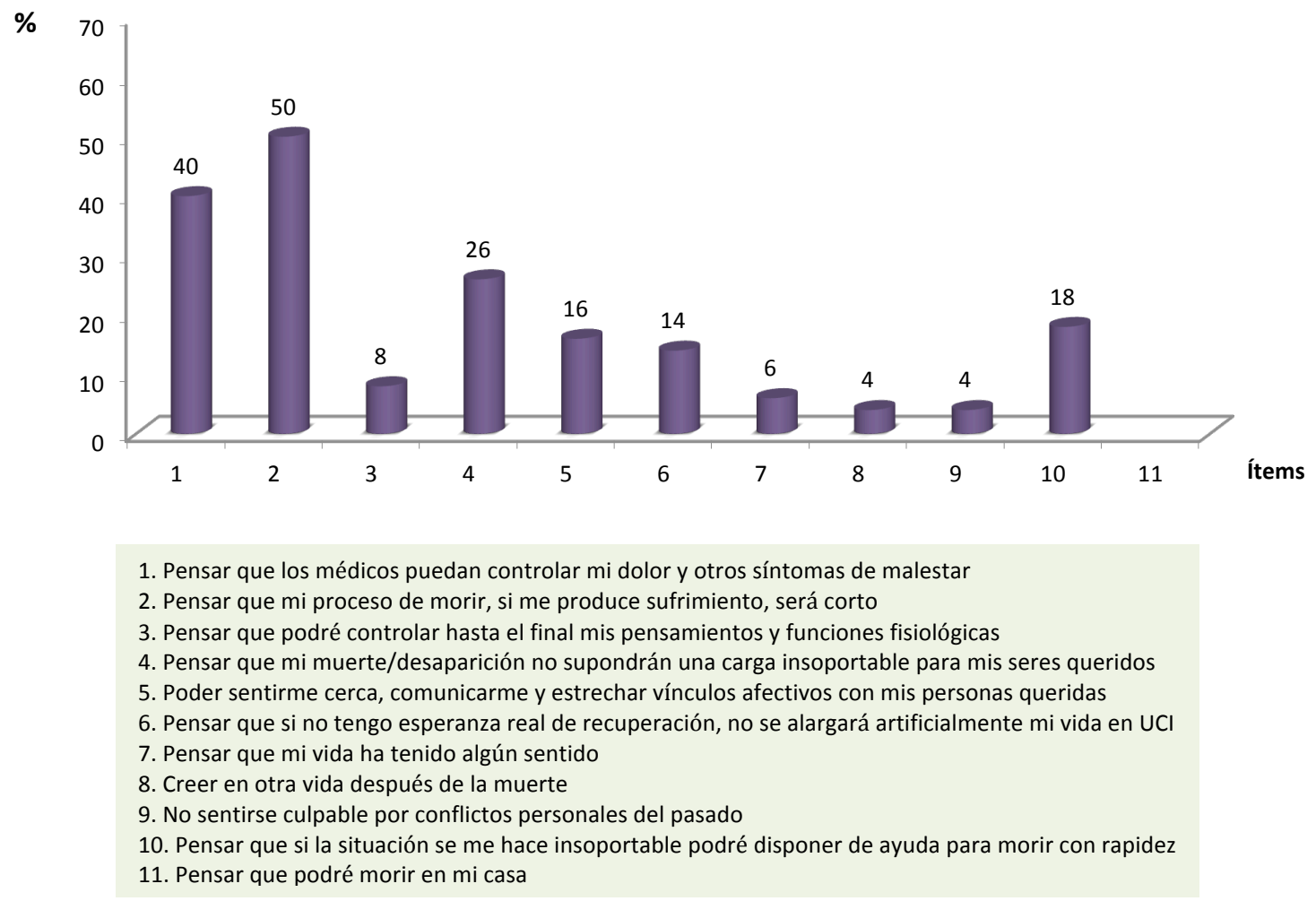

\subsubsection{Valoración del proceso de información y toma de decisiones}

Otro de los objetivos de la presente tesis ha sido analizar la valoración de los pacientes sobre la información proporcionada y el proceso de toma de decisiones en el ámbito clínico. Con la finalidad de facilitar su comprensión, los resultados obtenidos en el cuestionario CITD se agruparán en distintas subescalas: importancia otorgada a 
los pacientes, a los familiares, a los médicos y a los psicólogos en el proceso; satisfacción con la información; preferencias en el estilo de información del médico; y participación en la toma de decisiones.

Respecto a la importancia que se concede a cada uno de los agentes implicados en el proceso de información y toma de decisiones, los pacientes ingresados en la UCI valoran con una puntuación media de 16,94 (DT=3,97) sobre un total de 21 puntos, el papel que la propia persona enferma tiene en el proceso. En cuanto a la importancia que conceden a la familia en este proceso, la media obtenida ha sido de 9,44 (DT=5,15) de un total de 21 puntos. El papel del médico ha obtenido una puntuación total de 4,47 $(\mathrm{DT}=1,18)$ sobre un total de 6 puntos. Y finalmente, el papel del psicólogo en el proceso ha sido valorado con una media de 2,28 (DT=0,89) sobre un total de 3 puntos.

Dado que las categorías presentadas están compuestas por un número diferente de ítems hemos calculado la proporción de cada una de ellas sobre 100 para poder conocer la importancia relativa de los distintos agentes implicados en el proceso de información y toma de decisiones. De esta manera, tal y como se observa en la Gráfica 25 los pacientes valoran que en el proceso de información y toma de decisiones el papel más importante lo ha de tener la propia persona enferma. En segundo lugar y por orden de importancia estaría el psicólogo seguido de cerca por el papel del médico en este proceso. Por último, los pacientes otorgan menor importancia a los familiares en el proceso de información y toma de decisiones.

Gráfica 25. Proporción de respuestas sobre la importancia de los agentes implicados en el proceso de información y toma de decisiones desde el punto de vista de los pacientes

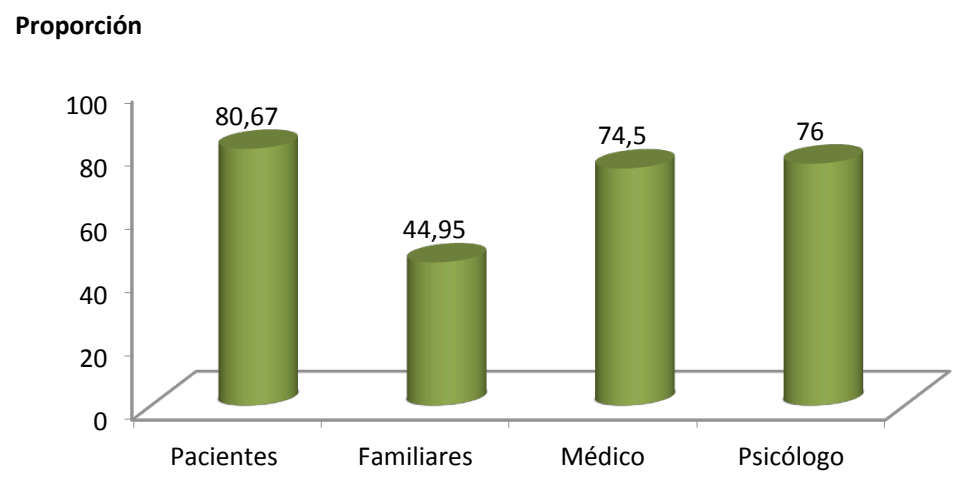

Al analizar la satisfacción de los pacientes respecto a la cantidad y la claridad de la información recibida se ha obtenido una puntuación media de 2,39 (DT=1,09) y de 2,44 (DT=1,09) respectivamente sobre un total de 3 puntos. Así, el 72,2\% de los pacientes afirma estar totalmente de acuerdo con haber recibido suficiente información 
sobre el estado, tratamiento y pronóstico de la enfermedad. Y el 77,8\% refieren haber tenido la oportunidad de aclarar todas sus dudas (véase Tabla 10).

En cuanto a las preferencias de los pacientes sobre el estilo del médico a la hora de informar los resultados muestran, sobre un total de 3 puntos, una puntuación media de 2 puntos $(\mathrm{DT}=1,24)$ para aquel estilo en el que el médico se calla lo que aún no es seguro y una puntuación media de 1,68 $(\mathrm{DT}=1,37)$ en el caso de que el médico anticipe posibles sospechas. En términos de frecuencias y atendiendo a la opción de respuesta "totalmente de acuerdo" podemos observar una distribución bastante homogénea en ambos estilos del médico a la hora de informar. No obstante, las diferencias aumentan al contemplar más opciones de respuesta. Concretamente, el 72,2\% de los pacientes están bastante/totalmente de acuerdo con que el médico se guarde lo que aún no es seguro, mientras que el 55,5\% prefiere que éste anticipe posibles sospechas (véase Tabla 10).

Finalmente y en relación con el hecho particular de participar en la toma de decisiones médicas relevantes, se ha analizado por un lado en qué medida el paciente se siente capacitado para este propósito habiéndose obtenido una puntuación media de $2,44(\mathrm{DT}=0,98)$ y por otro lado en qué medida esto sería percibido como una carga y no tanto como un privilegio, en cuyo caso se ha obtenido una media de 1,11 (DT=1,28). El rango de ambas puntuaciones oscila entre 0 y 3 puntos. Estos resultados, equivalen a decir que el 72,2\% de los pacientes se siente totalmente capacitado para participar en decisiones médicas que repercutan en su persona así como también que el 50\% no considera en absoluto que el hecho de participar en una decisión relevante sea una carga. No obstante, para el 22,2\% de los pacientes sí sería una carga (véase Tabla 10).

Tabla 10. Porcentajes obtenidos en la satisfacción ante la información, preferencias en el estilo del médico a la hora de informar y participación en la toma de decisiones (TD) desde el punto de vista de los pacientes

\begin{tabular}{|c|c|c|c|c|}
\hline CITD & Nada & Algo & Bastante & Totalmente \\
\hline \multicolumn{5}{|l|}{ Satisfacción con la información } \\
\hline $\begin{array}{l}\text {-He recibido suficiente información sobre el estado, pronóstico y tratamiento de } \\
\text { la enfermedad }\end{array}$ & 11,1 & 11,1 & 5,6 & 72,2 \\
\hline -Los médicos me han dado la oportunidad de aclarar todas mis dudas & 11,1 & 11,1 & 0 & 77,8 \\
\hline \multicolumn{5}{|l|}{ Estilo del médico } \\
\hline $\begin{array}{l}\text {-En cuanto al estilo del médico prefiero que éste sea directo y anticipe posibles } \\
\text { sospechas }\end{array}$ & 33,3 & 11,1 & 11,1 & 44,4 \\
\hline $\begin{array}{l}\text {-En cuanto al estilo del médico prefiero que éste se guarde lo que aún no es } \\
\text { seguro }\end{array}$ & 22,2 & 5,6 & 22,2 & 50 \\
\hline \multicolumn{5}{|l|}{ Participación en TD } \\
\hline -Me siento capacitado para participar en la TD sobre la salud & 5,6 & 16,7 & 5,6 & 72,2 \\
\hline -Poder participar en una decisión médica sería más una carga que un privilegio & 50 & 11,1 & 16,7 & 22,2 \\
\hline
\end{tabular}




\subsubsection{RESULTADOS DIFERENCIALES DENTRO DEL GRUPO DE PACIENTES}

Tras analizar los resultados descriptivos obtenidos a partir de los distintos cuestionarios utilizados en la evaluación de los pacientes, a continuación presentaremos los resultados diferenciales relativos a dichas puntuaciones en función de variables sociodemográficas y clínicas dentro de este mismo grupo. En concreto, se han analizado las diferencias en función del género, la edad, el nivel cultural, el estado civil y el número de hijos, así como también se han explorado dichas diferencias en función de variables clínicas, como la patología que motivó el ingreso del paciente.

Según el tipo de variable analizada, se han realizado los análisis estadísticos pertinentes ya comentados en el capítulo dedicado al método.

\subsubsection{Análisis diferenciales en función del género}

Mediante la prueba $\mathrm{t}$ de Student, se analizaron las puntuaciones de los distintos cuestionarios para averiguar si existían diferencias significativas $(p \leq, 050)$ en función del género.

En primer lugar se analizaron las diferencias en las puntuaciones relativas a síntomas de ansiedad y depresión (véase Tabla 11). A este respecto cabe señalar que en los resultados obtenidos mediante los diferentes instrumentos (HADS, STAI y percepción subjetiva de malestar) se ha obtenido un mayor grado de ansiedad en las mujeres, siendo estas diferencias significativas a nivel estadístico sólo en el caso de la ansiedad-rasgo $(t=-2,14 ; p=, 038)$. En cuanto a los síntomas de depresión evaluados mediante el BDI, aun siendo las puntuaciones mayores en los hombres, estas diferencias no llegan a alcanzar significación estadística. Mediante el HADS y el EA3, son las mujeres las que obtienen una media superior en depresión aunque tampoco las diferencias son significativas. De igual forma, no se han obtenido diferencias en la percepción subjetiva de estado de ánimo deprimido. 
Tabla 11. Análisis diferencial en función del género de la ansiedad, depresión y percepción subjetiva de estado de ánimo (pacientes)

\begin{tabular}{|c|c|c|c|c|c|}
\hline Cuestionarios & Género & $\bar{X}$ & DT & $\mathbf{t}$ & $\begin{array}{c}\text { Sig. } \\
p \leq, 050\end{array}$ \\
\hline \multirow[t]{2}{*}{ Total HADS Ansiedad } & Hombre & 6,52 & 4,70 & $-1,54$ & 128 \\
\hline & Mujer & 8,68 & 6,51 & & \\
\hline \multirow[t]{2}{*}{ Total HADS Depresión } & Hombre & 7 & 5,27 & $-0,53$ & ,596 \\
\hline & Mujer & 7,84 & 7,37 & & \\
\hline \multirow[t]{2}{*}{ STAI- Estado } & Hombre & 15,15 & 9,69 & $-1,74$ & 088 \\
\hline & Mujer & 21,06 & 13,70 & & \\
\hline \multirow[t]{2}{*}{ STAI- Rasgo } & Hombre & 11,73 & 7,83 & $-2,14$ & ,038 \\
\hline & Mujer & 18 & 12,62 & & \\
\hline \multirow[t]{2}{*}{ BDI } & Hombre & 13,54 & 9,30 & 0,64 & ,525 \\
\hline & Mujer & 11,60 & 10,69 & & \\
\hline \multirow[t]{2}{*}{ EA1-Malestar general } & Hombre & 4,28 & 3,05 & $-0,39$ & ,696 \\
\hline & Mujer & 4,62 & 2,80 & & \\
\hline \multirow[t]{2}{*}{ EA2-Ansiedad y Nerviosismo } & Hombre & 2,73 & 3,02 & $-0,81$ & ,420 \\
\hline & Mujer & 3,44 & 3,14 & & \\
\hline \multirow[t]{2}{*}{ EA3-Estado de ánimo deprimido } & Hombre & 2,25 & 2,83 & $-0,07$ & 941 \\
\hline & Mujer & 2,31 & 3,32 & & \\
\hline
\end{tabular}

Al analizar las diferencias en la valoración de la estancia en UCI tanto a nivel global como en relación con aspectos más concretos de la unidad, no se han encontrado diferencias significativas entre las puntuaciones medias de hombres y mujeres. Tan sólo en el ítem 8 "valoración del afecto o apoyo emocional recibido del personal de enfermería", las diferencias rozan la significación estadística $(t=-1,79 ; p=, 078)$ a favor de las mujeres (véase Tabla 12). Si bien no se han obtenido diferencias significativas, los resultados muestran puntuaciones ligeramente superiores en las mujeres respecto a la valoración de todos los aspectos incluidos en el cuestionario excepto el respeto a la intimidad y las posibilidades de distraerse, mejor valorados por los hombres. 
Tabla 12. Análisis diferencial en función del género de la Valoración de la estancia en UCI (pacientes)

\begin{tabular}{|c|c|c|c|c|c|}
\hline Ítem & Género & $\bar{X}$ & DT & $\mathbf{t}$ & $\begin{array}{l}\text { Sig. } \\
p \leq, 050\end{array}$ \\
\hline \multirow{2}{*}{$\begin{array}{l}\text { En qué grado está siendo agradable/desagradable su } \\
\text { estancia en } \mathrm{UCl} \text { sin considerar los problemas médicos }\end{array}$} & Hombre & 4,06 & 1,36 & \multirow[t]{2}{*}{$-0,01$} & \multirow[t]{2}{*}{,994 } \\
\hline & Mujer & 4,07 & 0,88 & & \\
\hline \multicolumn{6}{|l|}{ Valoración de los siguientes aspectos } \\
\hline \multirow[t]{2}{*}{ 1. Cuidados médicos } & Hombre & 4,62 & 0,53 & \multirow[t]{2}{*}{$-1,69$} & \multirow[t]{2}{*}{,096 } \\
\hline & Mujer & 4,87 & 0,35 & & \\
\hline \multirow[t]{2}{*}{ 2. Atención de los médicos } & Hombre & 4,72 & 0,49 & \multirow[t]{2}{*}{$-0,06$} & \multirow[t]{2}{*}{,949 } \\
\hline & Mujer & 4,73 & 0,59 & & \\
\hline \multirow[t]{2}{*}{ 3. Atención de enfermeras/os } & Hombre & 4,70 & 0,75 & \multirow[t]{2}{*}{$-0,48$} & \multirow[t]{2}{*}{,632 } \\
\hline & Mujer & 4,80 & 0,41 & & \\
\hline \multirow[t]{2}{*}{ 4. Atención de auxiliares de enfermería } & Hombre & 4,68 & 0,76 & \multirow[t]{2}{*}{$-0,92$} & \multirow[t]{2}{*}{,362 } \\
\hline & Mujer & 4,87 & 0,35 & & \\
\hline \multirow[t]{2}{*}{ 5. Claridad de la información recibida } & Hombre & 4,35 & 0,92 & \multirow[t]{2}{*}{$-0,96$} & \multirow[t]{2}{*}{,341 } \\
\hline & Mujer & 4,60 & 0,74 & & \\
\hline \multirow[t]{2}{*}{ 6. Cantidad de la información recibida } & Hombre & 4,19 & 0,98 & \multirow[t]{2}{*}{$-1,44$} & \multirow[t]{2}{*}{ 156 } \\
\hline & Mujer & 4,60 & 0,82 & & \\
\hline \multirow[t]{2}{*}{ 7. Trato del personal de enfermería } & Hombre & 4,68 & 0,55 & \multirow[t]{2}{*}{$-1,21$} & \multirow[t]{2}{*}{,229 } \\
\hline & Mujer & 4,87 & 0,35 & & \\
\hline \multirow{2}{*}{$\begin{array}{l}\text { 8. Afecto/apoyo emocional del personal de } \\
\text { enfermería }\end{array}$} & Hombre & 4,42 & 0,93 & \multirow[t]{2}{*}{$-1,79$} & \multirow[t]{2}{*}{,078 } \\
\hline & Mujer & 4,87 & 0,35 & & \\
\hline \multirow[t]{2}{*}{ 9. Respeto a la intimidad } & Hombre & 4,49 & 0,72 & 0,40 & 687 \\
\hline & Mujer & 4,40 & 0,83 & & \\
\hline 10. Atención a los familiares & Hombre & 4,65 & 0,57 & $-0,50$ & 617 \\
\hline & Mujer & 4,73 & 0,46 & & \\
\hline 11. Atención de necesidades psicológicas en paciente & Hombre & 4,58 & 0,66 & $-0,78$ & ,436 \\
\hline y familia & Mujer & 4,73 & 0,59 & & \\
\hline 12. Calidad de las instalaciones (comodidad, & Hombre & 4,32 & 0,81 & $-0,96$ & ,341 \\
\hline & Mujer & 4,53 & 0,52 & & \\
\hline 13. Posibilidades de distraerse & Hombre & 2,48 & 1,41 & 0,62 &, 538 \\
\hline & Mujer & 2,21 & 1,31 & & \\
\hline 14. Silencio y tranquilidad en la sala & Hombre & 3,13 & 1,28 & $-0,19$ & 847 \\
\hline & Mujer & 3,20 & 0,94 & & \\
\hline 15. Régimen de visitas & Hombre & 3,57 & 1,09 & $-1,17$ & ,247 \\
\hline & Mujer & 3,93 & 0,79 & & \\
\hline
\end{tabular}

En cuanto al análisis diferencial de los distintos factores estresantes, cabe señalar que aunque en la mayoría de los ítems la puntuación media ha sido mayor en el grupo de las mujeres, estas diferencias tampoco han sido significativas a nivel estadístico, si bien rozan la significación en el ítem 26 "estar separado de los familiares más cercanos" $(t=-1,92 ; p=, 060)$ y en el ítem 40 que mide el grado de estrés general $(t=-1,95 ; p=, 056)$ (véase Tabla 13) con una puntuación mayor de las mujeres en estos aspectos. 
Tabla 13. Análisis diferencial en función del género de los Factores estresantes en UCI (pacientes)

\begin{tabular}{|c|c|c|c|c|c|}
\hline Ítem & Género & $\bar{X}$ & DT & $\mathbf{t}$ & $\begin{array}{l}\text { Sig. } \\
p \leq, 050\end{array}$ \\
\hline \multirow[t]{2}{*}{ 1. No disponer de baño en el box } & Hombre & 1,57 & 1,62 & $-0,18$ & ,859 \\
\hline & Mujer & 1,67 & 1,82 & & \\
\hline \multirow[t]{2}{*}{ 2. Tener que estar en la cama/sillón todo el día } & Hombre & 2,29 & 1,41 & $-0,46$ & 647 \\
\hline & Mujer & 2,50 & 1,57 & & \\
\hline \multirow[t]{2}{*}{ 3. Estar hospitalizado lejos de casa } & Hombre & 0,95 & 1,45 & $-0,09$ & ,924 \\
\hline & Mujer & 1 & 1,41 & & \\
\hline \multirow[t]{2}{*}{ 4. Dormir en una cama que no es la suya } & Hombre & 1,04 & 1,49 & $-1,59$ & ,116 \\
\hline & Mujer & 1,83 & 1,69 & & \\
\hline \multirow[t]{2}{*}{ 5. Utilizar la cuña de cama } & Hombre & 2,25 & 1,62 & 0,13 & 894 \\
\hline & Mujer & 2,18 & 1,72 & & \\
\hline \multirow[t]{2}{*}{ 6. Que no respondan al timbre de aviso } & Hombre & 1,39 & 1,44 & $-0,65$ &, 522 \\
\hline & Mujer & 1,78 & 1,72 & & \\
\hline \multirow[t]{2}{*}{ 7. Dormir junto a otros enfermos en la unidad } & Hombre & 0,55 & 1,04 & $-0,09$ & ,922 \\
\hline & Mujer & 0,58 & 0,90 & & \\
\hline \multirow[t]{2}{*}{ 8. Tener que ser ayudado para ir al baño } & Hombre & 1,85 & 1,59 & $-0,07$ & ,947 \\
\hline & Mujer & 1,89 & 1,54 & & \\
\hline \multirow[t]{2}{*}{ 9. Tener que comer en la cama en una postura incómoda } & Hombre & 1,10 & 1,26 & $-1,70$ & ,094 \\
\hline & Mujer & 1,83 & 1,59 & & \\
\hline \multirow{2}{*}{$\begin{array}{l}\text { 10.Estar ingresado en la unidad junto a otras personas } \\
\text { gravemente enfermas }\end{array}$} & Hombre & 0,69 & 1,19 & $-0,61$ & ,541 \\
\hline & Mujer & 0,92 & 0,99 & & \\
\hline \multirow[t]{2}{*}{ 11.Estar al cuidado de sanitarios desconocidos } & Hombre & 0,20 & 0,61 & $-0,23$ & 817 \\
\hline & Mujer & 0,25 & 0,62 & & \\
\hline \multirow[t]{2}{*}{ 12.Tener demasiadas visitas } & Hombre & 0,51 & 1,04 & $-0,09$ & ,924 \\
\hline & Mujer & 0,54 & 1,21 & & \\
\hline \multirow{2}{*}{$\begin{array}{l}\text { 13.Tener que estar todo el tiempo desnudo, únicamente } \\
\text { cubierto con una sábana }\end{array}$} & Hombre & 0,96 & 1,30 & $-1,40$ & 167 \\
\hline & Mujer & 1,58 & 1,68 & & \\
\hline \multirow[t]{2}{*}{ 14. Necesitar ayuda para comer } & Hombre & 1,02 & 1,04 & $-0,84$ & ,405 \\
\hline & Mujer & 1,33 & 1,43 & & \\
\hline \multirow{2}{*}{$\begin{array}{l}\text { 15. No poder ver la TV/escuchar la radio/leer el periódico } \\
\text { cuando uno quiere }\end{array}$} & Hombre & 1,04 & 1,16 & 1,02 & ,314 \\
\hline & Mujer & 0,67 & 1,07 & & \\
\hline \multirow{2}{*}{$\begin{array}{l}\text { 16. Escuchar ruidos de máquinas o gente hablar } \\
\text { constantemente }\end{array}$} & Hombre & 0,88 & 1,25 & $-1,62$ & 111 \\
\hline & Mujer & 1,58 & 1,73 & & \\
\hline \multirow[t]{2}{*}{ 17.Estar las luces todo el día encendidas } & Hombre & 0,94 & 1,24 & $-1,63$ & 109 \\
\hline & Mujer & 1,67 & 1,87 & & \\
\hline \multirow{2}{*}{$\begin{array}{l}\text { 18. No tener a los familiares y amigos acompañándole a lo } \\
\text { largo del día }\end{array}$} & Hombre & 1,62 & 1,39 & $-1,68$ & ,099 \\
\hline & Mujer & 2,42 & 1,73 & & \\
\hline \multirow[t]{2}{*}{ 19.Estar aislado en la habitación por prescripción médica } & Hombre & 0,83 & 1,34 & 1,05 & 302 \\
\hline & Mujer & 0,29 & 0,49 & & \\
\hline \multirow[t]{2}{*}{ 20.Tener dolor } & Hombre & 2,57 & 1,42 & $-1,55$ & 127 \\
\hline & Mujer & 3,33 & 0,87 & & \\
\hline \multirow{2}{*}{$\begin{array}{l}\text { 21. No saber con seguridad o no entender en qué consiste } \\
\text { la enfermedad }\end{array}$} & Hombre & 1,77 & 1,48 & $-0,08$ & ,936 \\
\hline & Mujer & 1,82 & 1,94 & & \\
\hline 22. Pensar que le puede ocurrir algo grave & Hombre & 1,77 & 1,57 & $-0,44$ & ,664 \\
\hline & Mujer & 2 & 1,71 & & \\
\hline 23. Pensar si podrá volver a su vida normal después de salir & Hombre & 1,23 & 1,31 & 0,31 & ,755 \\
\hline del hospital & Mujer & 1,09 & 1,37 & & \\
\hline 24. No poder ocuparse de la familia como hasta ahora & Hombre & 1,35 & 1,23 & $-0,37$ & ,711 \\
\hline venía haciendo & Mujer & 1,50 & 1,45 & & \\
\hline 25. No saber con seguridad cómo se quedará después de la & Hombre & 1,33 & 1,37 & $-0,40$ & 691 \\
\hline operación & Mujer & 1,56 & 1,74 & & \\
\hline
\end{tabular}

(Sigue detrás) 


\begin{tabular}{|c|c|c|c|c|c|}
\hline Ítem & Género & $\bar{X}$ & DT & $\mathbf{t}$ & $\begin{array}{l}\text { Sig. } \\
p \leq, 050\end{array}$ \\
\hline \multirow[t]{2}{*}{ 26. Estar separado de sus familiares más cercanos } & Hombre & 1,82 & 1,32 & $-1,92$ & 060 \\
\hline & Mujer & 2,67 & 1,61 & & \\
\hline \multirow{2}{*}{$\begin{array}{l}\text { 27. No saber cuándo le darán el alta de la unidad de } \\
\text { cuidados intensivos }\end{array}$} & Hombre & 1,37 & 1,41 & $-0,80$ & ,425 \\
\hline & Mujer & 1,75 & 1,60 & & \\
\hline \multirow[t]{2}{*}{ 28. Haber sido hospitalizado de repente, sin esperarlo } & Hombre & 1,52 & 1,52 & 0,60 & ,551 \\
\hline & Mujer & 1,20 & 1,62 & & \\
\hline \multirow{2}{*}{$\begin{array}{l}\text { 29. No saber los resultados/razones de los } \\
\text { tratamientos/pruebas que le hacen }\end{array}$} & Hombre & 1,17 & 1,25 & $-1,12$ & ,269 \\
\hline & Mujer & 1,64 & 1,21 & & \\
\hline \multirow{2}{*}{$\begin{array}{l}\text { 30. Pensar que puede tener dolor a causa de la } \\
\text { operación/análisis/pruebas }\end{array}$} & Hombre & 1,90 & 1,43 & 0,19 & ,848 \\
\hline & Mujer & 1,80 & 1,62 & & \\
\hline \multirow[t]{2}{*}{ 31. No saber cuándo van a hacerle cosas a uno } & Hombre & 1,09 & 1,27 & $-0,64$ & ,527 \\
\hline & Mujer & 1,36 & 1,21 & & \\
\hline \multirow{2}{*}{$\begin{array}{l}\text { 32. No obtener alivio para el dolor aun tomando } \\
\text { medicación }\end{array}$} & Hombre & 2,31 & 1,51 & 0,15 & 877 \\
\hline & Mujer & 2,22 & 1,64 & & \\
\hline \multirow[t]{2}{*}{ 33. Ver que el personal del hospital tiene prisa } & Hombre & 0,71 & 1,20 & 0,10 & ,917 \\
\hline & Mujer & 0,67 & 1,37 & & \\
\hline \multirow{2}{*}{$\begin{array}{l}\text { 34. Que sanitarios hablen deprisa o usen palabras que no } \\
\text { pueden entender }\end{array}$} & Hombre & 0,92 & 1,13 & 0,05 & ,958 \\
\hline & Mujer & 0,90 & 1,52 & & \\
\hline \multirow[t]{2}{*}{ 35. Que el personal sanitario no conteste a sus preguntas } & Hombre & 1,93 & 1,44 & 1,06 & ,299 \\
\hline & Mujer & 1,29 & 1,38 & & \\
\hline \multirow{2}{*}{$\begin{array}{l}\text { 36. Que no le den la medicación para el dolor cuando lo } \\
\text { necesita }\end{array}$} & Hombre & 2,17 & 1,49 & 0,90 & ,374 \\
\hline & Mujer & 1,67 & 1,41 & & \\
\hline \multirow{2}{*}{$\begin{array}{l}\text { 37. Pensar en la posible pérdida de dinero a causa de la } \\
\text { enfermedad }\end{array}$} & Hombre & 0,56 & 1,07 & 0,16 & 870 \\
\hline & Mujer & 0,50 & 0,76 & & \\
\hline \multirow[t]{2}{*}{ 38. Sentir olores extraños en el hospital } & Hombre & 0,37 & 0,76 & $-1,74$ & ,088 \\
\hline & Mujer & 0,92 & 1,56 & & \\
\hline \multirow[t]{2}{*}{ 39. Tener que comer a horas diferentes a las habituales } & Hombre & 0,47 & 0,93 & $-0,36$ & 717 \\
\hline & Mujer & 0,58 & 1,16 & & \\
\hline \multirow[t]{2}{*}{ 40. Nivel de estrés en general } & Hombre & 1,57 & 1,17 & $-1,95$ & 056 \\
\hline & Mujer & 2,33 & 1,37 & & \\
\hline
\end{tabular}

Al analizar la calidad de vida de los pacientes no se han obtenido diferencias estadísticamente significativas en función del género ni antes $(t=0,85 ; p=, 399) \mathrm{ni}$ después $(t=0,25 ; p=, 80)$ del ingreso en $\mathrm{UCI}$, si bien observamos en ambos casos puntuaciones mayores en los hombres (véase Tabla 14).

Tabla 14. Análisis diferencial en función del género en la calidad de vida de los pacientes

\begin{tabular}{|c|c|c|c|c|c|}
\hline Ítem & Género & $\bar{X}$ & DT & $\mathbf{t}$ & $\begin{array}{c}\text { Sig. } \\
p \leq, 050\end{array}$ \\
\hline \multirow[t]{2}{*}{ 1. Puntuación total en CV previa al ingreso } & Hombre & 6,63 & 1,94 & 0,85 & ,399 \\
\hline & Mujer & 6,13 & 2,06 & & \\
\hline \multirow[t]{2}{*}{ 2. Puntuación total en CV después del ingreso } & Hombre & 11,56 & 2,22 & 0,25 & ,800 \\
\hline & Mujer & 11,40 & 2,06 & & \\
\hline
\end{tabular}

Por lo que respecta al proceso de morir, se han obtenido diferencias en la valoración que hombres y mujeres han realizado sobre distintos factores que podrían 
ayudarles a morir en paz (véase Tabla 15). Estas diferencias han sido significativas a nivel estadístico en ítems de contenido más relacional como "pensar que mi muerte no suponga una carga insoportable para las personas queridas" ( $t=-2,22 ; p=, 031)$ y "poder sentirme cerca, comunicarme y estrechar vínculos afectivos con mis seres queridos" $(\mathrm{t}=-2,22 ; \mathrm{p}=, 031)$. De la misma forma, las diferencias también han sido significativas en "creer en otra vida después de la muerte" $(\mathrm{t}=-2,36 ; \mathrm{p}=, 022)$ y "no sentirse culpable por conflictos personales del pasado" ( $\mathrm{t}=-2,03 ; \mathrm{p}=, 048)$. Las diferencias descritas apuntan hacia puntuaciones medias más altas en estos factores en el caso de las mujeres. Otro aspecto en el que se han observado diferencias que rozan la significación ha sido el "pensar que podré morir en mi casa" ( $t=1,77 ; p=, 083)$ aunque este factor ha sido más valorado por los hombres.

Tabla 15. Análisis diferencial en función del género de los distintos factores del Cuestionario de Ayuda a Morir en Paz (CAMP) (pacientes)

\begin{tabular}{|c|c|c|c|c|c|}
\hline Ítem & Género & $\overline{\boldsymbol{X}}$ & DT & $\mathbf{t}$ & $\begin{array}{l}\text { Sig. } \\
p \leq, 050\end{array}$ \\
\hline \multirow[t]{2}{*}{ 1. Controlar mi dolor y otros síntomas de malestar } & Hombre & 3,46 & 0,94 & $-0,69$ & ,497 \\
\hline & Mujer & 3,64 & 0,67 & & \\
\hline \multirow[t]{2}{*}{ 2. Mi proceso de morir, si produce sufrimiento, será corto } & Hombre & 3,56 & 0,79 & 1,05 & ,299 \\
\hline & Mujer & 3,27 & 0,90 & & \\
\hline \multirow[t]{2}{*}{ 3.Controlar hasta el final pensamientos y funciones fisiológicas } & Hombre & 2,28 & 1,52 & $-1,29$ & ,202 \\
\hline & Mujer & 2,91 & 0,94 & & \\
\hline \multirow{2}{*}{$\begin{array}{l}\text { 4. Mi muerte no supondrá una carga insoportable para mis seres } \\
\text { queridos }\end{array}$} & Hombre & 2,65 & 1,44 & $-2,22$ & ,031 \\
\hline & Mujer & 3,64 & 0,50 & & \\
\hline \multirow{2}{*}{$\begin{array}{l}\text { 5. Poder sentirme cerca, comunicarme y estrechar vínculos } \\
\text { afectivos con mis personas queridas }\end{array}$} & Hombre & 2,72 & 1,28 & $-2,22$ & ,031 \\
\hline & Mujer & 3,64 & 0,92 & & \\
\hline \multirow{2}{*}{$\begin{array}{l}\text { 6. Sin esperanza real de recuperación, no se alargará } \\
\text { artificialmente mi vida en } \mathrm{UCl}\end{array}$} & Hombre & 2,44 & 1,62 & $-1,19$ & ,239 \\
\hline & Mujer & 3,09 & 1,58 & & \\
\hline \multirow[t]{2}{*}{ 7. Pensar que mi vida ha tenido algún sentido } & Hombre & 2,69 & 0,92 & $-1,73$ & ,091 \\
\hline & Mujer & 3,27 & 1,19 & & \\
\hline \multirow[t]{2}{*}{ 8. Creer en otra vida después de la muerte } & Hombre & 1,31 & 1,43 & $-2,36$ &, 022 \\
\hline & Mujer & 2,54 & 1,81 & & \\
\hline \multirow[t]{2}{*}{ 9. No sentirse culpable por conflictos personales del pasado } & Hombre & 1,92 & 1,30 & $-2,03$ & ,048 \\
\hline & Mujer & 2,82 & 1,25 & & \\
\hline \multirow{2}{*}{$\begin{array}{l}\text { 10. Si la situación se me hace insoportable disponer de ayuda para } \\
\text { morir con rapidez }\end{array}$} & Hombre & 3,13 & 1,23 & 1,10 & ,276 \\
\hline & Mujer & 2,64 & 1,57 & & \\
\hline \multirow[t]{2}{*}{ 11. Poder morir en mi casa } & Hombre & 1,45 & 1,59 & 1,77 & ,083 \\
\hline & Mujer & 0,54 & 1,04 & & \\
\hline
\end{tabular}

Por último, respecto a la valoración del proceso de información y toma de decisiones en función del género (véase Tabla 16) no se han obtenido diferencias estadísticamente significativas en ninguno de los aspectos evaluados. No obstante, cabe señalar que el papel que han concedido las mujeres a cada uno de los agentes 
implicados en el proceso ha sido ligeramente superior al de los hombres, tal como se observa en la Tabla 16. Asimismo, las mujeres se muestran algo más satisfechas en relación con la cantidad y claridad de la información recibida ( $\bar{X}=6$ vs $\bar{X}=4,69)$. En cuanto al estilo del médico, son los hombres quienes valoran ligeramente más que las mujeres $(\overline{\mathrm{X}}=1,69$ vs $\overline{\mathrm{X}}=1,50)$ el que los médicos anticipen posibles sospechas. Y respecto a la participación en la toma de decisiones médicas relevantes, las mujeres se sienten ligeramente más capacitadas que los hombres ( $\bar{X}=3$ vs $\bar{X}=2,37)$ así como también perciben algo más que los hombres como una carga $(\bar{X}=1,50$ vs $\bar{X}=1,06)$ el hecho de participar en decisiones relevantes.

Tabla 16. Valoración diferencial en función del género del proceso de información y toma de decisiones (TD) (pacientes)

\begin{tabular}{|c|c|c|c|c|c|}
\hline CITD & Género & $\overline{\boldsymbol{X}}$ & DT & $\mathbf{t}$ & $\begin{array}{l}\text { Sig. } \\
p \leq, 050\end{array}$ \\
\hline \multicolumn{6}{|l|}{ Importancia de los distintos agentes implicados } \\
\hline \multirow[t]{2}{*}{ Papel de la familia en la información y toma de decisiones } & Hombre & 9,43 & 5,53 & $-0,02$ & ,986 \\
\hline & Mujer & 9,50 & 0,71 & & \\
\hline \multirow[t]{2}{*}{ Papel del paciente en la información y toma de decisiones } & Hombre & 16,64 & 4,16 & $-0,77$ & ,452 \\
\hline & Mujer & 19 & 1,41 & & \\
\hline \multirow[t]{2}{*}{ Papel del médico en la información y toma de decisiones } & Hombre & 4,40 & 1,18 & $-0,66$ &, 517 \\
\hline & Mujer & 5 & 1,41 & & \\
\hline \multirow{2}{*}{ Papel del psicólogo en la información y toma de decisiones } & Hombre & 2,19 & 0,91 & $-1,23$ & ,237 \\
\hline & Mujer & 3 & 0 & & \\
\hline \multicolumn{6}{|l|}{ Satisfacción con la información } \\
\hline $\begin{array}{l}\text { Satisfacción con la cantidad y la claridad de la información } \\
\text { recibida }\end{array}$ & $\begin{array}{l}\text { Hombre } \\
\text { Mujer }\end{array}$ & $\begin{array}{c}4,69 \\
6\end{array}$ & $\begin{array}{c}2,27 \\
0\end{array}$ & $-0,79$ & ,438 \\
\hline \multicolumn{6}{|l|}{ Estilo del médico } \\
\hline $\begin{array}{l}\text { En cuanto al estilo del médico prefiero que éste sea directo y } \\
\text { anticipe posibles sospechas }\end{array}$ & $\begin{array}{l}\text { Hombre } \\
\text { Mujer }\end{array}$ & $\begin{array}{l}1,69 \\
1,50\end{array}$ & $\begin{array}{l}1,35 \\
2,12\end{array}$ & 0,17 & ,862 \\
\hline $\begin{array}{l}\text { En cuanto al estilo del médico prefiero que éste se guarde lo que } \\
\text { aún no es seguro }\end{array}$ & $\begin{array}{l}\text { Hombre } \\
\text { Mujer }\end{array}$ & $\begin{array}{l}2 \\
2\end{array}$ & $\begin{array}{l}1,26 \\
1,41\end{array}$ & 0 & 1 \\
\hline \multicolumn{6}{|l|}{ Participación en TD } \\
\hline Me siento capacitado para participar en la TD sobre la salud & $\begin{array}{l}\text { Hombre } \\
\text { Mujer }\end{array}$ & $\begin{array}{c}2,37 \\
3\end{array}$ & $\begin{array}{c}1,02 \\
0\end{array}$ & $-0,84$ & ,413 \\
\hline $\begin{array}{l}\text { Poder participar en una decisión médica sería más una carga que } \\
\text { un privilegio }\end{array}$ & $\begin{array}{l}\text { Hombre } \\
\text { Mujer }\end{array}$ & $\begin{array}{l}1,06 \\
1,50\end{array}$ & $\begin{array}{l}1,24 \\
2,12\end{array}$ & $-0,44$ & ,662 \\
\hline
\end{tabular}

\subsubsection{Análisis diferenciales en función del estado civil}

Para explorar las diferencias según el estado civil de los pacientes en las distintas variables dependientes incluidas en el estudio en un principio se llevaron a cabo análisis ANOVA de un factor con la finalidad de analizar posibles diferencias entre los 
cuatro grupos establecidos, es decir, entre solteros, casados o con pareja, divorciados/separados y viudos. Sin embargo, dado el bajo tamaño de la muestra en algunas de las citadas categorías del estado civil hemos distribuido la muestra en dos grupos, tener pareja (incluiría casados o con pareja) y no tener pareja (incluiría solteros, divorciados/separados y viudos), siendo pertinente en este caso realizar pruebas t de Student.

En cuanto a la ansiedad, la depresión y la percepción subjetiva del estado de ánimo (véase Tabla 17) no se han obtenido diferencias estadísticamente significativas en función del estado civil, si bien es cierto que los pacientes sin pareja puntúan más bajo en los distintos cuestionarios que evalúan ansiedad y depresión, a excepción de la subescala de ansiedad del cuestionario HADS. En esta subescala los pacientes sin pareja presentan una puntuación ligeramente superior $(\bar{X}=7,53$; DT $=3,79)$ a la de los pacientes que sí tienen pareja en la actualidad $(\bar{X}=6,36 ; \mathrm{DT}=5,40)$.

Tabla 17. Análisis diferencial en función del estado civil de la ansiedad, depresión y estado de ánimo de los pacientes

\begin{tabular}{|c|c|c|c|c|c|}
\hline Cuestionarios & Estado civil & $\bar{X}$ & DT & $\mathbf{T}$ & $\begin{array}{c}\text { Sig. } \\
p \leq, 050\end{array}$ \\
\hline \multirow[t]{2}{*}{ Total HADS Ansiedad } & Sin pareja & 7,53 & 3,79 & 0,76 & ,449 \\
\hline & Con pareja & 6,36 & 5,40 & & \\
\hline \multirow[t]{2}{*}{ Total HADS Depresión } & Sin pareja & 4,67 & 3,18 & $-1,71$ & ,093 \\
\hline & Con pareja & 7,69 & 6,49 & & \\
\hline \multirow[t]{2}{*}{ STAI-Estado } & Sin pareja & 12,57 & 3,26 & $-0,98$ & 333 \\
\hline & Con pareja & 16,65 & 10,73 & & \\
\hline \multirow[t]{2}{*}{ STAI-Rasgo } & Sin pareja & 10,29 & 6,79 & $-0,56$ & ,582 \\
\hline & Con pareja & 12,58 & 10,24 & & \\
\hline \multirow[t]{2}{*}{ BDI } & Sin pareja & 9,57 & 6,65 & $-0,81$ & ,423 \\
\hline & Con pareja & 12,50 & 8,85 & & \\
\hline \multirow[t]{2}{*}{ EA1- Percepción de malestar general } & Sin pareja & 3,79 & 3,26 & $-0,57$ & ,568 \\
\hline & Con pareja & 4,34 & 2,99 & & \\
\hline \multirow[t]{2}{*}{ EA2- Percepción de Ansiedad y Nerviosismo } & Sin pareja & 2,57 & 2,79 & $-0,65$ & ,516 \\
\hline & Con pareja & 3,23 & 3,31 & & \\
\hline \multirow[t]{2}{*}{ EA3- Percepción de Estado de Ánimo Deprimido } & Sin pareja & 1,14 & 1,79 & $-1,39$ & 171 \\
\hline & Con pareja & 2,34 & 3,01 & & \\
\hline
\end{tabular}

Respecto a la valoración de la estancia en UCI (véase Tabla 18) de manera global no se han obtenido diferencias significativas en función del estado civil $(t=0,11$; $p=$,909). Sin embargo, al analizar por separado los distintos aspectos que incluye el cuestionario se han obtenido diferencias significativas por un lado en la valoración de los cuidados médicos $(t=2,13 ; p=, 039)$ más valorado por los pacientes sin pareja, y por 
otro lado en la valoración de las posibilidades de distraerse $(\mathrm{t}=-2,07 ; \mathrm{p}=, 045)$, aspecto mejor valorado por los pacientes con pareja. Los ítems restantes, en su mayoría, han sido valorados más positivamente por los pacientes sin pareja a excepción de los ítems relacionados con el respeto a la intimidad, las posibilidades de distraerse y el régimen de visitas que han obtenido puntuaciones ligeramente superiores en las valoraciones de los pacientes con pareja, si bien las diferencias no han sido significativas.

Tabla 18. Análisis diferencial en función del estado civil de la valoración de la estancia en UCI (pacientes)

\begin{tabular}{|c|c|c|c|c|c|}
\hline Ítem & Estado civil & $\bar{X}$ & DT & $\mathbf{t}$ & $\begin{array}{l}\text { Sig. } \\
p \leq, 050\end{array}$ \\
\hline \multirow{2}{*}{$\begin{array}{l}\text { En qué grado está siendo agradable/desagradable su } \\
\text { estancia en } \mathrm{UCl} \text { sin considerar los problemas médicos }\end{array}$} & Sin pareja & 4,08 & 1,44 & \multirow[b]{2}{*}{0,11} & \multirow[b]{2}{*}{ 909 } \\
\hline & Con pareja & 4,03 & 1,25 & & \\
\hline \multirow[t]{2}{*}{ Valoración de los siguientes aspectos } & \multirow[t]{2}{*}{ Estado civil } & \multirow[t]{2}{*}{$\bar{X}$} & \multirow[t]{2}{*}{ DT } & \multirow[t]{2}{*}{$t$} & \\
\hline & & & & & $p \leq, 050$ \\
\hline \multirow[t]{2}{*}{ 1. Cuidados médicos } & Sin pareja & 4,92 & 0,29 & \multirow[t]{2}{*}{2,13} & \multirow[t]{2}{*}{,039 } \\
\hline & Con pareja & 4,55 & 0,57 & & \\
\hline \multirow{2}{*}{ 2. Atención de los médicos } & Sin pareja & 4,92 & 0,29 & \multirow[t]{2}{*}{1,79} & \multirow[t]{2}{*}{, 080} \\
\hline & Con pareja & 4,58 & 0,62 & & \\
\hline \multirow[t]{2}{*}{ 3. Atención de las/os enfermeras/os } & Sin pareja & 4,83 & 0,39 & \multirow[t]{2}{*}{0,67} & \multirow[t]{2}{*}{, 506} \\
\hline & Con pareja & 4,71 & 0,59 & & \\
\hline \multirow[t]{2}{*}{ 4. Atención de las/os auxiliares de enfermería } & Sin pareja & 4,83 & 0,39 & \multirow[t]{2}{*}{0,67} & \multirow[t]{2}{*}{, 506} \\
\hline & Con pareja & 4,71 & 0,59 & & \\
\hline \multirow{2}{*}{ 5. Claridad de la información recibida } & Sin pareja & 4,75 & 0,45 & \multirow{2}{*}{1,26} & \multirow{2}{*}{,215 } \\
\hline & Con pareja & 4,43 & 0,82 & & \\
\hline \multirow[t]{2}{*}{ 6. Cantidad de la información recibida } & Sin pareja & 4,50 & 1,00 & \multirow[t]{2}{*}{0,78} & \multirow[t]{2}{*}{,441 } \\
\hline & Con pareja & 4,27 & 0,83 & & \\
\hline \multirow[t]{2}{*}{ 7. Trato por parte del personal de enfermería } & Sin pareja & 4,83 & 0,39 & \multirow[t]{2}{*}{0,73} & \multirow[t]{2}{*}{,467 } \\
\hline & Con pareja & 4,71 & 0,53 & & \\
\hline 8. Afecto/apoyo emocional del personal de enfermería & Sin pareja & 4,75 & 0,45 & 0,95 & ,347 \\
\hline & Con pareja & 4,55 & 0,67 & & \\
\hline 9. Respeto a la intimidad & Sin pareja & 4,25 & 0,87 & $-0,63$ &, 534 \\
\hline & Con pareja & 4,42 & 0,76 & & \\
\hline 10. Atención a los familiares & Sin pareja & 4,75 & 0,45 & 1,08 & ,285 \\
\hline & Con pareja & 4,53 & 0,63 & & \\
\hline 11. Atención de necesidades psicológicas en paciente y & Sin pareja & 4,83 & 0,39 & 1,41 & 166 \\
\hline & Con pareja & 4,50 & 0,78 & & \\
\hline 12. Calidad de las instalaciones (comodidad, higiene...) & Sin pareja & 4,50 & 0,67 & 1,13 & ,263 \\
\hline & Con pareja & 4,19 & 0,83 & & \\
\hline 13. Posibilidades de distraerse & Sin pareja & 1,73 & 1,42 & $-2,07$ &, 045 \\
\hline & Con pareja & 2,65 & 1,20 & & \\
\hline 14. Silencio o tranquilidad en la sala & Sin pareja & 3,58 & 0,90 & 1,09 & ,282 \\
\hline & Con pareja & 3,13 & 1,31 & & \\
\hline 15. Régimen de visitas & Sin pareja & 3,67 & 0,98 & $-0,32$ & ,751 \\
\hline & Con pareja & 3,77 & 0,99 & & \\
\hline
\end{tabular}

El análisis diferencial en función del estado civil de los estresores de UCI (véase Tabla 19) muestra diferencias estadísticamente significativas en el nivel de estrés 
general $(t=2,67 ; p=, 011)$ y en otros factores estresantes asociados a este contexto. Concretamente estas diferencias se observan en los ítems relacionados con "estar encamado/sentado en el sillón todo el día" ( $t=2,18 ; p=, 035)$, "no saber cuándo le darán el alta de $\mathrm{UCI}^{\prime}(\mathrm{t}=2,22 ; \mathrm{p}=, 032)$ y "haber sido hospitalizado de repente" $(\mathrm{t}=2,47$; $p=, 019)$. Cabe señalar que las citadas diferencias en el grado de estrés han sido a favor de los pacientes sin pareja.

Tabla 19. Análisis diferencial en función del estado civil de los Factores estresantes en UCI (pacientes)

\begin{tabular}{|c|c|c|c|c|c|}
\hline Ítem & Estado civil & $\bar{X}$ & DT & $\mathbf{t}$ & $\begin{array}{l}\text { Sig. } \\
p \leq, 050\end{array}$ \\
\hline \multirow[t]{2}{*}{ 1. No disponer de baño en el box } & Sin pareja & 1,09 & 1,45 & $-1,12$ & ,267 \\
\hline & Con pareja & 1,74 & 1,71 & & \\
\hline \multirow[t]{2}{*}{ 2.Tener que estar en la cama/sillón todo el día } & Sin pareja & 3 & 1,41 & 2,18 & 035 \\
\hline & Con pareja & 1,97 & 1,33 & & \\
\hline \multirow[t]{2}{*}{ 3.Estar hospitalizado lejos de casa } & Sin pareja & 1,54 & 1,86 & 1,84 & 074 \\
\hline & Con pareja & 0,68 & 1,06 & & \\
\hline \multirow[t]{2}{*}{ 4.Dormir en una cama que no es la suya } & Sin pareja & 1,70 & 1,89 & 1,21 & ,232 \\
\hline & Con pareja & 1 & 1,48 & & \\
\hline \multirow[t]{2}{*}{ 5.Utilizar la cuña de cama } & Sin pareja & 1,80 & 1,93 & $-0,73$ & ,471 \\
\hline & Con pareja & 2,24 & 1,55 & & \\
\hline \multirow[t]{2}{*}{ 6.Que no respondan al timbre de aviso } & Sin pareja & 1 & 1 & $-0,68$ &, 507 \\
\hline & Con pareja & 1,64 & 1,55 & & \\
\hline \multirow[t]{2}{*}{ 7.Dormir junto a otros enfermos en la unidad } & Sin pareja & 0,09 & 0,30 & $-1,73$ & ,090 \\
\hline & Con pareja & 0,55 & 0,85 & & \\
\hline \multirow[t]{2}{*}{ 8.Tener que ser ayudado para ir al baño } & Sin pareja & 1 & 1,53 & $-1,75$ & ,090 \\
\hline & Con pareja & 2,17 & 1,56 & & \\
\hline \multirow[t]{2}{*}{ 9.Tener que comer en la cama en una postura incómoda } & Sin pareja & 1,54 & 1,69 & 1,33 & 192 \\
\hline & Con pareja & 0,97 & 1,03 & & \\
\hline \multirow{2}{*}{$\begin{array}{l}\text { 10.Estar ingresado en la unidad junto a otras personas } \\
\text { gravemente enfermas }\end{array}$} & Sin pareja & 0,36 & 0,67 & $-0,77$ & ,448 \\
\hline & Con pareja & 0,58 & 0,85 & & \\
\hline \multirow[t]{2}{*}{ 11.Estar al cuidado de sanitarios desconocidos } & Sin pareja & 0 & 0 & $-1,33$ & ,285 \\
\hline & Con pareja & 0,19 & 0,48 & & \\
\hline \multirow[t]{2}{*}{ 12.Tener demasiadas visitas } & Sin pareja & 0,10 & 0,32 & $-1,09$ & ,924 \\
\hline & Con pareja & 0,46 & 1,04 & & \\
\hline \multirow{2}{*}{$\begin{array}{l}\text { 13.Tener que estar todo el tiempo desnudo, únicamente } \\
\text { cubierto con una sábana }\end{array}$} & Sin pareja & 1,20 & 1,48 & 0,18 & 855 \\
\hline & Con pareja & 1,09 & 1,56 & & \\
\hline \multirow[t]{2}{*}{ 14. Necesitar ayuda para comer } & Sin pareja & 1,30 & 1,34 & 0,52 & ,605 \\
\hline & Con pareja & 1,07 & 1,11 & & \\
\hline \multirow{2}{*}{$\begin{array}{l}\text { 15. No poder ver la TV/escuchar la radio/leer el periódico } \\
\text { cuando uno quiere }\end{array}$} & Sin pareja & 0,90 & 0,99 & $-0,16$ & 877 \\
\hline & Con pareja & 0,96 & 1,13 & & \\
\hline \multirow{2}{*}{$\begin{array}{l}\text { 16. Escuchar ruidos de máquinas o gente hablar } \\
\text { constantemente }\end{array}$} & Sin pareja & 1,36 & 1,57 & 1,42 & 164 \\
\hline & Con pareja & 0,74 & 1,12 & & \\
\hline \multirow[t]{2}{*}{ 17.Estar las luces todo el día encendidas } & Sin pareja & 1 & 1,61 & 0,36 & ,718 \\
\hline & Con pareja & 0,83 & 1,23 & & \\
\hline \multirow{2}{*}{$\begin{array}{l}\text { 18. No tener a los familiares y amigos acompañándole a lo } \\
\text { largo del día }\end{array}$} & Sin pareja & 1,64 & 1,69 & $-0,42$ & 673 \\
\hline & Con pareja & 1,87 & 1,48 & & \\
\hline \multirow[t]{2}{*}{ 19.Estar aislado en la habitación por prescripción médica } & Sin pareja & 0,33 & 0,58 & 0,27 & 789 \\
\hline & Con pareja & 0,25 & 0,45 & & \\
\hline \multirow[t]{2}{*}{ 20.Tener dolor } & Sin pareja & 2,25 & 1,39 & $-0,62$ & ,539 \\
\hline & Con pareja & 2,61 & 1,47 & & \\
\hline
\end{tabular}

(Sigue detrás) 
(Continuación Tabla 19)

\begin{tabular}{|c|c|c|c|c|c|}
\hline Ítem & Estado civil & $\bar{X}$ & DT & $\mathbf{t}$ & $\begin{array}{l}\text { Sig. } \\
p \leq, 050\end{array}$ \\
\hline \multirow{2}{*}{$\begin{array}{l}\text { 21. No saber con seguridad o no entender en qué consiste la } \\
\text { enfermedad }\end{array}$} & Sin pareja & 2,11 & 1,62 & \multirow[t]{2}{*}{1,68} & \multirow[t]{2}{*}{102} \\
\hline & Con pareja & 1,12 & 1,45 & & \\
\hline \multirow[t]{2}{*}{ 22.Pensar que le puede ocurrir algo grave } & Sin pareja & 1,78 & 1,79 & \multirow[t]{2}{*}{$-0,20$} & \multirow[t]{2}{*}{, 841} \\
\hline & Con pareja & 1,90 & 1,54 & & \\
\hline \multirow{2}{*}{$\begin{array}{l}\text { 23.Pensar si podrá volver a su vida normal después de salir del } \\
\text { hospital }\end{array}$} & Sin pareja & 0,70 & 0,82 & \multirow[t]{2}{*}{$-0,97$} & \multirow[t]{2}{*}{,335 } \\
\hline & Con pareja & 1,09 & 1,19 & & \\
\hline \multirow{2}{*}{$\begin{array}{l}\text { 24. No poder ocuparse de la familia como hasta ahora venía } \\
\text { haciendo }\end{array}$} & Sin pareja & 1 & 1,26 & \multirow[t]{2}{*}{$-0,72$} & \multirow[t]{2}{*}{,474 } \\
\hline & Con pareja & 1,32 & 1,27 & & \\
\hline \multirow{2}{*}{$\begin{array}{l}\text { 25. No saber con seguridad cómo se quedará después de la } \\
\text { operación }\end{array}$} & Sin pareja & 0,83 & 1,33 & \multirow[t]{2}{*}{$-0,61$} & \multirow[t]{2}{*}{,546 } \\
\hline & Con pareja & 1,23 & 1,39 & & \\
\hline \multirow[t]{2}{*}{ 26. Estar separado de sus familiares más cercanos } & Sin pareja & 1,91 & 1,58 & \multirow[t]{2}{*}{$-0,55$} & \multirow[t]{2}{*}{, 582} \\
\hline & Con pareja & 2,16 & 1,19 & & \\
\hline \multirow{2}{*}{$\begin{array}{l}\text { 27. No saber cuándo le darán el alta de la unidad de cuidados } \\
\text { intensivos }\end{array}$} & Sin pareja & 2,09 & 1,22 & \multirow[t]{2}{*}{2,22} & \multirow[t]{2}{*}{032} \\
\hline & Con pareja & 1,07 & 1,34 & & \\
\hline \multirow[t]{2}{*}{ 28. Haber sido hospitalizado de repente, sin esperarlo } & Sin pareja & 2,44 & 1,42 & \multirow[t]{2}{*}{2,47} & \multirow[t]{2}{*}{019} \\
\hline & Con pareja & 1,11 & 1,39 & & \\
\hline \multirow{2}{*}{$\begin{array}{l}\text { 29. No saber los resultados/razones de los } \\
\text { tratamientos/pruebas que le hacen }\end{array}$} & Sin pareja & 1,67 & 1,41 & \multirow[t]{2}{*}{1,28} & ,209 \\
\hline & Con pareja & 1,04 & 1,22 & & \\
\hline 30.Pensar que puede tener dolor a causa de la & Sin pareja & 2,25 & 1,39 & 1,00 & ,324 \\
\hline operación/análisis/pruebas & Con pareja & 1,67 & 1,43 & & \\
\hline 31.No saber cuándo van a hacerle cosas a uno & Sin pareja & 0,90 & 1,10 & $-0,61$ & ,543 \\
\hline & Con pareja & 1,18 & 1,30 & & \\
\hline 32.No obtener alivio para el dolor aún tomando medicación & Sin pareja & 2,33 & 1,03 & $-0,23$ & 818 \\
\hline & Con pareja & 2,47 & 1,35 & & \\
\hline 33.Ver que el personal del hospital tiene prisa & Sin pareja & 0,45 & 0,93 & 0,34 & ,735 \\
\hline & Con pareja & 0,35 & 0,79 & & \\
\hline 34.Que sanitarios hablen deprisa o usen palabras que no & Sin pareja & 0,86 & 1,21 & 0,03 & 973 \\
\hline pueden entender & Con pareja & 0,84 & 1,14 & & \\
\hline 35.Que el personal sanitario no conteste a sus preguntas & Sin pareja & 1 & 0,82 & $-1,19$ & ,250 \\
\hline & Con pareja & 1,86 & 1,35 & & \\
\hline 36.Que no le den la medicación para el dolor cuando lo & Sin pareja & 1,67 & 0,58 & $-0,26$ & ,794 \\
\hline necesita & Con pareja & 1,89 & 1,45 & & \\
\hline 37.Pensar en la posible pérdida de dinero a causa de la & Sin pareja & 0,89 & 1,45 & 1,36 & 182 \\
\hline enfermedad & Con pareja & 0,39 & 0,74 & & \\
\hline 38.Sentir olores extraños en el hospital & Sin pareja & 0,50 & 1,27 & 0,92 & ,361 \\
\hline & Con pareja & 0,23 & 0,62 & & \\
\hline 39.Tener que comer a horas diferentes a las habituales & Sin pareja & 0,33 & 0,71 & 0,14 & ,888 \\
\hline & Con pareja & 0,29 & 0,82 & & \\
\hline 40.Nivel de estrés en general & Sin pareja & 2,54 & 1,13 & 2,67 & 011 \\
\hline & Con pareja & 1,45 & 1,18 & & \\
\hline
\end{tabular}

En cuanto a la calidad de vida de los pacientes no se han obtenido diferencias estadísticamente significativas en función del estado civil ni antes $(t=-1,44 ; p=, 157)$ ni después ( $t=0,42 ; p=, 674)$ del ingreso en UCI (véase Tabla 20). No obstante, aún sin ser significativas podemos ver que previamente al ingreso las puntuaciones medias son mayores (peor calidad de vida) en los pacientes con pareja mientras que después del ingreso las puntuaciones son superiores en los participantes sin pareja. 
Tabla 20. Análisis diferencial en función del estado civil en la calidad de vida (CV) de los pacientes

\begin{tabular}{|l|c|ccc|}
\hline Ítem & Estado civil & $\bar{X}$ & DT & $\begin{array}{c}\text { Sig. } \\
\text { t } \leq, 050\end{array}$ \\
\hline 1. Puntuación total en CV previa al ingreso & Sin pareja & 5,82 & 1,54 & $-1,44$ \\
& Con pareja & 6,81 & 2,07 & 0,157 \\
\hline 2. Puntuación total en CV después del ingreso & Sin pareja & 12 & 1 & 0,42 \\
& Con pareja & 11,71 & 2,18 &
\end{tabular}

Al analizar la valoración diferencial de los distintos aspectos implicados en el proceso de morir que contempla el CAMP (véase Tabla 21) se han obtenido diferencias significativas en función del estado civil en el ítem que evalúa la importancia del "sentido de la vida" llegado el momento de la muerte $(\mathrm{t}=-2,11 ; \mathrm{p}=, 043)$, aspecto que ha sido más valorado por los pacientes con pareja.

Tabla 21. Análisis diferencial en función del estado civil de los distintos factores del Cuestionario de Ayuda a Morir en Paz (CAMP) (pacientes)

\begin{tabular}{|c|c|c|c|c|c|}
\hline Ítem & Estado civil & $\bar{X}$ & DT & $\mathbf{t}$ & $\begin{array}{l}\text { Sig. } \\
p \leq, 050\end{array}$ \\
\hline \multirow[t]{2}{*}{ 1. Controlar mi dolor y otros síntomas de malestar } & Sin pareja & 3,67 & 0,50 & $-0,11$ & 911 \\
\hline & Con pareja & 3,69 & 0,70 & & \\
\hline \multirow[t]{2}{*}{ 2. Mi proceso de morir, si produce sufrimiento, será corto } & Sin pareja & 3,44 & 0,88 & $-0,10$ & ,921 \\
\hline & Con pareja & 3,48 & 0,85 & & \\
\hline \multirow[t]{2}{*}{ 3.Controlar hasta el final pensamientos y funciones fisiológicas } & Sin pareja & 2,22 & 1,79 & $-0,06$ & ,952 \\
\hline & Con pareja & 2,26 & 1,54 & & \\
\hline \multirow{2}{*}{$\begin{array}{l}\text { 4. Mi muerte no supondrá una carga insoportable para mis } \\
\text { seres queridos }\end{array}$} & Sin pareja & 2,87 & 1,81 & 0,22 & 827 \\
\hline & Con pareja & 2,74 & 1,39 & & \\
\hline \multirow{2}{*}{$\begin{array}{l}\text { 5. Poder sentirme cerca, comunicarme y estrechar vínculos } \\
\text { afectivos con mis personas queridas }\end{array}$} & Sin pareja & 3,11 & 1,27 & 0,15 & 885 \\
\hline & Con pareja & 3,04 & 1,15 & & \\
\hline \multirow{2}{*}{$\begin{array}{l}\text { 6. Sin esperanza real de recuperación, no se alargará } \\
\text { artificialmente mi vida en } \mathrm{UCl}\end{array}$} & Sin pareja & 2 & 1,80 & $-0,60$ & ,550 \\
\hline & Con pareja & 2,39 & 1,59 & & \\
\hline \multirow[t]{2}{*}{ 7. Pensar que mi vida ha tenido algún sentido } & Sin pareja & 2,33 & 1 & $-2,11$ & ,043 \\
\hline & Con pareja & 2,95 & 0,64 & & \\
\hline \multirow[t]{2}{*}{ 8. Creer en otra vida después de la muerte } & Sin pareja & 1,37 & 1,51 & $-0,51$ & ,614 \\
\hline & Con pareja & 1,73 & 1,72 & & \\
\hline \multirow[t]{2}{*}{ 9. No sentirse culpable por conflictos personales del pasado } & Sin pareja & 2,33 & 0,87 & 0,41 & ,682 \\
\hline & Con pareja & 2,13 & 1,36 & & \\
\hline \multirow{2}{*}{$\begin{array}{l}\text { 10. Si la situación se me hace insoportable disponer de ayuda } \\
\text { para morir con rapidez }\end{array}$} & Sin pareja & 2,33 & 1,80 & $-1,57$ & ,126 \\
\hline & Con pareja & 3,17 & 1,15 & & \\
\hline \multirow[t]{2}{*}{ 11. Poder morir en mi casa } & Sin pareja & 0,87 & 1,36 & $-0,56$ &, 581 \\
\hline & Con pareja & 1,22 & 1,54 & & \\
\hline
\end{tabular}

Por lo que respecta al proceso de información y toma de decisiones (véase Tabla 22) si bien ninguna de las diferencias ha resultado ser significativa, encontramos que los pacientes con pareja conceden dentro del proceso un papel muy ligeramente 
superior al propio enfermo $(\overline{\mathrm{X}}=16,62 ; \mathrm{DT}=3,96)$ en comparación con el que le dan los pacientes que no tienen pareja actualmente $(\overline{\mathrm{X}}=16$; $\mathrm{DT}=5,59)$. En cambio, estos últimos conceden sutilmente mayor importancia al papel de la familia $(\overline{\mathrm{X}}=11$ vs $\bar{X}=10,12)$, al papel del médico $(\overline{\mathrm{X}}=4,80$ vs $\overline{\mathrm{X}}=4,50)$ y del psicólogo $(\overline{\mathrm{X}}=2,80$ vs $\overline{\mathrm{X}}=2,44)$ en el proceso, tal y como se observa en la Tabla 22.

En cuanto al resto de subescalas del cuestionario CITD, aun sin ser las diferencias significativas podemos apreciar que los pacientes sin pareja se muestran más satisfechos con la información $(\bar{X}=6$ vs $\bar{X}=4,22)$, prefieren más un estilo médico cauteloso, que se guarde lo que aún no es seguro ( $\bar{X}=2,40$ vs $\bar{X}=1,67)$ así como también se sienten más capacitados para participar en la toma de decisiones médicas ( $\bar{X}=2,60$ vs $\overline{\mathrm{X}}=2,22$ ) al comparar sus puntuaciones medias con las de los pacientes que tienen pareja. En cambio, estos últimos perciben más la participación en decisiones médicas como una carga $(\overline{\mathrm{X}}=1,33$ vs $\overline{\mathrm{X}}=0,60)$.

Tabla 22. Análisis diferencial en función del estado civil del proceso de información y toma de decisiones (pacientes)

\begin{tabular}{|c|c|c|c|c|c|}
\hline CITD & Estado civil & $\bar{X}$ & DT & $\mathbf{t}$ & $\begin{array}{l}\text { Sig. } \\
p \leq, 050\end{array}$ \\
\hline \multicolumn{6}{|l|}{ Importancia de los distintos agentes implicados } \\
\hline \multirow[t]{2}{*}{ Papel de la familia en la información y toma de decisiones } & Sin pareja & 11 & 4,69 & 0,27 & ,796 \\
\hline & Con pareja & 10,12 & 5,64 & & \\
\hline \multirow[t]{2}{*}{ Papel del paciente en la información y toma de decisiones } & Sin pareja & 16 & 5,59 & $-0,23$ & ,826 \\
\hline & Con pareja & 16,62 & 3,96 & & \\
\hline \multirow[t]{2}{*}{ Papel del médico en la información y toma de decisiones } & Sin pareja & 4,80 & 1,09 & 0,45 & 659 \\
\hline & Con pareja & 4,50 & 1,19 & & \\
\hline \multirow[t]{2}{*}{ Papel del psicólogo en la información y toma de decisiones } & Sin pareja & 2,80 & 0,45 & 0,98 & ,344 \\
\hline & Con pareja & 2,44 & 0,73 & & \\
\hline \multicolumn{6}{|l|}{ Satisfacción con la información } \\
\hline \multirow{2}{*}{$\begin{array}{l}\text { Satisfacción con la cantidad y la claridad de la información } \\
\text { recibida }\end{array}$} & Sin pareja & 6 & 0 & 1,43 & 178 \\
\hline & Con pareja & 4,22 & 2,73 & & \\
\hline \multicolumn{6}{|l|}{ Estilo del médico } \\
\hline \multirow{2}{*}{$\begin{array}{l}\text { En cuanto al estilo del médico prefiero que éste sea directo y } \\
\text { anticipe posibles sospechas }\end{array}$} & Sin pareja & 0,60 & 1,34 & $-1,79$ & ,099 \\
\hline & Con pareja & 1,89 & 1,27 & & \\
\hline \multirow{2}{*}{$\begin{array}{l}\text { En cuanto al estilo del médico prefiero que éste se guarde lo } \\
\text { que aún no es seguro }\end{array}$} & Sin pareja & 2,40 & 1,34 & 0,95 & ,363 \\
\hline & Con pareja & 1,67 & 1,41 & & \\
\hline \multicolumn{6}{|l|}{ Participación en TD } \\
\hline \multirow[t]{2}{*}{ Me siento capacitado para participar en la TD sobre la salud } & Sin pareja & 2,60 & 0,89 & 0,61 &, 553 \\
\hline & Con pareja & 2,22 & 1,20 & & \\
\hline \multirow{2}{*}{$\begin{array}{l}\text { Poder participar en una decisión médica sería más una carga } \\
\text { que un privilegio }\end{array}$} & Sin pareja & 0,60 & 0,89 & $-1,04$ & ,319 \\
\hline & Con pareja & 1,33 & 1,41 & & \\
\hline
\end{tabular}




\subsubsection{Análisis diferenciales en función de si los pacientes tienen o no hijos}

Otra variable en función de la cual se han realizado análisis diferenciales ha sido el número de hijos. Para este propósito se ha utilizado la prueba $\mathrm{t}$ de Student, analizando la existencia de diferencias en las distintas variables dependientes según los pacientes tengan o no hijos.

Respecto a los síntomas de ansiedad y depresión (véase Tabla 23) no se han obtenido diferencias estadísticamente significativas. Aun así podemos observar que las puntuaciones en depresión evaluadas mediante el HADS y el BDI son ligeramente superiores en los pacientes con hijos $(\bar{X}=6,09$ vs $\bar{X}=5,33 ; \bar{X}=12,10$ vs $\bar{X}=8,33$ respectivamente), al igual que se observa en las puntuaciones en ansiedad-estado (STAI) ( $\overline{\mathrm{X}}=17,30$ vs $\overline{\mathrm{X}}=12,67)$. En cambio las puntuaciones en ansiedad obtenidas mediante el HADS son ligeramente mayores en los pacientes sin hijos $(\bar{X}=9,17$ vs $\overline{\mathrm{X}}=6,56)$.

En cuanto a la percepción subjetiva del estado de ánimo, si bien no se han encontrado diferencias significativas entre los pacientes que tienen hijos y los que no, tal como se muestra en la Tabla 23 las puntuaciones en las tres subescalas, es decir, en percepción de malestar general, nerviosismo/ansiedad y estado de ánimo deprimido son algo mayores en el grupo de pacientes con hijos.

Tabla 23. Análisis diferencial en función del número de hijos de la ansiedad, depresión y estado de ánimo (pacientes)

\begin{tabular}{|c|c|c|c|c|c|}
\hline Cuestionarios & Número de hijos & $\bar{X}$ & DT & $\mathbf{t}$ & $\begin{array}{l}\text { Sig. } \\
p \leq, 050\end{array}$ \\
\hline \multirow[t]{2}{*}{ Total HADS Ansiedad } & Sin hijos & 9,17 & 4,17 & 1,10 & ,278 \\
\hline & Con hijos & 6,56 & 5,48 & & \\
\hline \multirow[t]{2}{*}{ Total HADS Depresión } & Sin hijos & 5,33 & 3,01 & $-0,28$ & 777 \\
\hline & Con hijos & 6,09 & 6,34 & & \\
\hline \multirow[t]{2}{*}{ STAI-Estado } & Sin hijos & 12,67 & 1,53 & $-0,69$ & ,497 \\
\hline & Con hijos & 17,30 & 11,36 & & \\
\hline \multirow[t]{2}{*}{ STAI-Rasgo } & Sin hijos & 14,33 & 6,66 & 0,37 & ,710 \\
\hline & Con hijos & 11,90 & 10,75 & & \\
\hline \multirow[t]{2}{*}{ BDI } & Sin hijos & 8,33 & 8,39 & $-0,64$ &, 529 \\
\hline & Con hijos & 12,10 & 9,61 & & \\
\hline \multirow[t]{2}{*}{ EA1- Percepción de malestar general } & Sin hijos & 4,17 & 3,49 & $-0,15$ & ,881 \\
\hline & Con hijos & 4,37 & 3,03 & & \\
\hline \multirow[t]{2}{*}{ EA2- Percepción de Ansiedad y Nerviosismo } & Sin hijos & 2,00 & 2,53 & $-1,06$ & ,296 \\
\hline & Con hijos & 3,50 & 3,27 & & \\
\hline \multirow[t]{2}{*}{ EA3- Percepción de Estado de Ánimo Deprimido } & Sin hijos & 1,17 & 1,47 & $-0,64$ &, 524 \\
\hline & Con hijos & 1,94 & 2,84 & & \\
\hline
\end{tabular}


En cuanto a la valoración de la estancia en UCI, tal como podemos observar en la Tabla 24 no se han encontrado tampoco diferencias estadísticamente significativas ni en la valoración global ni en ninguno de los aspectos evaluados en el cuestionario. Cabe señalar que en la valoración sobre la "atención que reciben los familiares", las diferencias entre los pacientes sin hijos y con hijos estarían próximas a la significación $(t=1,78 ; p=, 085)$ siendo este aspecto más valorado por los pacientes sin hijos. En esta misma línea y sin llegar a la significación estadística podemos observar que los pacientes sin hijos suelen valorar de forma más positiva la mayoría de aspectos relativos a la estancia en UCI, entre ellos los cuidados y la atenciones recibidas por los profesionales sanitarios incluida la atención de las necesidades psicológicas, el respeto a la intimidad y el silencio en la sala. En cambio son los pacientes con hijos quienes valoran ligeramente más las posibilidades de distraerse y el régimen de visitas.

Tabla 24. Análisis diferencial en función del número de hijos de la valoración dela estancia en UCI (pacientes)

\begin{tabular}{|c|c|c|c|c|c|}
\hline Ítem & $\begin{array}{l}\text { Número de } \\
\text { hijos }\end{array}$ & $\overline{\boldsymbol{X}}$ & DT & $\mathbf{t}$ & $\begin{array}{c}\text { Sig. } \\
p \leq, 050\end{array}$ \\
\hline $\begin{array}{l}\text { En qué grado está siendo agradable/desagradable su estancia } \\
\text { en UCl sin considerar los problemas médicos. }\end{array}$ & $\begin{array}{l}\text { Sin hijos } \\
\text { Con hijos }\end{array}$ & $\begin{array}{l}4,00 \\
4,11\end{array}$ & $\begin{array}{l}2,24 \\
1,15\end{array}$ & $-0,17$ & 867 \\
\hline Valoración de los siguientes aspectos & $\begin{array}{l}\text { Número de } \\
\text { hijos }\end{array}$ & $\bar{X}$ & DT & $\mathrm{t}$ & $\begin{array}{l}\text { Sig. } \\
p \leq, 050\end{array}$ \\
\hline 1. Cuidados médicos & $\begin{array}{l}\text { Sin hijos } \\
\text { Con hijos }\end{array}$ & $\begin{array}{c}5 \\
4,70\end{array}$ & $\begin{array}{c}0 \\
0,54\end{array}$ & 1,21 & ,237 \\
\hline 2. Atención de los médicos & $\begin{array}{l}\text { Sin hijos } \\
\text { Con hijos }\end{array}$ & $\begin{array}{c}5 \\
4,74\end{array}$ & $\begin{array}{c}0 \\
0,53\end{array}$ & 1,09 & ,285 \\
\hline 3. Atención de las/os enfermeras/os & $\begin{array}{l}\text { Sin hijos } \\
\text { Con hijos }\end{array}$ & $\begin{array}{c}5 \\
4,74\end{array}$ & $\begin{array}{c}0 \\
0,59\end{array}$ & 0,96 & ,344 \\
\hline 4. Atención de las/os auxiliares de enfermería & $\begin{array}{l}\text { Sin hijos } \\
\text { Con hijos }\end{array}$ & $\begin{array}{c}5 \\
4,70\end{array}$ & $\begin{array}{c}0 \\
0,61\end{array}$ & 1,07 & 291 \\
\hline 5. Claridad de la información recibida & $\begin{array}{l}\text { Sin hijos } \\
\text { Con hijos }\end{array}$ & $\begin{array}{l}4,40 \\
4,56\end{array}$ & $\begin{array}{l}0,89 \\
0,75\end{array}$ & $-0,41$ & ,682 \\
\hline 6. Cantidad de la información recibida & $\begin{array}{l}\text { Sin hijos } \\
\text { Con hijos }\end{array}$ & $\begin{array}{c}4 \\
4,41\end{array}$ & $\begin{array}{l}1,41 \\
0,79\end{array}$ & $-0,93$ & ,362 \\
\hline 7. Trato por parte del personal de enfermería & $\begin{array}{l}\text { Sin hijos } \\
\text { Con hijos }\end{array}$ & $\begin{array}{l}4,80 \\
4,70\end{array}$ & $\begin{array}{l}0,45 \\
0,54\end{array}$ & 0,37 & 712 \\
\hline 8. Afecto/apoyo emocional del personal de enfermería & $\begin{array}{l}\text { Sin hijos } \\
\text { Con hijos }\end{array}$ & $\begin{array}{c}5 \\
4,52\end{array}$ & $\begin{array}{c}0 \\
0,70\end{array}$ & 1,52 & 140 \\
\hline 9. Respeto a la intimidad & $\begin{array}{l}\text { Sin hijos } \\
\text { Con hijos }\end{array}$ & $\begin{array}{l}4,80 \\
4,18\end{array}$ & $\begin{array}{l}0,45 \\
0,88\end{array}$ & 1,51 & 141 \\
\hline 10. Atención a los familiares & $\begin{array}{l}\text { Sin hijos } \\
\text { Con hijos }\end{array}$ & $\begin{array}{c}5 \\
4,48\end{array}$ & $\begin{array}{c}0 \\
0,64\end{array}$ & 1,78 & ,085 \\
\hline 11. Atención de necesidades psicológicas en paciente y familia & $\begin{array}{l}\text { Sin hijos } \\
\text { Con hijos }\end{array}$ & $\begin{array}{c}5 \\
4,56\end{array}$ & $\begin{array}{c}0 \\
0,75\end{array}$ & 1,17 & ,253 \\
\hline 12. Calidad de las instalaciones (comodidad, higiene...) & $\begin{array}{l}\text { Sin hijos } \\
\text { Con hijos }\end{array}$ & $\begin{array}{l}4,80 \\
4,15\end{array}$ & $\begin{array}{l}0,45 \\
0,91\end{array}$ & 1,56 & ,130 \\
\hline 13. Posibilidades de distraerse & $\begin{array}{l}\text { Sin hijos } \\
\text { Con hijos }\end{array}$ & $\begin{array}{c}2 \\
2,38\end{array}$ & $\begin{array}{c}2 \\
1,39\end{array}$ & $-0,44$ & ,665 \\
\hline 14. Silencio o tranquilidad en la sala & $\begin{array}{l}\text { Sin hijos } \\
\text { Con hijos }\end{array}$ & $\begin{array}{l}3,60 \\
3,11\end{array}$ & $\begin{array}{l}1,14 \\
1,31\end{array}$ & 0,78 & ,442 \\
\hline 15. Régimen de visitas & $\begin{array}{l}\text { Sin hijos } \\
\text { Con hijos }\end{array}$ & $\begin{array}{l}3,40 \\
3,81\end{array}$ & $\begin{array}{l}1,14 \\
1,07\end{array}$ & $-0,79$ & ,438 \\
\hline
\end{tabular}


Por lo que respecta a los factores estresantes no se han encontrado diferencias significativas en el nivel de estrés general $(t=-0,55 ; p=, 583)$ (véase Tabla 25). En cambio estas diferencias llegan a ser significativas al analizar el grado de estrés que generan determinados aspectos dentro de la UCI, como son el hecho de "ser ayudado para ir al baño" ( $t=-2,41 ; p=, 025)$, "pensar en la posible pérdida de dinero a causa de la enfermedad" ( $t=2,48 ; p=, 020) y$ "sentir olores extraños en el hospital" $(t=2,74 ; p=, 011)$. En los dos últimos factores las diferencias encontradas han sido a favor de los pacientes sin hijos mientras que el ser ayudado para ir al baño ha generado más estrés en los pacientes con hijos.

Tabla 25. Análisis diferencial en función del número de hijos de los Factores estresantes en UCI (pacientes)

\begin{tabular}{|c|c|c|c|c|c|}
\hline Ítem & $\begin{array}{l}\text { Número de } \\
\text { hijos }\end{array}$ & $\overline{\boldsymbol{X}}$ & DT & $\mathbf{t}$ & $\begin{array}{l}\text { Sig. } \\
p \leq, 050\end{array}$ \\
\hline \multirow[t]{2}{*}{ 1. No disponer de baño en el box } & Sin hijos & 0,80 & 1,79 & $-1,26$ & ,217 \\
\hline & Con hijos & 1,85 & 1,70 & & \\
\hline \multirow[t]{2}{*}{ 2.Tener que estar en la cama/sillón todo el día } & Sin hijos & 2,20 & 1,64 & $-0,03$ & ,976 \\
\hline & Con hijos & 2,22 & 1,50 & & \\
\hline \multirow[t]{2}{*}{ 3.Estar hospitalizado lejos de casa } & Sin hijos & 1,00 & 2,00 & 0,36 & 719 \\
\hline & Con hijos & 0,76 & 1,09 & & \\
\hline \multirow[t]{2}{*}{ 4.Dormir en una cama que no es la suya } & Sin hijos & 1,75 & 2,06 & 0,81 & ,423 \\
\hline & Con hijos & 1,04 & 1,58 & & \\
\hline \multirow[t]{2}{*}{ 5.Utilizar la cuña de cama } & Sin hijos & 1,00 & 1,73 & $-1,69$ & 102 \\
\hline & Con hijos & 2,33 & 1,58 & & \\
\hline \multirow[t]{2}{*}{ 6.Que no respondan al timbre de aviso } & Sin hijos & 1,50 & 0,71 & $-0,11$ & ,918 \\
\hline & Con hijos & 1,64 & 1,75 & & \\
\hline \multirow[t]{2}{*}{ 7.Dormir junto a otros enfermos en la unidad } & Sin hijos & 0,80 & 1,30 & 1,49 & 146 \\
\hline & Con hijos & 0,29 & 0,54 & & \\
\hline \multirow[t]{2}{*}{ 8.Tener que ser ayudado para ir al baño } & Sin hijos & 0,25 & 0,50 & $-2,41$ & 025 \\
\hline & Con hijos & 2,21 & 1,58 & & \\
\hline \multirow[t]{2}{*}{ 9.Tener que comer en la cama en una postura incómoda } & Sin hijos & 0 & 0 & $-1,63$ & 113 \\
\hline & Con hijos & 1,11 & 1,34 & & \\
\hline \multirow{2}{*}{$\begin{array}{l}\text { 10.Estar ingresado en la unidad junto a otras personas } \\
\text { gravemente enfermas }\end{array}$} & Sin hijos & 0,20 & 0,45 & $-0,91$ & ,372 \\
\hline & Con hijos & 0,56 & 0,85 & & \\
\hline \multirow[t]{2}{*}{ 11.Estar al cuidado de sanitarios desconocidos } & Sin hijos & 0 & 0 & $-0,84$ & ,405 \\
\hline & Con hijos & 0,18 & 0,48 & & \\
\hline \multirow[t]{2}{*}{ 12.Tener demasiadas visitas } & Sin hijos & 0,20 & 0,45 & $-0,56$ &, 579 \\
\hline & Con hijos & 0,48 & 1,08 & & \\
\hline \multirow{2}{*}{$\begin{array}{l}\text { 13.Tener que estar todo el tiempo desnudo, únicamente } \\
\text { cubierto con una sábana }\end{array}$} & Sin hijos & 0,40 & 0,89 & $-1,11$ & ,277 \\
\hline & Con hijos & 1,26 & 1,68 & & \\
\hline \multirow[t]{2}{*}{ 14.Necesitar ayuda para comer } & Sin hijos & 0,75 & 0,96 & $-0,68$ &, 504 \\
\hline & Con hijos & 1,21 & 1,28 & & \\
\hline \multirow{2}{*}{$\begin{array}{l}\text { 15.No poder ver la TV/escuchar la radio/leer el periódico cuando } \\
\text { uno quiere }\end{array}$} & Sin hijos & 1,20 & 1,09 & 0,42 & 677 \\
\hline & Con hijos & 0,96 & 1,19 & & \\
\hline \multirow[t]{2}{*}{ 16.Escuchar ruidos de máquinas o gente hablar constantemente } & Sin hijos & 1,60 & 1,34 & 1,09 & ,284 \\
\hline & Con hijos & 0,89 & 1,34 & & \\
\hline \multirow[t]{2}{*}{ 17.Estar las luces todo el día encendidas } & Sin hijos & 0,25 & 0,50 & $-1,08$ & ,288 \\
\hline & Con hijos & 1,08 & 1,49 & & \\
\hline \multirow{2}{*}{$\begin{array}{l}\text { 18.No tener a los familiares y amigos acompañándole a lo largo } \\
\text { del día }\end{array}$} & Sin hijos & 2,20 & 1,79 & 0,48 &, 634 \\
\hline & Con hijos & 1,81 & 1,65 & & \\
\hline \multirow[t]{2}{*}{ 19.Estar aislado en la habitación por prescripción médica } & Sin hijos & 0 & - & $-0,56$ & ,588 \\
\hline & Con hijos & 0,27 & 0,47 & & \\
\hline \multirow[t]{2}{*}{ 20.Tener dolor } & Sin hijos & 2,67 & 1,15 & 0,08 & ,937 \\
\hline & Con hijos & 2,59 & 1,56 & & \\
\hline \multirow{2}{*}{$\begin{array}{l}\text { 21.No saber con seguridad o no entender en qué consiste la } \\
\text { enfermedad }\end{array}$} & Sin hijos & 2 & 1,82 & 0,73 & ,473 \\
\hline & Con hijos & 1,33 & 1,65 & & \\
\hline \multirow[t]{2}{*}{ 22.Pensar que le puede ocurrir algo grave } & Sin hijos & 2,80 & 1,64 & 1,20 & ,239 \\
\hline & Con hijos & 1,81 & 1,69 & & \\
\hline
\end{tabular}


(Continuación Tabla 25)

\begin{tabular}{|c|c|c|c|c|c|}
\hline Ítem & $\begin{array}{l}\text { Número de } \\
\text { hijos }\end{array}$ & $\bar{X}$ & DT & $\mathbf{t}$ & $\begin{array}{l}\text { Sig. } \\
p \leq, 050\end{array}$ \\
\hline \multirow{2}{*}{$\begin{array}{l}\text { 23.Pensar si podrá volver a su vida normal después de salir del } \\
\text { hospital }\end{array}$} & Sin hijos & 1 & 1,41 & 0 & 1 \\
\hline & Con hijos & 1 & 1,21 & & \\
\hline \multirow{2}{*}{$\begin{array}{l}\text { 24.No poder ocuparse de la familia como hasta ahora venía } \\
\text { haciendo }\end{array}$} & Sin hijos & 1,80 & 1,30 & 0,86 & ,396 \\
\hline & Con hijos & 1,26 & 1,29 & & \\
\hline $\begin{array}{l}\text { 25.No saber con seguridad cómo se quedará después de la } \\
\text { operación }\end{array}$ & $\begin{array}{l}\text { Sin hijos } \\
\text { Con hijos }\end{array}$ & $\begin{array}{c}0 \\
1,15\end{array}$ & $\begin{array}{c}0 \\
1,57\end{array}$ & $-1,24$ & ,236 \\
\hline 26. Estar separado de sus familiares más cercanos & $\begin{array}{l}\text { Sin hijos } \\
\text { Con hijos }\end{array}$ & $\begin{array}{l}2,60 \\
2,11\end{array}$ & $\begin{array}{l}1,52 \\
1,31\end{array}$ & 0,75 & 459 \\
\hline $\begin{array}{l}\text { 27.No saber cuándo le darán el alta de la unidad de cuidados } \\
\text { intensivos }\end{array}$ & $\begin{array}{l}\text { Sin hijos } \\
\text { Con hijos }\end{array}$ & $\begin{array}{l}1,75 \\
1,22\end{array}$ & $\begin{array}{l}1,50 \\
1,42\end{array}$ & 0,69 & ,497 \\
\hline 28. Haber sido hospitalizado de repente, sin esperarlo & $\begin{array}{l}\text { Sin hijos } \\
\text { Con hijos }\end{array}$ & $\begin{array}{c}2 \\
1,18\end{array}$ & $\begin{array}{l}1,83 \\
1,43\end{array}$ & 1,01 & ,322 \\
\hline $\begin{array}{l}\text { 29.No saber los resultados/razones de los tratamientos/pruebas } \\
\text { que le hacen }\end{array}$ & $\begin{array}{l}\text { Sin hijos } \\
\text { Con hijos }\end{array}$ & $\begin{array}{l}1,60 \\
1,05\end{array}$ & $\begin{array}{l}1,82 \\
1,24\end{array}$ & 0,82 & ,421 \\
\hline $\begin{array}{l}\text { 30.Pensar que puede tener dolor a causa de la } \\
\text { operación/análisis/pruebas }\end{array}$ & $\begin{array}{l}\text { Sin hijos } \\
\text { Con hijos }\end{array}$ & $\begin{array}{c}2 \\
1,70\end{array}$ & $\begin{array}{l}1,63 \\
1,34\end{array}$ & 0,39 & ,696 \\
\hline 31.No saber cuándo van a hacerle cosas a uno & $\begin{array}{l}\text { Sin hijos } \\
\text { Con hijos }\end{array}$ & $\begin{array}{l}0,20 \\
1,36\end{array}$ & $\begin{array}{l}0,45 \\
1,36\end{array}$ & $-1,86$ & 075 \\
\hline 32. No obtener alivio para el dolor aún tomando medicación & $\begin{array}{l}\text { Sin hijos } \\
\text { Con hijos }\end{array}$ & $\begin{array}{l}1,75 \\
2,73\end{array}$ & $\begin{array}{l}1,26 \\
1,16\end{array}$ & $-1,48$ & 157 \\
\hline 33.Ver que el personal del hospital tiene prisa & $\begin{array}{l}\text { Sin hijos } \\
\text { Con hijos }\end{array}$ & $\begin{array}{l}0,60 \\
0,41\end{array}$ & $\begin{array}{l}1,34 \\
0,84\end{array}$ & 0,43 & ,672 \\
\hline $\begin{array}{l}\text { 34.Que sanitarios hablen deprisa o usen palabras que no pueden } \\
\text { entender }\end{array}$ & $\begin{array}{l}\text { Sin hijos } \\
\text { Con hijos }\end{array}$ & $\begin{array}{l}1,20 \\
0,85\end{array}$ & $\begin{array}{l}1,64 \\
1,09\end{array}$ & 0,58 & ,567 \\
\hline 35.Que el personal sanitario no conteste a sus preguntas & $\begin{array}{l}\text { Sin hijos } \\
\text { Con hijos }\end{array}$ & $\begin{array}{l}1,50 \\
1,70\end{array}$ & $\begin{array}{l}1,73 \\
1,25\end{array}$ & $-0,24$ & 812 \\
\hline 36.Que no le den la medicación para el dolor cuando lo necesita & $\begin{array}{l}\text { Sin hijos } \\
\text { Con hijos }\end{array}$ & $\begin{array}{l}1 \\
2\end{array}$ & $\begin{array}{c}1 \\
1,35\end{array}$ & $-1,19$ & ,253 \\
\hline $\begin{array}{l}\text { 37.Pensar en la posible pérdida de dinero a causa de la } \\
\text { enfermedad }\end{array}$ & $\begin{array}{l}\text { Sin hijos } \\
\text { Con hijos }\end{array}$ & $\begin{array}{l}1,50 \\
0,30\end{array}$ & $\begin{array}{l}1,91 \\
0,63\end{array}$ & 2,48 & 020 \\
\hline 38.Sentir olores extraños en el hospital & $\begin{array}{l}\text { Sin hijos } \\
\text { Con hijos }\end{array}$ & $\begin{array}{c}1 \\
0,08\end{array}$ & $\begin{array}{l}1,73 \\
0,27\end{array}$ & 2,74 & 011 \\
\hline 39.Tener que comer a horas diferentes a las habituales & $\begin{array}{l}\text { Sin hijos } \\
\text { Con hijos }\end{array}$ & $\begin{array}{l}0,50 \\
0,29\end{array}$ & $\begin{array}{c}1 \\
0,82\end{array}$ & 0,45 & ,655 \\
\hline 40.Nivel de estrés en general & $\begin{array}{l}\text { Sin hijos } \\
\text { Con hijos }\end{array}$ & $\begin{array}{l}1,60 \\
1,96\end{array}$ & $\begin{array}{l}1,34 \\
1,34\end{array}$ & $-0,55$ & ,583 \\
\hline
\end{tabular}

En cuanto a la calidad de vida no se han obtenido diferencias estadísticamente significativas en función del número de hijos de los pacientes ni antes $(\mathrm{t}=-1,49 ; \mathrm{p}=, 146)$ ni después $(t=-0,43 ; p=, 669)$ del ingreso en UCI (véase Tabla 26), aunque sin ser significativas, se observan puntuaciones medias ligeramente mayores en los pacientes con hijos tanto antes como después del ingreso.

Tabla 26. Análisis diferencial en función del número de hijos en la calidad de vida (CV) de los pacientes

\begin{tabular}{|c|c|c|c|c|c|}
\hline Ítem & $\begin{array}{l}\text { Número de } \\
\text { hijos }\end{array}$ & $\bar{X}$ & DT & $\mathbf{t}$ & $\begin{array}{c}\text { Sig. } \\
p \leq, 050\end{array}$ \\
\hline \multirow[t]{2}{*}{ 1. Puntuación total en CV previa al ingreso } & Sin hijos & 5,40 & 0,55 & $-1,49$ & 146 \\
\hline & Con hijos & 6,88 & 2,18 & & \\
\hline \multirow[t]{2}{*}{ 2. Puntuación total en $\mathrm{CV}$ después del ingreso } & Sin hijos & 11,20 & 3,03 & $-0,43$ & 669 \\
\hline & Con hijos & 11,65 & 1,98 & & \\
\hline
\end{tabular}


Al analizar la valoración diferencial de los distintos factores implicados en el proceso de morir que contempla el CAMP (véase Tabla 27) no se han obtenido diferencias estadísticamente significativas en función del número de hijos de los pacientes. No obstante, aun sin llegar a la significación estadística cabe señalar que los pacientes con hijos parecen valorar más aspectos relacionales como "poder estar cerca y estrechar vínculos afectivos con las personas queridas" ( $\bar{X}=3,25$ vs $\bar{X}=3)$, que "su muerte no sea una carga insoportable para los demás" ( $\bar{X}=3,20$ vs $\bar{X}=2,67)$, así como otros factores relativos a "pensar que su vida ha tenido algún sentido" $(\overline{\mathrm{X}}=2,95$ vs $\bar{X}=2,33)$, "no alargar artificialmente la vida en una UCI" ( $\bar{X}=2,30$ vs $\bar{X}=1,33)$ y "pensar que pudieran controlar hasta el final los pensamientos y las funciones fisiológicas" $(\overline{\mathrm{X}}=2,65$ vs $\overline{\mathrm{X}}=1)$, siendo este último aspecto el que estaría más próximo a la significación estadística $(\mathrm{t}=-1,83 ; \mathrm{p}=, 082)$. Por el contrario, las puntuaciones de los pacientes sin hijos han sido ligeramente mayores en factores como "el control del dolor y los síntomas de malestar" ( $\overline{\mathrm{X}}=4$ vs $\overline{\mathrm{X}}=3,70)$, pensar que pudieran "disponer de ayuda para morir con rapidez si la situación se hiciera insoportable" $(\bar{X}=3,67$ vs $\bar{X}=2,80)$ y "no sentirse culpable por conflictos personales del pasado" ( $\overline{\mathrm{X}}=2,67$ vs $\overline{\mathrm{X}}=2,10)$.

Tabla 27. Análisis diferencial en función del número de hijos de los distintos factores del Cuestionario de Ayuda a Morir en Paz (CAMP) (pacientes)

\begin{tabular}{|c|c|c|c|c|c|}
\hline Ítem & $\begin{array}{l}\text { Número de } \\
\text { hijos }\end{array}$ & $\bar{X}$ & DT & $\mathbf{t}$ & $\begin{array}{l}\text { Sig. } \\
p \leq, 050\end{array}$ \\
\hline \multirow[t]{2}{*}{ 1. Controlar mi dolor y otros síntomas de malestar } & Sin hijos & 4 & 0 & 0,69 & ,495 \\
\hline & Con hijos & 3,70 & 0,73 & & \\
\hline \multirow[t]{2}{*}{ 2. Mi proceso de morir, si produce sufrimiento, será corto } & Sin hijos & 3,33 & 1,15 & $-0,12$ & 907 \\
\hline & Con hijos & 3,40 & 0,88 & & \\
\hline \multirow[t]{2}{*}{ 3.Controlar hasta el final pensamientos y funciones fisiológicas } & Sin hijos & 1 & 1,73 & $-1,83$ & ,082 \\
\hline & Con hijos & 2,65 & 1,42 & & \\
\hline \multirow{2}{*}{$\begin{array}{l}\text { 4. Mi muerte no supondrá una carga insoportable para mis } \\
\text { seres queridos }\end{array}$} & Sin hijos & 2,67 & 2,31 & $-0,69$ & ,492 \\
\hline & Con hijos & 3,20 & 1,06 & & \\
\hline \multirow{2}{*}{$\begin{array}{l}\text { 5. Poder sentirme cerca, comunicarme y estrechar vínculos } \\
\text { afectivos con mis personas queridas }\end{array}$} & Sin hijos & 3 & 1,73 & $-0,38$ & ,708 \\
\hline & Con hijos & 3,25 & 0,97 & & \\
\hline \multirow{2}{*}{$\begin{array}{l}\text { 6. Sin esperanza real de recuperación, no se alargará } \\
\text { artificialmente mi vida en } \mathrm{UCl}\end{array}$} & Sin hijos & 1,33 & 2,31 & $-0,89$ & ,384 \\
\hline & Con hijos & 2,30 & 1,69 & & \\
\hline \multirow[t]{2}{*}{ 7. Pensar que mi vida ha tenido algún sentido } & Sin hijos & 2,33 & 0,58 & $-1,47$ & 156 \\
\hline & Con hijos & 2,95 & 0,69 & & \\
\hline \multirow[t]{2}{*}{ 8. Creer en otra vida después de la muerte } & Sin hijos & 1,67 & 1,53 & $-0,02$ & ,987 \\
\hline & Con hijos & 1,68 & 1,73 & & \\
\hline \multirow[t]{2}{*}{ 9. No sentirse culpable por conflictos personales del pasado } & Sin hijos & 2,67 & 0,58 & 0,81 & ,424 \\
\hline & Con hijos & 2,10 & 1,16 & & \\
\hline \multirow{2}{*}{$\begin{array}{l}\text { 10. Si la situación se me hace insoportable disponer de ayuda } \\
\text { para morir con rapidez }\end{array}$} & Sin hijos & 3,67 & 0,58 & 0,97 & ,344 \\
\hline & Con hijos & 2,80 & 1,51 & & \\
\hline \multirow[t]{2}{*}{ 11. Poder morir en mi casa } & Sin hijos & 1 & 1,73 & 0,17 & ,863 \\
\hline & Con hijos & 0,85 & 1,35 & & \\
\hline
\end{tabular}


Por lo que respecta al proceso de información y toma de decisiones (véase Tabla 28) sí que se han obtenido diferencias significativas a nivel estadístico en el papel que se concede al paciente en el proceso de información y toma de decisiones $(\mathrm{t}=-2,94$; $p=, 019)$ siendo este aspecto más importante para los pacientes con hijos. En el resto de subescalas analizadas, si bien las diferencias no llegan a la significación podemos observar que los pacientes con hijos valoran ligeramente más el papel del psicólogo en el proceso $(\overline{\mathrm{X}}=2,60$ vs $\overline{\mathrm{X}}=2,50)$, se muestran ligeramente más satisfechos con la información $(\overline{\mathrm{X}}=5$ vs $\overline{\mathrm{X}}=3)$ y a la hora de ser informados prefieren un estilo médico más directo y que anticipe posibles sospechas $(\bar{X}=1,70$ vs $\bar{X}=0)$. En la subescala relativa a la participación en decisiones médicas relevantes son los pacientes sin hijos quienes parecen sentirse más capacitados para participar en ellas $(\bar{X}=3$ vs $\bar{X}=2,10)$, mientras que no se ha obtenido diferencia alguna en cuanto al hecho de percibir la participación como carga o privilegio $(\mathrm{t}=0 ; \mathrm{p}=1)$, tal como se observa en la Tabla 28.

Tabla 28. Análisis diferencial en función del número de hijos del proceso de información y toma de decisiones de los pacientes

\begin{tabular}{|c|c|c|c|c|c|}
\hline CITD & $\begin{array}{l}\text { Número de } \\
\text { hijos }\end{array}$ & $\bar{X}$ & DT & $\mathbf{t}$ & $\begin{array}{l}\text { Sig. } \\
p \leq, 050\end{array}$ \\
\hline \multicolumn{6}{|l|}{ Importancia de los distintos agentes implicados } \\
\hline \multirow[t]{2}{*}{ Papel de la familia en la información y toma de decisiones } & Sin hijos & 17 & - & 1,38 & 204 \\
\hline & Con hijos & 9,67 & 5,02 & & \\
\hline \multirow[t]{2}{*}{ Papel del paciente en la información y toma de decisiones } & Sin hijos & 8 & - & $-2,94$ & 019 \\
\hline & Con hijos & 17,4 & 3,05 & & \\
\hline \multirow[t]{2}{*}{ Papel del médico en la información y toma de decisiones } & Sin hijos & 5 & - & 0,38 & ,716 \\
\hline & Con hijos & 4,50 & 1,27 & & \\
\hline \multirow[t]{2}{*}{ Papel del psicólogo en la información y toma de decisiones } & Sin hijos & 2,50 & 0,71 & $-0,18$ & ,857 \\
\hline & Con hijos & 2,60 & 0,69 & & \\
\hline \multicolumn{6}{|l|}{ Satisfacción con la información } \\
\hline \multirow{2}{*}{$\begin{array}{l}\text { Satisfacción con la cantidad y la claridad de la información } \\
\text { recibida }\end{array}$} & Sin hijos & 3 & 4,24 & $-1,05$ & ,317 \\
\hline & Con hijos & 5 & 2,16 & & \\
\hline \multicolumn{6}{|l|}{ Estilo del médico } \\
\hline \multirow{2}{*}{$\begin{array}{l}\text { En cuanto al estilo del médico prefiero que éste sea directo y } \\
\text { anticipe posibles sospechas }\end{array}$} & Sin hijos & 0 & 0 & $-1,73$ & 114 \\
\hline & Con hijos & 1,70 & 1,34 & & \\
\hline \multirow{2}{*}{$\begin{array}{l}\text { En cuanto al estilo del médico prefiero que éste se guarde lo } \\
\text { que aún no es seguro }\end{array}$} & Sin hijos & 3 & 0 & 1,26 & ,234 \\
\hline & Con hijos & 1,60 & 1,50 & & \\
\hline \multicolumn{6}{|l|}{ Participación en TD } \\
\hline \multirow[t]{2}{*}{ Me siento capacitado para participar en la TD sobre la salud } & Sin hijos & 3 & 0 & 1,02 & ,330 \\
\hline & Con hijos & 2,10 & 1,19 & & \\
\hline \multirow{2}{*}{$\begin{array}{l}\text { Poder participar en una decisión médica sería más una carga } \\
\text { que un privilegio }\end{array}$} & Sin hijos & 1 & 1,41 & 0 & 1 \\
\hline & Con hijos & 1 & 1,25 & & \\
\hline
\end{tabular}




\subsubsection{Análisis diferenciales en función de la patología de ingreso}

Se han realizado análisis diferenciales en función de la patología que motivó el ingreso en UCI, concretamente análisis ANOVA de un factor, para conocer si la afectación emocional de los pacientes así como su valoración sobre distintos aspectos implicados en estas unidades podría estar modulado por la patología presente.

En relación con las puntuaciones obtenidas en ansiedad, depresión y percepción subjetiva de estado de ánimo, si bien no se han obtenido diferencias estadísticamente significativas en función de la patología podemos observar en la Tabla 29 que las mayores puntuaciones en ansiedad corresponden a los pacientes neuroquirúrgicos (HADS) y con traumatismos, especialmente cuando no hay afectación del sistema nervioso central (STAI-Estado) y en depresión (HADS y BDI) corresponden a pacientes neuroquirúrgicos. En cuanto a la percepción subjetiva de malestar son los pacientes neuroquirúrgicos quienes puntúan más alto en las tres subescalas aun sin alcanzar la significación (véase Tabla 29).

Tabla 29. Análisis diferencial en función de la patología de la ansiedad, depresión y percepción de estado de ánimo (pacientes)

\begin{tabular}{|c|c|c|c|c|c|}
\hline Ítem & Patología & $\bar{X}$ & DT & $\mathbf{F}$ & $\begin{array}{c}\text { Sig. } \\
p \leq, 050\end{array}$ \\
\hline \multirow[t]{7}{*}{ Total HADS Ansiedad } & Coronario & 6,63 & 5,99 & 0,92 & ,488 \\
\hline & Enfermedad médica & 6,07 & 3,89 & & \\
\hline & Neuroquirúrgico & 14 & 4,24 & & \\
\hline & Séptico & 6,28 & 4,39 & & \\
\hline & Respiratorio & 6,43 & 5,99 & & \\
\hline & Traumatismos SNC & 9,50 & 3,42 & & \\
\hline & Traumatismo sin SNC & 8,29 & 5,99 & & \\
\hline \multirow[t]{7}{*}{ Total HADS Depresión } & Coronario & 7,78 & 6,91 & 1,87 & 100 \\
\hline & Enfermedad médica & 2,79 & 2,15 & & \\
\hline & Neuroquirúrgico & 11 & 9,89 & & \\
\hline & Séptico & 8,43 & 5,35 & & \\
\hline & Respiratorio & 7 & 5,16 & & \\
\hline & Traumatismos SNC & 6,50 & 4,51 & & \\
\hline & Traumatismo sin SNC & 9,29 & 4,11 & & \\
\hline \multirow[t]{7}{*}{ STAI-Estado } & Coronario & 16,10 & 12,04 & 0,39 & 876 \\
\hline & Enfermedad médica & 12,50 & 4,42 & & \\
\hline & Neuroquirúrgico & 18 & - & & \\
\hline & Séptico & 17,50 & 5,92 & & \\
\hline & Respiratorio & 19,50 & 12,85 & & \\
\hline & Traumatismos SNC & 20 & 13,29 & & \\
\hline & Traumatismo sin SNC & 21,43 & 16,29 & & \\
\hline
\end{tabular}




\begin{tabular}{|c|c|c|c|c|c|}
\hline Ítem & Patología & $\bar{X}$ & DT & $\mathbf{F}$ & $\begin{array}{c}\text { Sig. } \\
p \leq, 050\end{array}$ \\
\hline \multirow[t]{7}{*}{ STAI-Rasgo } & Coronario & 15,26 & 11,12 & 0,47 & 828 \\
\hline & Enfermedad médica & 10,17 & 4,31 & & \\
\hline & Neuroquirúrgico & 5 & - & & \\
\hline & Séptico & 13,50 & 8,43 & & \\
\hline & Respiratorio & 17 & 13,87 & & \\
\hline & Traumatismos SNC & 10,75 & 7,54 & & \\
\hline & Traumatismo sin SNC & 15,14 & 10,69 & & \\
\hline \multirow[t]{7}{*}{ BDI } & Coronario & 13,11 & 9,63 & 1,76 & 134 \\
\hline & Enfermedad médica & 4,17 & 2,40 & & \\
\hline & Neuroquirúrgico & 26 & - & & \\
\hline & Séptico & 15 & 8,45 & & \\
\hline & Respiratorio & 17 & 6,87 & & \\
\hline & Traumatismos SNC & 8,25 & 6,85 & & \\
\hline & Traumatismo sin SNC & 16,71 & 14,54 & & \\
\hline \multirow[t]{7}{*}{ EA1- Malestar general } & Coronario & 3,69 & 2,68 & 0,91 & ,491 \\
\hline & Enfermedad médica & 4,23 & 3,14 & & \\
\hline & Neuroquirúrgico & 8 & 1,41 & & \\
\hline & Séptico & 5,29 & 2,98 & & \\
\hline & Respiratorio & 4,43 & 3,59 & & \\
\hline & Traumatismos SNC & 5 & 2,16 & & \\
\hline & Traumatismo sin SNC & 3,71 & 3,49 & & \\
\hline \multirow[t]{7}{*}{ EA2- Ansiedad y Nerviosismo } & Coronario & 2,19 & 2,84 & 1,70 & 137 \\
\hline & Enfermedad médica & 2,08 & 2,29 & & \\
\hline & Neuroquirúrgico & 8 & 1,41 & & \\
\hline & Séptico & 3,86 & 2,16 & & \\
\hline & Respiratorio & 3,29 & 3,73 & & \\
\hline & Traumatismos SNC & 3,75 & 3,50 & & \\
\hline & Traumatismo sin SNC & 3,43 & 3,73 & & \\
\hline \multirow[t]{7}{*}{ EA3- Estado de Ánimo Deprimido } & Coronario & 1,73 & 2,36 & 1,39 & ,230 \\
\hline & Enfermedad médica & 1,38 & 2,33 & & \\
\hline & Neuroquirúrgico & 6 & 2,83 & & \\
\hline & Séptico & 4 & 3,87 & & \\
\hline & Respiratorio & 2,43 & 3,21 & & \\
\hline & Traumatismos SNC & 2,25 & 2,87 & & \\
\hline & Traumatismos sin SNC & 2,43 & 3,64 & & \\
\hline
\end{tabular}

Al analizar la valoración de la estancia en UCI en función de la patología de ingreso no se han obtenido diferencias estadísticamente significativas en ninguno de los aspectos considerados, aunque cabe señalar que en la valoración global de la estancia estas diferencias rozan la significación estadística $(F=2,24 ; p=, 053)$ siendo los pacientes coronarios quienes presentan mayores puntuaciones (véase Tabla 30).

$\mathrm{Al}$ analizar los distintos aspectos recogidos en el cuestionario de valoración de la estancia en UCI, podemos apreciar que en la mayoría, los grupos de diagnóstico que presentan puntuaciones más elevadas han sido el de los pacientes neuroquirúrgicos, 
pacientes con traumatismos que afectan el SNC y los pacientes con enfermedad médica previa, aun estando lejos de alcanzar la significación estadística.

Tabla 30. Análisis diferencial en función de la patología de la valoración de la estancia en UCI (pacientes)

\begin{tabular}{|c|c|c|c|c|c|}
\hline Ítem & Patología & $\bar{X}$ & DT & $\mathbf{F}$ & $\begin{array}{l}\text { Sig. } \\
p \leq, 050\end{array}$ \\
\hline \multirow{7}{*}{$\begin{array}{l}\text { En qué grado está siendo } \\
\text { agradable/desagradable su estancia en } \mathrm{UCl} \text { sin } \\
\text { considerar los problemas médicos. }\end{array}$} & \multirow{3}{*}{$\begin{array}{l}\text { Coronario } \\
\text { Enfermedad médica } \\
\text { Neuroquirúrgico }\end{array}$} & 4,48 & 0,66 & \multirow[t]{7}{*}{2,24} & \multirow[t]{7}{*}{,053 } \\
\hline & & 4,08 & 1,24 & & \\
\hline & & 2,50 & 3,53 & & \\
\hline & Séptico & 3,71 & 1,25 & & \\
\hline & Respiratorio & 4,29 & 1,11 & & \\
\hline & Traumatismos SNC & 2,33 & 2,08 & & \\
\hline & Traumatismo sin SNC & 4 & 1,41 & & \\
\hline \multirow[t]{2}{*}{ Valoración de los siguientes aspectos } & \multirow[t]{2}{*}{ Patología } & \multirow[t]{2}{*}{$\bar{X}$} & \multirow[t]{2}{*}{ DT } & \multirow[t]{2}{*}{ F } & Sig. \\
\hline & & & & & $p \leq, 050$ \\
\hline \multirow[t]{7}{*}{ 1. Cuidados médicos } & Coronario & 4,69 & 0,56 & \multirow[t]{7}{*}{1,21} & \multirow[t]{7}{*}{,314 } \\
\hline & Enfermedad médica & 4,83 & 0,39 & & \\
\hline & Neuroquirúrgico & 4,50 & 0,71 & & \\
\hline & Séptico & 4,57 & 0,53 & & \\
\hline & Respiratorio & 4,71 & 0,49 & & \\
\hline & Traumatismos SNC & 5 & 0 & & \\
\hline & Traumatismo sin SNC & 4,29 & 0,49 & & \\
\hline \multirow[t]{7}{*}{ 2. Atención de los médicos } & Coronario & 4,74 & 0,54 & \multirow[t]{7}{*}{0,24} & \multirow[t]{7}{*}{,961 } \\
\hline & Enfermedad médica & 4,83 & 0,39 & & \\
\hline & Neuroquirúrgico & 4,50 & 0,71 & & \\
\hline & Séptico & 4,71 & 0,49 & & \\
\hline & Respiratorio & 4,71 & 0,76 & & \\
\hline & Traumatismos SNC & 4,67 & 0,58 & & \\
\hline & Traumatismo sin SNC & 4,57 & 0,53 & & \\
\hline \multirow[t]{7}{*}{ 3. Atención de las/os enfermeras/os } & Coronario & 4,78 & 0,52 & \multirow[t]{7}{*}{0,62} & \multirow[t]{7}{*}{,716 } \\
\hline & Enfermedad médica & 4,75 & 0,62 & & \\
\hline & Neuroquirúrgico & 5 & 0 & & \\
\hline & Séptico & 4,71 & 0,49 & & \\
\hline & Respiratorio & 4,29 & 1,49 & & \\
\hline & Traumatismos SNC & 5 & 0 & & \\
\hline & Traumatismo sin SNC & 4,71 & 0,49 & & \\
\hline \multirow[t]{7}{*}{ 4. Atención de las/os auxiliares de enfermería } & Coronario & 4,74 & 0,54 & \multirow[t]{7}{*}{0,43} & \multirow[t]{7}{*}{855} \\
\hline & Enfermedad médica & 4,75 & 0,62 & & \\
\hline & Neuroquirúrgico & 5 & 0 & & \\
\hline & Séptico & 4,57 & 0,53 & & \\
\hline & Respiratorio & 4,43 & 1,51 & & \\
\hline & Traumatismos SNC & 5 & 0 & & \\
\hline & Traumatismo sin SNC & 4,86 & 0,38 & & \\
\hline \multirow[t]{7}{*}{ 5. Claridad de la información recibida } & Coronario & 4,50 & 0,80 & \multirow[t]{7}{*}{1,38} & \multirow[t]{7}{*}{,240 } \\
\hline & Enfermedad médica & 4,75 & 0,62 & & \\
\hline & Neuroquirúrgico & 5 & 0 & & \\
\hline & Séptico & 3,71 & 1,49 & & \\
\hline & Respiratorio & 4,14 & 0,89 & & \\
\hline & Traumatismos SNC & 4,33 & 0,58 & & \\
\hline & Traumatismo sin SNC & 4,29 & 0,76 & & \\
\hline
\end{tabular}


(Continuación Tabla 30)

\begin{tabular}{|c|c|c|c|c|c|}
\hline Valoración de los siguientes aspectos & Patología & $\bar{X}$ & DT & $\mathbf{F}$ & $\begin{array}{c}\text { Sig. } \\
p \leq, 050\end{array}$ \\
\hline \multirow[t]{7}{*}{ 6. Cantidad de la información recibida } & Coronario & 4,36 & 0,85 & 0,68 & 667 \\
\hline & Enfermedad médica & 4,58 & 0,79 & & \\
\hline & Neuroquirúrgico & 4,50 & 0,71 & & \\
\hline & Séptico & 3,86 & 1,57 & & \\
\hline & Respiratorio & 4,14 & 0,89 & & \\
\hline & Traumatismos SNC & 3,67 & 1,53 & & \\
\hline & Traumatismo $\sin$ SNC & 4,29 & 0,76 & & \\
\hline \multirow[t]{7}{*}{ 7. Trato por parte del personal de enfermería } & Coronario & 4,74 & 0,54 & 0,19 & ,978 \\
\hline & Enfermedad médica & 4,75 & 0,45 & & \\
\hline & Neuroquirúrgico & 5 & 0 & & \\
\hline & Séptico & 4,71 & 0,49 & & \\
\hline & Respiratorio & 4,57 & 0,79 & & \\
\hline & Traumatismos SNC & 4,67 & 0,58 & & \\
\hline & Traumatismo sin SNC & 4,71 & 0,49 & & \\
\hline \multirow{7}{*}{$\begin{array}{l}\text { 8. Afecto/apoyo emocional del personal de } \\
\text { enfermería }\end{array}$} & Coronario & 4,48 & 0,67 & 0,77 &, 595 \\
\hline & Enfermedad médica & 4,75 & 0,62 & & \\
\hline & Neuroquirúrgico & 5 & 0 & & \\
\hline & Séptico & 4,71 & 0,49 & & \\
\hline & Respiratorio & 4 & 1,82 & & \\
\hline & Traumatismos SNC & 4,67 & 0,58 & & \\
\hline & Traumatismo $\sin$ SNC & 4,43 & 0,79 & & \\
\hline \multirow[t]{7}{*}{ 9. Respeto a la intimidad } & Coronario & 4,48 & 0,79 & 0,81 &, 564 \\
\hline & Enfermedad médica & 4,58 & 0,51 & & \\
\hline & Neuroquirúrgico & 5 & 0 & & \\
\hline & Séptico & 4,14 & 1,07 & & \\
\hline & Respiratorio & 4,29 & 0,49 & & \\
\hline & Traumatismos SNC & 5 & 0 & & \\
\hline & Traumatismo sin SNC & 4,57 & 0,79 & & \\
\hline \multirow[t]{7}{*}{ 10. Atención a los familiares } & Coronario & 4,50 & 0,67 & 1,26 & 291 \\
\hline & Enfermedad médica & 4,83 & 0,39 & & \\
\hline & Neuroquirúrgico & 5 & 0 & & \\
\hline & Séptico & 4,86 & 0,38 & & \\
\hline & Respiratorio & 4,43 & 0,53 & & \\
\hline & Traumatismos SNC & 5 & 0 & & \\
\hline & Traumatismo sin SNC & 4,71 & 0,49 & & \\
\hline \multirow{7}{*}{$\begin{array}{l}\text { 11. Atención de necesidades psicológicas en } \\
\text { paciente y familia }\end{array}$} & Coronario & 4,61 & 0,58 & 0,98 & ,450 \\
\hline & Enfermedad médica & 4,72 & 0,90 & & \\
\hline & Neuroquirúrgico & 5 & - & & \\
\hline & Séptico & 4,43 & 0,53 & & \\
\hline & Respiratorio & 4,17 & 0,75 & & \\
\hline & Traumatismos SNC & 5 & 0 & & \\
\hline & Traumatismo sin SNC & 4,83 & 0,41 & & \\
\hline \multirow{7}{*}{$\begin{array}{l}\text { 12. Calidad de las instalaciones (comodidad, } \\
\text { higiene...) }\end{array}$} & Coronario & 4,30 & 0,97 & 0,68 & ,668 \\
\hline & Enfermedad médica & 4,50 & 0,52 & & \\
\hline & Neuroquirúrgico & 5 & 0 & & \\
\hline & Séptico & 4,43 & 0,53 & & \\
\hline & Respiratorio & 4 & 0,58 & & \\
\hline & Traumatismos SNC & 4,67 & 0,58 & & \\
\hline & Traumatismo sin SNC & 4,29 & 0,76 & & \\
\hline
\end{tabular}

(Sigue detrás) 


\begin{tabular}{|c|c|c|c|c|c|}
\hline Valoración de los siguientes aspectos & Patología & $\bar{X}$ & DT & $\mathrm{F}$ & $\begin{array}{c}\text { Sig. } \\
\mathrm{p} \leq, 050\end{array}$ \\
\hline \multirow[t]{7}{*}{ 13. Posibilidades de distraerse } & Coronario & 2,86 & 1,46 & 1,11 & ,370 \\
\hline & Enfermedad médica & 2,10 & 1,59 & & \\
\hline & Neuroquirúrgico & 2 & 0 & & \\
\hline & Séptico & 1,86 & 1,07 & & \\
\hline & Respiratorio & 1,86 & 1,07 & & \\
\hline & Traumatismos SNC & 2 & 1 & & \\
\hline & Traumatismo $\sin$ SNC & 3 & 1,55 & & \\
\hline \multirow[t]{7}{*}{ 14. Silencio o tranquilidad en la sala } & Coronario & 3,39 & 1,12 & 1,56 & 177 \\
\hline & Enfermedad médica & 3,58 & 1,08 & & \\
\hline & Neuroquirúrgico & 2,50 & 2,12 & & \\
\hline & Séptico & 2,86 & 0,89 & & \\
\hline & Respiratorio & 2,29 & 1,25 & & \\
\hline & Traumatismos SNC & 2,33 & 1,15 & & \\
\hline & Traumatismo $\sin$ SNC & 3 & 1,26 & & \\
\hline \multirow[t]{7}{*}{ 15. Régimen de visitas } & Coronario & 3,74 & 0,91 & 0,64 & ,701 \\
\hline & Enfermedad médica & 3,83 & 1,11 & & \\
\hline & Neuroquirúrgico & 2,50 & 0,71 & & \\
\hline & Séptico & 3,57 & 1,13 & & \\
\hline & Respiratorio & 3,29 & 1,60 & & \\
\hline & Traumatismos SNC & 3,67 & 0,58 & & \\
\hline & Traumatismo sin SNC & 3,71 & 0,76 & & \\
\hline
\end{tabular}

En cuanto a la escala de factores estresantes asociados a una UCI se han obtenido diferencias estadísticamente significativas en función de la patología de ingreso. Tal como se observa en la Tabla 31, estas diferencias se muestran en el "nivel de estrés en general" $(\mathrm{F}=2,67 ; \mathrm{p}=, 025)$ y en los siguientes ítems: "dormir en una cama que no es la suya" $(F=2,69 ; p=, 024)$, "tener que comer en la cama en una postura incómoda" $(F=2,78 ; p=, 020)$, "tener demasiadas visitas" $(F=3,16 ; p=, 011)$, "tener que estar todo el tiempo desnudo, cubierto con una sábana" (F=2,70; $\mathrm{p}=, 023)$, "escuchar ruidos constantes" ( $F=7,69 ; p=, 000)$, "luces todo el día encendidas" ( $F=13,06 ; p=, 000)$, "no saber en qué consiste la enfermedad" ( $F=3,39 ; \mathrm{p}=, 008)$, "no saber cuándo le darán el alta de $\mathrm{UCI}^{\prime}(\mathrm{F}=4,04 ; \mathrm{p}=, 002)$, "pensar que pueda tener dolor por operación/pruebas" $(F=2,86 ; p=, 020)$, "no saber cuándo van a hacerle cosas" $(F=2,68 ; p=, 026)$, "que los sanitarios hablen rápido o usen palabras que no puedan entender" $(F=2,65 ; p=, 029)$, "que no le den la medicación para el dolor cuando lo necesite" ( $F=3,52 ; p=, 009)$, "sentir olores extraños en el hospital" $(\mathrm{F}=2,54 ; \mathrm{p}=, 031)$ y "comer a horas diferentes a las habituales" ( $F=12,49 ; \mathrm{p}=, 000)$.

Profundizando en el análisis de estas diferencias se han llevado a cabo comparaciones por parejas (prueba Scheffé) las cuales han mostrado que algunas medias difieren significativamente. Tal es el caso del ítem 16 "escuchar ruidos 
constantes" $(F=7,69 ; p=, 000)$ que ha resultado ser más estresante en los pacientes sépticos frente a los pacientes coronarios. Respecto al ítem 17 "luces todo el día encendidas" ( $F=13,06 ; \mathrm{p}=, 000)$ los resultados indican que este factor ha sido más estresante para los pacientes neuroquirúrgicos y sépticos frente a los coronarios y aquellos con enfermedad médica previa. Igualmente, este factor ha generado más estrés en los pacientes respiratorios frente a los coronarios así como también ha generado más estrés en los pacientes sépticos frente a los que padecían traumatismos con afectación del SNC. Otro de los factores en el que las medias difieren significativamente ha sido el ítem 21 "no saber en qué consiste la enfermedad" ( $F=3,39$; $p=, 008)$ obteniéndose mayores puntuaciones en los pacientes sépticos frente a los coronarios. Y finalmente, en el ítem 39 "comer a horas diferentes a las habituales" $(\mathrm{F}=12,49 ; \mathrm{p}=, 000)$ han sido los pacientes neuroquirúrgicos quienes han puntuado más alto frente al resto de patologías. Asimismo, este factor ha generado más estrés en los pacientes con traumatismos sin afectación del SNC frente a los pacientes coronarios.

En la Tabla 31, a pesar de la ingente cantidad de datos, mostraremos el análisis diferencial según la patología de ingreso de todos los factores estresantes contemplados en el cuestionario, puesto que creemos que esta información puede ser relevante a nivel clínico.

Tabla 31. Análisis diferencial en función de la patología de los distintos Factores estresantes de UCI (pacientes)

\begin{tabular}{|c|c|c|c|c|c|c|}
\hline Ítem & Patología & $\bar{X}$ & DT & $\mathbf{F}$ & $\begin{array}{c}\text { Sig. } \\
\text { p } \leq, 050\end{array}$ & Prueba Scheffé \\
\hline \multirow{7}{*}{$\begin{array}{l}\text { 1.No disponer de baño } \\
\text { en el box }\end{array}$} & Coronario & 1,68 & 1,57 & 0,56 & 756 & \\
\hline & Enfermedad médica & 1 & 1,63 & & & \\
\hline & Neuroquirúrgico & 1 & 1,41 & & & \\
\hline & Séptico & 2,14 & 1,86 & & & \\
\hline & Respiratorio & 2,17 & 1,72 & & & \\
\hline & Traumatismo SNC & 2 & 2 & & & \\
\hline & Traumatismo sin SNC & 1,29 & 1,89 & & & \\
\hline \multirow{7}{*}{$\begin{array}{l}\text { 2.Tener que estar en la } \\
\text { cama/sillón todo el día }\end{array}$} & Coronario & 2,20 & 1,47 & 0,48 & ,817 & \\
\hline & Enfermedad médica & 2 & 1,41 & & & \\
\hline & Neuroquirúrgico & 3,50 & 0,71 & & & \\
\hline & Séptico & 2,71 & 1,70 & & & \\
\hline & Respiratorio & 2,50 & 1,64 & & & \\
\hline & Traumatismo SNC & 2,67 & 0,58 & & & \\
\hline & Traumatismo sin SNC & 2,57 & 1,27 & & & \\
\hline
\end{tabular}


(Continuación Tabla 31)

\begin{tabular}{|c|c|c|c|c|c|c|}
\hline Ítem & Patología & $\bar{X}$ & DT & $\mathbf{F}$ & $\begin{array}{c}\text { Sig. } \\
p \leq, 050\end{array}$ & Prueba Scheffé \\
\hline \multirow{7}{*}{$\begin{array}{l}\text { 3.Estar hospitalizado } \\
\text { lejos de casa }\end{array}$} & Coronario & 0,76 & 1,26 & 1,99 & 087 & \\
\hline & Enfermedad médica & 0,56 & 0,73 & & & \\
\hline & Neuroquirúrgico & 2 & 2,83 & & & \\
\hline & Séptico & 2,40 & 2,19 & & & \\
\hline & Respiratorio & 0,67 & 1,21 & & & \\
\hline & Traumatismo SNC & 2,33 & 2,08 & & & \\
\hline & Traumatismo $\sin$ SNC & 0,57 & 0,98 & & & \\
\hline \multirow{7}{*}{$\begin{array}{l}\text { 4. Dormir en una cama } \\
\text { que no es la suya. }\end{array}$} & Coronario & 1,12 & 1,57 & 2,69 & 024 & \\
\hline & Enfermedad médica & 0,70 & 1,06 & & & \\
\hline & Neuroquirúrgico & 2 & 1,41 & & & \\
\hline & Séptico & 2,86 & 1,68 & & & \\
\hline & Respiratorio & 0,67 & 1,21 & & & \\
\hline & Traumatismos SNC & 2,33 & 2,08 & & & \\
\hline & Traumatismo sin SNC & 0,33 & 0,82 & & & \\
\hline \multirow{7}{*}{$\begin{array}{l}\text { 5.Utilizar la cuña de } \\
\text { cama }\end{array}$} & Coronario & 2,48 & 1,61 & 1,52 & 190 & \\
\hline & Enfermedad médica & 1,30 & 1,77 & & & \\
\hline & Neuroquirúrgico & 4 & - & & & \\
\hline & Séptico & 3 & 1,26 & & & \\
\hline & Respiratorio & 2,80 & 1,64 & & & \\
\hline & Traumatismo SNC & 2 & 2 & & & \\
\hline & Traumatismo sin SNC & 1,43 & 1,27 & & & \\
\hline \multirow{7}{*}{$\begin{array}{l}\text { 6.Que no respondan al } \\
\text { timbre de aviso }\end{array}$} & Coronario & 0,83 & 1,33 & 0,41 & 864 & \\
\hline & Enfermedad médica & 1,33 & 1,37 & & & \\
\hline & Neuroquirúrgico & 2 & 2,83 & & & \\
\hline & Séptico & 2 & 1,67 & & & \\
\hline & Respiratorio & 2 & 2 & & & \\
\hline & Traumatismo SNC & 1 & - & & & \\
\hline & Traumatismo sin SNC & 1,60 & 1,14 & & & \\
\hline \multirow{7}{*}{$\begin{array}{l}\text { 7.Dormir junto a otros } \\
\text { enfermos en la unidad }\end{array}$} & Coronario & 0,32 & 0,69 & 1,61 & 163 & \\
\hline & Enfermedad médica & 0,50 & 0,97 & & & \\
\hline & Neuroquirúrgico & 1,50 & 2,12 & & & \\
\hline & Séptico & 1 & 1,15 & & & \\
\hline & Respiratorio & 0,17 & 0,41 & & & \\
\hline & Traumatismo SNC & 1,67 & 1,53 & & & \\
\hline & Traumatismo $\sin$ SNC & 0,71 & 1,49 & & & \\
\hline \multirow{7}{*}{$\begin{array}{l}\text { 8.Tener que ser } \\
\text { ayudado para ir al } \\
\text { baño }\end{array}$} & Coronario & 2,21 & 1,58 & 0,69 & 655 & \\
\hline & Enfermedad médica & 0,86 & 1,21 & & & \\
\hline & Neuroquirúrgico & 1,50 & 0,71 & & & \\
\hline & Séptico & 2,00 & 1,58 & & & \\
\hline & Respiratorio & 1,50 & 1,76 & & & \\
\hline & Traumatismo SNC & 2,00 & 2,00 & & & \\
\hline & Traumatismo $\sin \mathrm{SNC}$ & 1,83 & 1,72 & & & \\
\hline \multirow{7}{*}{$\begin{array}{l}\text { 9.Tener que comer en } \\
\text { la cama en una postura } \\
\text { incómoda }\end{array}$} & Coronario & 1,08 & 1,22 & 2,78 &, 020 & \\
\hline & Enfermedad médica & 0,67 & 1,12 & & & \\
\hline & Neuroquirúrgico & 0,50 & 0,71 & & & \\
\hline & Séptico & 2,86 & 1,07 & & & \\
\hline & Respiratorio & 1,83 & 1,33 & & & \\
\hline & Traumatismo SNC & 1,00 & 1,72 & & & \\
\hline & Traumatismo $\sin \mathrm{SNC}$ & 1,00 & 1,41 & & & \\
\hline
\end{tabular}

(Sigue detrás) 
(Continuación Tabla 31)

\begin{tabular}{|c|c|c|c|c|c|c|}
\hline Ítem & Patología & $\bar{X}$ & DT & $\mathbf{F}$ & $\begin{array}{l}\text { Sig. } \\
p \leq, 050\end{array}$ & Prueba Scheffé \\
\hline \multirow{7}{*}{$\begin{array}{l}\text { 10.Estar ingresado en } \\
\text { la unidad junto a otras } \\
\text { personas gravemente } \\
\text { enfermas }\end{array}$} & Coronario & 0,48 & 0,92 & 0,91 & ,493 & \\
\hline & Enfermedad médica & 0,60 & 0,97 & & & \\
\hline & Neuroquirúrgico & 2 & 2,82 & & & \\
\hline & Séptico & 1,17 & 1,60 & & & \\
\hline & Respiratorio & 1,17 & 0,98 & & & \\
\hline & Traumatismo SNC & 0,67 & 1,15 & & & \\
\hline & Traumatismo $\sin$ SNC & 0,86 & 1,46 & & & \\
\hline \multirow{7}{*}{$\begin{array}{l}\text { 11.Estar al cuidado de } \\
\text { sanitarios } \\
\text { desconocidos }\end{array}$} & Coronario & 0,08 & 0,28 & 1,64 & 155 & \\
\hline & Enfermedad médica & 0,1 & 0,32 & & & \\
\hline & Neuroquirúrgico & 0 & 0 & & & \\
\hline & Séptico & 0,29 & 0,76 & & & \\
\hline & Respiratorio & 0,83 & 1,33 & & & \\
\hline & Traumatismos SNC & 0 & 0 & & & \\
\hline & Traumatismo sin SNC & 0,43 & 0,79 & & & \\
\hline \multirow{7}{*}{$\begin{array}{l}\text { 12.Tener demasiadas } \\
\text { visitas }\end{array}$} & Coronario & 0,41 & 0,79 & 3,16 & ,011 & \\
\hline & Enfermedad médica & 0,30 & 0,67 & & & \\
\hline & Neuroquirúrgico & 0 & 0 & & & \\
\hline & Séptico & 1,83 & 1,83 & & & \\
\hline & Respiratorio & 0 & 0 & & & \\
\hline & Traumatismo SNC & 0 & 0 & & & \\
\hline & Traumatismo sin SNC & 0,33 & 0,52 & & & \\
\hline \multirow{7}{*}{$\begin{array}{l}\text { 13. Estar todo el } \\
\text { tiempo desnudo, } \\
\text { únicamente cubierto } \\
\text { con una sábana }\end{array}$} & Coronario & 0,67 & 1,20 & 2,70 & ,023 & \\
\hline & Enfermedad médica & 0,70 & 1,34 & & & \\
\hline & Neuroquirúrgico & 2 & 1,41 & & & \\
\hline & Séptico & 1,14 & 0,69 & & & \\
\hline & Respiratorio & 2,50 & 1,64 & & & \\
\hline & Traumatismo SNC & 2,67 & 2,31 & & & \\
\hline & Traumatismo $\sin$ SNC & 1 & 1,15 & & & \\
\hline \multirow{7}{*}{$\begin{array}{l}\text { 14.Necesitar ayuda } \\
\text { para comer1 }\end{array}$} & Coronario & 0,82 & 1,09 & 1,49 & ,202 & \\
\hline & Enfermedad médica & 0,56 & 0,53 & & & \\
\hline & Neuroquirúrgico & 1 & 1,41 & & & \\
\hline & Séptico & 1,71 & 1,25 & & & \\
\hline & Respiratorio & 1,83 & 1,60 & & & \\
\hline & Traumatismo SNC & 1 & 1,41 & & & \\
\hline & Traumatismo $\sin$ SNC & 1,43 & 0,98 & & & \\
\hline \multirow{7}{*}{$\begin{array}{l}\text { 15.No poder ver la TV, } \\
\text { escuchar la radio, leer } \\
\text { periódico, etc. cuando } \\
\text { uno quiere }\end{array}$} & Coronario & 0,77 & 0,87 & 1,21 & ,317 & \\
\hline & Enfermedad médica & 1,10 & 1,29 & & & \\
\hline & Neuroquirúrgico & 0,50 & 0,71 & & & \\
\hline & Séptico & 0,57 & 0,79 & & & \\
\hline & Respiratorio & 1 & 1,41 & & & \\
\hline & Traumatismo SNC & 1,33 & 1,53 & & & \\
\hline & Traumatismo $\sin$ SNC & 2 & 1,67 & & & \\
\hline \multirow{7}{*}{$\begin{array}{l}\text { 16. Escuchar ruidos } \\
\text { constantes. }\end{array}$} & Coronario & 0,24 & 0,52 & 7,69 & ,000 & Sépt> EnfMéd, Cor \\
\hline & Enfermedad médica & 0,90 & 1,19 & & & \\
\hline & Neuroquirúrgico & 3 & 1,41 & & & \\
\hline & Séptico & 3 & 1,53 & & & \\
\hline & Respiratorio & 1,5 & 1,52 & & & \\
\hline & Traumatismo SNC & 1 & 1 & & & \\
\hline & Traumatismo sin SNC & 1,14 & 1,34 & & & \\
\hline
\end{tabular}

(Sigue detrás) 
(Continuación Tabla 31)

\begin{tabular}{|c|c|c|c|c|c|c|}
\hline Ítem & Patología & $\bar{X}$ & DT & $\mathbf{F}$ & $\begin{array}{c}\text { Sig. } \\
p \leq, 050\end{array}$ & Prueba Scheffé \\
\hline \multirow{7}{*}{$\begin{array}{l}\text { 17. Luces todo el día } \\
\text { encendidas. }\end{array}$} & Coronario & 0,33 & 0,64 & \multirow[t]{7}{*}{13,06} & \multirow[t]{7}{*}{,000 } & \multirow{7}{*}{$\begin{array}{c}\text { Sépt, Neuro> } \\
\text { Cor,EnfMéd } \\
\text { Sépt }>\text { Tr SNC } \\
\text { Resp>Cor }\end{array}$} \\
\hline & Enfermedad médica & 0,22 & 0,67 & & & \\
\hline & Neuroquirúrgico & 3 & 1,41 & & & \\
\hline & Séptico & 3,29 & 0,95 & & & \\
\hline & Respiratorio & 2 & 1,41 & & & \\
\hline & Traumatismo SNC & 0,67 & 1,15 & & & \\
\hline & Traumatismo $\sin$ SNC & 1,57 & 1,39 & & & \\
\hline \multirow{7}{*}{$\begin{array}{l}\text { 18. No tener a los } \\
\text { familiares } \\
\text { acompañándolo todo } \\
\text { el día }\end{array}$} & Coronario & 1,25 & 1,19 & \multirow[t]{7}{*}{1,35} & \multirow[t]{7}{*}{,250 } & \\
\hline & Enfermedad médica & 1,90 & 1,73 & & & \\
\hline & Neuroquirúrgico & 1 & 1,41 & & & \\
\hline & Séptico & 2,86 & 1,46 & & & \\
\hline & Respiratorio & 2 & 1,79 & & & \\
\hline & Traumatismo SNC & 2 & 2 & & & \\
\hline & Traumatismo sin SNC & 2 & 1,29 & & & \\
\hline \multirow{7}{*}{$\begin{array}{l}\text { 19.Estar aislado por } \\
\text { prescripción médica }\end{array}$} & Coronario & 0,71 & 1,49 & \multirow[t]{7}{*}{1,68} & \multirow[t]{7}{*}{ 172 } & \\
\hline & Enfermedad médica & 0,17 & 0,41 & & & \\
\hline & Neuroquirúrgico & 2 & 2,83 & & & \\
\hline & Séptico & 2 & 1,15 & & & \\
\hline & Respiratorio & 0,50 & 0,84 & & & \\
\hline & Traumatismo SNC & 0 & - & & & \\
\hline & Traumatismo sin SNC & 0,25 & 0,50 & & & \\
\hline \multirow[t]{7}{*}{ 20. Tener dolor } & Coronario & 2,14 & 1,39 & \multirow[t]{7}{*}{1,84} & \multirow[t]{7}{*}{ 113 } & \\
\hline & Enfermedad médica & 2,83 & 0,98 & & & \\
\hline & Neuroquirúrgico & 4 & 0 & & & \\
\hline & Séptico & 3,83 & 0,41 & & & \\
\hline & Respiratorio & 3 & 1,55 & & & \\
\hline & Traumatismo SNC & 2,67 & 2,31 & & & \\
\hline & Traumatismo sin SNC & 2,57 & 1,13 & & & \\
\hline \multirow{7}{*}{$\begin{array}{l}\text { 21.No saber en qué } \\
\text { consiste la } \\
\text { enfermedad. }\end{array}$} & Coronario & 1,12 & 1,32 & \multirow[t]{7}{*}{3,39} & \multirow[t]{7}{*}{,008 } & \multirow[t]{7}{*}{ Sépt $>$ Cor } \\
\hline & Enfermedad médica & 1,44 & 1,74 & & & \\
\hline & Neuroquirúrgico & 3 & 1,41 & & & \\
\hline & Séptico & 3,67 & 0,52 & & & \\
\hline & Respiratorio & 2,67 & 1,50 & & & \\
\hline & Traumatismo SNC & 1,33 & 1,53 & & & \\
\hline & Traumatismo $\sin$ SNC & 1,57 & 1,27 & & & \\
\hline \multirow{7}{*}{$\begin{array}{l}\text { 22.Pensar que le puede } \\
\text { ocurrir algo grave }\end{array}$} & Coronario & 1,52 & 1,41 & \multirow[t]{7}{*}{0,57} & \multirow[t]{7}{*}{,755 } & \\
\hline & Enfermedad médica & 2,33 & 1,66 & & & \\
\hline & Neuroquirúrgico & 2 & 2,83 & & & \\
\hline & Séptico & 1,86 & 1,77 & & & \\
\hline & Respiratorio & 1,67 & 1,63 & & & \\
\hline & Traumatismo SNC & 3 & 1,73 & & & \\
\hline & Traumatismo sin SNC & 2 & 1,87 & & & \\
\hline \multirow{7}{*}{$\begin{array}{l}\text { 23.Pensar si podrá } \\
\text { volver a su vida normal } \\
\text { la salir del hospital }\end{array}$} & Coronario & 1,16 & 1,18 & 0,72 & 638 & \\
\hline & Enfermedad médica & 0,78 & 1,09 & & & \\
\hline & Neuroquirúrgico & 1,50 & 2,12 & & & \\
\hline & Séptico & 1,57 & 1,99 & & & \\
\hline & Respiratorio & 1,67 & 1,37 & & & \\
\hline & Traumatismo SNC & 0,33 & 0,58 & & & \\
\hline & Traumatismo sin SNC & 1,67 & 1,37 & & & \\
\hline
\end{tabular}

(Sigue detrás) 
(Continuación Tabla 31)

\begin{tabular}{|c|c|c|c|c|c|c|}
\hline Ítem & Patología & $\bar{X}$ & DT & $\mathbf{F}$ & $\begin{array}{c}\text { Sig. } \\
p \leq, 050\end{array}$ & Prueba Scheffé \\
\hline \multirow{7}{*}{$\begin{array}{l}\text { 24.No poder ocuparse } \\
\text { de la familia como } \\
\text { venía haciendo }\end{array}$} & Coronario & 0,88 & 1,01 & 1,92 & ,095 & \\
\hline & Enfermedad médica & 1,40 & 1,17 & & & \\
\hline & Neuroquirúrgico & 3 & 0 & & & \\
\hline & Séptico & 1,57 & 1,51 & & & \\
\hline & Respiratorio & 1,67 & 1,63 & & & \\
\hline & Traumatismo SNC & 1 & 1 & & & \\
\hline & Traumatismo sin SNC & 2,14 & 1,34 & & & \\
\hline \multirow{7}{*}{$\begin{array}{l}\text { 25.No sabe cómo } \\
\text { quedará después de la } \\
\text { operación }\end{array}$} & Coronario & 1,17 & 1,11 & 0,79 &, 579 & \\
\hline & Enfermedad médica & 1,50 & 1,97 & & & \\
\hline & Neuroquirúrgico & 1 & - & & & \\
\hline & Séptico & 2,33 & 1,37 & & & \\
\hline & Respiratorio & 0,50 & 0,58 & & & \\
\hline & Traumatismo SNC & 1 & 1,41 & & & \\
\hline & Traumatismo $\sin$ SNC & 1,71 & 1,89 & & & \\
\hline \multirow{7}{*}{$\begin{array}{l}\text { 26.Estar separado de } \\
\text { los familiares más } \\
\text { cercanos }\end{array}$} & Coronario & 1,44 & 1,04 & 1,96 &, 088 & \\
\hline & Enfermedad médica & 2,10 & 1,59 & & & \\
\hline & Neuroquirúrgico & 3 & 1,41 & & & \\
\hline & Séptico & 2,86 & 1,57 & & & \\
\hline & Respiratorio & 2 & 1,67 & & & \\
\hline & Traumatismo SNC & 3,33 & 1,15 & & & \\
\hline & Traumatismo sin SNC & 1,71 & 1,38 & & & \\
\hline \multirow{7}{*}{$\begin{array}{l}\text { 27.No saber cuándo le } \\
\text { darán el alta de UCl. }\end{array}$} & Coronario & 0,68 & 0,90 & 4,04 &, 002 & \\
\hline & Enfermedad médica & 1,33 & 1,58 & & & \\
\hline & Neuroquirúrgico & 3,50 & 0,71 & & & \\
\hline & Séptico & 2,57 & 1,39 & & & \\
\hline & Respiratorio & 2 & 1,41 & & & \\
\hline & Traumatismo SNC & 2,33 & 1,15 & & & \\
\hline & Traumatismo sin SNC & 2 & 1,73 & & & \\
\hline \multirow{7}{*}{$\begin{array}{l}\text { 28. Haber sido } \\
\text { hospitalizado de } \\
\text { repente }\end{array}$} & Coronario & 1,05 & 1,32 & 1,48 & ,204 & \\
\hline & Enfermedad médica & 1,30 & 1,57 & & & \\
\hline & Neuroquirúrgico & 3,50 & 0,71 & & & \\
\hline & Séptico & 1,80 & 1,64 & & & \\
\hline & Respiratorio & 1,50 & 1,64 & & & \\
\hline & Traumatismo SNC & 1 & 1,41 & & & \\
\hline & Traumatismo sin SNC & 2,43 & 1,72 & & & \\
\hline \multirow{7}{*}{$\begin{array}{l}\text { 29.No saber los } \\
\text { resultados/razones de } \\
\text { los tratamientos }\end{array}$} & Coronario & 0,70 & 1,08 & 1,25 & ,299 & \\
\hline & Enfermedad médica & 1,56 & 1,13 & & & \\
\hline & Neuroquirúrgico & 2 & 2,83 & & & \\
\hline & Séptico & 1,43 & 0,98 & & & \\
\hline & Respiratorio & 1,60 & 1,51 & & & \\
\hline & Traumatismo SNC & 2 & 1,73 & & & \\
\hline & Traumatismo sin SNC & 1,57 & 1,13 & & & \\
\hline \multirow{7}{*}{$\begin{array}{l}\text { 30.Pensar que pueda } \\
\text { tener dolor por la } \\
\text { operación/pruebas. }\end{array}$} & Coronario & 1,20 & 1,19 & 2,86 &, 020 & \\
\hline & Enfermedad médica & 1,14 & 1,46 & & & \\
\hline & Neuroquirúrgico & 2 & 2,83 & & & \\
\hline & Séptico & 3 & 1,15 & & & \\
\hline & Respiratorio & 2,60 & 1,14 & & & \\
\hline & Traumatismo SNC & 2 & 1,73 & & & \\
\hline & Traumatismo sin SNC & 2,80 & 0,84 & & & \\
\hline
\end{tabular}

(Sigue detrás) 
(Continuación Tabla 31)

\begin{tabular}{|c|c|c|c|c|c|c|}
\hline Ítem & Patología & $\bar{X}$ & DT & $\mathbf{F}$ & $\begin{array}{c}\text { Sig. } \\
p \leq, 050\end{array}$ & Prueba Scheffé \\
\hline \multirow{7}{*}{$\begin{array}{l}\text { 31. No sabe cuándo van } \\
\text { a hacerle cosas. }\end{array}$} & Coronario & 0,48 & 0,68 & 2,67 & ,026 & \\
\hline & Enfermedad médica & 1 & 1,05 & & & \\
\hline & Neuroquirúrgico & 2,50 & 0,71 & & & \\
\hline & Séptico & 1,67 & 1,21 & & & \\
\hline & Respiratorio & 2 & 1,58 & & & \\
\hline & Traumatismo SNC & 1,33 & 1,53 & & & \\
\hline & Traumatismo sin SNC & 1,50 & 1,64 & & & \\
\hline \multirow{7}{*}{$\begin{array}{l}\text { 32.No obtener alivio } \\
\text { para el dolor aún } \\
\text { tomando medicación }\end{array}$} & Coronario & 1,46 & 1,05 & 2,02 & ,090 & \\
\hline & Enfermedad médica & 1,86 & 1,46 & & & \\
\hline & Neuroquirúrgico & 4 & 0 & & & \\
\hline & Séptico & 3,33 & 1,63 & & & \\
\hline & Respiratorio & 2,40 & 1,67 & & & \\
\hline & Traumatismo SNC & 2 & 1,41 & & & \\
\hline & Traumatismo sin SNC & 2,80 & 1,79 & & & \\
\hline \multirow{7}{*}{$\begin{array}{l}\text { 33.Ver que el personal } \\
\text { del hospital tiene prisa }\end{array}$} & Coronario & 0,33 & 0,87 & 1,89 & 099 & \\
\hline & Enfermedad médica & 0,20 & 0,42 & & & \\
\hline & Neuroquirúrgico & 1,50 & 2,12 & & & \\
\hline & Séptico & 1,14 & 1,68 & & & \\
\hline & Respiratorio & 1,67 & 1,63 & & & \\
\hline & Traumatismo SNC & 1,33 & 1,53 & & & \\
\hline & Traumatismo sin SNC & 1 & 1,53 & & & \\
\hline \multirow{7}{*}{$\begin{array}{l}\text { 34.Que los sanitarios } \\
\text { hablen rápido o usen } \\
\text { palabras que no } \\
\text { puedan entender. }\end{array}$} & Coronario & 0,44 & 0,62 & 2,65 & 029 & \\
\hline & Enfermedad médica & 0,60 & 1,07 & & & \\
\hline & Neuroquirúrgico & 2,50 & 0,71 & & & \\
\hline & Séptico & 2,25 & 1,71 & & & \\
\hline & Respiratorio & 1,20 & 1,79 & & & \\
\hline & Traumatismo SNC & 1,67 & 1,53 & & & \\
\hline & Traumatismo sin SNC & 1 & 1,09 & & & \\
\hline \multirow{7}{*}{$\begin{array}{l}\text { 35.Que los sanitarios } \\
\text { no contesten a sus } \\
\text { preguntas }\end{array}$} & Coronario & 1,40 & 1,43 & 1,21 & ,331 & \\
\hline & Enfermedad médica & 1,71 & 1,70 & & & \\
\hline & Neuroquirúrgico & 4 & - & & & \\
\hline & Séptico & 2,80 & 1,64 & & & \\
\hline & Respiratorio & 2,20 & 0,45 & & & \\
\hline & Traumatismo SNC & 1 & - & & & \\
\hline & Traumatismo $\sin$ SNC & 1,25 & 0,96 & & & \\
\hline \multirow{7}{*}{$\begin{array}{l}\text { 36.Que no le den la } \\
\text { medicación para el } \\
\text { dolor cuando lo } \\
\text { necesite. }\end{array}$} & Coronario & 1,25 & 1,06 & 3,52 & ,009 & \\
\hline & Enfermedad médica & 1,43 & 0,98 & & & \\
\hline & Neuroquirúrgico & 4 & 0 & & & \\
\hline & Séptico & 2,83 & 1,83 & & & \\
\hline & Respiratorio & 3,20 & 1,09 & & & \\
\hline & Traumatismo SNC & 1 & - & & & \\
\hline & Traumatismo sin SNC & 2,75 & 1,26 & & & \\
\hline \multirow{7}{*}{$\begin{array}{l}\text { 37.Pensar en la posible } \\
\text { pérdida de dinero a } \\
\text { causa de la } \\
\text { enfermedad }\end{array}$} & Coronario & 0,50 & 0,88 & 0,49 & 815 & \\
\hline & Enfermedad médica & 1 & 1,51 & & & \\
\hline & Neuroquirúrgico & 0 & 0 & & & \\
\hline & Séptico & 0,60 & 0,89 & & & \\
\hline & Respiratorio & 0,67 & 1,21 & & & \\
\hline & Traumatismo SNC & 0 & 0 & & & \\
\hline & Traumatismo sin SNC & 0,60 & 1,34 & & & \\
\hline
\end{tabular}

(Sigue detrás) 


\begin{tabular}{|c|c|c|c|c|c|c|}
\hline Ítem & Patología & $\bar{X}$ & DT & $\mathbf{F}$ & $\begin{array}{l}\text { Sig. } \\
p \leq, 050\end{array}$ & Prueba Scheffé \\
\hline \multirow{7}{*}{$\begin{array}{l}\text { 38.Sentir olores } \\
\text { extraños en el hospital. }\end{array}$} & Coronario & 0,08 & 0,28 & 2,54 & ,031 & \\
\hline & Enfermedad médica & 0,50 & 1,27 & & & \\
\hline & Neuroquirúrgico & 1,50 & 2,12 & & & \\
\hline & Séptico & 1,43 & 1,39 & & & \\
\hline & Respiratorio & 0,40 & 0,89 & & & \\
\hline & Traumatismo SNC & 0,33 & 0,58 & & & \\
\hline & Traumatismo sin SNC & 0,71 & 1,11 & & & \\
\hline \multirow{7}{*}{$\begin{array}{l}\text { 39.Comer a horas } \\
\text { diferentes a las } \\
\text { habituales. }\end{array}$} & Coronario & 0,04 & 0,20 & 12,49 & ,000 & Neuro>Cor, \\
\hline & Enfermedad médica & 0,22 & 0,44 & & & EnfMéd, Sépt, \\
\hline & Neuroquirúrgico & 3,50 & 0,71 & & & $\begin{array}{l}\text { sin SNC } \\
\text { sind }\end{array}$ \\
\hline & Séptico & 1 & 1,41 & & & $\operatorname{Tr}$ Sin SNC>Cor \\
\hline & Respiratorio & 0,33 & 0,52 & & & \\
\hline & Traumatismo SNC & 0 & 0 & & & \\
\hline & Traumatismo sin SNC & 1,43 & 0,98 & & & \\
\hline \multirow{7}{*}{$\begin{array}{l}\text { 40. Nivel de estrés en } \\
\text { general. }\end{array}$} & Coronario & 1,20 & 1 & 2,67 & 025 & \\
\hline & Enfermedad médica & 1,60 & 1,17 & & & \\
\hline & Neuroquirúrgico & 2,50 & 0,71 & & & \\
\hline & Séptico & 2,86 & 0,89 & & & \\
\hline & Respiratorio & 2,33 & 1,63 & & & \\
\hline & Traumatismo SNC & 2 & 1 & & & \\
\hline & Traumatismo sin SNC & 1,43 & 1,27 & & & \\
\hline
\end{tabular}

Respecto a la calidad de vida de los pacientes en función de su patología sí se han obtenido diferencias estadísticamente significativas tanto en la calidad de vida previa al ingreso $(\mathrm{F}=2,51 ; \mathrm{p}=, 033)$ siendo las puntuaciones medias mayores para el grupo de pacientes neuroquirúrgicos, como en la calidad de vida después de ingresar en UCI $(F=2,40 ; p=, 040)$ (véase Tabla 32) en cuyo caso las puntuaciones mayores corresponden a los pacientes con traumatismos sin afectación del SNC. No obstante, las comparaciones entre los distintos grupos diagnósticos a través de las pruebas Scheffé no han mostrado que las medias difieran significativamente. 
Tabla 32. Análisis diferencial en función de la patología sobre la calidad de vida (CV) de los pacientes

\begin{tabular}{|c|c|c|c|c|c|c|}
\hline Ítem & Patología & $\bar{X}$ & DT & $\mathbf{F}$ & $\begin{array}{c}\text { Sig. } \\
p \leq, 050\end{array}$ & $\begin{array}{l}\text { Prueba } \\
\text { Scheffé }\end{array}$ \\
\hline \multirow{7}{*}{$\begin{array}{l}\text { 1. Puntuación total en CV } \\
\text { previa al ingreso }\end{array}$} & Coronario & 7,27 & 2,21 & 2,51 & ,033 & - \\
\hline & Enfermedad médica & 5,54 & 0,69 & & & \\
\hline & Neuroquirúrgico & 8 & 2,83 & & & \\
\hline & Séptico & 6,43 & 1,81 & & & \\
\hline & Respiratorio & 7,43 & 2,64 & & & \\
\hline & Traumatismos SNC & 5 & 0 & & & \\
\hline & Traumatismo sin SNC & 5,43 & 0,53 & & & \\
\hline \multirow{7}{*}{$\begin{array}{l}\text { 2. Puntuación total en CV } \\
\text { después del ingreso }\end{array}$} & Coronario & 11,41 & 1,89 & 2,40 & ,040 & - \\
\hline & Enfermedad médica & 9,82 & 2,75 & & & \\
\hline & Neuroquirúrgico & 10,50 & 4,95 & & & \\
\hline & Séptico & 11,86 & 1,34 & & & \\
\hline & Respiratorio & 12 & 1,83 & & & \\
\hline & Traumatismos SNC & 12,50 & 1 & & & \\
\hline & Traumatismo sin SNC & 13,14 & 1,07 & & & \\
\hline
\end{tabular}

En el análisis de la valoración diferencial de los distintos factores del CAMP relativos al proceso de morir (véase Tabla 33) se han obtenido diferencias estadísticamente significativas en función de la patología de ingreso. Concretamente estas diferencias se observan en aspectos relativos a "pensar que puedan controlar hasta el final los pensamientos y las funciones fisiológicas" ( $F=3,15 ; p=, 012)$ más valorado por los pacientes con enfermedad médica previa, así como "pensar que su muerte no supondrá una carga insoportable para sus seres queridos" $(F=2,56 ; p=, 034)$ aspecto que ha resultado ser más importante para los pacientes sépticos. Si bien es cierto que se han obtenido diferencias, al realizar comparaciones entre las medias (prueba Scheffé) estas diferencias no han mostrado significación estadística. 
Tabla 33. Análisis diferencial en función de la patología de los distintos factores del Cuestionario de Ayuda a Morir en Paz (CAMP) (pacientes)

\begin{tabular}{|c|c|c|c|c|c|c|}
\hline Ítem & Patología & $\bar{X}$ & DT & $\mathbf{F}$ & $\begin{array}{c}\text { Sig. } \\
p \leq, 050\end{array}$ & $\begin{array}{l}\text { Prueba } \\
\text { Scheffé }\end{array}$ \\
\hline \multirow{7}{*}{$\begin{array}{l}\text { 1. Controlar mi dolor y } \\
\text { otros síntomas de } \\
\text { malestar }\end{array}$} & Coronario & 3,41 & 0,79 & \multirow{7}{*}{0,95} & \multirow{7}{*}{,469 } & \\
\hline & Enfermedad médica & 3,71 & 0,75 & & & \\
\hline & Neuroquirúrgico & 2,50 & 2,12 & & & \\
\hline & Séptico & 3,71 & 0,49 & & & \\
\hline & Respiratorio & 3,67 & 0,52 & & & \\
\hline & Traumatismos SNC & 4 & 0 & & & \\
\hline & Traumatismo sin SNC & 3,14 & 1,46 & & & \\
\hline \multirow{7}{*}{$\begin{array}{l}\text { 2. Mi proceso de morir, } \\
\text { si produce sufrimiento, } \\
\text { será corto }\end{array}$} & Coronario & 3,59 & 0,87 & \multirow{7}{*}{0,89} & \multirow{7}{*}{,508 } & \\
\hline & Enfermedad médica & 3,29 & 0,95 & & & \\
\hline & Neuroquirúrgico & 3 & 0 & & & \\
\hline & Séptico & 3,86 & 0,38 & & & \\
\hline & Respiratorio & 3,33 & 0,82 & & & \\
\hline & Traumatismos SNC & 4 & 0 & & & \\
\hline & Traumatismo sin SNC & 3,14 & 1,07 & & & \\
\hline \multirow{7}{*}{$\begin{array}{l}\text { 3. Controlar hasta el } \\
\text { final pensamientos y } \\
\text { funciones fisiológicas }\end{array}$} & Coronario & 2,23 & 1,60 & \multirow[t]{7}{*}{3,15} & \multirow[t]{7}{*}{,012 } & \\
\hline & Enfermedad médica & 3,43 & 0,79 & & & \\
\hline & Neuroquirúrgico & 1 & 1,41 & & & \\
\hline & Séptico & 3,14 & 0,69 & & & \\
\hline & Respiratorio & 3 & 1,26 & & & \\
\hline & Traumatismos SNC & 1 & 1 & & & \\
\hline & Traumatismo sin SNC & 1,43 & 1,13 & & & \\
\hline \multirow{6}{*}{$\begin{array}{l}\text { 4. Mi muerte no } \\
\text { supondrá una carga } \\
\text { insoportable para mis } \\
\text { seres queridos }\end{array}$} & $\begin{array}{c}\text { Coronario } \\
\text { Enfermedad médica }\end{array}$ & $\begin{array}{l}2,50 \\
3,57\end{array}$ & $\begin{array}{l}1,59 \\
0,53\end{array}$ & \multirow[t]{6}{*}{2,56} & \multirow[t]{6}{*}{,034 } & - \\
\hline & Neuroquirúrgico & 1,50 & 0,71 & & & \\
\hline & Séptico & 3,71 & 0,49 & & & \\
\hline & Respiratorio & 3,50 & 0,84 & & & \\
\hline & Traumatismos SNC & 2,67 & 1,53 & & & \\
\hline & Traumatismo sin SNC & 1,83 & 1,47 & & & \\
\hline \multirow{6}{*}{$\begin{array}{l}\text { 5. Poder sentirme } \\
\text { cerca, comunicarme y } \\
\text { estrechar vínculos } \\
\text { afectivos con mis } \\
\text { personas queridas }\end{array}$} & $\begin{array}{c}\text { Coronario } \\
\text { Enfermedad médica }\end{array}$ & $\begin{array}{l}2,76 \\
3,86\end{array}$ & $\begin{array}{l}1,30 \\
0,38\end{array}$ & \multirow[t]{6}{*}{1,44} & \multirow[t]{6}{*}{,222 } & \\
\hline & Neuroquirúrgico & 3 & 0 & & & \\
\hline & Séptico & 2,71 & 1,60 & & & \\
\hline & Respiratorio & 3,17 & 1,17 & & & \\
\hline & Traumatismos SNC & 3,67 & 0,58 & & & \\
\hline & Traumatismo sin SNC & 2,14 & 1,46 & & & \\
\hline \multirow{6}{*}{$\begin{array}{l}\text { 6. Sin esperanza real de } \\
\text { recuperación, no se } \\
\text { alargará artificialmente } \\
\text { mi vida en } \mathrm{UCl}\end{array}$} & $\begin{array}{l}\text { Coronario } \\
\text { Enfermedad médica }\end{array}$ & $\begin{array}{l}2,23 \\
2,43\end{array}$ & $\begin{array}{l}1,68 \\
1,81\end{array}$ & \multirow[t]{6}{*}{1,37} & \multirow[t]{6}{*}{,248 } & \\
\hline & Neuroquirúrgico & 1,50 & 2,12 & & & \\
\hline & Séptico & 3,71 & 0,49 & & & \\
\hline & Respiratorio & 3,50 & 0,84 & & & \\
\hline & Traumatismos SNC & 2,67 & 2,31 & & & \\
\hline & Traumatismo sin SNC & 2 & 1,91 & & & \\
\hline \multirow[t]{6}{*}{$\begin{array}{l}\text { 7. Pensar que mi vida } \\
\text { ha tenido algún sentido }\end{array}$} & $\begin{array}{c}\text { Coronario } \\
\text { Enfermedad médica }\end{array}$ & $\begin{array}{l}2,35 \\
3,43\end{array}$ & $\begin{array}{l}0,79 \\
0,53\end{array}$ & \multirow[t]{6}{*}{1,93} & \multirow[t]{6}{*}{,098 } & \\
\hline & Neuroquirúrgico & 3,50 & 0,71 & & & \\
\hline & Séptico & 3,14 & 1,46 & & & \\
\hline & Respiratorio & 3,33 & 0,82 & & & \\
\hline & Traumatismos SNC & 2,67 & 0,58 & & & \\
\hline & Traumatismo sin SNC & 2,43 & 1,27 & & & \\
\hline
\end{tabular}

(Sigue detrás) 


\begin{tabular}{|c|c|c|c|c|c|c|}
\hline Ítem & Patología & $\bar{X}$ & DT & $\mathbf{F}$ & $\begin{array}{c}\text { Sig. } \\
p \leq, 050\end{array}$ & $\begin{array}{l}\text { Prueba } \\
\text { Scheffé }\end{array}$ \\
\hline \multirow[t]{6}{*}{$\begin{array}{l}\text { 8. Creer en otra vida } \\
\text { después de la muerte }\end{array}$} & $\begin{array}{c}\text { Coronario } \\
\text { Enfermedad médica }\end{array}$ & $\begin{array}{l}1,33 \\
2,71\end{array}$ & $\begin{array}{l}1,63 \\
1,70\end{array}$ & \multirow[t]{6}{*}{0,91} & \multirow[t]{6}{*}{,498 } & \\
\hline & Neuroquirúrgico & 0,50 & 0,71 & & & \\
\hline & Séptico & 1,86 & 1,86 & & & \\
\hline & Respiratorio & 1,20 & 0,84 & & & \\
\hline & Traumatismos SNC & 2 & 2 & & & \\
\hline & Traumatismo sin SNC & 1,43 & 1,51 & & & \\
\hline \multirow{6}{*}{$\begin{array}{l}\text { 9. No sentirse culpable } \\
\text { por conflictos } \\
\text { personales del pasado }\end{array}$} & $\begin{array}{c}\text { Coronario } \\
\text { Enfermedad médica }\end{array}$ & $\begin{array}{c}1,71 \\
3\end{array}$ & $\begin{array}{l}1,31 \\
0,82\end{array}$ & \multirow[t]{6}{*}{1,12} & \multirow[t]{6}{*}{,365 } & \\
\hline & Neuroquirúrgico & 2 & 1,41 & & & \\
\hline & Séptico & 2,43 & 1,81 & & & \\
\hline & Respiratorio & 2 & 1,09 & & & \\
\hline & Traumatismos SNC & 3 & 0 & & & \\
\hline & Traumatismo sin SNC & 2 & 1,41 & & & \\
\hline \multirow{6}{*}{$\begin{array}{l}\text { 10. Si la situación se me } \\
\text { hace insoportable } \\
\text { disponer de ayuda para } \\
\text { morir con rapidez }\end{array}$} & $\begin{array}{c}\text { Coronario } \\
\text { Enfermedad médica }\end{array}$ & $\begin{array}{l}3,12 \\
1,86\end{array}$ & $\begin{array}{l}1,27 \\
1,77\end{array}$ & \multirow[t]{6}{*}{1,23} & \multirow[t]{6}{*}{,310 } & \\
\hline & Neuroquirúrgico & 3 & 1,41 & & & \\
\hline & Séptico & 3,14 & 1,46 & & & \\
\hline & Respiratorio & 3,67 & 0,52 & & & \\
\hline & Traumatismos SNC & 3,33 & 0,58 & & & \\
\hline & Traumatismo sin SNC & 3 & 1,26 & & & \\
\hline \multirow[t]{6}{*}{$\begin{array}{l}\text { 11. Poder morir en mi } \\
\text { casa }\end{array}$} & $\begin{array}{c}\text { Coronario } \\
\text { Enfermedad médica }\end{array}$ & $\begin{array}{l}1,06 \\
0,29\end{array}$ & $\begin{array}{l}1,57 \\
0,49\end{array}$ & \multirow[t]{6}{*}{1,23} & \multirow[t]{6}{*}{,313 } & \\
\hline & Neuroquirúrgico & 3 & 0 & & & \\
\hline & Séptico & 1,29 & 1,70 & & & \\
\hline & Respiratorio & 1,50 & 1,64 & & & \\
\hline & Traumatismos SNC & 1,67 & 1,53 & & & \\
\hline & Traumatismo $\sin$ SNC & 1,86 & 1,77 & & & \\
\hline
\end{tabular}

Por lo que respecta al proceso de información y toma de decisiones (véase Tabla 34) el análisis diferencial en función de la patología no muestra diferencias significativas en ninguna de las subescalas consideradas. No obstante, cabe señalar que aun sin alcanzar la significación, los pacientes sépticos son los que otorgan mayor importancia a la familia. Respecto a la importancia del propio paciente podemos apreciar mayores puntuaciones en el caso de los pacientes respiratorios y neuroquirúrgicos, siendo a su vez estos últimos quienes conceden mayor relevancia al papel del médico en el proceso. En cuanto al papel del psicólogo, las mayores puntuaciones medias corresponden a los pacientes con enfermedad médica previa. Siguiendo con este análisis diferencial también podemos observar que las mayores puntuaciones en la subescala de satisfacción con la información pertenecen a los pacientes neuroquirúrgicos los que a su vez perciben más como una carga que como un privilegio el participar en decisiones médicas relevantes. Atendiendo a la participación en decisiones relevantes, las puntuaciones son muy parecidas en casi 
todos los grupos de pacientes a excepción de los coronarios quienes perciben sentirse menos capacitados. Igualmente, son los pacientes neuroquirúrgicos los que muestran mayor preferencia hacia un estilo del médico más directo y que pueda anticipar posibles sospechas. En cambio respecto a las preferencias hacia un médico más prudente a la hora de informar, guardándose lo que aún no es seguro, han mostrado mayores puntuaciones los pacientes sépticos, aunque como ya hemos comentado en ningún caso las diferencias han resultado significativas. Tal como podemos observar en la Tabla 34, en las respuestas del cuestionario CITD no hemos obtenido representación del grupo de pacientes con traumatismos.

Tabla 34. Análisis diferencial en función de la patología de la valoración del proceso de información y toma de decisiones en los pacientes

\begin{tabular}{|c|c|c|c|c|c|}
\hline CITD & Patología & $\bar{X}$ & DT & $\mathbf{F}$ & $\begin{array}{c}\text { Sig. } \\
p \leq, 050\end{array}$ \\
\hline \multicolumn{6}{|l|}{ Importancia de los distintos partes implicadas } \\
\hline $\begin{array}{l}\text { Papel de la familia en la información y toma de } \\
\text { decisiones }\end{array}$ & $\begin{array}{c}\text { Coronario } \\
\text { Enfermedad médica } \\
\text { Neuroquirúrgico } \\
\text { Séptico } \\
\text { Respiratorio }\end{array}$ & $\begin{array}{c}7,33 \\
11,60 \\
6 \\
12 \\
7\end{array}$ & $\begin{array}{c}6,74 \\
4,04 \\
- \\
3 \\
-\end{array}$ & 0,77 &, 564 \\
\hline $\begin{array}{l}\text { Papel del paciente en la información y toma de } \\
\text { decisiones }\end{array}$ & $\begin{array}{c}\text { Coronario } \\
\text { Enfermedad médica } \\
\text { Neuroquirúrgico } \\
\text { Séptico } \\
\text { Respiratorio }\end{array}$ & $\begin{array}{c}17,17 \\
17,20 \\
19 \\
14,67 \\
19\end{array}$ & $\begin{array}{c}3,82 \\
5,36 \\
- \\
3,51 \\
-\end{array}$ & 0,32 & 859 \\
\hline $\begin{array}{l}\text { Papel del médico en la información y toma de } \\
\text { decisiones }\end{array}$ & $\begin{array}{c}\text { Coronario } \\
\text { Enfermedad médica } \\
\text { Neuroquirúrgico } \\
\text { Séptico } \\
\text { Respiratorio }\end{array}$ & $\begin{array}{c}4,14 \\
4,60 \\
6 \\
4,67 \\
4\end{array}$ & $\begin{array}{c}1,46 \\
0,55 \\
- \\
1,53 \\
-\end{array}$ & 0,56 & 694 \\
\hline $\begin{array}{l}\text { CITD. Papel del psicólogo en la información y } \\
\text { toma de decisiones }\end{array}$ & $\begin{array}{c}\text { Coronario } \\
\text { Enfermedad médica } \\
\text { Neuroquirúrgico } \\
\text { Séptico } \\
\text { Respiratorio }\end{array}$ & $\begin{array}{c}2 \\
2,83 \\
2 \\
2 \\
2\end{array}$ & $\begin{array}{l}1,15 \\
0,41 \\
- \\
1 \\
-\end{array}$ & 0,83 & ,528 \\
\hline \multicolumn{6}{|l|}{ Satisfacción con la información } \\
\hline $\begin{array}{l}\text { Satisfacción con la cantidad y la claridad de la } \\
\text { información }\end{array}$ & $\begin{array}{c}\text { Coronario } \\
\text { Enfermedad médica } \\
\text { Neuroquirúrgico } \\
\text { Séptico } \\
\text { Respiratorio }\end{array}$ & $\begin{array}{c}5,14 \\
4,33 \\
6 \\
4,67 \\
5\end{array}$ & $\begin{array}{c}2,27 \\
2,66 \\
- \\
2,31 \\
-\end{array}$ & 0,15 & ,958 \\
\hline \multicolumn{6}{|l|}{ Estilo del médico } \\
\hline $\begin{array}{l}\text { En cuanto al estilo del médico prefiero que éste } \\
\text { sea directo y anticipe posibles sospechas }\end{array}$ & $\begin{array}{c}\text { Coronario } \\
\text { Enfermedad médica } \\
\text { Neuroquirúrgico } \\
\text { Séptico } \\
\text { Respiratorio }\end{array}$ & $\begin{array}{c}2,14 \\
0,83 \\
3 \\
1,33 \\
3\end{array}$ & $\begin{array}{c}1,21 \\
1,33 \\
- \\
1,53 \\
-\end{array}$ & 1,40 & ,288 \\
\hline $\begin{array}{l}\text { En cuanto al estilo del médico prefiero que éste se } \\
\text { guarde lo que aún no es seguro }\end{array}$ & $\begin{array}{c}\text { Coronario } \\
\text { Enfermedad médica } \\
\text { Neuroquirúrgico } \\
\text { Séptico } \\
\text { Respiratorio }\end{array}$ & $\begin{array}{c}1,57 \\
2,17 \\
2 \\
2,67 \\
2\end{array}$ & $\begin{array}{c}1,51 \\
1,33 \\
- \\
0,58 \\
-\end{array}$ & 0,39 & ,812 \\
\hline
\end{tabular}

(Sigue detrás) 
(Continuación Tabla 34)

\begin{tabular}{|c|c|c|c|c|c|}
\hline CITD & Patología & $\bar{x}$ & DT & $\mathbf{F}$ & $\begin{array}{c}\text { Sig. } \\
p \leq, 050\end{array}$ \\
\hline \multicolumn{6}{|l|}{ Participación en TD } \\
\hline $\begin{array}{l}\text { Me siento capacitado para participar en la TD } \\
\text { sobre la salud }\end{array}$ & $\begin{array}{c}\text { Coronario } \\
\text { Enfermedad médica } \\
\text { Neuroquirúrgico } \\
\text { Séptico } \\
\text { Respiratorio }\end{array}$ & $\begin{array}{l}1,71 \\
3 \\
2 \\
3 \\
3\end{array}$ & $\begin{array}{c}1,25 \\
0 \\
- \\
0 \\
-\end{array}$ & 2,42 & 102 \\
\hline $\begin{array}{l}\text { Poder participar en una decisión médica sería más } \\
\text { una carga que un privilegio }\end{array}$ & $\begin{array}{c}\text { Coronario } \\
\text { Enfermedad médica } \\
\text { Neuroquirúrgico } \\
\text { Séptico } \\
\text { Respiratorio }\end{array}$ & $\begin{array}{c}1 \\
0,83 \\
3 \\
1,67 \\
0\end{array}$ & $\begin{array}{c}1,15 \\
1,33 \\
- \\
1,53\end{array}$ & 0,95 & 467 \\
\hline
\end{tabular}

\subsubsection{Relación entre las variables evaluadas y la edad}

En este apartado presentaremos los resultados de los análisis estadísticos que nos han permitido explorar la relación entre las distintas variables dependientes incluidas en el estudio y la edad de los pacientes ingresados en la UCI. En este sentido, se han llevado a cabo correlaciones de Pearson de la edad con la ansiedad, la depresión, la percepción subjetiva del estado de ánimo, la valoración de la estancia en UCI, los factores estresantes, la calidad de vida, los factores que ayudarían a morir en paz así como la valoración del proceso de información y toma de decisiones.

Respecto a la sintomatología ansiosa-depresiva, tal como muestra la Tabla 35 no se han obtenido correlaciones significativas a nivel estadístico en ninguna de las escalas utilizadas: HADS-Ansiedad ( $\mathrm{r}=-0,17 ; \mathrm{p}=, 152)$, HADS-Depresión $(\mathrm{r}=0,12$; $\mathrm{p}=, 324)$, STAIAnsiedad estado $(\mathrm{r}=-0,19 ; \mathrm{p}=, 186)$, STAI-Ansiedad rasgo $(\mathrm{r}=-0,01 ; \mathrm{p}=, 918)$, BDIDepresión $(\mathrm{r}=0,09 ; \mathrm{p}=, 560)$. Igualmente, la relación entre la edad y las distintas subescalas de la percepción subjetiva de estado de ánimo tampoco ha resultado significativa: malestar general $(r=-0,11 ; p=381)$, ansiedad/nerviosismo $(r=0,08 ; p=, 527)$ y estado de ánimo deprimido $(r=0,10 ; p=, 392)$ (véase Tabla 35).

Tabla 35. Correlaciones de Pearson entre la edad y los síntomas de ansiedad-depresión y percepción subjetiva de malestar (pacientes)

\begin{tabular}{|lc}
\hline Cuestionarios & Edad \\
\hline Total HADS Ansiedad & $-0,17(p=, 152)$ \\
\hline Total HADS- Depresión & $0,12(p=, 324)$ \\
STAI- Estado & $-0,19(p=, 186)$ \\
STAI- Rasgo & $-0,01(p=, 918)$ \\
BDI & $0,09(p=, 560)$ \\
EA1-Malestar general & $-0,11(p=, 381)$ \\
EA2-Ansiedad y Nerviosismo & $0,08(p=, 527)$ \\
EA3-Estado de ánimo deprimido & $0,10(p=, 392)$ \\
\hline
\end{tabular}


En cuanto a la valoración global de la estancia en UCI los resultados no muestran tampoco correlaciones significativas con la edad $(r=0,09 ; p=, 499)$. Sin embargo, al analizar los diferentes ítems que componen la escala se ha obtenido que la valoración de la "atención médica recibida" correlaciona de forma negativa a nivel estadístico con la edad ( $r=-0,36 ; p=, 005)$, lo cual es indicativo de que a mayor edad de los pacientes menor es la valoración que hacen de este aspecto (véase Tabla 36).

Tabla 36. Correlaciones de Pearson entre la edad y la Valoración de la estancia en UCI (pacientes)

\begin{tabular}{|c|c|}
\hline Ítem & Edad \\
\hline $\begin{array}{l}\text { - En qué grado está siendo agradable/desagradable su estancia en UCl sin considerar los } \\
\text { problemas médicos }\end{array}$ & $0,09(p=, 499)$ \\
\hline \multicolumn{2}{|l|}{ Valoración de los siguientes aspectos } \\
\hline 1. Cuidados médicos & $-0,19(p=, 139)$ \\
\hline 2. Atención de los médicos & $-0,36(p=, 005)$ \\
\hline 3. Atención de las/os enfermeras/os & $0,00(p=, 972)$ \\
\hline 4. Atención de las/os auxiliares de enfermería & $0,03(p=, 813)$ \\
\hline 5. Claridad de la información recibida & $-0,20(p=, 113)$ \\
\hline 6. Cantidad de la información recibida & $-0,13(p=, 321)$ \\
\hline 7. Trato por parte del personal de enfermería & $-0,01(p=, 926)$ \\
\hline 8. Afecto/apoyo emocional del personal de enfermería & $0,03(p=, 830)$ \\
\hline 9. Respeto a la intimidad & $-0,02(p=, 845)$ \\
\hline 10. Atención a los familiares & $-0,19(p=, 125)$ \\
\hline 11. Atención de necesidades psicológicas en paciente y familia & $-0,22(p=, 091)$ \\
\hline 12. Calidad de las instalaciones (comodidad, higiene...) & $-0,11(p=, 398)$ \\
\hline 13. Posibilidades de distraerse & $0,10(p=, 436)$ \\
\hline 14. Silencio o tranquilidad en la sala & $0,03(p=, 823)$ \\
\hline 15. Régimen de visitas & $-0,02(p=, 863)$ \\
\hline
\end{tabular}

Al analizar la escala de Factores estresantes de UCI no se han obtenido relaciones significativas con la edad de los pacientes (véase Tabla 37), aunque podemos observar correlaciones negativas que rozan la significación estadística entre la edad y "ver que el personal del hospital tiene prisa" ( $\mathrm{r}=-0,25 ; \mathrm{p}=, 058)$, "pensar en la posible pérdida de dinero a causa de la enfermedad" $(\mathrm{r}=-0,26 ; \mathrm{p}=, 058)$ y el "grado de estrés en general" $(\mathrm{r}=-0,23 ; \mathrm{p}=, 070)$. Estos resultados irían en la línea de que a medida que aumenta la edad menor es el estrés general percibido así como el estrés asociado a los dos factores comentados, es decir, "ver que el personal tiene prisa" y "pensar en la pérdida de dinero a causa de la enfermedad". 
Tabla 37. Correlaciones de Pearson entre la edad y los Factores estresantes en UCI (pacientes)

1. No disponer de baño en el box

2. Tener que estar en la cama/sillón todo el día $-0,11(p=, 392)$

3. Estar hospitalizado lejos de casa

$0,21(p=, 135)$

4. Dormir en una cama que no es la suya

5. Utilizar la cuña de cama

6. Que no respondan al timbre de aviso

7. Dormir junto a otros enfermos en la unidad

8. Tener que ser ayudado para ir al baño $0,01(p=, 946)$

9. Tener que comer en la cama en una postura incómoda

10. Estar ingresado en la unidad junto a otras personas gravemente enfermas

11. Estar al cuidado de sanitarios desconocidos

12. Tener demasiadas visitas

13. Tener que estar todo el tiempo desnudo, únicamente cubierto con una sábana

14. Necesitar ayuda para comer

15. No poder ver la TV/escuchar la radio/leer el periódico cuando uno quiere

17. Estar las luces todo el día encendidas

18. No tener a los familiares y amigos acompañándole a lo largo del día

21. No saber con seguridad o no entender en qué consiste la enfermedad

22. Pensar que le puede ocurrir algo grave

23. Pensar si podrá volver a su vida normal después de salir del hospital

24. No poder ocuparse de la familia como hasta ahora venía haciendo

25. No saber con seguridad cómo se quedará después de la operación

26. Estar separado de sus familiares más cercanos

27. No saber cuándo le darán el alta de la unidad de cuidados intensivos

28. Haber sido hospitalizado de repente, sin esperarlo

29. No saber los resultados/razones de los tratamientos/pruebas que le hacen

Por lo que respecta a la calidad de vida de los pacientes (véase Tabla 38), las correlaciones con la edad sólo han sido significativas en la calidad de vida previa al ingreso $(\mathrm{r}=0,33 ; \mathrm{p}=, 010)$ de manera que a mayor edad menor es la calidad de vida de 
los pacientes (puntuaciones mayores), no encontrándose prácticamente relación lineal alguna entre la edad y la calidad de vida después del ingreso de UCI $(r=0,01 ; p=, 955)$.

Tabla 38. Correlaciones de Pearson entre la edad y la calidad de vida de los pacientes

\begin{tabular}{|lc}
\hline Ítem & Edad \\
\hline 1. Puntuación total en CV previa al ingreso & $\mathbf{0 , 3 3}(\mathbf{p}=, \mathbf{0 1 0})$ \\
2. Puntuación total en CV después del ingreso & $0,01(p=, 955)$
\end{tabular}

Si nos centramos en el "Cuestionario de Ayuda para Morir en Paz" (véase Tabla 39), los resultados relativos al análisis del proceso de morir no muestran relaciones significativas entre las puntuaciones obtenidas en los distintos factores y la edad de los pacientes.

Tabla 39. Correlaciones de Pearson entre la edad y los factores del CAMP (pacientes)

\begin{tabular}{lc} 
Ítem & Edad \\
\hline $\begin{array}{l}\text { 1. Controlar mi dolor y otros síntomas de malestar } \\
\text { 2. Mi proceso de morir, si produce sufrimiento, será corto }\end{array}$ & $-0,24(p=, 097)$ \\
$\begin{array}{l}\text { 3.Controlar hasta el final pensamientos y funciones fisiológicas } \\
\text { 4. Mi muerte no supondrá una carga insoportable para mis seres queridos }\end{array}$ & $0,06(p=, 687)$ \\
$\begin{array}{l}\text { 5. Poder sentirme cerca, comunicarme y estrechar vínculos afectivos con mis personas } \\
\text { queridas }\end{array}$ & $-0,06(p=, 666)$ \\
$\begin{array}{l}\text { 6. Sin esperanza real de recuperación, no se alargará artificialmente mi vida en UCl } \\
\text { 7. Pensar que mi vida ha tenido algún sentido }\end{array}$ & $-0,05(p=, 733)$ \\
8. Creer en otra vida después de la muerte & $0,14(p=, 347)$ \\
9. No sentirse culpable por conflictos personales del pasado & $0,07(p=, 646)$ \\
10. Si la situación se me hace insoportable disponer de ayuda para morir con rapidez & $-0,01(p=, 969)$ \\
11. Poder morir en mi casa & $-0,02(p=, 912)$ \\
\hline
\end{tabular}

Por último y en relación con la valoración del proceso de información y la toma de decisiones, no se han obtenido tampoco relaciones significativas con la edad en ninguna de las subescalas del cuestionario (véase Tabla 40).

Tabla 40. Correlaciones de Pearson entre la edad y la Valoración del proceso de información y toma de decisiones (pacientes) 
Satisfacción con la información

Satisfacción con la cantidad y la claridad de la información recibida

Estilo del médico

En cuanto al estilo del médico prefiero que éste sea directo y anticipe posibles sospechas

\subsubsection{Relación entre las variables evaluadas y el nivel de estudios}

Continuando con el análisis de las distintas variables dependientes incluidas en el estudio, a continuación presentaremos los resultados de las correlaciones de Spearman realizadas entre el nivel de estudios y la ansiedad, la depresión, la percepción subjetiva del estado de ánimo, la valoración de la estancia en UCI, los factores estresantes, la calidad de vida, los factores que ayudarían a morir en paz y la valoración del proceso de información y toma de decisiones.

Respecto a los síntomas de ansiedad y depresión (véase Tabla 41) no se han obtenido relaciones significativas a nivel estadístico con el nivel de estudios en ninguna de las escalas utilizadas: HADS-Ansiedad $(r=0,14 ; \mathrm{p}=, 327)$, HADS-Depresión $(\mathrm{r}=0,02$; $\mathrm{p}=, 861)$, STAI-Ansiedad estado $(\mathrm{r}=0,04 ; \mathrm{p}=, 810)$, STAI-Ansiedad rasgo $(\mathrm{r}=0,08 ; \mathrm{p}=, 649)$, BDI-Depresión $(\mathrm{r}=-0,04 ; \mathrm{p}=, 846)$. De la misma forma, si atendemos a la percepción subjetiva del estado de ánimo, las relaciones tampoco han sido significativas si bien rozan la significación estadística en la subescala de percepción del estado de ánimo deprimido $(\mathrm{r}=0,28 ; \mathrm{p}=, 052)$ de modo que al parecer a mayor nivel de estudios, mayor percepción de estado de ánimo deprimido (véase Tabla 41).

Tabla 41. Correlaciones de Spearman entre el nivel de estudios y los síntomas de ansiedad-depresión y percepción subjetiva de estado de ánimo (pacientes)

\begin{tabular}{ll} 
Cuestionarios & Nivel estudios \\
\hline Total HADS Ansiedad & $0,14(p=, 327)$ \\
\hline Total HADS Depresión & $0,02(p=, 861)$ \\
STAI- Estado & $0,04(p=, 810)$ \\
STAI- Rasgo & $0,08(p=, 649)$ \\
BDI & $-0,04(p=, 846)$ \\
EA1-Malestar general & $0,11(p=, 431)$ \\
EA2-Ansiedad y Nerviosismo & $0,15(p=, 311)$ \\
EA3-Estado de ánimo deprimido & $0,28(p=, 052)$
\end{tabular}


En cuanto a la valoración de la estancia en UCI las correlaciones no han sido significativas en ninguno de los aspectos valorados (véase Tabla 42), si bien la valoración de la atención de las necesidades psicológicas sería el único caso en que la relación se acercaría a la significación $(r=0,26 ; p=, 094)$.

Tabla 42. Correlaciones de Spearman entre el nivel de estudios y la Valoración de la estancia en UCI (pacientes)

\begin{tabular}{|c|c|}
\hline \multirow{2}{*}{$\begin{array}{l}\text { Ítem } \\
\text { - En qué grado está siendo agradable/desagradable su estancia } \\
\text { en UCl sin considerar los problemas médicos }\end{array}$} & Nivel estudios \\
\hline & $0,03(p=, 852)$ \\
\hline \multicolumn{2}{|l|}{ Valoración de los siguientes aspectos } \\
\hline 1. Cuidados médicos & $0,15(p=, 326)$ \\
\hline 2. Atención de los médicos & $0,03(p=, 825)$ \\
\hline 3. Atención de las/os enfermeras/os & $0,21(p=, 161)$ \\
\hline 4. Atención de las/os auxiliares de enfermería & $0,21(p=, 161)$ \\
\hline 5. Claridad de la información recibida & $0,18(p=, 250)$ \\
\hline 6. Cantidad de la información recibida & $0,03(p=, 851)$ \\
\hline 7. Trato por parte del personal de enfermería & $0,23(p=, 135)$ \\
\hline 8. Afecto/apoyo emocional del personal de enfermería & $0,06(p=, 712)$ \\
\hline 9. Respeto a la intimidad & $0,01(p=, 944)$ \\
\hline 10. Atención a los familiares & $-0,13(p=, 403)$ \\
\hline 11. Atención de necesidades psicológicas en paciente y familia & $0,26(p=, 094)$ \\
\hline 12. Calidad de las instalaciones (comodidad, higiene...) & $0,22(p=, 145)$ \\
\hline 13. Posibilidades de distraerse & $-0,02(p=, 923)$ \\
\hline 14. Silencio o tranquilidad en la sala & $-0,19(p=, 227)$ \\
\hline 15. Régimen de visitas & $0,01(p=, 951)$ \\
\hline
\end{tabular}

Por lo que respecta a la Escala de Factores estresantes (véase Tabla 43) no se han obtenido relaciones significativas entre el nivel de estudios y el nivel de estrés en general $(r=0,11 ; p=, 466)$. En cambio sí se han obtenido relaciones significativas a nivel estadístico entre el nivel de estudios y dos ítems de la escala: "estar hospitalizado lejos de casa" $(r=0,35 ; p=, 028)$ y "estar al cuidado de sanitarios desconocidos" $(r=0,35$; $p=, 021)$ siendo en ambos factores las relaciones de signo positivo, lo cual indicaría que a mayor nivel de estudios mayor grado de estrés generarían estos dos factores en los pacientes. 
Tabla 43. Correlaciones de Spearman entre el nivel de estudios y los Factores estresantes (pacientes)

$$
\text { Ítem }
$$

1. No disponer de baño en el box

$0,17(p=, 282$

2. Tener que estar en la cama/sillón todo el día

$0,20(p=, 195)$

3. Estar hospitalizado lejos de casa

$0,35(p=, 028)$

4. Dormir en una cama que no es la suya

5. Utilizar la cuña de cama

6. Que no respondan al timbre de aviso

7. Dormir junto a otros enfermos en la unidad

$0,17(p=, 262)$

$-0,00(p=, 991)$

$-0,15(p=, 530)$

$-0,11(p=, 478)$

8. Tener que ser ayudado para ir al baño

9. Tener que comer en la cama en una postura incómoda

$0,01(p=, 937)$

$0,21(p=, 187)$

$0,03(p=, 825)$

$0,35(p=, 021)$

11. Estar al cuidado de sanitarios desconocidos

12. Tener demasiadas visitas

13. Tener que estar todo el tiempo desnudo, únicamente cubierto con una sábana

$0,19(p=, 249)$

$-0,12(p=, 462)$

14. Necesitar ayuda para comer

15. No poder ver la TV/escuchar la radio/leer el periódico cuando uno quiere

$0,10(p=, 544)$

$-0,02(p=, 919)$

16. Escuchar ruidos de máquinas o gente hablar constantemente

$-0,02(p=, 887)$

$-0,17(p=, 282)$

$0,04(p=, 814)$

$0,31(p=, 224)$

$0,27(p=, 114)$

$0,00(p=, 976)$

$0,23(p=, 152)$

$0,07(p=, 677)$

$-0,09(p=, 550)$

$0,12(p=, 607)$

$0,07(p=, 676)$

$-0,10(p=, 514)$

$-0,14(p=, 415)$

$0,08(p=, 633)$

$-0,12(p=, 486)$

$0,04(p=, 788)$

$-0,09(p=, 650)$

$0,14(p=, 365)$

$0,03(p=, 885)$

$0,11(p=, 643)$

$-0,14(p=, 520)$

$-0,06(p=, 725)$

$0,15(p=, 332)$

$0,17(p=, 274)$

38. Sentir olores extraños en el hospital

39. Tener que comer a horas diferentes a las habituales

40. Nivel de estrés en general

Al analizar la calidad de vida de los pacientes (véase Tabla 44), las correlaciones con el nivel de estudios no han sido significativas ni antes $(\mathrm{r}=-0,27 ; \mathrm{p}=, 082)$ ni después del ingreso en UCI $(r=-0,13 ; p=, 399)$ aunque las relaciones entre el nivel de estudios y la calidad de vida previa al ingreso estarían cerca de lograr la significación, de manera que a medida que aumentarían los estudios de los pacientes menores serían las puntuaciones, lo que indicaría mejor calidad de vida. 
Tabla 44. Correlaciones de Spearman entre el nivel de estudios y la calidad de vida de los pacientes

Ítem Nivel de estudios

$\begin{array}{ll}\text { 1. Puntuación total en } \mathrm{CV} \text { previa al ingreso } & -0,27(p=, 082) \\ \text { 2. Puntuación total en } \mathrm{CV} \text { después del ingreso } & -0,13(p=, 399)\end{array}$

En cuanto al análisis en función del nivel de estudios de los distintos factores que ayudarían en el proceso de morir (CAMP), como podemos observar en la Tabla 45 se han obtenido relaciones estadísticamente significativas y de signo positivo en "creer en otra vida después de la muerte" $(r=0,39 ; p=, 029)$ y "no sentirse culpable por conflictos personales del pasado" $(\mathrm{r}=0,42 ; \mathrm{p}=, 013)$ lo cual parece indicar que a medida que aumenta el nivel de estudios los pacientes darían más importancia a estos dos factores llegado el momento de su muerte. De igual forma, se han obtenido relaciones casi significativas y positivas con el hecho de pensar "que el proceso sea corto en caso de sufrimiento" $(\mathrm{r}=0,34 ; \mathrm{p}=, 052)$, aspecto que también parece ser más importante en los pacientes con mayor nivel de estudios.

Tabla 45. Correlaciones de Spearman entre el nivel de estudios y los factores del CAMP (pacientes)

\begin{tabular}{|c|c|}
\hline Ítem & Nivel estudios \\
\hline 1. Controlar mi dolor y otros síntomas de malestar & $0,08(p=, 651)$ \\
\hline 2. Mi proceso de morir, si produce sufrimiento, será corto & $0,34(p=, 052)$ \\
\hline 3.Controlar hasta el final pensamientos y funciones fisiológicas & $0,10(p=, 554)$ \\
\hline 4. Mi muerte no supondrá una carga insoportable para mis seres queridos & $0,02(p=, 909)$ \\
\hline $\begin{array}{l}\text { 5. Poder sentirme cerca, comunicarme y estrechar vínculos afectivos con mis personas } \\
\text { queridas }\end{array}$ & $0,26(p=, 136)$ \\
\hline 6. Sin esperanza real de recuperación, no se alargará artificialmente mi vida en UCI & $0,09(p=, 603)$ \\
\hline 7. Pensar que mi vida ha tenido algún sentido & $-0,07(p=, 688)$ \\
\hline 8. Creer en otra vida después de la muerte & $0,39(p=, 029)$ \\
\hline 9. No sentirse culpable por conflictos personales del pasado & $0,42(p=, 013)$ \\
\hline 10. Si la situación se me hace insoportable disponer de ayuda para morir con rapidez & $0,26(p=, 135)$ \\
\hline 11. Poder morir en mi casa & $0,17(p=, 346)$ \\
\hline
\end{tabular}

En relación con la valoración del proceso de información y la toma de decisiones, no se han obtenido relaciones significativas con el nivel de estudios en ninguna de las subescalas del cuestionario (véase Tabla 46). 
Tabla 46. Correlaciones de Pearson entre el nivel de estudios y la Valoración del proceso de información y toma de decisiones (pacientes)

\begin{tabular}{|c|c|}
\hline CITD & Nivel estudios \\
\hline \multicolumn{2}{|l|}{ Importancia de los distintos agentes implicados } \\
\hline Papel de la familia en la información y toma de decisiones & $-0,25(p=, 383)$ \\
\hline Papel del paciente en la información y toma de decisiones & $0,30(p=, 293)$ \\
\hline Papel del médico en la información y toma de decisiones & $-0,09(p=, 735)$ \\
\hline Papel del psicólogo en la información y toma de decisiones & $0,28(p=, 287)$ \\
\hline \multicolumn{2}{|l|}{ Satisfacción con la información } \\
\hline Satisfacción con la cantidad y la claridad de la información recibida & $0,23(p=, 383)$ \\
\hline \multicolumn{2}{|l|}{ Estilo del médico } \\
\hline En cuanto al estilo del médico prefiero que éste sea directo y anticipe posibles sospechas & $0,27(p=, 313)$ \\
\hline En cuanto al estilo del médico prefiero que éste se guarde lo que aún no es seguro & $-0,22(p=, 402)$ \\
\hline \multicolumn{2}{|l|}{ Participación en TD } \\
\hline Me siento capacitado para participar en la TD sobre la salud & $0,21(p=, 434)$ \\
\hline Poder participar en una decisión médica sería más una carga que un privilegio & $-0,03(p=, 911)$ \\
\hline
\end{tabular}

\subsubsection{ANÁliSIS DE REGRESIÓN EN LA MUESTRA DE PACIENTES}

Por último, para el grupo de pacientes se han llevado a cabo análisis de regresión para conocer qué variables independientes podrían explicar aquellas otras variables más directamente relacionadas con la afectación psicológica y el malestar asociado a la experiencia de estar ingresado en una unidad de cuidados intensivos.

Las variables dependientes seleccionadas han sido por un lado las puntuaciones relativas a los síntomas de ansiedad y depresión, y por otro lado la valoración global de la estancia en UCI y el nivel de estrés general experimentado por los pacientes en este contexto, ya que estas dos últimas variables pueden proporcionar datos más específicos del entorno de una UCI. Respecto a las variables de tipo más emocional y dado que en la investigación se habían incluido diferentes medidas sobre sintomatología ansioso-depresiva, cabe señalar que hemos considerado pertinente llevar a cabo un análisis correlacional entre las mismas, confirmándose correlaciones significativas a nivel estadístico tanto entre las puntuaciones de las escalas que miden ansiedad, es decir, entre el HADS y el STAI-Estado $(r=0,57 ; p=, 000)$ así como entre las puntuaciones en depresión evaluadas mediante HADS y BDI $(r=0,68 ; p=, 000)$. Por tanto, con la finalidad de simplificar los análisis de regresión se han seleccionado como representativas de la sintomatología de ansiedad y depresión las puntuaciones totales obtenidas en las correspondientes subescalas del cuestionario HADS. 
En cuanto a las variables independientes a incluir en el análisis se han seleccionado por un lado las distintas variables sociodemográficas y clínicas. Asimismo, pensamos que en el caso de la valoración de la estancia y el nivel de estrés general el hecho de incluir como variables independientes otras de carácter más emocional, como las puntuaciones en síntomas de ansiedad y depresión, podría aportar información relevante. Así, las variables independientes consideradas en los análisis de regresión han sido las siguientes: género, edad, estado civil, número de hijos, nivel de estudios y patología de ingreso. Y además, tal como hemos comentado, en la valoración de la estancia en UCI y el nivel de estrés general se incluirán la puntuación total en ansiedad y depresión evaluadas mediante el HADS.

Tras seleccionar las variables criterio y las variables independientes se ha realizado el análisis de regresión lineal, analizándose tanto la capacidad predicitiva de cada variable por separado como de forma conjunta mediante el método de pasos sucesivos (stepwise). En la Tabla 47 se muestran los principales resultados obtenidos.

Respecto a la valoración global de la estancia en UCI, la ecuación de regresión obtenida indica que las variables demográficas y médicas no son predictoras de esta valoración, mientras que la ansiedad sí predice la valoración global de la estancia $(\beta=-$ $0,39 ; \mathrm{p}=, 038)$ explicando por sí sola el $11,9 \%$ de la varianza. Concretamente, los resultados indican que una mayor ansiedad predice una puntuación menor en la valoración de la estancia, o lo que es lo mismo una valoración más negativa de la estancia (véase Tabla 47).

En relación con el nivel de estrés general de los pacientes en UCI, hemos incluido en el análisis de regresión las mismas variables independientes consideradas en el análisis de la valoración de la estancia en UCI. Así, los resultados del análisis de regresión (véase Tabla 47) muestran que de entre todas las variables independientes consideradas, la única que por sí sola predice el nivel de estrés general es el estado civil $(\beta=-0,39 ; p=, 011)$, explicando el $13 \%$ de la varianza, de modo que no tener pareja predice mayor grado de estrés general. En cambio, al incluir en el análisis de regresión todas las variables independientes hemos obtenido cinco modelos diferentes. En el primero, la variable predictora del nivel general de estrés ha sido la patología de ingreso $(\beta=0,55 ; p=, 002)$ explicando el $27,3 \%$ de la varianza. En el segundo modelo, la patología de ingreso $(\beta=0,46 ; p=, 007)$ y el género $(\beta=0,33 ; p=, 044)$ explican el $35,6 \%$ de la varianza. El modelo 3, que incluye como variables predictoras del estrés del paciente 
en UCI la patología $(\beta=-0,39 ; p=, 011)$, el género $(\beta=-0,39 ; p=, 011)$ y el estado civil $(\beta=-$ 0,39; $p=, 011)$, explica el 44,7\% de la varianza. En el modelo 4, además de la patología $(\beta=0,28 ; p=, 075)$, el género $(\beta=0,35 ; p=, 016)$ y el estado civil $(\beta=-0,52 ; p=, 004)$, se incluye el tener o no hijos $(\beta=0,33 ; p=, 039)$ como variables que de forma conjunta explican el $51,9 \%$ de la varianza. Y finalmente, el modelo 5 explicaría el mayor porcentaje de la varianza. Así, según este último modelo, el nivel de estrés general de los pacientes es explicado en un $58,5 \%$ de su varianza de forma conjunta mediante la patología $(\beta=0,25$; $p=, 097)$, el género $(\beta=0,24 ; p=, 090)$, el estado civil $(\beta=-0,58 ; p=, 001)$, el tener o no hijos $(\beta=0,55 ; p=, 004)$ y la edad $(\beta=-0,36 ; p=, 039)$. Los resultados descritos indicarían que ser mujer, no tener pareja, tener hijos y tener menor edad predecirían mayor nivel de estrés en los pacientes. Y en cuanto a la patología de ingreso, los resultados señalarían que ésta predice el nivel de estrés general si bien los datos obtenidos a partir del análisis de regresión no permiten interpretar qué grupos diagnósticos serían los que predecirían más estrés. En este sentido, con la finalidad de conocer qué patología conllevaría mayor nivel de estrés podríamos hacer referencia a los análisis diferenciales realizados al respecto, en los cuales hemos obtenido que los pacientes diagnosticados de enfermedad séptica son los que presentan niveles más elevados de estrés general.

Por último, en el análisis de las variables ansiedad y depresión, se han incluido todas las variables sociodemográficas (género, edad, estado civil, número de hijos y nivel de estudios) y clínicas-médicas (patología de ingreso). Los resultados del análisis de regresión realizado muestran que las variables independientes seleccionadas, analizadas tanto de forma individual como de forma conjunta mediante el método de pasos sucesivos, no predicen la ansiedad ni la depresión. 
Tabla 47. Análisis de regresión (pacientes)

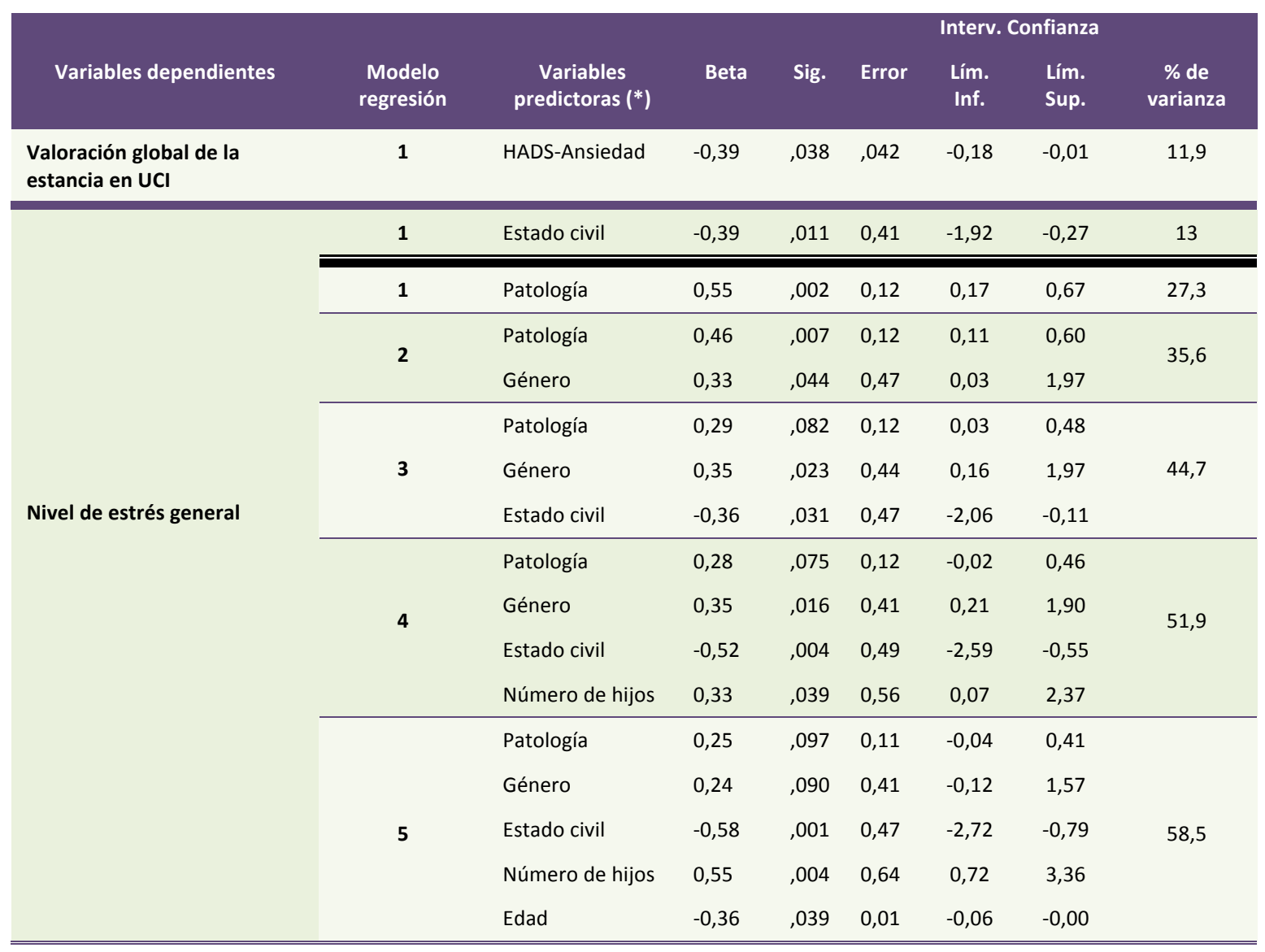

$\left.{ }^{*}\right)$ Codificación de las distintas variables independientes

\begin{tabular}{l|llll|} 
V. Independiente & \multicolumn{1}{|c}{ Patología } & \multicolumn{1}{c}{ Género } & \multicolumn{1}{c|}{ Estado civil } & Número de hijos \\
\hline 1. Coronario & 1. Hombre & 1. Sin pareja & 0. Sin hijos \\
2. Enfermedad médica & 2. Mujer & 2. Con pareja & 1. Con hijos \\
3. Neuroquirúrgico & & & \\
Codificación & 4. Séptico & & \\
5. Respiratorio & & \\
6. Traumatismos SNC & & \\
7. Traumatismo sin SNC & &
\end{tabular}




\subsection{RESULTADOS DE LA MUESTRA DE FAMILIARES}

\subsubsection{RESULTADOS DESCRIPTIVOS}

\subsubsection{Síntomas de ansiedad y depresión}

Los síntomas de ansiedad y depresión en el grupo de familiares al igual que en el de pacientes han sido evaluados mediante el HADS, el STAI y el BDI (instrumentos descritos en el capítulo 5) cuyos resultados detallaremos a continuación presentando en primer lugar los datos relativos a ansiedad y en segundo lugar los de depresión.

Los resultados obtenidos en síntomas de ansiedad a partir de la evaluación realizada con el HADS muestran una puntuación total media de 13,24 (DT=4,26) en una escala cuya máxima puntuación es de 21 puntos. Según la baremación utilizada en este instrumento, los valores obtenidos se situarían dentro del rango de lo que ya se consideraría como probable problema clínico (puntuaciones mayores de 10 puntos) (véase Gráfica 29). Atendiendo a la distribución de las puntuaciones obtenidas en la subescala de ansiedad del HADS vemos que el 76,4\% de los familiares presentaría un probable problema clínico, el $12,4 \%$ un posible problema clínico y sólo el $11,2 \%$ ha obtenido puntuaciones que se situarían dentro de la normalidad (véase Gráfica 26).

Gráfica 26. Distribución de las puntuaciones en Ansiedad según el baremo de la escala HADS (familiares)

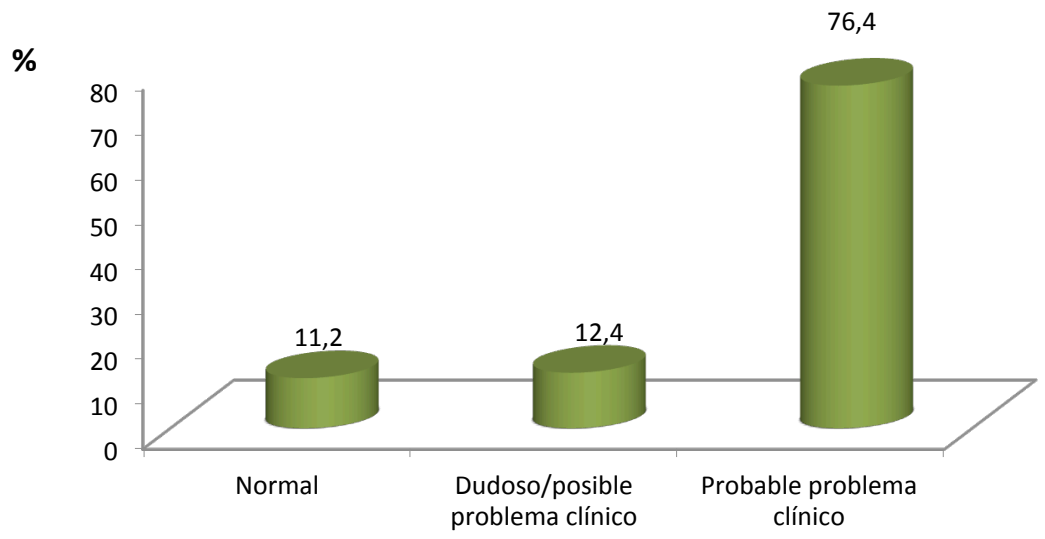

En cuanto a los síntomas de ansiedad evaluados mediante el cuestionario STAI, los resultados muestran una puntuación media en ansiedad-estado de 36,36 (DT=12,66) y en ansiedad-rasgo de 22,92 (DT=10,31) (véase Gráfica 29). Siguiendo las indicaciones del baremo del instrumento para la A-E, la puntuación obtenida en el caso de los hombres equivaldría al percentil 89 y en el caso de las mujeres al percentil 85 y para la 
A-R la puntuación se correspondería con el percentil 65 en los hombres y el percentil 45 en las mujeres. Al igual que ya comentamos en el apartado de resultados relativos a los pacientes, cabe recordar que el rango de puntuaciones del STAI, tanto en ansiedadestado como en ansiedad-rasgo, varía entre 0 y 60 . El punto de corte se establece en el percentil 75 .

Respecto a los síntomas de depresión, los resultados obtenidos mediante el HADS ofrecen una puntuación media de 11,48 (DT=4,65) lo cual atendiendo al baremo del cuestionario indicaría que la mayoría de la muestra se encuentra dentro del rango de lo que se consideraría probable problema clínico (>10 puntos) (véase Gráfica 29). Si analizamos la distribución de las puntuaciones obtenidas en esta subescala del HADS podemos observar que el 59,6\% de los familiares presentaría probable problema clínico, el 16,9\% posible problema clínico y el 23,6\% restante presentaría puntuaciones normales en depresión (véase Gráfica 27).

Gráfica 27. Distribución de las puntuaciones en Depresión según el baremo de la escala HADS (familiares)

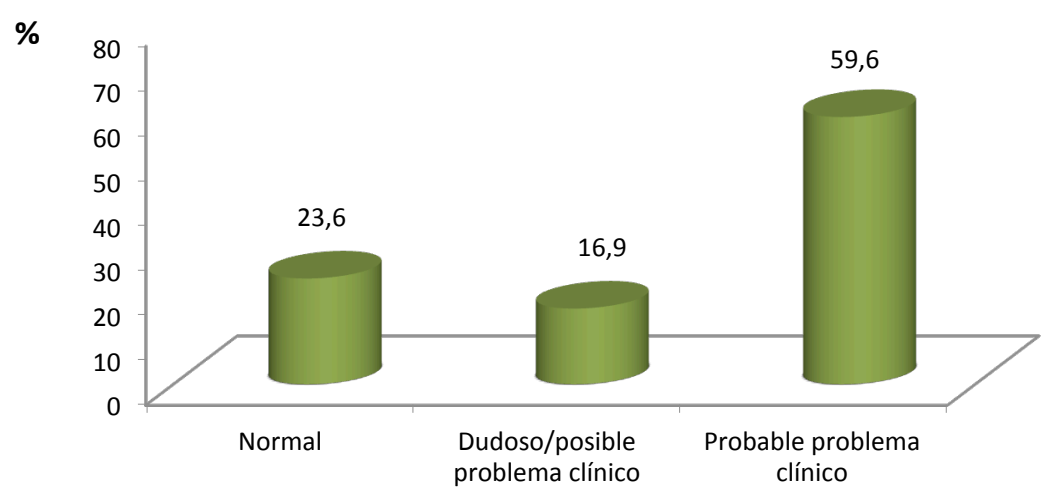

Por otro lado, los resultados de los síntomas de depresión evaluados mediante el cuestionario BDI, muestran una puntuación media de 16,60 (DT=8,54) sobre una puntuación total posible de 63 puntos. En este caso, la puntuación se correspondería con lo que se considera depresión leve (10-18 puntos) (véase Gráfica 29). Analizando la distribución de las puntuaciones obtenidas mediante el BDI observamos que éstas indican ausencia de depresión en el $20 \%$ de los familiares, mientras que el 37,5\% presenta un grado de depresión leve, el 35\% depresión moderada y el 7,5\% depresión grave (véase Gráfica 28). 
Gráfica 28. Distribución de las puntuaciones en Depresión según el baremo del cuestionario BDI (familiares)

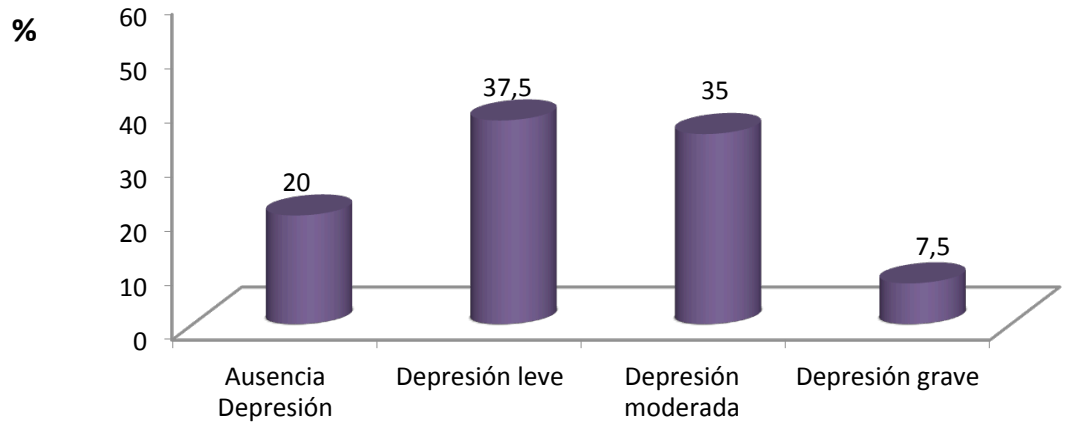

Gráfica 29. Medias de las puntuaciones totales en ansiedad y depresión en familiares evaluadas mediante distintos cuestionarios

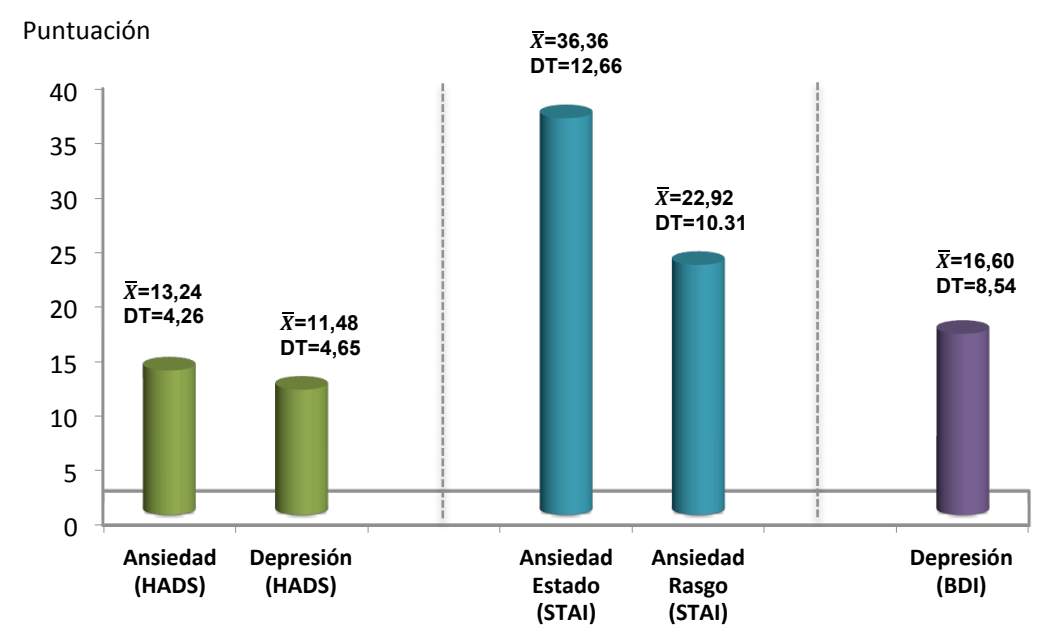

\subsubsection{Percepción subjetiva del malestar emocional}

Se evaluó la percepción subjetiva de malestar emocional que presentaban los familiares de los pacientes ingresados en la Unidad mediante la Escala de estado de ánimo. Así, los participantes valoraron en una escala de 0 a 10 el grado de malestar general, ansiedad y estado de ánimo deprimido que percibían en ellos mismos.

Como se aprecia en la Gráfica 30, las puntuaciones medias obtenidas en malestar general $(\bar{X}=6,41 ; \mathrm{DT}=2,57)$ y ánimo deprimido $(\bar{X}=6,43$; DT=2,86) son muy similares y ligeramente inferiores a la media obtenida en la percepción de ansiedad $(\bar{X}=7,07$; $\mathrm{DT}=2,25)$. 
Gráfica 30. Medias de las puntuaciones totales de malestar subjetivo en familiares (Escala 0-10)

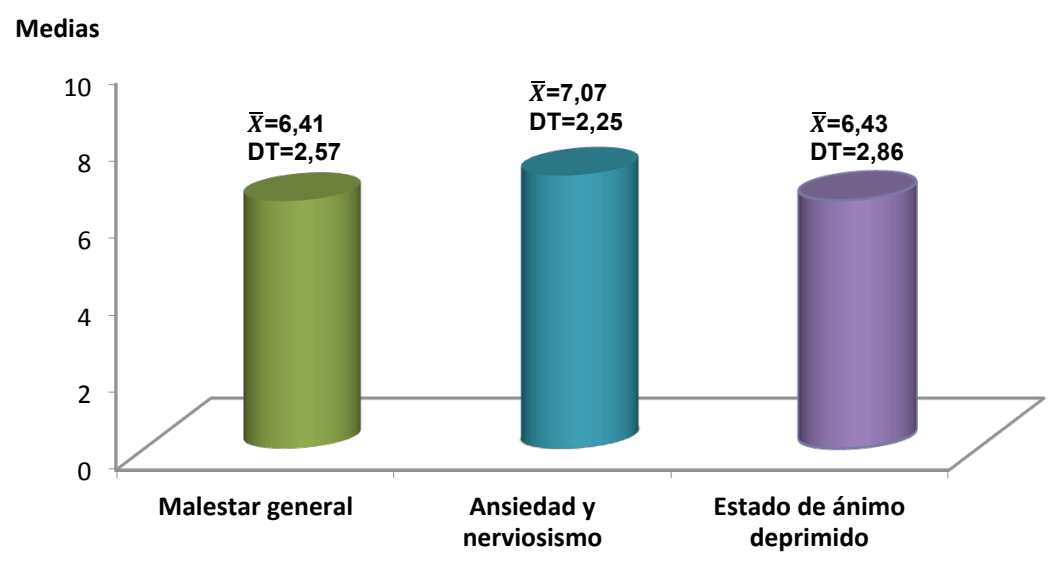

\subsubsection{Valoración de la estancia en la Unidad de Cuidados Intensivos}

Otro de los aspectos que consideramos relevante evaluar ha sido la valoración de la estancia en UCI desde el punto de vista de los familiares. En primer lugar los participantes han valorado de forma global la estancia de su ser querido en la unidad sin tener en cuenta la situación médica que motivó su ingreso, obteniéndose una puntuación media de 3,31 ( $\mathrm{DT}=1,76)$ en una escala de 0 (muy desagradable) a 5 (muy agradable). En segundo lugar los familiares han valorado cuestiones particulares inherentes a este contexto como pueden ser los cuidados y atenciones recibidos a distintos niveles, el respeto a la intimidad, el silencio, el régimen de visitas, las instalaciones y las posibilidades de distraerse. Analizando los resultados obtenidos respecto a la valoración de cada uno de estos aspectos podemos observar que la mayoría de ítems han sido valorados de forma positiva con puntuaciones que superan los cuatro puntos sobre una puntuación total de 5. En este sentido, cabe señalar que las puntuaciones medias más altas corresponden a la valoración de la "atención de las necesidades psicológicas de pacientes y familiares" $(\bar{X}=4,79$; DT=0,57), los “cuidados médicos" $(\bar{X}=4,64 ; \mathrm{DT}=0,67)$, las “atenciones médicas" $(\bar{X}=4,59 ; \mathrm{DT}=0,73)$ seguido por la "atención de los auxiliares de enfermería" $(\bar{X}=4,52 ; \mathrm{DT}=0,69)$ y las "atenciones de enfermeros/as" $(\bar{X}=4,42 ; \mathrm{DT}=0,80)$. El resto de ítems aun habiendo sido menos valorados, presentan puntuaciones que todavía están por encima de los cuatro puntos a excepción de la valoración del "régimen de visitas" ( $\bar{X}=3,99 ; \mathrm{DT}=1,01)$, el "silencio y la tranquilidad en la sala" $(\bar{X}=3,68 ; \mathrm{DT}=1,22)$ y la valoración sobre las "posibilidades de distraerse" $(\bar{X}=2,03 ; \mathrm{DT}=1,68)$, siendo este último aspecto el que ha obtenido una puntuación media menor de todos ítems del cuestionario (véase Tabla 48 y Gráfica 31). 
Analizando los resultados obtenidos en términos de frecuencias y en relación con la valoración global de la estancia en UCI podemos observar que ésta ha sido valorada como muy agradable por el $34,7 \%$ de los familiares frente al 9,7\% de participantes que la han valorado como muy desagradable. El resto de porcentajes han sido distribuidos entre opciones de respuesta intermedias. En cuanto a la valoración del resto de ítems relativos a la estancia en UCI podemos observar que el $83,8 \%$ de los familiares han valorado "muy bien" la atención de las necesidades psicológicas de los pacientes y familiares. De la misma forma han sido "muy bien" valorados con porcentajes comprendidos entre el 70\% y 57\% los cuidados y atenciones del resto de profesionales sanitarios incluidos médicos y enfermería. Siguiendo en esta línea de valoraciones positivas, observamos que en torno a la mitad de los familiares han concedido la máxima puntuación a la valoración de aspectos como la claridad de la información recibida $(54,5 \%)$, la atención a los familiares $(54,1 \%)$ y el respeto a la intimidad $(48 \%)$. Mientras que otros ítems han sido "muy bien" valorados por porcentajes más reducidos de familiares. Tal es el caso del régimen de visitas (32,9\%), la calidad de las instalaciones (32\%), el silencio o tranquilidad en la sala $(25,7 \%)$ y las posibilidades de distraerse, aspecto al que tan sólo el 7,1\% de los familiares le ha concedido la máxima valoración (véase Tabla 49).

Atendiendo a los resultados obtenidos en las categorías de respuesta más negativas podemos ver que sólo cinco ítems de los quince que componen el cuestionario han sido "muy mal" valorados por los familiares. No obstante, los porcentajes encontrados en esta opción de respuesta podemos considerar que son más bien reducidos. Concretamente, los familiares han valorado como "muy mal" las posibilidades de distraerse (32,9\%), el apoyo emocional recibido por enfermería $(2,7 \%)$, el silencio en la sala $(2,7 \%)$, la calidad de las instalaciones $(1,3 \%)$ y el régimen de visitas $(1,3 \%)$. 
Tabla 48. Puntuaciones medias de los ítems del Cuestionario de Valoración de la estancia en UCI según los familiares

\begin{tabular}{|c|c|c|}
\hline Ítem & $\bar{X}$ & DT \\
\hline $\begin{array}{l}\text { - En qué grado está siendo agradable/desagradable su estancia en UCI sin considerar los } \\
\text { problemas médicos. }\end{array}$ & 3,31 & 1,76 \\
\hline Valoración de los siguientes aspectos & $\bar{X}$ & DT \\
\hline 1. Cuidados médicos & 4,64 & 0,67 \\
\hline 2. Atención de los médicos & 4,59 & 0,73 \\
\hline 3. Atención de las/os enfermeras/os & 4,42 & 0,80 \\
\hline 4. Atención de las/os auxiliares de enfermería & 4,52 & 0,69 \\
\hline 5. Claridad de la información recibida & 4,31 & 0,93 \\
\hline 6. Cantidad de la información recibida & 4,12 & 0,94 \\
\hline 7. Trato por parte del personal de enfermería & 4,47 & 0,66 \\
\hline 8. Afecto/apoyo emocional del personal de enfermería & 4,05 & 1,16 \\
\hline 9. Respeto a la intimidad & 4,31 & 0,85 \\
\hline 10. Atención a los familiares & 4,36 & 0,87 \\
\hline 11. Atención de necesidades psicológicas en paciente y familia & 4,79 & 0,57 \\
\hline 12. Calidad de las instalaciones (comodidad, higiene...) & 4 & 0,99 \\
\hline 13. Posibilidades de distraerse & 2,03 & 1,68 \\
\hline 14. Silencio o tranquilidad en la sala & 3,68 & 1,22 \\
\hline 15. Régimen de visitas & 3,99 & 1,01 \\
\hline
\end{tabular}

Gráfica 31. Puntuaciones medias de los ítems del Cuestionario de Valoración de la estancia en UCI según los familiares

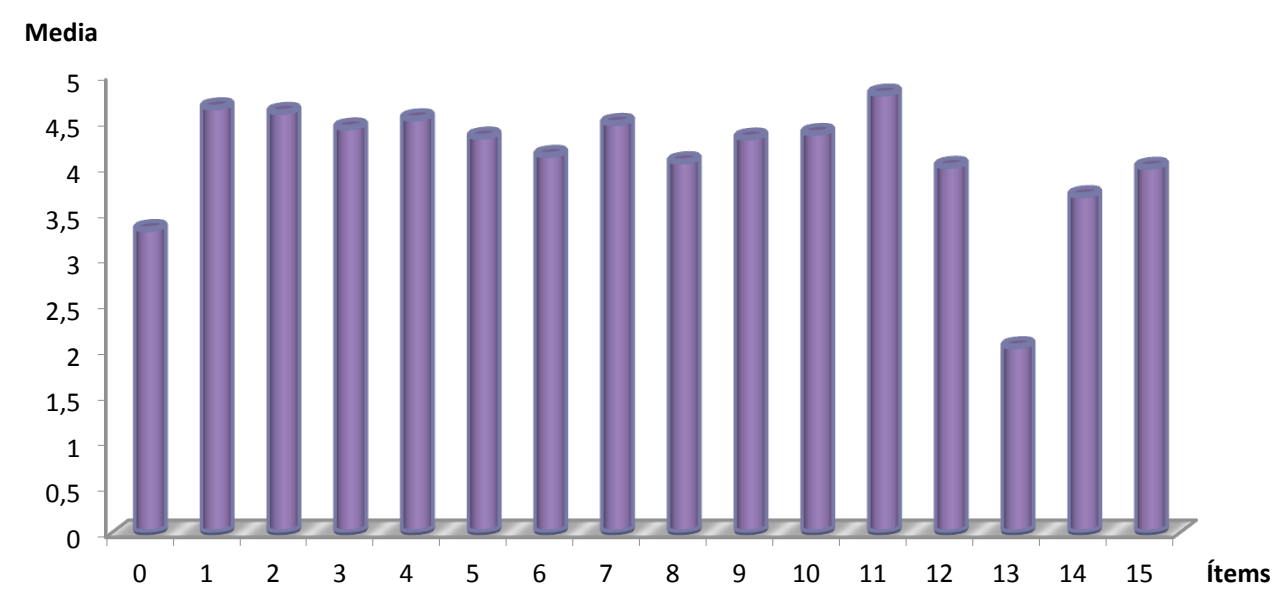
0 . En qué grado la estancia en UCI ha sido agradable o desagradable, sin considerar problemas médicos.
8. Afecto/apoyo emocional recibido por enfermería.
1. Cuidados médicos.
9. Respeto a la intimidad
2. Atención de los médicos.
3. Atención de los enfermeros/as.
10. Atención a los familiares.
4. Atención de los auxiliares de enfermería.
11. Atención a necesidades psicológicas de pacientes y familiares.
5. Claridad de la información recibida.
12. Calidad de las instalaciones.
6. Cantidad de la información recibida.
13. Posibilidades de distraerse.
7. Trato por parte del personal de enfermería.
14. Silencio y tranquilidad en la sala.
15. Régimen de visitas. 
Tabla 49. Porcentajes en las distintas opciones de respuesta de los ítems del Cuestionario de Valoración de la estancia en UCI según los familiares

\begin{tabular}{|c|c|c|c|c|c|c|}
\hline Ítem & $\begin{array}{c}\text { Muy } \\
\text { desagradable }\end{array}$ & $\begin{array}{c}\text { Bastante } \\
\text { desagradable }\end{array}$ & $\begin{array}{c}\text { Algo } \\
\text { desagradable }\end{array}$ & $\begin{array}{c}\text { Algo } \\
\text { agradable }\end{array}$ & $\begin{array}{l}\text { Bastante } \\
\text { agradable }\end{array}$ & $\begin{array}{c}\text { Muy } \\
\text { agradable }\end{array}$ \\
\hline $\begin{array}{l}\text { - En qué grado está siendo } \\
\text { agradable/desagradable su } \\
\text { estancia en UCl sin considerar } \\
\text { los problemas médicos }\end{array}$ & 9,7 & 13,9 & 8,3 & 6,9 & 26,4 & 34,7 \\
\hline $\begin{array}{l}\text { Valoración de los siguientes } \\
\text { aspectos }\end{array}$ & Muy mal & Bastante mal & Algo mal & Algo bien & $\begin{array}{l}\text { Bastante } \\
\text { bien }\end{array}$ & Muy bien \\
\hline 1. Cuidados médicos & 0 & 1,3 & 0 & 2,6 & 26 & 70,1 \\
\hline 2. Atención de los médicos & 0 & 1,3 & 0 & 6,6 & 22,4 & 69,7 \\
\hline $\begin{array}{l}\text { 3. Atención de las/os } \\
\text { enfermeras/os }\end{array}$ & 0 & 0 & 2,6 & 11,8 & 26,3 & 59,2 \\
\hline $\begin{array}{l}\text { 4. Atención de las/os } \\
\text { auxiliares de enfermería }\end{array}$ & 0 & 0 & 0 & 11 & 26 & 63 \\
\hline $\begin{array}{l}\text { 5. Claridad de la } \\
\text { información recibida }\end{array}$ & 0 & 1,3 & 5,2 & 9,1 & 29,9 & 54,5 \\
\hline $\begin{array}{l}\text { 6. Cantidad de la } \\
\text { información recibida }\end{array}$ & 0 & 0 & 9,1 & 11,7 & 37,7 & 41,6 \\
\hline $\begin{array}{l}\text { 7. Trato por parte del } \\
\text { personal de enfermería }\end{array}$ & 0 & 0 & 0 & 9,2 & 34,2 & 56,6 \\
\hline $\begin{array}{l}\text { 8. Afecto/apoyo emocional } \\
\text { del personal de } \\
\text { enfermería }\end{array}$ & 2,7 & 1,4 & 4,1 & 16,4 & 30,1 & 45,2 \\
\hline 9. Respeto a la intimidad & 0 & 1,3 & 4 & 5,3 & 41,3 & 48 \\
\hline 10. Atención a los familiares & 0 & 2,7 & 0 & 9,5 & 33,8 & 54,1 \\
\hline $\begin{array}{l}\text { 11. Atención de necesidades } \\
\text { psicológicas en paciente y } \\
\text { familia }\end{array}$ & 0 & 1,4 & 0 & 0 & 14,9 & 83,8 \\
\hline $\begin{array}{l}\text { 12. Calidad de las } \\
\text { instalaciones } \\
\text { (comodidad, higiene...) }\end{array}$ & 1,3 & 1,3 & 4 & 14,7 & 46,7 & 32 \\
\hline $\begin{array}{l}\text { 13. Posibilidades de } \\
\text { distraerse }\end{array}$ & 32,9 & 4,3 & 17,1 & 25,7 & 12,9 & 7,1 \\
\hline $\begin{array}{l}\text { 14. Silencio o tranquilidad en } \\
\text { la sala }\end{array}$ & 2,7 & 4,1 & 8,1 & 18,9 & 40,5 & 25,7 \\
\hline 15. Régimen de visitas & 1,3 & 1,3 & 5,3 & 14,5 & 44,7 & 32,9 \\
\hline
\end{tabular}

\subsubsection{Percepción de estrés en UCI desde el punto de vista de los familiares}

Conocer el grado de estrés percibido por los familiares de los pacientes ingresados en la unidad ha sido una cuestión relevante en nuestra investigación. En este sentido se ha analizado tanto la percepción global como el estrés asociado a distintos aspectos de la experiencia de tener ingresado en UCI a un ser querido. 
Los resultados obtenidos en la escala de factores estresantes se muestran en la Tabla 50 donde podemos apreciar que la puntuación media en estrés general de los familiares es de 3,03 (DT=1,03) en un rango de 0 a 4 puntos. Si analizamos la distribución de la muestra en función de las distintas opciones de respuesta observamos que los mayores porcentajes en cuanto a la percepción global de estrés corresponden a las categorías de muchísimo (40,5\%) y mucho estrés (33,8\%) (véase Gráfica 32).

Gráfica 32. Nivel general de estrés en Familiares de UCI

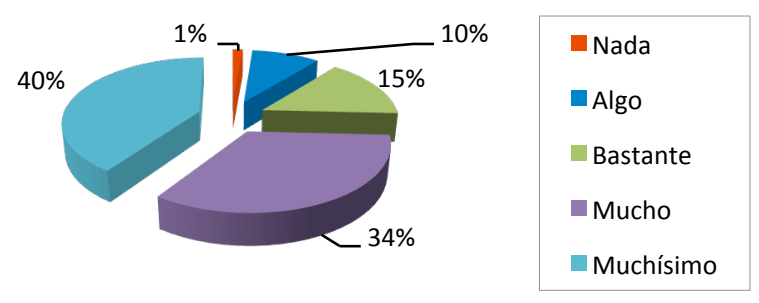

Al analizar el resto de ítems de la Escala de Factores Estresantes para los familiares de UCI observamos que los factores que han obtenido las puntuaciones medias mayores están relacionados con el hecho de que al paciente le pueda ocurrir algo grave $(\bar{X}=3,68 ; \mathrm{DT}=0,85)$ o incluso que pueda morir $(\bar{X}=3,48 ; \mathrm{DT}=1,17)$ seguido por el ítem relativo a que el ingreso en estas unidades suele ser inesperado $(\bar{X}=3,10$; $\mathrm{DT}=1,29$ ). Igualmente, han alcanzado puntuaciones altas (puntuaciones medias próximas a 3 puntos) ítems referentes tanto a posibles secuelas que impidan al paciente volver a su vida normal (ítem 4) como al dolor que éste pueda experimentar (ítem $1 \mathrm{e}$ ítem 14). Otros factores que también generan un grado de estrés considerable (puntuaciones medias superiores a 2 puntos) están relacionados con el estrés causado por la incertidumbre asociada a una intervención quirúrgica (ítem 6), estar separado del enfermo (ítem 7), que el paciente manifieste temor (ítem 37) y no saber en qué consiste la enfermedad (ítem 2) ni cuándo van a darle el alta de UCI (ítem 8). En cambio los factores que han sido valorados como menos estresantes por la familia son el tener demasiados horarios de visita $(\bar{X}=0,37 ; \mathrm{DT}=0,93)$, tener que comer a horas poco habituales para acudir a las visitas $(\bar{X}=0,45$; DT $=0,98)$ y que el enfermo esté al cuidado de sanitarios desconocidos $(\bar{X}=0,49 ; \mathrm{DT}=1,05)$. Otros ítems que también han obtenido puntuaciones bajas (inferiores a un punto) están relacionadas con la posible pérdida de dinero a causa de la enfermedad $(\bar{X}=0,60 ; \mathrm{DT}=1,14)$, tener que ver durante las visitas a otros enfermos muy graves $(\bar{X}=0,62 ; \mathrm{DT}=1,13)$, los horarios de visitas $(\bar{X}=0,79$; 
$\mathrm{DT}=1,35)$, que el paciente sea atendido por diferentes médicos $(\bar{X}=0,86 ; \mathrm{DT}=1,22)$, pensar que el tiempo de información resulta insuficiente $(\bar{X}=0,93 ; \mathrm{DT}=1,36)$ y sentir olores extraños $(\bar{X}=0,93 ; \mathrm{DT}=1,44)$.

Tabla 50. Medias de los factores estresantes en familiares de pacientes ingresados en UCI

\begin{tabular}{|c|c|c|c|}
\hline \multicolumn{2}{|c|}{ Ítem } & \multirow{2}{*}{$\begin{array}{c}\bar{X} \\
2,84\end{array}$} & \multirow{2}{*}{$\begin{array}{c}\text { DT } \\
1,29\end{array}$} \\
\hline 1. & Que el enfermo pueda tener dolor & & \\
\hline 2. & No saber con seguridad o no entender en qué consiste la enfermedad & 2,35 & 1,44 \\
\hline 3. & Pensar que le puede ocurrir algo grave & 3,68 & 0,85 \\
\hline 4. & Pensar si podrá volver a su vida normal después de salir del hospital & 2,89 & 1,49 \\
\hline 5. & No poder ocuparse usted de la familia como hasta ahora venía haciendo & 1,87 & 1,63 \\
\hline 6. & No saber con seguridad cómo quedará después de la operación & 2,72 & 1,45 \\
\hline 7. & Estar separado del enfermo & 2,67 & 1,42 \\
\hline 8. & No saber cuándo le darán el alta de la unidad de cuidados intensivos & 2,14 & 1,54 \\
\hline 9. & Haber sido hospitalizado de repente, sin esperarlo & 3,10 & 1,29 \\
\hline 10. & No saber los resultados/razones de los tratamientos/pruebas que le hacen & 1,74 & 1,47 \\
\hline 11. & Tener que organizarse para poder acudir a las visitas & 0,92 & 1,24 \\
\hline 12. & Pensar que puede tener dolor a causa de la operación/análisis & 2,35 & 1,31 \\
\hline 13. & No saber cuándo van a hacerle cosas al enfermo & 1,62 & 1,43 \\
\hline 14. & Pensar que el paciente pueda no obtener alivio para el dolor aun tomando medicación & 2,88 & 1,25 \\
\hline 15. & Ver que el personal del hospital tiene prisa & 1,37 & 1,57 \\
\hline 16. & El hospital en que está ingresado el paciente se encuentra lejos de casa & 1,29 & 1,58 \\
\hline 17. & Que sanitarios hablen deprisa o usen palabras que no pueden entender & 1,19 & 1,37 \\
\hline 18. & Que el personal sanitario no conteste a sus preguntas & 1,94 & 1,48 \\
\hline 19. & Tener que dormir fuera del domicilio habitual & 1,45 & 1,74 \\
\hline 20. & Preocupación por que no le den la medicación para el dolor cuando la necesita & 1,67 & 1,55 \\
\hline 21. & Pensar en la posible pérdida de dinero a causa de la enfermedad & 0,60 & 1,14 \\
\hline 22. & Sentir olores extraños en el hospital & 0,93 & 1,44 \\
\hline 23. & Tener que comer a horas diferentes a las habituales para poder ir a las visitas & 0,45 & 0,98 \\
\hline 24. & No poder llamar al paciente por teléfono & 1,50 & 1,72 \\
\hline 25. & Que el enfermo esté al cuidado de sanitarios desconocidos & 0,49 & 1,05 \\
\hline 26. & Tener demasiados horarios de visita & 0,37 & 0,93 \\
\hline 27. & Tener que ver en la sala durante las visitas a otros enfermos muy graves & 0,62 & 1,13 \\
\hline 28. & Miedo a que el paciente pueda morir & 3,48 & 1,17 \\
\hline 29. & Que el paciente sea atendido por diferentes médicos durante su ingreso & 0,86 & 1,22 \\
\hline 30. & Que los familiares sean informados por diferentes médicos & 1,20 & 1,40 \\
\hline 31. & Esperar para entrar a las diferentes horas de visita & 1,54 & 1,51 \\
\hline 32. & No poder estar junto al enfermo todo el tiempo (restringida la permanencia en la unidad) & 1,77 & 1,64 \\
\hline 33. & Tener que desplazarse a diario para visitar al enfermo en las 4 horas de visita & 1,07 & 1,50 \\
\hline 34. & Los horarios en que están concertadas las visitas al enfermo en la unidad & 0,79 & 1,35 \\
\hline 35. & Que el enfermo permanezca solo durante todo el día junto a otros pacientes graves & 1,29 & 1,43 \\
\hline 36. & Que el paciente no descanse adecuadamente por el ruido & 1,24 & 1,34 \\
\hline 37. & Que el paciente manifieste temor & 2,45 & 1,41 \\
\hline 38. & Que el paciente tenga que permanecer aislado por prescripción médica & 1,83 & 1,59 \\
\hline 39. & Pensar que el tiempo de información para los familiares resulta insuficiente & 0,93 & 1,36 \\
\hline 40. & Nivel de estrés en general & 3,03 & 1,03 \\
\hline
\end{tabular}


El análisis en términos de frecuencias de los resultados obtenidos mediante la Escala de Factores Estresantes puede aportar información relevante a nivel clínico. En este sentido, como podemos apreciar en la Tabla 51 los datos muestran que a un porcentaje considerable de los familiares les genera de "mucho a muchísimo" estrés pensar que le pueda ocurrir algo grave a su ser querido $(91,8 \%)$ o que pueda morir (85\%), el haber sido hospitalizados inesperadamente en UCI $(75,7 \%)$ y que el paciente no obtenga alivio para el dolor aun tomando medicación (73,7\%). Otros factores que también generan estrés para un porcentaje importante de familiares están relacionados con el hecho de pensar si el paciente podrá volver a su vida normal al salir del hospital $(68,5 \%)$, no saber cómo quedará después de la intervención quirúrgica $(65,7 \%)$, estar separado del enfermo (60,3\%) y no saber en qué consiste la enfermedad (60,3\%). Y en menor medida, aproximadamente para la mitad de los familiares resulta estresante que el paciente manifieste temor $(53,4 \%)$ y otros aspectos relacionados con el dolor como pensar que pueda tener dolor por las pruebas o análisis $(47,8 \%)$ y que no le den la medicación para el dolor cuando la necesite $(40,9 \%)$.

En cuanto a los factores menos estresantes podemos observar en la Tabla 51 que para un porcentaje importante de familiares no genera "nada" de estrés el tener demasiados horarios de visita $(81,4 \%)$, que el enfermo esté al cuidado de sanitarios desconocidos $(76,4 \%)$, tener que comer a horas diferentes para poder ir a ver a su ser querido $(75,7 \%)$ y pensar en la posible pérdida de dinero por la enfermedad $(71,2 \%)$. En porcentajes más modestos, a los familiares evaluados no les genera estrés ver en la sala durante las visitas otros enfermos muy graves $(68,9 \%)$, los horarios en que están concertadas las visitas $(66,2 \%)$, sentir olores extraños en el hospital (63\%) y pensar que el tiempo dedicado a la información es insuficiente (61,6\%). No obstante, no podemos obviar que estos mismos aspectos generan estrés en un nada despreciable $18 \%$ a $38 \%$ de los familiares. 
Tabla 51. Porcentajes de los principales estresores en familiares de pacientes de UCI

\begin{tabular}{|c|c|c|c|c|c|c|}
\hline \multicolumn{2}{|c|}{ Ítem } & \multirow{2}{*}{$\begin{array}{l}\text { Nada } \\
9\end{array}$} & \multirow{2}{*}{$\begin{array}{l}\text { Algo } \\
7,5\end{array}$} & \multirow{2}{*}{$\begin{array}{l}\text { Bastante } \\
14,9\end{array}$} & \multirow{2}{*}{$\begin{array}{l}\text { Mucho } \\
28,4\end{array}$} & \multirow{2}{*}{$\begin{array}{l}\text { Muchísimo } \\
40,3\end{array}$} \\
\hline 1. & Que el enfermo pueda tener dolor & & & & & \\
\hline 2. & No saber/no entender en qué consiste la enfermedad & 17,5 & 14,3 & 7,9 & 36,5 & 23,8 \\
\hline 3. & Pensar que le puede ocurrir algo grave & 2,7 & 1,4 & 4,1 & 8,2 & 83,6 \\
\hline 4. & Pensar si podrá volver a su vida normal al salir del hospital & 15,1 & 4,1 & 12,3 & 13,7 & 54,8 \\
\hline 5. & No poder ocuparse usted de la familia como hasta ahora & 32,8 & 13,4 & 14,9 & 11,9 & 26,9 \\
\hline 6. & No saber con seguridad cómo quedará tras la operación & 12,5 & 12,5 & 9,4 & 21,9 & 43,8 \\
\hline 7. & Estar separado del enfermo & 11 & 13,7 & 15,1 & 17,8 & 42,5 \\
\hline 8. & No saber cuándo le darán el alta de UCI & 22,9 & 14,3 & 17,1 & 17,1 & 28,6 \\
\hline 9. & Haber sido hospitalizado de repente, sin esperarlo & 10 & 1,4 & 12,9 & 20 & 55,7 \\
\hline 10. & No saber los resultados/razones tratamientos & 28,8 & 18,2 & 21,2 & 13,6 & 18,2 \\
\hline 11. & Tener que organizarse para poder acudir a las visitas & 57,5 & 11 & 19,2 & 6,8 & 5,5 \\
\hline 12. & Pensar que puede tener dolor a causa de operación/análisis & 11,6 & 14,5 & 26,1 & 23,2 & 24,6 \\
\hline 13. & No saber cuándo van a hacerle cosas al enfermo & 30,4 & 23,2 & 13 & 20,3 & 13 \\
\hline 14. & $\begin{array}{l}\text { Pensar que el paciente no obtenga alivio para el dolor aún } \\
\text { tomando medicación }\end{array}$ & 8,8 & 7 & 10,5 & 35,1 & 38,6 \\
\hline 15. & Ver que el personal del hospital tiene prisa & 48,5 & 10,3 & 14,7 & 8,8 & 17,6 \\
\hline 16. & El hospital se encuentra lejos de casa & 52,1 & 9,9 & 11,3 & 9,9 & 16,9 \\
\hline 17. & Sanitarios hablen deprisa/usen palabras que no entienden & 45,6 & 19,3 & 14 & 12,3 & 8,8 \\
\hline 18. & Que el personal sanitario no conteste a sus preguntas & 27,1 & 8,3 & 29,2 & 14,6 & 20,8 \\
\hline 19. & Tener que dormir fuera del domicilio habitual & 52,8 & 7,5 & 5,7 & 9,4 & 24,5 \\
\hline 20. & $\begin{array}{l}\text { Preocupación por si no le dan medicación para el dolor } \\
\text { cuando necesite }\end{array}$ & 39,4 & 9,1 & 10,6 & 27,3 & 13,6 \\
\hline 21. & Pensar en la posible pérdida de dinero por la enfermedad & 71,2 & 12,3 & 6,8 & 4,1 & 5,5 \\
\hline 22. & Sentir olores extraños en el hospital & 63 & 11 & 8,2 & 5,5 & 12,3 \\
\hline 23. & Tener que comer a horas diferentes para ir a las visitas & 75,7 & 14,9 & 2,7 & 2,7 & 4,1 \\
\hline 24. & No poder llamar al paciente por teléfono & 51,4 & 5,7 & 7,1 & 12,9 & 22,9 \\
\hline 25. & Que el enfermo esté al cuidado de sanitarios desconocidos & 76,4 & 11,1 & 4,2 & 4,2 & 4,2 \\
\hline 26. & Tener demasiados horarios de visita & 81,4 & 10 & 1,4 & 4,3 & 2,9 \\
\hline 27. & Ver en la sala durante las visitas otros enfermos muy graves & 68,9 & 14,9 & 6,8 & 4,1 & 5,4 \\
\hline 28. & Miedo a que el paciente pueda morir & 6,8 & 2,7 & 5,5 & 5,5 & 79,5 \\
\hline 29. & Paciente sea atendido por distintos médicos durante ingreso & 55,4 & 20,3 & 14,9 & 1,4 & 8,1 \\
\hline 30. & Que los familiares sean informados por diferentes médicos & 45,9 & 20,3 & 12,2 & 10,8 & 10,8 \\
\hline 31. & Esperar para entrar a las diferentes horas de visita & 36,5 & 20,3 & 12,2 & 14,9 & 16,2 \\
\hline 32. & No poder estar junto al enfermo todo el tiempo & 33,8 & 18,9 & 10,8 & 9,5 & 27 \\
\hline 33. & $\begin{array}{l}\text { Tener que desplazarse para visitar al enfermo en las } 4 \text { horas } \\
\text { de visita }\end{array}$ & 57,7 & 14,1 & 5,6 & 8,5 & 14,1 \\
\hline 34. & Los horarios en que están concertadas las visitas en la unidad & 66,2 & 15,5 & 1,4 & 7 & 9,9 \\
\hline 35. & $\begin{array}{l}\text { Que el enfermo permanezca solo junto a otros pacientes } \\
\text { graves }\end{array}$ & 46,5 & 12,7 & 14,1 & 18,3 & 8,5 \\
\hline 36. & Que el paciente no descanse adecuadamente por el ruido & 43,3 & 17,9 & 17,9 & 13,4 & 7,5 \\
\hline 37. & Que el paciente manifieste temor & 13,3 & 13,3 & 20 & 21,7 & 31,7 \\
\hline 38. & Que el paciente permanezca aislado por prescripción médica & 32,1 & 13,2 & 18,9 & 11,3 & 24,5 \\
\hline 39. & $\begin{array}{l}\text { Pensar que tiempo de información para los familiares es } \\
\text { insuficiente }\end{array}$ & 61,6 & 9,6 & 9,6 & 12,3 & 6,8 \\
\hline 40. & Nivel de estrés en general & 1,4 & 9,5 & 14,9 & 33,8 & 40,5 \\
\hline
\end{tabular}


En la Gráfica 33 podemos ver los principales factores estresantes en familiares de UCI, mostrándose sólo los diez factores que han obtenido mayores puntuaciones medias.

Gráfica 33. Principales factores estresantes en familiares de UCI

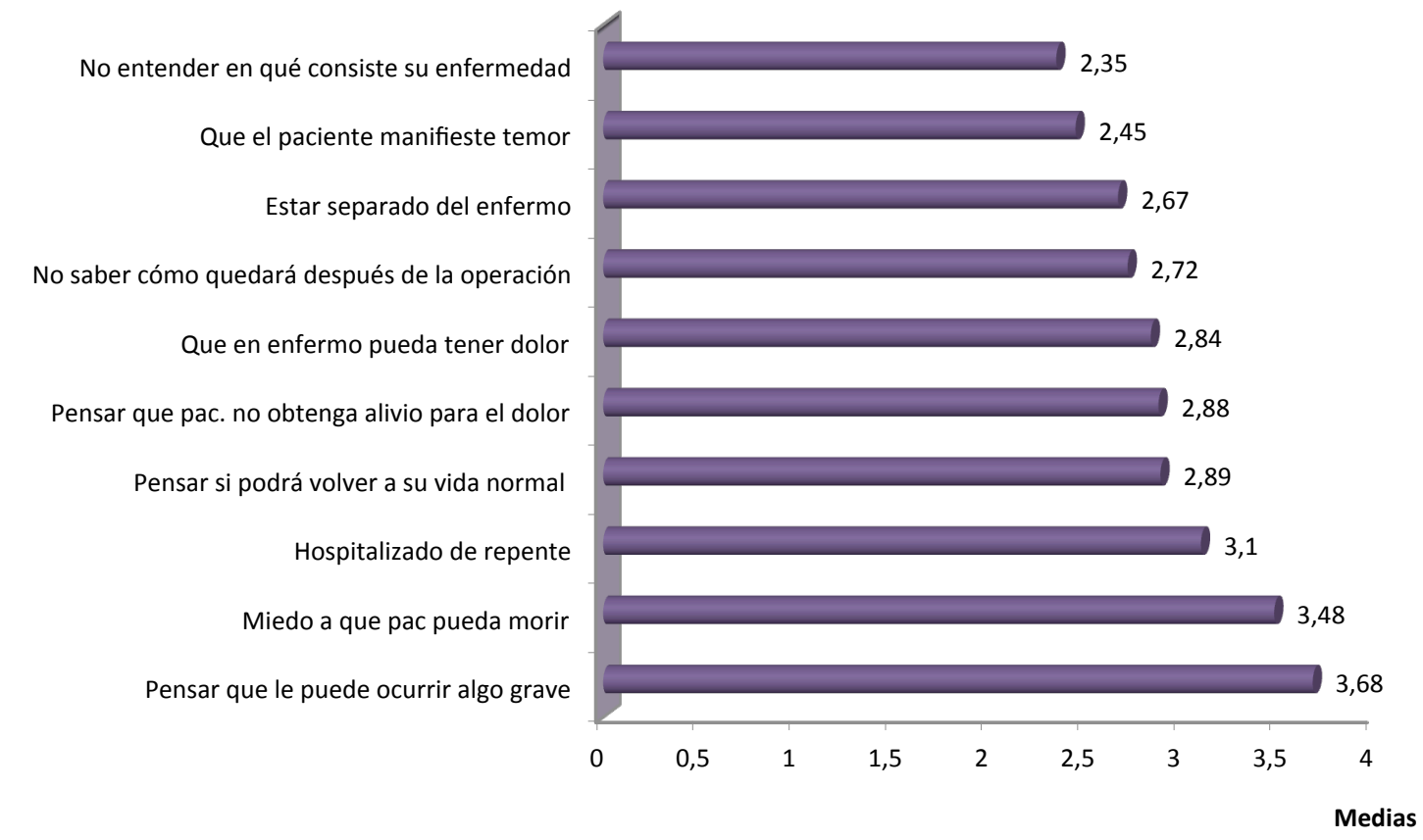

\subsubsection{Adaptación al ingreso de un ser querido en UCI}

Otro aspecto importante a evaluar en la muestra de familiares ha sido el grado de interferencia que produce en la vida de la familia el ingreso de un ser querido en UCI. A este respecto, los resultados muestran una afectación global media de la vida de los familiares de 3,84 $(\mathrm{DT}=1,18)$ sobre un total de 5 puntos. Concretamente, el 58,8\% de los familiares refieren que su vida se ha visto afectada de mucho a muchísimo como consecuencia del ingreso en UCI (véase Tabla 52).

Analizando la posible afectación de la familia por áreas, en una escala de 0 a 5 puntos, podemos observar que las más afectadas han sido el tiempo libre $(\bar{X}=3,49$; $\mathrm{DT}=1,59)$ y el trabajo $(\bar{X}=2,92 ; \mathrm{DT}=1,83)$ seguido por la vida social habitual $(\bar{X}=2,59$; $\mathrm{DT}=1,85)$. Mientras que las esferas en las que se ha experimentado menor afectación han sido la relación de pareja $(\bar{X}=2,13 ; \mathrm{DT}=2,04)$ y la vida familiar en general $(\bar{X}=2,44$; $\mathrm{DT}=1,89)$. Así, los resultados en términos de frecuencias muestran que para un porcentaje considerable de familiares el ingreso ha interferido "de mucho a muchísimo" en su tiempo libre $(60 \%)$ y en porcentajes algo más reducidos se ha visto 
afectado el trabajo $(41,2 \%)$ y la vida social $(37,5 \%)$. Si bien es cierto que la relación de pareja y la vida familiar en general han sido las áreas que han mostrado menor grado de interferencia, no podemos desestimar que éstas se han visto afectadas de manera importante (mucho o muchísimo) en el 31,1\% y 35\% de los familiares respectivamente (véase Tabla 52).

Tabla 52. Grado de interferencia en las distintas esferas de la vida de los familiares de UCI

\begin{tabular}{|c|c|c|c|c|c|c|c|c|c|}
\hline \multirow{2}{*}{\multicolumn{2}{|c|}{ Niveles de interferencia }} & \multirow{2}{*}{$\bar{X}$} & \multirow{2}{*}{ DT } & \multicolumn{6}{|c|}{ GRADO DE INTERFERENCIA (\%) } \\
\hline & & & & Nada & Casi nada & Poco & Bastante & Mucho & Muchísimo \\
\hline 8. & Trabajo & 2,92 & 1,83 & 20 & 2,5 & 12,5 & 23,8 & 12,5 & 28,7 \\
\hline 9. & Vida social & 2,59 & 1,85 & 25 & 5 & 13,8 & 18,8 & 17,5 & 20 \\
\hline 10. & Tiempo libre & 3,49 & 1,59 & 10 & 2,5 & 11,3 & 16,3 & 25 & 35 \\
\hline 11. & Relación de pareja & 2,13 & 2,04 & 39,2 & 4,1 & 14,9 & 10,8 & 8,1 & 23 \\
\hline 12. & Vida familiar & 2,44 & 1,89 & 27,5 & 6,3 & 16,3 & 15 & 15 & 20 \\
\hline 13. & Escala global & 3,84 & 1,18 & 1,3 & 1,3 & 10 & 28,7 & 17,5 & 41,3 \\
\hline
\end{tabular}

\subsubsection{Necesidades de los familiares en UCI}

La evaluación de las necesidades de los familiares se ha llevado a cabo mediante el Cuestionario de Necesidades de los Familiares de pacientes de Cuidados Intensivos (CCFNI) versión breve, que incluye ítems cuyo contenido está relacionado con la atención médica al paciente, la comunicación e información al familiar, la atención personal al familiar y posibles mejoras, todos ellos valorados en una escala de 1 (casi todas las veces) a 5 (nunca) puntos.

Los resultados obtenidos muestran mayores puntuaciones medias, es decir, menor satisfacción en dos ítems relativos a la atención personal recibida por los propios familiares, concretamente, en los ítems “ ¿le ha explicado el personal del hospital el equipamiento que está utilizándose?” $(\bar{X}=2,99 ; \mathrm{DT}=1,20)$ y “¿muestra algún miembro del equipo interés por cómo está usted?" $(\bar{X}=2,63 ; \mathrm{DT}=1,23)$. En el resto de ítems evaluados, tal como se observa en la Tabla 53 se han obtenido puntuaciones medias inferiores a 2 puntos. En este sentido, cabe subrayar que las menores puntuaciones medias, es decir, los ítems que han sido mejor valorados están relacionados con la atención médica del paciente y en particular se trata de los ítems “estoy muy satisfecho con las atenciones médicas recibidas por el paciente" ( $\bar{X}=1,18$; $\mathrm{DT}=0,45)$ y “ ¿usted siente que se le están dando los mejores cuidados posibles al paciente?" $(\bar{X}=1,21 ; \mathrm{DT}=0,44)$. 
Si analizamos con más detalle estos datos, en términos de frecuencias podemos observar que los familiares muestran en porcentajes considerables el mayor grado de satisfacción ("casi todas las veces") en ítems relativos a las atenciones médicas recibidas por el paciente $(84,7 \%)$ y los cuidados médicos recibidos $(80,6 \%)$ refiriendo además el 47,8\% de los familiares que estos cuidados no pueden ser mejorados. En esta misma línea aunque en porcentajes ligeramente menores, la familia comprende lo que le sucede al paciente y el porqué de las pruebas $(77,8 \%)$, siente que el personal sanitario se preocupa por su ser querido $(76,4 \%)$ así como también admiten que la información recibida ha sido sincera $(74 \%)$ y clara $(67,1 \%)$. Y en cuanto al hecho de estar en la sala de espera el $73,6 \%$ de los familiares refieren no haberse sentido nunca solos y aislados en la misma.

Si bien se han obtenido porcentajes importantes de satisfacción, no podemos desestimar que al 50\% de los familiares "nunca" se les ha explicado en qué consiste el equipamiento utilizado así como que en el 35,6\% de los casos ningún miembro del equipo de UCI ha mostrado interés en cómo se pueda sentir ese familiar en particular. Igualmente, respecto a las necesidades que han obtenido mejor valoración es importante considerar que aun así, no han sido totalmente satisfechas para un nada despreciable $15-33 \%$ de los familiares (véase Tabla 54).

Tabla 53. Medias en el Cuestionario de las necesidades de los familiares en UCI

1. ¿Usted siente que se le están dando los mejores cuidados posibles al paciente?

2. ¿Usted siente que el personal del hospital se preocupa por el paciente?

3. ¿Le dan explicaciones sobre el estado del paciente en términos que pueda comprender?

4. ¿Usted siente que le están dando información sincera sobre el estado y progreso del paciente?

5. ¿Usted comprende lo que le sucede al paciente y el motivo de las pruebas?

6. ¿Están siendo atentos los miembros del equipo con usted?

7. ¿Muestra algún miembro del equipo interés por cómo está usted?

8. ¿Le ha explicado el personal del hospital el equipamiento que está utilizándose?

9. Estoy muy satisfecho con las atenciones médicas recibidas por el paciente

10. ¿Usted se siente solo y aislado en la sala de espera?

11. ¿Hay algunas cosas respecto a los cuidados médicos recibidos por el paciente que podrían ser $1,85 \quad 1,02$ mejoradas? 
Tabla 54. Porcentaje de las necesidades de los familiares de UCI

1. ¿Usted siente que se le están dando los

80,6 mejores cuidados posibles al paciente?

2. ¿Usted siente que el personal del hospital se preocupa por el paciente?

3. ¿Le dan explicaciones sobre el estado del paciente en términos que pueda comprender?

4. ¿Usted siente que le están dando información sincera sobre el estado y progreso del paciente?

5. ¿Usted comprende lo que le sucede al paciente y el motivo de las pruebas?

6. ¿Están siendo atentos los miembros del equipo con usted?

7. ¿Muestra algún miembro del equipo interés por cómo está usted?

8. ¿Le ha explicado el personal del hospital el equipamiento que está utilizándose?

9. Estoy muy satisfecho con las atenciones médicas recibidas por el paciente

10. ¿Usted se siente solo y aislado en la sala de espera?

11. ¿Hay algunas cosas respecto a los cuidados médicos recibidos por el paciente que podrían ser mejoradas?

\begin{tabular}{|c|c|c|}
\hline 18,1 & 1,4 & 0 \\
\hline 20,8 & 2,8 & 0 \\
\hline 23,3 & 8,2 & 0 \\
\hline 16,4 & 9,6 & 0 \\
\hline 12,5 & 8,3 & 1,4 \\
\hline 26 & 8,2 & 2,7 \\
\hline 17,8 & 19,2 & 35,6 \\
\hline 9,7 & 19,4 & 50 \\
\hline 12,5 & 2,8 & 0 \\
\hline 5,6 & 16,7 & 73,6 \\
\hline 10,1 & 30,4 & 47,8 \\
\hline
\end{tabular}

\subsubsection{Valoración sobre el proceso de morir}

Teniendo en cuenta las connotaciones de gravedad asociadas al ingreso en una UCI donde la muerte en numerosas ocasiones es una realidad inevitable consideramos relevante analizar los aspectos que según los familiares podrían ayudar a facilitar este proceso si fueran ellos mismos los que se enfrentaran a esta realidad.

Los resultados de la valoración de los distintos ítems del Cuestionario de Ayuda a Morir en Paz (CAMP) (véase Gráfica 34) muestran en una escala de 0 a 4 que para los familiares llegado el momento de la muerte lo más importante sería "poder comunicarse y estrechar vínculos afectivos con sus seres queridos" $(\bar{X}=3,45 ; \mathrm{DT}=0,91)$ seguido por "acortar el proceso en caso de sufrimiento" ( $\bar{X}=3,17 ; \mathrm{DT}=1,08)$, "controlar el dolor y los síntomas de malestar" $(\bar{X}=3,16$; DT=1,00), "pensar que su muerte no supondrá una carga insoportable para sus seres queridos" $(\bar{X}=3,11 ; \mathrm{DT}=1,13)$ al igual que otros aspectos de naturaleza más existencial como "pensar que su vida ha tenido algún sentido" $(\bar{X}=3,02 ; \mathrm{DT}=1,12)$. En menor medida para los familiares también es 
importante pensar que "si la situación se hace insoportable podrán disponer de ayuda para morir con rapidez" ( $\bar{X}=2,85 ; \mathrm{DT}=1,19)$, pensar que "si no hay una esperanza real de recuperación no se alargará artificialmente su vida en una $\mathrm{UCI}^{\prime \prime}(\bar{X}=2,74 ; \mathrm{DT}=1,30)$ seguido de cerca por el hecho de "no sentirse culpable por conflictos personales del pasado" ( $\bar{X}=2,71 ; \mathrm{DT}=1,35)$. Mientras que los factores que han obtenido puntuaciones medias menores, es decir, aquellos a los que los familiares conceden menor importancia son pensar que pudieran "morir en casa" $(\bar{X}=1,11 ; \mathrm{DT}=1,46)$ o "creer en otra vida después de la muerte" $(\bar{X}=1,33 ; \mathrm{DT}=1,44)$.

En términos de frecuencias, tal como se observa en la Tabla 55, los resultados muestran que un porcentaje considerable de familiares daría "muchísima" importancia al hecho de poder sentirse cerca, comunicarse y estrechar vínculos afectivos con los seres queridos (62,5\%). En menor medida, si bien en porcentajes que oscilan en torno a la mitad de los familiares, se concede muchísima importancia a acortar el proceso si hay sufrimiento $(54,7 \%)$, pensar que su muerte no será una carga insoportable para los demás $(50 \%)$ y controlar el dolor y otros síntomas de malestar (47,6\%). En cambio estos porcentajes son mucho más reducidos en el caso de ítems relacionados con poder morir en casa $(9,5 \%)$ o creer en otra vida después de la muerte $(14,1 \%)$.

Gráfica 34. Medias de las puntuaciones en los factores del Cuestionario de Ayuda a Morir en Paz (CAMP) (familiares)

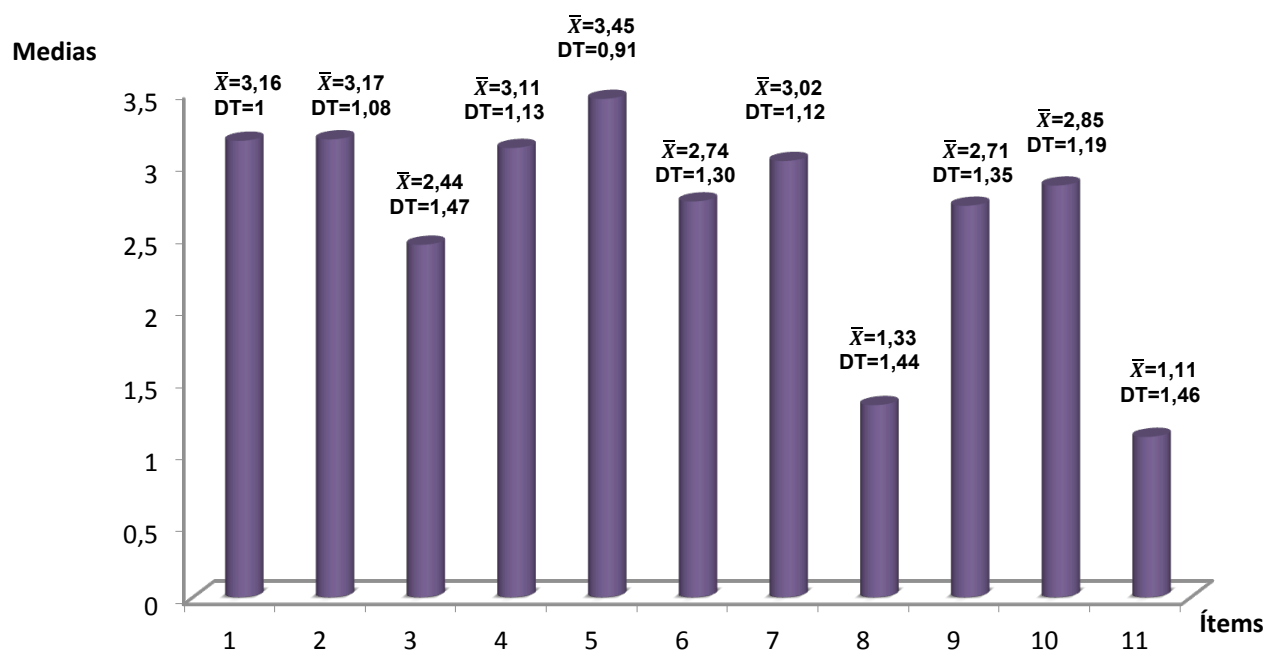

1.- Pensar que los médicos puedan controlar mi dolor y otros síntomas de malestar

2.- Pensar que mi proceso de morir, si me produce sufrimiento, será corto

3.- Pensar que podré controlar hasta el final mis pensamientos y funciones fisiológicas

4.- Pensar que mi muerte/desaparición no supondrán una carga insoportable para mis seres queridos

5.- Poder sentirme cerca, comunicarme y estrechar vínculos afectivos con mis personas queridas

6.- Pensar que si no tengo esperanza real de recuperación, no se alargará artificialmente mi vida en $\mathrm{UCI}$

7.- Pensar que mi vida ha tenido algún sentido

8.- Creer en otra vida después de la muerte

9.- No sentirse culpable por conflictos personales del pasado

10.- Pensar que si la situación se me hace insoportable podré disponer de ayuda para morir con rapidez

11.- Pensar que podré morir en mi casa 
Tabla 55. Porcentajes de los distintos factores del Cuestionario de Ayuda a Morir en Paz (CAMP) (familiares)

\begin{tabular}{|c|c|c|c|c|c|}
\hline Ítem & Nada & Poco & Bastante & Mucho & Muchísimo \\
\hline 1. Controlar mi dolor y otros síntomas de malestar & 1,6 & 6,3 & 14,3 & 30,2 & 47,6 \\
\hline 2. Mi proceso de morir, si produce sufrimiento, será corto & 1,6 & 7,8 & 17,2 & 18,8 & 54,7 \\
\hline 3.Controlar hasta el final pensamientos y funciones fisiológicas & 15,9 & 12,7 & 15,9 & 22,2 & 33,3 \\
\hline $\begin{array}{l}\text { 4. Mi muerte no supondrá una carga insoportable para mis } \\
\text { seres queridos }\end{array}$ & 3,2 & 9,7 & 9,7 & 27,4 & 50 \\
\hline $\begin{array}{l}\text { 5. Poder sentirme cerca, comunicarme y estrechar vínculos } \\
\text { afectivos con mis personas queridas }\end{array}$ & 3,1 & 1,6 & 4,7 & 28,1 & 62,5 \\
\hline $\begin{array}{l}\text { 6. Sin esperanza real de recuperación, no se alargará } \\
\text { artificialmente mi vida en } \mathrm{UCl}\end{array}$ & 8,1 & 11,3 & 17,7 & 24,2 & 38,7 \\
\hline 7. Pensar que mi vida ha tenido algún sentido & 4,7 & 4,7 & 18,8 & 28,1 & 43,8 \\
\hline 8. Creer en otra vida después de la muerte & 37,5 & 31,3 & 6,3 & 10,9 & 14,1 \\
\hline 9. No sentirse culpable por conflictos personales del pasado & 11,1 & 9,5 & 12,7 & 30,2 & 36,5 \\
\hline $\begin{array}{l}\text { 10. Si la situación se me hace insoportable disponer de ayuda } \\
\text { para morir con rapidez }\end{array}$ & 6,6 & 8,2 & 14,8 & 34,4 & 36,1 \\
\hline 11. Poder morir en mi casa & 55,6 & 12,7 & 6,3 & 15,9 & 9,5 \\
\hline
\end{tabular}

Profundizando en el análisis del proceso de morir se les pidió a los familiares que eligieran de entre los once factores que incluye el CAMP aquellos dos que más les ayudarían a tener una muerte en paz (véase Gráfica 35). En este sentido los familiares priorizan "poder sentirse cerca y estrechar vínculos con los seres queridos" $(45,2 \%)$ y "controlar el dolor y otros síntomas de malestar" (33,9\%).

Gráfica 35. Priorización de los dos factores (CAMP) que más ayudarían a morir en paz según los familiares (\%)

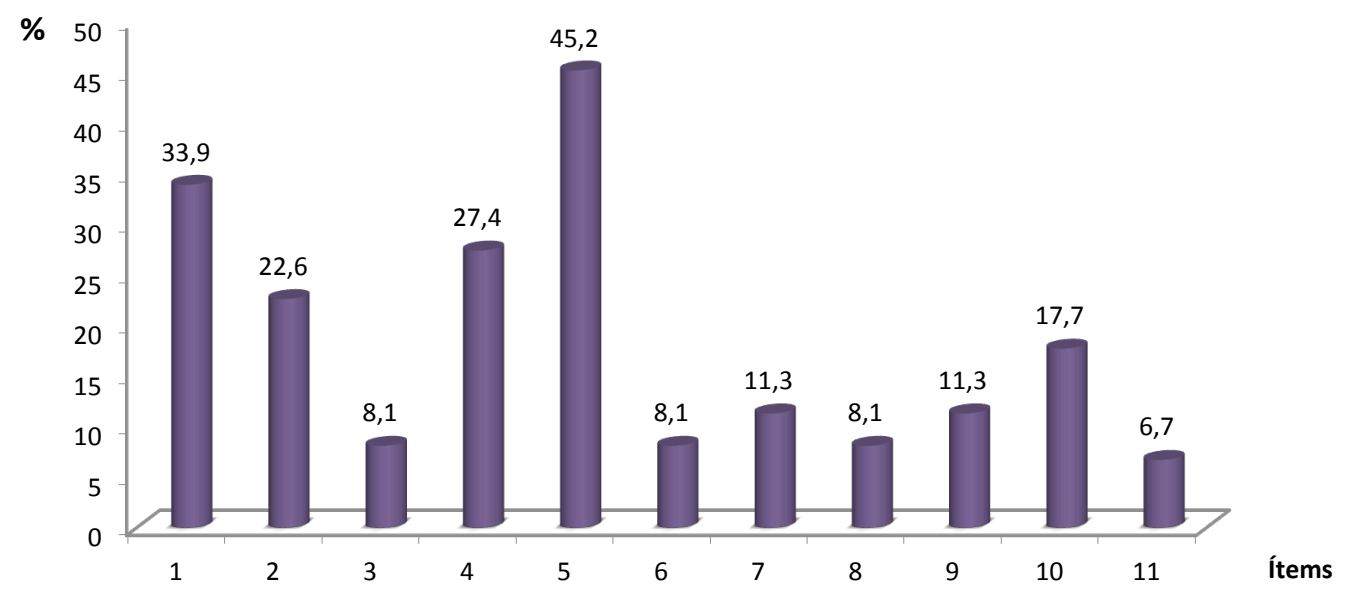

1.- Pensar que los médicos puedan controlar mi dolor y otros síntomas de malestar

2.- Pensar que mi proceso de morir, si me produce sufrimiento, será corto

3.- Pensar que podré controlar hasta el final mis pensamientos y funciones fisiológicas

4.- Pensar que mi muerte/desaparición no supondrán una carga insoportable para mis seres queridos

5.- Poder sentirme cerca, comunicarme y estrechar vínculos afectivos con mis personas queridas

6.- Pensar que si no tengo esperanza real de recuperación, no se alargará artificialmente mi vida en $\mathrm{UCl}$

7.- Pensar que mi vida ha tenido algún sentido

8.- Creer en otra vida después de la muerte

9.- No sentirse culpable por conflictos personales del pasado

10.- Pensar que si la situación se me hace insoportable podré disponer de ayuda para morir con rapidez

11.- Pensar que podré morir en mi casa 


\subsubsection{Valoración del proceso de información y toma de decisiones}

Analizar la valoración de los familiares sobre el proceso de información y toma de decisiones en el contexto de UCI ha sido otro de los objetivos de la presente investigación. Con la finalidad de facilitar la comprensión de los resultados obtenidos mediante el Cuestionario de Información y Toma de decisiones (CITD), al igual que hicimos en los resultados relativos a los pacientes, éstos se presentarán agrupados en distintas subescalas: importancia de los distintos agentes implicados en el proceso (pacientes, familiares, médicos y psicólogos); satisfacción con la información; preferencias en el estilo de información del médico; y la participación en la toma de decisiones.

En cuanto a la importancia que se concede a cada uno de los agentes implicados en el proceso de información y toma de decisiones, los familiares valoran con una puntuación media de 13,25 (DT=2,64) sobre un total de 21 puntos, el papel que la familia tiene en el proceso. En cuanto a la importancia que conceden a la persona enferma en este proceso, la media obtenida ha sido de 12,39 (DT=3,82) de un total de 21 puntos. El papel del médico ha obtenido una puntuación media de 3,71 (DT=1,38) sobre un total de 6 puntos. Y finalmente, el papel del psicólogo en el proceso ha sido valorado con una media de 2,56 $(\mathrm{DT}=0,56)$ sobre un total de 3 puntos.

Dado que las categorías sobre la importancia de las distintas partes implicadas están compuestas por un número diferente de ítems hemos calculado la proporción de cada una de ellas sobre 100 para poder conocer la importancia relativa de los distintos agentes implicados en el proceso de información y toma de decisiones. De esta manera, como podemos apreciar en la Gráfica 36, los familiares valoran que el psicólogo tiene un papel muy importante a la hora de afrontar una mala noticia o tener que tomar una decisión relevante. En segundo lugar y por orden de importancia en el proceso de información y toma de decisiones destacaría el papel de la familia seguido por el papel del médico en este proceso. Por último, desde el punto de vista de los familiares, serían los propios pacientes quienes desempeñarían un papel menos importante en el proceso de información y toma de decisiones. 
Gráfica 36. Proporción de respuestas sobre la importancia de los agentes implicados en el proceso de información y toma de decisiones desde el punto de vista de los familiares

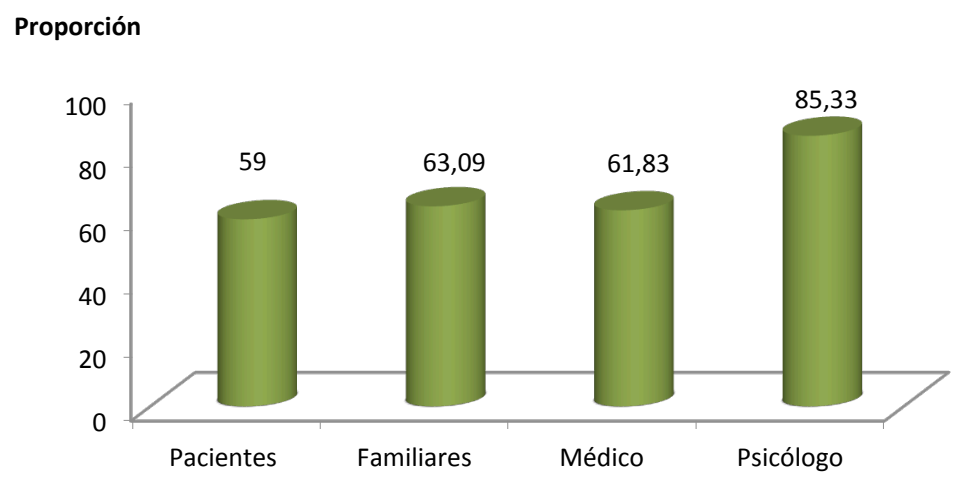

$\mathrm{Al}$ analizar la satisfacción respecto a la cantidad y la claridad de la información recibida desde el punto de vista de los familiares se ha obtenido una puntuación media de 2,44 (DT=0,56; DT=0,75 respectivamente) sobre un total de 3 puntos. Así, el 47,1\% de los familiares refiere estar totalmente de acuerdo con el hecho de haber recibido suficiente información sobre el estado, tratamiento y pronóstico de la enfermedad. Y el $55,9 \%$ afirman haber tenido la oportunidad de aclarar todas sus dudas. No obstante, un 2,9\% de los familiares sólo estaría "algo" de acuerdo con haber recibido suficiente información así como un 8,8\% de los mismos refieren estar "algo o nada" de acuerdo con el hecho de haber clarificado todas sus dudas (véase Tabla 56).

Atendiendo a las preferencias de los familiares sobre el estilo del médico a la hora de informar, los resultados muestran sobre un total de 3 puntos una puntuación media de 1,79 puntos (DT=1,27) para aquel estilo en el que el médico se guarda lo que aún no es seguro y una puntuación media de 1,76 (DT=1,23) en el caso de que el médico anticipe posibles sospechas. En términos de frecuencias y atendiendo a la opción de respuesta "totalmente de acuerdo" podemos observar una distribución bastante homogénea en ambos estilos del médico a la hora de informar, concretamente, el $42,4 \%$ de los familiares prefiere que el médico se guarde lo que aún no es seguro, mientras que el $38,2 \%$ prefiere que éste anticipe posibles sospechas (véase Tabla 56).

Finalmente y respecto al hecho particular de participar en la toma de decisiones médicas relevantes, se ha analizado por un lado en qué medida el familiar se siente capacitado habiéndose obtenido una puntuación media de $1,79(\mathrm{DT}=0,98)$ y por otro lado, en qué medida participar en una decisión médica sería percibido como una carga y no tanto como un privilegio, en cuyo caso se ha obtenido una media de 1,21 $(\mathrm{DT}=1,24)$. El rango de ambas puntuaciones oscila entre 0 y 3 puntos. Si analizamos los 
resultados en términos de frecuencias observamos que sólo el $20,6 \%$ de los familiares se siente totalmente capacitado para participar en decisiones médicas, porcentaje que aumentaría a $76,5 \%$ si consideramos también a los familiares que se sienten bastante capacitados. Además, el 45,5\% de los familiares no considera en absoluto que el hecho de participar en una decisión relevante sea una carga frente a un 21,2\% que estaría totalmente de acuerdo en que dicha participación sería más una carga que un privilegio (véase Tabla 56).

Tabla 56. Porcentajes obtenidos en la satisfacción de la información, preferencias en el estilo del médico a la hora de informar y participación en la toma de decisiones (TD) desde el punto de vista de los familiares

\begin{tabular}{|c|c|c|c|c|}
\hline \multicolumn{5}{|l|}{ Satisfacción con la información } \\
\hline -Los médicos me han dado la oportunidad de aclarar todas mis dudas & 2,9 & 5,9 & 35,3 & 55,9 \\
\hline $\begin{array}{l}\text {-En cuanto al estilo del médico prefiero que éste sea directo y } \\
\text { anticipe posibles sospechas }\end{array}$ & 26,5 & 8,8 & 26,5 & 38,2 \\
\hline $\begin{array}{l}\text {-En cuanto al estilo del médico prefiero que éste se guarde lo que aún } \\
\text { no es seguro }\end{array}$ & 27,3 & 9,1 & 21,2 & 42,4 \\
\hline
\end{tabular}

\subsubsection{RESULTADOS DIFERENCIALES DENTRO DEL GRUPO DE FAMILIARES}

Después de analizar los resultados descriptivos obtenidos a partir de los distintos cuestionarios utilizados en la evaluación de los familiares, a continuación presentaremos los resultados diferenciales relativos a dichas puntuaciones en función de variables sociodemográficas como el género, la edad, el nivel cultural, el estado civil, el número de hijos, el parentesco con el paciente así como el lugar de residencia.

Según el tipo de variable analizada, se han realizado los análisis estadísticos pertinentes ya comentados en el capítulo dedicado al método. 


\subsubsection{Análisis diferenciales en función del género}

Las puntuaciones de los distintos cuestionarios han sido analizadas mediante la prueba $t$ de Student para conocer si existían diferencias significativas $(p \leq, 050)$ en función del género.

En primer lugar se analizaron las diferencias en las puntuaciones relativas a síntomas de ansiedad y depresión así como percepción subjetiva de malestar emocional (véase Tabla 57). Cabe señalar que en los resultados obtenidos mediante los diferentes instrumentos (HADS, STAI y Escala de Estado de ánimo) se observan puntuaciones medias mayores de ansiedad en el grupo de mujeres, siendo estas diferencias casi significativas a nivel estadístico en el caso de la puntuación en ansiedad evaluada mediante el HADS $(t=-1,98 ; p=, 051)$. En cuanto a los síntomas de depresión, los resultados también muestran mayores puntuaciones en las mujeres tanto en la evaluación realizada mediante el HADS y el BDI como en la percepción subjetiva de estado de ánimo deprimido, si bien estas diferencias han sido estadísticamente

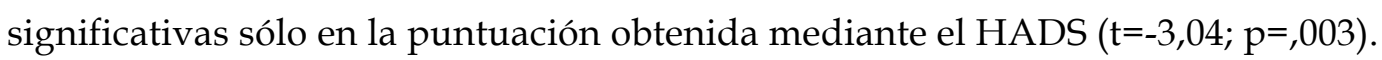

Tabla 57. Análisis diferencial en función del género de la ansiedad, depresión y percepción subjetiva de estado de ánimo (familiares)

\begin{tabular}{|c|c|c|c|c|c|}
\hline Cuestionarios & Género & $\bar{X}$ & DT & $\mathbf{t}$ & Sig. $p \leq, 050$ \\
\hline \multirow[t]{2}{*}{ Total HADS Ansiedad } & Hombre & 11,79 & 4,94 & $-1,98$ & 051 \\
\hline & Mujer & 13,77 & 3,88 & & \\
\hline \multirow[t]{2}{*}{ Total HADS Depresión } & Hombre & 9,12 & 3,90 & $-3,04$ & ,003 \\
\hline & Mujer & 12,35 & 4,62 & & \\
\hline \multirow[t]{2}{*}{ STAI- Estado } & Hombre & 31,42 & 12,72 & $-1,66$ & 105 \\
\hline & Mujer & 38,56 & 12,23 & & \\
\hline \multirow[t]{2}{*}{ STAI- Rasgo } & Hombre & 20,33 & 8,99 & $-1,05$ & ,302 \\
\hline & Mujer & 24,07 & 10,81 & & \\
\hline \multirow[t]{2}{*}{ BDI } & Hombre & 15,83 & 9,67 & $-0,37$ & ,715 \\
\hline & Mujer & 16,93 & 8,18 & & \\
\hline \multirow[t]{2}{*}{ EA1-Malestar general } & Hombre & 6,29 & 2,48 & $-0,26$ & ,795 \\
\hline & Mujer & 6,45 & 2,62 & & \\
\hline \multirow[t]{2}{*}{ EA2-Ansiedad y Nerviosismo } & Hombre & 6,67 & 2,20 & $-1,02$ & ,309 \\
\hline & Mujer & 7,22 & 2,27 & & \\
\hline \multirow[t]{2}{*}{ EA3-Estado de ánimo deprimido } & Hombre & 5,58 & 2,75 & $-1,72$ & ,088 \\
\hline & Mujer & 6,75 & 2,86 & & \\
\hline
\end{tabular}

Al analizar las diferencias en la valoración de la estancia en UCI tanto a nivel global como en relación con aspectos más concretos de la unidad, no se han encontrado diferencias significativas entre las puntuaciones medias de hombres y mujeres (véase Tabla 58). Aun sin ser significativas las diferencias, podemos observar que las 
puntuaciones medias en las mujeres son ligeramente superiores a las de los hombres en todos los aspectos evaluados a excepción del respeto a la intimidad, la calidad de las instalaciones y el silencio en la sala, ligeramente mejor valorados por los hombres.

Tabla 58. Análisis diferencial en función del género de la Valoración de la estancia en UCI (familiares)

\begin{tabular}{|c|c|c|c|c|c|}
\hline Ítem & Género & $\bar{X}$ & DT & $\mathbf{t}$ & $\begin{array}{l}\text { Sig. } \\
p \leq, 050\end{array}$ \\
\hline $\begin{array}{l}\text { En qué grado está siendo agradable/desagradable su } \\
\text { estancia en } \mathrm{UCl} \text { sin considerar los problemas médicos }\end{array}$ & $\begin{array}{l}\text { Hombre } \\
\text { Mujer }\end{array}$ & $\begin{array}{l}3,40 \\
3,27\end{array}$ & $\begin{array}{l}1,96 \\
1,70\end{array}$ & 0,28 & 781 \\
\hline \multicolumn{6}{|l|}{ Valoración de los siguientes aspectos } \\
\hline 1. Cuidados médicos & $\begin{array}{l}\text { Hombre } \\
\text { Mujer }\end{array}$ & $\begin{array}{l}4,59 \\
4,65\end{array}$ & $\begin{array}{l}0,50 \\
0,73\end{array}$ & $-0,38$ & 708 \\
\hline 2. Atención de los médicos & $\begin{array}{l}\text { Hombre } \\
\text { Mujer }\end{array}$ & $\begin{array}{l}4,45 \\
4,65\end{array}$ & $\begin{array}{l}0,67 \\
0,76\end{array}$ & $-1,04$ & ,300 \\
\hline 3. Atención de enfermeras/os & $\begin{array}{l}\text { Hombre } \\
\text { Mujer }\end{array}$ & $\begin{array}{l}4,32 \\
4,46\end{array}$ & $\begin{array}{l}0,72 \\
0,84\end{array}$ & $-0,71$ & ,480 \\
\hline 4. Atención de auxiliares de enfermería & $\begin{array}{l}\text { Hombre } \\
\text { Mujer }\end{array}$ & $\begin{array}{l}4,40 \\
4,57\end{array}$ & $\begin{array}{l}0,68 \\
0,69\end{array}$ & $-0,92$ & ,362 \\
\hline 5. Claridad de la información recibida & $\begin{array}{c}\text { Hombre } \\
\text { Mujer }\end{array}$ & $\begin{array}{l}4,18 \\
4,36\end{array}$ & $\begin{array}{l}1,09 \\
0,87\end{array}$ & $-0,77$ & ,445 \\
\hline 6. Cantidad de la información recibida & $\begin{array}{c}\text { Hombre } \\
\text { Mujer }\end{array}$ & $\begin{array}{l}4,04 \\
4,14\end{array}$ & $\begin{array}{l}0,99 \\
0,93\end{array}$ & $-0,42$ & 678 \\
\hline 7. Trato del personal de enfermería & $\begin{array}{c}\text { Hombre } \\
\text { Mujer }\end{array}$ & $\begin{array}{l}4,41 \\
4,50\end{array}$ & $\begin{array}{l}0,59 \\
0,69\end{array}$ & $-0,54$ & ,591 \\
\hline 8. Afecto/apoyo emocional del personal de enfermería & $\begin{array}{c}\text { Hombre } \\
\text { Mujer }\end{array}$ & $\begin{array}{l}3,89 \\
4,11\end{array}$ & $\begin{array}{l}1,41 \\
1,08\end{array}$ & $-0,69$ & ,490 \\
\hline 9. Respeto a la intimidad & $\begin{array}{c}\text { Hombre } \\
\text { Mujer }\end{array}$ & $\begin{array}{l}4,33 \\
4,29\end{array}$ & $\begin{array}{l}0,73 \\
0,90\end{array}$ & 0,17 & ,867 \\
\hline 10. Atención a los familiares & $\begin{array}{c}\text { Hombre } \\
\text { Mujer }\end{array}$ & $\begin{array}{l}4,35 \\
4,37\end{array}$ & $\begin{array}{l}0,59 \\
0,96\end{array}$ & $-0,09$ & ,929 \\
\hline $\begin{array}{l}\text { 11. Atención de necesidades psicológicas en paciente y } \\
\text { familia }\end{array}$ & $\begin{array}{l}\text { Hombre } \\
\text { Mujer }\end{array}$ & $\begin{array}{l}4,71 \\
4,83\end{array}$ & $\begin{array}{l}0,46 \\
0,61\end{array}$ & $-0,78$ & ,436 \\
\hline 12. Calidad de las instalaciones (comodidad, higiene...) & $\begin{array}{c}\text { Hombre } \\
\text { Mujer }\end{array}$ & $\begin{array}{l}4,04 \\
3,98\end{array}$ & $\begin{array}{l}0,89 \\
1,03\end{array}$ & 0,25 & 799 \\
\hline 13. Posibilidades de distraerse & $\begin{array}{l}\text { Hombre } \\
\text { Mujer }\end{array}$ & $\begin{array}{l}1,57 \\
2,22\end{array}$ & $\begin{array}{l}1,43 \\
1,75\end{array}$ & $-1,51$ & 136 \\
\hline 14. Silencio y tranquilidad en la sala & $\begin{array}{l}\text { Hombre } \\
\text { Mujer }\end{array}$ & $\begin{array}{l}3,82 \\
3,61\end{array}$ & $\begin{array}{l}0,79 \\
1,36\end{array}$ & 0,65 & ,516 \\
\hline 15. Régimen de visitas & $\begin{array}{l}\text { Hombre } \\
\text { Mujer }\end{array}$ & $\begin{array}{l}3,86 \\
4,04\end{array}$ & $\begin{array}{l}0,99 \\
1,03\end{array}$ & $-0,67$ & ,502 \\
\hline
\end{tabular}

El análisis diferencial de los distintos factores estresantes (véase Tabla 59) muestra diferencias estadísticamente significativas a favor de las mujeres en determinados aspectos como el estrés que genera el hecho de que el paciente tenga dolor $(\mathrm{t}=-2,14 ; \mathrm{p}=, 036)$ o pueda tenerlo por la realización de alguna operación o pruebas $(\mathrm{t}=-2,16 ; \mathrm{p}=, 034)$, no saber con seguridad cómo quedará después de la operación $(t=-2,58 ; p=, 012)$, ver que el personal del hospital tiene prisa $(t=-2,08 ; p=, 041)$ 
y sentir olores extraños en el hospital $(t=-2,03 ; p=, 046)$. En el resto de factores, aun sin ser las diferencias significativas, se observan puntuaciones medias mayores en el grupo de mujeres a excepción de siete factores, cuyas medias muestran ligeramente más estrés en los hombres. Estos ítems son los siguientes: "no saber cuándo le darán el alta de la UCI", "el hospital en que está ingresado el paciente se encuentra lejos de casa", "tener que dormir fuera del domicilio habitual", "tener que comer a horas diferentes a las habituales para ir a las visitas", "miedo a que el paciente pueda morir", "los horarios en que están concertadas las visitas al enfermo en la unidad" y "pensar que el tiempo de información para los familiares resulta insuficiente".

Tabla 59. Análisis diferencial en función del género de los Factores estresantes en UCI (familiares)

\begin{tabular}{|c|c|c|c|c|c|}
\hline Ítem & Género & $\bar{X}$ & DT & $\mathbf{t}$ & $\begin{array}{l}\text { Sig. } \\
p \leq, 050\end{array}$ \\
\hline \multirow{2}{*}{ 1. Que el enfermo pueda tener dolor } & Hombre & 2,32 & 1,29 & $-2,14$ & ,036 \\
\hline & Mujer & 3,04 & 1,24 & & \\
\hline \multirow{2}{*}{$\begin{array}{l}\text { 2. No saber con seguridad o no entender en qué } \\
\text { consiste la enfermedad }\end{array}$} & Hombre & 2 & 1,24 & $-1,22$ & ,226 \\
\hline & Mujer & 2,49 & 1,50 & & \\
\hline \multirow[t]{2}{*}{ 3. Pensar que le puede ocurrir algo grave } & Hombre & 3,61 & 0,85 & $-0,42$ & 673 \\
\hline & Mujer & 3,71 & 0,85 & & \\
\hline \multirow{2}{*}{$\begin{array}{l}\text { 4. Pensar si podrá volver a su vida normal después } \\
\text { de salir del hospital }\end{array}$} & Hombre & 2,44 & 1,69 & $-1,48$ & 144 \\
\hline & Mujer & 3,04 & 1,40 & & \\
\hline \multirow{2}{*}{$\begin{array}{l}\text { 5. No poder ocuparse usted de la familia como hasta } \\
\text { ahora venía haciendo }\end{array}$} & Hombre & 1,40 & 1,35 & $-1,26$ & ,212 \\
\hline & Mujer & 2 & 1,69 & & \\
\hline \multirow{2}{*}{$\begin{array}{l}\text { 6. No saber con seguridad cómo quedará después de } \\
\text { la operación }\end{array}$} & Hombre & 2 & 1,45 & $-2,58$ & ,012 \\
\hline & Mujer & 3 & 1,37 & & \\
\hline \multirow[t]{2}{*}{ 7. Estar separado del enfermo } & Hombre & 2,26 & 1,52 & $-1,46$ & 148 \\
\hline & Mujer & 2,81 & 1,37 & & \\
\hline \multirow{2}{*}{$\begin{array}{l}\text { 8. No saber cuándo le darán el alta de la Unidad de } \\
\text { Cuidados Intensivos }\end{array}$} & Hombre & 2,17 & 1,65 & 0,07 & ,940 \\
\hline & Mujer & 2,13 & 1,52 & & \\
\hline \multirow[t]{2}{*}{ 9. Haber sido hospitalizado de repente, sin esperarlo } & Hombre & 2,84 & 1,50 & $-1,02$ & ,310 \\
\hline & Mujer & 3,19 & 1,20 & & \\
\hline \multirow{2}{*}{$\begin{array}{l}\text { 10. No saber los resultados/razones de los } \\
\text { tratamientos/pruebas que le hacen }\end{array}$} & Hombre & 1,23 & 1,15 & $-1,67$ & 099 \\
\hline & Mujer & 1,92 & 1,54 & & \\
\hline \multirow[t]{2}{*}{ 11. Tener que organizarse para acudir a las visitas } & Hombre & 0,83 & 1,04 & $-0,33$ & ,743 \\
\hline & Mujer & 0,94 & 1,31 & & \\
\hline \multirow{2}{*}{$\begin{array}{l}\text { 12. Pensar que pueda tener dolor a causa de la } \\
\text { operación/análisis }\end{array}$} & Hombre & 1,76 & 1,25 & $-2,16$ & ,034 \\
\hline & Mujer & 2,54 & 1,29 & & \\
\hline \multirow[t]{2}{*}{ 13. No saber cuándo van a hacerle cosas al enfermo } & Hombre & 1,28 & 0,89 & $-1,19$ & 238 \\
\hline & Mujer & 1,74 & 1,57 & & \\
\hline \multirow{2}{*}{$\begin{array}{l}\text { 14. Pensar que el paciente pueda no obtener alivio } \\
\text { para el dolor aún tomando medicación }\end{array}$} & Hombre & 2,85 & 0,69 & $-0,10$ & 920 \\
\hline & Mujer & 2,89 & 1,38 & & \\
\hline \multirow[t]{2}{*}{ 15. Ver que el personal del hospital tiene prisa } & Hombre & 0,72 & 1,18 & $-2,08$ & 041 \\
\hline & Mujer & 1,60 & 1,64 & & \\
\hline \multirow{2}{*}{$\begin{array}{l}\text { 16. El hospital en que está ingresado el paciente se } \\
\text { encuentra lejos de casa }\end{array}$} & Hombre & 1,42 & 1,83 & 0,40 & 689 \\
\hline & Mujer & 1,25 & 1,49 & & \\
\hline \multirow{2}{*}{$\begin{array}{l}\text { 17. Que sanitarios hablen deprisa o usen palabras que } \\
\text { no puedan entender }\end{array}$} & Hombre & 0,93 & 1,09 & $-0,85$ & 397 \\
\hline & Mujer & 1,29 & 1,45 & & \\
\hline \multirow{2}{*}{$\begin{array}{l}\text { 18. Que el personal sanitario no conteste a sus } \\
\text { preguntas }\end{array}$} & Hombre & 1,91 & 1,81 & $-0,07$ & 943 \\
\hline & Mujer & 1,95 & 1,39 & & \\
\hline \multirow[t]{2}{*}{ 19. Tener que dormir fuera del domicilio habitual } & Hombre & 1,85 & 1,95 & 0,94 & ,353 \\
\hline & Mujer & 1,32 & 1,67 & & \\
\hline \multirow{2}{*}{$\begin{array}{l}\text { 20. Preocupación por que no le den la medicación } \\
\text { para el dolor cuando la necesita }\end{array}$} & Hombre & 1,35 & 1,32 & $-0,97$ & ,337 \\
\hline & Mujer & 1,77 & 1,62 & & \\
\hline \multirow{2}{*}{$\begin{array}{l}\text { 21. Pensar en la posible pérdida de dinero a causa de } \\
\text { la enfermedad }\end{array}$} & Hombre & 0,21 & 0,53 & $-1,77$ & ,081 \\
\hline & Mujer & 0,74 & 1,26 & & \\
\hline \multirow[t]{2}{*}{ 22. Sentir olores extraños en el hospital } & Hombre & 0,37 & 1,01 & $-2,03$ & ,046 \\
\hline & Mujer & 1,13 & 1,52 & & \\
\hline
\end{tabular}


(Continuación Tabla 59)

\begin{tabular}{|c|c|c|c|c|c|}
\hline Ítem & Género & $\bar{X}$ & DT & $\mathbf{t}$ & $\begin{array}{l}\text { Sig. } \\
p \leq, 050\end{array}$ \\
\hline \multirow{2}{*}{$\begin{array}{l}\text { 23. Tener que comer a horas diferentes a las } \\
\text { habituales para poder ir a las visitas }\end{array}$} & Hombre & 0,53 & 1,02 & 0,41 & 682 \\
\hline & Mujer & 0,42 & 0,97 & & \\
\hline \multirow[t]{2}{*}{ 24. No poder llamar al paciente por teléfono } & Hombre & 0,81 & 1,38 & $-1,85$ & 068 \\
\hline & Mujer & 1,70 & 1,77 & & \\
\hline \multirow{2}{*}{$\begin{array}{l}\text { 25. Que el enfermo esté al cuidado de sanitarios } \\
\text { desconocidos }\end{array}$} & Hombre & 0,17 & 0,38 & $-1,51$ & ,136 \\
\hline & Mujer & 0,59 & 1,17 & & \\
\hline \multirow[t]{2}{*}{ 26. Tener demasiados horarios de visita } & Hombre & 0,19 & 0,40 & $-0,89$ & ,374 \\
\hline & mujer & 0,43 & 1,04 & & \\
\hline \multirow{2}{*}{$\begin{array}{l}\text { 27. Tener que ver en la sala durante las visitas a otros } \\
\text { enfermos muy graves }\end{array}$} & Hombre & 0,47 & 0,77 & $-0,66$ & ,512 \\
\hline & Mujer & 0,67 & 1,23 & & \\
\hline \multirow[t]{2}{*}{ 28. Miedo a que el paciente pueda morir } & Hombre & 3,50 & 1,15 & 0,08 & 932 \\
\hline & mujer & 3,47 & 1,18 & & \\
\hline \multirow{2}{*}{$\begin{array}{l}\text { 29. Que el paciente sea atendido por diferentes } \\
\text { médicos durante su ingreso }\end{array}$} & Hombre & 0,79 & 1,27 & $-0,31$ & ,757 \\
\hline & Mujer & 0,89 & 1,21 & & \\
\hline \multirow{2}{*}{$\begin{array}{l}\text { 30. Que los familiares sean informados por diferentes } \\
\text { médicos }\end{array}$} & Hombre & 0,95 & 1,31 & $-0,92$ & ,362 \\
\hline & Mujer & 1,29 & 1,44 & & \\
\hline \multirow[t]{2}{*}{ 31. Esperar a entrar a las diferentes horas de visita } & Hombre & 1,47 & 1,43 & $-0,22$ & ,825 \\
\hline & Mujer & 1,56 & 1,55 & & \\
\hline \multirow{2}{*}{$\begin{array}{l}\text { 32. No poder estar junto al enfermo todo el tiempo } \\
\text { (restringida la permanencia en la unidad) }\end{array}$} & Hombre & 1,32 & 1,29 & $-1,41$ & 163 \\
\hline & Mujer & 1,93 & 1,73 & & \\
\hline \multirow{2}{*}{$\begin{array}{l}\text { 33. Tener que desplazarse a diario para visitar al } \\
\text { enfermo en las } 4 \text { horas de visita }\end{array}$} & Hombre & 0,56 & 0,89 & $-1,55$ & ,126 \\
\hline & Mujer & 1,22 & 1,62 & & \\
\hline \multirow{2}{*}{$\begin{array}{l}\text { 34. Los horarios en que están concertadas las visitas } \\
\text { al enfermo en la unidad }\end{array}$} & Hombre & 0,82 & 1,29 & 0,12 & ,904 \\
\hline & Mujer & 0,78 & 1,38 & & \\
\hline \multirow{2}{*}{$\begin{array}{l}\text { 35. Que el enfermo permanezca solo durante todo el } \\
\text { día junto a otros pacientes graves }\end{array}$} & Hombre & 1,16 & 1,50 & $-0,49$ & ,626 \\
\hline & Mujer & 1,35 & 1,41 & & \\
\hline \multirow{2}{*}{$\begin{array}{l}\text { 36. Que el paciente no descanse adecuadamente por } \\
\text { el ruido }\end{array}$} & Hombre & 0,94 & 1,12 & $-0,96$ & ,341 \\
\hline & Mujer & 1,72 & 3,21 & & \\
\hline \multirow[t]{2}{*}{ 37. Que el paciente manifieste temor } & Hombre & 2,29 & 1,38 & $-0,49$ & ,622 \\
\hline & Mujer & 2,50 & 1,43 & & \\
\hline \multirow{2}{*}{$\begin{array}{l}\text { 38. Que el paciente tenga que permanecer aislado } \\
\text { por prescripción médica }\end{array}$} & Hombre & 1,40 & 1,64 & $-1,24$ & 219, \\
\hline & Mujer & 2 & 1,56 & & \\
\hline \multirow{2}{*}{$\begin{array}{l}\text { 39. Pensar que el tiempo de información para los } \\
\text { familiares resulta insuficiente }\end{array}$} & Hombre & 1,10 & 1,37 & 0,65 & ,520 \\
\hline & Mujer & 0,87 & 1,36 & & \\
\hline \multirow[t]{2}{*}{ 40. Nivel de estrés en general } & Hombre & 2,79 & 1,03 & $-1,16$ & 248 \\
\hline & Mujer & 3,11 & 1,03 & & \\
\hline
\end{tabular}

En cuanto al análisis diferencial de la adaptación de la familia al ingreso de un ser querido en UCI (véase Tabla 60) se han obtenido diferencias significativas a nivel estadístico en la interferencia producida a nivel social, área más afectada en las mujeres $(t=-2,06 ; p=, 043)$. Si bien el resto de diferencias no han sido significativas, otras áreas que también presentan mayor grado de interferencia en las mujeres han sido el trabajo $(\bar{X}=3$ vs $\bar{X}=2,73)$ y el tiempo libre $(\bar{X}=3,60$ vs $\bar{X}=3,18)$. Mientras que los hombres presentan mayor grado de afectación en la relación de pareja $(\bar{X}=2,37$ vs $\bar{X}=2,05)$ y la vida familiar $(\bar{X}=2,73$ vs $\bar{X}=2,33)$. 
Tabla 60. Análisis diferencial en función del género del Grado de interferencia en las distintas esferas de la vida de los familiares de UCI

\begin{tabular}{|c|c|c|c|c|c|c|}
\hline \multicolumn{2}{|c|}{ Niveles de interferencia } & Género & $\bar{X}$ & DT & $\mathbf{t}$ & Sig. $p \leq, 050$ \\
\hline \multirow[t]{2}{*}{1.} & Trabajo & Hombre & 2,73 & 1,80 & $-0,59$ &, 554 \\
\hline & & Mujer & 3 & 1,84 & & \\
\hline \multirow[t]{2}{*}{2.} & Vida social & Hombre & 1,91 & 1,79 & $-2,06$ & 043 \\
\hline & & Mujer & 2,84 & 1,82 & & \\
\hline \multirow[t]{2}{*}{3.} & Tiempo libre & Hombre & 3,18 & 1,59 & $-1,05$ & ,295 \\
\hline & & Mujer & 3,60 & 1,59 & & \\
\hline \multirow[t]{2}{*}{4.} & Relación de pareja & Hombre & 2,37 & 1,92 & 0,58 & ,566 \\
\hline & & Mujer & 2,05 & 2,08 & & \\
\hline \multirow[t]{2}{*}{5.} & Vida familiar & Hombre & 2,73 & 1,72 & 0,84 & ,401 \\
\hline & & Mujer & 2,33 & 1,95 & & \\
\hline \multirow[t]{2}{*}{6.} & Escala global & Hombre & 3,86 & 0,99 & 0,12 & 904 \\
\hline & & Mujer & 3,83 & 1,26 & & \\
\hline
\end{tabular}

Por lo que respecta a las necesidades de los familiares en UCI (véase Tabla 61) se han obtenido diferencias estadísticamente significativas a favor de las mujeres en la valoración de los "cuidados recibidos por el paciente" ( $t=-2,02 ; p=, 047)$. Asimismo, aunque sin ser significativas las diferencias, las mujeres han puntuado más alto y por tanto están menos satisfechas que los hombres con la percepción de que "el personal del hospital se preocupa por el paciente $(\bar{X}=1,31$ vs $\bar{X}=1,14)$, las "atenciones médicas recibidas por el paciente" $(\bar{X}=1,23$ vs $\bar{X}=1,05)$ así como también creen más que los hombres que los “cuidados médicos podrían ser mejorados" ( $\bar{X}=1,88$ vs $\bar{X}=1,78)$. En cambio son los hombres los que se muestran menos satisfechos con las "explicaciones sobre el estado del paciente" ( $\bar{X}=1,52$ vs $\bar{X}=1,40)$, la "información recibida" ( $\bar{X}=1,48$ vs $\bar{X}=1,31$ ), el "interés mostrado por algún miembro en cómo está él/ella" ( $\bar{X}=2,81$ vs $\bar{X}=2,56)$ y las "explicaciones sobre el equipamiento utilizado" $(\bar{X}=3,05$ vs $\bar{X}=2,96)$.

Tabla 61. Análisis diferencial en función del género de las Necesidades de los familiares en UCI

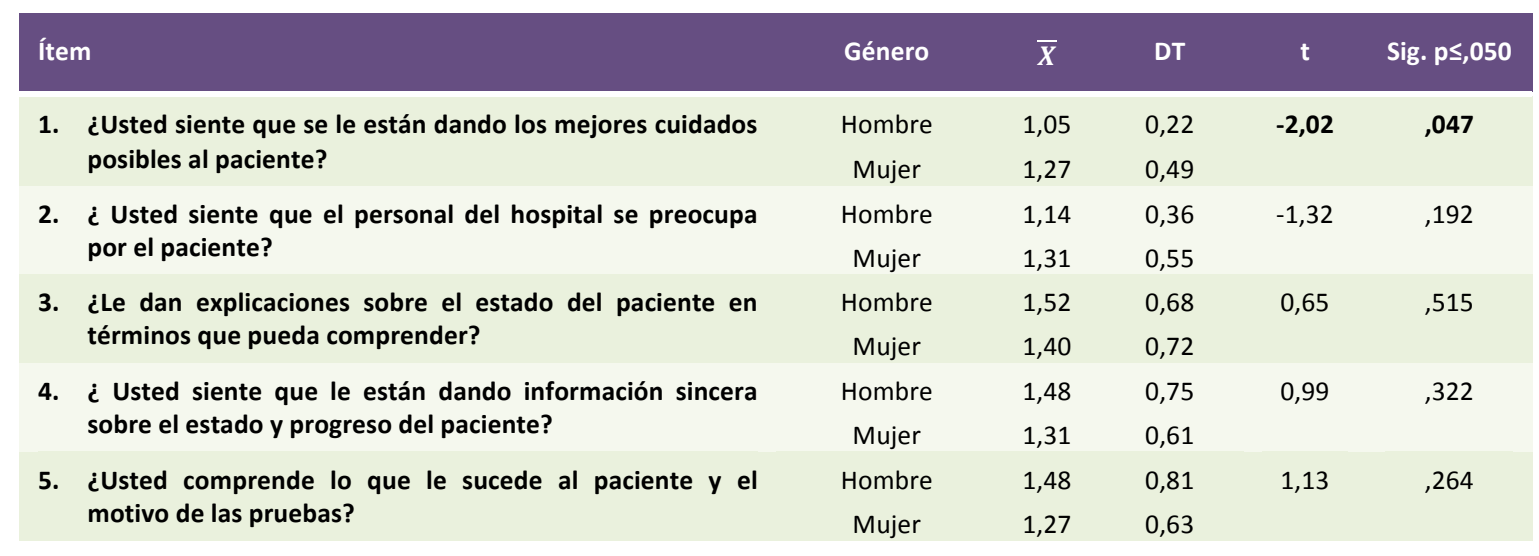

(Sigue detrás) 


\begin{tabular}{|c|c|c|c|c|c|}
\hline Ítem & Género & $\bar{X}$ & DT & $\mathbf{t}$ & Sig. $p \leq, 050$ \\
\hline $\begin{array}{l}\text { 6. ¿Están siendo atentos los miembros del equipo con } \\
\text { usted? }\end{array}$ & $\begin{array}{l}\text { Hombre } \\
\text { Mujer }\end{array}$ & $\begin{array}{l}1,52 \\
1,50\end{array}$ & $\begin{array}{l}0,81 \\
0,75\end{array}$ & 0,12 & ,905 \\
\hline $\begin{array}{l}\text { 7. ¿Muestra algún miembro del equipo interés por cómo } \\
\text { está usted? }\end{array}$ & $\begin{array}{l}\text { Hombre } \\
\text { Mujer }\end{array}$ & $\begin{array}{l}2,81 \\
2,56\end{array}$ & $\begin{array}{l}1,12 \\
1,27\end{array}$ & 0,79 & ,432 \\
\hline $\begin{array}{l}\text { 8. ¿Le ha explicado el personal del hospital el equipamiento } \\
\text { que está utilizándose? }\end{array}$ & $\begin{array}{l}\text { Hombre } \\
\text { Mujer }\end{array}$ & $\begin{array}{l}3,05 \\
2,96\end{array}$ & $\begin{array}{l}1,16 \\
1,23\end{array}$ & 0,28 & ,783 \\
\hline $\begin{array}{l}\text { 9. Estoy muy satisfecho con las atenciones médicas } \\
\text { recibidas por el paciente }\end{array}$ & $\begin{array}{l}\text { Hombre } \\
\text { Mujer }\end{array}$ & $\begin{array}{l}1,05 \\
1,23\end{array}$ & $\begin{array}{l}0,22 \\
0,51\end{array}$ & $-1,61$ & 112 \\
\hline 10. ¿Usted se siente solo y aislado en la sala de espera? & $\begin{array}{l}\text { Hombre } \\
\text { Mujer }\end{array}$ & $\begin{array}{l}1,19 \\
1,49\end{array}$ & $\begin{array}{l}0,40 \\
0,88\end{array}$ & $-1,49$ & 140 \\
\hline $\begin{array}{l}\text { 11. ¿Hay algunas cosas respecto a los cuidados médicos } \\
\text { recibidos por el paciente que podrían ser mejoradas? }\end{array}$ & $\begin{array}{l}\text { Hombre } \\
\text { Mujer }\end{array}$ & $\begin{array}{l}1,78 \\
1,88\end{array}$ & $\begin{array}{c}1 \\
1,03\end{array}$ & $-0,37$ & 711 \\
\hline
\end{tabular}

En cuanto al proceso de morir (véase Tabla 62), las mujeres han puntuado más alto en prácticamente todos los ítems del CAMP, resultando significativas las diferencias relativas a aspectos más existenciales como "pensar que su vida haya tenido algún sentido" ( $t=-2,48 ; p=, 016)$. Aun sin ser significativo, podemos observar en la Tabla 62 que para los hombres adquiere más importancia el hecho de "no alargar artificialmente la vida en una $\mathrm{UCI}^{\prime}(\bar{X}=2,94$ vs $\bar{X}=2,67)$ y el "poder controlar hasta el final los pensamientos y las funciones fisiológicas" ( $\bar{X}=2,69$ vs $\bar{X}=2,36)$.

Tabla 62. Análisis diferencial en función del género de los distintos factores del Cuestionario de Ayuda a Morir en Paz (CAMP) (familiares)

\begin{tabular}{|c|c|c|c|c|c|}
\hline Ítem & Género & $\bar{X}$ & DT & $\mathbf{t}$ & $\begin{array}{l}\text { Sig. } \\
p \leq, 050\end{array}$ \\
\hline \multirow[t]{2}{*}{ 1. Controlar mi dolor y otros síntomas de malestar } & Hombre & 3,12 & 1,15 & $-0,15$ & ,878 \\
\hline & Mujer & 3,17 & 0,96 & & \\
\hline \multirow[t]{2}{*}{ 2. Mi proceso de morir, si produce sufrimiento, será corto } & Hombre & 3,06 & 1,24 & $-0,47$ & ,643 \\
\hline & Mujer & 3,21 & 1,03 & & \\
\hline \multirow[t]{2}{*}{ 3.Controlar hasta el final pensamientos y funciones fisiológicas } & Hombre & 2,69 & 1,30 & 0,76 & ,448 \\
\hline & Mujer & 2,36 & 1,52 & & \\
\hline \multirow[t]{2}{*}{ 4. Mi muerte no supondrá una carga insoportable para mis seres queridos } & Hombre & 2,75 & 1,53 & $-1,50$ & 138 \\
\hline & Mujer & 3,24 & 0,95 & & \\
\hline \multirow{2}{*}{$\begin{array}{l}\text { 5. Poder sentirme cerca, comunicarme y estrechar vínculos afectivos con } \\
\text { mis personas queridas }\end{array}$} & Hombre & 3,31 & 0,87 & $-0,71$ & ,478 \\
\hline & Mujer & 3,50 & 0,92 & & \\
\hline \multirow{2}{*}{$\begin{array}{l}\text { 6. Sin esperanza real de recuperación, no se alargará artificialmente mi } \\
\text { vida en UCI }\end{array}$} & Hombre & 2,94 & 1,29 & 0,69 & ,491 \\
\hline & Mujer & 2,67 & 1,32 & & \\
\hline \multirow[t]{2}{*}{ 7. Pensar que mi vida ha tenido algún sentido } & Hombre & 2,44 & 1,50 & $-2,48$ & ,016 \\
\hline & Mujer & 3,21 & 0,89 & & \\
\hline \multirow[t]{2}{*}{ 8. Creer en otra vida después de la muerte } & Hombre & 0,81 & 1,05 & $-1,68$ & 098 \\
\hline & Mujer & 1,50 & 1,52 & & \\
\hline \multirow[t]{2}{*}{ 9. No sentirse culpable por conflictos personales del pasado } & Hombre & 2,62 & 1,31 & $-0,30$ & ,762 \\
\hline & Mujer & 2,74 & 1,37 & & \\
\hline \multirow{2}{*}{$\begin{array}{l}\text { 10. Si la situación se me hace insoportable disponer de ayuda para morir } \\
\text { con rapidez }\end{array}$} & Hombre & 2,69 & 1,35 & $-0,64$ & ,525 \\
\hline & Mujer & 2,91 & 1,14 & & \\
\hline \multirow[t]{2}{*}{ 11. Poder morir en mi casa } & Hombre & 0,81 & 1,33 & $-0,95$ & ,348 \\
\hline & Mujer & 1,21 & 1,50 & & \\
\hline
\end{tabular}


Por último, respecto a la valoración del proceso de información y toma de decisiones en función del género (véase Tabla 63) se han obtenido diferencias estadísticamente significativas en el papel que se le concede a la familia en el proceso de información y toma de decisiones $(t=-2,82 ; p=, 008)$ y en las preferencias hacia un estilo médico que no informe sobre lo que todavía no es seguro $(t=-2,33 ; p=, 026)$, siendo en ambos casos mayores las puntuaciones de las mujeres. Si bien el resto de diferencias no han sido significativas, cabe señalar que el papel concedido por las mujeres a los otros agentes implicados en el proceso ha sido ligeramente superior al de los hombres. Asimismo, las mujeres también se muestran algo más satisfechas con la información $(\overline{\mathrm{X}}=4,92$ vs $\overline{\mathrm{X}}=4,75)$. En cambio, se observan puntuaciones ligeramente mayores en los hombres respecto a las preferencias hacia un estilo médico más directo, que anticipe posibles sospechas $(\overline{\mathrm{X}}=1,87$ vs $\overline{\mathrm{X}}=1,73)$ así como en aspectos relacionados con la participación en la toma de decisiones, sintiéndose en este sentido los hombres más capacitados $(\overline{\mathrm{X}}=2$ vs $\overline{\mathrm{X}}=1,73)$ a la vez que también perciben más como una carga el hecho de participar en una decisión relevante $(\bar{X}=1,62$ vs $\bar{X}=1,08)$.

Tabla 63. Valoración diferencial en función del género del proceso de información y toma de decisiones (TD) en los familiares

\begin{tabular}{|c|c|c|c|c|c|}
\hline CITD & Género & $\overline{\boldsymbol{X}}$ & DT & $\mathbf{t}$ & $\begin{array}{l}\text { Sig. } \\
p \leq, 050\end{array}$ \\
\hline \multicolumn{6}{|l|}{ Importancia de los distintos agentes implicados } \\
\hline \multirow[t]{2}{*}{ Papel de la familia en la información y toma de decisiones } & Hombre & 11 & 2,31 & $-2,82$ & ,008 \\
\hline & Mujer & 13,88 & 2,40 & & \\
\hline \multirow[t]{2}{*}{ Papel del paciente en la información y toma de decisiones } & Hombre & 11,86 & 4,67 & $-0,41$ & ,682 \\
\hline & Mujer & 12,54 & 3,65 & & \\
\hline \multirow[t]{2}{*}{ Papel del médico en la información y toma de decisiones } & Hombre & 3,12 & 1,88 & $-1,38$ & 178 \\
\hline & Mujer & 3,88 & 1,18 & & \\
\hline \multirow[t]{2}{*}{ Papel del psicólogo en la información y toma de decisiones } & Hombre & 2,50 & 0,53 & $-0,33$ & ,740 \\
\hline & Mujer & 2,58 & 0,58 & & \\
\hline \multicolumn{6}{|l|}{ Satisfacción con la información } \\
\hline \multirow{2}{*}{$\begin{array}{l}\text { Satisfacción con la cantidad y la claridad de la información } \\
\text { recibida }\end{array}$} & Hombre & 4,75 & 1,16 & $-0,38$ & 709 \\
\hline & Mujer & 4,92 & 1,13 & & \\
\hline \multicolumn{6}{|l|}{ Estilo del médico } \\
\hline \multirow{2}{*}{$\begin{array}{l}\text { En cuanto al estilo del médico prefiero que éste sea directo y } \\
\text { anticipe posibles sospechas }\end{array}$} & Hombre & 1,87 & 1,25 & 0,28 & 777 \\
\hline & Mujer & 1,73 & 1,25 & & \\
\hline \multirow{2}{*}{$\begin{array}{l}\text { En cuanto al estilo del médico prefiero que éste se guarde lo } \\
\text { que aún no es seguro }\end{array}$} & Hombre & 0,86 & 1,21 & $-2,33$ & 026 \\
\hline & Mujer & 2,04 & 1,18 & & \\
\hline \multicolumn{6}{|l|}{ Participación en TD } \\
\hline \multirow[t]{2}{*}{ Me siento capacitado para participar en la TD sobre la salud } & Hombre & 2 & 1,31 & 0,67 & ,504 \\
\hline & Mujer & 1,73 & 0,87 & & \\
\hline \multirow{2}{*}{$\begin{array}{l}\text { Poder participar en una decisión médica sería más una carga } \\
\text { que un privilegio }\end{array}$} & Hombre & 1,62 & 1,41 & 1,08 & ,288 \\
\hline & Mujer & 1,08 & 1,19 & & \\
\hline
\end{tabular}




\subsubsection{Análisis diferenciales en función del estado civil}

Para explorar las diferencias según el estado civil de los familiares en las distintas variables dependientes incluidas en el estudio hemos estimado conveniente distribuir la muestra en dos grupos, tener pareja y no tener pareja, debido al bajo tamaño muestral en algunas categorías del estado civil. Así, "tener pareja" incluiría estar casado o vivir con pareja, mientras que en la categoría de "no tener pareja" se incluiría estar soltero, divorciado/separado y viudo. En este caso, para el análisis diferencial en función del estado civil se utilizarán pruebas t de Student.

En cuanto a la sintomatología ansiosa-depresiva (véase Tabla 64) evaluada mediante distintas escalas podemos observar mayor grado de ansiedad (HADS, STAIEstado y STAI-Rasgo) y mayor grado de depresión (HADS y BDI) en los familiares con pareja, resultando ser estas diferencias significativas a nivel estadístico en el caso de las puntuaciones obtenidas en la subescala de ansiedad del HADS ( $t=-2,57 ; p=, 012)$. Los resultados relativos a la percepción subjetiva de malestar general muestran puntuaciones ligeramente mayores en los familiares con pareja $(\overline{\mathrm{X}}=6,50$ vs $\overline{\mathrm{X}}=5,78)$.

Tabla 64. Análisis diferencial en función del estado civil de la ansiedad, depresión y estado de ánimo (familiares)

\begin{tabular}{|c|c|c|c|c|c|}
\hline Cuestionarios & Estado civil & $\bar{X}$ & DT & $\mathbf{t}$ & $\begin{array}{l}\text { Sig. } \\
p \leq, 050\end{array}$ \\
\hline \multirow[t]{2}{*}{ Total HADS Ansiedad } & Sin pareja & 11,13 & 4,34 & $-2,57$ & ,012 \\
\hline & Con pareja & 13,70 & 3,99 & & \\
\hline \multirow[t]{2}{*}{ Total HADS Depresión } & Sin pareja & 10,09 & 4,22 & $-1,61$ & 110 \\
\hline & Con pareja & 11,95 & 4,89 & & \\
\hline \multirow[t]{2}{*}{ STAI-Estado } & Sin pareja & 30,58 & 12,79 & $-1,41$ & ,168 \\
\hline & Con pareja & 36,68 & 11,65 & & \\
\hline \multirow[t]{2}{*}{ STAI-Rasgo } & Sin pareja & 21,08 & 11,87 & $-0,33$ & ,746 \\
\hline & Con pareja & 22,32 & 9,74 & & \\
\hline \multirow[t]{2}{*}{ BDI } & Sin pareja & 15,08 & 8,26 & $-0,42$ & 677 \\
\hline & Con pareja & 16,39 & 8,98 & & \\
\hline \multirow[t]{2}{*}{ EA1- Percepción de malestar general } & Sin pareja & 5,78 & 2,92 & $-1,18$ & ,243 \\
\hline & Con pareja & 6,50 & 2,30 & & \\
\hline \multirow[t]{2}{*}{ EA2- Percepción de Ansiedad y Nerviosismo } & Sin pareja & 6,96 & 2,58 & 0,04 & ,966 \\
\hline & Con pareja & 6,93 & 2,09 & & \\
\hline \multirow{2}{*}{$\begin{array}{l}\text { EA3- Percepción de Estado de Ánimo } \\
\text { Deprimido }\end{array}$} & Sin pareja & 6,39 & 3,31 & 0,20 & ,842 \\
\hline & Con pareja & 6,25 & 2,69 & & \\
\hline
\end{tabular}

Respecto a la valoración de la estancia en UCI (véase Tabla 65) de manera global no se han obtenido diferencias significativas en función del estado civil $(t=0,36 ; p=, 722)$ si bien las puntuaciones obtenidas por los familiares sin pareja han sido ligeramente 
mayores. Al analizar cada uno de los aspectos que incluye el cuestionario observamos diferencias significativas en la valoración de la "atención de los médicos" ( $\mathrm{t}=-2,16$; $\mathrm{p}=, 035)$, la "cantidad de la información recibida" ( $\mathrm{t}=-3,08 ; \mathrm{p}=, 003)$ y el "silencio y tranquilidad en la sala" ( $\mathrm{t}=-2,54 ; \mathrm{p}=, 013)$, que han sido mejor valorados por los familiares con pareja. Igualmente, rozando la significación estadística se han obtenido puntuaciones mayores en la valoración de la "claridad de la información" por parte de los participantes con pareja $(\mathrm{t}=-1,94 ; \mathrm{p}=, 056)$. Cabe señalar, aun sin ser las diferencias significativas, que los familiares con pareja han valorado más positivamente la mayoría de los ítems restantes, excepto aquellos relativos al apoyo emocional recibido por enfermería, la atención a las necesidades psicológicas y las posibilidades de distraerse que han obtenido mejor valoración en los familiares sin pareja.

Tabla 65. Análisis diferencial en función del estado civil de la valoración de la estancia en UCI (familiares)

\begin{tabular}{|c|c|c|c|c|c|}
\hline Ítem & Estado civil & $\bar{X}$ & DT & $\mathbf{t}$ & $\begin{array}{c}\text { Sig. } \\
p \leq, 050\end{array}$ \\
\hline \multirow{2}{*}{$\begin{array}{l}\text { En qué grado está siendo } \\
\text { agradable/desagradable su estancia en UCI } \\
\text { sin considerar los problemas médicos }\end{array}$} & Sin pareja & 3,43 & 1,66 & 0,36 & ,722 \\
\hline & Con pareja & 3,26 & 1,83 & & \\
\hline \multirow[t]{2}{*}{ Valoración de los siguientes aspectos } & Estado civil & $\bar{X}$ & DT & $t$ & \\
\hline & & & & & $p \leq, 050$ \\
\hline \multirow[t]{2}{*}{ 1. Cuidados médicos } & Sin pareja & 4,57 & 0,59 & $-0,77$ & ,444 \\
\hline & Con pareja & 4,71 & 0,70 & & \\
\hline \multirow[t]{2}{*}{ 2. Atención de los médicos } & Sin pareja & 4,33 & 1,06 & $-2,16$ & 035 \\
\hline & Con pareja & 4,74 & 0,53 & & \\
\hline \multirow[t]{2}{*}{ 3. Atención de las/os enfermeras/os } & Sin pareja & 4,43 & 0,81 & $-0,15$ & ,880 \\
\hline & Con pareja & 4,46 & 0,79 & & \\
\hline \multirow{2}{*}{$\begin{array}{l}\text { 4. Atención de las/os auxiliares de } \\
\text { enfermería }\end{array}$} & Sin pareja & 4,48 & 0,68 & $-0,69$ & ,491 \\
\hline & Con pareja & 4,59 & 0,65 & & \\
\hline \multirow[t]{2}{*}{ 5. Claridad de la información recibida } & Sin pareja & 4,14 & 1,01 & $-1,94$ & ,056 \\
\hline & Con pareja & 4,53 & 0,64 & & \\
\hline \multirow[t]{2}{*}{ 6. Cantidad de la información recibida } & Sin pareja & 3,71 & 1,00 & $-3,08$ & ,003 \\
\hline & Con pareja & 4,39 & 0,78 & & \\
\hline \multirow[t]{2}{*}{ 7. Trato por parte del personal de enfermería } & Sin pareja & 4,43 & 0,75 & $-0,54$ & ,593 \\
\hline & Con pareja & 4,52 & 0,61 & & \\
\hline \multirow{2}{*}{$\begin{array}{l}\text { 8. Afecto/apoyo emocional del personal de } \\
\text { enfermería }\end{array}$} & Sin pareja & 4,40 & 1,05 & 1,49 & 141 \\
\hline & Con pareja & 3,94 & 1,21 & & \\
\hline \multirow[t]{2}{*}{ 9. Respeto a la intimidad } & Sin pareja & 4,33 & 0,86 & $-0,07$ & ,946 \\
\hline & Con pareja & 4,35 & 0,72 & & \\
\hline \multirow[t]{2}{*}{ 10. Atención a los familiares } & Sin pareja & 4,40 & 0,99 & $-0,13$ & ,893 \\
\hline & Con pareja & 4,43 & 0,71 & & \\
\hline \multirow{2}{*}{$\begin{array}{l}\text { 11. Atención de necesidades psicológicas en } \\
\text { paciente y familia }\end{array}$} & Sin pareja & 4,85 & 0,37 & 0,13 & ,893 \\
\hline & Con pareja & 4,84 & 0,37 & & \\
\hline \multirow{2}{*}{$\begin{array}{l}\text { 12. Calidad de las instalaciones (comodidad, } \\
\text { higiene...) }\end{array}$} & Sin pareja & 4 & 0,63 & $-0,26$ & ,795 \\
\hline & Con pareja & 4,06 & 0,99 & & \\
\hline \multirow[t]{2}{*}{ 13. Posibilidades de distraerse } & Sin pareja & 2,10 & 1,33 & 0,27 & ,788 \\
\hline & Con pareja & 1,98 & 1,86 & & \\
\hline \multirow[t]{2}{*}{ 14. Silencio o tranquilidad en la sala } & Sin pareja & 3,19 & 1,36 & $-2,54$ & 013 \\
\hline & Con pareja & 3,96 & 1,05 & & \\
\hline \multirow[t]{2}{*}{ 15. Régimen de visitas } & Sin pareja & 3,95 & 0,80 & $-0,18$ & ,861 \\
\hline & Con pareja & 4 & 1,12 & & \\
\hline
\end{tabular}


En relación con los estresores de UCI, el análisis diferencial en función del estado civil (véase Tabla 66) muestra mayor grado de estrés general en los familiares con pareja, si bien estas diferencias no son significativas a nivel estadístico $(t=-0,32 ; p=, 748)$. Analizando otros factores estresantes en el contexto de UCI se observan diferencias significativas a favor de los participantes con pareja en el grado de estrés asociado a "no saber con seguridad cómo quedará el paciente después de una intervención quirúrgica" ( $t=-1,99 ; p=, 050)$. Y diferencias casi significativas relativas al hecho de "no entender en qué consiste la enfermedad" $(t=1,81 ; p=, 075)$, aspecto que ha resultado ser más estresante para los familiares sin pareja. Respecto al resto de ítems incluidos en la escala no se han obtenido diferencias significativas.

Tabla 66. Análisis diferencial en función del estado civil de los Factores estresantes en UCI (familiares)

\begin{tabular}{|c|c|c|c|c|c|}
\hline Ítem & Estado civil & $\bar{X}$ & DT & $\mathbf{t}$ & $\begin{array}{c}\text { Sig. } \\
p \leq, 050\end{array}$ \\
\hline 1. Que el enfermo pueda tener dolor & Sin pareja & $\begin{array}{c}3 \\
283\end{array}$ & 0,97 & 0,47 & 639 \\
\hline $\begin{array}{l}\text { 2. No saber con seguridad o no entender en qué } \\
\text { consiste la enfermedad }\end{array}$ & $\begin{array}{l}\text { Sin pareja } \\
\text { Con pareja }\end{array}$ & $\begin{array}{l}2,89 \\
2,18\end{array}$ & $\begin{array}{l}1,33 \\
1,45\end{array}$ & 1,81 & 075 \\
\hline 3. Pensar que le puede ocurrir algo grave & $\begin{array}{l}\text { Sin pareja } \\
\text { Con pareja }\end{array}$ & $\begin{array}{l}3,45 \\
3,79\end{array}$ & $\begin{array}{l}1,14 \\
0,68\end{array}$ & $-1,52$ & 132 \\
\hline $\begin{array}{l}\text { 4. Pensar si podrá volver a su vida normal después de } \\
\text { salir del hospital }\end{array}$ & $\begin{array}{l}\text { Sin pareja } \\
\text { Con pareja }\end{array}$ & $\begin{array}{l}2,90 \\
2,83\end{array}$ & $\begin{array}{l}1,48 \\
1,55\end{array}$ & 0,19 & ,852 \\
\hline $\begin{array}{l}\text { 5. No poder ocuparse usted de la familia como hasta } \\
\text { ahora venía haciendo }\end{array}$ & $\begin{array}{l}\text { Sin pareja } \\
\text { Con pareja }\end{array}$ & $\begin{array}{l}1,42 \\
2,04\end{array}$ & $\begin{array}{l}1,54 \\
1,65\end{array}$ & $-1,41$ & 164 \\
\hline $\begin{array}{l}\text { 6. No saber con seguridad cómo quedará después de la } \\
\text { operación }\end{array}$ & $\begin{array}{l}\text { Sin pareja } \\
\text { Con pareja }\end{array}$ & $\begin{array}{l}2,06 \\
2,91\end{array}$ & $\begin{array}{l}1,53 \\
1,41\end{array}$ & $-1,99$ & ,050 \\
\hline 7. Estar separado del enfermo & $\begin{array}{l}\text { Sin pareja } \\
\text { Con pareja }\end{array}$ & $\begin{array}{l}2,57 \\
2,70\end{array}$ & $\begin{array}{l}1,53 \\
1,43\end{array}$ & $-0,34$ & 734 \\
\hline $\begin{array}{l}\text { 8. No saber cuándo le darán el alta de la Unidad de } \\
\text { Cuidados Intensivos }\end{array}$ & $\begin{array}{l}\text { Sin pareja } \\
\text { Con pareja }\end{array}$ & $\begin{array}{l}1,89 \\
2,13\end{array}$ & $\begin{array}{l}1,56 \\
1,57\end{array}$ & $-0,55$ &, 584 \\
\hline 9. Haber sido hospitalizado de repente, sin esperarlo & $\begin{array}{l}\text { Sin pareja } \\
\text { Con pareja }\end{array}$ & $\begin{array}{l}3,15 \\
3,02\end{array}$ & $\begin{array}{l}1,31 \\
1,34\end{array}$ & 0,36 & ,722 \\
\hline $\begin{array}{l}\text { 10. No saber los resultados/razones de los } \\
\text { tratamientos/pruebas que le hacen }\end{array}$ & $\begin{array}{l}\text { Sin pareja } \\
\text { Con pareja }\end{array}$ & $\begin{array}{l}1,81 \\
1,73\end{array}$ & $\begin{array}{l}1,54 \\
1,48\end{array}$ & 0,19 & ,848 \\
\hline 11. Tener que organizarse para acudir a las visitas & $\begin{array}{l}\text { Sin pareja } \\
\text { Con pareja }\end{array}$ & $\begin{array}{c}1 \\
0,85\end{array}$ & $\begin{array}{l}1,41 \\
1,19\end{array}$ & 0,45 & ,656 \\
\hline $\begin{array}{l}\text { 12. Pensar que pueda tener dolor a causa de la } \\
\text { operación/análisis }\end{array}$ & $\begin{array}{l}\text { Sin pareja } \\
\text { Con pareja }\end{array}$ & $\begin{array}{l}2,63 \\
2,27\end{array}$ & $\begin{array}{l}1,21 \\
1,37\end{array}$ & 1 & ,319 \\
\hline 13. No saber cuándo van a hacerle cosas al enfermo & $\begin{array}{l}\text { Sin pareja } \\
\text { Con pareja }\end{array}$ & $\begin{array}{l}2,05 \\
1,41\end{array}$ & $\begin{array}{l}1,36 \\
1,47\end{array}$ & 1,66 & 103 \\
\hline $\begin{array}{l}\text { 14. Pensar que el paciente pueda no obtener alivio para } \\
\text { el dolor aun tomando medicación }\end{array}$ & $\begin{array}{l}\text { Sin pareja } \\
\text { Con pareja }\end{array}$ & $\begin{array}{l}3,17 \\
2,78\end{array}$ & $\begin{array}{l}1,04 \\
1,34\end{array}$ & 1,07 & ,291 \\
\hline 15. Ver que el personal del hospital tiene prisa & $\begin{array}{l}\text { Sin pareja } \\
\text { Con pareja }\end{array}$ & $\begin{array}{l}1,85 \\
1,20\end{array}$ & $\begin{array}{l}1,49 \\
1,60\end{array}$ & 1,54 & 129 \\
\hline $\begin{array}{l}\text { 16. El hospital en que está ingresado el paciente se } \\
\text { encuentra lejos de casa }\end{array}$ & $\begin{array}{l}\text { Sin pareja } \\
\text { Con pareja }\end{array}$ & $\begin{array}{l}1,20 \\
1,15\end{array}$ & $\begin{array}{l}1,61 \\
1,47\end{array}$ & 0,12 & 907 \\
\hline $\begin{array}{l}\text { 17. Que sanitarios hablen deprisa o usen palabras que } \\
\text { no puedan entender }\end{array}$ & $\begin{array}{l}\text { Sin pareja } \\
\text { Con pareja }\end{array}$ & $\begin{array}{c}1,69 \\
1\end{array}$ & $\begin{array}{l}1,40 \\
1,35\end{array}$ & 1,67 & 100 \\
\hline $\begin{array}{l}\text { 18. Que el personal sanitario no conteste a sus } \\
\text { preguntas }\end{array}$ & $\begin{array}{l}\text { Sin pareja } \\
\text { Con pareja }\end{array}$ & $\begin{array}{l}2,54 \\
1,87\end{array}$ & $\begin{array}{l}1,29 \\
1,49\end{array}$ & 1,32 & 193 \\
\hline 19. Tener que dormir fuera del domicilio habitual & $\begin{array}{l}\text { Sin pareja } \\
\text { Con pareja }\end{array}$ & $\begin{array}{c}1 \\
1,51\end{array}$ & $\begin{array}{l}1,65 \\
1,75\end{array}$ & $-0,96$ & ,341 \\
\hline $\begin{array}{l}\text { 20. Preocupación por que no le den la medicación para } \\
\text { el dolor cuando la necesita }\end{array}$ & $\begin{array}{l}\text { Sin pareja } \\
\text { Con pareja }\end{array}$ & $\begin{array}{l}1,95 \\
1,58\end{array}$ & $\begin{array}{l}1,61 \\
1,56\end{array}$ & 0,84 & ,403 \\
\hline
\end{tabular}


(Continuación Tabla 66)

\begin{tabular}{|c|c|c|c|c|c|}
\hline Ítem & Estado civil & $\bar{X}$ & DT & $\mathbf{t}$ & $\begin{array}{l}\text { Sig. } \\
p \leq, 050\end{array}$ \\
\hline $\begin{array}{l}\text { 21. Pensar en la posible pérdida de dinero a causa de la } \\
\text { enfermedad }\end{array}$ & $\begin{array}{l}\text { Sin pareja } \\
\text { Con pareja }\end{array}$ & $\begin{array}{l}0,71 \\
0,56\end{array}$ & $\begin{array}{l}1,35 \\
1,07\end{array}$ & 0,50 & ,619 \\
\hline 22. Sentir olores extraños en el hospital & $\begin{array}{l}\text { Sin pareja } \\
\text { Con pareja }\end{array}$ & $\begin{array}{l}0,62 \\
1,10\end{array}$ & $\begin{array}{l}1,28 \\
1,52\end{array}$ & $-1,28$ & ,206 \\
\hline $\begin{array}{l}\text { 23. Tener que comer a horas diferentes a las habituales } \\
\text { para poder ir a las visitas }\end{array}$ & $\begin{array}{l}\text { Sin pareja } \\
\text { Con pareja }\end{array}$ & $\begin{array}{l}0,14 \\
0,56\end{array}$ & $\begin{array}{l}0,48 \\
1,15\end{array}$ & $-1,61$ & 112 \\
\hline 24. No poder llamar al paciente por teléfono & $\begin{array}{l}\text { Sin pareja } \\
\text { Con pareja }\end{array}$ & $\begin{array}{l}1,33 \\
1,52\end{array}$ & $\begin{array}{l}1,71 \\
1,72\end{array}$ & $-0,42$ & 679 \\
\hline $\begin{array}{l}\text { 25. Que el enfermo esté al cuidado de sanitarios } \\
\text { desconocidos }\end{array}$ & $\begin{array}{l}\text { Sin pareja } \\
\text { Con pareja }\end{array}$ & $\begin{array}{l}0,48 \\
0,45\end{array}$ & $\begin{array}{l}1,08 \\
1,02\end{array}$ & 0,12 & ,914 \\
\hline 26. Tener demasiados horarios de visita & $\begin{array}{l}\text { Sin pareja } \\
\text { Con pareja }\end{array}$ & $\begin{array}{l}0,29 \\
0,42\end{array}$ & $\begin{array}{l}0,72 \\
1,04\end{array}$ & $-0,56$ &, 578 \\
\hline $\begin{array}{l}\text { 27. Tener que ver en la sala durante las visitas a otros } \\
\text { enfermos muy graves }\end{array}$ & $\begin{array}{l}\text { Sin pareja } \\
\text { Con pareja }\end{array}$ & $\begin{array}{l}0,57 \\
0,60\end{array}$ & $\begin{array}{l}0,87 \\
1,25\end{array}$ & $-0,11$ & 914 \\
\hline 28. Miedo a que el paciente pueda morir & $\begin{array}{l}\text { Sin pareja } \\
\text { Con pareja }\end{array}$ & $\begin{array}{l}3,45 \\
3,54\end{array}$ & $\begin{array}{l}1,36 \\
1,03\end{array}$ & $-0,30$ & ,762 \\
\hline $\begin{array}{l}\text { 29. Que el paciente sea atendido por diferentes } \\
\text { médicos durante su ingreso }\end{array}$ & $\begin{array}{l}\text { Sin pareja } \\
\text { Con pareja }\end{array}$ & $\begin{array}{l}0,86 \\
0,81\end{array}$ & $\begin{array}{l}1,19 \\
1,27\end{array}$ & 0,14 & ,891 \\
\hline $\begin{array}{l}\text { 30. Que los familiares sean informados por diferentes } \\
\text { médicos }\end{array}$ & $\begin{array}{l}\text { Sin pareja } \\
\text { Con pareja }\end{array}$ & $\begin{array}{l}1,48 \\
1,02\end{array}$ & $\begin{array}{l}1,44 \\
1,41\end{array}$ & 1,23 & ,223 \\
\hline 31. Esperar a entrar a las diferentes horas de visita & $\begin{array}{l}\text { Sin pareja } \\
\text { Con pareja }\end{array}$ & $\begin{array}{l}1,57 \\
1,54\end{array}$ & $\begin{array}{l}1,43 \\
1,59\end{array}$ & 0,07 & ,942 \\
\hline $\begin{array}{l}\text { 32. No poder estar junto al enfermo todo el tiempo } \\
\text { (restringida la permanencia en la unidad) }\end{array}$ & $\begin{array}{l}\text { Sin pareja } \\
\text { Con pareja }\end{array}$ & $\begin{array}{l}1,86 \\
1,67\end{array}$ & $\begin{array}{l}1,65 \\
1,68\end{array}$ & 0,43 & ,665 \\
\hline $\begin{array}{l}\text { 33. Tener que desplazarse a diario para visitar al } \\
\text { enfermo en las } 4 \text { horas de visita }\end{array}$ & $\begin{array}{l}\text { Sin pareja } \\
\text { Con pareja }\end{array}$ & $\begin{array}{l}1,38 \\
0,93\end{array}$ & $\begin{array}{l}1,72 \\
1,47\end{array}$ & 1,09 & ,278 \\
\hline $\begin{array}{l}\text { 34. Los horarios en que están concertadas las visitas al } \\
\text { enfermo en la unidad }\end{array}$ & $\begin{array}{l}\text { Sin pareja } \\
\text { Con pareja }\end{array}$ & $\begin{array}{l}0,71 \\
0,85\end{array}$ & $\begin{array}{l}1,23 \\
1,44\end{array}$ & $-0,38$ & 708 \\
\hline $\begin{array}{l}\text { 35. Que el enfermo permanezca solo durante todo el } \\
\text { día junto a otros pacientes graves }\end{array}$ & $\begin{array}{l}\text { Sin pareja } \\
\text { Con pareja }\end{array}$ & $\begin{array}{l}1,10 \\
1,27\end{array}$ & $\begin{array}{l}1,41 \\
1,39\end{array}$ & $-0,44$ &, 664 \\
\hline $\begin{array}{l}\text { 36. Que el paciente no descanse adecuadamente por el } \\
\text { ruido }\end{array}$ & $\begin{array}{l}\text { Sin pareja } \\
\text { Con pareja }\end{array}$ & $\begin{array}{l}1,35 \\
1,20\end{array}$ & $\begin{array}{l}1,39 \\
1,36\end{array}$ & 0,39 & ,694 \\
\hline 37. Que el paciente manifieste temor & $\begin{array}{l}\text { Sin pareja } \\
\text { Con pareja }\end{array}$ & $\begin{array}{l}2,59 \\
2,37\end{array}$ & $\begin{array}{l}1,37 \\
1,39\end{array}$ & 0,53 & ,597 \\
\hline $\begin{array}{l}\text { 38. Que el paciente tenga que permanecer aislado por } \\
\text { prescripción médica }\end{array}$ & $\begin{array}{l}\text { Sin pareja } \\
\text { Con pareja }\end{array}$ & $\begin{array}{l}2,12 \\
1,66\end{array}$ & $\begin{array}{l}1,65 \\
1,58\end{array}$ & 0,96 & ,343 \\
\hline $\begin{array}{l}\text { 39. Pensar que el tiempo de información para los } \\
\text { familiares resulta insuficiente }\end{array}$ & $\begin{array}{l}\text { Sin pareja } \\
\text { Con pareja }\end{array}$ & $\begin{array}{l}1,29 \\
0,77\end{array}$ & $\begin{array}{l}1,55 \\
1,28\end{array}$ & 1,44 & 154 \\
\hline 40. Nivel de estrés en general & $\begin{array}{l}\text { Sin pareja } \\
\text { Con pareja }\end{array}$ & $\begin{array}{l}2,95 \\
3,04\end{array}$ & $\begin{array}{l}1,12 \\
1,03\end{array}$ & $-0,32$ & 748 \\
\hline
\end{tabular}

En cuanto al análisis diferencial de la adaptación de la familia al ingreso de un ser querido en UCI (véase Tabla 67), se observa mayor grado de interferencia en los familiares sin pareja a nivel global $(\overline{\mathrm{X}}=3,91$ vs $\overline{\mathrm{X}}=3,74)$, social $(\overline{\mathrm{X}}=3,09$ vs $\overline{\mathrm{X}}=2,39)$ y en la vida familiar general $(\overline{\mathrm{X}}=2,64$ vs $\overline{\mathrm{X}}=2,30)$. Mientras que el trabajo, la vida de pareja y el tiempo libre presentan mayor afectación en los familiares que sí tienen pareja. No obstante cabe señalar que en ningún caso estas diferencias en función del estado civil han resultado significativas a nivel estadístico. 
Tabla 67. Análisis diferencial en función del estado civil del Grado de interferencia en las distintas esferas de la vida de los familiares de UCI

\begin{tabular}{|c|c|c|c|c|c|c|}
\hline \multicolumn{2}{|c|}{ Niveles de interferencia } & Estado civil & $\bar{X}$ & DT & $\mathbf{t}$ & $\begin{array}{c}\text { Sig. } \\
(p \leq, 050)\end{array}$ \\
\hline \multirow[t]{2}{*}{1.} & Trabajo & Sin pareja & 2,91 & 1,90 & $-0,03$ & 973 \\
\hline & & Con pareja & 2,92 & 1,74 & & \\
\hline \multirow[t]{2}{*}{2.} & Vida social & Sin pareja & 3,09 & 1,57 & 1,51 & 136 \\
\hline & & Con pareja & 2,39 & 1,90 & & \\
\hline \multirow[t]{2}{*}{3.} & Tiempo libre & Sin pareja & 3,36 & 1,56 & $-0,36$ & ,717 \\
\hline & & Con pareja & 3,51 & 1,59 & & \\
\hline \multirow[t]{2}{*}{4.} & Relación de pareja & Sin pareja & 1,71 & 1,99 & $-0,76$ & ,449 \\
\hline & & Con pareja & 2,13 & 2,02 & & \\
\hline \multirow[t]{2}{*}{5.} & Vida familiar & Sin pareja & 2,64 & 1,92 & 0,69 & ,489 \\
\hline & & Con pareja & 2,30 & 1,89 & & \\
\hline \multirow[t]{2}{*}{6.} & Escala global & Sin pareja & 3,91 & 1,06 & 0,57 & ,569 \\
\hline & & Con pareja & 3,74 & 1,24 & & \\
\hline
\end{tabular}

Por lo que respecta a las necesidades de los familiares en UCI podemos observar en la Tabla 68 que los familiares sin pareja presentan puntuaciones mayores (menor satisfacción) en gran parte de las necesidades analizadas, siendo estas diferencias significativas a nivel estadístico respecto a la percepción de que los "cuidados médicos podrían mejorarse" ( $\mathrm{t}=2,44 ; \mathrm{p}=, 017)$ y casi significativas en relación con que "los miembros del equipo son atentos con la familia" ( $t=1,88 ; \mathrm{p}=, 065)$. Por otro lado, si bien las diferencias no han sido significativas, los familiares con pareja han obtenido puntuaciones ligeramente superiores, es decir, valoran de forma menos positiva el “interés mostrado por cómo se siente el familiar en particular" ( $\bar{X}=2,65$ vs $\bar{X}=2,50)$.

Tabla 68. Análisis diferencial en función del estado civil de las Necesidades de los familiares en UCI

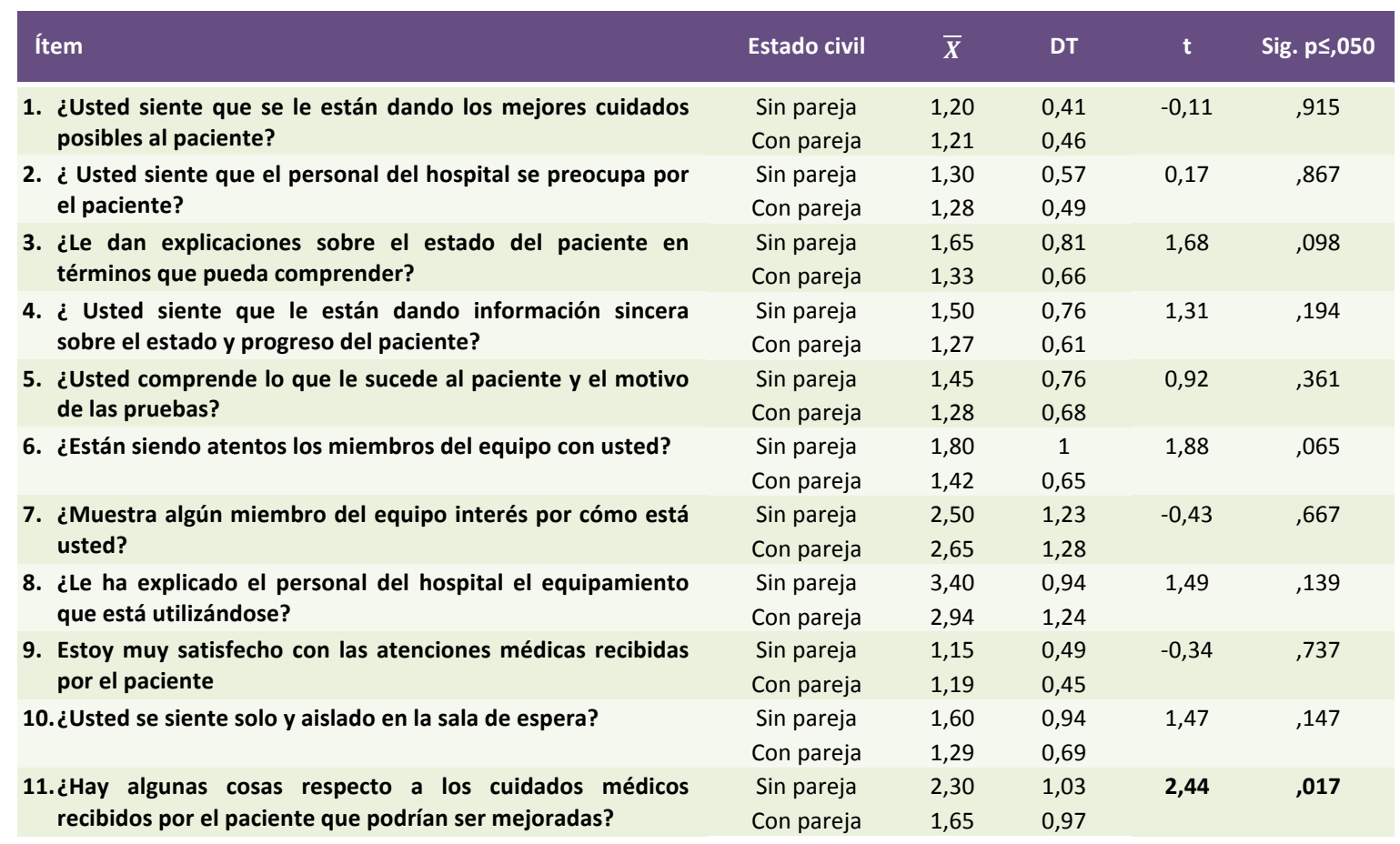


En cuanto al proceso de morir (véase Tabla 69), no se han obtenido diferencias significativas en función del estado civil en ninguno de los factores que incluye el CAMP. No obstante, aun sin llegar a la significación estadística, podemos observar que los familiares con pareja presentan mayores puntuaciones en factores relativos al “control del dolor y síntomas de malestar" ( $\bar{X}=3,28$ vs $\bar{X}=2,94)$, "acortar el proceso si hay sufrimiento" ( $\overline{\mathrm{X}}=3,27$ vs $\overline{\mathrm{X}}=3,06)$, "no alargar artificialmente la vida en $\mathrm{UCI}^{\prime \prime}(\overline{\mathrm{X}}=2,88$ vs $\bar{X}=2,61)$, "sentirse cerca de los seres queridos" ( $\bar{X}=3,50$ vs $\bar{X}=3,33)$ y pensar que pueda "morir en casa" ( $\bar{X}=1,12$ vs $\bar{X}=1,06)$. En cambio, los familiares sin pareja parecen dar más importancia al "control de los pensamientos y las funciones fisiológicas hasta el final" ( $\bar{X}=2,94$ vs $\bar{X}=2,28)$, que su "muerte no suponga una carga para los demás" $(\bar{X}=3,28$ vs $\bar{X}=3,02)$, pensar que su “vida ha tenido algún sentido" $(\bar{X}=3,11$ vs $\bar{X}=2,98)$, "creer en otra vida después de la muerte" ( $\bar{X}=1,56$ vs $\bar{X}=1,29)$, "no sentirse culpable" $(\overline{\mathrm{X}}=3,06$ vs $\overline{\mathrm{X}}=2,60)$ y "disponer de ayuda para morir con rapidez si la situación se hace insoportable" ( $\overline{\mathrm{X}}=2,94$ vs $\overline{\mathrm{X}}=2,83)$.

Tabla 69. Análisis diferencial en función del estado civil de los distintos factores del Cuestionario de Ayuda a Morir en Paz (CAMP) (familiares)

\begin{tabular}{|c|c|c|c|c|c|}
\hline Ítem & Estado civil & $\overline{\boldsymbol{X}}$ & DT & $\mathbf{t}$ & $\begin{array}{l}\text { Sig. } \\
p \leq, 050\end{array}$ \\
\hline \multirow[t]{2}{*}{ 1. Controlar mi dolor y otros síntomas de malestar } & Sin pareja & 2,94 & 1,26 & $-1,19$ & ,240 \\
\hline & Con pareja & 3,28 & 0,88 & & \\
\hline \multirow[t]{2}{*}{ 2. Mi proceso de morir, si produce sufrimiento, será corto } & Sin pareja & 3,06 & 1,11 & $-0,72$ & ,474 \\
\hline & Con pareja & 3,27 & 1,06 & & \\
\hline \multirow[t]{2}{*}{ 3.Controlar hasta el final pensamientos y funciones fisiológicas } & Sin pareja & 2,94 & 1,21 & 1,62 & 110 \\
\hline & Con pareja & 2,28 & 1,55 & & \\
\hline \multirow{2}{*}{$\begin{array}{l}\text { 4. Mi muerte no supondrá una carga insoportable para mis } \\
\text { seres queridos }\end{array}$} & Sin pareja & 3,28 & 1,13 & 0,78 & ,436 \\
\hline & Con pareja & 3,02 & 1,16 & & \\
\hline \multirow{2}{*}{$\begin{array}{l}\text { 5. Poder sentirme cerca, comunicarme y estrechar vínculos } \\
\text { afectivos con mis personas queridas }\end{array}$} & Sin pareja & 3,33 & 1,08 & $-0,65$ &, 521 \\
\hline & Con pareja & 3,50 & 0,85 & & \\
\hline \multirow{2}{*}{$\begin{array}{l}\text { 6. Sin esperanza real de recuperación, no se alargará } \\
\text { artificialmente mi vida en } \mathrm{UCl}\end{array}$} & Sin pareja & 2,61 & 1,14 & $-0,75$ & ,456 \\
\hline & Con pareja & 2,88 & 1,33 & & \\
\hline \multirow[t]{2}{*}{ 7. Pensar que mi vida ha tenido algún sentido } & Sin pareja & 3,11 & 1,13 & 0,42 &, 674 \\
\hline & Con pareja & 2,98 & 1,13 & & \\
\hline \multirow[t]{2}{*}{ 8. Creer en otra vida después de la muerte } & Sin pareja & 1,56 & 1,42 & 0,64 &, 523 \\
\hline & Con pareja & 1,29 & 1,46 & & \\
\hline \multirow[t]{2}{*}{ 9. No sentirse culpable por conflictos personales del pasado } & Sin pareja & 3,06 & 0,99 & 1,23 & ,225 \\
\hline & Con pareja & 2,60 & 1,42 & & \\
\hline \multirow{2}{*}{$\begin{array}{l}\text { 10. Si la situación se me hace insoportable disponer de ayuda } \\
\text { para morir con rapidez }\end{array}$} & Sin pareja & 2,94 & 0,99 & 0,33 & ,740 \\
\hline & Con pareja & 2,83 & 1,30 & & \\
\hline \multirow[t]{2}{*}{ 11. Poder morir en mi casa } & Sin pareja & 1,06 & 1,59 & $-0,14$ & ,885 \\
\hline & Con pareja & 1,12 & 1,45 & & \\
\hline
\end{tabular}


Finalmente, respecto a la valoración del proceso de información y toma de decisiones en función del estado civil (véase Tabla 70), si bien no se han obtenido diferencias estadísticamente significativas podemos observar que los familiares con pareja, frente a los que no la tienen, conceden ligeramente más importancia a la familia $(\overline{\mathrm{X}}=13,28$ vs $\overline{\mathrm{X}}=13,14)$ y al médico $(\overline{\mathrm{X}}=3,74$ vs $\overline{\mathrm{X}}=3,57)$ en el proceso. Por el contrario, aquellos familiares sin pareja dan más importancia al propio paciente $(\bar{X}=13,43$ vs $\overline{\mathrm{X}}=12,11$ ). Asimismo, los resultados de este análisis diferencial muestran que los familiares con pareja refieren estar más satisfechos con la información $(\bar{X}=4,93$ vs $\bar{X}=4,71$ ), prefieren más que los que no tienen pareja un estilo médico cauteloso, que se guarde lo que aún no es seguro $(\overline{\mathrm{X}}=1,81$ vs $\overline{\mathrm{X}}=1,71)$ y se sienten más capacitados para participar en decisiones médicas $(\overline{\mathrm{X}}=1,81$ vs $\overline{\mathrm{X}}=1,71)$, a la vez que para ellos el hecho de participar en una decisión relevante sería más una carga que un privilegio $(\bar{X}=1,27$ vs $\overline{\mathrm{X}}=1$ ) en comparación con los que no tienen pareja.

Tabla 70. Valoración diferencial en función del estado civil del proceso de información y toma de decisiones (TD) en los familiares

\begin{tabular}{|c|c|c|c|c|c|}
\hline CITD & Estado civil & $\bar{X}$ & DT & $\mathbf{t}$ & $\begin{array}{l}\text { Sig. } \\
p \leq, 050\end{array}$ \\
\hline \multicolumn{6}{|l|}{ Importancia de los distintos agentes implicados } \\
\hline \multirow[t]{2}{*}{ Papel de la familia en la información y toma de decisiones } & Sin pareja & 13,14 & 3,58 & $-0,12$ & ,906 \\
\hline & Con pareja & 13,28 & 2,41 & & \\
\hline \multirow[t]{2}{*}{ Papel del paciente en la información y toma de decisiones } & Sin pareja & 13,43 & 3,26 & 0,80 & ,428 \\
\hline & Con pareja & 12,11 & 3,96 & & \\
\hline \multirow[t]{2}{*}{ Papel del médico en la información y toma de decisiones } & Sin pareja & 3,57 & 1,51 & $-0,28$ & ,778 \\
\hline & Con pareja & 3,74 & 1,37 & & \\
\hline \multirow[t]{2}{*}{ Papel del psicólogo en la información y toma de decisiones } & Sin pareja & 2,57 & 0,53 & 0,07 & 948 \\
\hline & Con pareja & 2,56 & 0,58 & & \\
\hline \multicolumn{6}{|l|}{ Satisfacción con la información } \\
\hline \multirow{2}{*}{$\begin{array}{l}\text { Satisfacción con la cantidad y la claridad de la información } \\
\text { recibida }\end{array}$} & Sin pareja & 4,71 & 1,11 & $-0,44$ &, 663 \\
\hline & Con pareja & 4,93 & 1,14 & & \\
\hline \multicolumn{6}{|l|}{ Estilo del médico } \\
\hline \multirow{2}{*}{$\begin{array}{l}\text { En cuanto al estilo del médico prefiero que éste sea directo y } \\
\text { anticipe posibles sospechas }\end{array}$} & Sin pareja & 2 & 1,41 & 0,56 & ,579 \\
\hline & Con pareja & 1,70 & 1,20 & & \\
\hline \multirow{2}{*}{$\begin{array}{l}\text { En cuanto al estilo del médico prefiero que éste se guarde lo } \\
\text { que aún no es seguro }\end{array}$} & Sin pareja & 1,71 & 1,25 & $-0,17$ & ,866 \\
\hline & Con pareja & 1,81 & 1,29 & & \\
\hline \multicolumn{6}{|l|}{ Participación en TD } \\
\hline \multirow[t]{2}{*}{ Me siento capacitado para participar en la TD sobre la salud } & Sin pareja & 1,71 & 1,25 & $-0,24$ & ,813 \\
\hline & Con pareja & 1,81 & 0,92 & & \\
\hline \multirow{2}{*}{$\begin{array}{l}\text { Poder participar en una decisión médica sería más una carga } \\
\text { que un privilegio }\end{array}$} & Sin pareja & 1 & 1,29 & $-0,50$ & 619 \\
\hline & Con pareja & 1,27 & 1,25 & & \\
\hline
\end{tabular}




\subsubsection{Análisis diferenciales en función de si los familiares tienen o no hijos}

Otra variable sociodemográfica en función de la cual se han llevado a cabo análisis diferenciales ha sido el número de hijos. Concretamente, se ha utilizado la prueba $t$ de Student para explorar la existencia de diferencias en las distintas variables dependientes según si los familiares tienen o no hijos.

En cuanto a la sintomatología ansiosa y depresiva (véase Tabla 71), en primer lugar haremos referencia a los síntomas de ansiedad. Si bien no se han obtenido diferencias estadísticamente significativas, los resultados muestran en los familiares con hijos puntuaciones ligeramente mayores en la ansiedad evaluada mediante el HADS ( $\bar{X}=13,04$ vs $\bar{X}=11,50)$ y en ansiedad estado (STAI) ( $\bar{X}=33,57$ vs $\bar{X}=31,60$ ). En segundo lugar, analizando los resultados relativos a los síntomas de depresión podemos ver que en la evaluación realizada mediante el HADS aparecen puntuaciones mayores en depresión también en los familiares con hijos ( $\bar{X}=12,43$ vs $\bar{X}=8,87)$, siendo el único caso en el que las diferencias han resultado significativas $(t=-2,66 ; p=, 010)$.

Analizando la percepción subjetiva del estado de ánimo si bien no se han encontrado diferencias significativas entre los familiares que tienen hijos y los que no, podemos observar en la Tabla 71 que las puntuaciones en malestar general $(\bar{X}=6,75$ vs $\bar{X}=6,22)$ y ansiedad $(\bar{X}=7,19$ vs $\bar{X}=6,94)$ son muy ligeramente superiores en los familiares sin hijos, mientras que los familiares con hijos presentan mayor percepción subjetiva de estado de ánimo deprimido $(\overline{\mathrm{X}}=6,37$ vs $\overline{\mathrm{X}}=6,19)$.

Tabla 71. Análisis diferencial en función del número de hijos de la ansiedad, depresión y percepción de estado de ánimo (familiares)

\begin{tabular}{|c|c|c|c|c|c|}
\hline Cuestionarios & Número de hijos & $\bar{X}$ & DT & $\mathbf{t}$ & $\begin{array}{c}\text { Sig. } \\
p \leq, 050\end{array}$ \\
\hline \multirow[t]{2}{*}{ Total HADS Ansiedad } & Sin hijos & 11,50 & 5,16 & $-1,27$ & ,209 \\
\hline & Con hijos & 13,04 & 3,87 & & \\
\hline \multirow[t]{2}{*}{ Total HADS Depresión } & Sin hijos & 8,87 & 3,01 & $-2,66$ & ,010 \\
\hline & Con hijos & 12,43 & 6,34 & & \\
\hline \multirow[t]{2}{*}{ STAI-Estado } & Sin hijos & 31,60 & 13,27 & $-0,37$ & 718 \\
\hline & Con hijos & 33,57 & 12,83 & & \\
\hline \multirow[t]{2}{*}{ STAI-Rasgo } & Sin hijos & 22 & 13,03 & 0,37 & ,716 \\
\hline & Con hijos & 20,21 & 10,71 & & \\
\hline \multirow[t]{2}{*}{ BDI } & Sin hijos & 14,80 & 8,39 & 0,19 & ,844 \\
\hline & Con hijos & 14,14 & 7,64 & & \\
\hline \multirow[t]{2}{*}{ EA1- Percepción de malestar general } & Sin hijos & 6,75 & 2,69 & 0,75 & ,456 \\
\hline & Con hijos & 6,22 & 2,35 & & \\
\hline \multirow[t]{2}{*}{ EA2- Percepción de Ansiedad y Nerviosismo } & Sin hijos & 7,19 & 2,32 & 0,39 & 699 \\
\hline & Con hijos & 6,94 & 2,19 & & \\
\hline \multirow[t]{2}{*}{ EA3- Percepción de Estado de Ánimo Deprimido } & Sin hijos & 6,19 & 3,19 & $-0,21$ & ,835 \\
\hline & Con hijos & 6,37 & 2,93 & & \\
\hline
\end{tabular}


En cuanto a la valoración de la estancia en UCI, como podemos observar en la Tabla 72, a nivel global no se han obtenido diferencias estadísticamente significativas, si bien las puntuaciones son ligeramente mayores en los familiares sin hijos $(\bar{X}=3,58$ vs $\overline{\mathrm{X}}=3,17)$. Analizando los distintos ítems incluidos en el cuestionario, se han obtenido diferencias significativas a nivel estadístico en la valoración del "afecto /apoyo recibido del personal de enfermería" $(\mathrm{t}=2,15 ; \mathrm{p}=, 037)$ y en la valoración de la "atención a los familiares" ( $t=2,01 ; \mathrm{p}=, 050)$, ambos aspectos mejor valorados por los familiares sin hijos. Estos mismos familiares, y rozando la significación estadística, han valorado de forma más positiva el "respeto a la intimidad" $(t=1,88 ; p=, 066)$. Atendiendo al resto de ítems, aun sin ser las diferencias significativas, podemos apreciar que los familiares sin hijos valoran más la “atención de enfermeras $(\overline{\mathrm{X}}=4,69$ vs $\overline{\mathrm{X}}=4,46)$ y auxiliares de enfermería" ( $\overline{\mathrm{X}}=4,82$ vs $\overline{\mathrm{X}}=4,52)$, la "calidad de las instalaciones" $(\overline{\mathrm{X}}=4$ vs $\overline{\mathrm{X}}=3,89)$ y las “posibilidades de distraerse" ( $\overline{\mathrm{X}}=2,67$ vs $\overline{\mathrm{X}}=1,77)$. En cambio, podemos observar que los familiares con hijos puntúan más alto en la valoración de los "cuidados médicos" $(\overline{\mathrm{X}}=4,80$ vs $\overline{\mathrm{X}}=4,69)$ y “atenciones médicas" ( $\overline{\mathrm{X}}=4,76$ vs $\overline{\mathrm{X}}=4,46)$, así como en el "silencio en la sala" ( $\overline{\mathrm{X}}=3,97$ vs $\overline{\mathrm{X}}=3,77)$.

Tabla 72. Análisis diferencial en función del número de hijos de la valoración de la estancia en UCI (familiares)

\begin{tabular}{|c|c|c|c|c|c|}
\hline Ítem & Número de hijos & $\overline{\boldsymbol{X}}$ & DT & $\mathbf{t}$ & $\begin{array}{l}\text { Sig. } \\
p \leq, 050\end{array}$ \\
\hline $\begin{array}{l}\text { En qué grado está siendo agradable/desagradable su } \\
\text { estancia en } \mathrm{UCl} \text { sin considerar los problemas médicos }\end{array}$ & $\begin{array}{l}\text { Sin hijos } \\
\text { Con hijos }\end{array}$ & $\begin{array}{l}3,58 \\
3,17\end{array}$ & $\begin{array}{l}1,97 \\
1,87\end{array}$ & 0,66 &, 515 \\
\hline Valoración de los siguientes aspectos & Número de hijos & $\bar{X}$ & DT & $\mathbf{t}$ & $\begin{array}{c}\text { Sig. } \\
p \leq, 050\end{array}$ \\
\hline 1. Cuidados médicos & $\begin{array}{l}\text { Sin hijos } \\
\text { Con hijos }\end{array}$ & $\begin{array}{l}4,69 \\
4,80\end{array}$ & $\begin{array}{l}0,63 \\
0,46\end{array}$ & $-0,70$ & ,486 \\
\hline 2. Atención de los médicos & $\begin{array}{l}\text { Sin hijos } \\
\text { Con hijos }\end{array}$ & $\begin{array}{l}4,46 \\
4,76\end{array}$ & $\begin{array}{l}1,19 \\
0,49\end{array}$ & $-1,29$ & 203 \\
\hline 3. Atención de las/os enfermeras/os & $\begin{array}{l}\text { Sin hijos } \\
\text { Con hijos }\end{array}$ & $\begin{array}{l}4,69 \\
4,46\end{array}$ & $\begin{array}{l}0,48 \\
0,74\end{array}$ & 1,04 & ,304 \\
\hline 4. Atención de las/os auxiliares de enfermería & $\begin{array}{l}\text { Sin hijos } \\
\text { Con hijos }\end{array}$ & $\begin{array}{l}4,82 \\
4,52\end{array}$ & $\begin{array}{l}0,40 \\
0,68\end{array}$ & 1,36 & 180 \\
\hline 5. Claridad de la información recibida & $\begin{array}{l}\text { Sin hijos } \\
\text { Con hijos }\end{array}$ & $\begin{array}{l}4,46 \\
4,51\end{array}$ & $\begin{array}{l}0,66 \\
0,67\end{array}$ & $-0,24$ & ,814 \\
\hline 6. Cantidad de la información recibida & $\begin{array}{l}\text { Sin hijos } \\
\text { Con hijos }\end{array}$ & $\begin{array}{l}4,23 \\
4,29\end{array}$ & $\begin{array}{l}1,01 \\
0,75\end{array}$ & $-0,24$ &, 813 \\
\hline 7. Trato por parte del personal de enfermería & $\begin{array}{l}\text { Sin hijos } \\
\text { Con hijos }\end{array}$ & $\begin{array}{l}4,54 \\
4,54\end{array}$ & $\begin{array}{l}0,78 \\
0,59\end{array}$ & 0,01 & 993 \\
\hline $\begin{array}{l}\text { 8. Afecto/apoyo emocional del personal de } \\
\text { enfermería }\end{array}$ & $\begin{array}{l}\text { Sin hijos } \\
\text { Con hijos }\end{array}$ & $\begin{array}{l}4,67 \\
3,85\end{array}$ & $\begin{array}{l}0,78 \\
1,25\end{array}$ & 2,15 & 037 \\
\hline 9. Respeto a la intimidad & $\begin{array}{l}\text { Sin hijos } \\
\text { Con hijos }\end{array}$ & $\begin{array}{l}4,69 \\
4,27\end{array}$ & $\begin{array}{l}0,63 \\
0,72\end{array}$ & 1,88 & ,066 \\
\hline 10. Atención a los familiares & $\begin{array}{l}\text { Sin hijos } \\
\text { Con hijos }\end{array}$ & $\begin{array}{l}4,77 \\
4,33\end{array}$ & $\begin{array}{l}0,44 \\
0,74\end{array}$ & 2,01 & ,050 \\
\hline
\end{tabular}

(Sigue detrás) 


\begin{tabular}{|c|c|c|c|c|c|}
\hline Valoración de los siguientes aspectos & Número de hijos & $\bar{X}$ & DT & $t$ & $\begin{array}{c}\text { Sig. } \\
p \leq, 050\end{array}$ \\
\hline \multirow{2}{*}{$\begin{array}{l}\text { 11. Atención de necesidades psicológicas en paciente } \\
\text { y familia }\end{array}$} & Sin hijos & 4,92 & 0,29 & \multirow[t]{2}{*}{0,58} & \multirow[t]{2}{*}{, 562} \\
\hline & Con hijos & 4,85 & 0,36 & & \\
\hline \multirow{2}{*}{$\begin{array}{l}\text { 12. Calidad de las instalaciones (comodidad, } \\
\text { higiene...) }\end{array}$} & Sin hijos & 4 & 0,71 & \multirow[t]{2}{*}{0,34} & \multirow[t]{2}{*}{,733 } \\
\hline & Con hijos & 3,89 & 0,99 & & \\
\hline \multirow[t]{2}{*}{ 13. Posibilidades de distraerse } & Sin hijos & 2,67 & 1,49 & \multirow[t]{2}{*}{1,56} & \multirow[t]{2}{*}{ 126 } \\
\hline & Con hijos & 1,77 & 1,80 & & \\
\hline \multirow[t]{2}{*}{ 14. Silencio o tranquilidad en la sala } & Sin hijos & 3,77 & 0,93 & \multirow[t]{2}{*}{$-0,58$} & \multirow[t]{2}{*}{, 565} \\
\hline & Con hijos & 3,97 & 1,16 & & \\
\hline \multirow[t]{2}{*}{ 15. Régimen de visitas } & Sin hijos & 4,15 & 0,80 & \multirow[t]{2}{*}{0,11} & \multirow[t]{2}{*}{915} \\
\hline & Con hijos & 4,12 & 0,85 & & \\
\hline
\end{tabular}

Por lo que respecta a los factores estresantes no se han encontrado diferencias significativas en el nivel de estrés general $(t=-0,08 ; p=, 938)$ entre los familiares que tienen hijos y los que no (véase Tabla 73). En cambio estas diferencias logran la significación estadística en el grado de estrés que generan determinados aspectos dentro de la UCI, como el hecho de que el "paciente esté al cuidado de sanitarios desconocidos" ( $\mathrm{t}=2,59 ; \mathrm{p}=, 013)$ y pensar que el "tiempo de información resulta insuficiente" ( $t=2,39 ; p=, 021)$ causando ambos factores más estrés en los familiares que no tienen hijos. En el resto de factores que incluye la escala, las diferencias encontradas no han sido significativas, si bien podemos observar que a los familiares que sí tienen hijos les genera más estrés "pensar que le pueda ocurrir algo grave al paciente" $(\bar{X}=3,76$ vs $\bar{X}=3,50)$, "no poder ocuparse de la familia como hasta ahora" ( $\bar{X}=1,89$ vs $\bar{X}=1,61)$, "no saber con seguridad como quedará después de la operación" ( $\bar{X}=2,75$ vs $\bar{X}=2,15)$, "no saber cuándo le darán el alta de $\mathrm{UCI}^{\prime}(\overline{\mathrm{X}}=2,14$ vs $\overline{\mathrm{X}}=2,08)$, pensar que pueda "tener dolor por análisis/operación" ( $\overline{\mathrm{X}}=2,29$ vs $\overline{\mathrm{X}}=2,14)$, pensar que "no obtenga alivio para el dolor aun con medicación" ( $\overline{\mathrm{X}}=3$ vs $\overline{\mathrm{X}}=2,71$ ), ver que el "personal del hospital tiene prisa" ( $\bar{X}=1,25$ vs $\bar{X}=1,21)$, pensar en la "posible pérdida de dinero a causa de la enfermedad" ( $\bar{X}=0,59$ vs $\bar{X}=0,29)$, "sentir olores extraños en el hospital" ( $\bar{X}=1,10$ vs $\bar{X}=0,50)$, "miedo a que el paciente pueda morir" $(\bar{X}=3,59$ vs $\bar{X}=3,43)$, "esperar para entrar a la visita" ( $\bar{X}=1,59$ vs $\bar{X}=1,36)$ y que el "enfermo permanezca sólo junto a otros pacientes graves" ( $\overline{\mathrm{X}}=1,35$ vs $\overline{\mathrm{X}}=0,92)$. 
Tabla 73. Análisis diferencial en función del número de hijos de los Factores estresantes en UCI (familiares)

\begin{tabular}{|c|c|c|c|c|c|}
\hline Ítem & $\begin{array}{l}\text { Número } \\
\text { de hijos }\end{array}$ & $\bar{X}$ & DT & $\mathbf{t}$ & $\begin{array}{l}\text { Sig. } \\
p \leq, 050\end{array}$ \\
\hline \multirow[t]{2}{*}{ 1. Que el enfermo pueda tener dolor } & Sin hijos & 3,07 & 1,14 & 0,39 & ,696 \\
\hline & Con hijos & 2,90 & 1,39 & & \\
\hline \multirow{2}{*}{$\begin{array}{l}\text { 2. No saber con seguridad o no entender en qué } \\
\text { consiste la enfermedad }\end{array}$} & Sin hijos & 2,69 & 1,32 & 1,28 & 209 \\
\hline & Con hijos & 2,09 & 1,47 & & \\
\hline \multirow[t]{2}{*}{ 3. Pensar que le puede ocurrir algo grave } & Sin hijos & 3,50 & 1,16 & $-0,92$ & ,359 \\
\hline & Con hijos & 3,76 & 0,76 & & \\
\hline \multirow{2}{*}{$\begin{array}{l}\text { 4. Pensar si podrá volver a su vida normal después de } \\
\text { salir del hospital }\end{array}$} & Sin hijos & 2,86 & 1,70 & 0,10 & ,918 \\
\hline & Con hijos & 2,81 & 1,55 & & \\
\hline \multirow{2}{*}{$\begin{array}{l}\text { 5. No poder ocuparse usted de la familia como hasta } \\
\text { ahora venía haciendo }\end{array}$} & Sin hijos & 1,61 & 1,66 & $-0,51$ & ,616 \\
\hline & Con hijos & 1,89 & 1,64 & & \\
\hline \multirow{2}{*}{$\begin{array}{l}\text { 6. No saber con seguridad cómo quedará después de la } \\
\text { operación }\end{array}$} & Sin hijos & 2,15 & 1,72 & $-1,16$ & ,254 \\
\hline & Con hijos & 2,75 & 1,50 & & \\
\hline \multirow[t]{2}{*}{ 7. Estar separado del enfermo } & Sin hijos & 2,64 & 1,55 & 0,07 & ,947 \\
\hline & Con hijos & 2,61 & 1,48 & & \\
\hline \multirow{2}{*}{$\begin{array}{l}\text { 8. No saber cuándo le darán el alta de la Unidad de } \\
\text { Cuidados Intensivos }\end{array}$} & Sin hijos & 2,08 & 1,49 & $-0,12$ & 901 \\
\hline & Con hijos & 2,14 & 1,55 & & \\
\hline \multirow[t]{2}{*}{ 9. Haber sido hospitalizado de repente, sin esperarlo } & Sin hijos & 3,21 & 1,19 & 0,37 & ,7009 \\
\hline & Con hijos & 3,06 & 1,35 & & \\
\hline \multirow{2}{*}{$\begin{array}{l}\text { 10. No saber los resultados/razones de los } \\
\text { tratamientos/pruebas que le hacen }\end{array}$} & Sin hijos & 1,93 & 1,49 & 0,32 & ,750 \\
\hline & Con hijos & 1,78 & 1,41 & & \\
\hline \multirow[t]{2}{*}{ 11. Tener que organizarse para acudir a las visitas } & Sin hijos & 1,14 & 1,35 & 1,57 & 123 \\
\hline & Con hijos & 0,59 & 1,01 & & \\
\hline \multirow{2}{*}{$\begin{array}{l}\text { 12. Pensar que pueda tener dolor a causa de la } \\
\text { operación/análisis }\end{array}$} & Sin hijos & 2,14 & 1,46 & $-0,34$ & ,736 \\
\hline & Con hijos & 2,29 & 1,38 & & \\
\hline \multirow[t]{2}{*}{ 13. No saber cuándo van a hacerle cosas al enfermo } & Sin hijos & 1,85 & 1,28 & 0,98 & ,333 \\
\hline & Con hijos & 1,39 & 1,49 & & \\
\hline \multirow{2}{*}{$\begin{array}{l}\text { 14. Pensar que el paciente pueda no obtener alivio } \\
\text { para el dolor aun tomando medicación }\end{array}$} & Sin hijos & 2,71 & 1,20 & $-0,71$ & ,484 \\
\hline & Con hijos & 3 & 1,24 & & \\
\hline 15. Ver que el personal del hospital tiene prisa & Sin hijos & 1,21 & 1,25 & $-0,07$ & 941 \\
\hline & Con hijos & 1,25 & 1,63 & & \\
\hline 16. El hospital en que está ingresado el paciente se & Sin hijos & 1,07 & 1,49 & 0,03 & 976 \\
\hline encuentra lejos de casa & Con hijos & 1,06 & 1,45 & & \\
\hline 17. Que sanitarios hablen deprisa o usen palabras que & Sin hijos & 1,15 & 1,21 & 0,26 & 798 \\
\hline no puedan entender & Con hijos & 1,04 & 1,40 & & \\
\hline 18. Que el personal sanitario no conteste a sus & Sin hijos & 2,25 & 1,21 & 0,52 & ,607 \\
\hline preguntas & Con hijos & 2 & 1,41 & & \\
\hline 19. Tener que dormir fuera del domicilio habitual & Sin hijos & 1,83 & 1,75 & 1,63 & 111 \\
\hline & Con hijos & 0,92 & 1,50 & & \\
\hline 20. Preocupación por que no le den la medicación & Sin hijos & 2,36 & 1,45 & 1,47 & 148 \\
\hline para el dolor cuando la necesita & Con hijos & 1,62 & 1,63 & & \\
\hline 21. Pensar en la posible pérdida de dinero a causa de & Sin hijos & 0,29 & 0,61 & $-0,92$ & ,361 \\
\hline la enfermedad & Con hijos & 0,59 & 1,19 & & \\
\hline 22. Sentir olores extraños en el hospital & Sin hijos & 0,50 & 1,16 & $-1,35$ & 183 \\
\hline & Con hijos & 1,11 & 1,52 & & \\
\hline 23. Tener que comer a horas diferentes a las & Sin hijos & 0,50 & 0,94 & 0,21 & ,833 \\
\hline habituales para poder ir a las visitas & Con hijos & 0,43 & 1,04 & & \\
\hline 24. No poder llamar al paciente por teléfono & Sin hijos & 1,57 & 1,83 & 0,25 & ,803 \\
\hline & Con hijos & 1,43 & 1,74 & & \\
\hline 25. Que el enfermo esté al cuidado de sanitarios & Sin hijos & 0,93 & 1,54 & 2,59 & ,013 \\
\hline desconocidos & Con hijos & 0,19 & 0,52 & & \\
\hline 26. Tener demasiados horarios de visita & Sin hijos & 0,43 & 1,09 & 0,82 & ,418 \\
\hline & Con hijos & 0,22 & 0,71 & & \\
\hline 27. Tener que ver en la sala durante las visitas a otros & Sin hijos & 0,64 & 1,15 & 0,98 & ,330 \\
\hline enfermos muy graves & Con hijos & 0,35 & 0,86 & & \\
\hline 28. Miedo a que el paciente pueda morir & Sin hijos & 3,43 & 1,28 & $-0,46$ & ,646 \\
\hline & Con hijos & 3,59 & 1,09 & & \\
\hline 29. Que el paciente sea atendido por diferentes & Sin hijos & 1,07 & 1,44 & 1,31 & 196 \\
\hline médicos durante su ingreso & Con hijos & 0,59 & 1,04 & & \\
\hline 30. Que los familiares sean informados por diferentes & Sin hijos & 1,14 & 1,41 & 1,01 & ,317 \\
\hline médicos & Con hijos & 0,76 & 1,14 & & \\
\hline 31. Esperar a entrar a las diferentes horas de visita & Sin hijos & 1,36 & 1,59 & $-0,47$ & ,639 \\
\hline & Con hijos & 1,59 & 1,61 & & \\
\hline
\end{tabular}

(Sigue detrás) 
(Continuación Tabla 73)

\begin{tabular}{|c|c|c|c|c|c|c|}
\hline Ítem & & $\begin{array}{l}\text { Número } \\
\text { de hijos }\end{array}$ & $\overline{\boldsymbol{X}}$ & DT & $\mathbf{t}$ & $\begin{array}{l}\text { Sig. } \\
p \leq, 050\end{array}$ \\
\hline & \multirow{2}{*}{$\begin{array}{l}\text { No poder estar junto al enfermo todo el tiempo } \\
\text { (restringida la permanencia en la unidad) }\end{array}$} & Sin hijos & 1,86 & 1,70 & 0,43 & ,666 \\
\hline & & Con hijos & 1,62 & 1,74 & & \\
\hline & \multirow{2}{*}{$\begin{array}{l}\text { Tener que desplazarse a diario para visitar al } \\
\text { enfermo en las } 4 \text { horas de visita }\end{array}$} & Sin hijos & 1,36 & 1,74 & 0,85 & ,401 \\
\hline & & Con hijos & 0,95 & 1,47 & & \\
\hline \multirow[t]{2}{*}{34.} & \multirow{2}{*}{$\begin{array}{l}\text { Los horarios en que están concertadas las visitas } \\
\text { al enfermo en la unidad }\end{array}$} & Sin hijos & 1,07 & 1,49 & 0,72 & ,477 \\
\hline & & Con hijos & 0,76 & 1,36 & & \\
\hline \multirow[t]{2}{*}{35.} & \multirow{2}{*}{$\begin{array}{l}\text { Que el enfermo permanezca solo durante todo el } \\
\text { día junto a otros pacientes graves }\end{array}$} & Sin hijos & 0,92 & 1,04 & $-0,92$ & ,360 \\
\hline & & Con hijos & 1,35 & 1,55 & & \\
\hline \multirow[t]{2}{*}{36.} & \multirow{2}{*}{$\begin{array}{l}\text { Que el paciente no descanse adecuadamente por } \\
\text { el ruido }\end{array}$} & Sin hijos & 1,21 & 1,25 & 0,07 & 941 \\
\hline & & Con hijos & 1,18 & 1,40 & & \\
\hline \multirow[t]{2}{*}{37.} & \multirow[t]{2}{*}{ Que el paciente manifieste temor } & Sin hijos & 2,43 & 1,34 & 0,27 & ,787 \\
\hline & & Con hijos & 2,30 & 1,51 & & \\
\hline \multirow[t]{2}{*}{38.} & \multirow{2}{*}{$\begin{array}{l}\text { Que el paciente tenga que permanecer aislado por } \\
\text { prescripción médica }\end{array}$} & Sin hijos & 2,07 & 1,59 & 1,06 & ,296 \\
\hline & & Con hijos & 1,48 & 1,71 & & \\
\hline \multirow{2}{*}{\multicolumn{2}{|c|}{$\begin{array}{l}\text { 39. Pensar que el tiempo de información para los } \\
\text { familiares resulta insuficiente }\end{array}$}} & Sin hijos & 1,64 & 1,39 & 2,39 & 021 \\
\hline & & Con hijos & 0,68 & 1,25 & & \\
\hline \multirow{2}{*}{\multicolumn{2}{|c|}{ 40. Nivel de estrés en general }} & Sin hijos & 3 & 1,04 & $-0,08$ & ,938 \\
\hline & & Con hijos & 3,03 & 1,12 & & \\
\hline
\end{tabular}

El análisis diferencial de la adaptación de la familia al ingreso en UCI, tal como puede observarse en la Tabla 74, no muestra diferencias significativas a nivel estadístico en ninguna de las áreas consideradas, es decir, hay muy pocas diferencias en el nivel de interferencia experimentado por los familiares que tienen hijos y los que no. Y concretamente en la afectación de la vida de pareja estas diferencias en función del número de hijos son nulas $(\mathrm{t}=0 ; \mathrm{p}=1)$.

Tabla 74. Análisis diferencial en función del número de hijos sobre el Grado de interferencia en las distintas esferas de la vida de los familiares de UCI

\begin{tabular}{|c|c|c|c|c|c|}
\hline Niveles de interferencia & Número de hijos & $\bar{X}$ & DT & $\mathbf{t}$ & Sig. $p \leq, 050$ \\
\hline \multirow[t]{2}{*}{ 1. Trabajo } & Sin hijos & 3,40 & 1,29 & 1,26 & 213 \\
\hline & Con hijos & 2,74 & 1,87 & & \\
\hline \multirow[t]{2}{*}{ 2. Vida social } & Sin hijos & 2,67 & 1,49 & 0,09 & 931 \\
\hline & Con hijos & 2,62 & 1,91 & & \\
\hline \multirow[t]{2}{*}{ 3. Tiempo libre } & Sin hijos & 3,07 & 1,71 & $-0,61$ &, 544 \\
\hline & Con hijos & 3,38 & 1,71 & & \\
\hline \multirow[t]{2}{*}{ 4. Relación de pareja } & Sin hijos & 2 & 1,75 & 0 & 1 \\
\hline & Con hijos & 2 & 2,17 & & \\
\hline \multirow[t]{2}{*}{ 5. Vida familiar } & Sin hijos & 2,47 & 2,13 & $-0,06$ & ,955 \\
\hline & Con hijos & 2,50 & 1,90 & & \\
\hline \multirow[t]{2}{*}{ 6. Escala global } & Sin hijos & 3,67 & 1,05 & $-0,38$ & ,705 \\
\hline & Con hijos & 3,81 & 1,31 & & \\
\hline
\end{tabular}

En cuanto a las necesidades de los familiares en UCI (véase Tabla 75) no se han obtenido diferencias significativas en función del número de hijos, si bien estas diferencias rozan la significación respecto al sentimiento de "soledad que pueden experimentar los familiares en la sala de espera" $(t=1,76 ; p=, 085)$, siendo mayor entre 
aquellos que no tienen hijos. Analizando los resultados obtenidos podemos observar, aun sin ser significativo, mayor necesidad o que éstas se han visto menos satisfechas en los familiares sin hijos en cuestiones relacionadas con las "explicaciones recibidas sobre el estado del paciente" ( $\overline{\mathrm{X}}=1,54$ vs $\overline{\mathrm{X}}=1,31)$ y la "comprensión" de las mismas $(\overline{\mathrm{X}}=1,61$ vs $\bar{X}=1,28)$, la "información recibida" ( $\bar{X}=1,46$ vs $\bar{X}=1,26)$, la "atención de los miembros del equipo hacia la familia" ( $\overline{\mathrm{X}}=1,54$ vs $\overline{\mathrm{X}}=1,44)$ y la "satisfacción con las atenciones médicas" ( $\overline{\mathrm{X}}=1,23$ vs $\overline{\mathrm{X}}=1,13)$. Mientras que los familiares que tienen hijos se muestran menos satisfechos con los "cuidados médicos" ( $\bar{X}=1,20$ vs $\bar{X}=1,15)$, el "interés mostrado por cómo se siente el familiar en particular" $(\overline{\mathrm{X}}=2,64$ vs $\overline{\mathrm{X}}=2,08)$ y la "explicación sobre el equipamiento utilizado" ( $\overline{\mathrm{X}}=3,15$ vs $\overline{\mathrm{X}}=2,85)$. Igualmente, cabe señalar que en relación con la percepción de que el "personal del hospital se preocupa por el paciente" prácticamente no se ha obtenido ninguna diferencia entre los familiares que tienen hijos y los que no $(t=0 ; p=1)$.

Tabla 75. Análisis diferencial en función del número de hijos sobre las Necesidades de los familiares en $\mathrm{UCI}$

\begin{tabular}{|c|c|c|c|c|c|}
\hline Ítem & $\begin{array}{l}\text { Número de } \\
\text { hijos }\end{array}$ & $\bar{X}$ & DT & $\mathbf{t}$ & $\begin{array}{l}\text { Sig. } \\
p \leq, 050\end{array}$ \\
\hline \multirow{2}{*}{$\begin{array}{l}\text { 1. ¿Usted siente que se le están dando los mejores cuidados } \\
\text { posibles al paciente? }\end{array}$} & Sin hijos & 1,15 & 0,37 & \multirow[t]{2}{*}{$-0,36$} & \multirow[t]{2}{*}{, 722} \\
\hline & Con hijos & 1,20 & 0,47 & & \\
\hline \multirow{2}{*}{$\begin{array}{l}\text { 2. ¿Usted siente que el personal del hospital se preocupa } \\
\text { por el paciente? }\end{array}$} & Sin hijos & 1,23 & 0,59 & \multirow[t]{2}{*}{0} & \multirow[t]{2}{*}{1} \\
\hline & Con hijos & 1,23 & 0,48 & & \\
\hline \multirow{2}{*}{$\begin{array}{l}\text { 3. ¿Le dan explicaciones sobre el estado del paciente en } \\
\text { términos que pueda comprender? }\end{array}$} & Sin hijos & 1,54 & 0,78 & \multirow[t]{2}{*}{1,05} & \multirow[t]{2}{*}{ 299 } \\
\hline & Con hijos & 1,31 & 0,65 & & \\
\hline \multirow{2}{*}{$\begin{array}{l}\text { 4. ¿Usted siente que le están dando información sincera } \\
\text { sobre el estado y progreso del paciente? }\end{array}$} & Sin hijos & 1,46 & 0,66 & \multirow[t]{2}{*}{1,05} & \multirow[t]{2}{*}{,300 } \\
\hline & Con hijos & 1,26 & 0,59 & & \\
\hline \multirow{2}{*}{$\begin{array}{l}\text { 5. ¿Usted comprende lo que le sucede al paciente y el } \\
\text { motivo de las pruebas? }\end{array}$} & Sin hijos & 1,61 & 0,87 & \multirow[t]{2}{*}{1,37} & \multirow[t]{2}{*}{,178 } \\
\hline & Con hijos & 1,28 & 0,72 & & \\
\hline \multirow{2}{*}{$\begin{array}{l}\text { 6. ¿Están siendo atentos los miembros del equipo con } \\
\text { usted? }\end{array}$} & Sin hijos & 1,54 & 0,88 & \multirow[t]{2}{*}{0,42} & \multirow[t]{2}{*}{,675 } \\
\hline & Con hijos & 1,44 & 0,72 & & \\
\hline \multirow{2}{*}{$\begin{array}{l}\text { 7. ¿Muestra algún miembro del equipo interés por cómo } \\
\text { está usted? }\end{array}$} & Sin hijos & 2,08 & 1,11 & \multirow[t]{2}{*}{$-1,36$} & \multirow[t]{2}{*}{ 180 } \\
\hline & Con hijos & 2,64 & 1,35 & & \\
\hline \multirow{2}{*}{$\begin{array}{l}\text { 8. ¿Le ha explicado el personal del hospital el equipamiento } \\
\text { que está utilizándose? }\end{array}$} & Sin hijos & 2,85 & 1,07 & \multirow[t]{2}{*}{$-0,82$} & \multirow[t]{2}{*}{,417 } \\
\hline & Con hijos & 3,15 & 1,20 & & \\
\hline \multirow{2}{*}{$\begin{array}{l}\text { 9. Estoy muy satisfecho con las atenciones médicas } \\
\text { recibidas por el paciente }\end{array}$} & Sin hijos & 1,23 & 0,59 & \multirow[t]{2}{*}{0,69} & \multirow[t]{2}{*}{,491 } \\
\hline & Con hijos & 1,13 & 0,41 & & \\
\hline \multirow[t]{2}{*}{ 10. ¿Usted se siente solo y aislado en la sala de espera? } & Sin hijos & 1,61 & 0,87 & \multirow[t]{2}{*}{$-0,05$} & \multirow[t]{2}{*}{958} \\
\hline & Con hijos & 1,63 & 0,97 & & \\
\hline \multirow{2}{*}{$\begin{array}{l}\text { 11. ¿Hay algunas cosas respecto a los cuidados médicos } \\
\text { recibidos por el paciente que podrían ser mejoradas? }\end{array}$} & Sin hijos & 1,61 & 1,03 & \multirow[t]{2}{*}{1,76} & \multirow[t]{2}{*}{085} \\
\hline & Con hijos & 1,65 & 0,97 & & \\
\hline
\end{tabular}


Al analizar la valoración diferencial de los distintos factores implicados en el proceso de morir que contempla el CAMP (véase Tabla 76) no se han obtenido diferencias estadísticamente significativas en función del número de hijos. No obstante, sin llegar a la significación, los resultados muestran que los familiares sin hijos dan ligeramente más importancia al "control del pensamiento y las funciones fisiológicas" $(\bar{X}=2,58$ vs $\bar{X}=2,37)$, pensar que su "vida ha tenido algún sentido" $(\bar{X}=3,25$ vs $\bar{X}=2,94)$, “creer en otra vida después de la muerte" $(\bar{X}=1,75$ vs $\bar{X}=1,34)$ y "disponer de ayuda para morir con rapidez si la situación se hiciera insoportable" $(\overline{\mathrm{X}}=2,92$ vs $\overline{\mathrm{X}}=2,72)$. En cambio, los familiares con hijos han puntuado algo más en aspectos relativos al “control del dolor" ( $\overline{\mathrm{X}}=3,18$ vs $\overline{\mathrm{X}}=3,08)$, “acortar el sufrimiento" ( $\overline{\mathrm{X}}=3,29$ vs $\overline{\mathrm{X}}=2,75)$, " no alargar artificialmente la vida en $\operatorname{UCI}^{\prime}(\bar{X}=2,91$ vs $\bar{X}=2,33)$, "no sentirse culpable por conflictos del pasado" ( $\overline{\mathrm{X}}=2,82$ vs $\overline{\mathrm{X}}=2,58)$ y pensar que pudieran "morir en casa" $(\overline{\mathrm{X}}=1,11$ vs $\overline{\mathrm{X}}=0,67)$.

Tabla 76. Análisis diferencial en función del número de hijos de los distintos factores del Cuestionario de Ayuda a Morir en Paz (CAMP) (familiares)

\begin{tabular}{|c|c|c|c|c|c|}
\hline Ítem & $\begin{array}{l}\text { Número de } \\
\text { hijos }\end{array}$ & $\bar{X}$ & DT & $\mathbf{t}$ & $\begin{array}{l}\text { Sig. } \\
p \leq, 050\end{array}$ \\
\hline \multirow[t]{2}{*}{ 1. Controlar mi dolor y otros síntomas de malestar } & Sin hijos & 3,08 & 0,99 & $-0,26$ & 796 \\
\hline & Con hijos & 3,18 & 1,09 & & \\
\hline \multirow[t]{2}{*}{ 2. Mi proceso de morir, si produce sufrimiento, será corto } & Sin hijos & 2,75 & 1,29 & $-1,44$ & 156 \\
\hline & Con hijos & 3,29 & 1,04 & & \\
\hline \multirow[t]{2}{*}{ 3.Controlar hasta el final pensamientos y funciones fisiológicas } & Sin hijos & 2,58 & 1,16 & 0,43 & ,668 \\
\hline & Con hijos & 2,37 & 1,55 & & \\
\hline \multirow{2}{*}{$\begin{array}{l}\text { 4. Mi muerte no supondrá una carga insoportable para mis } \\
\text { seres queridos }\end{array}$} & Sin hijos & 3,25 & 1,21 & 0,28 & ,780 \\
\hline & Con hijos & 3,15 & 1,05 & & \\
\hline \multirow{2}{*}{$\begin{array}{l}\text { 5. Poder sentirme cerca, comunicarme y estrechar vínculos } \\
\text { afectivos con mis personas queridas }\end{array}$} & Sin hijos & 3,58 & 0,79 & 0,42 & ,674 \\
\hline & Con hijos & 3,46 & 0,92 & & \\
\hline \multirow{2}{*}{$\begin{array}{l}\text { 6. Sin esperanza real de recuperación, no se alargará } \\
\text { artificialmente mi vida en } \mathrm{UCl}\end{array}$} & Sin hijos & 2,33 & 1,37 & $-1,35$ & ,183 \\
\hline & Con hijos & 2,91 & 1,24 & & \\
\hline \multirow[t]{2}{*}{ 7. Pensar que mi vida ha tenido algún sentido } & Sin hijos & 3,25 & 0,96 & 0,87 & 389 \\
\hline & Con hijos & 2,94 & 1,08 & & \\
\hline \multirow[t]{2}{*}{ 8. Creer en otra vida después de la muerte } & Sin hijos & 1,75 & 1,71 & 0,77 & ,445 \\
\hline & Con hijos & 1,34 & 1,53 & & \\
\hline \multirow[t]{2}{*}{ 9. No sentirse culpable por conflictos personales del pasado } & Sin hijos & 2,58 & 1,38 & $-0,54$ & ,589 \\
\hline & Con hijos & 2,82 & 1,29 & & \\
\hline \multirow{2}{*}{$\begin{array}{l}\text { 10. Si la situación se me hace insoportable disponer de ayuda } \\
\text { para morir con rapidez }\end{array}$} & Sin hijos & 2,92 & 1,16 & 0,43 & ,669 \\
\hline & Con hijos & 2,73 & 1,35 & & \\
\hline \multirow[t]{2}{*}{ 11. Poder morir en mi casa } & Sin hijos & 0,67 & 1,15 & $-0,91$ & ,365 \\
\hline & Con hijos & 1,11 & 1,55 & & \\
\hline
\end{tabular}


Respecto a la valoración del proceso de información y toma de decisiones en función del número de hijos (véase Tabla 77), si bien no se han obtenido diferencias estadísticamente significativas, podemos observar que los familiares sin hijos, frente a los que sí tienen hijos, conceden ligeramente más importancia al paciente $(\bar{X}=13,50$ vs $\overline{\mathrm{X}}=11,92)$ y a la familia $(\overline{\mathrm{X}}=15$ vs $\overline{\mathrm{X}}=13,16)$ en el proceso. Igualmente, analizando el resto de subescalas vemos que estos familiares muestran más satisfacción con la información $(\bar{X}=5,50$ vs $\bar{X}=4,88)$, mayor preferencia hacia un estilo médico en el que se guarden lo que aún no es seguro $(\bar{X}=2$ vs $\bar{X}=1,80)$, así como también perciben el hecho de participar en una decisión relevante más como una carga que como un privilegio ( $\bar{X}=1,50$ vs $\bar{X}=1,16)$ en comparación con los familiares que sí tienen hijos. Por otro lado, los resultados obtenidos indican que sin ser las diferencias significativas, los familiares con hijos dan más importancia al médico ( $\overline{\mathrm{X}}=3,92$ vs $\overline{\mathrm{X}}=2,50)$ en decisiones relevantes. Asimismo, estos familiares frente a los que no tienen hijos, prefieren un estilo médico más directo, que anticipe posibles sospechas $(\bar{X}=1,73$ vs $\bar{X}=1)$ así como se sienten más capacitados para participar en decisiones médicas $(\overline{\mathrm{X}}=1,88$ vs $\overline{\mathrm{X}}=1)$.

Tabla 77. Valoración diferencial en función del número de hijos del proceso de información y toma de decisiones (TD) en los familiares

\begin{tabular}{|c|c|c|c|c|c|}
\hline CITD & $\begin{array}{l}\text { Número de } \\
\text { hijos }\end{array}$ & $\overline{\boldsymbol{X}}$ & DT & $\mathbf{t}$ & $\begin{array}{l}\text { Sig. } \\
p \leq, 050\end{array}$ \\
\hline \multicolumn{6}{|l|}{ Importancia de los distintos agentes implicados } \\
\hline \multirow[t]{2}{*}{ Papel de la familia en la información y toma de decisiones } & Sin hijos & 15 & - & 0,75 & 458 \\
\hline & Con hijos & 13,16 & 2,39 & & \\
\hline \multirow[t]{2}{*}{ Papel del paciente en la información y toma de decisiones } & Sin hijos & 13,50 & 4,95 & 0,54 & ,597 \\
\hline & Con hijos & 11,92 & 3,97 & & \\
\hline \multirow[t]{2}{*}{ Papel del médico en la información y toma de decisiones } & Sin hijos & 2,50 & 0,71 & $-1,45$ & 158 \\
\hline & Con hijos & 3,92 & 1,35 & & \\
\hline \multirow[t]{2}{*}{ Papel del psicólogo en la información y toma de decisiones } & Sin hijos & 2,50 & 0,71 & $-0,18$ & ,859 \\
\hline & Con hijos & 2,58 & 0,58 & & \\
\hline \multicolumn{6}{|l|}{ Satisfacción con la información } \\
\hline \multirow{2}{*}{$\begin{array}{l}\text { Satisfacción con la cantidad y la claridad de la información } \\
\text { recibida }\end{array}$} & Sin hijos & 5,50 & 0,71 & 0,74 & ,464 \\
\hline & Con hijos & 4,88 & 1,14 & & \\
\hline \multicolumn{6}{|l|}{ Estilo del médico } \\
\hline \multirow{2}{*}{$\begin{array}{l}\text { En cuanto al estilo del médico prefiero que éste sea directo y } \\
\text { anticipe posibles sospechas }\end{array}$} & Sin hijos & 1 & 1,41 & $-0,81$ & 424 \\
\hline & Con hijos & 1,73 & 1,22 & & \\
\hline \multirow{2}{*}{$\begin{array}{l}\text { En cuanto al estilo del médico prefiero que éste se guarde lo } \\
\text { que aún no es seguro }\end{array}$} & Sin hijos & 2 & 1,41 & 0,21 & ,835 \\
\hline & Con hijos & 1,80 & 1,29 & & \\
\hline \multicolumn{6}{|l|}{ Participación en TD } \\
\hline \multirow[t]{2}{*}{ Me siento capacitado para participar en la TD sobre la salud } & Sin hijos & 1 & 1,41 & $-1,24$ & 227 \\
\hline & Con hijos & 1,88 & 0,95 & & \\
\hline \multirow{2}{*}{$\begin{array}{l}\text { Poder participar en una decisión médica sería más una carga } \\
\text { que un privilegio }\end{array}$} & Sin hijos & 1,50 & 2,12 & 0,38 & ,710 \\
\hline & Con hijos & 1,16 & 1,18 & & \\
\hline
\end{tabular}




\subsubsection{Análisis diferenciales en función del grado de parentesco con el paciente}

Con tal de conocer cómo puede modular el grado de parentesco con el paciente la puntuación en las distintas variables dependientes, se ha realizado un análisis ANOVA de las puntuaciones de los cuestionarios utilizados en la evaluación de los familiares. Se ha considerado la posible existencia de diferencias en función de que el familiar fuera la pareja, el hijo, el hermano, el padre, la madre u otro familiar del paciente ingresado.

En primer lugar haremos referencia a los resultados relativos a la sintomatología ansiosa y depresiva (véase Tabla 78).

Las puntuaciones obtenidas en ansiedad no muestran diferencias estadísticamente significativas en función del parentesco con el paciente $(\mathrm{F}=1,95$; $p=, 095)$ en ninguna de las escalas utilizadas, si bien podemos apreciar que las mayores puntuaciones en ansiedad están representadas por parentescos diferentes en función de la escala utilizada. Así mediante el HADS, es la pareja quien presenta mayor grado de ansiedad seguida muy de cerca por la madre, mientras que en el STAI-Estado es el hermano/a quien alcanza una puntuación mayor. En cuanto a los síntomas de depresión evaluados mediante el HADS y el BDI, sólo se han obtenido diferencias significativas a nivel estadístico en las puntuaciones obtenidas mediante el HADS $(\mathrm{F}=4,51 ; \mathrm{p}=, 001)$. Profundizando en el análisis de estas diferencias en depresión, se han llevado a cabo comparaciones por parejas (prueba Scheffé), las cuales han mostrado que algunas medias difieren significativamente, como es el caso del mayor grado de depresión que presentan las parejas frente a los hijos. Si bien la prueba Scheffé no ha mostrado diferencias significativas respecto al ser madre o hijo, cabe señalar que la puntuación media en depresión por parte de las madres es superior a la que presentan las parejas. Para finalizar los resultados relativos a la sintomatología ansiosa y depresiva, haremos referencia a la percepción subjetiva de estado de ánimo. En este sentido cabe señalar que no se han obtenido diferencias estadísticamente significativas en ninguna de las subescalas, si bien en la percepción subjetiva de ansiedad dichas diferencias rozan la significación $(F=2,09 ; p=, 076)$, siendo las madres quienes perciben a nivel subjetivo mayor grado de ansiedad y nerviosismo. 
Tabla 78. Análisis diferencial en función del parentesco de la ansiedad, depresión y percepción de estado de ánimo (familiares)

\begin{tabular}{|c|c|c|c|c|c|c|}
\hline Cuestionarios & Parentesco & $\bar{X}$ & DT & $\mathbf{F}$ & $\begin{array}{c}\text { sig. } \\
p \leq, 050\end{array}$ & $\begin{array}{l}\text { Prueba } \\
\text { Scheffé }\end{array}$ \\
\hline \multirow[t]{6}{*}{ Total HADS Ansiedad } & Pareja & 14,65 & 4,35 & 1,95 & ,095 & \\
\hline & $\mathrm{Hijo/a}$ & 11,84 & 4,25 & & & \\
\hline & Hermano/a & 12 & 2,24 & & & \\
\hline & Padre & 10,50 & 4,95 & & & \\
\hline & Madre & 13,56 & 1,74 & & & \\
\hline & Otro familiar & 11,33 & 5,69 & & & \\
\hline \multirow[t]{6}{*}{ Total HADS Depresión } & Pareja & 13,59 & 4,69 & 4,51 & ,001 & Pareja \\
\hline & $\mathrm{Hijo} / \mathrm{a}$ & 9 & 3,60 & & & Hijo \\
\hline & Hermano/a & 9,20 & 2,86 & & & \\
\hline & Padre & 11 & 4,24 & & & \\
\hline & Madre & 13,67 & 3,77 & & & \\
\hline & Otro familiar & 10,33 & 9,50 & & & \\
\hline \multirow[t]{6}{*}{ STAI-Estado } & Pareja & 36,20 & 12,41 & 2,12 & 091 & \\
\hline & $\mathrm{Hijo} / \mathrm{a}$ & 32,75 & 11,70 & & & \\
\hline & Hermano/a & 56 & - & & & \\
\hline & Padre & 16 & - & & & \\
\hline & Madre & 39 & 5,25 & & & \\
\hline & Otro familiar & 16 & - & & & \\
\hline \multirow[t]{6}{*}{ STAI-Rasgo } & Pareja & 24,33 & 10,75 & 1,09 & ,385 & \\
\hline & $\mathrm{Hijo/a}$ & 19,50 & 10,22 & & & \\
\hline & Hermano/a & 40 & - & & & \\
\hline & Padre & 21 & - & & & \\
\hline & Madre & 22,33 & 8,94 & & & \\
\hline & Otro familiar & 12 & - & & & \\
\hline \multirow[t]{6}{*}{ BDI } & Pareja & 18,25 & 9,39 & 0,87 &, 515 & \\
\hline & $\mathrm{Hijo} / \mathrm{a}$ & 13 & 8,72 & & & \\
\hline & Hermano/a & 22 & - & & & \\
\hline & Padre & 11 & - & & & \\
\hline & Madre & 16,67 & 4,59 & & & \\
\hline & Otro familiar & 8 & - & & & \\
\hline \multirow[t]{6}{*}{ EA1- Percepción de malestar general } & Pareja & 6,82 & 2,52 & 1,32 & ,264 & \\
\hline & $\mathrm{Hijo/a}$ & 6,34 & 2,31 & & & \\
\hline & Hermano/a & 5,60 & 2,07 & & & \\
\hline & Padre & 3,50 & 2,12 & & & \\
\hline & Madre & 5,44 & 2,92 & & & \\
\hline & Otro familiar & 4,67 & 4,04 & & & \\
\hline \multirow[t]{6}{*}{ EA2- Percepción de Ansiedad y Nerviosismo } & Pareja & 7,33 & 2,39 & 2,09 & ,076 & \\
\hline & $\mathrm{Hijo/a}$ & 6,91 & 1,87 & & & \\
\hline & Hermano/a & 5,80 & 2,68 & & & \\
\hline & Padre & 4 & 1,41 & & & \\
\hline & Madre & 7,56 & 1,67 & & & \\
\hline & Otro familiar & 4,67 & 2,52 & & & \\
\hline \multirow{6}{*}{$\begin{array}{l}\text { EA3- Percepción de Estado de Ánimo } \\
\text { Deprimido }\end{array}$} & Pareja & 6,36 & 3,19 & 1,30 & ,271 & \\
\hline & $\mathrm{Hijo/a}$ & 6,06 & 2,59 & & & \\
\hline & Hermano/a & 6 & 3,24 & & & \\
\hline & Padre & 6,50 & 0,71 & & & \\
\hline & Madre & 7,89 & 2,03 & & & \\
\hline & Otro familiar & 3,33 & 2,08 & & & \\
\hline
\end{tabular}


Al analizar la valoración de la estancia en UCI en función del grado de parentesco no se han obtenido diferencias estadísticamente significativas en ninguno de los ítems considerados en la escala (véase Tabla 79). En cuanto a la valoración global de la estancia sin tener en cuenta la situación médica del paciente, si bien las diferencias no son significativas, podemos observar que las madres presentan mayor puntuación al igual que la categoría de "otro familiar" normalmente representada por amigos muy cercanos, lo que indicaría que para éstos, la estancia del paciente en UCI ha resultado bastante agradable. Respecto a los ítems restantes, podemos apreciar que el padre o la madre suelen presentar puntuaciones mayores en casi todos los aspectos valorados, sin llegar a la significación estadística.

Tabla 79. Análisis diferencial en función del parentesco sobre la valoración de la estancia en UCI (familiares)

\begin{tabular}{|c|c|c|c|c|c|}
\hline Ítem & Parentesco & $\bar{X}$ & DT & $\mathbf{F}$ & $\begin{array}{c}\text { Sig. } \\
p \leq, 050\end{array}$ \\
\hline \multirow{6}{*}{$\begin{array}{l}\text { En qué grado está siendo agradable/desagradable } \\
\text { su estancia en } \mathrm{UCl} \text { sin considerar los problemas } \\
\text { médicos }\end{array}$} & Pareja & 3,11 & 1,87 & \multirow[t]{6}{*}{0,55} & \multirow[t]{6}{*}{,740 } \\
\hline & $\mathrm{Hijo} / \mathrm{a}$ & 3,21 & 1,82 & & \\
\hline & Hermano/a & 3,75 & 1,26 & & \\
\hline & Padre & 2,50 & 3,54 & & \\
\hline & Madre & 4 & 1,31 & & \\
\hline & Otro familiar & 4 & 0 & & \\
\hline Valoración de los siguientes aspectos & Parentesco & $\bar{X}$ & DT & $\mathbf{F}$ & $\begin{array}{c}\text { Sig. } \\
p \leq, 050\end{array}$ \\
\hline \multirow[t]{6}{*}{ 1. Cuidados médicos } & Pareja & 4,60 & 0,89 & \multirow[t]{6}{*}{0,35} & \multirow[t]{6}{*}{, 879} \\
\hline & Hijo/a & 4,72 & 0,46 & & \\
\hline & Hermano/a & 4,60 & 0,55 & & \\
\hline & Padre & 5 & 0 & & \\
\hline & Madre & 4,75 & 0,46 & & \\
\hline & Otro familiar & 4,33 & 0,58 & & \\
\hline \multirow[t]{6}{*}{ 2. Atención de los médicos } & Pareja & 4,62 & 0,86 & \multirow[t]{6}{*}{0,56} & \multirow[t]{6}{*}{,732 } \\
\hline & Hijo/a & 4,60 & 0,64 & & \\
\hline & Hermano/a & 4,60 & 0,55 & & \\
\hline & Padre & 5 & 0 & & \\
\hline & Madre & 4,75 & 0,71 & & \\
\hline & Otro familiar & 4 & 1 & & \\
\hline \multirow[t]{6}{*}{ 3. Atención de las/os enfermeras/os } & Pareja & 4,41 & 0,91 & \multirow[t]{6}{*}{1} & \multirow[t]{6}{*}{,423 } \\
\hline & $\mathrm{Hijo/a}$ & 4,32 & 0,80 & & \\
\hline & Hermano/a & 4,60 & 0,55 & & \\
\hline & Padre & 4,50 & 0,71 & & \\
\hline & Madre & 5 & 0 & & \\
\hline & Otro familiar & 4,67 & 0,58 & & \\
\hline \multirow[t]{6}{*}{ 4. Atención de las/os auxiliares de enfermería } & Pareja & 4,55 & 0,74 & \multirow[t]{6}{*}{0,85} & \multirow[t]{6}{*}{, 521} \\
\hline & $\mathrm{Hijo/a}$ & 4,45 & 0,67 & & \\
\hline & Hermano/a & 4,60 & 0,55 & & \\
\hline & Padre & 4,50 & 0,71 & & \\
\hline & Madre & 5 & 0 & & \\
\hline & Otro familiar & 4,67 & 0,58 & & \\
\hline
\end{tabular}

(Sigue detrás) 
(Continuación Tabla 79)

\begin{tabular}{|c|c|c|c|c|c|}
\hline Valoración de los siguientes aspectos & Parentesco & $\bar{X}$ & DT & $\mathbf{F}$ & $\begin{array}{c}\text { Sig. } \\
p \leq, 050\end{array}$ \\
\hline \multirow[t]{6}{*}{ 5. Claridad de la información recibida } & Pareja & 4,37 & 0,72 & \multirow[t]{6}{*}{0,49} & \multirow[t]{6}{*}{,781 } \\
\hline & Hijo/a & 4,48 & 0,65 & & \\
\hline & Hermano/a & 4,60 & 0,55 & & \\
\hline & Padre & 5 & 0 & & \\
\hline & Madre & 4,37 & 1,19 & & \\
\hline & Otro familiar & 4 & 1,73 & & \\
\hline \multirow[t]{6}{*}{ 6. Cantidad de la información recibida } & Pareja & 4,17 & 0,87 & \multirow[t]{6}{*}{0,57} & \multirow[t]{6}{*}{,719 } \\
\hline & Hijo/a & 4,24 & 0,93 & & \\
\hline & Hermano/a & 4 & 0,71 & & \\
\hline & Padre & 5 & 0 & & \\
\hline & Madre & 4,12 & 0,99 & & \\
\hline & Otro familiar & 3,67 & 1,53 & & \\
\hline \multirow[t]{6}{*}{ 7. Trato por parte del personal de enfermería } & Pareja & 4,59 & 0,68 & \multirow[t]{6}{*}{1,77} & \multirow[t]{6}{*}{ 131 } \\
\hline & Hijo/a & 4,28 & 0,68 & & \\
\hline & Hermano/a & 4,40 & 0,55 & & \\
\hline & Padre & 4,50 & 0,71 & & \\
\hline & Madre & 5 & 0 & & \\
\hline & Otro familiar & 4,67 & 0,58 & & \\
\hline \multirow{6}{*}{$\begin{array}{l}\text { 8. Afecto/apoyo emocional del personal de } \\
\text { enfermería }\end{array}$} & Pareja & 3,93 & 1,14 & \multirow[t]{6}{*}{1,22} & \multirow[t]{6}{*}{,311 } \\
\hline & Hijo/a & 4,04 & 1,27 & & \\
\hline & Hermano/a & 3,50 & 1,73 & & \\
\hline & Padre & 5 & - & & \\
\hline & Madre & 4,87 & 0,35 & & \\
\hline & Otro familiar & 4,33 & 0,58 & & \\
\hline \multirow[t]{6}{*}{ 9. Respeto a la intimidad } & Pareja & 4,32 & 0,86 & \multirow[t]{6}{*}{0,47} & \multirow[t]{6}{*}{,799 } \\
\hline & Hijo/a & 4,44 & 0,65 & & \\
\hline & Hermano/a & 4 & 0,71 & & \\
\hline & Padre & 4 & 0 & & \\
\hline & Madre & 4,25 & 1,03 & & \\
\hline & Otro familiar & 4,67 & 0,58 & & \\
\hline \multirow[t]{6}{*}{ 10. Atención a los familiares } & Pareja & 4,34 & 0,77 & \multirow[t]{6}{*}{0,37} & \multirow[t]{6}{*}{,868 } \\
\hline & Hijo/a & 4,44 & 0,92 & & \\
\hline & Hermano/a & 4,25 & 0,50 & & \\
\hline & Padre & 4,50 & 0,71 & & \\
\hline & Madre & 4,75 & 0,71 & & \\
\hline & Otro familiar & 4,33 & 0,58 & & \\
\hline \multirow{6}{*}{$\begin{array}{l}\text { 11. Atención de necesidades psicológicas en } \\
\text { paciente y familia }\end{array}$} & Pareja & 4,93 & 0,26 & \multirow[t]{6}{*}{1,11} & \multirow[t]{6}{*}{,362 } \\
\hline & Hijo/a & 4,79 & 0,41 & & \\
\hline & Hermano/a & 4,60 & 0,55 & & \\
\hline & Padre & 5 & 0 & & \\
\hline & Madre & 4,87 & 0,35 & & \\
\hline & Otro familiar & 4,67 & 0,58 & & \\
\hline \multirow{6}{*}{$\begin{array}{l}\text { 12. Calidad de las instalaciones (comodidad, } \\
\text { higiene...) }\end{array}$} & Pareja & 4,13 & 1,04 & 1,69 & 148 \\
\hline & Hijo/a & 3,87 & 0,68 & & \\
\hline & Hermano/a & 4,25 & 0,96 & & \\
\hline & Padre & 4,50 & 0,71 & & \\
\hline & Madre & 4,50 & 0,53 & & \\
\hline & Otro familiar & 3 & 1 & & \\
\hline
\end{tabular}

(Sigue detrás) 


\begin{tabular}{|c|c|c|c|c|c|}
\hline Valoración de los siguientes aspectos & Parentesco & $\bar{X}$ & DT & $\mathrm{F}$ & $\begin{array}{c}\text { Sig. } \\
p \leq, 050\end{array}$ \\
\hline \multirow[t]{6}{*}{ 13. Posibilidades de distraerse } & Pareja & 2,07 & 1,86 & \multirow[t]{6}{*}{0,88} & \multirow[t]{6}{*}{, 500} \\
\hline & $\mathrm{Hijo/a}$ & 2,12 & 1,51 & & \\
\hline & Hermano/a & 2,50 & 1,29 & & \\
\hline & Padre & 0 & 0 & & \\
\hline & Madre & 2,43 & 1,90 & & \\
\hline & Otro familiar & 1 & 1,41 & & \\
\hline \multirow[t]{6}{*}{ 14. Silencio o tranquilidad en la sala } & Pareja & 3,93 & 1,05 & \multirow[t]{6}{*}{1,27} & \multirow[t]{6}{*}{289} \\
\hline & Hijo/a & 3,36 & 1,11 & & \\
\hline & Hermano/a & 4 & 0,82 & & \\
\hline & Padre & 5 & 0 & & \\
\hline & Madre & 3,37 & 1,85 & & \\
\hline & Otro familiar & 3,67 & 1,53 & & \\
\hline \multirow[t]{6}{*}{ 15. Régimen de visitas } & Pareja & 3,93 & 1,09 & \multirow[t]{6}{*}{1} & \multirow[t]{6}{*}{, 422} \\
\hline & Hijo/a & 3,92 & 0,95 & & \\
\hline & Hermano/a & 3,80 & 1,79 & & \\
\hline & Padre & 4,50 & 0,71 & & \\
\hline & Madre & 4,62 & 0,52 & & \\
\hline & Otro familiar & 3,33 & 0,58 & & \\
\hline
\end{tabular}

En cuanto a los factores estresantes asociados a UCI (véase Tabla 80), en el nivel de estrés general las diferencias en función del parentesco rozan la significación estadística $(\mathrm{F}=2,18 ; \mathrm{p}=, 067)$ siendo las madres las que presentan mayor grado de estrés. Analizando el resto de ítems de la escala podemos observar que se han obtenido diferencias significativas en el grado de estrés que generan por un lado ciertos factores asociados a que el "enfermo tenga dolor" $(\mathrm{F}=2,49 ; \mathrm{p}=, 042)$ incluso tomando medicación para aliviarlo $(\mathrm{F}=3,36 ; \mathrm{p}=, 016)$, factores que han resultado ser más estresantes para madres y hermanos respectivamente; y por otro lado el hecho de "estar separado del enfermo" $(F=2,65 ; p=, 030)$ factor con puntuaciones mayores en el grupo de hermanos. En esta misma línea, se han obtenido diferencias casi significativas en el grado de estrés que genera "pensar si el paciente podrá volver a su vida normal al salir del hospital" $(F=2,20 ; p=, 065)$ y "haber sido hospitalizado de repente en $\mathrm{UCI}^{\prime}(\mathrm{F}=2,02 ; \mathrm{p}=, 088)$ con puntuaciones medias mayores en las madres y hermanos respectivamente.

Cabe señalar que debido al bajo tamaño muestral en algunas categorías, en las que sólo contamos con un sujeto como es el caso del grupo de los padres, no se ha podido llevar a cabo la prueba Scheffé en aquellos ítems en los que se han obtenido diferencias significativas para comparar las puntuaciones por parejas. 
Tabla 80. Análisis diferencial en función del parentesco de los distintos Factores estresantes de UCI (familiares)

\begin{tabular}{|c|c|c|c|c|c|c|}
\hline \multicolumn{2}{|c|}{ Ítem } & \multirow{2}{*}{$\begin{array}{c}\text { Parentesco } \\
\text { Pareja }\end{array}$} & \multirow{2}{*}{$\begin{array}{c}\bar{X} \\
3,16\end{array}$} & \multirow{2}{*}{\begin{tabular}{|l} 
DT \\
1,31
\end{tabular}} & \multirow{2}{*}{$\begin{array}{c}F \\
2,49\end{array}$} & \multirow{2}{*}{$\begin{array}{c}\text { Sig. } p \leq, 050 \\
, 042\end{array}$} \\
\hline 1. & Que el enfermo pueda tener dolor & & & & & \\
\hline & & $\mathrm{Hijo} / \mathrm{a}$ & 3 & 1,09 & & \\
\hline & & Hermano/a & 1,75 & 1,71 & & \\
\hline & & Padre & 2 & - & & \\
\hline & & Madre & 3 & 1,22 & & \\
\hline & & Otro familiar & 1 & 1 & & \\
\hline & No saber/no entender en qué consiste la & Pareja & 2,37 & 1,53 & 0,25 & ,935 \\
\hline & enfermedad & $\mathrm{Hijo} / \mathrm{a}$ & 2,50 & 1,37 & & \\
\hline & & Hermano/a & 2,33 & 1,15 & & \\
\hline & & Padre & 1 & - & & \\
\hline & & Madre & 2,14 & 1,86 & & \\
\hline & & Otro familiar & 2,67 & 1,53 & & \\
\hline \multirow[t]{6}{*}{3.} & Pensar que le puede ocurrir algo grave & Pareja & 3,68 & 1,06 & 0,95 & ,458 \\
\hline & & $\mathrm{Hijo/a}$ & 3,70 & 0,61 & & \\
\hline & & Hermano/a & 4 & 0 & & \\
\hline & & Padre & 4 & - & & \\
\hline & & Madre & 3,75 & 0,71 & & \\
\hline & & Otro familiar & 2,67 & 1,53 & & \\
\hline \multirow[t]{6}{*}{4.} & Pensar si podrá volver a su vida normal al & Pareja & 3,11 & 1,45 & 2,20 & 065 \\
\hline & salir del hospital & $\mathrm{Hijo/a}$ & 2,89 & 1,55 & & \\
\hline & & Hermano/a & 2,25 & 1,71 & & \\
\hline & & Padre & 0 & - & & \\
\hline & & Madre & 3,25 & 0,89 & & \\
\hline & & Otro familiar & 1 & 1 & & \\
\hline \multirow[t]{6}{*}{5.} & No poder ocuparse usted de la familia como & Pareja & 2,11 & 1,85 & 0,39 & ,851 \\
\hline & hasta ahora & $\mathrm{Hijo} / \mathrm{a}$ & 1,84 & 1,46 & & \\
\hline & & Hermano/a & 2 & 2,83 & & \\
\hline & & Padre & 1 & - & & \\
\hline & & Madre & 1,25 & 1,58 & & \\
\hline & & Otro familiar & 1,67 & 1,53 & & \\
\hline \multirow[t]{6}{*}{6.} & No saber con seguridad cómo quedará tras la & Pareja & 3 & 1,30 & 0,91 & 483 \\
\hline & operación & $\mathrm{Hijo} / \mathrm{a}$ & 2,48 & 1,60 & & \\
\hline & & Hermano/a & 2 & 2 & & \\
\hline & & Padre & 1 & - & & \\
\hline & & Madre & 3 & 1,26 & & \\
\hline & & Otro familiar & 2 & 2 & & \\
\hline \multirow[t]{6}{*}{7.} & Estar separado del enfermo & Pareja & 2,96 & 1,45 & 2,65 & ,030 \\
\hline & & $\mathrm{Hijo} / \mathrm{a}$ & 2,67 & 1,33 & & \\
\hline & & Hermano/a & 2 & 1,73 & & \\
\hline & & Padre & 0 & - & & \\
\hline & & Madre & 3,12 & 0,99 & & \\
\hline & & Otro familiar & 0,67 & 1,15 & & \\
\hline
\end{tabular}

(Sigue detrás) 
(Continuación Tabla 80)

\begin{tabular}{|c|c|c|c|c|c|c|}
\hline \multicolumn{2}{|c|}{ Ítem } & Parentesco & $\overline{\boldsymbol{X}}$ & DT & $\mathbf{F}$ & Sig. $p \leq, 050$ \\
\hline \multirow[t]{6}{*}{8.} & \multirow[t]{6}{*}{ No saber cuándo le darán el alta de UCI } & Pareja & 2,18 & 1,54 & \multirow[t]{6}{*}{1,01} & \multirow[t]{6}{*}{,419 } \\
\hline & & Hijo/a & 2,20 & 1,55 & & \\
\hline & & Hermano/a & 2,67 & 1,53 & & \\
\hline & & Padre & 0 & - & & \\
\hline & & Madre & 2 & 1,60 & & \\
\hline & & Otro familiar & 0,67 & 1,15 & & \\
\hline & \multirow{6}{*}{$\begin{array}{l}\text { Haber sido hospitalizado de repente, sin } \\
\text { esperarlo }\end{array}$} & Pareja & 3,31 & 1,09 & \multirow[t]{6}{*}{2,02} & \multirow[t]{6}{*}{088} \\
\hline & & Hijo/a & 2,77 & 1,56 & & \\
\hline & & Hermano/a & 3,75 & 0,50 & & \\
\hline & & Padre & 0 & - & & \\
\hline & & Madre & 3,43 & 0,79 & & \\
\hline & & Otro familiar & 3 & 1 & & \\
\hline \multirow[t]{6}{*}{10.} & No saber los resultados/razones & Pareja & 2,04 & 1,65 & \multirow[t]{6}{*}{1,40} & \multirow[t]{6}{*}{,236 } \\
\hline & \multirow[t]{5}{*}{ tratamientos } & Hijo/a & 1,91 & 1,31 & & \\
\hline & & Hermano/a & 1,67 & 2,08 & & \\
\hline & & Padre & 0 & - & & \\
\hline & & Madre & 0,71 & 0,95 & & \\
\hline & & Otro familiar & 1 & 1 & & \\
\hline \multirow[t]{6}{*}{11.} & \multirow{6}{*}{$\begin{array}{l}\text { Tener que organizarse para poder acudir a } \\
\text { las visitas }\end{array}$} & Pareja & 1 & 1,36 & \multirow[t]{6}{*}{1,31} & \multirow[t]{6}{*}{,271 } \\
\hline & & Hijo/a & 1,18 & 1,33 & & \\
\hline & & Hermano/a & 0,33 & 0,58 & & \\
\hline & & Padre & 0 & - & & \\
\hline & & Madre & 0,25 & 0,46 & & \\
\hline & & Otro familiar & 0 & 0 & & \\
\hline \multirow[t]{6}{*}{12.} & \multirow{6}{*}{$\begin{array}{l}\text { Pensar que puede tener dolor a causa de } \\
\text { operación/análisis }\end{array}$} & Pareja & 2,59 & 1,15 & \multirow[t]{6}{*}{1,65} & \multirow[t]{6}{*}{ 160 } \\
\hline & & Hijo/a & 2,33 & 1,39 & & \\
\hline & & Hermano/a & 3 & 1,41 & & \\
\hline & & Padre & 0 & - & & \\
\hline & & Madre & 2,50 & 1,38 & & \\
\hline & & Otro familiar & 1 & 1 & & \\
\hline \multirow[t]{6}{*}{13.} & \multirow{6}{*}{$\begin{array}{l}\text { No saber cuándo van a hacerle cosas al } \\
\text { enfermo }\end{array}$} & Pareja & 1,52 & 1,47 & \multirow[t]{6}{*}{0,42} & ,834 \\
\hline & & Hijo/a & 1,72 & 1,34 & & \\
\hline & & Hermano/a & 1,67 & 2,08 & & \\
\hline & & Padre & 1 & - & & \\
\hline & & Madre & 2 & 1,91 & & \\
\hline & & Otro familiar & 0,67 & 1,15 & & \\
\hline 14. & Pensar que el paciente no obtenga alivio & Pareja & 2,87 & 1,22 & 3,36 & ,016 \\
\hline & para el dolor aún tomando medicación & Hijo/a & 3 & 1,08 & & \\
\hline & & Hermano/a & 4 & 0 & & \\
\hline & & Padre & - & - & & \\
\hline & & Madre & 3,25 & 1,50 & & \\
\hline & & Otro familiar & 0,67 & 1,15 & & \\
\hline
\end{tabular}

(Sigue detrás) 
(Continuación Tabla 80)

\begin{tabular}{|c|c|c|c|c|c|}
\hline Ítem & Parentesco & $\bar{X}$ & DT & $\mathbf{F}$ & Sig. $p \leq, 050$ \\
\hline \multirow[t]{6}{*}{ 15. Ver que el personal del hospital tiene prisa } & Pareja & 1,89 & 1,80 & 1,44 & 222 \\
\hline & Hijo/a & 1,28 & 1,31 & & \\
\hline & Hermano/a & 1 & 2 & & \\
\hline & Padre & 0 & - & & \\
\hline & Madre & 0,86 & 1,21 & & \\
\hline & Otro familiar & 0 & 0 & & \\
\hline \multirow[t]{6}{*}{ 16. El hospital se encuentra lejos de casa } & Pareja & 1,22 & 1,60 & 1,21 & 315 \\
\hline & $\mathrm{Hijo} / \mathrm{a}$ & 1,07 & 1,44 & & \\
\hline & Hermano/a & 1,25 & 1,89 & & \\
\hline & Padre & 0 & - & & \\
\hline & Madre & 2,33 & 1,50 & & \\
\hline & Otro familiar & 0 & 0 & & \\
\hline \multirow{6}{*}{$\begin{array}{l}\text { 17. Sanitarios hablen deprisa/usen palabras que } \\
\text { no entienden }\end{array}$} & Pareja & 1,33 & 1,58 & 0,32 & ,860 \\
\hline & $\mathrm{Hijo} / \mathrm{a}$ & 1,17 & 1,29 & & \\
\hline & Hermano/a & 0,67 & 0,58 & & \\
\hline & Padre & - & - & & \\
\hline & Madre & 1,50 & 1,52 & & \\
\hline & Otro familiar & 0,67 & 1,15 & & \\
\hline \multirow{6}{*}{$\begin{array}{l}\text { 18. Que el personal sanitario no conteste a sus } \\
\text { preguntas }\end{array}$} & Pareja & 2,09 & 1,50 & 0,15 & 962 \\
\hline & Hijo/a & 2 & 1,30 & & \\
\hline & Hermano/a & 1,50 & 2,12 & & \\
\hline & Padre & - & - & & \\
\hline & Madre & 1,75 & 2,06 & & \\
\hline & Otro familiar & 2,50 & 2,12 & & \\
\hline \multirow{6}{*}{$\begin{array}{l}\text { 19. Tener que dormir fuera del domicilio } \\
\text { habitual }\end{array}$} & Pareja & 1,12 & 1,68 & 1,06 & ,388 \\
\hline & Hijo/a & 1,62 & 1,67 & & \\
\hline & Hermano/a & 2 & 2,83 & & \\
\hline & Padre & - & - & & \\
\hline & Madre & 2,20 & 2,05 & & \\
\hline & Otro familiar & 0 & 0 & & \\
\hline \multirow{6}{*}{$\begin{array}{l}\text { 20. Preocupación por si no le dan medicación } \\
\text { para el dolor cuando necesite }\end{array}$} & Pareja & 1,88 & 1,56 & 1,64 & 164 \\
\hline & $\mathrm{Hijo} / \mathrm{a}$ & 2,04 & 1,54 & & \\
\hline & Hermano/a & 0 & 0 & & \\
\hline & Padre & 0 & - & & \\
\hline & Madre & 0,87 & 1,64 & & \\
\hline & Otro familiar & 1 & 1 & & \\
\hline \multirow{6}{*}{$\begin{array}{l}\text { 21. Pensar en la posible pérdida de dinero por la } \\
\text { enfermedad }\end{array}$} & Pareja & 1 & 1,41 & 1,42 & ,230 \\
\hline & Hijo/a & 0,52 & 1,05 & & \\
\hline & Hermano/a & 0 & 0 & & \\
\hline & Padre & 1 & - & & \\
\hline & Madre & 0,12 & 0,35 & & \\
\hline & Otro familiar & 0 & 0 & & \\
\hline
\end{tabular}

(Sigue detrás) 
(Continuación Tabla 80)

\begin{tabular}{|c|c|c|c|c|c|}
\hline Ítem & Parentesco & $\overline{\boldsymbol{X}}$ & DT & $\mathbf{F}$ & Sig. $p \leq, 050$ \\
\hline \multirow[t]{6}{*}{ 22. Sentir olores extraños en el hospital } & Pareja & 1,11 & 1,55 & \multirow[t]{6}{*}{0,98} & \multirow[t]{6}{*}{,434 } \\
\hline & Hijo/a & 0,93 & 1,49 & & \\
\hline & Hermano/a & 2 & 1,63 & & \\
\hline & Padre & 0 & - & & \\
\hline & Madre & 0,50 & 0,93 & & \\
\hline & Otro familiar & 0 & 0 & & \\
\hline \multirow{6}{*}{$\begin{array}{l}\text { 23. Tener que comer a horas diferentes para ir a } \\
\text { las visitas }\end{array}$} & Pareja & 0,71 & 1,36 & \multirow[t]{6}{*}{0,85} & \multirow[t]{6}{*}{, 522} \\
\hline & Hijo/a & 0,29 & 0,72 & & \\
\hline & Hermano/a & 0 & 0 & & \\
\hline & Padre & 0 & - & & \\
\hline & Madre & 0,37 & 0,52 & & \\
\hline & Otro familiar & 0 & 0 & & \\
\hline \multirow[t]{6}{*}{ 24. No poder llamar al paciente por teléfono } & Pareja & 1,44 & 1,72 & \multirow[t]{6}{*}{1,24} & \multirow[t]{6}{*}{ 301 } \\
\hline & Hijo/a & 1,89 & 1,76 & & \\
\hline & Hermano/a & 0,33 & 0,58 & & \\
\hline & Padre & 0 & - & & \\
\hline & Madre & 1,25 & 1,75 & & \\
\hline & Otro familiar & 0 & 0 & & \\
\hline \multirow{6}{*}{$\begin{array}{l}\text { 25. Que el enfermo esté al cuidado de sanitarios } \\
\text { desconocidos }\end{array}$} & Pareja & 0,52 & 1,12 & \multirow[t]{6}{*}{0,38} & \multirow[t]{6}{*}{862} \\
\hline & Hijo/a & 0,59 & 1,22 & & \\
\hline & Hermano/a & 0 & 0 & & \\
\hline & Padre & 0 & - & & \\
\hline & Madre & 0,50 & 0,76 & & \\
\hline & Otro familiar & 0 & 0 & & \\
\hline \multirow[t]{6}{*}{ 26. Tener demasiados horarios de visita } & Pareja & 0,39 & 0,99 & \multirow[t]{6}{*}{0,13} & \multirow[t]{6}{*}{,985 } \\
\hline & Hijo/a & 0,41 & 0,97 & & \\
\hline & Hermano/a & 0 & 0 & & \\
\hline & Padre & 0 & - & & \\
\hline & Madre & 0,37 & 1,06 & & \\
\hline & Otro familiar & 0,33 & 0,58 & & \\
\hline \multirow{6}{*}{$\begin{array}{l}\text { 27. Ver en la sala durante las visitas otros } \\
\text { enfermos muy graves }\end{array}$} & Pareja & 0,71 & 1,30 & \multirow[t]{6}{*}{0,63} & \multirow[t]{6}{*}{680} \\
\hline & Hijo/a & 0,74 & 1,19 & & \\
\hline & Hermano/a & 0 & 0 & & \\
\hline & Padre & 0 & - & & \\
\hline & Madre & 0,37 & 0,74 & & \\
\hline & Otro familiar & 0 & 0 & & \\
\hline \multirow[t]{6}{*}{ 28. Miedo a que el paciente pueda morir } & Pareja & 3,25 & 1,38 & \multirow[t]{6}{*}{0,82} & \multirow[t]{6}{*}{,537 } \\
\hline & Hijo/a & 3,70 & 0,77 & & \\
\hline & Hermano/a & 4 & 0 & & \\
\hline & Padre & 4 & - & & \\
\hline & Madre & 3,50 & 1,41 & & \\
\hline & Otro familiar & 2,67 & 2,31 & & \\
\hline
\end{tabular}

(Sigue detrás) 
(Continuación Tabla 80)

\begin{tabular}{|c|c|c|c|c|c|c|}
\hline \multicolumn{2}{|c|}{ Ítem } & Parentesco & $\bar{X}$ & DT & $\mathbf{F}$ & Sig. $p \leq, 050$ \\
\hline \multirow[t]{6}{*}{29.} & \multirow{6}{*}{$\begin{array}{l}\text { Paciente sea atendido por distintos médicos } \\
\text { durante ingreso }\end{array}$} & Pareja & 0,86 & 1,43 & \multirow[t]{6}{*}{0,41} & \multirow[t]{6}{*}{,838 } \\
\hline & & $\mathrm{Hijo/a}$ & 1,04 & 1,22 & & \\
\hline & & Hermano/a & 0,25 & 0,50 & & \\
\hline & & Padre & 0 & - & & \\
\hline & & Madre & 0,75 & 1,03 & & \\
\hline & & Otro familiar & 0,67 & 0,58 & & \\
\hline \multirow[t]{6}{*}{30.} & \multirow{6}{*}{$\begin{array}{l}\text { Que los familiares sean informados por } \\
\text { diferentes médicos }\end{array}$} & Pareja & 1,25 & 1,53 & \multirow[t]{6}{*}{0,47} & \multirow[t]{6}{*}{ 798 } \\
\hline & & $\mathrm{Hijo} / \mathrm{a}$ & 1,33 & 1,52 & & \\
\hline & & Hermano/a & 0,50 & 0,58 & & \\
\hline & & Padre & 0 & - & & \\
\hline & & Madre & 1,12 & 1,13 & & \\
\hline & & Otro familiar & 0,67 & 0,58 & & \\
\hline \multirow[t]{6}{*}{31.} & \multirow{6}{*}{$\begin{array}{l}\text { Esperar para entrar a las diferentes horas de } \\
\text { visita }\end{array}$} & Pareja & 1,86 & 1,71 & \multirow[t]{6}{*}{1,45} & \multirow[t]{6}{*}{ 218 } \\
\hline & & $\mathrm{Hijo/a}$ & 1,70 & 1,41 & & \\
\hline & & Hermano/a & 1 & 0,82 & & \\
\hline & & Padre & 0 & - & & \\
\hline & & Madre & 0,75 & 1,39 & & \\
\hline & & Otro familiar & 0,33 & 0,58 & & \\
\hline \multirow[t]{6}{*}{32.} & \multirow{6}{*}{$\begin{array}{l}\text { No poder estar junto al enfermo todo el } \\
\text { tiempo }\end{array}$} & Pareja & 1,89 & 1,79 & \multirow[t]{6}{*}{0,74} & \multirow[t]{6}{*}{,594 } \\
\hline & & $\mathrm{Hijo/a}$ & 1,78 & 1,62 & & \\
\hline & & Hermano/a & 0,75 & 0,96 & & \\
\hline & & Padre & 0 & - & & \\
\hline & & Madre & 2,12 & 1,81 & & \\
\hline & & Otro familiar & 1 & 1 & & \\
\hline \multirow[t]{6}{*}{33.} & Tener que desplazarse para visitar al & Pareja & 1,04 & 1,53 & \multirow[t]{6}{*}{0,76} & \multirow[t]{6}{*}{, 580} \\
\hline & \multirow[t]{5}{*}{ enfermo en las 4 horas de visita } & $\mathrm{Hijo/a}$ & 1,18 & 1,59 & & \\
\hline & & Hermano/a & 0,33 & 0,58 & & \\
\hline & & Padre & 0 & - & & \\
\hline & & Madre & 1,62 & 1,77 & & \\
\hline & & Otro familiar & 0 & 0 & & \\
\hline \multirow[t]{6}{*}{34.} & \multirow{6}{*}{$\begin{array}{l}\text { Los horarios en que están concertadas las } \\
\text { visitas en la unidad }\end{array}$} & Pareja & 0,85 & 1,41 & \multirow[t]{6}{*}{0,46} & ,801 \\
\hline & & $\mathrm{Hijo/a}$ & 0,89 & 1,34 & & \\
\hline & & Hermano/a & 0 & 0 & & \\
\hline & & Padre & 0 & - & & \\
\hline & & Madre & 1 & 1,85 & & \\
\hline & & Otro familiar & 0,33 & 0,58 & & \\
\hline 35. & Que el enfermo permanezca solo junto a & Pareja & 1,32 & 1,47 & 0,69 & ,634 \\
\hline & otros pacientes graves & $\mathrm{Hijo/a}$ & 1,23 & 1,18 & & \\
\hline & & Hermano/a & 1,50 & 1,91 & & \\
\hline & & Padre & 0 & - & & \\
\hline & & Madre & 1,43 & 1,90 & & \\
\hline & & Otro familiar & 0 & 0 & & \\
\hline
\end{tabular}

(Sigue detrás) 
(Continuación Tabla 80)

\begin{tabular}{|c|c|c|c|c|c|}
\hline Ítem & Parentesco & $\overline{\boldsymbol{X}}$ & DT & $\mathbf{F}$ & Sig. $p \leq, 050$ \\
\hline \multirow{6}{*}{$\begin{array}{l}\text { 36. Que el paciente no descanse adecuadamente } \\
\text { por el ruido }\end{array}$} & Pareja & 1,29 & 1,29 & \multirow[t]{6}{*}{0,80} & \multirow[t]{6}{*}{, 554} \\
\hline & Hijo/a & 1,31 & 1,35 & & \\
\hline & Hermano/a & 0,67 & 1,15 & & \\
\hline & Padre & 0 & - & & \\
\hline & Madre & 1,83 & 1,83 & & \\
\hline & Otro familiar & 0,33 & 0,58 & & \\
\hline 37. Que el paciente manifieste temor & Pareja & 2,29 & 1,49 & \multirow[t]{6}{*}{0,40} & \multirow[t]{6}{*}{, 808} \\
\hline & Hijo/a & 2,62 & 1,24 & & \\
\hline & Hermano/a & 2,67 & 1,53 & & \\
\hline & Padre & - & - & & \\
\hline & Madre & 2,40 & 2,19 & & \\
\hline & Otro familiar & 1,67 & 0,58 & & \\
\hline \multirow{6}{*}{$\begin{array}{l}\text { 38. Que el paciente permanezca aislado por } \\
\text { prescripción médica }\end{array}$} & Pareja & 1,74 & 1,54 & \multirow[t]{6}{*}{0,39} & \multirow[t]{6}{*}{810} \\
\hline & $\mathrm{Hijo} / \mathrm{a}$ & 1,60 & 1,57 & & \\
\hline & Hermano/a & 2,50 & 2,12 & & \\
\hline & Padre & - & - & & \\
\hline & Madre & 2,67 & 2,31 & & \\
\hline & Otro familiar & 2 & 2 & & \\
\hline \multirow{6}{*}{$\begin{array}{l}\text { 39. Pensar que el tiempo de información para } \\
\text { los familiares es insuficiente }\end{array}$} & Pareja & 0,89 & 1,37 & \multirow[t]{6}{*}{0,42} & \multirow[t]{6}{*}{831} \\
\hline & Hijo/a & 1,07 & 1,33 & & \\
\hline & Hermano/a & 1 & 2 & & \\
\hline & Padre & 0 & - & & \\
\hline & Madre & 1 & 1,60 & & \\
\hline & Otro familiar & 0 & 0 & & \\
\hline \multirow[t]{6}{*}{ 40. Nivel de estrés en general } & Pareja & 3,14 & 1,04 & \multirow[t]{6}{*}{2,18} & \multirow[t]{6}{*}{067} \\
\hline & Hijo/a & 3,04 & 0,98 & & \\
\hline & Hermano/a & 2,50 & 1,29 & & \\
\hline & Padre & 3 & - & & \\
\hline & Madre & 3,37 & 0,92 & & \\
\hline & Otro familiar & 1,33 & 0,58 & & \\
\hline
\end{tabular}

Al analizar el grado de adaptación de los familiares al ingreso en UCI (véase Tabla 81) se han obtenido diferencias estadísticamente significativas en todas las áreas analizadas excepto la vida familiar general $(\mathrm{F}=1,84 ; \mathrm{p}=, 117)$. Así, los resultados han mostrado diferencias significativas en el grado de interferencia producido en las siguientes áreas: trabajo $(\mathrm{F}=2,81 ; \mathrm{p}=, 023)$, vida social $(\mathrm{F}=3,99 ; \mathrm{p}=, 003)$, tiempo libre $(F=3,06 ; p=, 015)$, relación de pareja $(F=4,28 ; p=, 002)$ y vida en general $(F=5,75 ; p=, 000)$. En todas estas áreas la pareja ha presentado puntuaciones mayores a excepción de la interferencia en la relación de pareja, en la cual han mostrado mayor afectación los padres. Analizando con más detalle estas diferencias se han realizado comparaciones por parejas (prueba Scheffé) las cuales muestran que sólo algunas medias difieren 
significativamente. En el área social se ha obtenido mayor grado de afectación en la pareja frente a los hermanos. En cuanto a la relación de pareja, los resultados de la prueba Scheffé indican que la afectación de la propia pareja es significativamente mayor que la de las madres. Y finalmente, respecto a la interferencia producida a nivel global, los resultados muestran puntuaciones medias mayores en las parejas respecto a los hijos y otros familiares.

Tabla 81. Análisis diferencial en función del parentesco sobre el Grado de interferencia en las distintas esferas de la vida de los familiares de UCI

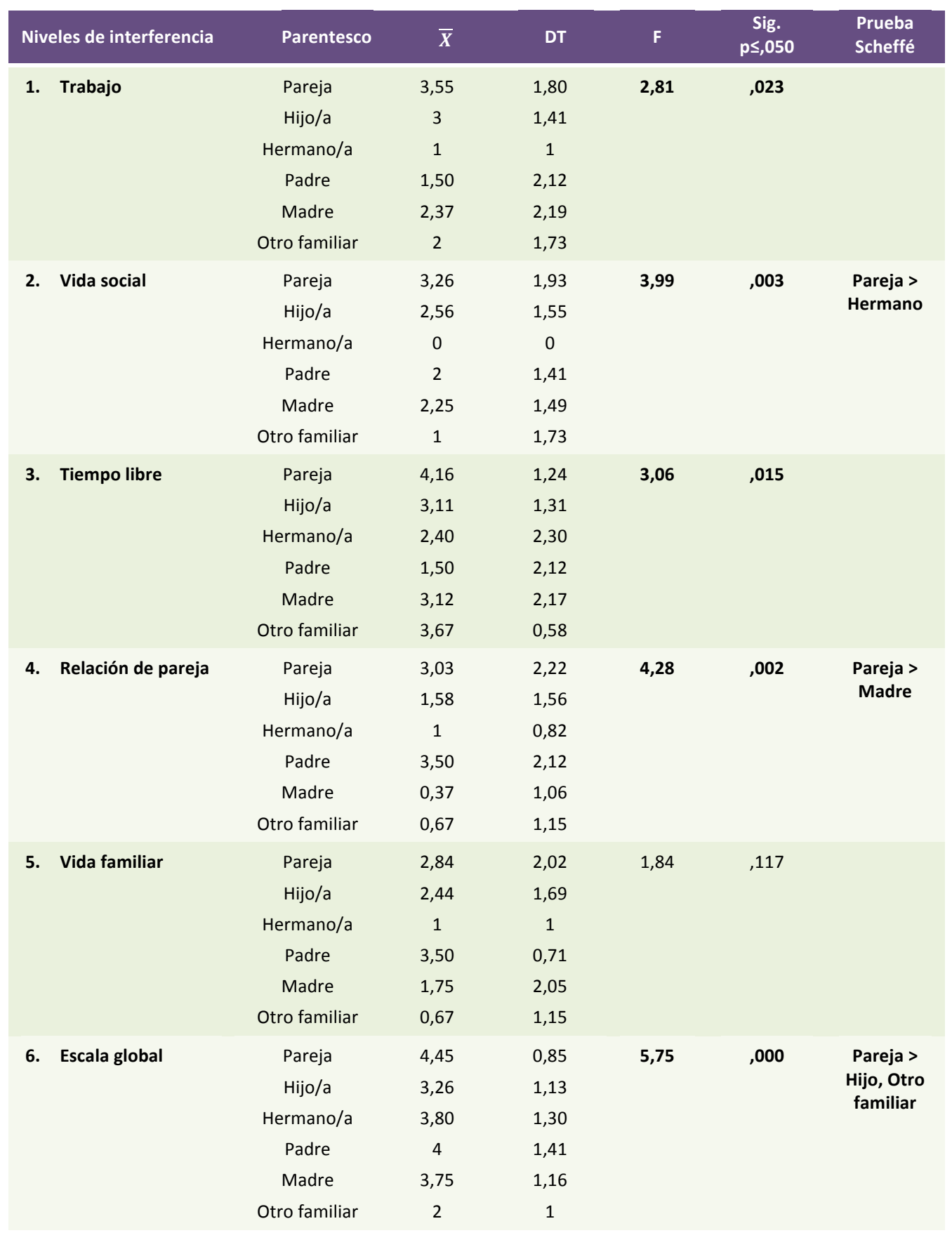


Respecto a las necesidades de los familiares en UCI, podemos observar en la Tabla 82, que se han obtenido diferencias significativas en función del grado de parentesco en la valoración de si los "miembros del equipo están atentos con el familiar" ( $F=3,17 ; p=, 013)$, siendo los hermanos quienes han puntuado más alto, es decir, muestran menor satisfacción. Analizando los ítems restantes, si bien las diferencias no han sido significativas, se aprecian puntuaciones mayores (menor satisfacción) en la categoría de hermanos en aquellas necesidades relacionadas con las explicaciones sobre el estado del paciente, la información y la satisfacción con las atenciones médicas. Asimismo, cerca de la significación estadística, los hermanos se muestran menos satisfechos con la comprensión de lo que le sucede al paciente $(\mathrm{F}=2,02$; $\mathrm{p}=, 088)$. Atendiendo a los resultados obtenidos en las otras necesidades del cuestionario, aun sin lograr la significación estadística, observamos que las puntuaciones que indican menor satisfacción están representadas en el caso del "interés mostrado en el familiar en particular" y las "explicaciones sobre el equipamiento utilizado" por la valoración de los padres; "los cuidados médicos", por la valoración de las madres; "que el personal del hospital se preocupa por el paciente", por la valoración de los hijos; y finalmente, los familiares incluidos en la categoría de "otros" se sienten más solos y aislados en la sala de espera.

Para completar este análisis diferencial se han llevado a cabo comparaciones por parejas (prueba Scheffé) mostrando aquellas medias que difieren significativamente. En este sentido y respecto a la valoración de si "los miembros del equipo son atentos con el familiar" observamos que las medias de los hermanos son significativamente mayores a las de la pareja y las madres.

Tabla 82. Análisis diferencial en función del parentesco de las necesidades de los familiares de UCI

\begin{tabular}{|c|c|c|c|c|c|c|}
\hline Ítem & Parentesco & $\overline{\boldsymbol{X}}$ & DT & $\mathbf{F}$ & $\begin{array}{c}\text { Sig. } \\
p \leq, 050\end{array}$ & $\begin{array}{l}\text { Prueba } \\
\text { Scheffé }\end{array}$ \\
\hline \multirow{6}{*}{$\begin{array}{l}\text { 1. ¿Usted siente que se le están dando los } \\
\text { cuidados posibles al paciente? }\end{array}$} & Pareja & 1,18 & 0,48 & 0,61 & 692 & \\
\hline & $\mathrm{Hijo} / \mathrm{a}$ & 1,24 & 0,44 & & & \\
\hline & Hermano/a & 1,33 & 0,58 & & & \\
\hline & Padre & 1 & 0 & & & \\
\hline & Madre & 1,43 & 0,53 & & & \\
\hline & Otro familiar & 1 & 0 & & & \\
\hline \multirow{6}{*}{$\begin{array}{l}\text { 2. ¿Usted siente que el personal del hospital se } \\
\text { preocupa por el paciente? }\end{array}$} & Pareja & 1,25 & 0,52 & 0,68 & ,642 & \\
\hline & $\mathrm{Hijo/a}$ & 1,40 & 0,58 & & & \\
\hline & Hermano/a & 1,33 & 0,58 & & & \\
\hline & Padre & 1 & 0 & & & \\
\hline & Madre & 1,14 & 0,38 & & & \\
\hline & Otro familiar & 1 & 0 & & & \\
\hline
\end{tabular}

(Sigue detrás) 
(Continuación Tabla 82)

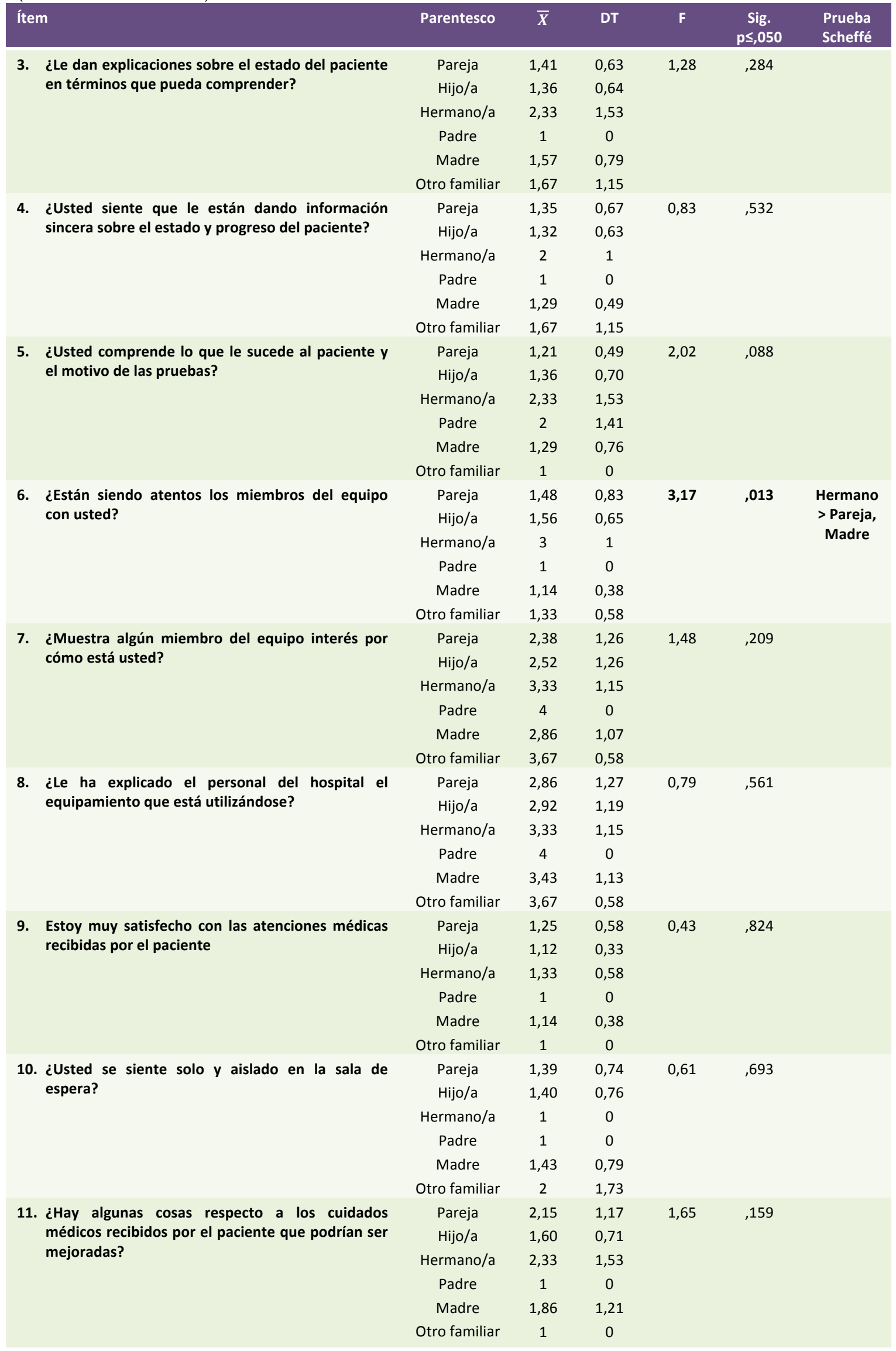


El análisis de los factores implicados en el proceso de morir que contempla el CAMP (véase Tabla 83) no muestra diferencias significativas en función del parentesco. Si bien las diferencias no son significativas, podemos observar en los resultados obtenidos que las puntuaciones de los padres son ligeramente superiores en factores relacionados con el "control de los síntomas físicos de malestar" y "acortar el proceso si hay sufrimiento". En cuanto al "control de los pensamientos y las funciones fisiológicas" son los padres y los hermanos quienes conceden más importancia. Estos mismos, junto a la pareja valoran más el hecho de "no alargar artificialmente la vida en UCI". Respecto a los otros factores del CAMP, observamos que los aspectos relacionales, como "poder estrechar vínculos con los seres queridos" y que la "muerte no suponga una carga insoportable para los demás", son más importantes para los hermanos. Igualmente, los hermanos han valorado más al final de la vida aspectos existenciales/espirituales como pensar que su "vida ha tenido algún sentido", "creer en otra vida después de la muerte" y "no sentirse culpables". Finalmente, "disponer de ayuda para morir con rapidez" ha sido más valorado por la pareja y otros familiares, así como el poder "morir en casa" ha resultado ser más importante para las madres.

Tabla 83. Análisis diferencial en función del parentesco de los distintos factores del Cuestionario de Ayuda a Morir en Paz (CAMP) (familiares)

\begin{tabular}{|c|c|c|c|c|c|}
\hline Ítem & Parentesco & $\bar{X}$ & DT & $\mathbf{F}$ & $\begin{array}{c}\text { Sig. } \\
p \leq, 050\end{array}$ \\
\hline \multirow[t]{6}{*}{ 1. Controlar mi dolor y otros síntomas de malestar } & Pareja & 3,31 & 1,01 & \multirow[t]{6}{*}{1,15} & \multirow[t]{6}{*}{,342 } \\
\hline & $\mathrm{Hijo/a}$ & 3 & 0,98 & & \\
\hline & Hermano/a & 3,75 & 0,50 & & \\
\hline & Padre & 4 & - & & \\
\hline & Madre & 2,57 & 1,13 & & \\
\hline & Otro familiar & 3,33 & 1,15 & & \\
\hline \multirow[t]{6}{*}{ 2. Mi proceso de morir, si produce sufrimiento, será corto } & Pareja & 3,29 & 0,91 & \multirow[t]{6}{*}{1,45} & \multirow[t]{6}{*}{,219 } \\
\hline & $\mathrm{Hijo/a}$ & 2,95 & 1,29 & & \\
\hline & Hermano/a & 4 & 0 & & \\
\hline & Padre & 4 & - & & \\
\hline & Madre & 2,57 & 1,13 & & \\
\hline & Otro familiar & 3,67 & 0,58 & & \\
\hline \multirow{6}{*}{$\begin{array}{l}\text { 3.Controlar hasta el final pensamientos y funciones } \\
\text { fisiológicas }\end{array}$} & Pareja & 2,61 & 1,47 & \multirow[t]{6}{*}{0,56} & \multirow[t]{6}{*}{,733 } \\
\hline & $\mathrm{Hijo/a}$ & 2,36 & 1,43 & & \\
\hline & Hermano/a & 3 & 2 & & \\
\hline & Padre & 3 & - & & \\
\hline & Madre & 1,71 & 1,49 & & \\
\hline & Otro familiar & 2,33 & 1,53 & & \\
\hline \multirow{6}{*}{$\begin{array}{l}\text { 4. Mi muerte no supondrá una carga insoportable para mis } \\
\text { seres queridos }\end{array}$} & Pareja & 3,24 & 1,05 & \multirow[t]{6}{*}{1,50} & \multirow[t]{6}{*}{ 203 } \\
\hline & $\mathrm{Hijo/a}$ & 2,95 & 1,25 & & \\
\hline & Hermano/a & 4 & 0 & & \\
\hline & Padre & 2 & - & & \\
\hline & Madre & 3,29 & 0,76 & & \\
\hline & Otro familiar & 2 & 1,73 & & \\
\hline
\end{tabular}

(Sigue detrás) 
(Continuación Tabla 83)

\begin{tabular}{|c|c|c|c|c|c|}
\hline Ítem & Parentesco & $\overline{\boldsymbol{X}}$ & DT & $\mathbf{F}$ & $\begin{array}{c}\text { Sig. } \\
p \leq, 050\end{array}$ \\
\hline \multirow{6}{*}{$\begin{array}{l}\text { 5. Poder sentirme cerca, comunicarme y estrechar vínculos } \\
\text { afectivos con mis personas queridas }\end{array}$} & Pareja & 3,44 & 1,01 & 0,54 & ,742 \\
\hline & $\mathrm{Hijo/a}$ & 3,54 & 0,67 & & \\
\hline & Hermano/a & 3,75 & 0,50 & & \\
\hline & Padre & 3 & - & & \\
\hline & Madre & 3 & 1,41 & & \\
\hline & Otro familiar & 3,67 & 0,58 & & \\
\hline \multirow{6}{*}{$\begin{array}{l}\text { 6. Sin esperanza real de recuperación, no se alargará } \\
\text { artificialmente mi vida en } \mathrm{UCl}\end{array}$} & Pareja & 3 & 1,08 & 0,55 & 740 \\
\hline & $\mathrm{Hijo/a}$ & 2,59 & 1,26 & & \\
\hline & Hermano/a & 3 & 2 & & \\
\hline & Padre & 3 & - & & \\
\hline & Madre & 2,43 & 1,72 & & \\
\hline & Otro familiar & 2 & 2 & & \\
\hline \multirow[t]{6}{*}{ 7. Pensar que mi vida ha tenido algún sentido } & Pareja & 3,04 & 1,13 & 1,86 & 115 \\
\hline & $\mathrm{Hijo} / \mathrm{a}$ & 3 & 1,15 & & \\
\hline & Hermano/a & 3,50 & 1 & & \\
\hline & Padre & 0 & - & & \\
\hline & Madre & 3,29 & 0,76 & & \\
\hline & Otro familiar & 2,67 & 0,58 & & \\
\hline \multirow[t]{6}{*}{ 8. Creer en otra vida después de la muerte } & Pareja & 1,29 & 1,44 & 0,56 & 728 \\
\hline & $\mathrm{Hijo/a}$ & 1,27 & 1,42 & & \\
\hline & Hermano/a & 2 & 1,41 & & \\
\hline & Padre & 0 & - & & \\
\hline & Madre & 1,71 & 1,89 & & \\
\hline & Otro familiar & 0,67 & 0,58 & & \\
\hline \multirow[t]{6}{*}{ 9. No sentirse culpable por conflictos personales del pasado } & Pareja & 2,61 & 1,42 & 0,26 & ,933 \\
\hline & $\mathrm{Hijo/a}$ & 2,68 & 1,39 & & \\
\hline & Hermano/a & 3,25 & 0,96 & & \\
\hline & Padre & 3 & - & & \\
\hline & Madre & 3 & 1,41 & & \\
\hline & Otro familiar & 2,33 & 1,53 & & \\
\hline \multirow{6}{*}{$\begin{array}{l}\text { 10. Si la situación se me hace insoportable disponer de } \\
\text { ayuda para morir con rapidez }\end{array}$} & Pareja & 3 & 1,29 & 0,37 & 863 \\
\hline & Hijo/a & 2,81 & 1,17 & & \\
\hline & Hermano/a & 2,25 & 1,71 & & \\
\hline & Padre & 2 & - & & \\
\hline & Madre & 2,86 & 0,89 & & \\
\hline & Otro familiar & 3 & 1 & & \\
\hline \multirow[t]{6}{*}{ 11. Poder morir en mi casa } & Pareja & 1,42 & 1,55 & 1,18 & ,329 \\
\hline & $\mathrm{Hijo/a}$ & 0,82 & 1,26 & & \\
\hline & Hermano/a & 0,75 & 1,50 & & \\
\hline & Padre & 0 & - & & \\
\hline & Madre & 1,71 & 1,79 & & \\
\hline & Otro familiar & 0 & 0 & & \\
\hline
\end{tabular}

Por lo que respecta al proceso de información y toma de decisiones (véase Tabla 84) el análisis diferencial en función del parentesco no muestra diferencias significativas en ninguna de las subescalas consideradas. No obstante, si analizamos la importancia concedida a los distintos agentes implicados en el proceso, aun sin alcanzar la significación, observamos que los hermanos dan más importancia a la familia; las madres al propio paciente y al médico; y respecto al papel del psicólogo 
ante decisiones relevantes es la pareja quien le da más importancia. Continuando con este análisis diferencial, se aprecia que las mayores puntuaciones en la satisfacción de la información corresponden a los padres, quienes a su vez perciben más como una carga el hecho de participar en una decisión relevante, en comparación con el resto de familiares. En cuanto a las preferencias de un estilo médico más directo a la hora de informar, podemos observar que la mayor puntuación corresponde a la categoría de otro familiar, mientras que son las madres las que prefieren más un estilo prudente, en el que se guarden lo que aún no es seguro. Por último, en relación con la participación en decisiones médicas también son las madres las que se perciben más capaces, respecto al resto de familiares.

Tabla 84. Valoración diferencial en función del parentesco del proceso de información y toma de decisiones (TD) en familiares

\begin{tabular}{|c|c|c|c|c|c|}
\hline CITD & Parentesco & $\bar{X}$ & DT & $\mathbf{F}$ & $\begin{array}{l}\text { Sig. } \\
p \leq, 050\end{array}$ \\
\hline \multicolumn{6}{|l|}{ Importancia de los distintos agentes implicados } \\
\hline \multirow[t]{6}{*}{ Papel de la familia en la información y toma de decisiones } & Pareja & 12,61 & 1,80 & 0,77 & ,582 \\
\hline & $\mathrm{Hijo} / \mathrm{a}$ & 13,67 & 3,34 & & \\
\hline & Hermano/a & 16 & 4,24 & & \\
\hline & Padre & 11 & - & & \\
\hline & Madre & 13 & 2,83 & & \\
\hline & Otro familiar & 13,50 & 0,71 & & \\
\hline \multirow[t]{6}{*}{ Papel del paciente en la información y toma de decisiones } & Pareja & 13,57 & 3,69 & 1,42 & ,250 \\
\hline & $\mathrm{Hijo} / \mathrm{a}$ & 11,83 & 3,54 & & \\
\hline & Hermano/a & 8 & 1,41 & & \\
\hline & Padre & 7 & - & & \\
\hline & Madre & 14 & 1,41 & & \\
\hline & Otro familiar & 13 & 7,07 & & \\
\hline \multirow[t]{6}{*}{ Papel del médico en la información y toma de decisiones } & Pareja & 4,20 & 1,08 & 1,90 & ,126 \\
\hline & Hijo/a & 2,83 & 1,40 & & \\
\hline & Hermano/a & 4 & 2,83 & & \\
\hline & Padre & 3 & - & & \\
\hline & Madre & 4,50 & 0,71 & & \\
\hline & Otro familiar & 4,50 & 0,71 & & \\
\hline \multirow[t]{6}{*}{ Papel del psicólogo en la información y toma de decisiones } & Pareja & 2,73 & 0,46 & 0,62 & 687 \\
\hline & $\mathrm{Hijo} / \mathrm{a}$ & 2,42 & 0,67 & & \\
\hline & Hermano/a & 2,50 & 0,71 & & \\
\hline & Padre & 2 & - & & \\
\hline & Madre & 2,50 & 0,71 & & \\
\hline & Otro familiar & 2,50 & 0,71 & & \\
\hline \multicolumn{6}{|l|}{ Satisfacción con la información } \\
\hline \multirow{6}{*}{$\begin{array}{l}\text { Satisfacción con la cantidad y la claridad de la información } \\
\text { recibida }\end{array}$} & Pareja & 4,80 & 1,14 & 0,55 & ,737 \\
\hline & $\mathrm{Hijo} / \mathrm{a}$ & 5,08 & 0,99 & & \\
\hline & Hermano/a & 4 & 1,41 & & \\
\hline & Padre & 6 & - & & \\
\hline & Madre & 4,50 & 2,12 & & \\
\hline & Otro familiar & 5 & 1,41 & & \\
\hline
\end{tabular}

(Sigue detrás) 


\begin{tabular}{|c|c|c|c|c|c|}
\hline CITD & Parentesco & $\overline{\boldsymbol{X}}$ & DT & $\mathbf{F}$ & $\begin{array}{c}\text { Sig. } \\
p \leq, 050\end{array}$ \\
\hline \multicolumn{6}{|l|}{ Estilo del médico } \\
\hline \multirow{6}{*}{$\begin{array}{l}\text { En cuanto al estilo del médico prefiero que éste sea } \\
\text { directo y anticipe posibles sospechas }\end{array}$} & Pareja & 2 & 1,13 & 1,18 & ,345 \\
\hline & $\mathrm{Hijo} / \mathrm{a}$ & 1,58 & 1,24 & & \\
\hline & Hermano/a & 1,50 & 2,12 & & \\
\hline & Padre & 0 & - & & \\
\hline & Madre & 1 & 1,41 & & \\
\hline & Otro familiar & 3 & 0 & & \\
\hline \multirow{6}{*}{$\begin{array}{l}\text { En cuanto al estilo del médico prefiero que éste se guarde } \\
\text { lo que aún no es seguro }\end{array}$} & Pareja & 1,57 & 1,34 & 1,04 & ,413 \\
\hline & $\mathrm{Hijo} / \mathrm{a}$ & 2,25 & 1,14 & & \\
\hline & Hermano/a & 1,50 & 2,12 & & \\
\hline & Padre & 1 & - & & \\
\hline & Madre & 2,50 & 0,71 & & \\
\hline & Otro familiar & 0,50 & 0,71 & & \\
\hline \multicolumn{6}{|l|}{ Participación en TD } \\
\hline \multirow{6}{*}{$\begin{array}{l}\text { Me siento capacitado para participar en la TD sobre la } \\
\text { salud }\end{array}$} & Pareja & 1,67 & 1,11 & 0,27 & ,923 \\
\hline & $\mathrm{Hijo} / \mathrm{a}$ & 1,75 & 0,96 & & \\
\hline & Hermano/a & 2 & 1,41 & & \\
\hline & Padre & 2 & - & & \\
\hline & Madre & 2,50 & 0,71 & & \\
\hline & Otro familiar & 2 & 0 & & \\
\hline \multirow{6}{*}{$\begin{array}{l}\text { Poder participar en una decisión médica sería más una } \\
\text { carga que un privilegio }\end{array}$} & Pareja & 1,20 & 1,26 & 0,68 & ,639 \\
\hline & $\mathrm{Hijo} / \mathrm{a}$ & 1,36 & 1,36 & & \\
\hline & Hermano/a & 1 & 1,41 & & \\
\hline & Padre & 3 & - & & \\
\hline & Madre & 0,50 & 0,71 & & \\
\hline & Otro familiar & 0,50 & 0,71 & & \\
\hline
\end{tabular}

\subsubsection{Análisis diferenciales en función del lugar de residencia}

Otra variable sociodemográfica en función de la cual se han realizado análisis diferenciales ha sido el lugar de residencia de los familiares. Esta variable está categorizada en cuatro grupos según si el familiar vive en la misma ciudad de Castellón (Castellón ciudad), en otras localidades de la provincia (Castellón provincia), fuera de la provincia de Castellón (España) o en el extranjero. Dado que el número de sujetos en algunos de estos grupos ha sido muy reducido, hemos considerado pertinente llevar a cabo un análisis diferencial que incluya sólo las dos categorías más representativas, es decir, Castellón ciudad y Castellón provincia.

De esta manera, para conocer si el lugar de residencia de los familiares modula las puntuaciones obtenidas en las distintas variables dependientes de la investigación se han realizado pruebas t de Student.

Los resultados relativos a los síntomas de ansiedad evaluados mediante las distintas escalas (HADS y STAI) muestran puntuaciones mayores en los familiares que 
residen fuera de la ciudad de Castellón, si bien las diferencias sólo han sido significativas a nivel estadístico en las puntuaciones obtenidas en ansiedad estado (STAI) $(\mathrm{t}=-2,18 ; \mathrm{p}=, 043)$. En cuanto a los síntomas de depresión también se observa mayor grado de afectación en los familiares que viven en Castellón provincia, tanto en la evaluación realizada mediante el HADS como en la llevada a cabo mediante el BDI, aunque sólo en este último caso ha resultado ser significativa a nivel estadístico ( $t=-$ 2,99; $\mathrm{p}=, 008)$ (véase Tabla 85).

Respecto a la percepción de malestar subjetivo tal como se aprecia en la Tabla 85, las puntuaciones medias en las tres subescalas son mayores en el grupo de familiares que residen en Castellón provincia, si bien estas diferencias sólo han resultado significativas a nivel estadístico en la percepción de malestar general $(\mathrm{t}=-2,59$; $\mathrm{p}=, 012)$ y casi significativas en la percepción de ansiedad y nerviosismo ( $\mathrm{t}=-1,94$; $\mathrm{p}=, 057)$.

Tabla 85. Análisis diferencial en función del lugar de residencia de la ansiedad, depresión y percepción de estado de ánimo (familiares)

\begin{tabular}{|c|c|c|c|c|c|}
\hline Cuestionarios & Lugar de residencia & $\bar{X}$ & DT & $\mathbf{t}$ & $\begin{array}{c}\text { Sig. } \\
p \leq, 050\end{array}$ \\
\hline \multirow[t]{2}{*}{ Total HADS Ansiedad } & Castellón ciudad & 12,03 & 4,29 & $-1,35$ & 182 \\
\hline & Castellón provincia & 13,33 & 3,16 & & \\
\hline \multirow[t]{2}{*}{ Total HADS Depresión } & Castellón ciudad & 10,77 & 4,52 & $-0,78$ & ,437 \\
\hline & Castellón provincia & 11,70 & 5,12 & & \\
\hline \multirow[t]{2}{*}{ STAI-Estado } & Castellón ciudad & 29,91 & 14,78 & $-2,18$ & ,043 \\
\hline & Castellón provincia & 41,89 & 8,02 & & \\
\hline \multirow[t]{2}{*}{ STAI-Rasgo } & Castellón ciudad & 19,27 & 11,32 & $-1,11$ & ,281 \\
\hline & Castellón provincia & 25 & 11,63 & & \\
\hline \multirow[t]{2}{*}{ BDI } & Castellón ciudad & 12 & 5,51 & $-2,99$ & ,008 \\
\hline & Castellón provincia & 19,78 & 6,08 & & \\
\hline \multirow[t]{2}{*}{ EA1- Percepción de malestar general } & Castellón ciudad & 5,41 & 2,60 & $-2,59$ & ,012 \\
\hline & Castellón provincia & 6,96 & 2,05 & & \\
\hline \multirow{2}{*}{$\begin{array}{l}\text { EA2- Percepción de Ansiedad y } \\
\text { Nerviosismo }\end{array}$} & Castellón ciudad & 6,51 & 2,46 & $-1,94$ & 057 \\
\hline & Castellón provincia & 7,56 & 1,58 & & \\
\hline \multirow{2}{*}{$\begin{array}{l}\text { EA3- Percepción de Estado de Ánimo } \\
\text { Deprimido }\end{array}$} & Castellón ciudad & 6 & 2,63 & $-0,84$ & ,403 \\
\hline & Castellón provincia & 6,59 & 3,07 & & \\
\hline
\end{tabular}

El análisis diferencial de la valoración de la estancia en UCI (véase Tabla 86) si bien no muestra diferencias significativas a nivel global $(t=0,62 ; p=, 541)$, podemos observar que con independencia de la situación médica del paciente son los familiares que residen en Castellón ciudad quienes presentan mayor puntuación media. En cambio sí se han obtenido diferencias significativas a nivel estadístico en la valoración de dos aspectos: la "cantidad de la información recibida" ( $t=-2 ; p=, 050)$ mejor valorado 
por los participantes que residen en Castellón provincia, y la "calidad de las instalaciones" ( $\mathrm{t}=2,07 ; \mathrm{p}=, 044)$, en este último caso son los familiares de Castellón ciudad quienes presentan mayores puntuaciones medias.

En cuanto al resto de aspectos valorados en el cuestionario, aun sin ser las diferencias significativas, podemos observar que los familiares que viven en Castellón provincia presentan puntuaciones medias mayores en prácticamente todos los ítems, excepto en aquel que valora el "silencio o tranquilidad en la sala" con puntuaciones mayores en el grupo de familiares que viven en la ciudad de Castellón.

Tabla 86. Análisis diferencial en función del lugar de residencia sobre la valoración de la estancia en UCI (familiares)

\begin{tabular}{|c|c|c|c|c|c|}
\hline Ítem & Lugar de residencia & $\bar{X}$ & DT & $\mathbf{t}$ & $\begin{array}{c}\text { Sig. } \\
p \leq, 050\end{array}$ \\
\hline \multirow{2}{*}{$\begin{array}{l}\text { En qué grado está siendo agradable/desagradable su } \\
\text { estancia en } \mathrm{UCI} \text { sin considerar los problemas médicos. }\end{array}$} & Castellón ciudad & 3,22 & 1,69 & \multirow[t]{2}{*}{0,62} & \multirow[t]{2}{*}{, 541} \\
\hline & Castellón provincia & 2,91 & 1,97 & & \\
\hline Valoración de los siguientes aspectos & Lugar de residencia & $\bar{X}$ & DT & t & $\begin{array}{c}\text { Sig. } \\
p \leq, 050\end{array}$ \\
\hline \multirow[t]{2}{*}{ 1. Cuidados médicos } & Castellón ciudad & 4,67 & 0,54 & \multirow[t]{2}{*}{$-0,19$} & \multirow[t]{2}{*}{846} \\
\hline & Castellón provincia & 4,69 & 0,56 & & \\
\hline \multirow[t]{2}{*}{ 2. Atención de los médicos } & Castellón ciudad & 4,39 & 0,93 & \multirow[t]{2}{*}{$-1,59$} & \multirow[t]{2}{*}{117} \\
\hline & Castellón provincia & 4,74 & 0,54 & & \\
\hline \multirow[t]{2}{*}{ 3. Atención de las/os enfermeras/os } & Castellón ciudad & 4,39 & 0,79 & \multirow[t]{2}{*}{$-0,50$} & \multirow[t]{2}{*}{619} \\
\hline & Castellón provincia & 4,50 & 0,74 & & \\
\hline \multirow[t]{2}{*}{ 4. Atención de las/os auxiliares de enfermería } & Castellón ciudad & 4,52 & 0,63 & \multirow[t]{2}{*}{$-0,16$} & \multirow[t]{2}{*}{877} \\
\hline & Castellón provincia & 4,54 & 0,74 & & \\
\hline \multirow[t]{2}{*}{ 5. Claridad de la información recibida } & Castellón ciudad & 4,30 & 0,88 & \multirow[t]{2}{*}{$-0,78$} & \multirow[t]{2}{*}{,437 } \\
\hline & Castellón provincia & 4,48 & 0,73 & & \\
\hline \multirow[t]{2}{*}{ 6. Cantidad de la información recibida } & Castellón ciudad & 3,85 & 1 & \multirow[t]{2}{*}{-2} & \multirow[t]{2}{*}{, 050} \\
\hline & Castellón provincia & 4,35 & 0,77 & & \\
\hline \multirow[t]{2}{*}{ 7. Trato por parte del personal de enfermería } & Castellón ciudad & 4,42 & 0,71 & \multirow[t]{2}{*}{$-0,30$} & \multirow[t]{2}{*}{,766 } \\
\hline & Castellón provincia & 4,48 & 0,59 & & \\
\hline \multirow{2}{*}{$\begin{array}{l}\text { 8. Afecto/apoyo emocional del personal de } \\
\text { enfermería }\end{array}$} & Castellón ciudad & 3,84 & 1,24 & \multirow[t]{2}{*}{$-1,57$} & \multirow[t]{2}{*}{122} \\
\hline & Castellón provincia & 4,32 & 0,84 & & \\
\hline \multirow[t]{2}{*}{ 9. Respeto a la intimidad } & Castellón ciudad & 4,18 & 0,73 & \multirow[t]{2}{*}{$-1,09$} & 279 \\
\hline & Castellón provincia & 4,41 & 0,79 & & \\
\hline 10. Atención a los familiares & Castellón ciudad & 4,13 & 0,88 & $-1,54$ & 129 \\
\hline & Castellón provincia & 4,48 & 0,73 & & \\
\hline 11. Atención de necesidades psicológicas en paciente & Castellón ciudad & 4,75 & 0,44 & $-1,48$ & 145 \\
\hline y familia & Castellón provincia & 4,91 & 0,29 & & \\
\hline 12. Calidad de las instalaciones (comodidad, & Castellón ciudad & 4,09 & 0,73 & 2,07 & 044 \\
\hline higiene...) & Castellón provincia & 3,59 & 1,05 & & \\
\hline 13. Posibilidades de distraerse & Castellón ciudad & 1,71 & 1,37 & $-0,72$ & ,474 \\
\hline & Castellón provincia & 2,05 & 2,01 & & \\
\hline 14. Silencio o tranquilidad en la sala & Castellón ciudad & 3,82 & 1,18 & 0,78 & ,441 \\
\hline & Castellón provincia & 3,54 & 1,40 & & \\
\hline 15. Régimen de visitas & Castellón ciudad & 3,91 & 0,93 & $-0,72$ & 474 \\
\hline & Castellón provincia & 4,09 & 0,90 & & \\
\hline
\end{tabular}


Respecto a los factores estresantes asociados a UCI (véase Tabla 87), a nivel general no se han obtenido diferencias significativas $(t=-0,99 ; p=, 324)$, si bien los familiares que residen en otras poblaciones de la provincia de Castellón presentan puntuaciones ligeramente superiores. Analizando el resto de ítems de la escala vemos que se han obtenido diferencias significativas a nivel estadístico en el grado de estrés que generan los siguientes factores: "no poder ocuparse de la familia como hasta ahora" ( $\mathrm{t}=-2,44 ; \mathrm{p}=, 018)$, "no saber con seguridad cómo quedará tras la operación" ( $\mathrm{t}=$ 2,06; $\mathrm{p}=, 045)$, "no saber cuándo le darán el alta de UCI" ( $\mathrm{t}=-2,54 ; \mathrm{p}=, 014)$, "pensar que el paciente pueda tener dolor por una operación o pruebas" ( $t=-2,28 ; p=, 027)$ ", "que el hospital esté lejos del domicilio familiar" ( $t=-2,21 ; p=, 032)$, "tener que dormir fuera del domicilio habitual" ( $t=-3,52 ; p=, 001), "$ no poder estar junto al enfermo todo el tiempo" $(t=-3 ; p=, 004)$, $)$, "tener que desplazarse a diario para visitar al enfermo en los cuatro horarios de visita" ( $t=-3,57 ; p=, 001)$, "los horarios en que están concertadas las visitas" $(\mathrm{t}=-2,94 ; \mathrm{p}=, 005)$ y que "el paciente tenga que permanecer aislado por prescripción médica" ( $t=-2,47 ; p=, 018)$. Cabe señalar que estas diferencias significativas han sido a favor de los familiares que residen en Castellón provincia.

Asimismo, continuando con el análisis diferencial, se han obtenido diferencias que rozan la significación estadística en los factores relativos a "pensar que el tiempo de información resulta insuficiente" $(\mathrm{t}=-1,93 ; \mathrm{p}=, 059)$ y que "el paciente esté al cuidado de sanitarios desconocidos" ( $\mathrm{t}=-1,91 ; \mathrm{p}=, 062)$, cuyas puntuaciones también han sido mayores en el grupo de familiares que residen fuera de la ciudad de Castellón.

Tabla 87. Análisis diferencial en función del lugar de residencia de los distintos Factores estresantes de UCI (familiares)

\begin{tabular}{|c|c|c|c|c|c|c|}
\hline Ítem & & Lugar de residencia & $\bar{X}$ & DT & $\mathbf{t}$ & $\begin{array}{c}\text { Sig. } \\
p \leq, 050\end{array}$ \\
\hline \multirow[t]{2}{*}{1.} & \multirow[t]{2}{*}{ Que el enfermo pueda tener dolor } & Castellón ciudad & 2,79 & 1,26 & $-0,85$ & ,401 \\
\hline & & Castellón provincia & 3,10 & 1,29 & & \\
\hline \multirow[t]{2}{*}{2.} & \multirow{2}{*}{$\begin{array}{l}\text { No saber/no entender en qué consiste la } \\
\text { enfermedad }\end{array}$} & Castellón ciudad & 2,37 & 1,47 & 0,65 & ,516 \\
\hline & & Castellón provincia & 2,06 & 1,63 & & \\
\hline \multirow[t]{2}{*}{3.} & \multirow[t]{2}{*}{ Pensar que le puede ocurrir algo grave } & Castellón ciudad & 3,60 & 0,97 & $-0,69$ & 491 \\
\hline & & Castellón provincia & 3,76 & 0,54 & & \\
\hline \multirow[t]{2}{*}{4.} & \multirow{2}{*}{$\begin{array}{l}\text { Pensar si podrá volver a su vida normal al salir del } \\
\text { hospital }\end{array}$} & Castellón ciudad & 2,63 & 1,44 & 0,03 & 975 \\
\hline & & Castellón provincia & 2,62 & 1,80 & & \\
\hline \multirow[t]{2}{*}{5.} & \multirow{2}{*}{$\begin{array}{l}\text { No poder ocuparse usted de la familia como hasta } \\
\text { ahora }\end{array}$} & Castellón ciudad & 1,29 & 1,59 & $-2,44$ & ,018 \\
\hline & & Castellón provincia & 2,43 & 1,59 & & \\
\hline \multirow[t]{2}{*}{6.} & \multirow{2}{*}{$\begin{array}{l}\text { No saber con seguridad cómo quedará tras la } \\
\text { operación }\end{array}$} & Castellón ciudad & 2,32 & 1,55 & $-2,06$ & ,045 \\
\hline & & Castellón provincia & 3,21 & 1,23 & & \\
\hline \multirow[t]{2}{*}{7.} & \multirow[t]{2}{*}{ Estar separado del enfermo } & Castellón ciudad & 2,55 & 1,48 & $-1,49$ & 141 \\
\hline & & Castellón provincia & 3,15 & 1,27 & & \\
\hline \multirow[t]{2}{*}{8.} & \multirow[t]{2}{*}{ No saber cuándo le darán el alta de UCI } & Castellón ciudad & 1,57 & 1,45 & $-2,54$ & 014 \\
\hline & & Castellón provincia & 2,63 & 1,38 & & \\
\hline
\end{tabular}


(Continuación Tabla 87)

\begin{tabular}{|c|c|c|c|c|c|c|}
\hline Ítem & & Lugar de residencia & $\bar{X}$ & DT & $\mathbf{t}$ & $\begin{array}{l}\text { Sig. } \\
p \leq, 050\end{array}$ \\
\hline \multirow[t]{2}{*}{9.} & \multirow[t]{2}{*}{ Haber sido hospitalizado de repente, sin esperarlo } & Castellón ciudad & 2,71 & 1,44 & $-1,76$ & ,085 \\
\hline & & Castellón provincia & 3,41 & 1,06 & & \\
\hline \multirow[t]{2}{*}{10.} & \multirow[t]{2}{*}{ No saber los resultados/razones tratamientos } & Castellón ciudad & 1,61 & 1,42 & $-0,29$ & 769 \\
\hline & & Castellón provincia & 1,74 & 1,56 & & \\
\hline \multirow[t]{2}{*}{11.} & \multirow{2}{*}{$\begin{array}{l}\text { Tener que organizarse para poder acudir a las } \\
\text { visitas }\end{array}$} & Castellón ciudad & 0,64 & 1,11 & $-1,74$ & ,088 \\
\hline & & Castellón provincia & 1,24 & 1,34 & & \\
\hline \multirow[t]{2}{*}{12.} & \multirow{2}{*}{$\begin{array}{l}\text { Pensar que puede tener dolor a causa de } \\
\text { operación/análisis }\end{array}$} & Castellón ciudad & 2,14 & 1,35 & $-2,28$ & 027 \\
\hline & & Castellón provincia & 3 & 1,21 & & \\
\hline \multirow[t]{2}{*}{13.} & \multirow[t]{2}{*}{ No saber cuándo van a hacerle cosas al enfermo } & Castellón ciudad & 1,43 & 1,36 & $-0,74$ & ,462 \\
\hline & & Castellón provincia & 1,75 & 1,65 & & \\
\hline \multirow[t]{2}{*}{14.} & \multirow{2}{*}{$\begin{array}{l}\text { Pensar que el paciente no obtenga alivio para el } \\
\text { dolor aun tomando medicación }\end{array}$} & Castellón ciudad & 3,08 & 1,10 & 0,36 & ,718 \\
\hline & & Castellón provincia & 2,94 & 1,44 & & \\
\hline \multirow[t]{2}{*}{15.} & \multirow[t]{2}{*}{ Ver que el personal del hospital tiene prisa } & Castellón ciudad & 1,30 & 1,70 & $-0,11$ & ,916 \\
\hline & & Castellón provincia & 1,35 & 1,53 & & \\
\hline \multirow[t]{2}{*}{16.} & \multirow[t]{2}{*}{ El hospital se encuentra lejos de casa } & Castellón ciudad & 0,50 & 1,20 & $-2,21$ & 032 \\
\hline & & Castellón provincia & 1,29 & 1,27 & & \\
\hline 17. & Sanitarios hablen deprisa/usen palabras que no & Castellón ciudad & 1,19 & 1,33 & 0,86 & ,396 \\
\hline & entienden & Castellón provincia & 0,82 & 1,29 & & \\
\hline 18. & Que el personal sanitario no conteste a sus & Castellón ciudad & 1,94 & 1,14 & $-0,28$ & ,785 \\
\hline & preguntas & Castellón provincia & 2,08 & 1,55 & & \\
\hline 19. & Tener que dormir fuera del domicilio habitual & Castellón ciudad & 0,47 & 0,87 & $-3,52$ & 001 \\
\hline & & Castellón provincia & 2,21 & 1,80 & & \\
\hline 20. & Preocupación por si no le dan medicación para el & Castellón ciudad & 1,89 & 1,59 & 1,14 & ,262 \\
\hline & dolor cuando necesite & Castellón provincia & 1,33 & 1,68 & & \\
\hline 21. & Pensar en la posible pérdida de dinero por la & Castellón ciudad & 0,58 & 1,15 & 0,35 & ,726 \\
\hline & enfermedad & Castellón provincia & 0,48 & 0,87 & & \\
\hline 22. & Sentir olores extraños en el hospital & Castellón ciudad & 0,97 & 1,56 & 0,04 & 971 \\
\hline & & Castellón provincia & 0,95 & 1,43 & & \\
\hline 23. & Tener que comer a horas diferentes para ir a las & Castellón ciudad & 0,19 & 0,75 & $-1,78$ & 081 \\
\hline & visitas & Castellón provincia & 0,62 & 0,97 & & \\
\hline 24. & No poder llamar al paciente por teléfono & Castellón ciudad & 1,42 & 1,71 & $-0,50$ & 618 \\
\hline & & Castellón provincia & 1,67 & 1,79 & & \\
\hline 25. & Que el enfermo esté al cuidado de sanitarios & Castellón ciudad & 0,23 & 0,62 & $-1,91$ & ,062 \\
\hline & desconocidos & Castellón provincia & 0,76 & 1,37 & & \\
\hline 26. & Tener demasiados horarios de visita & Castellón ciudad & 0,29 & 0,78 & $-0,72$ & ,474 \\
\hline & & Castellón provincia & 0,48 & 1,08 & & \\
\hline 27. & Ver en la sala durante las visitas otros enfermos & Castellón ciudad & 0,42 & 0,76 & $-1,60$ & 115 \\
\hline & muy graves & Castellón provincia & 0,90 & 1,41 & & \\
\hline 28. & Miedo a que el paciente pueda morir & Castellón ciudad & 3,43 & 1,28 & $-0,25$ & 800 \\
\hline & & Castellón provincia & 3,52 & 1,21 & & \\
\hline 29. & Paciente sea atendido por distintos médicos & Castellón ciudad & 0,64 & 1,14 & $-1,17$ &, 247 \\
\hline & durante ingreso & Castellón provincia & 1,05 & 1,32 & & \\
\hline 30. & Que los familiares sean informados por diferentes & Castellón ciudad & 1 & 1,29 & $-1,16$ & ,251 \\
\hline & médicos & Castellón provincia & 1,48 & 1,66 & & \\
\hline 31. & Esperar para entrar a las diferentes horas de visita & Castellón ciudad & 1,42 & 1,54 & $-1,18$ & ,245 \\
\hline & & Castellón provincia & 1,95 & 1,69 & & \\
\hline 32. & No poder estar junto al enfermo todo el tiempo & Castellón ciudad & 1,32 & 1,47 & -3 &, 004 \\
\hline & & Castellón provincia & 2,67 & 1,74 & & \\
\hline 33. & Tener que desplazarse para visitar al enfermo en las & Castellón ciudad & 0,42 & 1,06 & $-3,57$ & 001 \\
\hline & 4 horas de visita & Castellón provincia & 1,81 & 1,75 & & \\
\hline 34. & Los horarios en que están concertadas las visitas en & Castellón ciudad & 0,35 & 0,91 & $-2,94$ & ,005 \\
\hline & la unidad & Castellón provincia & 1,38 & 1,59 & & \\
\hline 35. & Que el enfermo permanezca solo junto a otros & Castellón ciudad & 1,20 & 1,42 & $-1,13$ & ,264 \\
\hline & pacientes graves & Castellón provincia & 1,65 & 1,31 & & \\
\hline 36. & Que el paciente no descanse adecuadamente por el & Castellón ciudad & 1,21 & 1,37 & 0,16 & 874 \\
\hline & ruido & Castellón provincia & 1,15 & 1,39 & & \\
\hline 37. & Que el paciente manifieste temor & Castellón ciudad & 2,50 & 1,38 & $-0,83$ & ,413 \\
\hline & & Castellón provincia & 2,84 & 1,30 & & \\
\hline
\end{tabular}

(Sigue detrás) 
(Continuación Tabla 87)

\begin{tabular}{|c|c|c|c|c|c|c|}
\hline Ítem & & Lugar de residencia & $\bar{X}$ & DT & $\mathbf{t}$ & $\begin{array}{l}\text { Sig. } \\
p \leq, 050\end{array}$ \\
\hline 38. & $\begin{array}{l}\text { Que el paciente permanezca aislado por } \\
\text { prescripción médica }\end{array}$ & $\begin{array}{l}\text { Castellón ciudad } \\
\text { Castellón provincia }\end{array}$ & $\begin{array}{l}1,43 \\
2,67\end{array}$ & $\begin{array}{l}1,47 \\
1,54\end{array}$ & $-2,47$ & ,018 \\
\hline 39. & $\begin{array}{l}\text { Pensar que el tiempo de información para los } \\
\text { familiares es insuficiente }\end{array}$ & $\begin{array}{l}\text { Castellón ciudad } \\
\text { Castellón provincia }\end{array}$ & $\begin{array}{l}0,45 \\
1,09\end{array}$ & $\begin{array}{l}0,85 \\
1,55\end{array}$ & $-1,93$ & 059 \\
\hline 40. & Nivel de estrés en general & $\begin{array}{l}\text { Castellón ciudad } \\
\text { Castellón provincia }\end{array}$ & $\begin{array}{l}2,90 \\
3,19\end{array}$ & $\begin{array}{l}1,01 \\
1,03\end{array}$ & $-0,99$ & ,324 \\
\hline
\end{tabular}

Los resultados relativos a la adaptación de la familia al ingreso en UCI (véase Tabla 88) no muestran diferencias estadísticamente significativas ni a nivel global $(\mathrm{t}=0,13 ; \mathrm{p}=, 900)$ ni en ninguna de la áreas analizadas: trabajo $(\mathrm{t}=0,38 ; \mathrm{p}=, 707)$, vida social $(t=0,71 ; p=, 480)$, tiempo libre $(t=0,13 ; p=, 899)$, relación de pareja $(t=1,11 ; p=, 274)$ y vida familiar $(t=-0,97 ; p=, 334)$.

Tabla 88. Análisis diferencial en función del lugar de residencia del Grado de interferencia en las distintas esferas de la vida de los familiares de UCI

\begin{tabular}{|c|c|c|c|c|c|}
\hline Niveles de interferencia & Lugar de residencia & $\bar{X}$ & DT & $\mathbf{t}$ & $\begin{array}{c}\text { Sig. } \\
p \leq, 050\end{array}$ \\
\hline \multirow[t]{2}{*}{ 1. Trabajo } & Castellón ciudad & 3 & 1,57 & 0,38 & 707 \\
\hline & Castellón provincia & 2,83 & 1,95 & & \\
\hline \multirow[t]{2}{*}{ 2. Vida social } & Castellón ciudad & 2,78 & 1,74 & 0,71 & ,480 \\
\hline & Castellón provincia & 2,43 & 1,90 & & \\
\hline \multirow[t]{2}{*}{ 3. Tiempo libre } & Castellón ciudad & 3,44 & 1,54 & 0,13 & ,899 \\
\hline & Castellón provincia & 3,39 & 1,59 & & \\
\hline \multirow[t]{2}{*}{ 4. Relación de pareja } & Castellón ciudad & 2,26 & 1,98 & 1,11 & ,274 \\
\hline & Castellón provincia & 1,63 & 2,06 & & \\
\hline \multirow[t]{2}{*}{ 5. Vida familiar } & Castellón ciudad & 1,97 & 1,65 & $-0,97$ & ,334 \\
\hline & Castellón provincia & 2,43 & 1,97 & & \\
\hline \multirow[t]{2}{*}{ 6. Escala global } & Castellón ciudad & 3,69 & 1,14 & 0,13 & 900 \\
\hline & Castellón provincia & 3,65 & 1,40 & & \\
\hline
\end{tabular}

Respecto a las necesidades de los familiares en UCI podemos observar en la Tabla 89 que se han obtenido diferencias significativas en función del lugar de residencia en la valoración de si los miembros del equipo están atentos con el familiar $(\mathrm{t}=2,93 ; \mathrm{p}=, 005)$, mostrando mayores puntuaciones medias (es decir, menor satisfacción) los familiares que residen en la ciudad de Castellón. Analizando el resto de ítems que incluye el cuestionario, sin ser las diferencias significativas, se observan puntuaciones ligeramente superiores en los familiares que viven en Castellón respecto a la valoración de las "explicaciones sobre el estado del paciente", la "comprensión de lo que le sucede y los motivos por los que le hacen pruebas", el "interés mostrado por algún miembro del equipo en cómo está el familiar en particular" y las "explicaciones sobre el equipamiento utilizado". En cambio, se aprecian medias mayores en los 
familiares que residen en Castellón provincia en aquellas valoraciones relacionadas con los "cuidados al paciente", la "percepción de que el personal se preocupa por el paciente", la percepción de que la "información es sincera", las "atenciones médicas recibidas" así como estos familiares también "se sienten más solos y aislados en la sala de espera", si bien ninguna de estas diferencias ha sido significativa.

Tabla 89. Análisis diferencial en función del lugar de residencia de las necesidades de los familiares de $\mathrm{UCI}$

\begin{tabular}{|c|c|c|c|c|c|}
\hline Ítem & Lugar de residencia & $\bar{X}$ & DT & $\mathbf{t}$ & $\begin{array}{c}\text { Sig. } \\
p \leq, 050\end{array}$ \\
\hline \multirow{2}{*}{$\begin{array}{l}\text { 1. ¿Usted siente que se le están dando los } \\
\text { mejores cuidados posibles al paciente? }\end{array}$} & Castellón ciudad & 1,18 & 0,39 & \multirow[t]{2}{*}{$-1,25$} & \multirow[t]{2}{*}{,216 } \\
\hline & Castellón provincia & 1,35 & 0,59 & & \\
\hline \multirow{2}{*}{$\begin{array}{l}\text { 2. ¿Usted siente que el personal del hospital } \\
\text { se preocupa por el paciente? }\end{array}$} & Castellón ciudad & 1,24 & 0,50 & \multirow[t]{2}{*}{$-0,41$} & \multirow[t]{2}{*}{,680 } \\
\hline & Castellón provincia & 1,30 & 0,47 & & \\
\hline \multirow{2}{*}{$\begin{array}{l}\text { 3. ¿Le dan explicaciones sobre el estado del } \\
\text { paciente en términos que pueda } \\
\text { comprender? }\end{array}$} & Castellón ciudad & 1,51 & 0,83 & \multirow[t]{2}{*}{1,52} & \multirow[t]{2}{*}{ 136 } \\
\hline & Castellón provincia & 1,20 & 0,52 & & \\
\hline \multirow{2}{*}{$\begin{array}{l}\text { 4. ¿Usted siente que le están dando } \\
\text { información sincera sobre el estado y } \\
\text { progreso del paciente? }\end{array}$} & Castellón ciudad & 1,27 & 0,63 & \multirow[t]{2}{*}{-042} & \multirow[t]{2}{*}{,673 } \\
\hline & Castellón provincia & 1,35 & 0,67 & & \\
\hline \multirow{2}{*}{$\begin{array}{l}\text { 5. ¿Usted comprende lo que le sucede al } \\
\text { paciente y el motivo de las pruebas? }\end{array}$} & Castellón ciudad & 1,30 & 0,77 & \multirow[t]{2}{*}{0,55} & \multirow[t]{2}{*}{,584 } \\
\hline & Castellón provincia & 1,20 & 0,41 & & \\
\hline \multirow{2}{*}{$\begin{array}{l}\text { 6. ¿Están siendo atentos los miembros del } \\
\text { equipo con usted? }\end{array}$} & Castellón ciudad & 1,79 & 0,93 & \multirow[t]{2}{*}{2,93} & \multirow[t]{2}{*}{, 005} \\
\hline & Castellón provincia & 1,15 & 0,37 & & \\
\hline \multirow{2}{*}{$\begin{array}{l}\text { 7. ¿Muestra algún miembro del equipo } \\
\text { interés por cómo está usted? }\end{array}$} & Castellón ciudad & 2,88 & 1,24 & \multirow[t]{2}{*}{0,91} & \multirow[t]{2}{*}{,366 } \\
\hline & Castellón provincia & 2,55 & 1,32 & & \\
\hline \multirow{2}{*}{$\begin{array}{l}\text { 8. ¿Le ha explicado el personal del hospital el } \\
\text { equipamiento que está utilizándose? }\end{array}$} & Castellón ciudad & 3,21 & 1,11 & \multirow[t]{2}{*}{0,35} & \multirow[t]{2}{*}{,728 } \\
\hline & Castellón provincia & 3,10 & 1,16 & & \\
\hline \multirow{2}{*}{$\begin{array}{l}\text { 9. Estoy muy satisfecho con las atenciones } \\
\text { médicas recibidas por el paciente }\end{array}$} & Castellón ciudad & 1,12 & 0,41 & \multirow[t]{2}{*}{$-0,97$} & \multirow[t]{2}{*}{, 338} \\
\hline & Castellón provincia & 1,25 & 0,55 & & \\
\hline \multirow{2}{*}{$\begin{array}{l}\text { 10. ¿Usted se siente solo y aislado en la sala de } \\
\text { espera? }\end{array}$} & Castellón ciudad & 1,19 & 0,59 & \multirow[t]{2}{*}{$-0,83$} & \multirow[t]{2}{*}{,409 } \\
\hline & Castellón provincia & 1,35 & 0,81 & & \\
\hline \multirow{2}{*}{$\begin{array}{l}\text { 11. ¿Hay algunas cosas respecto a los cuidados } \\
\text { médicos recibidos por el paciente que } \\
\text { podrían ser mejoradas? }\end{array}$} & Castellón ciudad & 1,88 & 0,99 & \multirow[t]{2}{*}{1,33} & \multirow[t]{2}{*}{ 187 } \\
\hline & Castellón provincia & 1,53 & 0,77 & & \\
\hline
\end{tabular}

El análisis de la valoración diferencial de los distintos factores relativos al proceso de morir que incluye el cuestionario CAMP (véase Tabla 90) no muestra diferencias estadísticamente significativas en función del lugar de residencia. No obstante, las diferencias rozan la significación estadística en dos factores: "pensar que mi vida ha tenido algún sentido" ( $t=-1,90 ; p=, 063)$ y "acortar el proceso de morir si hay sufrimiento" ( $\mathrm{t}=-1,79 ; \mathrm{p}=, 080)$, ambos factores más valorados por los familiares que viven en Castellón provincia. Asimismo, aun sin ser las diferencias significativas, estos familiares también parecen dar más importancia al "control del dolor y síntomas de malestar" ( $\overline{\mathrm{X}}=3,37$ vs $\overline{\mathrm{X}}=2,96)$, "no alargar la vida artificialmente en una UCI" $(\overline{\mathrm{X}}=3$ vs $\bar{X}=2,82)$, “creer en otra vida después de la muerte” ( $\bar{X}=1,53$ vs $\bar{X}=1,03)$, “disponer de 
ayuda para morir con rapidez" ( $\overline{\mathrm{X}}=3,26$ vs $\overline{\mathrm{X}}=2,67)$ y "poder morir en casa" ( $\mathrm{X}=1,21$ vs $\overline{\mathrm{X}}=0,89)$.

Tabla 90. Análisis diferencial en función del lugar de residencia de los distintos factores del Cuestionario de Ayuda a Morir en Paz (CAMP) (familiares)

\begin{tabular}{|c|c|c|c|c|c|}
\hline Ítem & Lugar de residencia & $\bar{X}$ & DT & $\mathbf{t}$ & $\begin{array}{l}\text { Sig. } \\
p \leq, 050\end{array}$ \\
\hline \multirow[t]{2}{*}{ 1. Controlar mi dolor y otros síntomas de malestar } & Castellón ciudad & 2,96 & 1,17 & $-1,32$ & 192 \\
\hline & Castellón provincia & 3,37 & 0,76 & & \\
\hline \multirow{2}{*}{$\begin{array}{l}\text { 2. Mi proceso de morir, si produce sufrimiento, será } \\
\text { corto }\end{array}$} & Castellón ciudad & 2,93 & 1,09 & $-1,79$ & 080 \\
\hline & Castellón provincia & 3,47 & 0,90 & & \\
\hline \multirow{2}{*}{$\begin{array}{l}\text { 3. Controlar hasta el final pensamientos y funciones } \\
\text { fisiológicas }\end{array}$} & Castellón ciudad & 2,52 & 1,50 & 0,09 & ,924 \\
\hline & Castellón provincia & 2,47 & 1,61 & & \\
\hline \multirow{2}{*}{$\begin{array}{l}\text { 4. Mi muerte no supondrá una carga insoportable } \\
\text { para mis seres queridos }\end{array}$} & Castellón ciudad & 3,25 & 0,93 & 0,30 & ,765 \\
\hline & Castellón provincia & 3,16 & 1,17 & & \\
\hline \multirow{2}{*}{$\begin{array}{l}\text { 5. Poder sentirme cerca, comunicarme y estrechar } \\
\text { vínculos afectivos con mis personas queridas }\end{array}$} & Castellón ciudad & 3,38 & 0,86 & 0,21 & ,832 \\
\hline & Castellón provincia & 3,31 & 1,20 & & \\
\hline \multirow{2}{*}{$\begin{array}{l}\text { 6. Sin esperanza real de recuperación, no se alargará } \\
\text { artificialmente mi vida en } \mathrm{UCl}\end{array}$} & Castellón ciudad & 2,82 & 1,22 & $-0,48$ & 633 \\
\hline & Castellón provincia & 3 & 1,29 & & \\
\hline \multirow[t]{2}{*}{ 7. Pensar que mi vida ha tenido algún sentido } & Castellón ciudad & 2,79 & 1,24 & $-1,90$ & ,063 \\
\hline & Castellón provincia & 3,42 & 0,90 & & \\
\hline \multirow[t]{2}{*}{ 8. Creer en otra vida después de la muerte } & Castellón ciudad & 1,03 & 1,29 & $-1,18$ & ,244 \\
\hline & Castellón provincia & 1,53 & 1,58 & & \\
\hline \multirow{2}{*}{$\begin{array}{l}\text { 9. No sentirse culpable por conflictos personales del } \\
\text { pasado }\end{array}$} & Castellón ciudad & 2,82 & 1,19 & 0,49 & ,627 \\
\hline & Castellón provincia & 2,63 & 1,46 & & \\
\hline \multirow{2}{*}{$\begin{array}{l}\text { 10. Si la situación se me hace insoportable disponer de } \\
\text { ayuda para morir con rapidez }\end{array}$} & Castellón ciudad & 2,67 & 1,36 & $-1,71$ & ,094 \\
\hline & Castellón provincia & 3,26 & 0,81 & & \\
\hline \multirow[t]{2}{*}{ 11. Poder morir en mi casa } & Castellón ciudad & 0,89 & 1,45 & $-0,71$ & 478 \\
\hline & Castellón provincia & 1,21 & 1,55 & & \\
\hline
\end{tabular}

Por lo que respecta al proceso de información y toma de decisiones (véase Tabla 91) el análisis diferencial en función del lugar de residencia no muestra diferencias significativas en ninguna de las subescalas consideradas. No obstante, si analizamos la importancia concedida a los distintos agentes implicados en el proceso, aun sin alcanzar la significación, observamos que los familiares que residen en Castellón provincia presentan puntuaciones ligeramente mayores en el papel que se concede a todos los agentes, es decir, a la familia $(\bar{X}=13,57$ vs $\bar{X}=12,88)$, al paciente $(\bar{X}=12,46$ vs $\overline{\mathrm{X}}=11,94)$, al médico $(\overline{\mathrm{X}}=4,14$ vs $\overline{\mathrm{X}}=3,33)$ y al psicólogo $(\overline{\mathrm{X}}=2,64$ vs $\overline{\mathrm{X}}=2,50)$.

Atendiendo al resto de subescalas del cuestionario CITD, observamos que los familiares que viven en Castellón provincia puntúan ligeramente más en la preferencia de un estilo médico más prudente, que se guarde aquella información que aún no es segura $(\bar{X}=2,07$ vs $\bar{X}=1,59)$. Asimismo, estos familiares perciben más como una carga el 
hecho de participar en una decisión médica ( $\bar{X}=1,38$ vs $\bar{X}=1,22)$. En cambio, los familiares que residen en Castellón ciudad presentan puntuaciones mayores en la preferencia de un estilo médico más directo, que anticipe sospechas $(\overline{\mathrm{X}}=1,83$ vs $\overline{\mathrm{X}}=1,64)$. No obstante, estas diferencias no han sido significativas.

Tabla 91. Valoración diferencial en función del lugar de residencia del proceso de información y toma de decisiones (TD) en familiares

\begin{tabular}{|c|c|c|c|c|c|}
\hline CITD & Lugar de residencia & $\bar{X}$ & DT & $\mathbf{t}$ & $\begin{array}{c}\text { Sig. } \\
p \leq, 050\end{array}$ \\
\hline \multicolumn{6}{|l|}{ Importancia de los distintos agentes implicados } \\
\hline \multirow{2}{*}{$\begin{array}{l}\text { Papel de la familia en la información y toma de } \\
\text { decisiones }\end{array}$} & Castellón ciudad & 12,88 & 2,83 & \multirow[t]{2}{*}{$-0,71$} & \multirow[t]{2}{*}{,483 } \\
\hline & Castellón provincia & 13,57 & 2,50 & & \\
\hline \multirow{2}{*}{$\begin{array}{l}\text { Papel del paciente en la información y toma de } \\
\text { decisiones }\end{array}$} & Castellón ciudad & 11,94 & 3,90 & \multirow[t]{2}{*}{$-0,37$} & \multirow[t]{2}{*}{,716 } \\
\hline & Castellón provincia & 12,46 & 3,82 & & \\
\hline \multirow{2}{*}{$\begin{array}{l}\text { Papel del médico en la información y toma de } \\
\text { decisiones }\end{array}$} & Castellón ciudad & 3,33 & 1,41 & \multirow[t]{2}{*}{$-1,67$} & \multirow[t]{2}{*}{106} \\
\hline & Castellón provincia & 4,14 & 1,29 & & \\
\hline \multirow{2}{*}{$\begin{array}{l}\text { Papel del psicólogo en la información y toma de } \\
\text { decisiones }\end{array}$} & Castellón ciudad & 2,50 & 0,51 & \multirow[t]{2}{*}{$-0,70$} & \multirow[t]{2}{*}{,487 } \\
\hline & Castellón provincia & 2,64 & 0,63 & & \\
\hline \multicolumn{6}{|l|}{ Satisfacción con la información } \\
\hline \multirow{2}{*}{$\begin{array}{l}\text { Satisfacción con la cantidad y la claridad de la } \\
\text { información recibida }\end{array}$} & Castellón ciudad & 4,83 & 1,09 & \multirow[t]{2}{*}{$-0,06$} & \multirow[t]{2}{*}{,954 } \\
\hline & Castellón provincia & 4,86 & 1,23 & & \\
\hline \multicolumn{6}{|l|}{ Estilo del médico } \\
\hline \multirow{2}{*}{$\begin{array}{l}\text { En cuanto al estilo del médico prefiero que éste sea } \\
\text { directo y anticipe posibles sospechas }\end{array}$} & Castellón ciudad & 1,83 & 1,29 & \multirow[t]{2}{*}{0,41} & \multirow[t]{2}{*}{,681 } \\
\hline & Castellón provincia & 1,64 & 1,28 & & \\
\hline \multirow{2}{*}{$\begin{array}{l}\text { En cuanto al estilo del médico prefiero que éste se } \\
\text { guarde lo que aún no es seguro }\end{array}$} & Castellón ciudad & 1,59 & 1,33 & \multirow[t]{2}{*}{$-1,03$} & \multirow[t]{2}{*}{,312 } \\
\hline & Castellón provincia & 2,07 & 1,27 & & \\
\hline \multicolumn{6}{|l|}{ Participación en TD } \\
\hline \multirow{2}{*}{$\begin{array}{l}\text { Me siento capacitado para participar en la TD sobre } \\
\text { la salud }\end{array}$} & Castellón ciudad & 1,78 & 0,94 & \multirow[t]{2}{*}{0,18} & \multirow[t]{2}{*}{860} \\
\hline & Castellón provincia & 1,71 & 1,07 & & \\
\hline \multirow{2}{*}{$\begin{array}{l}\text { Poder participar en una decisión médica sería más } \\
\text { una carga que un privilegio }\end{array}$} & Castellón ciudad & 1,22 & 1,11 & \multirow[t]{2}{*}{$-0,35$} & \multirow[t]{2}{*}{,726 } \\
\hline & Castellón provincia & 1,38 & 1,44 & & \\
\hline
\end{tabular}

\subsubsection{Relación entre las variables evaluadas y la edad de los familiares}

Además de los análisis diferenciales descritos se han realizado aquellos análisis estadísticos que nos han permitido explorar la relación entre las distintas variables dependientes incluidas en el estudio y la edad de los familiares de UCI. En este sentido se han llevado a cabo correlaciones de Pearson de la edad con la ansiedad, la depresión, la percepción subjetiva del estado de ánimo, la valoración de la estancia en UCI, los factores estresantes, la adaptación al ingreso, las necesidades de los familiares, los factores que ayudarían a morir en paz así como la valoración del proceso de información y toma de decisiones. 
Los resultados de las correlaciones de Pearson realizadas con las puntuaciones de las distintas escalas que miden ansiedad y depresión (véase Tabla 92) muestran relación positiva estadísticamente significativa entre la edad de los familiares y la depresión evaluada mediante el HADS $(\mathrm{r}=0,34 ; \mathrm{p}=, 001)$, si bien la relación entre la edad y la depresión medida mediante el BDI no ha sido significativa $(r=-0,05 ; p=, 773)$. Respecto a los síntomas de ansiedad no se han obtenido relaciones significativas a nivel estadístico en ninguna de las escalas utilizadas. En cuanto a la percepción subjetiva de malestar, los resultados no muestran tampoco relaciones significativas de la edad con ninguna de las subescalas (malestar general, ansiedad y estado de ánimo deprimido).

Tabla 92. Correlaciones de Pearson entre la edad y los síntomas de ansiedad-depresión y percepción de estado de ánimo (familiares)

\begin{tabular}{|lc}
\hline Cuestionarios & Edad \\
\hline Total HADS- Ansiedad & $0,04(p=, 733)$ \\
\hline Total HADS- Depresión & $\mathbf{0 , 3 4}(p=, 001)$ \\
STAI- Estado & $0,00(p=, 988)$ \\
STAI- Rasgo & $0,14(p=, 412)$ \\
BDI & $-0,05(p=, 773)$ \\
\hline EA1-Malestar general & $-0,01(p=, 915)$ \\
EA2-Ansiedad y Nerviosismo & $-0,07(p=, 522)$ \\
EA3-Estado de ánimo deprimido & $0,11(p=, 312)$ \\
\hline
\end{tabular}

En cuanto a la valoración de la estancia en UCI (véase Tabla 93) a nivel global sin tener en cuenta la situación médica del paciente, los resultados no muestran relaciones significativas con la edad $(\mathrm{r}=0,16 ; \mathrm{p}=, 183)$. Sin embargo, al analizar los diferentes ítems que componen la escala observamos relación significativa y positiva con la edad en la valoración de la "atención médica recibida" ( $\mathrm{r}=0,36 ; \mathrm{p}=, 002)$, la "cantidad" y "claridad de la información" ( $r=0,34 ; \mathrm{p}=, 003$ y $\mathrm{r}=0,23 ; \mathrm{p}=, 048$, respectivamente), el "trato por parte del personal de enfermería" ( $r=0,27 ; p=, 023)$ y el "silencio en la sala" $(\mathrm{r}=0,32 ; \mathrm{p}=, 006)$. Atendiendo al signo de estas relaciones podríamos decir que los citados aspectos son mejor valorados a medida que aumenta la edad. Asimismo, la edad correlaciona a nivel estadísticamente significativo con la valoración del "respeto a la intimidad" $(\mathrm{r}=-0,25 ; \mathrm{p}=, 039)$ aunque en este caso la relación es negativa, por lo que a medida que aumenta la edad parece que este aspecto recibe peor valoración por las familias en UCI. 
Tabla 93. Correlaciones de Pearson entre la edad y la Valoración de la estancia en UCI (familiares)

\begin{tabular}{|c|c|}
\hline Ítem & Edad \\
\hline $\begin{array}{l}\text { - En qué grado está siendo agradable/desagradable su estancia } \\
\text { en UCl sin considerar los problemas médicos }\end{array}$ & $0,16(p=, 183)$ \\
\hline \multicolumn{2}{|l|}{ Valoración de los siguientes aspectos } \\
\hline 1. Cuidados médicos & $0,21(p=, 070)$ \\
\hline 2. Atención de los médicos & $0,36(p=, 002)$ \\
\hline 3. Atención de las/os enfermeras/os & $0,14(p=, 225)$ \\
\hline 4. Atención de las/os auxiliares de enfermería & $0,18(p=, 137)$ \\
\hline 5. Claridad de la información recibida & $0,23(p=, 048)$ \\
\hline 6. Cantidad de la información recibida & $0,34(p=, 003)$ \\
\hline 7. Trato por parte del personal de enfermería & $0,27(p=, 023)$ \\
\hline 8. Afecto/apoyo emocional del personal de enfermería & $-0,01(p=, 952)$ \\
\hline 9. Respeto a la intimidad & $-0,25(p=, 039)$ \\
\hline 10. Atención a los familiares & $0,11(p=, 360)$ \\
\hline 11. Atención de necesidades psicológicas en paciente y familia & $-0,03(p=, 791)$ \\
\hline 12. Calidad de las instalaciones (comodidad, higiene...) & $0,08(p=, 507)$ \\
\hline 13. Posibilidades de distraerse & $-0,13(p=, 306)$ \\
\hline 14. Silencio o tranquilidad en la sala & $0,32(p=, 006)$ \\
\hline 15. Régimen de visitas & $0,13(p=, 274)$ \\
\hline
\end{tabular}

Respecto a la escala de los Factores estresantes de UCI (véase Tabla 94) no se han obtenido correlaciones significativas entre la edad de los familiares y el nivel de estrés general ( $r=-0,08 ; \mathrm{p}=, 532)$. Sin embargo, al analizar las correlaciones de Pearson entre la edad y el resto de ítems que incluye la escala observamos relación significativa y de signo negativo entre la edad y el grado de estrés que generan los siguientes factores: "no saber los resultados/razones de los tratamientos" ( $r=-0,39 ; \mathrm{p}=, 002)$, "tener que organizarse para acudir a las visitas" ( $\mathrm{r}=-0,25 ; \mathrm{p}=, 042)$, "no saber cuándo van a hacerle cosas al enfermo" ( $\mathrm{r}=-0,26 ; \mathrm{p}=, 037)$, "que no le den la medicación para el dolor cuando la necesita" ( $\mathrm{r}=-0,27 ; \mathrm{p}=, 032)$, "que el paciente sea atendido por distintos médicos durante el ingreso" ( $\mathrm{r}=-0,25 ; \mathrm{p}=, 037)$ y "que los familiares sean informados por distintos médicos" ( $(\mathrm{r}=-0,29 ; \mathrm{p}=, 012)$. Así a medida que aumenta la edad de los familiares se observa que estos factores generan menor grado de estrés. Igualmente, estos resultados muestran relaciones negativas casi significativas a nivel estadístico entre la edad y el estrés que genera "que el paciente manifieste temor" ( $\mathrm{r}=-0,25$; $p=, 059)$, "que el enfermo permanezca solo todo el día junto a otros pacientes graves" $(\mathrm{r}=-0,23 ; \mathrm{p}=, 064) \mathrm{y}$ "tener que ver en la sala durante las visitas a otros enfermos graves" 
$(\mathrm{r}=-0,22 ; \mathrm{p}=, 062)$. Por último, los análisis de correlación de Pearson, muestran que no parece existir relación lineal alguna entre la edad y el estrés que causa el "miedo a que el paciente pueda morir" $(\mathrm{r}=0,00 ; \mathrm{p}=, 988)$ y factores relativos a las visitas como los "horarios" $(\mathrm{r}=0,00 ; \mathrm{p}=, 964)$ y el "tener que desplazarse a diario para ver al paciente en los cuatro horarios de visita" $(\mathrm{r}=0,00 ; \mathrm{p}=, 968)$.

Tabla 94. Correlaciones de Pearson entre la edad y los Factores estresantes en UCI (familiares)

\begin{tabular}{|c|c|c|}
\hline Ítem & & Edad \\
\hline 1. & Que el enfermo pueda tener dolor & $-0,08(p=, 532)$ \\
\hline 2. & No saber con seguridad o no entender en qué consiste la enfermedad & $-0,18(p=, 170)$ \\
\hline 3. & Pensar que le puede ocurrir algo grave & $0,04(p=, 759)$ \\
\hline 4. & Pensar si podrá volver a su vida normal después de salir del hospital & $-0,09(p=, 449)$ \\
\hline 5. & No poder ocuparse usted de la familia como hasta ahora venía haciendo & $-0,21(p=, 088)$ \\
\hline 6. & No saber con seguridad cómo quedará después de la operación & $-0,00(p=, 983)$ \\
\hline 7. & Estar separado del enfermo & $-0,11(p=, 358)$ \\
\hline 8. & No saber cuándo le darán el alta de la unidad de cuidados intensivos & $-0,10(p=, 403)$ \\
\hline 9. & Haber sido hospitalizado de repente, sin esperarlo & $-0,14(p=, 276)$ \\
\hline 10. & No saber los resultados/razones de los tratamientos/pruebas que le hacen & $-0,39(p=, 002)$ \\
\hline 11. & Tener que organizarse para poder acudir a las visitas & $-0,24(p=, 042)$ \\
\hline 12. & Pensar que puede tener dolor a causa de la operación/análisis & $-0,12(p=, 345)$ \\
\hline 13. & No saber cuándo van a hacerle cosas al enfermo & $-0,26(p=, 037)$ \\
\hline 14. & Pensar que el paciente pueda no obtener alivio para el dolor aún tomando medicación & $-0,12(p=, 392)$ \\
\hline 15. & Ver que el personal del hospital tiene prisa & $-0,18(p=, 144)$ \\
\hline 16. & El hospital en que está ingresado el paciente se encuentra lejos de casa & $0,13(p=, 284)$ \\
\hline 17. & Que sanitarios hablen deprisa o usen palabras que no pueden entender & $-0,05(p=, 713)$ \\
\hline 18. & Que el personal sanitario no conteste a sus preguntas & $-0,22(p=, 150)$ \\
\hline 19. & Tener que dormir fuera del domicilio habitual & $-0,07(p=, 648)$ \\
\hline 20. & Preocupación por que no le den la medicación para el dolor cuando la necesita & $-0,27(p=, 032)$ \\
\hline 21. & Pensar en la posible pérdida de dinero a causa de la enfermedad & $-0,07(p=, 573)$ \\
\hline 22. & Sentir olores extraños en el hospital & $-0,08(p=, 486)$ \\
\hline 23. & Tener que comer a horas diferentes a las habituales para poder ir a las visitas & $0,18(p=, 135)$ \\
\hline 24. & No poder llamar al paciente por teléfono & $-0,15(p=, 214)$ \\
\hline 25. & Que el enfermo esté al cuidado de sanitarios desconocidos & $-0,15(p=, 222)$ \\
\hline 26. & Tener demasiados horarios de visita & $-0,06(p=, 594)$ \\
\hline 27. & Tener que ver en la sala durante las visitas a otros enfermos muy graves & $-0,22(p=, 062)$ \\
\hline 28. & Miedo a que el paciente pueda morir & $0,00(p=, 988)$ \\
\hline 29. & Que el paciente sea atendido por diferentes médicos durante su ingreso & $-0,25(p=, 037)$ \\
\hline 30. & Que los familiares sean informados por diferentes médicos & $-0,29(p=, 012)$ \\
\hline 31. & Esperar para entrar a las diferentes horas de visita & $-0,17(p=, 170)$ \\
\hline 32. & No poder estar junto al enfermo todo el tiempo (restringida la permanencia en la unidad) & $-0,21(p=, 084)$ \\
\hline 33. & Tener que desplazarse a diario para visitar al enfermo en las 4 horas de visita & $0,00(p=, 968)$ \\
\hline 34. & Los horarios en que están concertadas las visitas al enfermo en la unidad & $0,00(p=, 964)$ \\
\hline 35. & Que el enfermo permanezca solo durante todo el día junto a otros pacientes graves & $-0,23(p=, 064)$ \\
\hline 36. & Que el paciente no descanse adecuadamente por el ruido & $-0,20(p=, 110)$ \\
\hline 37. & Que el paciente manifieste temor & $-0,25(p=, 059)$ \\
\hline 38. & Que el paciente tenga que permanecer aislado por prescripción médica & $-0,19(p=, 180)$ \\
\hline 39. & Pensar que el tiempo de información para los familiares resulta insuficiente & $-0,16(p=, 189)$ \\
\hline 40. & Nivel de estrés en general & $-0,14(p=, 261)$ \\
\hline
\end{tabular}

Los resultados del análisis de correlaciones de Pearson entre la edad y la adaptación de los familiares al ingreso de UCI no muestra relaciones significativas ni a nivel global ni en ninguna de las áreas analizadas (véase Tabla 95). 
Tabla 95. Correlaciones de Pearson entre la edad y la adaptación de la familia al ingreso en UCI

\begin{tabular}{lc} 
Niveles de interferencia & \multicolumn{1}{c}{ Edad } \\
\hline 1. Trabajo & $-0,21(p=, 063)$ \\
2. Vida social & $-0,00(p=, 971)$ \\
3. Tiempo libre & $-0,17(p=, 142)$ \\
4. Relación de pareja & $-0,04(p=, 717)$ \\
5. Vida familiar & $-0,03(p=, 779)$ \\
6. Escala global & $0,11(p=, 337)$
\end{tabular}

En cuanto a las necesidades de los familiares en UCI (véase Tabla 96) se ha obtenido una relación estadísticamente significativa y de signo negativo entre la edad y la valoración de "si los pacientes reciben los mejores cuidados médicos" ( $\mathrm{r}=-0,25$; $\mathrm{p}=, 043) \mathrm{y}$ "los miembros del equipo son atentos con el familiar" ( $\mathrm{r}=-0,24 ; \mathrm{p}=, 043)$. Igualmente, los resultados muestran relaciones casi significativas y de signo negativo respecto a la percepción de que "el personal del hospital se preocupa por el paciente" $(\mathrm{r}=-0,24 ; \mathrm{p}=, 052)$, de modo que a medida que aumenta la edad, menores serán las puntuaciones obtenidas en estos ítems, es decir, más satisfechas verán estas necesidades los familiares.

Tabla 96. Correlaciones de Pearson entre la edad y las necesidades de los familiares en UCI

\begin{tabular}{|c|c|}
\hline Ítem & Edad \\
\hline $\begin{array}{l}\text { 1. ¿Usted siente que se le están dando los mejores cuidados posibles al } \\
\text { paciente? }\end{array}$ & $-0,25(p=, 043)$ \\
\hline 2. ¿Usted siente que el personal del hospital se preocupa por el paciente? & $-0,24(p=, 052)$ \\
\hline $\begin{array}{l}\text { 3. ¿Le dan explicaciones sobre el estado del paciente en términos que } \\
\text { pueda comprender? }\end{array}$ & $-0,11(p=, 378)$ \\
\hline $\begin{array}{l}\text { 4. ¿Usted siente que le están dando información sincera sobre el estado y } \\
\text { progreso del paciente? }\end{array}$ & $-0,19(p=, 120)$ \\
\hline $\begin{array}{l}\text { 5. ¿Usted comprende lo que le sucede al paciente y el motivo de las } \\
\text { pruebas? }\end{array}$ & $-0,05(p=, 664)$ \\
\hline 6. ¿Están siendo atentos los miembros del equipo con usted? & $-0,24(p=, 043)$ \\
\hline 7. ¿Muestra algún miembro del equipo interés por cómo está usted? & $-0,09(p=, 455)$ \\
\hline $\begin{array}{l}\text { 8. ¿Le ha explicado el personal del hospital el equipamiento que está } \\
\text { utilizándose? }\end{array}$ & $0,02(p=, 885)$ \\
\hline $\begin{array}{l}\text { 9. Estoy muy satisfecho con las atenciones médicas recibidas por el } \\
\text { paciente }\end{array}$ & $-0,17(p=, 157)$ \\
\hline 10. ¿Usted se siente solo y aislado en la sala de espera? & $-0,03(p=, 784)$ \\
\hline $\begin{array}{l}\text { 11. ¿Hay algunas cosas respecto a los cuidados médicos recibidos por el } \\
\text { paciente que podrían ser mejoradas? }\end{array}$ & $-0,02(p=, 851)$ \\
\hline
\end{tabular}


Los resultados relativos a los factores que podrían ayudar en el proceso de morir (véase Tabla 97) no muestran relaciones significativas a nivel estadístico entre las puntuaciones obtenidas en los distintos factores que incluye el CAMP y la edad de los familiares, si bien en uno de los factores, "controlar hasta el final los pensamientos y las funciones fisiológicas", la relación con la edad es casi significativa $(r=-023 ; p=, 074)$ y de signo negativo, de manera que a más edad menor importancia se le concedería a este factor al final de la vida. Igualmente, los análisis correlacionales muestran que la importancia que se le concede llegado el momento de la muerte a "poder estar cerca de las personas queridas" ( $r=-0,00 ; p=, 993)$ y "pensar que pueda morir en casa" $(r=0,01$; $\mathrm{p}=$,932) prácticamente no parece mantener relación lineal con la edad.

Tabla 97. Correlaciones de Pearson entre la edad y los factores del CAMP (familiares)

1. Controlar mi dolor y otros síntomas de malestar

2. Mi proceso de morir, si produce sufrimiento, será corto

4. Mi muerte no supondrá una carga insoportable para mis seres queridos

5. Poder sentirme cerca, comunicarme y estrechar vínculos afectivos con mis personas queridas

6. Sin esperanza real de recuperación, no se alargará artificialmente mi vida en UCI

7. Pensar que mi vida ha tenido algún sentido

8. Creer en otra vida después de la muerte $-0,04(p=, 759)$

9. No sentirse culpable por conflictos personales del pasado

10. Si la situación se me hace insoportable disponer de ayuda para morir con rapidez

Finalmente, para completar los análisis de correlación realizados con la edad haremos referencia a los resultados de la valoración del proceso de información y la toma de decisiones. En este sentido, podemos observar en la Tabla 98 que no se han obtenido relaciones significativas con la edad en ninguna de las subescalas del cuestionario. 
Tabla 98. Correlaciones de Pearson entre la edad y la Valoración del proceso de información y toma de decisiones (familiares)

Importancia de los distintos agentes implicados

Papel de la familia en la información y toma de decisiones

$-0,20(p=, 273)$

Papel del paciente en la información y toma de decisiones

$-0,21(p=, 232)$

Papel del médico en la información y toma de decisiones

$-0,02(p=, 917)$

Papel del psicólogo en la información y toma de decisiones

$-0,06(p=, 738)$

Satisfacción con la información

Satisfacción con la cantidad y la claridad de la información recibida

$0,14(p=, 415)$

Estilo del médico

En cuanto al estilo del médico prefiero que éste sea directo y anticipe posibles sospechas

$-0,22(p=, 202)$

En cuanto al estilo del médico prefiero que éste se guarde lo que aún no es seguro

Participación en TD

Me siento capacitado para participar en la TD sobre la salud

$-0,19(p=, 273)$

Poder participar en una decisión médica sería más una carga que un privilegio

$0,24(p=, 171)$

$-0,04(p=, 843)$

\subsubsection{Relación entre las variables evaluadas y el nivel de estudios de los familiares}

Otra variable sociodemográfica en función de la cual se ha analizado la relación con las distintas variables evaluadas en la investigación ha sido el nivel de estudios. Así, se han realizado correlaciones de Spearman entre el nivel de estudios de los familiares y la ansiedad, la depresión, la percepción subjetiva de estado de ánimo, la valoración de la estancia en UCI, los factores estresantes, la adaptación de la familia al ingreso, las necesidades de los familiares, el proceso de morir y la valoración del proceso de información y la toma de decisiones.

Respecto a los síntomas de ansiedad y depresión (véase Tabla 99) se han obtenido relaciones significativas a nivel estadístico. Por un lado, los resultados muestran una correlación negativa entre el nivel de estudios y la ansiedad siendo ésta casi significativa a partir de la evaluación realizada mediante el HADS ( $r=-0,21 ; p=, 053)$ y significativa mediante el STAI-Estado $(\mathrm{r}=-0,45 ; \mathrm{p}=, 009)$. Por otro lado, y en cuanto a la depresión se observa una correlación significativa y también de signo negativo entre el nivel de estudios y los resultados obtenidos mediante el HADS $(r=-0,38 ; p=, 000)$ y el BDI $(r=-0,49 ; p=, 004)$. Estos datos indicarían que a medida que aumenta el nivel de estudios parecen disminuir los síntomas de ansiedad y depresión. 
Asimismo, si atendemos a la percepción subjetiva del malestar (véase Tabla 99), no se observan relaciones significativas entre el nivel de estudios y las subescalas de malestar general $(r=-0,04 ; p=, 699)$ y ansiedad $(r=-0,12 ; p=, 268)$. En cambio, los resultados muestran una relación significativa a nivel estadístico entre el nivel de estudios y la percepción subjetiva de estado de ánimo deprimido $(\mathrm{r}=-0,30 ; \mathrm{p}=, 007)$, de manera que a mayor nivel de estudios parece ser menor la percepción subjetiva de depresión.

Tabla 99. Correlaciones de Spearman entre el nivel de estudios y los síntomas de ansiedad-depresión y percepción de estado de ánimo (familiares)

\begin{tabular}{|c|c|}
\hline Cuestionarios & Nivel estudios \\
\hline Total HADS- Ansiedad & $-0,21(p=, 053)$ \\
\hline Total HADS- Depresión & $-0,38(p=, 000)$ \\
\hline STAI- Estado & $-0,45(p=, 009)$ \\
\hline STAI- Rasgo & $-0,21(p=, 237)$ \\
\hline BDI & $-0,49(p=, 004)$ \\
\hline EA1-Malestar general & $-0,04(p=, 699)$ \\
\hline EA2-Ansiedad y Nerviosismo & $-0,12(p=, 268)$ \\
\hline EA3-Estado de ánimo deprimido & $-0,30(p=, 007)$ \\
\hline
\end{tabular}

En cuanto a la valoración de la estancia en UCI (véase Tabla 100), a nivel global, es decir, sin considerar la situación medica del paciente no se ha obtenido una relación significativa con el nivel de estudios. Es más a la luz de los resultados parece prácticamente no existir relación lineal alguna entre ambos $(\mathrm{r}=-0,01 ; \mathrm{p}=, 910)$. Atendiendo a los distintos ítems que incluye el cuestionario, si bien no se han obtenido correlaciones significativas, observamos que el nivel de estudios correlaciona casi significativamente con la valoración de la claridad de la información recibida $(\mathrm{r}=-0,22$; $\mathrm{p}=, 062)$ y la valoración de la atención a los familiares $(\mathrm{r}=-0,22 ; \mathrm{p}=, 073)$, siendo en ambos casos la relación negativa. Es decir, parece que a medida que aumenta el nivel de estudios, disminuye la valoración positiva de estos dos aspectos. 
Tabla 100. Correlaciones de Spearman entre el nivel de estudios y la Valoración de la estancia en UCI (familiares)

\begin{tabular}{|c|c|}
\hline Ítem & Nivel estudios \\
\hline $\begin{array}{l}\text { - En qué grado está siendo agradable/desagradable su estancia } \\
\text { en UCI sin considerar los problemas médicos }\end{array}$ & $-0,02(p=, 890)$ \\
\hline \multicolumn{2}{|l|}{ Valoración de los siguientes aspectos } \\
\hline 1. Cuidados médicos & $-0,08(p=, 531)$ \\
\hline 2. Atención de los médicos & $-0,08(p=, 488)$ \\
\hline 3. Atención de las/os enfermeras/os & $-0,14(p=, 237)$ \\
\hline 4. Atención de las/os auxiliares de enfermería & $-0,15(p=, 226)$ \\
\hline 5. Claridad de la información recibida & $-0,22(p=, 062)$ \\
\hline 6. Cantidad de la información recibida & $-0,11(p=, 353)$ \\
\hline 7. Trato por parte del personal de enfermería & $-0,17(p=, 156)$ \\
\hline 8. Afecto/apoyo emocional del personal de enfermería & $-0,13(p=, 299)$ \\
\hline 9. Respeto a la intimidad & $0,09(p=, 473)$ \\
\hline 10. Atención a los familiares & $-0,22(p=, 073)$ \\
\hline 11. Atención de necesidades psicológicas en paciente y familia & $0,02(p=, 884)$ \\
\hline 12. Calidad de las instalaciones (comodidad, higiene...) & $0,07(p=, 579)$ \\
\hline 13. Posibilidades de distraerse & $0,04(p=, 759)$ \\
\hline 14. Silencio o tranquilidad en la sala & $-0,13(p=, 299)$ \\
\hline 15. Régimen de visitas & $-0,03(p=, 830)$ \\
\hline
\end{tabular}

Respecto a los factores estresantes asociados a UCI (véase Tabla 101) no se han obtenido relaciones significativas entre el nivel de estudios de los familiares y el nivel de estrés general $(\mathrm{r}=-0,05 ; \mathrm{p}=, 699)$. En cambio, al analizar las correlaciones de Spearman con el resto de ítems que incluye la escala observamos una relación significativa y de signo negativo entre el nivel de estudios y el grado de estrés que genera "pensar que le pueda ocurrir algo grave al paciente" $(r=-0,25 ; p=, 044)$. Asimismo, los resultados muestran una relación próxima a la significación estadística, de signo negativo entre el nivel de estudios y el estrés asociado a que "el paciente tenga que estar aislado por prescripción médica" $(r=-0,24 ; p=, 096)$. Estos datos indicarían que a medida que aumenta el nivel de estudios de los familiares parece que estos factores generen menor grado de estrés. Analizando el resto de ítems incluidos en la escala podemos decir que prácticamente no parece existir relación lineal entre el nivel de estudios y el estrés que generan los siguientes factores: "que el personal sanitario no conteste a sus preguntas" ( $\mathrm{r}=-0,01 ; \mathrm{p}=, 934)$ y "no poder llamar al paciente por teléfono" $(\mathrm{r}=-0,00 ; \mathrm{p}=, 977)$. 
Tabla 101. Correlaciones de Spearman entre el nivel de estudios y los Factores estresantes en UCI (familiares)

1. Que el enfermo pueda tener dolor

$-0,06(p=, 652)$

2. No saber con seguridad o no entender en qué consiste la enfermedad

$0,21(p=, 112)$

3. Pensar que le puede ocurrir algo grave

4. Pensar si podrá volver a su vida normal después de salir del hospital

$-0,25(p=, 044)$

5. No poder ocuparse usted de la familia como hasta ahora venía haciendo

$-0,04(p=, 767)$

$-0,05(p=, 687)$

6. No saber con seguridad cómo quedará después de la operación

$-0,14(p=, 286)$

7. Estar separado del enfermo

8. No saber cuándo le darán el alta de la unidad de cuidados intensivos

$-0,03(p=, 777)$

$-0,05(p=, 699)$

9. Haber sido hospitalizado de repente, sin esperarlo

$0,06(p=, 651)$

10. No saber los resultados/razones de los tratamientos/pruebas que le hacen

$0,20(p=, 115)$

11. Tener que organizarse para poder acudir a las visitas

$-0,02(p=, 897)$

12. Pensar que puede tener dolor a causa de la operación/análisis

$-0,17(p=, 188)$

13. No saber cuándo van a hacerle cosas al enfermo

$0,08(p=, 544)$

14. Pensar que el paciente pueda no obtener alivio para el dolor aún tomando medicación

$-0,17(p=, 229)$

15. Ver que el personal del hospital tiene prisa

$0,11(p=, 375)$

16. El hospital en que está ingresado el paciente se encuentra lejos de casa

$-0,13(p=, 315)$

17. Que sanitarios hablen deprisa o usen palabras que no pueden entender

$-0,15(p=, 281)$

18. Que el personal sanitario no conteste a sus preguntas

$-0,01(p=, 934)$

19. Tener que dormir fuera del domicilio habitual

$-0,03(p=, 817)$

20. Preocupación por que no le den la medicación para el dolor cuando la necesita

$0,05(p=, 697)$

21. Pensar en la posible pérdida de dinero a causa de la enfermedad

$0,07(p=, 577)$

22. Sentir olores extraños en el hospital

$0,04(p=, 763)$

23. Tener que comer a horas diferentes a las habituales para poder ir a las visitas

$-0,03(p=, 783)$

24. No poder llamar al paciente por teléfono

$-0,00(p=, 977)$

25. Que el enfermo esté al cuidado de sanitarios desconocidos

$-0,08(p=, 506)$

26. Tener demasiados horarios de visita

$0,10(p=, 414)$

27. Tener que ver en la sala durante las visitas a otros enfermos muy graves

$0,02(p=, 894)$

28. Miedo a que el paciente pueda morir

$-0,17(p=, 156)$

29. Que el paciente sea atendido por diferentes médicos durante su ingreso

$0,02(p=, 889)$

30. Que los familiares sean informados por diferentes médicos

$0,04(p=, 713)$

31. Esperar para entrar a las diferentes horas de visita

$-0,04(p=, 740)$

32. No poder estar junto al enfermo todo el tiempo (restringida la permanencia en la unidad)

$-0,08(p=, 505)$

33. Tener que desplazarse a diario para visitar al enfermo en las 4 horas de visita

$-0,14(p=, 275)$

34. Los horarios en que están concertadas las visitas al enfermo en la unidad

$-0,09(p=, 467)$

35. Que el enfermo permanezca solo durante todo el día junto a otros pacientes graves

$0,04(p=, 733)$

36. Que el paciente no descanse adecuadamente por el ruido

$-0,09(p=, 475)$

37. Que el paciente manifieste temor

$-0,10(p=, 463)$

38. Que el paciente tenga que permanecer aislado por prescripción médica

$-0,24(p=, 096)$

39. Pensar que el tiempo de información para los familiares resulta insuficiente

$0,07(p=, 573)$

40. Nivel de estrés en general

$-0,05(p=, 674)$

El resultado de las correlaciones de Spearman entre la adaptación de la familia al ingreso en UCI y su nivel de estudios (véase Tabla 102) no muestra relaciones significativas en ninguna de las esferas analizadas. 
Tabla 102. Correlaciones de Spearman entre el nivel de estudios y la adaptación de la familia al ingreso en $\mathrm{UCI}$

\begin{tabular}{|ll|}
\hline Niveles de interferencia & Nivel estudios \\
\hline 1. Trabajo & $0,10(p=, 390)$ \\
\hline 2. Vida social & $0,17(p=, 144)$ \\
\hline 3. Tiempo libre & $0,09(p=, 448)$ \\
4. Relación de pareja & $0,03(p=, 820)$ \\
\hline 5. Vida familiar & $0,20(p=, 090)$ \\
6. Escala global & $0,04(p=, 734)$
\end{tabular}

En relación con las necesidades de los familiares de UCI, no se han obtenido tampoco relaciones significativas entre el nivel de estudios y ninguno de los ítems que incluye el cuestionario (véase Tabla 103).

Tabla 103. Correlaciones de Spearman entre el nivel de estudios y las necesidades de los familiares de UCI

\begin{tabular}{|c|c|}
\hline Ítem & Nivel estudios \\
\hline 1. ¿Usted siente que se le están dando los mejores cuidados posibles al paciente? & $0,11(p=, 381)$ \\
\hline 2. ¿Usted siente que el personal del hospital se preocupa por el paciente? & $0,06(p=, 628)$ \\
\hline $\begin{array}{l}\text { 3. ¿Le dan explicaciones sobre el estado del paciente en términos que pueda } \\
\text { comprender? }\end{array}$ & $0,09(p=, 446)$ \\
\hline $\begin{array}{l}\text { 4. ¿Usted siente que le están dando información sincera sobre el estado y progreso } \\
\text { del paciente? }\end{array}$ & $0,05(p=, 688)$ \\
\hline 5. ¿Usted comprende lo que le sucede al paciente y el motivo de las pruebas? & $-0,06(p=, 620)$ \\
\hline 6. ¿Están siendo atentos los miembros del equipo con usted? & $0,07(p=, 589)$ \\
\hline 7. ¿Muestra algún miembro del equipo interés por cómo está usted? & $0,08(p=, 505)$ \\
\hline 8. ¿Le ha explicado el personal del hospital el equipamiento que está utilizándose? & $-0,13(p=, 301)$ \\
\hline 9. Estoy muy satisfecho con las atenciones médicas recibidas por el paciente & $0,03(p=, 818)$ \\
\hline 10. ¿Usted se siente solo y aislado en la sala de espera? & $-0,06(p=, 617)$ \\
\hline $\begin{array}{l}\text { 11. ¿Hay algunas cosas respecto a los cuidados médicos recibidos por el paciente que } \\
\text { podrían ser mejoradas? }\end{array}$ & $-0,03(p=, 828)$ \\
\hline
\end{tabular}

En cuanto a la valoración de los distintos factores del CAMP que podrían facilitar el proceso de morir (véase Tabla 104) los resultados muestran una relación estadísticamente casi significativa y de signo positivo entre el nivel de estudios y la importancia que se le concede a "creer en otra vida después de la muerte" $(r=0,25$; $\mathrm{p}=, 051)$, lo cual parece indicar que a medida que aumenta el nivel de estudios, más importancia se le da a este factor al final de la vida. Respecto al resto de ítems incluidos en el cuestionario no se han obtenido relaciones significativas con el nivel de estudios. 
Y además respecto a "pensar que pueda morir en mi casa" prácticamente no parece haber relación lineal con el nivel de estudios $(\mathrm{r}=0,01 ; \mathrm{p}=, 922)$.

Tabla 104. Correlaciones de Spearman entre el nivel de estudios y los factores del CAMP (familiares)

\begin{tabular}{|c|c|}
\hline Ítem & Nivel estudios \\
\hline 1. Controlar mi dolor y otros síntomas de malestar & $0,08(p=, 550)$ \\
\hline 2. Mi proceso de morir, si produce sufrimiento, será corto & $-0,04(p=, 776)$ \\
\hline 3.Controlar hasta el final pensamientos y funciones fisiológicas & $0,17(p=, 187)$ \\
\hline 4. Mi muerte no supondrá una carga insoportable para mis seres queridos & $0,12(p=, 365)$ \\
\hline $\begin{array}{l}\text { 5. Poder sentirme cerca, comunicarme y estrechar vínculos afectivos con mis } \\
\text { personas queridas }\end{array}$ & $-0,08(p=, 536)$ \\
\hline 6. Sin esperanza real de recuperación, no se alargará artificialmente mi vida en UCI & $0,10(p=, 435)$ \\
\hline 7. Pensar que mi vida ha tenido algún sentido & $-0,04(p=, 736)$ \\
\hline 8. Creer en otra vida después de la muerte & $0,25(p=, 051)$ \\
\hline 9. No sentirse culpable por conflictos personales del pasado & $0,21(p=, 106)$ \\
\hline 10. Si la situación se me hace insoportable disponer de ayuda para morir con rapidez & $0,12(p=, 357)$ \\
\hline 11. Poder morir en mi casa & $0,01(p=, 922)$ \\
\hline
\end{tabular}

Por último, los resultados de la valoración del proceso de información y la toma de decisiones, tal como podemos observar en la Tabla 105 no muestran relaciones significativas entre el nivel de estudios y las siguientes subescalas: importancia de los distintos agentes implicados en el proceso, es decir, la familia $(r=-0,04 ; p=, 832)$, el paciente $(\mathrm{r}=0,06 ; \mathrm{p}=, 728)$, el médico $(\mathrm{r}=-0,10 ; \mathrm{p}=$,567) y el psicólogo $(\mathrm{r}=0,19 ; \mathrm{p}=, 292)$; la satisfacción de la información $(\mathrm{r}=0,10 ; \mathrm{p}=, 103)$ y el estilo del médico a la hora de informar, tanto el estilo más directo $(\mathrm{r}=0,24 ; \mathrm{p}=, 165)$ como el que se guarda lo que aún no es seguro $(r=0,05 ; p=, 775)$. En cambio, podemos ver que se ha obtenido una relación significativa a nivel estadístico y de signo negativo en la subescala relativa a la participación en la toma de decisiones, concretamente entre el nivel de estudios y la percepción de capacidad para participar en una decisión médica $(r=-0,43 ; p=, 011)$, de modo que a mayor nivel de estudios, parece que los familiares se perciben menos capaces para participar en decisiones médicas relevantes.

Tabla 105. Correlaciones de Spearman entre el nivel de estudios y la Valoración del proceso de información y toma de decisiones (familiares)

Importancia de los distintos agentes implicados

Papel de la familia en la información y toma de decisiones

$-0,04(p=, 832)$

Papel del paciente en la información y toma de decisiones

$0,06(p=, 728)$

Papel del médico en la información y toma de decisiones

$-0,10(p=, 567)$

Papel del psicólogo en la información y toma de decisiones

$0,19(p=, 292)$

(Sigue detrás) 
Satisfacción con la información

Satisfacción con la cantidad y la claridad de la información recibida $0,10(p=, 103)$

Estilo del médico

En cuanto al estilo del médico prefiero que éste sea directo y anticipe posibles sospechas

$0,24(p=, 165)$

En cuanto al estilo del médico prefiero que éste se guarde lo que aún no es seguro

Participación en TD

Me siento capacitado para participar en la TD sobre la salud

$0,05(p=, 775)$

Poder participar en una decisión médica sería más una carga que un privilegio

$-0,43(p=, 011)$

$0,29(p=, 106)$

\subsubsection{ANÁLISIS DE REGRESIÓN EN LA MUESTRA DE FAMILIARES}

Para completar el estudio de la muestra de familiares se han llevado a cabo análisis de regresión con la finalidad de conocer qué variables independientes podrían predecir determinadas variables dependientes consideradas en la investigación.

De las distintas variables dependientes analizadas en el grupo de familiares, hemos seleccionado por un lado variables relativas a la afectación psicológica en términos de ansiedad y depresión, y por otro lado hemos intentado elegir aquellas variables que de alguna manera pudieran proporcionar información más específica del entorno de una UCI, considerándose en este sentido la inclusión de la valoración global de la estancia en UCI y el nivel de estrés general experimentado por los familiares en este contexto. En relación con las puntuaciones de ansiedad y depresión cabe señalar que, para simplificar los resultados y teniendo cuenta las correlaciones existentes entre las distintas medidas utilizadas, se seleccionaron las puntuaciones en ansiedad y depresión derivadas del HADS.

En cuanto a las variables independientes a incluir en el análisis se han seleccionado las distintas variables sociodemográficas, es decir, la edad, el género, el estado civil, el número de hijos, el nivel de estudios, el grado de parentesco con el paciente y el lugar de residencia. Asimismo, en el caso de la valoración de la estancia y el estrés general, además de las citadas variables independientes, se han incluido las puntuaciones en ansiedad y depresión, ya que podrían aportar información relevante a nivel clínico. 
Tras seleccionar las variables dependientes e independientes se han realizado dos tipos de análisis. Un primer análisis para analizar la capacidad predictiva de cada variable por separado y otro análisis incluyendo las distintas variables por el método de pasos sucesivos (stepwise).

Respecto a la valoración global de la estancia en UCI, sin tener en cuenta la situación médica del paciente, a nivel teórico podríamos pensar que las distintas variables sociodemográficas así como la ansiedad y la depresión serían importantes para explicar la valoración de la estancia en la unidad desde el punto de vista de la familia. No obstante, el análisis de regresión realizado muestra que estas variables, analizadas tanto de forma individual como de forma conjunta, no predicen a ningún nivel la valoración de la estancia en UCI.

En relación con el nivel de estrés general de los familiares de UCI, al considerar cada una de las variables independientes por separado, observamos que ninguna de las variables sociodemográficas explicaría el estrés de los familiares, mientras que tanto la ansiedad $(\beta=0,29 ; \mathrm{p}=, 013)$ como la depresión $(\beta=0,24 ; \mathrm{p}=, 036)$ por sí solas, predicen el estrés general, explicando el $7 \%$ y 4,6\% de la varianza respectivamente, de manera que a mayor sintomatología ansiosa y depresiva mayor sería el grado de estrés (véase Tabla 106). Por su parte, los resultados del análisis de regresión en el que se han incluido todas las variables independientes (es decir, variables sociodemográficas, ansiedad y depresión), muestran que la ansiedad $(\beta=0,35 ; p=, 024)$ predice el estrés general de los familiares, explicando el 10,1\% de la varianza.

Atendiendo al análisis de regresión relativo a la ansiedad, al considerar cada una de las variables independientes por separado hemos obtenido que la variable ansiedad podría ser predicha por las siguientes variables: el lugar de residencia $(\beta=0,24 ; p=, 043)$ con una varianza explicada del 4,5\%; el estado civil $(\beta=0,27 ; p=, 012)$ que explica el 6,3\% de la varianza; y el nivel de estudios $(\beta=-0,27 ; p=, 015)$ con una varianza explicada del $6 \%$ (véase Tabla 106). De esta manera, residir más lejos, tener pareja y un menor nivel de estudios podría predecir los síntomas de ansiedad. De forma conjunta las variables sociodemográficas no predicen la sintomatología ansiosa.

Finalmente, al analizar la depresión con cada una de las variables independientes por separado hemos obtenido que podría ser predicha por las siguientes variables independientes: el nivel de estudios $(\beta=-0,38 ; p=, 000)$ explicando el $13,3 \%$ de la varianza; la edad $(\beta=0,34 ; p=, 001)$ que explicaría el $10,7 \%$ de la varianza; el género 
$(\beta=0,31 ; p=, 003)$ explica el 8,6\% de la varianza; $y$ el número de hijos $(\beta=0,32 ; p=, 010)$ que explicaría el 8,7\% de la varianza (véase Tabla 106). De este modo, un menor nivel de estudios, mayor edad, ser mujer y tener hijos podría predecir los síntomas de depresión. Por otro lado, al considerar todas las variables sociodemográficas de forma conjunta, los resultados del análisis de regresión muestran que el nivel de estudios ( $\beta=-$ 0,36; $\mathrm{p}=, 008)$ predice los síntomas de depresión, explicando el 11,2\% de la varianza. Así, un menor nivel de estudios predeciría mayor depresión.

Tabla 106. Análisis de regresión en familiares consideradas las variables individualmente

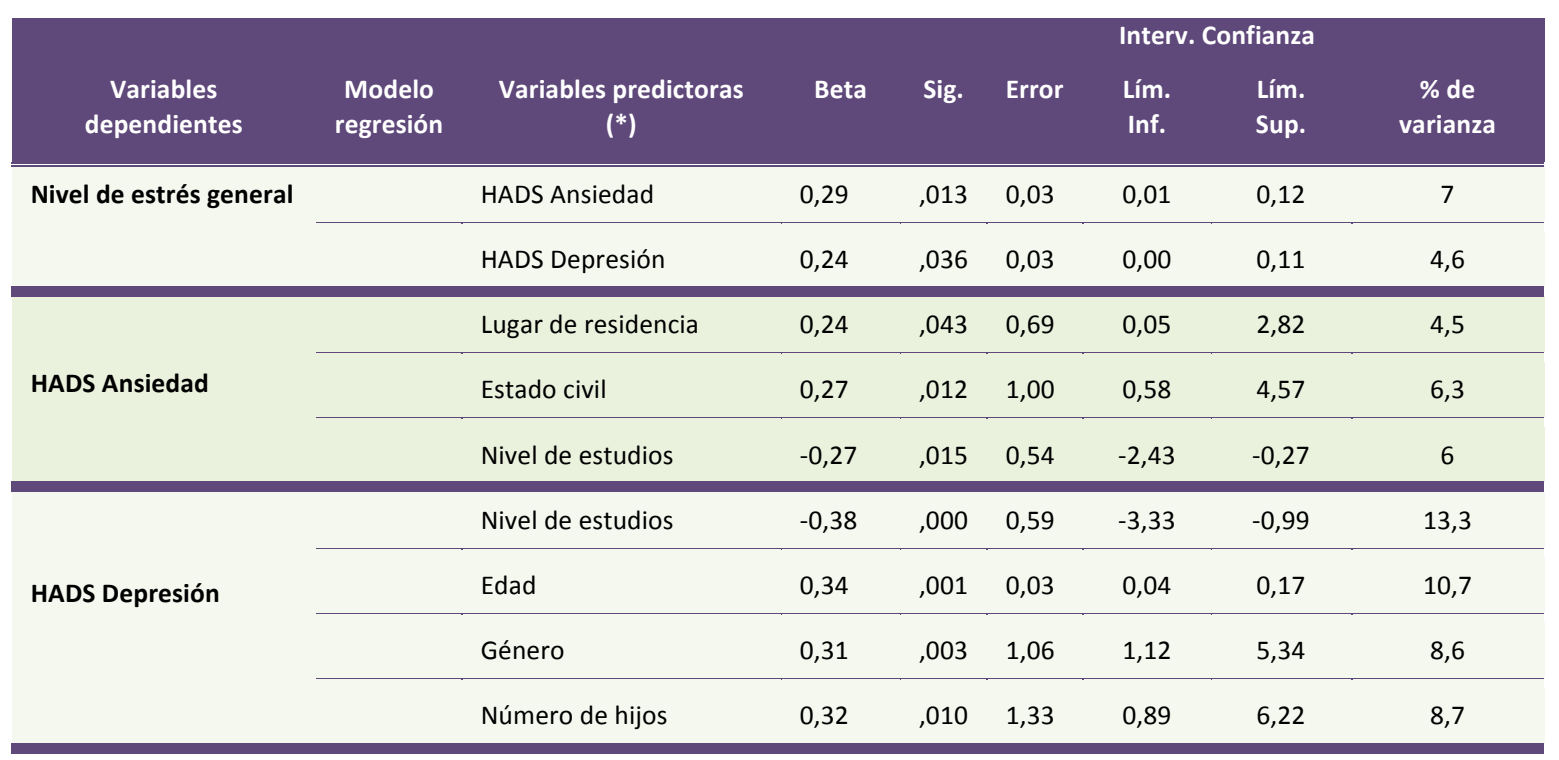

$\left.{ }^{*}\right)$ Codificación de las distintas variables independientes

\begin{tabular}{|l|lll|l|}
\hline V. Independiente & \multicolumn{1}{|c|}{ Género } & Estado civil & Número de hijos & Lugar de residencia \\
\hline 1. Hombre & 1. Sin pareja & 0. Sin hijos & 1. Castellón ciudad \\
\hline 2. Mujer & 2. Con pareja & 1. Con hijos & 2. Castellón provincia \\
\hline
\end{tabular}

\subsection{ANÁLISIS DIFERENCIALES ENTRE PACIENTES Y FAMILIARES}

En el último apartado de este capítulo, una vez analizados los resultados de la muestra de pacientes y familiares, presentaremos los resultados correspondientes al análisis diferencial llevado a cabo entre las dos muestras en aquellas variables comunes a ambos grupos. 
En este sentido, se ha realizado la prueba $\mathrm{t}$ de Student para conocer las diferencias entre pacientes y familiares en las siguientes variables: ansiedad, depresión, percepción subjetiva de estado de ánimo, nivel de estrés general, valoración de la estancia en UCI, factores que ayudarían en el proceso de morir y valoración del proceso de información y toma de decisiones.

Los resultados relativos a los síntomas de ansiedad muestran diferencias significativas a nivel estadístico tanto en las puntuaciones derivadas del HADS ( $t=-$ 8,13; $\mathrm{p}=, 000)$ como en las puntuaciones obtenidas mediante el STAI, es decir, en ansiedad estado $(\mathrm{t}=-7,51 ; \mathrm{p}=, 000)$ y ansiedad rasgo $(\mathrm{t}=-4,21 ; \mathrm{p}=, 000)$. Respecto a los síntomas de depresión se han obtenido diferencias estadísticamente significativas mediante el HADS ( $t=-5,12 ; p=, 000)$ y casi significativas en las puntuaciones medidas a través del cuestionario $\operatorname{BDI}(t=-1,86 ; p=, 066)$. Cabe señalar que las diferencias encontradas en ansiedad y depresión entre ambos grupos muestran puntuaciones medias mayores en los familiares (véase Tabla 107).

Respecto a la percepción subjetiva de estado de ánimo (véase Tabla 107) se han encontrado diferencias significativas en las tres subescalas analizadas. En este sentido, las puntuaciones medias en malestar general $(t=-4,59 ; p=, 000)$, percepción de ansiedad $(\mathrm{t}=-9,85 ; \mathrm{p}=, 000)$ y estado de ánimo deprimido $(\mathrm{t}=-8,93 ; \mathrm{p}=, 000)$ han sido significativamente superiores en el grupo de familiares.

En cuanto a la evaluación de los factores estresantes en UCI cabe señalar que los ítems utilizados en pacientes y familiares son diferentes. Por ello sólo hemos podido realizar el análisis diferencial entre ambos grupos en relación con el nivel de estrés general experimentado en $\mathrm{UCI}$, cuyos resultados muestran diferencias estadísticamente significativas a favor de los familiares $(\mathrm{t}=-6,67 ; \mathrm{p}=, 000)$ (véase Tabla 107).

Tabla 107. Puntuaciones medias en ansiedad, depresión, percepción subjetiva de estado de ánimo y estrés en pacientes y familiares

\begin{tabular}{|c|c|c|c|c|c|c|}
\hline & \multicolumn{2}{|c|}{ PACIENTES } & \multicolumn{2}{|c|}{ FAMILIARES } & \multirow{2}{*}{\multicolumn{2}{|c|}{ Sig. $p \leq, 050$}} \\
\hline Cuestionario & $\bar{X}$ & DT & $\bar{X}$ & DT & & \\
\hline Total HADS- Ansiedad & 7,09 & 5,29 & 13,24 & 4,26 & $-8,13$ & ,000 \\
\hline Total HADS- Depresión & 7,22 & 5,87 & 11,48 & 4,65 & $-5,12$ & ,000 \\
\hline STAI-Estado & 17,08 & 11,37 & 36,36 & 12,66 & $-7,51$ & ,000 \\
\hline STAI-Rasgo & 13,77 & 9,97 & 22,92 & 10,31 & $-4,21$ & ,000 \\
\hline BDI & 12,94 & 9,68 & 16,60 & 8,54 & $-1,86$ & ,066 \\
\hline
\end{tabular}

(Sigue detrás) 


\begin{tabular}{|c|c|c|c|c|c|c|}
\hline \multirow[b]{2}{*}{ Cuestionario } & \multicolumn{2}{|c|}{ PACIENTES } & \multicolumn{2}{|c|}{ FAMILIARES } & \multirow[b]{2}{*}{$\mathbf{t}$} & \multirow[b]{2}{*}{ Sig. $p \leq, 050$} \\
\hline & $\bar{X}$ & DT & $\bar{X}$ & DT & & \\
\hline EA1-Malestar general & 4,37 & 2,98 & 6,41 & 2,57 & $-4,59$ & ,000 \\
\hline EA2-Ansiedad y Nerviosismo & 2,89 & 3,04 & 7,07 & 2,25 & $-9,85$ & ,000 \\
\hline EA3-Estado de ánimo deprimido & 2,26 & 2,92 & 6,43 & 2,86 & $-8,93$ & 000 \\
\hline Factores estresantes- Estrés general & 1,72 & 1,24 & 3,03 & 1,03 & $-6,67$ & ,000 \\
\hline
\end{tabular}

El análisis de la valoración de la estancia en UCI (véase Tabla 108) muestra diferencias significativas a nivel estadístico entre los pacientes y familiares tanto a nivel global, sin considerar la situación médica del paciente $(t=2,83 ; p=, 005)$ como en la valoración de aspectos más concretos. En este sentido se han obtenido diferencias significativas en la valoración de la atención $(t=2,37 ; p=, 019)$, el trato $(t=2,45 ; p=, 016)$ y apoyo emocional $(t=2,68 ; p=, 008)$ recibido del personal de enfermería, así como en la valoración de la atención a los familiares $(t=2,40 ; p=, 018)$, la calidad de las instalaciones $(t=2,43 ; p=, 016)$ y el silencio en la sala $(t=-2,53 ; p=, 013)$. Estas diferencias muestran puntuaciones mayores por parte de los pacientes en todas las valoraciones citadas a excepción de la última, es decir, la valoración del silencio en la sala, que ha sido mejor valorado por los familiares.

Tabla 108. Puntuaciones medias de la Valoración de la estancia en UCI en pacientes y familiares

\begin{tabular}{|c|c|c|c|c|c|c|}
\hline & \multicolumn{2}{|c|}{ PACIENTES } & \multicolumn{2}{|c|}{ FAMILIARES } & \multirow[b]{2}{*}{$\mathrm{t}$} & \multirow[b]{2}{*}{ Sig. $p \leq, 050$} \\
\hline Ítem & $\overline{\mathbf{X}}$ & DT & $\overline{\mathbf{X}}$ & DT & & \\
\hline $\begin{array}{l}\text {-En qué grado está siendo agradable/desagradable su estancia en } \\
\text { UCI sin considerar los problemas médicos }\end{array}$ & 4,06 & 1,25 & 3,31 & 1,76 & 2,83 & ,005 \\
\hline 1. Cuidados médicos. & 4,68 & 0,50 & 4,64 & 0,68 & 0,40 & ,689 \\
\hline 2. Atención de los médicos & 4,73 & 0,52 & 4,59 & 0,73 & 1,21 & ,228 \\
\hline 3. Atención de las/os enfermeras/os & 4,73 & 0,68 & 4,42 & 0,80 & 2,37 & ,019 \\
\hline 4. Atención de las/os auxiliares de enfermería & 4,73 & 0,68 & 4,52 & 0,69 & 1,73 & ,085 \\
\hline 7. Trato por parte del personal de enfermería & 4,73 & 0,52 & 4,47 & 0,66 & 2,45 & ,016 \\
\hline 8. Afecto/apoyo emocional del personal de enfermería & 4,53 & 0,84 & 4,05 & 1,16 & 2,68 & ,008 \\
\hline 9. Respeto a la intimidad & 4,47 & 0,74 & 4,31 & 0,85 & 1,17 & ,246 \\
\hline 10. Atención a los familiares & 4,67 & 0,54 & 4,36 & 0,87 & 2,40 & 018 \\
\hline 11. Atención de necesidades psicológicas en paciente y familia & 4,62 & 0,64 & 4,79 & 0,57 & $-1,66$ & ,099 \\
\hline 12. Calidad de las instalaciones (comodidad, higiene...) & 4,37 & 0,75 & 4 & 0,99 & 2,43 & 016 \\
\hline 13. Posibilidades de distraerse & 2,41 & 1,38 & 2,03 & 1,68 & 1,40 & 164 \\
\hline
\end{tabular}


Analizando los resultados relativos a los factores que podrían ayudar en el proceso de morir (véase Tabla 109) se han obtenido diferencias significativas a nivel estadístico en los factores relacionados con "sentirse cerca, comunicarse y estrechar vínculos afectivos con los seres queridos" ( $\mathrm{t}=-2,63 ; \mathrm{p}=, 010)$ y "no sentirse culpable por conflictos personales del pasado" $(\mathrm{t}=-2,34 ; \mathrm{p}=, 021)$, resultando ambos factores más importantes en el grupo de familiares. Si bien en el resto de ítems del CAMP las diferencias no han sido significativas, cabe señalar que éstas rozan la significación estadística en la valoración de la importancia del "control del dolor y síntomas de malestar" $(\mathrm{t}=1,89 ; \mathrm{p}=, 061)$ y "acortar el proceso si hay sufrimiento" $(\mathrm{t}=1,79 ; \mathrm{p}=, 076)$, aspectos más valorados al final de la vida por los pacientes.

Tabla 109. Puntuaciones medias de los factores que ayudarían en el proceso de morir (CAMP) en pacientes y familiares

\begin{tabular}{|c|c|c|c|c|c|c|}
\hline \multirow[b]{2}{*}{ Ítem } & \multicolumn{2}{|c|}{ PACIENTES } & \multicolumn{2}{|c|}{ FAMILIARES } & \multirow[b]{2}{*}{$\mathbf{t}$} & \multirow[b]{2}{*}{ Sig. $p \leq, 050$} \\
\hline & $\overline{\boldsymbol{X}}$ & DT & $\bar{X}$ & DT & & \\
\hline 1. Controlar mi dolor y otros síntomas de malestar & 3,50 & 0,89 & 3,16 & 1 & 1,89 & ,061 \\
\hline $\begin{array}{l}\text { 2. Mi proceso de morir, si produce sufrimiento, será } \\
\text { corto }\end{array}$ & 3,50 & 0,81 & 3,17 & 1,08 & 1,79 & 076 \\
\hline $\begin{array}{l}\text { 3.Controlar hasta el final pensamientos y funciones } \\
\text { fisiológicas }\end{array}$ & 2,42 & 1,43 & 2,44 & 1,47 & $-0,09$ & ,929 \\
\hline $\begin{array}{l}\text { 4. Mi muerte no supondrá una carga insoportable } \\
\text { para mis seres queridos }\end{array}$ & 2,87 & 1,35 & 3,11 & 1,13 & $-1,01$ & ,317 \\
\hline $\begin{array}{l}\text { 5. Poder sentirme cerca, comunicarme y estrechar } \\
\text { vínculos afectivos con mis personas queridas }\end{array}$ & 2,92 & 1,26 & 3,45 & 0,91 & $-2,63$ & ,010 \\
\hline $\begin{array}{l}\text { 6. Sin esperanza real de recuperación, no se alargará } \\
\text { artificialmente mi vida en UCI }\end{array}$ & 2,58 & 1,62 & 2,74 & 1,30 & $-0,59$ & ,559 \\
\hline 7. Pensar que mi vida ha tenido algún sentido & 2,82 & 1 & 3,02 & 1,12 & $-0,97$ & ,335 \\
\hline 8. Creer en otra vida después de la muerte & 1,59 & 1,59 & 1,33 & 1,44 & 0,92 & ,357 \\
\hline $\begin{array}{l}\text { 9. No sentirse culpable por conflictos personales del } \\
\text { pasado }\end{array}$ & 2,12 & 1,33 & 2,71 & 1,35 & $-2,34$ & 021 \\
\hline $\begin{array}{l}\text { 10. Si la situación se me hace insoportable disponer } \\
\text { de ayuda para morir con rapidez }\end{array}$ & 3,02 & 1,31 & 2,85 & 1,19 & 0,70 & ,485 \\
\hline 11. Poder morir en mi casa & 1,24 & 1,52 & 1,11 & 1,46 & 0,47 & ,638 \\
\hline
\end{tabular}

Finalmente, el análisis diferencial de las puntuaciones obtenidas en la valoración del proceso de información y toma de decisiones (véase Tabla 110), muestra diferencias estadísticamente significativas en las subescalas relativas a la importancia 
de los distintos agentes implicados en el proceso y la participación en la toma de decisiones.

Respecto a la primera subescala, se han obtenido diferencias significativas en la importancia que se le concede en el proceso a la familia $(t=-3,41 ; p=, 001)$, más valorado por los familiares, y al paciente $(t=3,86$; $p=, 000)$ en cuyo caso se observan puntuaciones mayores en el grupo de pacientes. Continuando con la valoración que se le otorga a los otros agentes implicados en el proceso, podemos observar diferencias que rozan la significación estadística en el papel de los médicos $(t=1,95 ; p=, 057)$, más valorado por los pacientes. $\mathrm{Y}$ por último, si bien las diferencias no han sido significativas a nivel estadístico, en referencia al papel del psicólogo se han obtenido puntuaciones ligeramente superiores en los familiares.

En cuanto a la segunda subescala en la que se han obtenido diferencias significativas a nivel estadístico, podemos observar que los pacientes se sienten más capacitados que los familiares para tomar decisiones relacionadas con la salud $(t=2,28$; $p=, 027)$. En cambio, no se han obtenido diferencias significativas en percibir la participación en decisiones médicas como una carga, si bien las puntuaciones medias obtenidas han sido ligeramente superiores en los familiares. En esta línea cabe señalar que tampoco se han obtenido diferencias significativas en las otras dos subescalas del cuestionario CITD aunque podemos apreciar que los familiares se muestran ligeramente más satisfechos con la información y prefieren más que los pacientes un estilo médico directo que anticipe posible sospechas. 
Tabla 110. Puntuaciones medias en la valoración del proceso de información y toma de decisiones en pacientes y familiares

\begin{tabular}{|c|c|c|c|c|c|c|}
\hline \multirow{2}{*}{ CITD } & \multicolumn{2}{|c|}{ PACIENTES } & \multicolumn{2}{|c|}{ FAMILIARES } & \multirow[b]{2}{*}{$\mathbf{t}$} & \multirow[b]{2}{*}{ Sig. $p \leq, 050$} \\
\hline & $\bar{X}$ & DT & $\overline{\boldsymbol{X}}$ & DT & & \\
\hline Papel de la familia en la información y toma de decisiones & 9,44 & 5,15 & 13,25 & 2,64 & $-3,41$ & ,001 \\
\hline Papel del médico en la información y toma de decisiones & 4,47 & 1,18 & 3,71 & 1,38 & 1,95 & 057 \\
\hline Papel del psicólogo en la información y toma de decisiones & 2,28 & 0,89 & 2,56 & 0,56 & 1,39 & 170 \\
\hline \multicolumn{7}{|l|}{ Satisfacción con la información } \\
\hline $\begin{array}{l}\text { En cuanto al estilo del médico prefiero que éste sea directo y } \\
\text { anticipe posibles sospechas }\end{array}$ & 1,67 & 1,37 & 1,76 & 1,23 & $-0,26$ & 794 \\
\hline $\begin{array}{l}\text { En cuanto al estilo del médico prefiero que éste se guarde lo } \\
\text { que aún no es seguro }\end{array}$ & 2 & 1,24 & 1,79 & 1,27 & 0,58 & ,568 \\
\hline \multicolumn{7}{|l|}{ Participación en TD } \\
\hline Me siento capacitado para participar en la TD sobre la salud & 2,44 & 0,98 & 1,79 & 0,98 & 2,28 & 027 \\
\hline $\begin{array}{l}\text { Poder participar en una decisión médica sería más una carga } \\
\text { que un privilegio }\end{array}$ & 1,11 & 1,28 & 1,21 & 1,24 & $-0,27$ & 785 \\
\hline
\end{tabular}




\section{CAPÍTULO 7}

\section{DISCUSIÓN Y CONCLUSIONES}





\section{DISCUSIÓN Y CONCLUSIONES}

Los grandes avances acontecidos en el campo de la medicina durante los últimos años han hecho posible que enfermedades y/o situaciones clínicas antes irreversibles, sin prácticamente opciones de recuperación puedan contar en la actualidad con medios y procedimientos terapéuticos que posibiliten su curación. Gran parte de este arsenal terapéutico de última generación está disponible en las unidades de cuidados intensivos donde ingresan pacientes en situación crítica con el objetivo primordial de conseguir su supervivencia.

Si bien es cierto que una de las prioridades en UCI es intentar salvar la vida de la persona enferma, no podemos obviar que el ingreso en estas unidades donde se presupone la gravedad médica del paciente, conlleva un coste importante en términos de sufrimiento y afectación emocional tanto para la persona enferma como para sus familiares, sobre todo si tenemos en cuenta que este contexto presenta una serie de particularidades que le diferencian del resto de servicios del hospital. Tal es el caso de la alta tecnología utilizada para el tratamiento de los pacientes, la presencia de multitud de estímulos sensoriales extraños, la limitación de la autonomía de los enfermos, el aislamiento y soledad a la que muchas veces se ven sometidos y la gravedad médica del paciente con los razonables miedos al sufrimiento y a la muerte. Todos esto unido a la naturaleza inesperada del ingreso la mayoría de veces así como a la gran incertidumbre asociada al mismo ponen de relieve que el paso por estas unidades no es tarea sencilla y que requiere de un proceso de adaptación a lo largo del cual pueden aparecer diversas alteraciones emocionales.

Esta investigación ha pretendido acercarse a la realidad del ingreso en una Unidad de Cuidados Intensivos para conocer qué supone ser paciente de UCI así como tener a un ser querido ingresado en una unidad de estas características. Para ello hemos intentado analizar las principales repercusiones que en términos de afectación psicológica pueda tener esta experiencia, a la vez que hemos tratado de analizar e identificar aquellos aspectos que pudieran estar asociados a mayor impacto y malestar emocional en pacientes y familiares.

Tras recordar brevemente el motivo de la presente tesis doctoral y teniendo en cuenta las hipótesis formuladas, a continuación describiremos las principales 
conclusiones en tres grandes apartados: pacientes, familiares y comparación entre ambos grupos, y serán discutidos en el marco de la literatura científica sobre el tema.

\subsection{AFECTACIÓN EMOCIONAL DE PACIENTES}

\subsubsection{ANSIEDAD Y DEPRESIÓN}

En primer lugar, respecto a la afectación psicológica en términos de ansiedad y depresión, los resultados indican que los pacientes ingresados en la Unidad de Cuidados Intensivos presentan síntomas de ansiedad y depresión, si bien esta afectación es moderada.

Analizando los síntomas por separado y teniendo en cuenta que los distintos instrumentos utilizados en sentido estricto no permiten hablar de existencia de trastorno sino de grados de afectación, respecto a la ansiedad vemos que la puntuación media de los pacientes de UCI obtenida mediante el HADS no indicaría presencia de problema clínico. Sin embargo, si atendiéramos sólo a este dato estaríamos desestimando un porcentaje nada despreciable de pacientes $(20 \%)$ en los se observa sintomatología de ansiedad a nivel clínico, lo que desde la baremación de este instrumento se conoce como "probable problema clínico". Estos resultados van en la línea de los obtenidos en un estudio preliminar llevado a cabo por nuestro equipo de investigación (Gil, Ballester, Gómez, Ruiz \& Giménez, 2010) así como en la línea de uno de los pocos estudios realizados con pacientes ingresados en UCI en el momento de la evaluación, el cual muestra que el $24 \%$ de los pacientes críticos presenta síntomas clínicos de ansiedad (Rincon et al., 2005). Otro estudio realizado en UCI que también muestra puntuaciones en ansiedad consideradas normales es el llevado a cabo en Australia por Gustad, Chaboyer y Wallis (2005), si bien en esta investigación los pacientes han sido evaluados tras recibir la noticia de que iban a ser dados de alta de la Unidad, en cuyas circunstancias podría ser más adecuado hablar en términos de ansiedad por traslado (McKinney \& Melby, 2002).

Igualmente, a partir de los resultados obtenidos mediante el STAI podemos observar valores medios mayores en ansiedad estado que en ansiedad rasgo, es decir, tal como esperábamos, la ansiedad de los pacientes asociada a la situación particular del ingreso en UCI es mayor que la tendencia relativamente estable a percibir las situaciones como amenazadoras. Estos datos irían en la línea de los resultados que hemos obtenido en un estudio preliminar (Gil et al., 2010). No obstante, dada la escasez 
de estudios llevados a cabo dentro de UCI, no hemos podido comparar nuestros resultados con los de otros investigadores que ofrecieran cifras de prevalencia en ansiedad a partir del STAI. Por ello, en un intento por relacionar estos resultados con otros previos, si nos fijamos en los porcentajes que hemos obtenido podemos advertir que sólo en el caso de las mujeres (25\%) los datos de prevalencia serían similares a los del estudio realizado por Rincon et al. (2005).

En cuanto a los síntomas de depresión evaluados mediante el HADS y BDI, los pacientes de UCI presentan un valor medio que no indicaría presencia de problema clínico. No obstante, atendiendo a los valores que sí indicarían presencia de sintomatología clínica depresiva hemos obtenido datos de prevalencia que oscilarían entre un 23\% (BDI) y un 27\% (HADS), siendo estas cifras superiores a las encontradas en el ya citado estudio de Rincon et al. (2005). Cabe señalar que a diferencia de los resultados obtenidos por estos autores en los que la prevalencia de ansiedad era mayor que la de depresión, en nuestro estudio hemos obtenido a nivel clínico prevalencias similares en ansiedad y depresión, al igual que obtuvimos en un estudio previo (Gil et al., 2010).

Profundizando un poco más en el estudio de la sintomatología ansiosa y depresiva creemos que puede ser relevante comparar nuestros resultados, obtenidos en una muestra de pacientes críticos, con los encontrados en investigaciones realizadas con pacientes también hospitalizados, si bien en otros servicios del hospital. Así al comparar nuestros resultados con los obtenidos por Edo y Ballester (2006) tras evaluar a pacientes con VIH y enfermos oncológicos ingresados en dos hospitales de Castellón, podemos comprobar que las puntuaciones medias de nuestros pacientes en términos de ansiedad y depresión son mayores a las de los pacientes ingresados en la Unidad de Oncología, y menores a las de los pacientes con VIH ingresados en Medicina Interna. En este último caso podría estar influyendo el diagnóstico de los pacientes dadas las connotaciones negativas que puede tener asociadas la infección por VIH.

Otro dato relevante dentro de la afectación psicológica de los pacientes es la percepción subjetiva de su estado de ánimo. Así, los pacientes ingresados en UCI presentan mayor puntuación en percepción de malestar general que en ansiedad y estado de ánimo deprimido, siendo además las puntuaciones en percepción de ansiedad y depresión bastante similares, lo cual coincidiría con los resultados de las evaluaciones realizadas con otros instrumentos sobre los síntomas de ansiedad y depresión. Asimismo, nuestros resultados muestran valores más bajos en la percepción 
subjetiva de ansiedad y depresión que los encontrados en otro estudio realizado en San Francisco por Li y Puntillo (2006) con 15 pacientes críticos, cuya intensidad de los síntomas se evaluó al igual que en nuestro estudio mediante una escala de análogos visuales (0 a 10).

A partir de estos datos, y respecto a la hipótesis inicial sobre ansiedad y depresión en los pacientes de UCI "Los pacientes de UCI presentarán una importante afectación psicológica manifestada mediante sintomatología ansiosa y depresiva, así como percepción de malestar subjetivo", podemos concluir que ésta se cumple parcialmente. Es decir, los pacientes presentan síntomas de ansiedad y depresión, siendo la percepción subjetiva de su estado de ánimo congruente con la afectación real obtenida mediante la evaluación específica de sintomatología ansiosa y depresiva. No obstante, la afectación psicológica ha sido leve/moderada y por tanto menor que la que esperábamos en un principio. En este hecho podrían influir diversos factores dada la especial situación de amenaza que conlleva el ingreso en una unidad de estas características. Así, el paciente en el momento de la evaluación podría encontrarse en situación de shock, sin ser plenamente consciente de la realidad que está viviendo en UCI o también podría estar utilizando estrategias de afrontamiento evitativas o de negación, como mecanismo de defensa transitorio que le ayudara a amortiguar el impacto del ingreso en UCI. Estas reacciones emocionales han sido descritas por distintos autores como parte del proceso de adaptación a una enfermedad terminal o al final de la vida (Kübler-Ross, 1969; Buckman, 1988; Stedeford, 1984) pudiendo trasladarse a aquellas situaciones críticas en las que la vida se ve seriamente comprometida. Sin embargo, puede que la explicación sea mucho más sencilla y tenga como base la tendencia del clínico a victimizar a la persona enferma cuando en realidad ésta puede poseer recursos suficientes para afrontar adaptativamente la situación. O también sería posible que en estos momentos, el centro de interés de la persona y su atención se dirijan más a su estado físico que a su bienestar o malestar emocional.

Al analizar los resultados en ansiedad y depresión en función de distintas variables sociodemográficas y clínicas-médicas no se han obtenido diferencias significativas en ninguno de los casos, por lo que en el grado de ansiedad y depresión que experimentan los pacientes ingresados en UCI no parecen influir de forma 
significativa el género, el estado civil, el número de hijos, la edad, el nivel de estudios y la patología de ingreso.

No obstante, aun sin ser significativo hemos podido observar cierta tendencia a presentar mayor ansiedad en las mujeres. Estos datos confirman los resultados obtenidos en un estudio preliminar (Gil et al., 2010), e irían en la línea de los estudios que confirman mayor ansiedad en las mujeres en el contexto de UCI (Rattray et al., 2005) y a nivel general (Armstrong \& Khawaja, 2002; Dickstein, 2000). En cambio, respecto al estado civil, el número de hijos y la patología de ingreso los datos no permiten establecer ninguna tendencia puesto que se han obtenido resultados diferentes en función del instrumento utilizado. Lo mismo ocurre en cuanto al nivel de depresión, es decir, las diferencias tampoco han sido significativas y los resultados varían de unos instrumentos de evaluación a otros.

Por último, respecto a la percepción subjetiva de estado de ánimo cabe señalar que se ha obtenido una relación casi significativa entre la percepción de estado de ánimo deprimido y el nivel de estudios, de modo que a mayor nivel de estudios los pacientes parecen tener mayor percepción de ánimo deprimido.

A la luz de estos datos y teniendo en cuenta que las diferencias encontradas no han sido significativas, no podemos confirmar la hipótesis planteada inicialmente "Respecto a los sintomas de ansiedad y depresión esperamos obtener diferencias en función del género, la edad, el estado civil, el número de hijos y la patología de ingreso, siendo probablemente mayor la afectación en las mujeres, de edades más jóvenes, con pareja e hijos, y con una patología más grave. En cambio no esperamos encontrar tales diferencias en función del nivel de estudios".

Los resultados obtenidos no coinciden exactamente con nuestro planteamiento inicial. En un principio esperábamos obtener diferencias en ansiedad y depresión en función de distintas variables sociodemográficas como el género puesto que en la literatura científica parece existir consenso en la mayor presencia de sintomatología ansiosa-depresiva entre las mujeres (Dickstein, 2000). En cuanto al estado civil y tener o no hijos, parecía lógico pensar que el hecho de tener pareja e hijos pudiera conllevar mayor ansiedad y depresión en los pacientes, es decir, mayor malestar emocional al no poder desempeñar temporalmente su rol dentro de la familia, dejando de atender ciertas responsabilidades en el entorno familiar. En este sentido aun sin ser significativo podríamos considerar que los resultados obtenidos en depresión 
apuntarían en la línea de lo esperado puesto que las puntuaciones son ligeramente superiores en los pacientes con pareja e hijos.

En cuanto a la patología que ha motivado el ingreso en principio pensábamos que aquellos diagnósticos más graves conllevarían mayor presencia de síntomas de ansiedad y depresión. En cambio no se han obtenido diferencias significativas en función de la patología. Esto podría estar indicándonos que la patología en sí misma no sería un indicador de gravedad, pudiendo ser igualmente grave la situación de un paciente que ingresa por las complicaciones de una enfermedad crónica y la de un paciente que ingresa por las lesiones producidas como consecuencia de un accidente de tráfico.

Respecto a la edad en un principio nos inclinamos a pensar en la opción de que ser joven podría estar asociado a mayor sintomatología ansioso-depresiva motivado por la escasa familiaridad que pudieran tener con este tipo de experiencias junto con el mayor número de responsabilidades en comparación con las personas más mayores. Sin embargo, no hemos obtenido correlaciones significativas entre la edad y los síntomas de ansiedad y depresión.

Por último, no esperábamos encontrar diferencias en ansiedad y depresión en función del nivel de estudios, si bien los resultados han mostrado una relación casi significativa entre la percepción subjetiva del estado de ánimo deprimido y el nivel de estudios, lo cual podría indicarnos que los pacientes con más estudios perciben sentirse más deprimidos o más tristes en estas circunstancias. En este sentido podíamos preguntarnos si el mayor nivel de estudios es realmente el que correlaciona con esa mayor percepción de estado de ánimo deprimido o si tal vez estarían influyendo otras variables asociadas al nivel de estudios como el ritmo de actividad diario, o si tal vez existiera alguna tercera variable como el grado de introspección que suele ser mayor en personas con estudios y a su vez estar asociado a una mayor percepción de malestar físico y psicológico.

Antes de finalizar este apartado cabe señalar la dificultad encontrada a la hora de comparar nuestros resultados con otras investigaciones ya que si bien es cierto que en la literatura científica aparecen distintos estudios que ofrecen cifras de prevalencia en ansiedad y depresión relativas al contexto de UCI, al analizarlos con detalle observamos que en la mayoría de ellos la evaluación de los pacientes ha tenido lugar 
después del alta de UCI. Esta dificultad es si cabe mayor en el análisis de la afectación psicológica en función de variables sociodemográficas, haciéndose extensible al resto de variables analizadas como la valoración de la estancia, la percepción de estrés, la calidad de vida, el proceso de morir y el proceso de información y toma de decisiones.

\subsubsection{VALORACIÓN DE LA ESTANCIA EN LA UNIDAD DE CUIDADOS INTENSIVOS}

Respecto a la valoración de la estancia en UCI, sin considerar la situación médica del paciente, nuestros resultados informan de una valoración positiva tanto a nivel global como en relación con distintos aspectos inherentes a la unidad, entre los que cabe destacar las atenciones y cuidados de los distintos profesionales sanitarios de UCI, incluyéndose la labor de los psicólogos en este contexto.

Si bien podemos comprobar que los pacientes en líneas generales valoran de forma positiva su estancia en la unidad, es necesario dar un paso más allá y analizar aquellas cuestiones que han sido consideradas como más desagradables o molestas durante su estancia. En este sentido, cobrarían protagonismo las escasas posibilidades de distraerse, la falta de silencio en la sala y el régimen de visitas. Resultados similares se han encontrado en estudios previos, sobre todo en relación con la falta de tranquilidad en la sala y el régimen de visitas. Respecto al silencio en la sala, ya en 1967 De Meyer en un estudio llevado a cabo en cuatro UCIs de San Francisco obtuvo que entre las principales quejas identificadas por los pacientes críticos estaban el ruido y la falta de tranquilidad en la sala. Esto mismo ha sido confirmado en distintos trabajos posteriores, tanto en Europa (Balogh et al., 1993; Bentley et al., 1977; Kalfon et al., 2010) como en EE.UU (Lawson et al., 2010), mostrando niveles de ruido dentro de UCI por encima de los internacionalmente recomendados (Organización Mundial de la Salud, 2002). En referencia al régimen de visitas, otros autores portugueses (Novaes et al., 1997) y españoles (Ayllón et al., 2007) han encontrado gran malestar asociado a este aspecto en los pacientes evaluados. Y finalmente, respecto a las posibilidades de distracción del paciente en UCI, aspecto también valorado de forma negativa, cabe señalar que en la literatura revisada no hemos encontrado trabajos que analicen estas cuestiones. Si bien es cierto que éste sería un tema secundario especialmente al principio de la estancia en la unidad dada la gravedad del paciente, cabe tener en cuenta que las posibilidades de distracción aumentarían en importancia a medida que 
se alargara el tiempo de permanencia en la unidad, convirtiéndose en un factor a considerar dada la influencia que podría tener en el estado emocional del paciente. A este respecto contamos con toda la literatura científica que nos habla de la influencia negativa de la autoatención en el malestar físico y emocional y los beneficios de la distracción en el afrontamiento de síntomas físicos y psicológicos.

A la luz de estos datos y en referencia a la hipótesis inicial "La valoración global de la estancia en UCI será negativa identificando aspectos susceptibles de mejora", sólo podríamos confirmar la segunda parte de la hipótesis, es decir, aquella que se refiere a la identificación de aspectos susceptibles de mejora en una unidad de cuidados intensivos, ya que en referencia a la primera parte de la hipótesis los resultados obtenidos no muestran una valoración negativa de la estancia, tal como esperábamos encontrar basándonos en las revisiones realizadas sobre el impacto asociado al ingreso en UCI (Lloyd, 1993).

En cuanto a la valoración diferencial de la estancia en UCI, a nivel global los resultados no han mostrado diferencias significativas según el género, el estado civil, tener o no hijos, la edad, el nivel de estudios ni la patología de ingreso.

Analizando individualmente los distintos aspectos incluidos en la valoración de la estancia en UCI, por un lado observamos que no se han obtenido diferencias significativas en función del género, tener o no hijos, la patología de ingreso y el nivel de estudios. No obstante, en función del género las diferencias han rozado la significación respecto a la valoración del afecto o apoyo emocional recibido por enfermería, aspecto más valorado por las mujeres, lo cual podría estar asociado al mayor valor que en general las mujeres suelen conceder al componente emocional. Igualmente, se ha obtenido una relación casi significativa entre el nivel de estudios y la valoración sobre la atención de las necesidades psicológicas, de modo que a mayor nivel de estudios los pacientes valorarán de forma más positiva la atención de estas necesidades.

Los resultados sobre la valoración de algunos aspectos de la estancia en UCI sí muestran diferencias significativas en función del estado civil y la edad de los pacientes. Concretamente, en función del estado civil se han obtenido diferencias significativas en la valoración por un lado de los cuidados médicos, más valorado por los pacientes sin pareja, y por otro lado en la valoración de las posibilidades de 
distraerse, aspecto mejor valorado por los pacientes con pareja. Las diferencias relativas a la valoración de los cuidados médicos de alguna forma podrían apuntar hacia una total confianza en los cuidados médicos por parte de los pacientes sin pareja. Asimismo, el hecho de que los pacientes con pareja valoren más positivamente las posibilidades de distraerse también podría estar relacionado por ejemplo con que estos pacientes reciban más visitas a lo largo de su estancia en la unidad lo que podría contribuir a que se sientan menos solos y más distraídos. Y en función de la edad, los resultados muestran una relación significativa y de signo negativo entre la edad y la valoración de la atención médica recibida, es decir, a mayor edad de los pacientes menor es la valoración que hacen de este aspecto, lo cual podría interpretarse tal vez como que a medida que aumenta la edad los pacientes puedan ser más exigentes respecto a lo que esperan recibir en estas circunstancias, de ahí que su valoración sea menos positiva.

Con estos resultados podemos considerar que se cumple nuestra hipótesis de partida "Respecto a la valoración de la estancia en UCI esperamos encontrar diferencias en función de distintas variables sociodemográficas como el género, siendo las mujeres quienes valoren más aspectos de contenido emocional (por ejemplo, el apoyo por parte de los sanitarios)". Las diferencias en función del género parecen confirmarse a la vez que se han obtenido también diferencias en función de variables como el estado civil, la edad y el nivel de estudios.

\subsubsection{PERCEPCIÓN DE ESTRÉS EN UCI DESDE EL PUNTO DE VISTA DE LOS PACIENTES}

Tras analizar el grado de estrés asociado al ingreso en UCI podemos observar que más de la mitad de los pacientes refieren niveles intermedios de estrés general mientras que aproximadamente para una tercera parte la experiencia ha resultado en general muy estresante. Profundizando un poco más, los pacientes reconocen como potentes estresores aquellos más relacionados con las consecuencias directas de la propia enfermedad, destacando la experiencia de tener dolor y el estar encamado o sentado en el sillón todo el día, así como otros más vinculados a la esfera relacional/emocional, concretamente no poder estar con sus familiares más cercanos. Resultados similares se han obtenido en estudios previos sobre todo al considerar el dolor como el factor más estresante tanto en pacientes críticos (Ballester et al., 2006; 
Novaes et al., 1997; Novaes et al., 1999) como en pacientes médicos y quirúrgicos hospitalizados en otros servicios del hospital (Richart et al., 1993).

Sin embargo, respecto al grado de estrés que generan determinados aspectos como por ejemplo pensar que le pueda ocurrir algo grave o no saber exactamente en qué consiste la enfermedad, en contra de lo que podíamos esperar a priori dadas las connotaciones asociadas a estos dos aspectos, observamos que el nivel medio de estrés asociado a ellos es intermedio. Este hecho nos hace reflexionar sobre el instinto de supervivencia y el innato espíritu de lucha del ser humano, así como la gran confianza depositada en el personal sanitario que les lleva a creer en las posibilidades de superar esta situación crítica. Sin lugar a dudas esto puede ser adaptativo y resultar beneficioso para la recuperación del paciente, pues a su vez repercutirá positivamente en el estado de ánimo, pudiendo estar en parte aquí la clave de los niveles leves-moderados de afectación psicológica en términos de ansiedad y depresión comentados anteriormente.

Asimismo, se observa que algunos aspectos más relacionados con el funcionamiento y las rutinas de UCI no generan prácticamente estrés en los pacientes. Tal es el caso de estar al cuidado de sanitarios desconocidos, sentir olores extraños, tener demasiadas visitas, comer a horas diferentes a las habituales, dormir junto a otros enfermos y estar aislado por prescripción médica, cuestiones que pasan a ser secundarias en un contexto en el que la salud se ve seriamente comprometida.

Por lo tanto, nuestros resultados apoyarían la hipótesis inicial "La experiencia de UCI resultará estresante para los pacientes, identificando como más estresantes aquellos aspectos relacionados con la propia enfermedad", si bien es cierto que el grado de estrés general encontrado ha sido algo menor que el esperado en un principio.

Respecto al análisis diferencial de la percepción de estrés experimentada en UCI por los pacientes y con la finalidad de mostrar de forma clara los principales hallazgos encontrados, hemos estimado conveniente centrarnos de manera especial en el grado de estrés general.

En este sentido, los resultados han mostrado diferencias significativas en función del estado civil y la patología, así como diferencias casi significativas en función del género y la edad. Analizando cada una de estas variables observamos mayor grado de 
estrés general en los pacientes sin pareja, lo que nos lleva a pensar que en estas circunstancias el cónyuge puede ser considerado por el paciente como una fuente de apoyo importante. Asimismo, las diferencias encontradas según la patología indican que los pacientes sépticos presentan mayor nivel de estrés. A este respecto creemos relevante señalar que en ocasiones el diagnóstico de sepsis general presenta asociado si cabe mayor grado de incertidumbre que los otros diagnósticos dada la afectación global experimentada, lo cual sin duda alguna contribuiría de manera notable a la percepción de estrés que tienen los pacientes de UCI, en línea de lo que distintos autores afirman (Granja et al., 2005). En cambio según han encontrado otros investigadores (Novaes et al., 1997) la gravedad del diagnóstico no parece estar relacionada con el estrés experimentado.

En relación con el género, los resultados muestran que las mujeres tienden a percibir mayor nivel de estrés que los hombres. Estos datos van en la línea de los estudios que indican que las mujeres presentan mayor afectación psicológica (Dickstein, 2000; Rattray et al., 2005). En esta afectación se incluiría el estrés si tenemos en cuenta que distintas investigaciones señalan la presencia de una importante correlación entre los niveles de estrés y la sintomatología ansiosa (Apóstolo, Figueiredo, Mendes \& Rodrigues, 2011; Méndez, Giraldo, Aguirre-Acevedo \& Lopera, 2010).

Y por último, continuando con las diferencias encontradas en la percepción de estrés general tendríamos que hacer referencia a la edad, de modo que los resultados muestran niveles menores de estrés a medida que aumenta la edad, es decir, los pacientes más jóvenes presentarán mayor nivel de estrés. Resultados similares se han encontrado en un estudio llevado a cabo en España en el que si bien las relaciones no eran significativas, sí mostraban cierta tendencia a que el estrés disminuyera con la edad (Ayllón et al., 2007). Asimismo, Rattray et al. (2005) en su investigación también encontraron mayor afectación psicológica en los pacientes más jóvenes, aunque en su estudio hacían referencia explícita a los síntomas de ansiedad.

De esta manera podemos decir que el grado de estrés general es mayor en las mujeres, más jóvenes, sin pareja y cuyo diagnóstico al ingresar en UCI ha sido de sepsis.

En cambio, el tener o no hijos y el nivel de estudios no han mostrado ser relevantes en el grado de estrés general percibido por los pacientes. Estos resultados, 
concretamente los relativos al nivel de estudios, irían en la línea de los obtenidos en uno de los pocos estudios que han analizado el nivel de estrés en función de distintas variables sociodemográficas (Novaes et al., 1997).

A la luz de estos resultados podemos concluir que se cumple parcialmente nuestra hipótesis inicial: “En cuanto a la percepción de estrés, esperamos obtener diferencias según el género, la edad, el estado civil, el número de hijos, el nivel de estudios y la patología de ingreso, siendo probablemente mayor el grado de estrés general en las mujeres, de edades más jóvenes, con hijos y que presentan un menor nivel de estudios".

Si bien en la hipótesis de partida sobre la percepción de estrés nos hemos centrado sobre todo en el nivel de estrés general, creemos relevante comentar que también se han obtenido diferencias en función de algunas de las variables sociodemográficas en otros ítems de la escala de factores estresantes. Así, según el estado civil observamos que a los pacientes sin pareja les generan más estrés aspectos como haber sido hospitalizados de repente y no saber cuándo les darán el alta de UCI, lo cual puede llevarnos a pensar que los pacientes sin pareja puedan tener menos opciones a la hora de delegar ciertas responsabilidades que como consecuencia del ingreso dejan de ser atendidas, convirtiéndose en una posible fuente de malestar.

Igualmente, el hecho de tener o no hijos muestra diferencias por ejemplo en cuestiones relativas a tener que ser ayudados para ir al baño, lo cual genera más estrés en aquellos pacientes con hijos. Mientras que a los pacientes sin hijos les genera más estrés pensar en la posible pérdida de dinero como consecuencia de la enfermedad. Estos dos datos en principio llaman la atención ya que de la misma forma que hemos obtenido estas diferencias cabía la posibilidad también lógica de haber obtenido resultados totalmente opuestos, lo cual nos lleva a intuir que en estas diferencias pudieran estar influyendo otras variables como el nivel de dependencia que todavía tengan los hijos.

\subsubsection{CALIDAD DE VIDA}

Los resultados relativos a la calidad de vida de los pacientes en relación con la que tenían antes de ingresar en UCI muestran un empeoramiento significativo tanto a nivel general como en lo relativo a las diferentes dimensiones analizadas, es decir, 
movilidad, cuidado personal o autonomía, actividades habituales, dolor/malestar y ansiedad/depresión. Estos datos van en la línea de los obtenidos en un estudio preliminar realizado por nuestro equipo de investigación (Ballester, Gómez, Gil, Abizanda \& Bernat, 2010) y los encontrados en otras investigaciones sobre calidad de vida de los pacientes críticos después del alta de UCI (Badía et al., 2008; Cuthbertson et al., 2005). Así, podemos decir que nuestros resultados confirman la hipótesis inicial " $\mathbf{L} \boldsymbol{a}$ calidad de vida de los pacientes se verá seriamente afectada en relación con su situación previa al ingreso en UCI".

Asimismo, profundizando en el análisis de la calidad de vida de los pacientes durante su estancia en UCI hemos obtenido información relativa a la percepción que ellos mismos tienen acerca de su estado de salud en el momento de la evaluación en comparación con el que tenían un mes antes del ingreso en la unidad. En este sentido se observa que para casi la mitad de los pacientes su estado de salud actual es peor, mientras que para más de la tercera parte de los enfermos evaluados su estado de salud es mejor. De entrada estos resultados llaman considerablemente la atención. No obstante, se entenderían fácilmente si atendemos a la variabilidad del diagnóstico médico que puede motivar la hospitalización en la unidad, pues no es lo mismo el ingreso de un paciente como consecuencia de un accidente, sin problemas de salud anteriores, quien parece lógico pensar que percibirá peor calidad de vida en estos momentos que ingresar como consecuencia de los problemas derivados de una enfermedad grave quien en principio experimentará mejoría al ser tratado en UCI. De esta manera, parece tener sentido la argumentación de diferentes autores que defienden que tras el ingreso en UCI no necesariamente empeorará la calidad de vida sino que incluso ésta puede mejorar influido por diferentes factores entre los que destaca la categoría diagnóstica (Badia et al., 2001; Badía et al., 2008; Granja et al., 2002).

Al analizar la calidad de vida de los pacientes en función de variables sociodemográficas y clínicas-médicas observamos que no se han encontrado diferencias significativas en función del género, el estado civil, el tener o no hijos y el nivel de estudios. Sin embargo, las diferencias sí han sido significativas en función de la patología de ingreso, mostrando los resultados peor calidad de vida en los pacientes neuroquirúrgicos y aquellos con traumatismos sin afectación del sistema nervioso central antes y después del ingreso en UCI respectivamente. Asimismo, se ha obtenido una relación significativa entre la edad y la calidad de vida pero sólo en aquella previa 
al ingreso en UCI de modo que a mayor edad peor era la calidad de vida, lo cual estaría dentro de lo esperable dado el deterioro general asociado al aumento de edad. En cambio la relación entre la edad y la calidad de vida tras el ingreso en la UCI no ha sido significativa.

Así, centrándonos en el periodo de estancia del paciente en UCI vemos que la única variable en función de la cual se han obtenido diferencias en la calidad de vida de los pacientes ha sido la patología de ingreso, lo cual parece razonable si tenemos en cuenta que no todos los diagnósticos conllevan las mismas limitaciones. Además, el hecho de que la patología que conlleva una peor calidad de vida después del ingreso en UCI sea la presencia de traumatismos estaría dentro de lo esperable ya que normalmente los pacientes que ingresan por traumatismos suelen tener una buena calidad de vida previamente, al igual que el periodo de recuperación suele ser considerable. Cabe señalar que estos resultados relativos a las diferencias encontradas en la calidad de vida de los pacientes en función del diagnóstico van en la línea de los obtenidos en distintas investigaciones (Granja et al., 2002; Pettilä, Kaarlola \& Makelainen, 2000).

De esta manera, se confirma la hipótesis inicial "Respecto a la calidad de vida de los paciente esperamos obtener diferencias en función del diagnóstico de ingreso".

Finalmente, respecto al estudio de la calidad de vida de los pacientes críticos nos gustaría señalar que la mayoría de estudios realizados evalúan la calidad de vida meses e incluso años después del alta de UCI (Cuthbertson et al., 2010), lo cual ha dificultado la comparación de nuestros datos sobre calidad de vida obtenidos durante el periodo de ingreso.

\subsubsection{VALORACIÓN SOBRE EL PROCESO DE MORIR}

Los resultados relativos a la valoración del proceso de morir indican que llegado el momento de la muerte los pacientes concederían muchísima importancia a los aspectos relativos al control del dolor y los síntomas de malestar así como evitar el sufrimiento, disponer de ayuda para morir con rapidez si la situación se hiciera insoportable y no alargar artificialmente la vida en una UCI si no hay esperanza real de recuperación. Asimismo, desde el punto de vista de la persona enferma también sería importante ante la cercanía de la muerte poder estar con sus seres queridos y estrechar 
vínculos, preocupándoles además el que su muerte pudiera ser una carga insoportable para los demás. Estos datos van en la línea de los encontrados en uno de los primeros estudios que analizan los cuidados al final de la vida desde la perspectiva de la persona enferma llevado a cabo con pacientes crónicos ingresados en un hospital de Canadá (Singer et al., 1999). En lo relativo al contexto particular de UCI nuestros resultados confirman los que obtuvimos en un estudio preliminar llevado a cabo con pacientes críticos (Gil, Ballester, Ibáñez, Gómez \& Abizanda, 2010), al igual que hemos podido comprobar que coinciden con los conseguidos en una muestra de profesionales sanitarios de UCI (Gómez, 2011). El hecho de que las preferencias de pacientes y sanitarios al final de la vida sean similares puede ser debido a que los sanitarios a diario están en contacto con la persona enferma conociendo de primera mano todo lo que supone estar críticamente enfermo y percibir la muerte como próxima.

Si bien es cierto que los citados aspectos han sido identificados como los más importantes desde el punto de vista de los pacientes, en un intento por ahondar un poco más en aquello que sería prioritario al final de la vida hemos obtenido que en el caso de que tuvieran que elegir, los enfermos priorizan el hecho de que el proceso de morir si hay sufrimiento sea corto y poder controlar el dolor y otros síntomas de malestar dejando en segundo lugar el poder estar cerca de sus seres queridos. De esta manera, consideramos que se cumple la hipótesis "Ante una hipotética situación de enfrentarse al final de la vida los pacientes valorarán más los factores relacionados con el control de los síntomas físicos de malestar y sufrimiento".

Respecto al análisis diferencial en función de variables sociodemográficas y clínicas sobre la valoración de los aspectos más importantes al final de la vida los datos han mostrado diferencias significativas según el género, el estado civil, el nivel de estudios y la patología de ingreso.

De esta manera vemos que las mujeres, ante el hipotético caso de que se estuvieran enfrentando a la muerte, conceden más importancia por un lado a aquellos aspectos de contenido relacional / emocional como poder estar cerca de sus seres queridos y que su muerte no suponga una carga para los demás, así como también por otro lado a factores más espirituales o morales, tal es el caso de creer en otra vida después de la muerte y no sentirse culpable por conflictos personales del pasado. 
Respecto al estado civil, los pacientes con pareja valoran más ante el hipotético caso de que se estuvieran enfrentando al final de sus días el pensar que su vida ha tenido algún sentido. Parece ser que el hecho de compartir la vida con la pareja lleva a que los pacientes consideren más relevantes aspectos de carácter existencial frente a los que no tienen pareja.

En función de la patología observamos que los pacientes con enfermedad médica previa dan más importancia a poder controlar hasta el final los pensamientos y las funciones fisiológicas, posiblemente debido a que en el transcurso de la enfermedad hayan anticipado o incluso ya hayan experimentado parte de las limitaciones y/o consecuencias que pueden derivarse de su situación médica. Este hecho contribuiría a que el paciente priorizara el poder controlar hasta el final tanto pensamientos como funciones fisiológicas evitando también de esta manera sufrimiento a las personas que le rodean. Por otro lado, continuando con las diferencias encontradas según la categoría diagnóstica observamos que son los pacientes sépticos quienes más importancia dan al hecho de que su muerte no suponga una carga insoportable para sus seres queridos.

Y en referencia al nivel de estudios los resultados muestran una relación significativa y de signo positivo entre el nivel de estudios y la priorización de aspectos de corte moral o espiritual. Tal es el caso de creer en otra vida después de la muerte y no sentirse culpable por conflictos personales del pasado, de manera que a medida que aumenta el nivel de estudios los pacientes darían más importancia a estos dos factores llegado el momento de su muerte. De igual forma, los pacientes con más estudios también parecen dar más valor al hecho de acortar el proceso si éste conlleva sufrimiento. Así, por una parte los datos relativos a no sentirse culpable y que el proceso sea corto si hay sufrimiento podrían tener como denominador común un intento de evitar sufrimiento a los demás resolviendo para ello asuntos pendientes a la vez que remediar el sufrimiento propio de alguna forma aliviará el sufrimiento a las personas de su alrededor. Mientras que por otra parte, los resultados sobre la relación entre el nivel de estudios y el hecho de creer en otra vida después de la muerte no irían en la línea de lo esperado, lo que nos llevaría a pensar en la posible mediación de otra variable como las creencias religiosas, que han mostrado ser relevantes en la importancia concedida a creer en otra vida después de la muerte (Gómez, 2011; Ibáñez, 2009). 
Cabe señalar que nuestros resultados sobre las diferencias en función del género son similares a los obtenidos en dos estudios previos realizados con pacientes críticos (Gil et al., 2010; Ibáñez, 2009) así como también coinciden con los de otra investigación llevada a cabo en el contexto de UCI aunque en este caso con profesionales sanitarios (Gómez, 2011). Igualmente, en los citados estudios también se encontraron diferencias en función del nivel de estudios (Gil et al., 2010) y en función del estado civil (Gil et al., 2010; Gómez, 2011), si bien los factores en los que se han obtenido las diferencias no coinciden exactamente con los nuestros.

A modo de conclusión cabe señalar que a la hora de priorizar aquellos aspectos que facilitarían una muerte en paz desde el punto de vista de los pacientes han resultado ser relevantes el género, el estado civil, el nivel de estudios y la patología de ingreso. En cambio, variables como tener o no hijos y la edad no parecen ser importantes a la hora de elegir los factores que más ayudarían. Estos resultados irían en la línea de los obtenidos en otros estudios (Gil et al., 2010; Gómez, 2011; Ibáñez, 2009).

A partir de estos resultados podemos decir que se cumple la hipótesis inicial "Respecto a la valoración de los aspectos que podrían facilitar una muerte en paz esperamos encontrar sobre todo diferencias en función del género de manera que las mujeres darán más importancia a aspectos existenciales así como a otros más relacionales (por ejemplo, poder estar cerca de las personas queridas). Asimismo esperamos obtener diferencias en función de otras variables sociodemográficas y clínicas".

\subsubsection{VALORACIÓN DEL PROCESO DE INFORMACIÓN Y TOMA DE DECISIONES}

Por lo que respecta al proceso de información y toma de decisiones, los resultados muestran que desde el punto de vista de los pacientes el papel más importante en el proceso lo ha de tener el propio enfermo, seguido del psicólogo y el médico, dándole menos importancia al papel de la familia en el mismo. Cabe resaltar el hecho de que el psicólogo sea percibido por los pacientes tanto o más importante que el médico en el proceso de información y toma de decisiones, lo cual pone de relieve la necesidad de una atención multidisciplinar que incluya la presencia de los psicólogos 
en los distintos ámbitos de la salud y de manera particular en una UCI dada la especial vulnerabilidad y sufrimiento asociado al ingreso en estas unidades.

Estos resultados van en la línea de los obtenidos por Gómez (2011) en un trabajo realizado en esta misma UCI con profesionales sanitarios. De nuevo observamos que las valoraciones de los pacientes críticos y los sanitarios que les atienden coinciden. En cambio, si comparamos nuestros resultados con los encontrados por Bernat, Ballester y Abizanda (2012) en un estudio preliminar sobre la capacidad del paciente crítico en la toma de decisiones, observamos que la valoración de las personas implicadas en el proceso no es exactamente la misma, concediéndole más importancia al médico y al psicólogo que a sí mismos como pacientes. No obstante, nuestro estudio coincide con el de Bernat et al. (2012) en que el papel menos importante en el proceso es el de los familiares, al igual que se observa en el trabajo realizado por Gómez (2011).

En cuanto a la satisfacción con la información los pacientes refieren estar satisfechos con la información recibida sobre su pronóstico y tratamiento así como con la oportunidad de haber podido aclarar todas sus dudas. Asimismo, al preguntar sobre el hecho de participar en decisiones médicas, los resultados muestran que casi tres cuartas partes de los pacientes se sienten totalmente capacitados para participar en decisiones médicas que repercutan sobre sí mismos, a la vez que la mitad de los pacientes no perciben en absoluto como una carga el hecho de participar en una decisión relevante. No obstante, es importante considerar que algunos pacientes puedan percibir como una carga el participar en decisiones médicas relevantes (22\%). Estos resultados van en la línea de los obtenidos en el estudio de Bernat et al. (2012), citado anteriormente.

Y finalmente, respecto al estilo del médico a la hora de informar, los pacientes muestran mayor grado de preferencia hacia un estilo médico más prudente, que no diga lo que aún no es seguro. Estos datos indicarían que los pacientes en estas circunstancias prefieren no anticipar sobre cuestiones relacionadas con su situación médica, lo cual apoyaría los resultados relativos a la afectación psicológica (leve o moderada) en términos de ansiedad que presentan los pacientes, si tenemos en cuenta el papel de la anticipación en los síntomas de ansiedad.

Por todo lo comentado podemos decir que se cumple la siguiente hipótesis: "Respecto al proceso de información y la toma de decisiones, los pacientes concederán más importancia al rol que debe desempeñar el propio paciente percibiendo la 
participación en la toma de decisiones como un privilegio más que como una carga". No obstante, cabe matizar respecto a la valoración de la participación en la toma de decisiones que el hecho de que ésta no se perciba como una carga tampoco implicaría necesariamente que fuera un privilegio para los pacientes, tal como pone de manifiesto el ejemplo que mostramos a continuación.

Al preguntar a la paciente M. por el grado de acuerdo sobre la afirmación "para mi poder participar en una decisión médica sería más una carga que un privilegio", la paciente contesta sin apenas dudar que en absoluto sería una carga... No obstante, tras un breve silencio $M$. añade: "...pero tanto como un privilegio...no sé...".

Respecto al análisis diferencial de la valoración del proceso de información y la toma de decisiones los resultados no han mostrado diferencias significativas en función de variables sociodemográficas como el género, el estado civil, la edad y el nivel de estudios, así como tampoco muestran diferencias significativas en función de variables clínicas-médicas como la patología de ingreso. Estos resultados difieren en parte de los obtenidos en el estudio preliminar llevado a cabo por Bernat et al. (2012) en el que se ha analizado la relación entre la edad y el nivel de estudios con el proceso de información y la toma de decisiones obteniéndose relaciones significativas concretamente entre la edad y la escala correspondiente a la participación en decisiones relevantes.

Cabe señalar que en nuestro estudio únicamente se han obtenido diferencias significativas en función de la variable tener o no hijos, concretamente en la valoración de la importancia que el paciente se concede a sí mismo en el proceso de información y toma de decisiones, siendo más importante para los pacientes con hijos. En este sentido creemos relevante comentar a partir de la entrevista clínica mantenida con el paciente que si bien es cierto que en general se conceden a sí mismos el papel más importante en el proceso, en los casos en que éstos tienen hijos además hacen especial énfasis en la preferencia de tomar ellos mismos las decisiones, siempre que sea posible, con la finalidad de aliviar de angustia y sufrimiento a sus hijos ante decisiones médicas relevantes.

A partir de estos datos podemos decir que no se cumple la hipótesis inicial "Respecto al proceso de información y la toma de decisiones esperamos obtener 
diferencias en función de variables sociodemográficas como la edad", si bien los resultados han mostrado diferencias en función de tener o no hijos.

En este punto cabe recordar la escasez de estudios realizados con pacientes críticos y de manera especial aquellos que analizan en esta población posibles diferencias en función de variables sociodemográficas y clínicas ya que esto ha dificultado poder contrastar nuestros datos con los de otras investigaciones.

\subsubsection{PRINCIPALES VARIABLES PREDICTORAS DE LA AFECTACIÓN PSICOLÓGICA DE LOS PACIENTES}

Por último y para completar el estudio de los pacientes hemos tratado de analizar qué variables sociodemográficas y clínico-médicas tienen mayor influencia en la afectación psicológica y el malestar asociado a la experiencia de estar ingresado en una unidad de cuidados intensivos. Concretamente pretendíamos conocer la influencia de las citadas variables en la valoración global de la estancia en UCI, el nivel de estrés, la ansiedad y la depresión.

Respecto a la valoración global de la estancia en UCI parece lógico pensar desde un punto de vista teórico que las distintas variables demográficas (género, edad, estado civil, número de hijos y nivel de estudios), médicas (patología de ingreso) y emocionales (ansiedad y depresión) podrían ser importantes para explicar la valoración que los pacientes hacen de su estancia en la unidad. Sin embargo, los resultados han mostrado que de las variables analizadas la única que predice esta valoración es la ansiedad, de modo que niveles más altos de ansiedad explicarían una valoración más negativa.

Otra variable relevante en este contexto es el nivel de estrés general de los pacientes, el cual parece ser modulado de forma conjunta por la patología que motivó su ingreso, el género, el estado civil, el tener o no hijos y la edad. En este sentido los resultados han señalado que ser mujer, no tener pareja, tener hijos y ser más joven predecirían mayor nivel de estrés en los pacientes. Asimismo, en cuanto a la patología los resultados parecen indicar que un diagnóstico que implique en principio un buen estado de salud previo y menor previsibilidad en el ingreso, como pueden ser los traumatismos, tendrían mayor probabilidad de generar estrés. 
Finalmente, nuestros resultados han mostrado que los síntomas de ansiedad y depresión en los pacientes de UCI no parecen ser modulados por ninguna de las variables sociodemográficas mencionadas ni por la patología de ingreso.

Estos datos resultan un tanto sorprendentes pues a nivel teórico parecía lógico pensar que algunas de las variables sociodemográficas, como el género, podían relacionarse con una mayor sintomatología ansiosa y depresiva, en línea de lo que señalan distintos autores (Armstrong \& Khawaja, 2002; Dickstein, 2000). Esto añadido al hecho de haber encontrado que el nivel de estrés es predicho por distintas variables mientras que no ocurre lo mismo con la ansiedad y la depresión, plantean distintos interrogantes todavía sin respuesta y que será necesario abordar.

Cabe señalar que en la literatura revisada no hemos encontrado estudios que analicen variables moduladoras del malestar psicológico de los pacientes ingresados en UCI, lo cual dificulta la comparación de nuestros resultados. No obstante, podemos comprobar que nuestros datos difieren de los de Rattray et al. (2005) en un estudio llevado a cabo con pacientes varios meses después del alta de la unidad, en el que los autores encontraron que ser mujer y joven predecía mayor sintomatología ansiosa así como ser mujer también predecía mayor nivel de depresión.

\subsection{AFECTACIÓN EMOCIONAL DE FAMILIARES}

\subsubsection{ANSIEDAD Y DEPRESIÓN}

Los resultados relativos a la afectación psicológica de los familiares de UCI indican presencia de síntomas de ansiedad y depresión a partir de la evaluación realizada con los distintos instrumentos de evaluación.

Respecto a la ansiedad evaluada mediante el HADS observamos que la puntuación media de los familiares indica presencia de problema clínico. Concretamente, el $76,4 \%$ de los familiares presenta síntomas de ansiedad a nivel clínico. Resultados similares en cuanto a la prevalencia de los síntomas de ansiedad en familiares de pacientes críticos se han obtenido en diferentes investigaciones. Tal es el caso de dos estudios multicéntricos llevados a cabo en Francia (Pochard et al., 2001; Pochard et al., 2005) con cifras de prevalencia en ansiedad de 69,1\% y 73,4\% respectivamente, así como otro estudio realizado con familiares de una UCI de Brasil 
(Fumis \& Deheinzelin, 2009) cuya prevalencia ha sido del 71\%. Igualmente, cabe señalar que los resultados obtenidos mediante el STAI van en esta misma línea. Como era de esperar, los familiares muestran puntuaciones mayores en ansiedad-estado que en ansiedad-rasgo, es decir, mayor ansiedad asociada a la circunstancia particular de tener a un ser querido ingresado en UCI. Y además los resultados sobre la prevalencia en ansiedad-estado constituyen cifras realmente importantes: $81,5 \%$ para las mujeres y $58,3 \%$ para los hombres, datos similares a los que obtuvimos en un estudio preliminar (Gil et al., 2010).

En cuanto a los síntomas de depresión evaluados mediante el HADS y el BDI observamos puntuaciones medias indicativas de problema clínico y depresión leve respectivamente, según los baremos utilizados en cada una de las escalas. En este sentido, y atendiendo a los distintos instrumentos utilizados vemos que la prevalencia en depresión varía entre un 59,6\% (HADS) y un 42,5\% (BDI), porcentaje este último que incluye a los familiares con depresión moderada (35\%) y depresión grave (7,5\%). Podemos ver que nuestros resultados sobre prevalencia en depresión son superiores a los encontrados en distintos estudios como el de Maruiti, Galdeano y Farah (2008) tras la evaluación de 39 familiares en una UCI de Brasil (17,9\%), el de Anderson et al., (2009) realizado con 50 familiares de la UCI de un hospital americano (16\%) y el estudio de Gómez-Carretero, Monsalve, Soriano y de Andrés (2009) llevado a cabo en Valencia con 118 familiares (9,5\%). Asimismo, comprobamos que nuestros datos se asemejan, aun siendo los porcentajes algo mayores, a los obtenidos en dos estudios multicéntricos realizados en Francia por Pochard et al. (2001) y Pochard et al. (2005) en los que obtuvieron una prevalencia en depresión del 35,4\% y 35,3\% respectivamente.

Cabe señalar que estas diferencias halladas en la prevalencia de los síntomas de depresión de los familiares de UCI en distintas investigaciones puede deberse en parte a variables asociadas a la situación médica o gravedad del paciente ingresado en la unidad. De hecho, los participantes del estudio realizado por Gómez-Carretero et al. (2009) eran familiares de pacientes que de forma programada requerían ingresar en UCI después de una intervención quirúrgica, mientras que éste era uno de los criterios de exclusión en nuestro estudio, es decir, aquellos familiares de pacientes en los que se preveía una rápida recuperación como es el caso de los pacientes ingresados para control postoperatorio no se incluyeron en la investigación. De esta manera, vemos que nuestros resultados irían más en la línea de los encontrados en otros estudios llevados a cabo con familiares cuyo ser querido se encuentra gravemente traumatizado, con 
cáncer o próximos a morir cuya prevalencia en depresión gira en torno al 50\% (Fumis \& Deheinzelin, 2009; Pérez-San Gregorio et al., 1992).

Otro dato a considerar en cuanto a la afectación psicológica de los familiares de UCI es la percepción subjetiva de su estado de ánimo. En este sentido los familiares refieren percibir más ansiedad y nerviosismo que estado de ánimo deprimido o malestar general.

Estos datos van en la línea de los resultados obtenidos en un estudio preliminar realizado por nuestro equipo de investigación (Gil, 2010), mostrando además que la percepción subjetiva de estado de ánimo es congruente con la afectación en términos de ansiedad y depresión obtenida a través de los distintos instrumentos de evaluación utilizados.

Cabe tener en consideración que en la literatura científica revisada no henos encontrado ningún estudio sobre la percepción subjetiva de malestar emocional en familiares de UCI dificultándose así la comparación de nuestros resultados.

A la luz de estos resultados, podemos confirmar la hipótesis de partida "Los familiares de UCI presentarán una importante afectación psicológica manifestada mediante sintomatología ansiosa y depresiva, y una elevada percepción de malestar subjetivo".

Además, cabe subrayar que nuestro estudio así como toda la literatura científica revisada sobre los síntomas de ansiedad y depresión en familiares de UCI evidencian mayor prevalencia en ansiedad que en depresión.

Al analizar los resultados en ansiedad y depresión en función de distintas variables sociodemográficas hemos obtenido diferencias en función del género a favor de las mujeres siendo estas diferencias significativas y casi significativas en la depresión y ansiedad respectivamente, evaluadas mediante el HADS. Nuestros resultados van en la línea de los obtenidos en distintos estudios con familiares de UCI que muestran mayor afectación en síntomas de ansiedad y depresión en las mujeres (Fumis \& Deheinzelin, 2009; Pochard et al., 2001), así como también coinciden con los datos de otros estudios que afirman que las mujeres presentan mayor probabilidad que los hombres de experimentar depresión ante un acontecimiento vital estresante (Maciejewski, Prigerson \& Mazure, 2001). 
Completando el análisis en función del género, cabe señalar que en la percepción subjetiva de estado de ánimo no se aprecian diferencias significativas, si bien estarían próximas a la significación en el caso de la percepción subjetiva de estado de ánimo deprimido. De esta manera podemos decir que las mujeres presentan más síntomas de ansiedad y depresión que los hombres así como parecen percibir a nivel subjetivo mayor tristeza o estado de ánimo deprimido.

Respecto al estado civil los resultados han mostrado mayor afectación en términos de ansiedad y depresión en los familiares con pareja llegando las diferencias a ser significativas en la ansiedad evaluada mediante el HADS. Y en cuanto a la percepción subjetiva del estado de ánimo los resultados no han mostrado diferencias significativas si bien apuntan a una mayor percepción de malestar en los familiares con pareja. Cabe señalar que no hemos podido comparar estos datos con los de otros estudios al no haber encontrado estudios en la literatura revisada que analicen la ansiedad y depresión en UCI en función del estado civil.

En un intento por analizar globalmente nuestros resultados en función de tener o no hijos, encontramos cierta tendencia a presentar más afectación en ansiedad y depresión en los familiares con hijos. No obstante, pensamos que el hecho en sí mismo de tener o no hijos no sería tan relevante a la hora de encontrar diferencias en ansiedad y depresión como pudiera serlo la etapa evolutiva en la que estos hijos se encuentran y el nivel de dependencia que tienen de los padres. Por ello, en ocasiones los hijos podrían verse como una fuente de apoyo mientras que en otros casos tener hijos podría suponer una fuente de estrés adicional al no poder atender sus necesidades tal como venían haciendo hasta el momento del ingreso en UCI.

Los resultados relativos al análisis en función del grado de parentesco con el paciente no han mostrado diferencias significativas en los síntomas de ansiedad, en línea de los resultados obtenidos por Delva et al. (2002). En cambio, sí se observan diferencias significativas en los síntomas de depresión evaluados mediante el HADS, siendo las madres y las parejas quienes presentan mayores puntuaciones. Estos resultados coinciden en parte con los del estudio multicéntrico realizado por Pochard et al. (2005) en Francia, en el que analizaron los síntomas de ansiedad y depresión en función ser esposo/esposa del paciente $\mathrm{u}$ otro familiar. Estos autores encontraron también más síntomas de ansiedad y depresión en la categoría de esposo/a, si bien las diferencias en su estudio fueron significativas en los síntomas de ansiedad. 
Estos resultados que muestran más síntomas de depresión en las parejas pueden entenderse fácilmente en este contexto, desde el marco de lo que supone para el cónyuge enfrentarse a distintas pérdidas, ya sea por la propia muerte del paciente o por diferentes pérdidas secundarias a su situación médica (como pueden ser secuelas importantes a nivel cognitivo consecuencia de un accidente cerebro-vascular o de traumatismos craneoencefálicos severos) viéndose alterado notablemente el proyecto vital que tenía la pareja. En este sentido, a partir del testimonio de muchas parejas cabe subrayar el gran sufrimiento experimentado ante estas situaciones de pérdida, sintiéndose totalmente abatidos al verse truncados todos los planes de futuro que tenían con su ser querido, llegando a sentir que su vida en estos momentos carece de sentido. Distintas investigaciones relativas a la pérdida de la pareja aportan resultados similares (Stroebe, Hansson \& Schut, 2008; Zisook \& Shuchter, 1991). Asimismo, nuestros resultados también muestran puntuaciones altas en depresión en las madres, lo cual iría en la línea de los resultados encontrados en la literatura revisada ante la pérdida de un hijo (Leahy, 1992; Wijngaards-de Meij et al., 2008).

Respecto a la percepción subjetiva de estado de ánimo cabe señalar que no se han obtenido diferencias estadísticamente significativas, si bien en la percepción subjetiva de ansiedad en función del parentesco roza la significación siendo las madres quienes perciben a nivel subjetivo mayor grado de ansiedad y nerviosismo.

En cuanto al lugar de residencia observamos mayores puntuaciones tanto en ansiedad como en depresión en aquellos familiares que residen más lejos del hospital, es decir, en aquellos familiares que no viven en la misma ciudad de Castellón, siendo las diferencias significativas a nivel estadístico en los resultados obtenidos mediante el STAI-Estado y el BDI. Así, el hecho de que los familiares no residan en la misma ciudad en la que se encuentra el hospital conlleva mayor afectación psicológica, la cual puede estar influida por diversos aspectos que no hacen más que añadir malestar a la experiencia de ingreso de un ser querido. En este sentido los propios familiares destacan sobre todo aquellos aspectos que por el hecho de residir fuera de la ciudad dificultan la posibilidad de estar cerca del paciente. Tal es el caso de tener que desplazarse varias veces al día hasta el hospital para acudir a las visitas; en ocasiones la larga distancia entre el domicilio familiar y el hospital sólo permite hacer un viaje al día lo cual contribuye de manera importante al malestar de la familia ya que no pueden acompañar a su ser querido el tiempo que les gustaría; y en el mejor de los casos, es decir, cuando a pesar de la distancia acuden a más visitas suele ser a costa de 
pasar todo el día en la sala de espera del hospital con el agotamiento que esto conlleva a medida que se alarga la estancia en la unidad. Igualmente, un motivo de preocupación en la mayoría de familiares es poder llegar al hospital lo más rápido posible ante un cambio en el estado del paciente, en lo cual interfiere la lejanía del domicilio familiar.

Estas circunstancias interferirán de manera notable en algo tan significativo para la familia como lo es poder estar cerca de la persona querida (Bijttebier at al., 2001; Delva et al., 2002; Mendonca \& Warren, 1998) incrementando sin duda alguna el impacto emocional del ingreso en UCI (Kentish-Barnes, Lemiale, Chaize, Pochard \& Azoulay, 2009). Cabe subrayar que no hemos podido comparar los resultados obtenidos en función del lugar de residencia ya que en la literatura revisada no hemos encontrado estudios que analicen esta variable.

En cuanto a la relación de los síntomas de ansiedad y depresión con la edad, los resultados no muestran relación significativa entre la edad y la ansiedad, a diferencia de los resultados obtenidos por Delva et al. (2002) en un estudio realizado en Bélgica según el cual la ansiedad de los familiares de UCI parecía disminuir a medida que aumentaba la edad. En cambio, nuestros datos sí muestran una relación significativa de signo positivo entre la edad y los síntomas de depresión evaluados mediante el HADS, lo cual indica que a medida que aumenta la edad de los familiares aumentará la presencia de sintomatología depresiva.

No obstante, cabe señalar que los resultados relativos a los síntomas de depresión en función de la edad obtenidos a partir del BDI, contradicen en parte los obtenidos mediante el HADS, ya que la relación aun sin alcanzar la significación estadística es de signo negativo, lo cual iría en la línea de los resultados obtenidos en síntomas de depresión en población general (Christensen et al., 1999). Estos datos nos llevan a pensar que tal vez una explicación a las diferencias obtenidas entre los dos instrumentos se encuentre en el contenido de los ítems, puesto que el HADS parece centrarse sobre todo en aspectos emocionales (Zigmond \& Snaith, 1983) mientras que el $\mathrm{BDI}$, aunque mide también aspectos fisiológicos y conductuales, se centra de manera especial en los aspectos cognitivos (Beck et al., 1961). Asimismo respecto a la correlación positiva hallada entre la edad y la depresión creemos relevante comentar que aunque en líneas generales los resultados indican que a medida que aumenta la edad aumentará la sintomatología, con estos datos no necesariamente estaríamos hablando de rangos de edad realmente elevados sino que cabe la posibilidad de que 
esa mayor edad se corresponda en nuestro contexto con familiares de edad media que tienen gran cantidad de responsabilidades a su cargo las cuales muchas veces resultan difíciles de compaginar (trabajo, hijos, cuidado del paciente, etc.). En este sentido, hubiera sido relevante contrastar nuestros resultados con los de otros estudios realizados con familiares de UCI, lo cual no ha sido posible a partir de la literatura científica revisada.

Por último, los resultados han mostrado una relación significativa y negativa entre el nivel de estudios y los síntomas de ansiedad y depresión, de modo que a menor nivel de estudios, los familiares presentarán mayor sintomatología ansiosa y depresiva, así como mayor percepción subjetiva de estado de ánimo deprimido. Estos resultados coinciden con los obtenidos en el estudio de Delva et al. (2002) respecto a la relación del nivel educativo con la ansiedad, no habiéndose incluido en dicha investigación el análisis de los síntomas de depresión.

A la luz de estos resultados podemos decir que se cumple en parte la hipótesis inicial "Respecto a los síntomas de ansiedad y depresión esperamos obtener diferencias según el género, la edad, el estado civil, el número de hijos, el grado de parentesco y el lugar de residencia, siendo probablemente mayor la afectación en las mujeres, de edades más jóvenes, con pareja e hijos, que viven más lejos del hospital y que son madres del paciente ingresado en UCI. Mientras que no esperamos obtener diferencias tan claras en función del nivel de estudios".

Resumiendo, nuestros resultados confirman mayor afectación en las mujeres, con pareja, que viven lejos del hospital, tal como señala nuestra hipótesis de partida. Respecto al grado de parentesco esperábamos obtener mayor ansiedad y depresión en las madres, lo cual sólo podemos confirmar respecto a los síntomas de depresión. En cambio las diferencias encontradas según la edad no confirman la hipótesis inicial dado que se esperaba mayor afectación a menor edad, mientras que los resultados obtenidos han mostrado sólo diferencias en depresión y además en sentido contrario al esperado, es decir, más depresión a mayor edad. Respecto a las otras dos variables analizadas, tener o no hijos y el nivel de estudios cabe señalar que los datos tampoco confirman la hipótesis inicial. Así, nuestros resultados por un lado muestran diferencias en función del nivel de estudios (menor nivel de estudios, mayor afectación), si bien no esperábamos obtener resultados significativos al respecto. Por otro lado, sí se esperaban diferencias según los familiares tuvieran o no hijos mientras 
que nuestros datos indican que esta variable no parece ser tan relevante en la afectación psicológica de la familia en UCI.

\subsubsection{VALORACIÓN DE LA ESTANCIA EN LA UNIDAD DE CUIDADOS INTENSIVOS}

Respecto a la valoración de la estancia en UCI los resultados obtenidos muestran que los familiares valoran a nivel global la estancia de su ser querido en UCI, sin tener en cuenta su situación médica, como "algo agradable", dado el valor alcanzado en la puntuación media. No obstante, no podemos desestimar que para casi una cuarta parte de los familiares la estancia en UCI ha sido bastante o muy desagradable.

En cuanto a la valoración de los distintos aspectos inherentes a la unidad, vemos que la mayoría han sido valorados de forma positiva. En este sentido, destacan las valoraciones sobre los cuidados y atenciones de los distintos profesionales sanitarios de UCI, y de manera especial la atención de las necesidades psicológicas de pacientes y familiares, habiendo sido el aspecto que ha recibido mayor puntuación. Este hecho pone de relieve la importancia que tiene para las personas sometidas a gran impacto emocional, como son los familiares de UCI, el poder aliviar el sufrimiento y malestar psicológico que están experimentando en esos momentos, a la vez que valoran muy positivamente todo aquello que pudiera aliviar el malestar psicológico de su ser querido en UCI. En este sentido muchos familiares insisten en lo importante que sería para ellos el que un psicólogo clínico evaluara a nivel psicológico el estado del paciente. Asimismo, cabe señalar que otros aspectos importantes dentro de una UCI como son la claridad de la información recibida y el respeto a la intimidad, también han sido valorados positivamente.

Tal como hemos comentado la mayor parte de los aspectos de UCI han sido bien valorados por los familiares. Sin embargo, es necesario tener en cuenta aquellos otros con valoraciones si no negativas, más modestas, con la finalidad de poder atenderlos mejorando de esta manera la calidad de la estancia en una Unidad con características tan especiales como es la UCI. Así, los aspectos de UCI con menor valoración han sido el silencio en la sala y las posibilidades de distraerse, siendo este último el que ha obtenido una valoración más negativa y sobre el que sería importante incidir. 
Todos estos resultados van en la línea de los que obtuvimos en un estudio preliminar realizado con familiares de pacientes ingresados en la misma UCI (Gil, 2010) en el que los aspectos más valorados también fueron el hecho de que un psicólogo atendiera las necesidades psicológicas de pacientes y familiares así como los cuidados y atenciones del resto de profesionales de la UCI.

Igualmente, si atendemos a los resultados obtenidos respecto a la valoración de la claridad de la información recibida observamos que éstos son similares a los obtenidos por Bernat, Tejedor y Sanchís (2000) en un estudio realizado en la misma UCI, en el que la mayoría de familiares respondieron que la información médica recibida fue clara y concreta, lo cual tiene si cabe más importancia en el contexto de una UCI dada la gran incertidumbre asociada a la experiencia de tener a un ser querido en situación crítica.

En cambio, los resultados relativos al respeto de la intimidad difieren de los encontrados en otros estudios como el de Fridh et al. (2007) y el de Plakas et al. (2009) llevados a cabo en Suecia y Grecia respectivamente. Si bien es cierto que la privacidad/intimidad es considerada muy importante en el contexto de UCI (FaberLangendoen \& Lanken, 2000; Troug et al., 2001; Zafortea et al., 2010) lamentablemente no siempre se tiene en consideración. De esta manera, a partir de las valoraciones (positivas) obtenidas de los familiares sobre el respeto a la intimidad podemos considerar la UCI en la que hemos realizado la investigación un entorno privilegiado, lo cual puede haberse visto facilitado por la disposición de la propia unidad dado que los pacientes se encuentran en habitaciones individuales ubicadas dentro de una sala mayor, a diferencia de otras unidades de cuidados intensivos cuya estructura arquitectónica no favorece la privacidad o intimidad de los pacientes.

Respecto a la valoración del silencio en la sala de UCI los familiares conceden puntuaciones que podríamos considerar como neutras, es decir, no lo valoran de forma negativa si bien creen que sería un aspecto a mejorar. De hecho, en los comentarios que hacen al respecto refieren preocupación por si la falta de silencio en la unidad pudiera interferir en el descanso y recuperación de su ser querido. Estos datos van en la línea de la literatura científica revisada sobre el nivel de ruido objetivo que hay en las UCIs, originado por el ritmo de trabajo y la alta tecnología asociada a este entorno (Konkani \& Oakley, 2011; Lawson et al., 2010).

Y finalmente, respecto a las posibilidades de distracción, aún habiendo sido el aspecto con valoración más negativa tanto en el presente estudio como en un trabajo 
preliminar realizado por nuestro equipo de investigación (Gil, 2010), cabe decir que en la literatura revisada no hemos encontrado ninguna investigación que verse sobre este tema. Por ello no ha sido posible comparar nuestros resultados con los de otros estudios.

A partir de estos datos y en referencia a la hipótesis original "La valoración global de la estancia del paciente en UCI desde el punto de vista de los familiares será negativa identificando aspectos susceptibles de mejora", podemos decir que ésta se cumple en cuanto a la identificación de aspectos a mejorar dentro de la unidad. En cambio, la parte de la hipótesis que hace referencia explícitamente a la valoración de la estancia no se cumple plenamente ya que si bien la estancia ha sido valorada de forma negativa por un porcentaje nada despreciable de familiares, los resultados obtenidos no permiten concluir que la valoración global haya sido negativa.

Profundizando en el estudio de la estancia en UCI, los resultados relativos a la valoración diferencial de la misma a nivel global, con independencia de la situación médica, no han mostrado diferencias significativas en función de ninguna de las variables sociodemográficas consideradas (género, estado civil, tener o no hijos, parentesco, lugar de residencia, edad y nivel de estudios).

Analizando individualmente los distintos aspectos incluidos en la valoración de la estancia en UCI, tampoco se han obtenido diferencias significativas en función del género, grado de parentesco y nivel de estudios. Sin embargo, en la valoración de algunos aspectos particulares de la estancia en UCI sí se han obtenido diferencias significativas en función del estado civil, tener o no hijos, el lugar de residencia y la edad. Concretamente, en función del estado civil hemos observado que son los familiares con pareja quienes valoran más la atención de los médicos, la cantidad de la información recibida y el silencio en la sala. Asimismo, el afecto o apoyo recibido del personal de enfermería y la atención a los familiares han sido mejor valorados por los familiares sin hijos. En cuanto al lugar de residencia los resultados muestran que los familiares que no viven en la misma ciudad de Castellón han valorado más la cantidad de la información recibida, mientras que la calidad de las instalaciones ha sido mejor valorada por los familiares de Castellón ciudad. Por último, en función de la edad observamos que a medida que aumenta la edad los familiares valoran de forma más 
positiva la atención médica recibida, la cantidad y claridad de la información, el trato por parte del personal de enfermería y el silencio en la sala. Mientras que el respeto a la intimidad ha sido valorado de forma menos positiva a medida que aumenta la edad del familiar, lo cual no implica que este aspecto no sea importante para los familiares de más edad sino más bien todo lo contrario, es decir, con el paso de los años los familiares valoran si cabe más los aspectos relacionados con la privacidad y la intimidad estimando que éstos podrían ser mejorados dada la relevancia que tienen en el contexto de UCI, tal como señalan distintos autores (Faber-Langendoen \& Lanken, 2000; Troug et al., 2001; Zafortea et al., 2010).

A partir de estos resultados podemos considerar que en líneas generales se cumple la hipótesis inicial "Respecto a la valoración de la estancia en UCI no habrá diferencias significativas en función de las distintas variables sociodemográficas (género, edad, estado civil, número de hijos, grado de parentesco, lugar de residencia y nivel de estudios)", puesto que a nivel global no se han obtenido diferencias significativas en función de ninguna de las variables.

\subsubsection{PERCEPCIÓN DE ESTRÉS EN UCI DESDE EL PUNTO DE VISTA DE LOS FAMILIARES}

Al analizar el grado de estrés que genera en la familia tener a un ser querido ingresado en UCI observamos que para prácticamente todos los familiares la experiencia global es estresante en mayor o menor medida, con un predominio de los que la consideran muy estresante. Es decir, aproximadamente tres cuartas partes de los familiares perciben el ingreso en UCI como un acontecimiento que genera mucho/muchísimo estrés. Resultados similares se han obtenido en estudios previos (Chui \& Chan, 2007; O’Farrell, Murray \& Hotz, 2000).

Si intentamos concretar un poco sobre qué factores contribuyen a generar estrés en este contexto, los resultados muestran que para los familiares son muy estresantes los aspectos relacionados sobre todo con la gravedad médica del paciente, como por ejemplo que le pueda ocurrir algo grave a su ser querido, que pueda morir, que no obtenga alivio para el dolor y pensar si podrá volver a su vida normal después de salir del hospital. Tal como podemos comprobar estos factores coinciden con aquellos que en la literatura científica revisada conllevan mayor grado de incertidumbre y dudas en la familia generando por tanto niveles importantes de estrés (Curtis, 1983; Johansson et 
al., 2005). En este sentido, también hemos observado que el hecho de que la hospitalización sea inesperada resulta estresante para un porcentaje importante de familiares, habiéndose considerado este hecho en otros estudios como uno de los principales factores de riesgo para presentar sintomatología sobre todo ansiosa en la familia (Delva et al., 2002). Además, otro aspecto que contribuye a hacer de esta experiencia más estresante para los familiares es el estar separado de su ser querido, dado el horario restringido de visitas. Resultados similares se han obtenido en el estudio de Da Costa et al. (2010) al considerar entre los principales factores generadores de estrés para la familia el no poder estar acompañando al paciente.

Continuando con el análisis de la percepción de estrés en UCI cabe mencionar que algunos aspectos no generan prácticamente estrés en los familiares como por ejemplo que el paciente esté al cuidado de sanitarios desconocidos o pensar en la posible pérdida de dinero como consecuencia de la enfermedad. Asimismo, llama la atención que entre los factores menos estresantes para los familiares se encuentren aquellos que afectan directamente a su propia persona como es el caso de tener demasiados horarios de visitas, tener que comer a horas diferentes y organizarse para acudir al hospital, etc. Estos resultados ponen de manifiesto que lo más importante para la familia tras el ingreso en UCI es todo lo relacionado con el estado de salud de su ser querido pasando a un segundo lugar otros aspectos relativos al cuidado del propio familiar e incluso a las responsabilidades que éste pueda tener en otros contextos. Estos datos irían en la línea de lo que señala el estudio de Vandall-Walker et al. (2007) realizado en Canadá.

De esta manera, podemos decir que se confirma la hipótesis de partida "La experiencia de UCI resultará muy estresante para la familia, identificando como más estresantes aquellos aspectos relacionados con la gravedad del paciente y con el hecho de no poder estar junto a él".

Respecto al análisis diferencial de la percepción de estrés, a nivel general no ha mostrado diferencias significativas en función de las distintas variables sociodemográficas consideradas. No obstante, estas diferencias han alcanzado casi la significación en función del grado de parentesco, siendo las madres las que presentan en general más estrés. Resultados similares se han obtenido en el estudio de Chui \& Chan (2007) en el que muestran diferencias en función de la relación de parentesco con 
el paciente, siendo los padres quienes presentan mayor grado de estrés. En este mismo trabajo se han obtenido diferencias en el nivel de estrés en función de los estudios y la edad, aspectos que no han resultado significativos en el nivel de estrés general de nuestros familiares.

Si bien es cierto que a nivel global prácticamente no encontramos diferencias, éstas parecen más evidentes al analizar de manera individual los distintos ítems de la escala. Así, según el género hemos observado que a las mujeres les genera más estrés pensar que el paciente tenga dolor, no saber con seguridad cómo quedará después de la operación, ver que el personal del hospital tiene prisa y sentir olores extraños en el hospital. Estos datos irían en la línea de los estudios que señalan mayor nivel de estrés (Chui \& Chan, 2007) y afectación emocional (Armstrong \& Khawaja, 2002; Dickstein, 2000) en las mujeres.

En cuanto al estado civil, los resultados han mostrado que a los familiares con pareja les resulta más estresante no saber con seguridad cómo quedará el paciente después de una intervención quirúrgica, mientras que el hecho de no entender en qué consiste la enfermedad ha generado más estrés en los familiares sin pareja.

Respecto a tener o no hijos, las diferencias que hemos obtenido señalan que ciertos aspectos como que el paciente esté al cuidado de sanitarios desconocidos y pensar que el tiempo de información resulta insuficiente son más estresantes para los familiares que no tienen hijos. Estos datos podrían interpretarse desde el punto de vista en que los hijos sean considerados como un apoyo importante para el resto de la familia en este contexto, de ahí que su ausencia pueda influir en una mayor percepción de estrés en relación con algunos factores. A este respecto cabe decir que nuestros datos son más bien exploratorios ya que en la literatura científica revisada no se han encontrado estudios similares con los que poder compararlos, al igual que tampoco se han encontrado estudios diferenciales que contemplen la variable relativa a tener hijos.

En función del parentesco con el paciente los resultados han mostrado diferencias significativas en el grado de estrés que generan factores asociados a que el enfermo tenga dolor, los cuales han resultado ser más estresantes para las parejas y hermanos; y a estar separado del enfermo, también más estresante para los hermanos. Igualmente, se han obtenido diferencias casi significativas en el grado de estrés que genera pensar si el paciente podrá volver a su vida normal al salir del hospital y haber sido hospitalizado de repente en UCI más estresantes para las madres y hermanos 
respectivamente. Estos datos revelan que el ser hermano del paciente ingresado conlleva en algunos aspectos mayor grado de estrés, si bien en la literatura científica revisada no se les ha prestado demasiada atención.

Respecto al lugar de residencia, el análisis diferencial ha mostrado como es de esperar que el hecho de que el hospital esté lejos del domicilio familiar genera más estrés en los familiares que no viven en la misma ciudad. Asimismo, para estos familiares que residen más lejos del hospital también resultan más estresantes aquellos factores en los que esta mayor distancia y tiempo invertido en los viajes puedan interferir, como es el caso de no poder ocuparse de la familia al igual que siempre, tener que dormir fuera del domicilio habitual, no poder estar junto al enfermo todo el tiempo, no saber cuándo le darán el alta de UCI, tener que desplazarse a diario para visitar al enfermo en los cuatro horarios de visita y los horarios en que están concertadas las visitas.

Los resultados en función de la edad evidencian que a medida que aumenta la edad de los familiares los siguientes factores parecen generar menor grado de estrés: no saber los resultados/razones de los tratamientos, tener que organizarse para acudir a las visitas, no saber cuándo van a hacerle cosas al enfermo, que no le den la medicación para el dolor cuando la necesita, que el paciente sea atendido por distintos médicos durante el ingreso y que los familiares sean informados por distintos médicos. Estos datos parecen indicar que a medida que avanza la edad y con ella los años de experiencia, la importancia que se le concede a algunos factores puede ser menor como por ejemplo tener que organizarse para acudir a las visitas. Al mismo tiempo podemos intuir que el hecho de que estos factores generen menos estrés también puede ser indicativo de que los familiares de más edad puedan confiar más en el equipo médico de la unidad, de ahí que les genere menos estrés que el paciente sea atendido por diferentes médicos así como ellos mismos ser informados por médicos distintos.

Finalmente en cuanto al nivel de estudios hemos obtenido que a menor nivel de estudios de los familiares mayor es el grado de estrés que genera pensar que le pueda ocurrir algo grave al paciente.

A partir de estos resultados y teniendo en cuenta la hipótesis inicial "En cuanto a la percepción de estrés, esperamos obtener diferencias según el género, la edad, el estado civil, el número de hijos, el grado de parentesco, el lugar de residencia y el nivel de estudios, siendo probablemente mayor el grado de estrés general en las mujeres, de 
edades más jóvenes, con pareja e hijos, que viven más lejos del hospital, que son madres del paciente ingresado en UCI y que presentan un menor nivel de estudios" podemos decir que ésta se cumple en parte. Así, se han obtenido diferencias en función de las distintas variables sociodemográficas si bien estas diferencias se han encontrado respecto a diversos factores estresantes y no tanto en el grado de estrés general. En lo referente a la percepción de estrés general sólo se confirmaría la hipótesis en la variable relativa al grado de parentesco destacando el mayor estrés de las madres.

\subsubsection{ADAPTACIÓN AL INGRESO DE UN SER QUERIDO EN UCI}

Respecto al grado de interferencia en la vida de los familiares que produce el ingreso de un ser querido en UCI observamos una afectación global considerable en casi la totalidad de los familiares, tal como manifiestan diversos autores (Hupcey \& Penrod, 2000; Van Horn \& Tesh, 2000). Así el ingreso en UCI supone una ruptura en la vida cotidiana de la familia por lo que parece obvio pensar que todas las áreas de la vida de estas personas se verán afectadas en mayor o menor medida.

Analizando por separado los diferentes ámbitos de sus vidas vemos que la mayor interferencia se produce en el tiempo libre y en el trabajo. Resultados similares se han obtenido en un estudio piloto realizado en la misma UCI por Gómez, Gil y Ballester (2009). En este sentido, muchos familiares refieren haber visto afectada seriamente su dinámica habitual pasando a no tener prácticamente tiempo libre ni poder atender plenamente sus responsabilidades laborales. En estos momentos los familiares refieren no tener otro pensamiento que poder estar cerca de su ser querido por lo que suelen acudir a todas las visitas que les es permitido, y en algunos casos incluso permanecen en el hospital todo el día por miedo a ser llamados ante un cambio en el estado del paciente, lo cual interfiere de manera notable en su tiempo libre. Asimismo, dado el impacto de la situación que están viviendo, una parte importante de los familiares presenta dificultades en la ejecución de sus obligaciones laborales llegando en algunos casos a ser aconsejable el cese temporal de las mismas.

Si tenemos en cuenta que el tiempo libre de la familia es una de las áreas más afectadas no sorprende que la vida social de los mismos también experimente cierto grado de interferencia. En principio parece lógico pensar que ambas esferas, es decir, el tiempo libre y su vida social puedan verse afectadas al mismo nivel. En cambio, los 
familiares en la evaluación refieren una notable diferencia en el grado de interferencia experimentado, siendo menor la afectación de la vida social puesto que siguen manteniendo las relaciones de amistad e incluso a veces éstas pueden verse fortalecidas.

Por último, cabe señalar que las dos áreas con menor afectación han sido la relación de pareja y la vida familiar en general. Tras el ingreso es necesario un reajuste importante en la dinámica familiar lo cual inevitablemente repercutirá en la vida de pareja y en la familia en conjunto. No obstante, el grado de interferencia será menor que en el resto de áreas analizadas e incluso para algunos familiares pueden constituir una importante fuente de apoyo y consuelo. En este sentido cabe ser prudentes y no generalizar los resultados ya que en otros casos ese reajuste en los roles familiares puede constituir en sí mismo una fuente de estrés añadido a la gravedad de la situación que viven (Díaz \& Díaz, 2004).

A la luz de estos resultados la hipótesis inicial "El ingreso de un ser querido en UCI interferirá notablemente en distintos ámbitos de funcionamiento de la vida de sus familiares" se ve confirmada.

Profundizando en su estudio, el análisis diferencial del grado de interferencia que produce el ingreso de un ser querido en UCI, a nivel global ha mostrado diferencias sólo en función del grado de parentesco, siendo la pareja la que presenta mayor afectación.

Los resultados relativos al resto de áreas analizadas de manera individual no ha mostrado diferencias en función del estado civil, tener o no hijos, el lugar de residencia, la edad y el nivel de estudios. En cambio, se han obtenido diferencias en la adaptación al ingreso en función de dos variables, el género y el grado de parentesco. Respecto al género, las diferencias aparecen en el área social, la cual se ha visto más afectada en las mujeres. Y analizando los datos según el grado de parentesco vemos diferencias en todas las áreas excepto en la vida familiar general. Es decir, hay diferencias en la adaptación de los familiares al trabajo, la vida social, el tiempo libre, la relación de pareja y la vida de manera global, tal como hemos comentado unas líneas más arriba. Cabe señalar que en todas estas áreas es la pareja la que presenta mayor grado de interferencia, a excepción del área relativa a la relación propia de pareja, en la que han sido los padres quienes han presentado mayor afectación. Estos resultados van en la 
línea de los obtenidos por Gómez et al. (2009) en un estudio preliminar llevado a cabo con familiares de la misma UCI.

Respecto al área relativa a la relación de pareja nos gustaría señalar que por un lado son los padres quienes presentan mayor afectación mientras que el menor grado de interferencia se observa en las madres. Este dato resulta un tanto sorprendente puesto que el grado de parentesco de ambos (padre-madre) respecto al paciente es el mismo. En este sentido, posibles explicaciones podríamos encontrarlas en la variedad en la implicación emocional, en los roles que tiene cada miembro de la familia así como en un afrontamiento diferencial en función del género, en línea de lo que señalan algunos autores ante la pérdida de un hijo (Doka \& Martin, 2010).

Estos datos confirmarán la hipótesis inicial "Respecto a la adaptación de la familia al ingreso en UCI esperamos obtener diferencias en función del grado de parentesco con el paciente". Es decir, se han obtenido diferencias en función del parentesco, tal como contemplábamos en la hipótesis, así como también en función del género.

\subsubsection{NECESIDADES DE LOS FAMILIARES EN UCI}

Otro conjunto de variables analizadas de manera particular en los familiares han sido aquellas relacionadas con la satisfacción de sus necesidades en UCI. En general los resultados señalan mayor satisfacción en todo lo relativo a la atención y cuidados médicos recibidos por el paciente percibiendo además que los profesionales sanitarios muestran su parte más humana manifestando en general preocupación por el paciente. Resultados similares se han obtenido en un estudio multicéntrico realizado en Francia (Azoulay et al., 2001) así como en otro trabajo llevado a cabo en Suecia por Karlsson, Tisell, Engström y Andershed (2011).

Asimismo los familiares también refieren estar satisfechos, aunque en menor medida, con la comprensión de lo que le sucede al paciente y la claridad y honestidad de la información recibida, en línea de los resultados obtenidos en un estudio realizado en Canadá por Bailey et al. (2010).

Estos datos evidencian que los aspectos en los que la familia se muestra más satisfecha pertenecen a las categorías de las necesidades reconocidas como más relevantes en diferentes estudios, es decir, a las necesidades de seguridad e 
información (Bijttebier et al., 2001; Gómez-Calcerrada, 2004; Margall et al., 1993; Maxwell et al., 2007; Molter, 1979). Igualmente, la satisfacción de estas cuestiones particulares que acabamos de comentar, como por ejemplo los cuidados de salud recibidos por el paciente y la claridad de la información, parece estar asociada con la satisfacción global de los familiares (Auerbach et al., 2005; Heyland et al., 2002). No obstante, aun viéndose satisfechas estas necesidades por la mayoría de familiares no podemos desestimar los porcentajes, por reducidos que sean, de aquellos familiares que muestran menor satisfacción.

Si bien es cierto que identificar los aspectos de mayor satisfacción para la familia en la unidad es importante, pues permitirá reforzar a los profesionales sanitarios en su desempeño a estos niveles, es necesario analizar los aspectos en los que la familia reporta menor grado de satisfacción con la finalidad de introducir cambios que de alguna manera repercutan positivamente en su bienestar. En este sentido, los familiares refieren menor satisfacción en la explicación recibida sobre el equipamiento utilizado, coincidiendo con los resultados de Auerbach et al., (2005), así como en el interés particular mostrado en ellos como familiares por parte del personal sanitario. A este respecto cabe recordar que aunque en la literatura científica revisada aparecían como secundarias distintas cuestiones relacionadas directamente con el confort de la familia (Gómez-Calcerrada, 2004; Hickey, 1990; Koller, 1991; Margall et al., 1993; Mendonca \& Warren, 1998), esto no implica que no puedan ser importantes para los familiares, sobre todo si son identificadas entre las menos satisfechas, tal como ocurre en nuestro estudio.

Asimismo, al evaluar las necesidades de los familiares nos parece relevante comentar que un porcentaje importante de los mismos refieren no haberse sentido nunca solos y aislados en la sala de espera. La soledad y el aislamiento en principio suelen tener connotaciones negativas por lo que a priori el no sentirse solo y aislado podría asociarse a mayor satisfacción en los familiares. No obstante, en determinados momentos estos aspectos pueden ser necesarios y adaptativos, convirtiéndose entonces la falta de soledad en motivo de insatisfacción. Todo esto pone de manifiesto la importancia de no presuponer nada y asegurarnos en la medida de lo posible de cuáles son las necesidades particulares de cada familiar.

A partir de estos resultados podemos concluir que la hipótesis de partida "Los familiares presentarán diferentes necesidades no satisfechas en UCI" se cumple siendo las principales necesidades aquellas relacionadas con las explicaciones del 
equipamiento utilizado y el interés mostrado hacia los familiares por parte del personal sanitario. De la misma forma cabe señalar que incluso las necesidades que han obtenido mejor valoración no han sido completamente satisfechas en todos los familiares.

Continuando con el estudio de las necesidades de los familiares en UCI, el análisis diferencial ha mostrado diferencias en función de distintas variables sociodemográficas como el género, el estado civil, el grado de parentesco con el paciente, el lugar de residencia y la edad. Cabe señalar que estas diferencias se muestran sobre todo en relación con dos de las necesidades evaluadas, concretamente las que hacen referencia a los cuidados del paciente y a las atenciones que recibe el propio familiar por parte de los sanitarios, necesidades que según los factores establecidos por Leske (1991) se incluirían en las categorías de seguridad y confort respectivamente.

De esta manera, respecto a los cuidados médicos observamos menor satisfacción en las mujeres y en los familiares sin pareja. $\mathrm{Y}$ en referencia a la atención recibida por el propio familiar observamos menor satisfacción entre los familiares sin pareja, hermanos del paciente y familiares que residen en la misma ciudad de Castellón. Asimismo, estas dos necesidades se ven más satisfechas a medida que aumenta la edad de los familiares.

En cambio, los resultados del análisis no muestran diferencias significativas en función del nivel de estudios, a diferencia de los resultados del estudio de Delva et al. (2002) en el que un menor nivel de estudios se relaciona con más necesidades a distintos niveles (seguridad, proximidad, apoyo y confort). De la misma forma tampoco se han obtenido diferencias significativas en función de tener o no hijos, si bien estas diferencias estarían próximas a la significación respecto al sentimiento de soledad experimentado por los familiares en la sala de espera, siendo mayor en los familiares sin hijos, resultado que no sorprende en absoluto ya que el no tener hijos puede reducir considerablemente el apoyo más inmediato que pueda recibir el familiar.

Si bien las necesidades de los familiares de UCI han sido el tema central de distintas investigaciones llevadas a cabo en este contexto (Bijttebier et al., 2001; Maxwell et al., 2007; Mendonca \& Warren, 1998; Molter, 1979), en la literatura revisada 
son escasos los estudios que analizan posibles diferencias en función de variables sociodemográficas, lo cual dificulta la comparación de resultados. En este sentido, sólo hemos podido comparar nuestros datos con los obtenidos en una investigación realizada en Bélgica (Delva et al., 2002) y de manera parcial, dado que la versión del instrumento y las variables sociodemográficas incluidas a estudio no eran exactamente las mismas. Así nuestros resultados irían en la línea de los del estudio de Delva et al. (2002) en cuanto a las diferencias en función del género, dado que en este estudio las mujeres son las que presentan más necesidad de seguridad, factor que como hemos citado anteriormente incluiría a los cuidados médicos. Igualmente, en este estudio también se han encontrado diferencias en función del parentesco con el paciente y la edad, que aunque no coinciden exactamente con nuestros datos, nos indicarían que estas variables parecen relevantes a la hora de determinar las necesidades de los familiares. Y finalmente, respecto al nivel de estudios si bien en nuestra investigación no se han obtenido diferencias, éstas sí se han confirmado en la de Delva et al. (2002), de manera que un menor nivel de estudios se relaciona con más necesidades a distintos niveles (seguridad, proximidad, apoyo y confort).

En resumen nuestros resultados apoyan la hipótesis de partida "En cuanto a las necesidades de los familiares esperamos encontrar diferencias en función de distintas variables sociodemográficas" confirmándose dichas diferencias en función del género, el estado civil, el grado de parentesco con el paciente, el lugar de residencia y la edad.

\subsubsection{VALORACIÓN SOBRE EL PROCESO DE MORIR}

Al preguntar a los familiares qué aspectos les ayudarían más si tuvieran que enfrentarse al final de la vida, por orden de preferencia los familiares refieren en primer lugar que lo que más les ayudaría a morir en paz sería poder comunicarse y estrechar vínculos afectivos con sus seres queridos, seguido por otros aspectos más directamente relacionados con el alivio del sufrimiento a lo largo del proceso, pensar que su muerte no suponga una carga insoportable para los demás y otro factor de corte más existencial, como el hecho de pensar que su vida ha tenido algún sentido. En cambio, los factores que menos les ayudarían en el proceso de morir han sido pensar que pudieran morir en casa y creer en otra vida después de la muerte. 
Estos resultados van en la línea de los obtenidos en un estudio preliminar realizado con 39 familiares de pacientes ingresados en la misma UCI (Ballester, Gil, Gil \& Gómez, 2011).

Igualmente, los resultados relativos a los aspectos más importantes al final de la vida coinciden en parte con los obtenidos en estudios previos realizados en otros contextos. Tal es el caso de la investigación llevada a cabo por Bayés et al. (2000) con 419 profesionales sanitarios españoles y la realizada por Brito, Bocaz, Bustos y González (2009) en Chile con 130 estudiantes de enfermería para quienes lo más importante llegado el momento de la muerte era poder sentirse cerca, comunicarse y estrechar vínculos con sus personas queridas.

En cuanto a los aspectos que menos ayudarían a morir en paz, nuestros resultados coinciden con los del estudio de Bayés et al. (2000) al señalar como menos importantes el hecho de morir en casa y creer en otra vida después de la muerte. Esto nos llevaría a pensar que lo más importante para los familiares no es dónde, sino cómo y con quién se muere. A la vez que el creer en otra vida después de la muerte podría estar condicionado al tipo de creencias religiosas de los participantes, aspecto que no hemos podido confirmar dado que en nuestra investigación no hemos recogido datos al respecto.

A partir de estos resultados podemos considerar que se cumple la hipótesis inicial "Ante la hipotética situación de que tuviesen que enfrentarse al final de la vida los familiares darán más importancia a aspectos relacionales como poder estar más tiempo junto a sus seres queridos" puesto que éste ha sido el aspecto prioritario al final de la vida desde el punto de vista de los familiares.

Si bien es cierto que los resultados muestran como más importantes unos aspectos sobre otros al final de la vida, cabe subrayar que todos los factores que contempla el cuestionario (CAMP) han sido elegidos por algún familiar, lo que pone de manifiesto la importancia de atender las diferencias individuales en general y de manera especial en circunstancias tan delicadas como enfrentarse al final de la vida.

Atendiendo al análisis diferencial de los aspectos prioritarios al final de la vida los resultados han mostrado diferencias significativas en función del género y casi significativas en función del nivel de estudios. Concretamente, respecto al género estas 
diferencias se aprecian en aspectos de corte existencial, siendo las mujeres quienes llegado el momento de la muerte conceden más importancia al hecho de pensar que su vida haya tenido algún sentido. Mientras que los resultados en función del nivel de estudios muestran diferencias en la importancia que se le concede a creer en otra vida después de la muerte, de manera que a medida que aumenta el nivel de estudios los familiares parecen dar más importancia a este factor. Estos resultados coinciden con los obtenidos previamente por Ibáñez (2009) y Ballester et al. (2011), los cuales también muestran diferencias en función del género y el nivel de estudios en el hecho de pensar que la vida ha tenido algún sentido y en la importancia de creer en otra vida, respectivamente. No obstante, los citados estudios no afirmaron una tendencia clara respecto a las diferencias según el nivel de estudios.

En cambio, otras variables como el estado civil, el tener o no hijos, el parentesco, el lugar de residencia y la edad tendrían menor importancia a la hora de elegir qué aspectos ayudarían a morir en paz.

A la luz de estos resultados podemos decir que se cumple en parte la hipótesis inicial "Respecto a la valoración de los aspectos que podrían facilitar una muerte en paz esperamos encontrar diferencias en función del género y el nivel de estudios. Así, las mujeres darán más importancia a aspectos existenciales así como a otros más relacionales como poder estar cerca de las personas queridas. Mientras que en función del nivel de estudios esperamos diferencias respecto a creer en otra vida después de la muerte siendo este aspecto más importante para los familiares de menos estudios". Es decir, se confirma que las diferencias en la valoración han tenido lugar en función del género y el nivel de estudios. Asimismo comprobamos que las mujeres tal como esperábamos han valorado más aspectos existenciales al final de la vida. Sin embargo, no se confirma que las mujeres en el hipotético caso de que se estuvieran enfrentando al final de la vida concedan más importancia que los hombres a poder estar cerca de los suyos. $\mathrm{Y}$ respecto al nivel de estudios, si bien confirmamos que hay diferencias en la importancia que se concede en estas circunstancias a creer en otra vida después de la muerte, observamos a diferencia de lo esperado, que a medida que aumentan los estudios más importancia se le concede a este factor. 


\subsubsection{VALORACIÓN DEL PROCESO DE INFORMACIÓN Y TOMA DE DECISIONES}

Los resultados relativos a la valoración del proceso de información y la toma de decisiones han mostrado que para los familiares el papel más importante en el proceso lo tiene el psicólogo, seguido de la familia y el médico, concediéndole el menor grado de importancia al paciente. Resultados que difieren del papel concedido a las distintas partes implicadas en el proceso desde el punto de vista de los profesionales sanitarios (Gómez, 2011) y los pacientes (Bernat, 2010) de UCI. Cabe señalar que no hemos encontrado en la literatura científica revisada trabajos sobre este tema desde la perspectiva del familiar lo que ha dificultado comparar nuestros resultados.

$\mathrm{Al}$ analizar estos datos llama la atención de manera notable la valoración de la familia sobre a quién concede el papel más y menos importante en el proceso. Por un lado, respecto a que el paciente sea considerado por los familiares como la parte menos importante en el proceso de información y la toma de decisiones, ciertos comentarios obtenidos en las entrevistas con las familias nos llevan a pensar que lejos de menospreciar su valía en el proceso, habría un intento por parte del familiar de proteger al paciente a la hora de tomar decisiones importantes en este contexto. Esto a su vez de alguna manera implicaría que la familia fuera informada al margen del paciente incurriendo en la conocida conspiración del silencio. E incluso avanzando un poco más, esta realidad podría ser reflejo de la dificultad de la familia para enfrentarse al sufrimiento de lo que está sucediendo, en línea de lo que señala Barbero (2006) en un trabajo sobre el derecho del paciente a la información.

Por otro lado, resulta un tanto sorprendente el hecho de que en un contexto de extrema gravedad médica los familiares concedan la mayor importancia al papel del psicólogo en el proceso de información y toma de decisiones, superando la importancia dada a los médicos. Estos datos irían en línea de los resultados que hemos obtenido en la valoración de la estancia en UCI donde cabe recordar que el aspecto mejor valorado ha sido la atención de las necesidades psicológicas de los pacientes y familiares. De alguna manera esta información puede ser indicativa del gran malestar experimentado por la familia en estas circunstancias, evidenciando la gran labor del psicólogo en este contexto como parte del equipo multidisciplinar de la UCI.

En cuanto a la satisfacción con la información la mayoría de familiares se muestran bastante o totalmente satisfechos con la información recibida sobre el estado, 
tratamiento y pronóstico de la enfermedad $(97,1 \%)$ y afirman haber tenido la oportunidad de aclarar todas sus dudas $(91,2 \%)$. Estos resultados van en la línea de los obtenidos en un estudio multicéntrico realizado en Canadá (Heyland et al., 2003). Asimismo, al preguntar sobre el hecho de participar en decisiones médicas, los resultados muestran que sólo una quinta parte de los familiares se siente "totalmente" capacitado siendo mayor el porcentaje de pacientes que se siente con "bastante" capacidad para hacerlo (55,9\%). Otro dato relevante sobre la participación en decisiones importantes es el hecho de que para la mitad de los familiares el participar en una decisión crítica sí pueda ser visto como una carga.

Y finalmente, en cuanto a las preferencias sobre el estilo del médico a la hora de informar los resultados no han mostrado una tendencia clara por parte de los familiares, es decir, los porcentajes obtenidos en relación con un estilo que anticipe posibles sospechas y un estilo más prudente que sólo haga referencia a lo que se sabe con certeza son bastante parecidos. Resultados similares se han obtenido en un estudio exploratorio sobre las experiencias globales de los familiares de UCI en Gran Bretaña (Hughes et al., 2005).

Por todo lo comentado podemos decir que la hipótesis "Respecto al proceso de información y la toma de decisiones, para los familiares el papel más importante en este proceso lo tendrá la familia percibiendo la participación en la toma de decisiones más como una carga que como un privilegio" no se cumple en referencia al papel más importante en el proceso ya que hemos observado que éste ha sido concedido al psicólogo y no al propio familiar (en segundo lugar). En cambio respecto a percibir la participación en decisiones relevantes como una carga, cabe señalar que se cumpliría aproximadamente para la mitad de los familiares.

Profundizando un poco más en el estudio de la valoración del proceso de información y toma de decisiones, cabe señalar que el análisis diferencial de las distintas subescalas consideradas en el CITD no ha mostrado diferencias en función del estado civil, tener o no hijos, el grado de parentesco, el lugar de residencia y la edad. Es decir, las citadas variables sociodemográficas no parecen ser relevantes en la valoración de la importancia de los distintos agentes implicados en este proceso (paciente, familia, médico y psicólogo), en la satisfacción con la información, en las preferencias en cuanto al estilo del médico a la hora de informar así como tampoco en 
la capacidad percibida para participar en decisiones relevantes y si esta participación sería una carga o un privilegio.

En cambio se han obtenido diferencias en función del género y del nivel de estudios en algunas subescalas. Concretamente las diferencias según el género muestran que las mujeres conceden más importancia a la familia en el proceso, esto es, se conceden mayor relevancia a ellas mismas lo cual de alguna manera haría referencia a una mayor implicación de las mujeres en este proceso lo cual sería acorde con que la mayoría de cuidadores primarios suelen ser mujeres (García, 2011). Asimismo, las mujeres muestran mayor preferencia hacia un estilo médico que no informe sobre lo que todavía no es seguro. En principio y teniendo en cuenta la mayor ansiedad asociada a las mujeres podíamos pensar en una posible tendencia a anticipar. Si bien esta tendencia en general suele estar presente ya que se plantean múltiples dudas sobre el estado y tratamientos del paciente, los datos parecen indicar que de la figura del médico esperan información realista y basada en pruebas, lo que puede favorecer la estabilidad emocional de estas personas.

Igualmente, los resultados han mostrado una relación significativa entre el nivel de estudios y la capacidad percibida para participar en una decisión médica relevante, con tendencia por parte de los familiares a percibirse menos capaces a medida que aumenta el nivel de estudios. De entrada estos resultados llaman la atención ya que en general suele asociarse mayor nivel de estudios a mayor capacidad (Jorm, Scott, Henderson \& Kay, 1988; O'Connor, Pollitt, Treasure, Brook \& Reiss, 1989). No obstante, cabe matizar que en nuestro trabajo no nos estamos refiriendo a mayor capacidad objetiva sino a la percepción de capacidad que tienen los familiares y además en una situación particular como lo es el ingreso de un ser querido en UCI. Si atendemos a estas peculiaridades tal vez podamos entender con mayor facilidad los resultados obtenidos puesto que en una UCI las decisiones médicas no sólo son muy relevantes sino que además presentan un componente emocional importante, dada la situación crítica del paciente. Esta argumentación iría en la línea del estudio de Anderson et al. (2009) según el cual los familiares que presentan síntomas de ansiedad y depresión se sienten menos capaces para participar en decisiones relativas al paciente. Por otra parte, tal vez la respuesta a esa menor percepción de capacidad también podría estar basada en una valoración sobre las consecuencias que la decisión tomada pudieran tener sobre la vida de la persona querida, no sintiéndose el familiar siempre con 
fuerzas para asumir parte de esa responsabilidad sobre todo en relación con decisiones médicas realmente importantes.

Asimismo, aunque en nuestro trabajo no se ha obtenido correlación significativa entre el nivel de estudios y percibir la participación en decisiones relevantes como carga o privilegio, sí se observa por el signo de la relación cierta tendencia a que los familiares de mayor nivel de estudios perciban la participación más como una carga. Estos resultados difieren de los encontrados en un estudio preliminar realizado en UCI con pacientes críticos por Bernat (2010) en el que se obtiene que a mayor nivel de estudios los pacientes tienden a percibir más como un privilegio participar en decisiones médicas importantes.

Cabe señalar que la importancia de la participación de los familiares en la toma de decisiones en una UCI contrasta con la escasez de estudios en la literatura científica revisada que analicen cuestiones relacionadas con el proceso de información y toma de decisiones en la familia, lo cual ha dificultado comparar nuestros datos con otros estudios realizados con muestras similares. En este sentido podemos considerar estos datos como exploratorios a la espera de ser contrastados en nuevas investigaciones.

Finalmente, a partir de lo comentado podemos considerar que se cumple la hipótesis inicial "En cuanto a la valoración del proceso de información y la toma de decisiones esperamos obtener diferencias significativas en función de algunas variables sociodemográficas".

\subsubsection{PRINCIPALES VARIABLES PREDICTORAS DE LA AFECTACIÓN PSICOLÓGICA DE LOS FAMILIARES}

Con la finalidad de profundizar en el estudio de la muestra de familiares hemos tratado de analizar qué variables sociodemográficas tienen mayor influencia en la afectación psicológica y el malestar asociado a la experiencia de tener a un ser querido ingresado en una Unidad de Cuidados Intensivos. En concreto pretendíamos conocer la influencia de las citadas variables en la valoración global de la estancia en UCI, el nivel de estrés, la ansiedad y la depresión, considerando además la influencia de variables clínicas psicológicas como la ansiedad y la depresión en la valoración de la estancia en UCI y el nivel de estrés. 
En este sentido, y respecto a la valoración global de la estancia en UCI los resultados del análisis de regresión han mostrado que esta valoración no parece ser explicada por ninguna de las variables consideradas, es decir, la edad, el género, el estado civil, el número de hijos, el nivel de estudios, el grado de parentesco con el paciente, el lugar de residencia, la ansiedad y la depresión no predicen la valoración de los familiares sobre la estancia en UCI de su ser querido. Si bien a nivel teórico podíamos intuir que las citadas variables fueran importantes en esta valoración.

En cuanto al nivel de estrés general de los familiares podemos decir que éste es modulado por los niveles de ansiedad y depresión, de modo que a mayor sintomatología ansiosa y depresiva mayor es el grado de estrés. Estos datos no sorprenden si tenemos en cuenta la correlación encontrada entre estas tres variables en distintos estudios (Apostolo et al., 2011; Méndez et al., 2010). Sin embargo, ninguna de las variables sociodemográficas analizadas (edad, género, estado civil, número de hijos, nivel de estudios, grado de parentesco con el paciente y lugar de residencia) predice el nivel de estrés general de los familiares, a diferencia de los resultados obtenidos en otras investigaciones que señalan que el estrés es predicho por un menor nivel de estudios (McAdam \& Puntillo, 2009) y ser mujer (McAdam \& Puntillo, 2009; Samuelson et al., 2007).

En referencia al papel modulador de distintas variables sociodemográficas en la ansiedad hemos encontrado que esta sintomatología parece ser explicada por el lugar de residencia, el estado civil y el nivel de estudios. De esta manera, residir más lejos, tener pareja y un menor nivel de estudios predeciría los síntomas de ansiedad. Estos resultados, concretamente los relativos al papel del nivel de estudios coinciden con los encontrados por McAdam y Puntillo (2009). No obstante, nuestros datos difieren en parte con los de estos autores y los resultados obtenidos por Pochard et al., (2001), quienes encontraron que ser esposa del paciente y mujer predecían la sintomatología ansiosa.

Y por último, los síntomas de depresión parecen ser explicados por el nivel de estudios, la edad, el género y el número de hijos. De modo que un menor nivel de estudios, mayor edad, ser mujer y tener hijos predeciría la sintomatología depresiva. Estos datos irían en la línea de los obtenidos en distintos estudios en los que el género (Gries et al., 2010; McAdam \& Puntillo, 2009; Pochard et al., 2001) y el nivel educativo (Gries et al., 2010; Paparrigopoulos et al., 2006) predicen la sintomatología depresiva. 


\subsection{COMPARACIÓN ENTRE PACIENTES Y FAMILIARES}

La situación de estar ingresado en una UCI puede presentar implicaciones diferentes desde el punto de vista de lo que supone o conlleva dicha experiencia para el paciente y su familia. En un intento por comprender mejor esta realidad en este trabajo se han llevado a cabo análisis diferenciales entre ambos grupos, cuyos resultados muestran al respecto diferencias significativas entre pacientes y familiares en todos los aspectos evaluados.

Analizando la afectación psicológica en términos de ansiedad y depresión hemos observado que ésta es mayor en la familia. Estos resultados confirmarían los obtenidos en un estudio preliminar llevado a cabo por nuestro equipo de investigación (Gil et al., 2010) e irían en la línea de las altas prevalencias en ansiedad y depresión mostradas en distintas investigaciones (Anderson et al., 2009; Fumis \& Deheinzelin, 2009; Pochard et al., 2001; Pochard et al., 2005) cuyas cifras son superiores a las encontradas en muestras de pacientes. Asimismo y completando la información relativa a la afectación emocional tras el ingreso en UCI, observamos que los familiares también perciben mayor grado de estrés general en esta situación.

En cuanto a la estancia en UCI, tras comparar la valoración de los pacientes sobre su estancia con las expectativas de los familiares al respecto, encontramos diferencias en la valoración global, es decir, sin considerar la situación médica la familia valora de forma más negativa que el paciente su estancia en la unidad. Esta tendencia general de la familia a sobreestimar el malestar del paciente también se ha reflejado en otros estudios como por ejemplo el llevado a cabo por Myhren et al. (2009) en Noruega con una muestra considerable de pacientes y de familiares tras el alta de UCI.

Igualmente, se observan diferencias en la valoración de otros aspectos más concretos de la estancia como la atención, el trato y apoyo emocional recibido del personal de enfermería, la atención a los familiares, la calidad de las instalaciones y el silencio en la sala. Cabe señalar que todos estos aspectos también han sido peor valorados por los familiares a excepción de la valoración del silencio en la sala, valorado de forma más positiva. Una posible explicación a que la familia perciba más silencio o tranquilidad en la sala de UCI podemos encontrarla en el hecho de que durante las visitas, en la medida de lo posible, los sanitarios no suelen llevar a cabo procedimientos terapéuticos que interfieran en la calidad del tiempo limitado que dura la visita al paciente. De igual forma dado que en este caso se trata de una percepción 
subjetiva parece lógico pensar que en esta valoración pueda influir el estado de salud de la persona así como los niveles de ruido ambiental de referencia, es decir, no percibirá el mismo nivel de ruido en la sala el paciente críticamente enfermo que el familiar que en principio no presenta enfermedad alguna y que llega a la visita procedente de la calle teniendo como referencia los niveles de contaminación acústica propios de una ciudad.

Respecto a la valoración del proceso de morir se observan diferencias entre pacientes y familiares en la priorización de los aspectos que facilitarían una muerte en paz, en el hipotético caso de que se estuvieran enfrentando al final de la vida. En este sentido, los factores relacionados con poder estar cerca, comunicarse y estrechar vínculos afectivos con los seres queridos así como no sentirse culpable por conflictos personales del pasado resultan más importantes para los familiares. Asimismo, los resultados también muestran diferencias casi significativas en referencia a la importancia concedida en estos momentos al hecho de poder controlar el dolor y los síntomas de malestar, siendo estos aspectos más valorados por los propios pacientes. Resultados similares se han obtenido por un lado en el estudio de Ibáñez (2009) en el que se analizan diferencias entre pacientes, familiares y población general y por otro lado en un estudio preliminar sobre la valoración diferencial del proceso de morir entre pacientes, familiares y sanitarios de UCI, en el que además se vio que las preferencias de los pacientes coincidían con las de los profesionales sanitarios (Ballester et al., 2007).

Por último, en la valoración del proceso de información y toma de decisiones también se observan diferencias entre pacientes y familiares, concretamente en la importancia concedida a las distintas partes implicadas en el proceso así como en la capacidad percibida para tomar decisiones importantes relacionadas con la salud. En este sentido, observamos que en el proceso de información y toma de decisiones pacientes y familiares dan más importancia al papel que ellos mismos pueden desempeñar en el proceso, es decir, para el paciente será más importante su propio papel en el proceso así como para el familiar también tendrá más importancia la familia. Y respecto a la capacidad para participar en decisiones médicas los pacientes se sienten más capacitados que los familiares para tomar decisiones relevantes relacionadas con la salud, lo cual podría estar influido por la menor afectación psicológica en términos de ansiedad y depresión tal como refieren Anderson et al. (2009).

Estos datos confirman casi en su totalidad la hipótesis de partida "Respecto a las diferencias entre el grupo de pacientes y familiares esperamos obtener una mayor 
afectación psicológica en términos de ansiedad, depresión y percepción subjetiva de malestar en los familiares. Asimismo, la familia valorará de forma más negativa la estancia en UCI de su ser querido, experimentará mayor grado de estrés, daría más importancia llegado el momento de la muerte a poder estar con su ser querido y estrechar vínculos afectivos. $Y$ en cuanto al proceso de información y la toma de decisiones, el papel de la familia en el proceso será más valorado por los familiares mientras que los pacientes darán más importancia al propio enfermo. Y finalmente, en referencia a la participación en decisiones médicas los pacientes se sentirán más capacitados y percibirán dicha participación menos como una carga dura de soportar que los familiares". A partir de nuestros resultados el único aspecto que no confirmaría la hipótesis hace referencia al hecho de que los pacientes perciban menos como una carga la participación en decisiones médicas, no habiéndose obtenido diferencias al respecto entre pacientes y familiares.

En definitiva, este estudio nos ha permitido conocer cuál es la afectación emocional de pacientes y familiares en una Unidad de Cuidados Intensivos proporcionándonos información relativa tanto a variables clínicas psicológicas como la ansiedad, la depresión y el nivel de estrés asociado a este contexto, como información relacionada con otras variables más directamente vinculadas al ingreso en UCI, por ejemplo la valoración de su estancia en la unidad, las necesidades de los familiares y posibles factores estresores. Asimismo, dadas las connotaciones de gravedad asociadas al entorno de UCI donde a diario se convive con el sufrimiento y la muerte, donde la toma de decisiones adquiere un cariz particular, a lo largo del presente estudio hemos intentado también analizar variables relativas al proceso de información y toma de decisiones así como conocer los principales factores que podrían facilitar una muerte digna. Además, hemos explorado la influencia de distintas variables sociodemográficas y clínico-médicas en la afectación emocional de pacientes y familiares.

Consideramos que nuestros hallazgos nos permiten acercarnos de primera mano a la realidad del ingreso en UCI para poder atender aquellos aspectos que son causa de malestar psicológico tanto en el paciente como en su familia y en definitiva ayudarles a mejorar su calidad de vida facilitando un afrontamiento adaptativo a esta situación. En este sentido, la utilidad de nuestros resultados sería doble: por un lado mejorar los 
aspectos emocionales a través de intervenciones breves como counselling en momentos críticos del proceso y por otro lado facilitar cambios estructurales o de funcionamiento de UCI que podrían disminuir el número de estresores. No obstante, es necesario ser conscientes de que este estudio presenta algunas limitaciones.

En primer lugar cabe señalar la reducida representatividad de la muestra ya que los datos corresponden a una sola UCI. En este sentido hemos tenido dificultades para evaluar a pacientes y familiares de otras unidades debido a que para ello es necesario un psicólogo con formación clínica específica en este ámbito. Como bien sabemos actualmente todavía no se incluye la figura del psicólogo como parte del equipo multidisciplinar de UCI, viéndose de esta manera considerablemente reducidas las posibilidades de obtener datos de otras unidades.

Otra de las limitaciones de nuestro trabajo ha sido el tamaño muestral, sin duda condicionado por la dificultad que conlleva la recogida de datos en un contexto de las características de UCI. La gravedad médica del paciente así como los procedimientos terapéuticos utilizados en este contexto muchas veces imposibilitan su evaluación. Por su parte los familiares se ven desbordados por la gravedad de la situación y por los múltiples cambios en su dinámica habitual, adoptando nuevos roles en el entorno familiar que limitan considerablemente el tiempo disponible. Claramente la prioridad del familiar cuando acude a UCI es visitar al enfermo y no ser evaluado a través de unos cuestionarios. Por ello hemos dejado a elección del familiar la posibilidad de participar en el estudio. Esta voluntariedad al mismo tiempo podría convertirse en posible fuente de sesgo, queriendo participar en el estudio aquellos familiares que pudieran estar experimentando mayor malestar emocional. Asimismo el disponer de un modesto número de participantes limita las posibilidades a la hora de llevar a cabo análisis diferenciales dada la reducida representacion en algunas categorías de las variables sociodemográficas o clínico-médicas.

Igualmente cabe subrayar la falta de trabajos llevados con pacientes críticos y sus familiares estando todavía ingresados en la UCI y de manera particular aquellos que analizan la afectación diferencial en función de variables sociodemográficas, lo cual ha limitado la comparación de nuestros resultados.

Pese a lo comentado consideramos que la presente tesis constituye una aproximación bastante completa a lo que supone ser paciente crítico y ser familiar de 
un paciente gravemente enfermo ingresado en una UCI, la mayoría de veces de forma inesperada, mostrándonos a la vez la necesidad de seguir profundizando en su estudio.

En este sentido entre las principales líneas futuras de investigación estarían por un lado replicar el estudio en otras unidades de cuidados intensivos a la vez que ampliar el tamaño de la muestra para poder llevar a cabo análisis diferenciales que nos permitieran contrastar los resultados obtenidos.

Igualmente, consideramos relevante la inclusión de nuevos datos demográficos y clínicos como por ejemplo las creencias religiosas, una medida objetiva de gravedad médica, procedimientos considerados invasivos o dolorosos, así como el tiempo exacto transcurrido desde el ingreso. Esta información nos permitiría profundizar en el estudio de las variables implicadas en la afectación emocional en UCI.

Asimismo entre las posibilidades futuras de continuar investigando en este ámbito cabe plantear la realización de estudios longitudinales que analicen la afectación de pacientes y familiares de UCI a más largo plazo habida cuenta de la literatura que encuentra una cierta prevalencia de TEPT en pacientes que han estado en una UCI meses después de su alta (Anderson, Arnold, Angus \& Bryce, 2008; Cuthbertson, Hull, Strachan \& Scott, 2004; Richter, Waydhas \& Pajonk, 2006).

Una vez analizada toda la información sobre la afectación emocional y posibles variables moduladoras estaríamos en disposición de elaborar e implementar programas de prevención y/o tratamiento dirigidos a disminuir el malestar y mejorar en la medida de lo posible la calidad de vida de pacientes y familiares sometidos al impacto del ingreso en UCI. 


\section{CAPÍTULO 8}

\section{PRINCIPALES CONCLUSIONES}





\section{RESUMEN DE LAS PRINCIPALES CONCLUSIONES}

A continuación se enumerarán las principales conclusiones obtenidas respecto a la afectación emocional de los pacientes y familiares de UCI.

\subsection{PACIENTES}

- La afectación psicológica de los pacientes considerada globalmente en términos de ansiedad y depresión ha sido leve o moderada, si bien un $20 \%$ muestra puntuaciones clínicas en ansiedad y un 23-27\% en depresión.

- En el grado de ansiedad y depresión que experimentan los pacientes ingresados en UCI no parecen influir el género, el estado civil, el número de hijos, la edad, el nivel de estudios y la patología de ingreso. Si bien las mujeres parecen presentar más sintomatología.

- La valoración de la estancia en UCI por parte de los pacientes ha sido positiva sin considerar la situación médica del paciente, tanto a nivel global como en relación con distintos aspectos inherentes a la unidad. No obstante, se han identificado como más desagradables o molestas durante su estancia las escasas posibilidades de distraerse, la falta de silencio en la sala y el régimen de visitas.

- La valoración global de la estancia en UCI no ha mostrado diferencias significativas en función de las variables sociodemográficas y clínico-médicas analizadas (género, estado civil, tener o no hijos, edad, nivel de estudios y patología de ingreso). En cambio en la valoración de aspectos concretos se observan diferencias significativas en función del estado civil y la edad. En este sentido, los cuidados médicos y las posibilidades de distraerse han sido valorados más positivamente por los pacientes sin pareja y con pareja respectivamente. Y respecto a la atención médica recibida la valoración de los pacientes parece ser menor a medida que aumenta la edad.

- Los pacientes presentan un nivel de estrés general intermedio, identificando como principales estresores aspectos relativos a las consecuencias directas de la propia enfermedad (por ejemplo, tener dolor y estar encamado todo el día) así como otros más vinculados a la esfera relacional/emocional, concretamente no poder estar con sus familiares más cercanos.

- El nivel de estrés general de los pacientes parece estar influido por el estado civil y la patología de ingreso. Asimismo encontramos diferencias casi significativas 
en función del género y la edad. De esta manera presentarán mayor nivel de estrés los pacientes sin pareja, con diagnóstico de sepsis, que sean mujeres de edades más jóvenes.

- La calidad de vida de los pacientes se ve seriamente afectada en relación con su situación previa al ingreso en UCI.

- En la calidad de vida de los pacientes parece ser relevante la patología que motivó su ingreso en UCI. Así, los pacientes ingresados por traumatismos son quienes presentan peor calidad de vida frente a aquellos con enfermedad médica previa que presentan mejor calidad de vida tras el ingreso.

- Ante la hipotética situación de enfrentarse al final de la vida los pacientes valoran más los factores relacionados con el control de los síntomas físicos de malestar y sufrimiento dejando en segundo lugar factores relacionales como estar cerca de la familia.

- En la priorización de aquellos aspectos que facilitarían una muerte en paz desde el punto de vista de los pacientes han resultado relevantes el género, el estado civil, el nivel de estudios y la patología de ingreso. En este sentido las mujeres conceden más importancia a aspectos de contenido relacional /emocional y a factores más espirituales o morales; los pacientes con pareja dan más importancia al sentido de la vida; los pacientes con enfermedad médica previa conceden más relevancia al control de los pensamientos y funciones fisiológicas hasta el final; para los pacientes sépticos será más importante el que su muerte no suponga una carga insoportable para los demás; y a medida que aumenta el nivel de estudios los pacientes dan más importancia a aspectos morales o espirituales. En cambio, variables como tener o no hijos y la edad no parecen ser importantes.

- En el proceso de información y toma de decisiones el papel más relevante para el paciente lo tiene él mismo dejando en último lugar a la familia, por detrás del psicólogo y el médico. Asimismo los pacientes refieren estar satisfechos con la información que se les da. Casi tres cuartas partes se sienten totalmente capacitados para participar en decisiones médicas que repercutan sobre sí mismos, aunque uno de cada cinco pacientes percibe en general como una carga la participación en una decisión relevante. Y prefieren a la hora de ser informados un estilo médico más prudente, que no diga lo que aún no es seguro en lugar de un estilo que anticipe futuros riesgos.

- Respecto a la valoración diferencial del proceso de información y toma de decisiones sólo se han obtenido diferencias en función de tener o no hijos, 
concretamente en la valoración de la importancia que el paciente se concede a sí mismo en el proceso, siendo más importante para los pacientes con hijos. En cambio en este proceso no parecen influir el género, el estado civil, la edad, el nivel de estudios y la patología de ingreso.

- En cuanto al papel modulador de distintas variables en la afectación psicológica podemos decir que el nivel de ansiedad de los pacientes predice la valoración global que hacen de su estancia. Igualmente, el nivel de estrés que perciben podría explicarse por distintas variables como la patología que motivó su ingreso, el género, el estado civil, el tener o no hijos y la edad. Mientras que la afectación psicológica de los pacientes en términos de ansiedad y depresión no parece estar modulada por ninguna de las variables demográficas y médicas consideradas.

\subsection{FAMILIARES}

- Los familiares de UCI presentan una importante afectación psicológica en términos de ansiedad y depresión siendo mayor la prevalencia de ansiedad. Concretamente un $76 \%$ y entre un $42-60 \%$ de los familiares presentan niveles clínicos de ansiedad y depresión respectivamente.

- En el grado de ansiedad y depresión que experimentan los familiares parecen influir el género, el estado civil, el lugar de residencia y el nivel de estudios. Así, hay mayor afectación en las mujeres, con pareja, que viven lejos del hospital y que presentan un menor nivel de estudios.

- La valoración global de la estancia en UCI por parte de los familiares ha sido algo positiva. Respecto a los distintos aspectos propios de la Unidad si bien en general han sido bien valorados, cabe decir que los aspectos con menor valoración han sido el silencio en la sala y las posibilidades de distraerse.

- La valoración diferencial de la estancia en UCI a nivel global no muestra diferencias en función de ninguna de las variables sociodemográficas analizadas (género, estado civil, tener o no hijos, parentesco, lugar de residencia, edad y nivel de estudios). No obstante, en la valoración de algunos aspectos particulares de la estancia en UCI sí se han obtenido diferencias significativas en función del estado civil, tener o no hijos, el lugar de residencia y la edad. 
- Los familiares perciben el ingreso en UCI como un acontecimiento que genera mucho o muchísimo estrés. Han identificado como importantes factores generadores de estrés aquellos relacionados sobre todo con la gravedad médica del paciente (por ejemplo, que le pueda ocurrir algo, que pueda morir, que no obtenga alivio para el dolor), lo inesperado del ingreso y no estar cerca de su ser querido.

- La percepción de estrés general de los familiares no ha mostrado diferencias significativas en función de ninguna de las variables sociodemográficas consideradas, si bien las diferencias son casi significativas en función del grado de parentesco, siendo las madres las que presentan en general más estrés.

- El ingreso en UCI interfiere notablemente en distintos ámbitos de funcionamiento de la vida de los familiares. Las áreas que se ven más afectadas son el tiempo libre y el trabajo.

- El grado de interferencia que produce el ingreso de un ser querido en UCI, a nivel global muestra diferencias sólo en función del parentesco con el paciente, siendo la pareja la que presenta mayor afectación. Asimismo en el área social se ven diferencias en función del género y parentesco, variable que además también influirá en el resto de áreas, excepto en la vida familiar general.

- En cuanto a las necesidades en UCI, los familiares muestran mayor satisfacción en todo lo relativo a la atención y cuidados médicos recibidos por el paciente. En cambio refieren menor satisfacción en la explicación recibida sobre el equipamiento utilizado y el interés particular mostrado en ellos como familiares por parte del personal sanitario.

- En las necesidades de los familiares en UCI parecen influir el género, el estado civil, el grado de parentesco con el paciente, el lugar de residencia y la edad. Cabe señalar que estas diferencias se muestran sobre todo en relación con dos necesidades, concretamente las que hacen referencia a los cuidados del paciente y a las atenciones que recibe el propio familiar por parte de los sanitarios.

- Ante la hipotética situación de enfrentarse al final de la vida, lo que más ayudaría a los familiares sería poder comunicarse y estrechar vínculos afectivos con sus seres queridos. En menor medida también serían importantes otros aspectos más directamente relacionados con el alivio del sufrimiento del paciente.

- En la valoración de los aspectos prioritarios al final de la vida parecen ser relevantes el género, sobre todo en aspectos de carácter existencial (las mujeres dan más importancia al hecho de pensar que su vida haya tenido algún sentido), 
y el nivel de estudios, en la importancia que se le concede a creer en otra vida después de la muerte (a medida que aumenta el nivel de estudios los familiares parecen dar más importancia a este factor).

- En el proceso de información y toma de decisiones el papel más relevante para la familia lo tiene el psicólogo seguido de la familia y el médico dejando en último lugar al paciente. Asimismo la mayoría de familiares se muestran satisfechos con la información recibida. En cuanto a la participación en decisiones médicas relevantes, sólo una quinta parte de los familiares se siente totalmente capacitado y algo más de la mitad de los familiares perciben como una carga el hecho de participar en ese proceso. En cuanto al estilo del médico a la hora de informar los familiares no muestran una preferencia clara.

- Respecto a la valoración de la información y la toma de decisiones se han obtenido diferencias en función del género y el nivel de estudios. De modo que las mujeres conceden más importancia a la familia en el proceso, así como muestran mayor preferencia hacia un estilo médico que no informe sobre lo que todavía no es seguro. Asimismo, los familiares tienden a percibirse menos capaces para participar en la toma de decisiones a medida que aumenta el nivel de estudios.

- En cuanto al papel modulador de distintas variables en la afectación psicológica podemos decir que el nivel de estrés general de los familiares podría explicarse por los niveles de ansiedad y depresión, de modo que a mayor sintomatología ansiosa y depresiva mayor es el grado de estrés. Asimismo, residir más lejos, tener pareja y un menor nivel de estudios predecirían los síntomas de ansiedad. Respecto a los síntomas de depresión cabe decir que serían explicados por un menor nivel de estudios, mayor edad, ser mujer y tener hijos. Mientras que la valoración de la estancia en UCI no parece ser explicada pon ninguna variable sociodemográfica ni tampoco por la ansiedad y la depresión.

\subsection{COMPARACIÓN ENTRE PACIENTES Y FAMILIARES}

- Los familiares presentan mayor afectación psicológica en términos de ansiedad y depresión que los pacientes. Asimismo la percepción de estrés general también es mayor en la familia. 
- La familia valora de forma más negativa que el paciente su estancia en la UCI tanto a nivel global como en relación con distintos aspectos de la unidad. El único aspectos mejor valorado por los familiares ha sido el silencio en la sala.

- Respecto a la valoración del proceso de morir, en el hipotético caso de que se tuvieran que enfrentar al final de la vida, los familiares conceden más importancia a aspectos relacionales / emocionales así como a otros de corte más moral como no sentirse culpable por conflictos del pasado. En cambio para los pacientes son más importantes el control del dolor y los síntomas de malestar.

- En cuanto a la valoración del proceso de información y la toma de decisiones, pacientes y familiares conceden más importancia a la labor que ellos mismos pueden desempeñar en el proceso. Y respecto a la participación en la toma de decisiones médicas, los pacientes se sienten más capacitados que los familiares para participar en dichas decisiones. 
CAPÍTULO 9

REFERENCIAS BIBLIOGRÁFICAS 



\section{REFERENCIAS BIBLIOGRÁFICAS}

Abbott, K. H., Sago, J. G., Breen, C. M., Abernethy, A. P., Tulsky, J. A. (2001). Families looking back: one year after discussion of withdrawal or withholding of lifesustaining support. Critical Care Medicine, 29, 197-201.

Abizanda, R., Ballester, R., Bernat, A., Ibáñez, P. Edo, M. T., Bisbal, E., Micó, M., Reig, R. \& Alvaro, R. (2006, septiembre). Psychological disturbances in patients admitted to ICU and their relatives. European Society of Intensive Care Medicine. 19th Annual Congress, Barcelona, España.

Abizanda, R., Bernat, A., Ballester, R., Bisbal, E., Vidal, B., Cubedo, M. \& Reig, R. (2008). Estrategias de información en una Unidad de Cuidados Intensivos polivalente. Medicina Intensiva, 32, 216-221.

Abizanda, R., Gil, B. \& Gómez, S. (2009). Comunicación en una UCI: aspectos asociados al paciente y la familia que la dificultan. En: R. Abizanda, R. Ballester \& M. D. Gil (Eds.), Comunicación médico-paciente en la UCI (pp. 29-34). Barcelona: Edikamed.

Agard, A. S. \& Harder, I. (2007). Relatives' experiences in intensive care. Finding a place in a world of uncertainty. Intensive and Critical Care Nursing, 23, 170-177.

Alasad, J. \& Ahmad, M. (2005). Communication with critically ill patients. Journal of Advanced Nursing, 50, 356-362.

Almerud, S., Alapack, R. J., Fridlund, B. \& Ekebergh, M. (2007). Of vigilance and invisibility - being a patient in technologically intense environments. Nursing in Critical Care, 12, 151-158.

American Board of Medical Specialties. (2006-2012). [Archivo de datos]. Disponible en http://www.abms.org/who_we_help/physicians/specialties.aspx

American Psychiatric Association. (2003). Manual diagnóstico y estadístico de los trastornos mentales ( $4^{\text {a }}$ Edición Texto revisado). Barcelona: Masson.

American Thoracic Society. (1997). Fair allocation of intensive care unit resources. American Journal of Respiratory and Critical Care Medicine, 156, 1282-1301.

Amoros, S. M., Arévalo, M. J., Maqueda, M. \& Pérez, E. (2008). Percepción de la intimidad en pacientes hospitalizados en una Unidad de Cuidados Intensivos. Enfermería Intensiva, 19, 193-203. 
Anderson, W. G., Arnold, R. M., Angus, D. C. \& Bryce, C. L. (2008). Posttraumatic Stress and Complicated Grief in Family Members of Patients in the Intensive Care Unit. Journal of General Internal Medicine, 23, 1871-1876.

Anderson, W. G., Arnold, R. M., Angus, D. C. \& Bryce, C. L. (2009). Passive decisionmaking preference is associated with anxiety and depression in relatives of patients in the intensive care unit. Journal of Critical Care, 24, 249-254.

Angus, D. C., Barnato, A. E., Linde-Zwirble, W. T., Weissfeld, L. A., Watson, R. S., Rickert, T. \& Rubenfeld, G. D. (2004). Use of intensive care at the end of life in the United States: An epidemiologic study. Critical Care Medicine, 32, 638-643.

Apóstolo, J. L. A., Figueiredo, M. H., Mendes, A. C. \& Rodrigues, M. A. (2011). Depresión, ansiedad y estrés en usuarios de cuidados primarios de salud. Revista Latino-Americana de Enfermagem, 19 (2). Recuperado el 28 de enero de 2012, de http://www.scielo.br/pdf/rlae/v19n2/es_17.pdf

Armstrong, K. A. \& Khawaja, N. G. (2002). Gender differences in anxiety: An investigation of the symptoms, cognitions, and sensitivity towards anxiety in a nonclinical population. Behavioural and Cognitive Psychotherapy, 30, 227-231.

Astedt-Kurki, P., Paavilainen, E., Tammentie, T. \& Paunonen-Ilmonen, M. (2001). Interaction between family members and health care providers in an acute care setting in Finland. Journal of Family Nursing, 7, 371-390.

Auerbach, S. M., Kiesler, D. J., Wartella, J., Rausch, S., Ward, K. R. \& Ivatury, R. (2005). Optimism, satisfaction with needs met, interpersonal perceptions of the healthcare team, and emotional distress in patients' family members during critical care hospitalization. American Journal of Critical Care, 14, 202-210.

Ayllón, N., Álvarez, M. \& González, M. (2007). Factores ambientales estresantes percibidos por los pacientes de una Unidad de Cuidados Intensivos. Enfermería Intensiva, 18, 159-167.

Azoulay, E. (2005). The End-of-Life Family Conference. American Journal of Respiratory and Critical Care Medicine, 171, 803-805.

Azoulay, E., Chevret, S., Leleu, G., Pochard, F., Barboteu, M., Adrie, C., Canoui, P., Le Gall, J. R. \& Schlemmer, B. (2000). Half the families of intensive care unit patients 
experience inadequate communication with physicians. Critical Care Medicine, 28, 3044-3049.

Azoulay, E., Pochard, F., Chevret, S., Arich, C., Brivet, F., Brun, F., Charles, P. E., Desmettre, T., Dubois, D., Galliot, R., Garrouste-Orgeas, M., Goldgran-Toledano, D., Herbecq, P., Joly, L.M., Jourdain, M., Kaidomar, M., Lepape, A., Letellier, N., Marie, O., Page, B., Parrot, A., Rodie-Talbere, P. A., Sermet, A., Tenaillon, A., Thuong, M., Tulasne, P., Le Gall, J. R., Schlemmer, B. \& the French Famirea Group. (2003). Family participation in care to the critically ill: opinions of families and staff. Intensive Care Medicine, 29, 1498-1504.

Azoulay, E., Pochard, F., Chevret, S., Lemaire, F., Mokhtari, M., Le Gall, J. R., Dhainaut, J. F. \& Schlemmer, B. (2001). Meeting the needs of Intensive Care Unit patient families. A Multicenter Study. American Journal of Respiratory and Critical Care Medicine, 163, 135-139.

Azoulay, E., Pochard, F., Kentish-Barnes, N., Chevret, S., Aboab, J., Adrie, C., Annane, D., Bleichner, G., Bollaert, P.E., Darmon, M., Fassier, T., Galliot, R., GarrousteOrgeas, M., Goulenok, C., Goldgran-Toledano, D., Hayon, J., Jourdain, M., Kaidomar, M., Laplace, C., Larché, J., Liotier, J., Papazian, L., Poisson, C., Reignier, J., Saidi, F. \& Schlemmer, B. (2005). Risk of Post-traumatic Stress Symptoms in family members of Intensive Care Unit patients. American Journal of Respiratory and Critical Care Medicine, 171, 987-994.

Badía, M., Trujillano, J., Serviá, L., March, J. \& Rodríguez, A. (2008). Cambios en la calidad de vida tras UCI según grupo diagnóstico. Comparación de dos instrumentos de medida. Medicina Intensiva, 32, 203-215.

Badia, X., Diaz-Prieto, A., Gorriz, M. T., Herdman, M., Torrado, H., Farrero, E. \& Cavanilles, J. M. (2001). Using the EuroQol-5D to measure changes in quality of life 12 months after discharge from an intensive care unit. Intensive Care Medicine, 27, 1901-1907.

Bailey, J. J., Sabbagh, M., Loiselle, C. G., Boileau, J. \& McVey, L. (2010). Supporting families in the ICU: A descriptive correlational study of informational support, anxiety, and satisfaction with care. Intensive and Critical Care Nursing, 26, 114-122.

Balogh, D., Kittinger, E., Benzer, A. \& Hackl, J.M. (1993). Noise in the ICU. Intensive Care Medicine, 19, 343-346. 
Ballard, K. S. (1981). Identification of environmental stressors for patients in a surgical intensive care unit. Issues in Mental Health Nursing, 3, 89-108.

Ballester, R., Abizanda, R., Edo, M., Ibáñez, M. P., Bernat, A. \& Bisbal, E. (2006, noviembre). Estresores para el paciente que ingresa en una Unidad de Cuidados Intensivos. V Congreso de la Asociación Española de Psicología Clínica y Psicopatología, Valencia, España.

Ballester, R., Abizanda, R., Edo, M. T, Ibáñez, M. P., Gil, B. \& Bernat, A. (2007, julio). ¿Qué nos ayudaría a morir en paz? Análisis diferenciales en los diferentes agentes implicados en una Unidad de Cuidados Intensivos. V World Congress of Behavioural \& Cognitive Therapies, Barcelona, España.

Ballester, R., Gil, M. D. \& Bernat, A. (2009). Comunicación en la UCI ante la muerte: la perspectiva de los profesionales sanitarios. En R. Abizanda, R. Ballester \& M. D. Gil (Coords.). Comunicación médico-paciente en la UCI (pp. 92-103). Barcelona: Edikamed.

Ballester, R., Gil, B., Gil, M. D. \& Gómez, S. (2011). Afrontamiento de la muerte en familiares de pacientes ingresados en una unidad de cuidados intensivos: valoración diferencial en función de variables sociodemográficas. Medicina Paliativa, 18, 38-45.

Ballester, R., Gómez, S., Gil, B., Abizanda, R. \& Bernat, A. (2010). Differences in the quality of life before and after admission to intensive care unit. International Journal of Behavioral Medicine, 17, 142.

Barbero, J. (2006). El derecho del paciente a la información: el arte de comunicar. Anales del Sistema Sanitario de Navarra, 29, 19-27.

Bascuñan, M. L., Roizblatt, A. \& Roizblatt, D. (2007). Comunicación de malas noticias en medicina: un estudio exploratorio. Revista de Medicina de la Universidad de Navarra, 51, 28-31.

Baskett, P .J. F. (2002). Peter J. Safar. Part Two. The University of Pittsburgh to the Safar Centre for Resuscitation Research 1961-2002. Resuscitation, 55, 3-7.

Baskett, P. (2003). Obituary: Peter J. Safar. Resuscitation, 59, 3-5.

Bayés, R. (2000). Los tiempos de espera en medicina. Medicina Clínica, 114, 464-467. 
Bayés, R. (2006a). Cuidados críticos y sufrimiento. Medicina clínica, 126, 576-578.

Bayés, R. (2006b). Los tiempos de espera en el ámbito de la salud. En R. Bayés (Ed.), Afrontando la vida, esperando la muerte (pp. 211-229). Madrid: Alianza Editorial, S.A.

Bayés, R. \& Borràs, F. X. (2005). ¿Qué son las necesidades espirituales?. Medicina Paliativa, 12, 99-107.

Bayés, R., Limonero, J. T., Romero, E. \& Arranz, P. (2000). ¿Qué puede ayudarnos a morir en paz? Medicina Clínica, 115, 579-582.

Beck, A. T., Ward, C. H., Mendelson, M., Mock, J. \& Erbaugm, J. (1961). An inventory for measuring depression. Archives of General Psychiatry, 4, 561-571.

Beck, A. T., Steer, R. A. \& Carbin, M. G. (1988). Psychometric properties of the Beck Depression Inventory: Twenty-five years of evaluation. Clinical Psychology Review, 8, 77-100.

Beeby, J. P. (2000). Intensive care nurses' experiences of caring. Intensive and Critical Care Nursing, 16, 151-163.

Benito, E., Barbero, J. \& Payás, A. (2008). El acompañamiento espiritual en cuidados paliativos. Una introducción y una propuesta. Madrid: Arán.

Bentley, S., Murphy, F. \& Dundley, H. (1977). Perceived noise in surgical wards and an intensive care area: an objective analysis. British Medical Journal, 2, 1503-1506.

Bergbom, I. \& Askvall, A. (2000). The nearest and dearest: a lifeline for ICU patients. Intensive and Critical Care Nursing, 16, 384-395.

Bernat, M. D. (2010). Capacidad del paciente crítico en la toma de decisiones durante su estancia en una Unidad de Cuidados Intensivos. Estudio preliminar. Trabajo de Investigación no publicado, Universitat Jaume I, Castellón.

Bernat, M. D., Ballester, R. \& Abizanda, R. (2012). ¿Es el paciente crítico competente para tomar decisiones? Razones psicológicas y psicopatológicas de la alteración cognitiva. Medicina Intensiva (En prensa). 
Bernat, R., López, J. \& Fontseca, J. (2000). Vivencias de los familiares del enfermo ingresado en la unidad de cuidados intensivos. Un estudio cualitativo. Enfermería Clínica, 10, 19-27.

Bernat, M. D., Tejedor, R. \& Sanchís, J. (2000). ¿Cómo valoran y comprenden los familiares la información proporcionada en una unidad de cuidados intensivos? Enfermería Intensiva, 11, 3-9.

Berthelsen, P. G. \& Cronqvist, M. (2003). The first intensive care unit in the world. Acta Anaesthesiologica Scandinavica, 47, 1190-1195.

Berti, D., Ferdinande, P. \& Moons, P. (2007). Beliefs and attitudes of intensive care nurses toward visits and open visiting policy. Intensive Care Medicine, 33, 10601065.

Bijttebier, P., Vanoost, S., Delva, D., Ferdinande, P. \& Frans, E. (2001). Needs of relatives of critical care patients: perceptions of relatives, physicians and nurses. Intensive Care Medicine, 27, 160-165.

Blanchard, D. \& Alavi, C. (2008). Asymmetry in the intensive care unit: redressing imbalance and meeting the needs of family. Nursing in Critical Care, 13, 225-231.

Bond, A. E., Draeger, C. R. L., Mandleco, B. \& Donnelly, M. (2003). Needs of Family Members of Patients With Severe Traumatic Brain Injury: Implications for Evidence-Based Practice. Critical Care Nurse, 23, 63-72.

Boss, P. (2002). Family stress management: a contextual approach. Thousand Oaks, California: Sage Publications.

Brito, D., Bocaz, T., Bustos, M. \& González, R. (2009). Actitudes, emociones y percepción de la preparación asistencial y emocional de los estudiantes de enfermería ante la muerte y el enfermo terminal. Medicina Paliativa, 16, 152-158.

Buckman, R. (1988). I don't know what to say: How to help and support someone who is dying. London: Papermac.

Burr, G. (1998). Contextualizing critical care family needs through triangulation: an Australian study. Intensive and Critical Care Nursing, 14, 161-169.

Caine, R. M. (1989). Families in crisis: making the critical difference. Focus on Critical Care, 16, 184-189. 
Caine, R. M. (2003). Psychological Influences in Critical Care: Perspectives from Psychoneuroimmunology. Critical Care Nurse, 23, 60-69.

Calvete, R., García, M. B., Uriel, P., Fernández, V. \& Medín, B. (2000). El sueño de los pacientes ingresados en una unidad de cuidados intensivos y los factores que lo alteran. Enfermería Intensiva, 11, 10-16.

Callahan, D. (2000). Death and the research imperative. The New England Journal of Medicine, 342, 654-656.

Campbell, E. M. \& Sanson-Fisher, R.W. (1998). Breaking bad news. 3: encouraging the adoption of best practices. Behavioral Medicine, 24, 73-80.

Casado, A., Muñoz, G., Ortega, N. \& Castellanos, A. (2005). Burnout en profesionales de los servicios paliativos, intensivos y urgencias de un gran hospital. Medicina Clínica, 124, 554-555.

Cassel, E. J. (1982). The nature of suffering and the goals of medicine. The New England Journal of Medicine, 306, 639-645.

Cassel, J. (1976). The contribution of the social environment to host resistance. American Journal of Epidemiology, 104, 107-123.

Castledine, G. (2001). Is nursing care losing its holistic focus? British Journal of Nursing, 10, 1091.

Celis-Rodríguez, E. \& Rubiano, S. (2007). Desarrollo del Cuidado Intensivo en Latinoamerica. Todo Hospital, 234, 97-100. Recuperado el 16 de diciembre de 2011, de http://www.asivamosensalud.org/descargas/Cuidado_Intensivo.pdf

Chaboyer, W., Kendall, E., Kendall, M. \& Foster, M. (2005). Transfer out of intensive care: a qualitative exploration of patient and family perceptions. Australian Critical Care, 18, 138-145.

Chew, S. L. (1986). Psychological reactions of intensive care patients. Care of the critically ill, 2, 62-65.

Christensen, H., Jorm, A. F., Mackinnon, A. J., Korten, A. E., Jacomb, P. A., Henderson, A. S. \& Rodgers, B. (1999). Age differences in depression and anxiety symptoms: a structural equation modelling analysis of data from a general population sample. Psychological Medicine, 29, 325-339. 
Chui, W. Y-Y. \& Chan, S. W-C. (2007). Stress and coping of Hong Kong Chinese family members during a critical illness. Journal of Clinical Nursing, 16, 372-381.

Comisión Nacional de Medicina Intensiva del Consejo Nacional de especialidades médicas. (1993) Programa de formación para médicos especialistas en Medicina Intensiva. Medicina Intensiva, 17, 293-300.

Couceiro, A. (2003). Tecnología, dolor y sufrimiento en las unidades de críticos. En R. Bayés (Ed.), Dolor y sufrimiento en la práctica clínica (pp. 53-67). Barcelona: Fundación Medicina y Humanidades Médicas.

Coulter, M. A. (1989). The needs of the family members of patients in intensive care units. Intensive Care Nursing, 5, 4-10.

Crawford, J. R., Henry, J. D., Crombie, H. C. \& Taylor, E. P. (2001). Normative data for the HADS from a large non-clinical sample. British Journal of Clinical Psychology, $40,429-434$.

Curtis, J. R. (2003). Measuring health status after critical illness: Where are we and where do we go from here? In: D. C. Angus \& J. Carlet (Eds.), Surviving Intensive Care. Update in Intensive Care and Emergency Medicine (Volume 39) (pp. 181-196). Germany: Springer-Verlag Berlin Heidelberg.

Curtis, N. M. (1983). Caring for Families during the "Unknown" period. Dimensions of Critical Care Nursing, 2, 248-254.

Curtis, J. R. \& Vincent, J. L. (2010). Ethics and end-of-life care for adults in the intensive care unit. The Lancet, 376, 1347-1353.

Cuthbertson, B. H., Hull, A., Strachan, M. \& Scott, J. (2004). Post-traumatic stress disorder after critical illness requiring general intensive care. Intensive Care Medicine, 30, 450-455.

Cuthbertson, B. H., Roughton, S., Jenkinson, D., MacLennan, G. \& Vale, L. (2010). Quality of life in the five years after intensive care: a cohort study. Critical Care, 14:R6. Recuperado el 2 de febrero de 2012, de http:/ / ccforum.com/content/14/1/R6

Cuthbertson, B. H., Scott, J., Strachan, M., Kilonzo, M. \& Vale, L. (2005). Quality of life before and after intensive care. Anaesthesia, 60, 332-339. 
Daaleman, T. P. \& VandeCreek, L. (2000). Placing religion and spirituality in end-of-life care. The Journal of the American Medical Association, 284, 2514-2517.

Da Costa, J. B, Felicetti, C. R., de Macedo, C. R. L., Miglioranza, D. C., Osaku, E. F., da Silva, G. L. G., Solstoski, J., Duarte, P. A. D., Triló, S., Mariko, S. \& Taba, S. (2010). Fatores estressantes para familiares de pacientes criticamente enfermos de uma unidade de terapia intensiva. Jornal Brasileiro de Psiquiatria, 59, 182-189.

Danis, M., Federman, D., Fins, J. J., Fox, E., Kastenbaum, B., Lanken, P. N., Long, K., Lowenstein, E., Lynn, J., Rouse, F. \& Tulsky, J. (1999). Incorporating palliative care into critical care education: Principles, challenges, and opportunities. Critical Care Medicine, 27, 2005-2013.

Davidson, J. E. (2009). Family-Centered Care: Meeting the Needs of Patients' Families and Helping Families Adapt to Critical Illness. Critical Care Nurse, 29, 28-34.

Davydow, D. S., Gifford, J. M., Desai, S. V., Bienvenu, O. J. \& Needham, D. M. (2009). Depression in general intensive care unit survivors: a systematic review. Intensive Care Medicine, 35, 796-809.

Deep, K., Griffith, C., \& Wilson, J. (2008). Communication and decision making about life-sustaining treatment: examining the experiences of resident physicians and seriously-ill hospitalized patients. Journal of General Internal Medicine, 23, 18771882.

Delva, D., Vanoost, S., Bijttebier, P., Lauwers, P. \& Wilmer, A. (2002). Needs and Feelings of Anxiety of Relatives of Patients Hospitalized in Intensive Care Units: Implications for Social Work. Social Work in Health Care, 35, 21-40. Recuperado el 22 de diciembre de 2011, de http:/ / dx.doi.org/10.1300/J010v35n04_02

De Meyer, T. J. (1967). The environment of the intensive care unit. Nursing Forum, 6, 262-272.

Díaz, A. \& Díaz, N. (2004). Ampliando horizontes: Una experiencia sobre las vivencias de los familiares de pacientes críticos. Nure Investigación, 10. Recuperado el 20 de diciembre de 2011, de http://www.fuden.es/FICHEROS_USUARIO/Originales_Imagenes/Original10 .pdf 
Dickstein, L. J. (2000). Gender differences in mood and anxiety disorders: From bench to bedside: American Psychiatric Press Review of Psychiatry. The American Journal of Psychiatry, 157, 1186-1187.

Doka, K. J. \& Martin, T. L. (2010). Grieving beyond gender. Understanding the ways men and women mourn. New York: Routledge.

Drinker, P. \& McKhann, C. F. (1929). The use of a new apparatus for the prolonged administration of artifical respiration: I. A fatal case of poliomielitis. Journal of the American medical Association (JAMA), 92, 1658-1660.

Dubois, M. J., Bergeron, N., Dumont, M., Dial, S. \& Skrobik, Y. (2001) Delirium in an intensive care unit: a study of risk factors. Intensive Care Medicine, 27, 1297-1304.

Dufault, K. \& Martocchio, B. C. (1985). Symposium on compassionate care and the dying experience. Hope: its spheres and dimensions. Nursing Clinics of North America, 20, 379-391.

Dyer, I. (1995). Preventing the ITU syndrome or how not to torture an ITU patient! Part 2. Intensive and Critical Care Nursing, 11, 223-232.

Dyer, I. (1996). Intensive care unit syndrome. Nursing Times, 92, 58-59.

Echeburúa, E. \& Corral, P. (1987). Escala de Inadaptación. Manuscrito no publicado.

Echeburúa, E., Corral, P. \& Fernández-Montalvo, J. (2000). Escala de In-adaptación: propiedades psicométricas en contextos clínicos. Análisis y Modificación de Conducta, 26, 325-340.

Eddleston, J. M., White, P. \& Guthrie, E. (2000). Survival, morbidity and quality of life after discharge from intensive care. Critical Care Medicine, 28, 2293-2299.

Edo, M. T. \& Ballester, R. (2006). Estado emocional y conducta de enfermedad en pacientes con VIH/Sida y enfermos oncológicos. Revista de Psicopatología y Psicología Clínica, 11, 79-90.

Eggenberger, S. K. \& Nelms, T. P. (2007). Being family: the family experience when an adult member is hospitalized with a critical illness. Journal of Clinical Nursing, 16, 1618-1628. 
Ely, E. W., Gautam, S., Margolin, R., Francis, J., May, L., Speroff, T., Truman, B., Dittus, R., Bernard, R. \& Inouye, S. K. (2001). The impact of delirium in the intensive care unit on hospital length of stay. Intensive Care Medicine, 27, 1892-1900.

Ely, E. W., Shintani, A., Truman, B., Speroff, T., Gordon, S. M., Harrell, F. E., Inouye, S. K., Bernard, G. R. \& Dittus, R. S. (2004). Delirium as a predictor of mortality in mechanically ventilated patients in the intensive care unit. The Journal of the American Medical Association, 291, 1753-1762.

Engström, C. G. (1954). Treatment of severe cases of respiratory paralisis by the Engstron Universal Respirator. British Medical Journal, 2, 666-669.

Engström, Å. \& Söderberg, S. (2004). The experiences of partners of critically ill persons in an intensive care unit. Intensive and Critical Care Nursing, 20, 299-308.

Engström, Å. \& Söderberg, S. (2007). Receiving power through confirmation: the meaning of close relatives for people who have been critical ill. Journal of Advanced Nursing, 59, 569-576.

EQ-5D (2000). Homepage of EQ-5D. Recuperado el 27 de diciembre de 2011, de http://www.euroqol.org/.

Eriksson, E., Lindahl, B. \& Bergbom, I. (2010). Visits in an intensive care unit. An observational hermeneutic study. Intensive and Critical Care Nursing, 26, 51-57.

Esteban, A., De la Cal, M. A. \& Gómez-Rubí, J. A. (1993). Intensive medicine in Spain. Intensive Care World, 10, 95-98.

Faber-Langendoen, K. \& Lanken, P. N. (2000). Dying patients in the intensive care unit: forgoing treatment, maintaining care. Annals of Internal Medicine, 133, 886-893.

Fairman, J. \& Lynaugh, J. E. (1998). Critical Care Nursing. Pennsylvania: University of Pennsylvania Press.

Fauri, D. P., Ettner, B. \& Kovacs, P. J. (2000). Bereavement services in acute care settings. Death Studies, 24, 51-64.

Ferdinande, P. (1997). Recommendations on minimal requirements for Intensive Care Departments. Intensive Care Medicine, 23, 226-232. 
Ferdinande, P. (1998). Minimal Requirements for Intensive Care Departments. En: European Society of Intensive Care Medicine (Eds.). Reports, guidelines and recommendations (pp. 11-22). Germany: Springer.

Forsgren, L. M. \& Eriksson, M. (2010). Delirium-Awareness, observation and interventions in intensive care units: A national survey of Swedish ICU head nurses. Intensive and Critical Care Nursing, 26, 296-303.

Fredriksen, S. T. D. \& Ringsberg, K. C. (2007). Living the situation stress-experiences among intensive care patients. Intensive and Critical Care Nursing, 23, 124-131.

Freichels, T. A. (1991). Needs of family members of patients in the intensive care unit over time. Critical Care Nursing Quarterly, 14, 16-29.

Fridh, I., Forsberg, A. \& Bergbom, I. (2007). End-of-life care in intensive care units family routines and environmental factors. Scandinavian Journal of Caring Sciences, 21, 25-31.

Friese, R. S. (2008). Sleep and recovery from critical illness and injury: a review of theory, current practice, and future directions. Critical Care Medicine, 36, 697-705.

Fumis, R. R. L. \& Deheinzelin, D. (2009). Family members of critically ill cancer patients: assessing the symptoms of anxiety and depression. Intensive Care Medicine, 35, 899-902.

García, B. C. (2011). Estudio cualitativo del perfil del cuidador primario, sus estilos de afrontamiento y el vinculo afectivo con el enfermo oncológico infantil. (Tesis doctoral, Universitat Ramón Llull). Recuperado el 22 de marzo de 2012, de http://www.tesisenred.net/bitstream/handle/10803/32141/tesis\%20doctoral\% 20bernardo\%20celso\%20garcia\%20romero\%20(abril\%202011)\%20url.pdf?sequenc $\mathrm{e}=1$.

García, F., Peres, D., De Cubber, M. \& Vincent, J. L. (2003). Long-term outcome in ICU patients: what about quality of life? Intensive Care Medicine, 29, 1286-1293.

Gelling, L. (1999). Causes of ICU psychosis: the environmental factors. Nursing in Critical Care, 4, 22-26.

Gil, B. (2010). Afectación emocional de pacientes y familiares en una Unidad de Cuidados intensivos. Trabajo de Investigación no publicado, Universitat Jaume I, Castellón. 
Gil, B., Ballester, R., Gómez, S., Ruiz, E. \& Giménez, C. (2010). Síntomas de ansiedad y depresión tras la hospitalización en una Unidad de Cuidados Intensivos. Fórum de Recerca.

Gil, B., Ballester, R., Ibáñez, M. P., Gómez, S. \& Abizanda, R. (2010). Influencia de las variables sociodemográficas en los factores que ayudarían a morir en paz en pacientes de UCI. Medicina Paliativa, 17, Supl. I, pp. 67.

Gill, C. J. \& Gill, G. C. (2005). Nightingale in Scutari: Her Legacy Reexamined. Clinical Infectious Diseases, 40, 1799-1805.

Gómez, J.A. (1998). Origen de la medicina intensiva en España: historia de una revolución. Medicina Intensiva, 22, 421-428.

Gómez, J. A. (2002). Ética en medicina crítica. Madrid: Triacastela.

Gómez, S. (2011). Estado emocional de los profesionales sanitarios en las Unidades de Cuidados Intensivos: Factores moduladores. Trabajo de Investigación no publicado, Universitat Jaume I, Castellón.

Gómez, S., Ballester, R. \& Gil, B. (2011). El cuestionario de necesidades de los familiares de pacientes de cuidados intensivos (CCFNI) versión breve: adaptación y validación en población española. Anales del Sistema Sanitario de Navarra, 34, 349361.

Gómez-Calcerrada, P. (2004). Detección de necesidades percibidas y niveles de ansiedad en los familiares de pacientes adultos ingresados en cuidados intensivos. Investigación \& Cuidados, 2, 5-14.

Gómez, S., Gil, B. \& Ballester, R. (2009). Grado de interferencia en los familiares de pacientes ingresados en una unidad de cuidados intensivos. Fórum de Recerca, 14. Recuperado el 21 de diciembre de 2011, de http://www.uji.es/bin/publ/edicions/jfi14/psico/13.pdf

Gómez-Carretero, P., Monsalve, V., Soriano, J. F. \& De Andrés, J. (2007). Alteraciones emocionales y necesidades psicológicas de pacientes en una Unidad de Cuidados Intensivos. Medicina Intensiva, 31, 318-325. 
Gómez-Carretero, P., Monsalve, V., Soriano, J. F. \& de Andrés, J. (2009). Satisfacción con la Información: Posible Variable Interviniente en el Estado de Ánimo de Cuidadores Primarios de Pacientes Críticos. Cínica y Salud, 20, 91-105.

González, C. E., Carroll, D. L., Elliott, J. S., Fitzgerald, P. A. \& Vallent, H. J. (2004). Visiting preferences of patients in the intensive care unit and in a complex care medical unit. American Journal of Critical Care, 13, 194-198.

González, G. \& García, F. (2008). Modelos organizativos en medicina intensiva: el modelo español. En E. Palencia (Dir.), Libro electrónico de medicina intensiva (sección 04.02.). Recuperado el 7 de noviembre de 2011, de http:/ / intensivos.uninet.edu/04/0400.html

Granberg, A., Bergbom-Engberg, I. \& Lundberg, D. (1996). Intensive care syndrome: a literature review. Intensive and Critical Care Nursing, 12, 173-182.

Granberg, A., Bergbom-Engberg, I. \& Lundberg, D. (1999). Acute confusion and unreal experiences in intensive care patients in relation to the ICU syndrome. Part II. Intensive and Critical Care Nursing, 15, 19-33.

Granberg-Axèll, A. (2001). The Intensive Care Unit Syndrome / Delirium, Patients' Perspective and Clinical Signs. Tesis no publicada, Lund University, Lund, Suecia.

Granberg-Axèll, A., Bergbom, I. \& Lundberg, D. (2001). Clinical signs of ICUsyndrome/delirium: an observational study. Intensive and Critical Care Nursing, 17, 72-93.

Granberg Axèll, A. I. R., Malmros, C. W., Bergbom, I. L. \& Lundberg, D. B. A. (2002). Intensive care unit syndrome/delirium is associated with anemia, drug therapy and duration of ventilation treatment. Acta Anaesthesiologica Scandinavica, 46, 726731.

Granja, C., Teixeira-Pinto, A. \& Costa-Pereira, A. (2002). Quality of life after intensive care -evaluation with EQ-5D questionnaire. Intensive Care Medicine, 28, 898-907.

Granja, C., Lopes, A., Moreira, S., Dias, C., Costa-Pereira, A., Carneiro, A. y JMIP Study Group. (2005). Patients' recollections of experiences in the intensive care unit may affect their quality of life. Critical Care, 9, R96-R109. Recuperado el 19 de diciembre de 2011 de la base de datos de E-Journals. 
Grau, A., Suñer, R., Abulí, P. \& Comas, P. (2003). Niveles de ansiedad y depresión en enfermos hospitalizados y su relación con la gravedad de la enfermedad. Medicina Clínica, 120, 370-375.

Gries, C. J., Engelberg, R. A., Kross, E. K., Zatzick, D., Nielsen, E. L., Downey, L. \& Curtis, J. R. (2010). Predictors of symptoms of Posttraumatic Stress and Depression in family members after patient death in the ICU. Chest, 137, 280-287.

Groom, K. N., Shaw, T. G., O'Connor, M. E., Howard, N. I. \& Pickens, A. (1998). Neurobehavioural symptoms and family functioning in traumatically braininjured adults. Archives of Clinical Neuropsychology, 13, 695-711.

Gustad, L. T., Chaboyer, W. \& Wallis, M. (2005). Performance of the faces anxiety scale in patients transferred from the ICU. Intensive and Critical Care Nursing, 21, 355360.

Halm, M. A., Titler, M. G., Kleiber, C., Johnson, S. K., Montgomery, L. A., Craft, M. J., Buckwalter, K., Nicholson, A. \& Megern, K. (1993). Behavioral Responses of Family Members during Critical Illness. Clinical Nursing Research, 2, 414-437.

Hammond, F. (1995). Involving families in care within the intensive care environment: a descriptive survey. Intensive and Critical Care Nursing, 1, 256-264.

Hampe, S. O. (1975). Needs of the grieving spouse in a hospital setting. Nursing Research, 24, 113-120.

Harvey, M. (1993). Volunteers in the critical care waiting room. Anaheim, CA: Society of Critical Care Medicine.

Hastings Center. Los fines de la medicina [trad. 2005]. Recuperado el 7 de noviembre de 2011, de http:/ / www.fundaciongrifols.org

Hatchett, C., Langley, G. \& Schmollgruber, S. (2010). Psychological sequelae following ICU admission at a level 1 academic South African hospital. South African Journal of Critical Care, 26, 52-58.

Henneman, E. A. \& Cardin, S. (2002). Family-centered critical care: a practical approach to making it happen. Critical Care Nurse, 22,12-19. 
Heras, A., Abizanda, R., Belenguer, A., Vidal, B., Ferrándiz, A., Micó, M. L. \& Álvaro, R. (2007). Unidades de Cuidados Intermedios. Consecuencias asistenciales en un hospital de referencia. Medicina Intensiva, 31, 353-360.

Herrero, M. J., Blanch, J., Peri, J. M., De Pablo, J., Pintor, L. \& Bulbena, A. (2003). A validation study of the hospital anxiety and depression scale (HADS) in a Spanish population. General Hospital Psychiatry, 25, 277-283.

Hewitt, J. (2002). Psycho-affective disorder in intensive care units: a review. Journal of Clinical Nursing, 11, 575-584.

Heyland, D. K., Cook, D. J., Rocker, G. M., Dodek, P. M., Kutsogiannis, D. J., Peters, S., Tranmer, J. E. \& O'Callaghan, C. J. (2003). Decision-making in the ICU: perspectives of the substitute decision-maker. Intensive Care Medicine, 29, 75-82.

Heyland, D. K., Rocker, G. M., Dodek, P. M., Kutsogiannis, D. J., Konopad, E., Cook, D. J., Peters, S., Tranmer, J. E. \& O'Callaghan, C. J. (2002). Family satisfaction with care in the intensive care unit: Results of a multiple center study. Critical Care Medicine, 30, 1413-1418.

Heyland, D. K. \& Tranmer, J. E. (2001). Measuring Family Satisfaction with Care in the Intensive Care Unit: The Development of a Questionnaire and Preliminary Results. Journal of Critical Care, 16, 142-149.

Hickey, M. (1990). Family needs in critical care. Heart and Lung, 19, 401-415.

Hickman, R. L., Daly, B. J., Douglas, S. L. \& Clochesy, J. M. (2010). Informational Coping Style and Depressive Symptoms in Family Decision Makers. American Journal of Critical Care, 19, 410-420.

Hidalgo, I., Vélez, Y. \& Pueyo, E. (2007). Qué es importante para los familiares de los pacientes de una unidad de cuidados intensivos. Enfermería Intensiva, 18, 106-114.

Hofhuis, J. G. M., Spronk, P. E., van Stel, H. F., Schrijvers, A. J. P., Rommes, J. H. \& Bakker, J. (2008). Experiences of critically ill patients in the ICU. Intensive and Critical Care Nursing, 24, 300-313.

Holden, J., Harrison, L. \& Johnson, M. (2002). Families, nurses and intensive care patients: a review of the literature. Journal of Clinical Nursing, 11, 140-148. 
Høye, S. \& Severinsson, E. (2010). Multicultural family members' experiences with nurses and the intensive care context: A hermeneutic study. Intensive and Critical Care Nursing, 26, 24-32.

Hughes, F., Bryan, K. \& Robbins, I. (2005). Relatives' experiences of critical care. Nursing in Critical Care, 10, 23-30.

Hupcey, J. E. (2000). Feeling Safe: The Psychosocial Needs of ICU Patients. Journal of Nursing Scholarship, 32, 361-367.

Hupcey, J. E. \& Penrod, J. (2000). Going it alone: The experiences of spouses of critically ill patients. Dimensions of Critical Care Nursing, 19, 44-49.

Ibáñez, M. P. (2009). Afrontamiento de la muerte en pacientes y familiares de UCI y población general: Variables moduladoras. Trabajo de Investigación no publicado, Universitat Jaume I, Castellón.

Ibsen, B. (1954). The Anaesthetist's viewpoint on the treatment of Respiratory Complications in Poliomyelitis during the Epidemic in Copenhagen, 1952. Proceedings of the Royal Society of Medicine, 47, 72-74.

Jamerson, P. A., Scheibmeir, M., Bott, M. J., Crighton, F., Hinton, R. H. \& Cobb, A. K. (1996). The experiences of families with a relative in the intensive care unit. Heart and Lung, 25, 467-474.

Johansson, I., Fridlund, B. \& Hildingh, C. (2005). What is supportive when an adult next-of-kin is in critical care? Nursing in Critical Care, 10, 289-298.

Johnson, D., Wilson, M., Cavanaugh, B., Bryden, C., Gudmundson, D. \& Moodley, O. (1998). Measuring the ability to meet family needs in an intensive care unit. Critical Care Medicine, 26, 266-271.

Jones, C., Skirrow, P., Griffiths, R. D., Humphris, G., Dawson, S. \& Eddleston, J. (2000). Predicting intensive care relatives at risk of post-traumatic stress disorder. British Journal of Anaesthesia, 84, 666P-667P.

Jones, C., Skirrow, P., Griffiths, R. D., Humphris, G., Ingleby, S., Eddleston, J., Waldmann, C. \& Gager, M. (2004). Posttraumatic in relatives of patients following intensive care. Intensive Care Medicine, 30, 456-460. 
Jorm, A. F., Scott, R., Henderson, A. S. \& Kay, D. W. A. (1988) Educational level differences on the Mini-Mental State: the role of test vias. Psychological Medicine, $18,727-731$.

Kalfon, P., Mimoz, O., Auquier, P., Loundou, A., Gauzit, R., Lepape, A., Laurens, J., Garrigues, B., Pottecher, T. \& Mallédant, Y. (2010). Development and validation of a questionnaire for quantitative assessment of perceived discomforts in critically ill patients. Intensive Care Medecine, 36, 1751-1758.

Karlsson, C., Tisell, A. Engström, Å. \& Andershed, B. (2011). Family members' satisfaction with critical care: a pilot study. Nursing in Critical Care, 16, 11-18.

Kass, J. E. (2008). To sleep in an intensive care unit, perchance to heal. Critical Care Medicine, 36, 988-989.

Kentish-Barnes, N., Lemiale, V., Chaize, M., Pochard, F. \& Azoulay, E. (2009). Assing burden in families of critical care patients. Critical Care Medicine, 37, S448-S456.

Kleiber, C., Halm, M., Titler, M., Montgomery, L. A., Johnson, S. K., Nicholson, A., Craft, M., Buckwalter, K. \& Megivern, K. (1994). Emotional responses of family members during a critical care hospitalization. American Journal of Critical Care, 3 , 70-76.

Koenig, H. G., George, L. K., Stangl, D. \& Tweed, D. L. (1995). Hospital stressors experienced by elderly medical patients: developing a Hospital Stress Index. International Journal of Psychiatry in Medicine, 25, 103-122.

Koenig, H. G., Larson, D. B. \& Weaver, A. J. (1998). Research on religion and serious mental illness. New Directions for Mental Health Services, 80, 81-95.

Koller, P. A. (1991). Family needs and coping strategies during illness crisis. AACN Clinical Issues, 2, 338-345.

Konkani, A. \& Oakley, B. (2011). Noise in hospital intensive care units - a critical review of a critical topic. Journal of Critical Care (en prensa).

Kübler-Ross (1969). On Death and Dying. New York: Macmillan. (Sobre la muerte y los moribundos. Traducción de 1993. Barcelona: Grijalbo).

Kuehn, B. M. (2010). Delirium often not Recognized or Treated despite serious Longterm Consequences. Journal of the American Medical Association, 304, 389-391. 
Lam, P. \& Beaulieu, M. (2004). Experiences of families in the neurological ICU: A "bedside phenomenon." Journal of Neuroscience Nursing, 36, 151-155.

Lang, P. J. (1968). Fear reduction and fear behavior: Problems in treating a construct. En J. M. Shlien (Ed.), Research in psychotherapy (Vol. I) (pp. 90-102). Washington: American Psychological Association.

Lange, P. (2001). Family stress in the intensive care unit. Critical Care Medicine, 29, 20252026.

Lasa, L., Ayuso-Mateos, J. L., Vázquez-Barquero, J. L., Díez-Manrique, F. J. \& Dowrick, C. F. (2000). The use of the Beck Depression Inventory to screen for depression in the general population: a preliminary analysis. Journal of Affective Disorders, 57, 261-265.

Lassen, H. C. A. (1954). The epidemic of poliomyelitis in Copenhagen, 1952. Proceedings of the Royal Society of Medicine, 47, 67-71.

Latour, J. M. (2005). Is family-centred care in critical care units that difficult? A view from Europe. Nursing in Critical Care, 10, 51-53.

Lawson, N., Thompson, K., Saunders, G., Saiz, J., Richardson, J., Brown, D., Ince, N., Caldwell, M. \& Pope, D. (2010). Sound Intensity and Noise Evaluation in a Critical Care Unit. American Journal of Critical Care, 19, 88-98.

Lazarus, R. S. (1966). Psychological stress and the coping process. New York: McGraw-Hill.

Lazarus, R. S. (1974). Psychological stress and coping in adaptation and illness. International Journal of Psychiatry in Medicine, 5, 321-333.

Lazarus, R. S. (1991). Emotion and Adaptation. New York: Oxford University Press.

Lazarus, R. S. (1993). From psychological stress to the emotions: A history of changing outlooks. Annual Review of Psychology, 44, 1-21

Lazarus, R. S. \& Folkman, S. (1984) Stress, Appraisal and Coping. New York: Springer Publishing Company.

Leahy, J. M. (1992). A Comparison of Depression in Women Bereaved of a Spouse, Child, or a Parent. Omega: Journal of Death and Dying, 26, 207-217. 
Lederer, M. A., Goode, T. \& Dowling, J. (2005). Origins and Development. The Critical Care Family Assistance Program. Chest, 128, 65S-75S.

Leske, J. S. (1991). Internal psychometric properties of the Critical Care Family Needs Inventory. Heart and Lung, 20, 236-244.

Leske, J. S. (2002). Interventions to decrease family anxiety. Critical Care Nurse, 22, 6165.

Leske, J. S. \& Pasquale, M. A. (2007). Family needs, interventions, and Presence. En N. Molter (Ed.), AACN protocols for practice: Creating healing environments (pp. 41). Sudbury, MA: Jones and Bartlett.

Levy, M. M. \& Carlet, J. (2001). Compassionate end-of-life care in the intensive care unit. Critical Care Medicine, 29 (supl. 2), N1.

Lewinsohn, P. M., Hoberman, H., Teri, L. \& Hautzinger, M. (1985). An integrative theory of depression. En S. Reiss \& R. Bootzin (dirs.), Theoretical issues in behavior therapy. New York: Academic.

Li, D. T. \& Puntillo, K. (2006). A pilot study on coexisting symptoms in intensive care patients. Applied Nursing Research, 19, 216-219.

Lin, S. M., Huang, C. D., Liu, C. Y., Lin, H. C., Wang, C. H., Huang, P. Y., Fang, Y. F., Shieh, M. H. \& Kuo, H. P. (2008). Risk factors for the development of early-onset delirium and the subsequent clinical outcome in mechanically ventilated patients. Journal of Critical Care, 23, 372-379.

Lindahl, B. (2005). Encounters between people and technology. Tesis doctoral, Umeå University, Umea, Suecia.

Lloyd, G. G. (1993). Psychological problems and the intensive care unit. British Medical Journal, 307, 458-459.

Llubià, C. (2008). El poder terapéutico de la escucha en medicina crítica. Fundación medicina y humanidades médicas. Recuperado el 19 de diciembre de 2011, de http://www.fundacionmhm.org/www_humanitas_es_numero27/revista.html

Llubià, C. \& Canet, J. (2000). Unidades de cuidados críticos: la difícil tarea de la información. Medicina Clínica, 114, 141-143. 
Löf, L., Berggrena, L. \& Ahlström, G. (2008). ICU patients' recall of emotional reactions in the trajectory from falling critically ill to hospital discharge: Follow-ups after 3 and 12 months. Intensive and Critical Care Nursing, 24, 108-121.

Long, D. M. (1989). A century of change in neurosurgery at Johns Hopkins: 1889- 1989. Journal of Neurosurgery, 71, 635-638.

López, S., Pastor, M. A., Rodríguez, J., Sánchez, S. \& Belmonte, J. (1990). Evaluación del estrés del paciente quirúrgico. Revista de Psicología de la Salud, 2, 113-126.

Maciejewski, P. K., Prigerson, H. G. \& Mazure, C. M. (2001). Sex differences in eventrelated risk for major depression. Psychological Medicine: A Journal of Research in Psychiatry and the Allied Sciences, 31, 593-604.

Marco, L. \& Bermejillo, E. (2000). Creencias y actitudes de las enfermeras de cuidados intensivos sobre el efecto que la visita abierta produce en el paciente, familia y enfermeras. Enfermería Intensiva, 11, 107-117.

Margall, M. A., Zazpe, C., Perochena, P., Labiano, J., Otano, C. \& Asiain, M. C. (1993). Necesidades de los familiares de pacientes ingresados en cuidados intensivos. Enfermería Intensiva, 4, 40-46.

Marks, I. (1986). Tratamiento de la neurosis: teoría y práctica de la psicoterapia conductual. Barcelona: Martínez Roca.

Maruiti, M. R., Galdeano, L. E. \& Farah, O. G. D. (2008). Anxiety and depressions in relatives of patients admitted in intensive care units. Acta Paulista de Enfermagem, $21,636-642$.

Maxwell, K. E., Stuenkel, D. \& Saylor, C. (2007). Needs of family members of critically ill patients: A comparison of nurse and family perceptions. Heart and Lung, 36, 367-376.

McAdam, J. L. \& Puntillo, K. (2009). Symptoms experienced by family members of patients in Intensive Care Units. American Journal of Critical Care, 18, 200-209.

McGuire, B. E., Basten, C. J., Ryan, C.J . \& Gallagher, J. (2000). Intensive Care Unit Syndrome: A Dangerous Misnomer. Archives of Internal Medicine, 160, 906-909. 
McKegney, F. P. (1966). The intensive care syndrome. The definition, treatment and prevention of a new disease of medical progress. Connecticut Medicine, 30, 633636.

McKinley, S., Nagy, S., Stein-Parbury, J., Bramwell, M. \& Hudson, J. (2002). Vulnerability and security in seriously ill patients in intensive care. Intensive and Critical Care Nursing, 18, 27-36.

McKinney, A. A. \& Deeny, P. (2002). Leaving the intensive care unit: a phenomenological study of the patients' experience. Intensive and Critical Care Nursing, 18, 320-331.

McKinney, A. A. \& Melby, V. (2002). Relocation stress in critical care: a review of the literature. Journal of Clinical Nursing, 11, 149-157.

Medina, C. E. (2002). Una breve historia de la poliomielitis. Medicina Universitaria, 4, 182-186.

Méndez, L., Giraldo, O., Aguirre-Acevedo, D. \& Lopera, F. (2010). Relación entre ansiedad, depresión, estrés y sobrecarga en cuidadores familiares de personas con demencia tipo alzheimer. Revista Chilena de Neuropsicología, 5, 137-145.

Mendonca, D. \& Warren, N. A. (1998). Perceived and unmet needs of critical care family members. Critical Care Nursing Quarterly, 21, 58-67.

Meriläinen, M., Kyngäs, H. \& Ala-Kokko, T. (2010). 24-Hour intensive care: An observational study of an environment and events. Intensive and Critical Care Nursing, 26, 246-253.

Ministerio de Sanidad, Política Social e Igualdad. (2011). Estadística de Establecimientos Sanitarios con Régimen de Internado, 2009 [Archivo de datos]. Disponible en http://www.mspsi.gob.es

Mishel, M. H. (1988). Uncertainty in illness. Image: Journal of Nursing Scholarship, 20, 225-232.

Mishel, M. H. \& Braden, C. J. (1988). Finding meaning: antecedents of uncertainty in illness. Nursing Research, 37, 98-103. 
Mitchell, M. L. \& Courtney, M. (2004). Reducing family members' anxiety and uncertainty in illness around transfer from intensive care: an intervention study. Intensive and Critical Care Nursing, 20, 223-231.

Mitchell, M. L., Courtney, M. \& Coyer, F. (2003). Understanding uncertainty and minimizing families' anxiety at the time of transfer from intensive care. Nursing and Health Sciences, 5, 207-217.

Molter, N. C. (1979). Needs of relatives of critically ill patients: a descriptive study. Heart and Lung, 8, 332-339.

Molter, N. C. \& Leske, J. S. (1983). Critical care family needs inventory. Copyright. Available from the authors.

Monzón, J. L., Saralegui, I., Abizanda, R., Cabré, L., Iribarren, S., Martín, M. C., Martínez, K. \& Grupo de Bioética de la SEMICYUC. (2008). Recomendaciones de tratamiento al final de la vida del paciente critico. Medicina Intensiva, 32, 121-133.

Mosenthal, A. C., Lee, K. F. \& Huffman, J. (2002). Palliative Care in the Surgical Intensive Care Unit. Journal of the American College of Surgeons, 194, 75-83.

Moser, D. K., Lee Chung, M., McKinley, S., Riegel, B., An, K., Cherrington, C. C. Blakely, W., Biddle, M., Frazier, S. K. \& Garvin, B. J. (2003). Critical care nursing practice regarding patient anxiety assessment and management. Intensive and Critical Care Nursing, 19, 276-288.

Mularski, R. A. (2006). Defining and measuring quality palliative and end-of-life care in the intensive care unit. Critical Care Medicine, 34, S309-316.

Myhren, H., Ekeberg, Ø., Langen, I. \& Stokland, O. (2004). Emotional strain, communication, and satisfaction of family members in the intensive care unit compared with expectations of the medical staff: experiences from a Norwegian University Hospital. Intensive Care Medicine, 30, 1791-1798.

Myhren, H., Tøien, K., Ekeberg, Ø., Karlsson, S., Sandvik, L. \& Stokland, O. (2009). Patients' memory and psychological distress after ICU stay compared with expectations of the relatives. Intensive Care Medicine, 35, 2078-2086.

Nelms, T. P. \& Eggenberger, S. K. (2010). The Essence of the Family Critical Illness Experience and Nurse-Family Meetings. Journal of Family Nursing, 16, 462-486. 
Nelson, J. E., Angus, D. C., Weissfeld, L. A., Puntillo, K. A., Danis, M., Deal, D., Levy, M. M. \& Cook, D. J. (2006). End-of-life care for the critically ill: A national intensive care unit survey. Critical Care Medicine, 34, 2547-2553.

Nelson, J. E. \& Danis, M. (2001). End-of-life care in the intensive care unit: where are we now? Critical Care Medicine, 29 (supl. 2), N2-N9.

Nelson, J. E. \& Meier, D. E. (1999a). Palliative care in the intensive care unit: part I. Journal of Intensive Care Medicine, 14, 130-139.

Nelson, J. E. \& Meier, D. E. (1999b). Palliative care in the intensive care unit: part II. Journal of Intensive Care Medicine, 14, 189-199.

Nicolás, A., Aizpitarte, E., Iruarrizaga, A., Vázquez, M., Margall, M. A. \& Asiain, M. C. (2002). Percepción de los pacientes quirúrgicos del sueño nocturno en una Unidad de Cuidados Intensivos. Enfermería Intensiva, 13, 57-67.

Nightingale, F. (1863). Notes on hospitals. London: Longman, Green, Longman, Roberts and Green.

Norris, L. O. \& Grove, S. K. (1986). Investigation of selected psychosocial needs of family members of critically ill patients. Heart and Lung, 15:194-199.

Novaes, M. A. F. P., Aronovich, A., Ferraz, M. B. \& Knobel, E. (1997). Stressors in ICU: patients' evaluation. Intensive Care Medicine, 23, 1282-1285.

Novaes, M. A. F. P., Knobel, E., Bork, A. M., Pavâo, O. F., Nogueira-Martins, L. A. \& Ferraz, M. B. (1999). Stressors in ICU: perception of the patient, relatives and health care team. Intensive Care Medicine, 25, 1421-1426.

Ocampo, B. (2009). Apuntes para la historia del cuidado intensivo en Colombia. En J. Eslava, J. R. Navarro \& L. E. Cruz (Eds.), Semiología del paciente crítico: la clínica y la monitoria invasiva, ¿son excluyentes o se complementan? (pp. 9-59). Bogotá: Sociedad Cundinamarquesa de Anestesiología.

O'Connor, D. W., Pollitt, P. A., Treasure, F. P., Brook, C. P. B. \& Reiss, B. B. (1989). The influence of education, social class and sex on Mini-Mental State scores. Psychological Medicine, 19, 771-776.

O'Farrell, P., Murray, J. \& Hotz, S. (2000). Psychological distress among spouses of patients undergoing cardiac rehabilitation. Heart and Lung, 29, 97-104. 
O'Hagan, K. (1984). Family crisis intervention in social services. Journal of Family Therapy, 6, 149-181.

Oransky, I. (2003). Obituary: Peter Safar. The Lancet, 362, 749.

Ouimet, S., Kavanagh, B. P., Gottfried, S. B. \& Skrobik, Y. (2007). Incidence, risk factors and consequences of ICU delirium. Intensive Care Medicine, 33, 66-73.

Palomeque, A. (2005). Cuidados intensivos y cuidados paliativos. Anales de Pediatría, 62, 409-411.

Paparrigopoulos, T., Melissaki, A., Efthymiou, A., Tsekou, H., Vadala, C., Kribeni, G., Pavlou, E. \& Soldatos, C. (2006). Short-term psychological impact on family members of intensive care unit patients. Journal of Psychosomatic Research, 61, 719722.

Paul, F. \& Rattray, J. (2008). Short- and long-term impact of critical illness on relatives: literature review. Journal of Advanced Nursing, 62, 276-292.

Payás, A., Barbero, J., Bayés, R., Benito, E., Giró, R. M., Maté, J., Rodeles, R. \& Tomás, C. M. (2008). ¿Cómo perciben los profesionales de paliativos ls necesidades espirituales del paciente al final de la vida?. Medicina Paliativa, 15, 225-237.

Penson, R. T., Gu, F., Harris, S., Thiel, M. M., Lawton, N., Fuller, A. F. \& Lynch, T. J. (2007). Hope. The Oncologist, 12, 1105-1113.

Perdomo, R. G. (1992). Medicina Intensiva y las Unidades de Cuidados Intensivos. Definición-Desarrollo Histórico-Utilización de sus Recursos. Revista Médica Hondureña, 60, 49-52.

Pérez-San Gregorio, M. A., Blanco-Picabia, A., Murillo-Cabezas, F., DominguezRoldán, J. M., Sánchez, B. \& Núñez-Roldán, A. (1992). Psychological problems in the family members of gravely traumatised patients admitted into an intensive care unit. Intensive Care Medicine, 18, 278-281.

Pettilä, V., Kaarlola, A. \& Makelainen, A. (2000) Health-related quality of life of multiple organ dysfunction patients one year after intensive care. Intensive Care Medicine, 26, 1473-1479.

Pincok, S. (2007). Bjørn Aage Ibsen. The Lancet, 370, 1538. 
Plakas, S., Cant, B. \& Taket, A. (2009). The experiences of families of critically ill patients in Greece: A social constructionist grounded theory study. Intensive and Critical Care Nursing, 25, 10-20.

Pochard, F., Azoulay, E., Chevret, S., Lemaire, F., Hubert, P., Canoui, P., Grassin, M., Zittoun, R., le Gall, J. R., Dhainaut, J. F. \& Schlemmer, B. for the French FAMIREA group (2001). Symptoms of anxiety and depression in family members of intensive care unit patients: Ethical hypothesis regarding decision-making capacity. Critical Care Medicine, 29, 1893-1897.

Pochard, F., Darmon, M., Fassier, T., Bollaert, P.E., Cheval, C., Coloigner, M., Merouani, A., Moulront, S., Pigne, E., Pingat, J., Zahar, J. R., Schlemmer, B. \& Azoulay, E. (2005). Symptoms of anxiety and depression in family members of intensive care unit patients before discharge or death. A prospective multicenter study. Journal of Critical Care, 20, 90-96.

Prayag, S. (2002). ICUs worldwide: Critical care in India. Critical Care, 6, 479-480. Recuperado el 29 de noviembre de 2011, de http:/ / ccforum.com/content/pdf/cc1544.pdf

Pryzby, B. J. (2005). Effects of nurse caring behaviours on family stress responses in critical care. Intensive and Critical Care Nursing, 21, 16-23.

Ptacek, J.T. \& Eberhardt, T. L. (1996). Breaking Bad News: A Review of the Literature. The Journal of the American Medical Association, 276, 496-502.

Quinio, P., Savry, C., Deghelt, A., Guilloux, M., Catineau, J. \& de Tinténiac, A. (2002). A multicenter survey of visiting policies in French intensive care units. Intensive Care Medicine, 28, 1389-1394.

Quinn, S., Redmond, K. \& Begley, C. (1996). The needs of relatives visiting critical care units as perceived by relatives and nurses. Intensive and Critical Care Nursing, 12, 168-172.

Quintana, J. M., Padierna, A., Esteban, C., Arostegui, I., Bilbao, A. \& Ruiz, I. (2003). Evaluation of the psychometric characteristics of the Spanish Version of the Hospital Anxiety and Depression Scale. Acta Psychiatrica Scandinavica, 107, 216221. 
Rattray, J., Crocker, C., Jones, M. \& Connaghan, J. (2010). Patients' perceptions of and emotional outcome after intensive care: results from a multicentre study. Nursing in Critical Care, 15, 86-93.

Rattray, J. E., Johnston, M. \& Wildsmith, J. A. W. (2005). Predictors of emotional outcomes of intensive care. Anaesthesia, 60, 1085-1092.

Real Academia Española. (2001). Diccionario de la lengua española (22.a ed.). Disponible en http://www.rae.es/rae.html

Richardson, A., Crow, W., Coghill, E. \& Turnock, C. (2007). A comparison of sleep assessment tools by nurses and patients in critical care. Journal of Clinical Nursing, $16,1660-1668$.

Richart, M., Cabrero, J. \& Reig, A. (1993). Hospitalización y estrés en el paciente: percepción diferencial de estresores entre paciente y personal de enfermería. Análisis y Modificación de Conducta, 19, 75-89.

Richter, J. C., Waydhas, C. \& Pajonk, F-G. (2006). Incidence of Posttraumatic Stress Disorder after Prolonged Surgical Intensive Care Unit Treatment. Psychosomatics, $47,223-230$.

Rincon, H. G., Granados, M., Unutzer, J., Gomez, M., Duran, R., Badiel, M., Salas, C., Martinez, J., Mejia, J., Ordóñez, C., Florez, N., Rosso, F. \& Echeverri, P. (2001). Prevalence, detection and treatment of anxiety, depression, and delirium in the Adult Critical Care Unit. Psychosomatics, 42, 391-396.

Ringdal, M., Kaety, P., Dag, L., Lotta, J. \& Ingegerd, B. (2009). Outcome after injury: Memories, Health-Related Quality of Life, Anxiety, and Symptoms of Depression after Intensive Care. Journal of Trauma-Injury Infection $\mathcal{E}$ Critical Care, 66, 12261233.

Robb, Y. A. (1998). Family nursing in intensive care part two: the needs of a family with a member in intensive care. Intensive and Critical Care Nursing, 14, 203-207.

Rodríguez, J. J., Martín, R., Jorge, R. M., Iniesta, J., Palazón, C., Carrión, F., Parra, F., López, A. \& Martínez, M. (2001). Síndrome confusional agudo en UCI: factores que influyen y actitud de enfermería. Enfermería Intensiva, 12, 3-9. 
Rowe, M. M. \& Allen, R.G. (2004). Spirituality as a means of coping with chronic illness. American Journal of Health Studies, 19, 62-67.

Rubenfeld, G. D. \& Curtis, J. R. (2001). End-of-life care in the intensive care unit: A research agenda. Critical Care Medicine, 29, 2001-2006.

Ruiz, J. \& Martín, M. C. (2006). Ciento cincuenta años de atención al enfermo crítico. Jano, 1614, 47-52.

Sabin, A. B., Ramos-Alvarez, M., Alvarez-Amezquita, J., Pelon, W., Michaels, R. M., Spigland, I., Koch, M. A., Barnes, J. M. \& Rhim, J. S. (1984). Live, Orally Given Poliovirus Vaccine: Effects of Rapid Mass Immunization on Population Under Conditions of Massive Enteric Infection With Other Viruses. The Journal of the American Medical Association, 251, 2988-2993.

Salk, J., (1983). The Virus of Poliomyelitis: From Discovery to Extinction. The Journal of the American Medical Association, 250, 808-810.

Samuelson, K. A. M., Lundberg, D. \& Fridlund, B. (2007). Stressful memories and psychological distress in adult mechanically ventilated intensive care patients - a 2-month follow-up study. Acta Anaesthesiologica Scandinavica, 51, 671-678.

Sandín, B. (1999). El estrés psicosocial. Madrid: Klinik.

Sandín, B. (2003). El estrés: Un análisis basado en el papel de los factores sociales. International Journal of Clinial and Health Psychology, 3, 141-157.

Sandín, B. \& Chorot, P. (1995). Concepto y categorización de los trastornos de ansiedad. En A. Belloch, B. Sandín \& F. Ramos (Eds.), Manual de psicopatología (Vol. 2 ) (pp. 53-80). Madrid: McGraw-Hill.

Sandiumenge, A., Torrado, H. \& Anglés, R. (2009). Trastornos psicológicos en el paciente crítico: depresión y síndrome de estrés postraumático. En C. Chamorro (Coord.), Analgesia, sedación y bloqueo neuromuscular del paciente crítico. Aspectos prácticos (pp. 123-136). Barcelona: Edikamed.

Sanz, J. \& Vázquez, C. (1998). Fiabilidad, validez y datos normativos del Inventario para la Depresión de Beck. Psicothema, 10, 303-318.

Scott, A. (2004). Managing anxiety in ICU patients: the role of pre-operative information provision. Nursing in Critical Care, 9, 72-79. 
Scragg, P., Jones, A. \& Fauvel, N. (2001). Psychological problems following ICU treatment. Anaesthesia, 56, 9-14.

Seisdedos, N. (1988) STAI. Cuestionario de ansiedad estado-rasgo. Madrid: TEA Ediciones, S.A.

Selye, H. (1974). Stress without distress. Philadelphia: Lippincott.

Sheaffer, H. (2010). The met and unmet needs of families of patients in the ICU and implications for social work practice. Doctorate in Social Work (DSW) Dissertations. Paper 2. Recuperado el 22 de diciembre de 2011, de http://repository upenn.edu/edissertations._sp2/2

Simpson, S. H. (1997). Reconnecting: the experiences of nurses caring for hopelessly ill patients in intensive care. Intensive Critical Care Nursing, 13, 189-197.

Singer, P. A., Martin, D. K. \& Kelner, M (1999). Quality End-of-Life Care: Patients' Perspectives. The Journal of the American Medical Association, 281, 163-168.

Sociedad Española de Medicina Intensiva, Crítica y Unidades Coronarias (SEMICYUC). (2011). Medicina Intensiva en España. Medicina Intensiva, 35, 92101.

Söderström, I. M. K., Saveman, B. I., Hagberg, M. S. \& Benzein, E. G. (2009). Family adaptation in relation to a family member's stay in ICU. Intensive and Critical Care Nursing, 25, 250-257.

Spielberger, C. D., Gorsuch, R. L. \& Lushene, R. (1983). Manual for the State-Trait Anxiety Inventory. Palo Alto, CA: Consulting Psychologists Press.

Sprung, C. L., Cohen, S. L., Sjokvist, P., Baras, M., Bulow, H. H., Hovilehto, S., Ledoux, D., Lippert, A., Maia, P., Phelan, D., Schobersberger, W., Wennberg, E. \& Woodcock, T. (2003). End-of-Life Practices in European Intensive Care Units. The Ethicus Study. Journal of the American Medical Association, 290, 790-797.

Stein-Parbury, J. \& McKinley, S. (2000). Patients' experiences of being in an intensive care unit: a select literature review. American Journal of Critical Care, 9, 20-27.

Stedeford, A. (1984). Facing death: patients, family, and professionals. London: William Heinemann. 
Stewart, J. L., Mishel, M. H., Lynn, M. R. \& Terhorst, L. (2010). Test of a Conceptual Model of Uncertainty in Children and Adolescents with Cancer. Research in Nursing and Health, 33, 179-191.

Stinnett, S. (1990). Women in Statistics: Sesquicentennial Activities. The American Statistician, 44, 74-80.

Storli, S. L., Lindseth, A. \& Asplund, K. (2008). A journey in quest of meaning: a hermeneutic-phenomenological study on living with memories from intensive care. Nursing in Critical Care, 13, 86-96.

Streater, C., Golledge, J., Sutherland, H., Easton, J., Macdonald, R., McNamara, R., Looise A. \& Gelling, L. (2001). The relocation experiences of relatives leaving a neurosciences critical care unit: a phenomenological study. Nursing in Critical Care, 6, 163-170.

Street, A. F., Love, A. \& Blackford, J. (2005). Managing family centered palliative care in aged and acute settings. Nursing and Health Sciences, 7, 45-55.

Stricker, K. H., Kimberger, O., Schmidlin, K., Zwahlen, M., Mohr, U. \& Rothen, H. U. (2009). Family satisfaction in the intensive care unit: what makes the difference? Intensive Care Medicine, 35, 2051-2059.

Stroebe, M., Hansson, R. \& Schut, H. (2008). Handbook of bereavement research and practice: Advances in theory and intervention. Washington, DC: American Psychological Association.

Sukantarat, K., Greer, S., Brett, S. \& Williamson, R. (2007). Physical and psychological sequelae of critical illness. British Journal of Health Psychology, 12, 65-74.

Tejero, A., Guimerá, E. M., Farré, J. M. \& Peri, J. M. (1986). Uso clínico del HADS (Hospital Anxiety and Depression Scale) en población psiquiátrica: un estudio de su sensibilidad, fiabilidad y validez. Revista Departamento Psiquiatría Facultad de Medicina de Barcelona, 13, 233-238.

Tembo, A. C. \& Parker, V. (2009). Factors that impact on sleep in intensive care patients. Intensive and Critical Care Nursing, 25, 314-322. 
Terol, M. C., López-Roig, S., Rodríguez-Marín, J., Martín-Aragón, M., Pastor, M. A. \& Reig, M. T. (2007). Propiedades psicométricas de la Escala Hospitalaria de Ansiedad y Estrés (HAD) en población española. Ansiedad y Estrés, 13, 163-176.

Titler, M. G., Cohen, M. Z. \& Craft, M. J. (1991). Impact of adult critical care hospitalization: perceptions of patients, spouses, children and nurses. Heart and Lung, 20, 174-182.

Todres, L., Fulbrook, P. \& Albarran, J. (2000). On the receiving end: a hermeneuticphenomenological analysis of the patient's struggle to cope with going through intensive care. Nursing in Critical Care, 5, 277-287.

Topf, M., Bookman, M. \& Arand, D. (1996). Effects of critical care unit noise on the subjective quality of sleep. Journal of Advanced Nursing, 24, 545-551.

Truog, R. D., Campbell, M. L., Curtis, J. R., Haas, C. E., Luce, J. M., Rubenfeld, G. D., Rushton, C. H. \& Kaufman, D. C. (2008). Recommendations for end-of-life care in the intensive care unit: A consensus statement by the American College of Critical Care Medicine. Critical Care Medicine, 36, 953-963.

Truog, R. D., Cist, A. F. M., Brackett, S. E., Burns, J. P., Curley, M. A. Q., Danis, M., DeVita, M. A., Rosenbaum, S. H., Rothenberg, D. M., Sprung, C. L., Webb, S. A., Wlody, G. S. \& Hurford, W. E. (2001). Recommendations for end-of-life care in the intensive care unit: The Ethics Committee of the Society of Critical Care Medicine. Critical Care Medicine, 29, 2332-2348.

Ulla, S. (2003). Aportaciones de la Psiconeuroinmunología a la Psicología Hospitalaria. En E. Remor, P. Arranz \& S. Ulla (Eds.), El psicólogo en el ámbito hospitalario (pp. 49-72). Bilbao: Desclée de Brouwer, S.A.

Vandall-Walker, V. \& Clark, A.M. (2011). It Starts With Access! A Grounded Theory of Family Members Working to Get Through Critical Illness. Journal of Family Nursing, 17, 148-181.

Vandall-Walker, V., Jensen, L. \& Oberle, K. (2007). Nursing Support for Family Members of Critically Ill Adults. Qualitative Health Research, 17, 1207-1218.

Vandekieft, G. K. (2001). Breaking Bad News. American Family Physician, 64, 1975-1978. 
Vandijck, D. M., Labeau, S. O., Geerinckx, C. E., De Puydt, E., Bolders, A. C., Claes, B. \& Blot, S. I. (2010). An evaluation of family-centered care services and organization of visiting policies in Belgian intensive care units: A multicenter survey. Heart and Lung, 39, 137-146.

Van Horn, E. \& Tesh, A. (2000). The effect of critical care hospitalization on family members: stress and responses. Dimensions of Critical Care Nursing, 19, 40-49.

Verhaeghe, S., Defloor, T., Van Zuuren, F., Duijnstee, M. \& Grypdonck, M. (2005). The needs and experiences of family members of adult patients in an intensive care unit: a review of the literature. Journal of Clinical Nursing, 14, 501-509.

Verhaeghe, S., Van Zuuren, F., Defloor, T., Duijnstee, M. S. A. \& Grypdonck, M. (2007). How does information influence hope in family members of traumatic coma patients in intensive care unit? Journal of Clinical Nursing, 16, 1488-1497.

Vila, J. (1984). Técnicas de reducción de ansiedad. En J. Mayor y F.J. Labrador (Eds.), Manual de modificación de conducta (pp. 229-260). Madrid: Alhambra.

Volicer, B. J. \& Bohanon, M. A. (1975). Hospital stress rating scale. Nursing Research, 24, 352-359.

Wåhlin, I., Ek, A. C. \& Idvall, E. (2006). Patient empowerment in intensive care-An interview study. Intensive and Critical Care Nursing, 22, 370-377.

Warren, N. (1993). Perceived needs of family members in the critical care waiting room. Critical Care Nursing Quarterly, 16, 56-63.

Wehler, M., Geise, A., Hadzionerovic, D., Aljukic, E., Reulbach, U., Hahn, E.G. \& Strauss, R. (2003). Health-related quality of life of patients with multiple organ dysfunction: Individual changes and comparison with normative population. Critical Care Medicine, 31, 1094-1101.

Weil, M. H. (1973). The Society of Critical Care Medicine, its history and its destiny. Critical Care Medicine, 1, 1-4.

Weil, M. H. \& Shoemaker, W. C. (2004). Pioneering contributions of Peter Safar to intensive care and the founding of the society of critical care medicine. Peter Safar, Physician, Scientist, Teacher, and Humanist. Critical Care Medicine, 32, S8S10. 
West, J. B. (2005). The physiological challenges of the 1952 Copenhagen poliomyelitis epidemic and a renaissance in clinical respiratory physiology. Journal of Applied Physiology, 99, 424-432.

Whitton, S. \& Pittiglio, L. I. (2011). Critical care open visiting hours. Critical Care Nursing Quarterly, 34, 361-366.

Wijngaards-de Meij, L., Stroebe, M., Schut, H., Stroebe, W., van den Bout, J., van der Heijden, P. G. M. \& Dijkstra, I. (2008). Parents grieving the loss of their child: Interdependence in coping. British Journal of Clinical Psychology, 47, 31-42.

Wikström, A. C. (2003). Technology - a supporter and challenger in everyday practice. A study of interaction in the intensive care unit. (Diss. Licentiate's degree). Gothenburg: Sahlgrenska Academy.

Wilkinson, P. (1995). A qualitative study to establish the self-perceived needs of family members in a general intensive care unit. Intensive and Critical Care Nursing, 11, 77-86.

Williams, C. M. A. (2005). The identification of family members' contribution to patients' care in the intensive care unit: a naturalistic inquiry. Nursing in Critical Care, 10, 6-14.

Williams, M. A., Lipsett, P. A., Rushton, C. H., Grochowski, E. C., Berkowitz, I. D., Mann, S. L., Shatzer, J. H., Short, M. P., Genel, M. (2003). The physician's role in discussing organ donation with families. Critical Care Medicine, 31, 1568-1573.

Organización Mundial de la Salud (WHO). (2002). Community Noise Environmental Health Criteria Document, External Review Draft. Geneva: WHO Publishing.

Young, E., Eddleston, J., Ingleby, S., Streets, J., McJanet, L., Wang, M. \& Glover, L. (2005). Returning home after intensive care: A comparison of symptoms of anxiety and depression in ICU and elective cardiac surgery patients and their relatives. Intensive Care Medicine, 31, 86-91.

Zaforteza, C., Prieto, S., Canet, T. P., Díaz, Y., Molina, M., Moreno, C., Nieto, A., Sánchez, A. \& Val, J. V. (2010). Mejorando el cuidado a los familiares del paciente crítico: estrategias consensuadas. Enfermería Intensiva, 21, 11-19. 
Zazpe, C., Margall, M. A., Otano, C., Perochena, M. P. \& Asiain, M. C. (1997). Meeting needs of family members of critically ill patients in a Spanish intensive care unit. Intensive and Critical Care Nursing, 13, 12-16.

Zigmond, A. S. \& Snaith, R. P. (1983). The Hospital Anxiety and Depression Scale. Acta Psychiatrica Scandinavica, 67, 361-370.

Zisook, S. \& Shuchter, S. R. (1991). Depression through the first year after the death of a spouse. The American Journal of Psychiatry,148, 1346-1352. 
ANEXOS 

ANEXO I

Requerimientos mínimos en una UCI 



\section{MINIMAL REQUIREMENTS FOR INTENSIVE CARE DEPARTMENTS (European Society of Intensive Care Medicine) (Ferdinande, 1997)}

Level of care

III II I

Operational guidelines

I. Intensive Care Department

The intensive care department represents a distinct organisational and geographic entity with specific characteristics in the hospital (medical, nursing, paramedical, technical, geographic environment)

II. Functional criteria

II.1. Multidisciplinary approach

Besides the $24 \mathrm{~h}$ coverage of the medical staff of the ICU, the following physicians should be on call and available:

1.Anaesthesiologist

2. General Surgeon

3.Neurosurgeon

4. Cardiovascular surgeon

5. Thoracic surgeon

6. Infectious disease specialist/microbiologist

7. Cardiologist

8. Gastroenterologist (emergency endoscopies)

9. Nephrologist

10. (Neuro)Radiologist

11. Trauma surgeon

12. Neurologist

13. Urologic surgeon

14. Obstetric-gynaecologic surgeon

15. Respiratory disease specialist

16. Hematologist

17. Pathologist

18. Orthopaedic surgeon

II. 2. The size of the functional unit in the ICD is minimally 6 beds and maximally 8 beds

II. 3. The ICD medical staff

II. 3.1. A Director of the ICD is appointed

This Director of the ICD is a physician who

1. is qualified in intensive care medicine and his own speciality (anaesthesiology, surgery, internal medicine and paediatrics) (except Spain)*

2. is able to give clinical, administrative and educational direction to the ICD

3. is regularly involved in the care of patients in the department

4. has the administrative task of unit management including diagnostic and therapeutic protocols

5. has final responsibility for the quality, safety and appropriateness of care in the department

\begin{tabular}{|c|c|}
\hline & E \\
\hline & $E$ \\
\hline & $E$ \\
\hline & $D$ \\
\hline & $D$ \\
\hline F & $\mathrm{E}$ \\
\hline$E$ & $E$ \\
\hline$E$ & $E$ \\
\hline$E$ & D \\
\hline $\mathrm{E}$ & $E$ \\
\hline$E$ & $E$ \\
\hline $\mathrm{E}$ & $E$ \\
\hline$D$ & $D$ \\
\hline $\mathrm{D}$ & $D$ \\
\hline $\mathrm{D}$ & $D$ \\
\hline D & $D$ \\
\hline 0 & 0 \\
\hline $\mathrm{E}$ & D \\
\hline D & $D$ \\
\hline $\mathrm{D}$ & $D$ \\
\hline $\mathrm{E}$ & $E$ \\
\hline $\mathrm{E}$ & $E$ \\
\hline$E$ & $E$ \\
\hline $\mathrm{E}$ & $E$ \\
\hline $\mathrm{E}$ & $\mathrm{E}$ \\
\hline & \\
\hline
\end{tabular}




\begin{tabular}{|c|c|c|c|}
\hline Level of care & III & II & 1 \\
\hline 6. is knowledgeable about developments in intensive care medicine & $\mathrm{E}$ & $\mathrm{E}$ & $\mathrm{E}$ \\
\hline $\begin{array}{l}\text { 7. participates in the continuing training in intensive care medicine in teaching } \\
\text { hospitals }\end{array}$ & $\mathrm{E}$ & $\mathrm{E}$ & $\mathrm{E}$ \\
\hline $\begin{array}{l}\text { 8. cannot occupy other top level medical directorships and spends } 75 \% \text { of } \\
\text { his/her clinical activity in the ICD }\end{array}$ & $\mathrm{E}$ & $\mathrm{E}$ & $\mathrm{D}$ \\
\hline 9. has the ability to review the appropriate use of ICD resources in the hospital & $\mathrm{E}$ & $\mathrm{E}$ & D \\
\hline $\begin{array}{l}\text { 10. is available to the ICD } 24 \mathrm{~h} \text { a day, } 7 \text { days a week for administrative and } \\
\text { clinical problems (or provides an equally qualified alternative) }\end{array}$ & $\mathrm{E}$ & $\mathrm{E}$ & $\mathrm{E}$ \\
\hline \multicolumn{4}{|l|}{ II. 3.2. Medical staff members are physicians } \\
\hline $\begin{array}{l}\text { 1. qualified for intensive care medicine and their own speciality of either } \\
\text { anaesthesia, surgery, internal medicine or paediatrics (except Spain)* }\end{array}$ & $\mathrm{E}$ & $\mathrm{E}$ & D \\
\hline 2. number of physicians available per functional unit of $6-8$ beds & 5 & 4 & 3 \\
\hline \multicolumn{4}{|l|}{ 3. with responsibility concerning } \\
\hline $\begin{array}{l}\text { 3.1. state-of-the-art treatment of the critically ill patient in a } 24 \mathrm{~h} \text { in-house } \\
\text { coverage }^{* *} \text { system }\end{array}$ & $\mathrm{E}$ & $\mathrm{E}$ & $\mathrm{D}$ \\
\hline 3.2. admission and discharge criteria & $\mathrm{E}$ & $\mathrm{E}$ & $\mathrm{E}$ \\
\hline 3.3. patient care including at least two clinical rounds a day & $\mathrm{E}$ & $\mathrm{E}$ & $\mathrm{E}$ \\
\hline 3.4. immediate availability and rotation in a continuous on-call system . & $\mathrm{E}$ & $\mathrm{E}$ & $\mathrm{E}$ \\
\hline \multicolumn{4}{|l|}{ II. 4. Nursing staff } \\
\hline \multicolumn{4}{|l|}{$\begin{array}{l}\text { 1. A head nurse for the ICD is appointed with authority and responsibility for } \\
\text { the appropriateness of nursing care and has }\end{array}$} \\
\hline - extensive experience in intensive care nursing & $\mathrm{E}$ & $\mathrm{E}$ & $\mathrm{E}$ \\
\hline - previous management experience & $\mathrm{E}$ & $\mathrm{E}$ & D \\
\hline \multicolumn{4}{|l|}{ The head nurse is prepared to participate } \\
\hline - in the training of unit staff & $\mathrm{E}$ & $\mathrm{E}$ & $\mathrm{E}$ \\
\hline - in continuing education & $\mathrm{E}$ & $\mathrm{E}$ & $\mathrm{E}$ \\
\hline - in research activity & $\mathrm{E}$ & D & $\mathrm{D}$ \\
\hline \multicolumn{4}{|l|}{ 2. Nursing staff } \\
\hline The intensive care nurse is additionally trained in intensive care nursing & $\mathrm{E}$ & $\mathrm{E}$ & $\mathrm{D}$ \\
\hline Nurse/patient ratio & $1 / 1$ & $1 / 1.6$ & $1 / 3$ \\
\hline Number of nurse full-time equivalents needed to run one bed & 6 & 4 & 2 \\
\hline They must participate in continuing training & $\mathrm{E}$ & $\mathrm{E}$ & $\mathrm{E}$ \\
\hline II.5. Physiotherapist: a dedicated physiotherapist available per 12 beds & $\mathrm{E}$ & $\mathrm{E}$ & $\mathrm{D}$ \\
\hline II.6. Technician: available on $24 \mathrm{~h}$ basis & $\mathrm{E}$ & D & D \\
\hline II.7. Radiology technicians: available around the clock & $\mathrm{E}$ & $\mathrm{E}$ & $\mathrm{E}$ \\
\hline II.8. Dietician: available during working hours & $\mathrm{D}$ & $\mathrm{D}$ & $\mathrm{D}$ \\
\hline II.9. Medical secretary: one medical secretary/12 beds & $\mathrm{E}$ & $\mathrm{E}$ & $\mathrm{E}$ \\
\hline II.10. Cleaning personnel familiar with ICU environment and infection & $\mathrm{E}$ & $\mathrm{E}$ & $\mathrm{E}$ \\
\hline
\end{tabular}
prevention protocols 


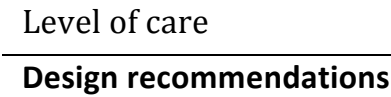

\section{Planning team}

Director of ICD

Head nurse

Architect

Administrator

Engineer

Safety officer

Hospital infection specialist

Representatives of referring departments

II. Floor plan + communications

Distinct entity

Controlled access

Separate public and professional/supply traffic

No through traffic

Priority horizontal access from:

- Emergency Department

- Operating Theatre

- Recovery Room

- Laboratory

- Functional testing facilities

Size:

Department at least 6 beds

Functional subunits of 6-8 beds

2.5-3 times surface of specific patient care area

\section{Accommodation}

\section{1. Patient area}

- minimum space adult cubicle $-25 \mathrm{~m}_{2}$ /bed single room- $20 \mathrm{~m}_{2}$ /bed common room

- rectangular floor plan

- $2.5 \mathrm{~m}$ traffic area beyond working area

- wide doorways (bed passage)

- daylight source per cubicle

III. 1.1. Management functions in patient room/area

a. Communication

telephone hospital

telephone external

intercom

emergency code alarm system

clock + calendar

$\begin{array}{lll}E & E & D \\ E & E & E \\ E & E & D \\ E & E & E \\ E & E & E\end{array}$

b. Administrative equipment

flow sheet charting surface

shelves (files, X-rays)

E E D

D D $O$

E D D

c. Negatoscope

$\begin{array}{lll}E & E & E \\ E & E & E \\ E & E & D \\ E & E & D \\ E & E & E \\ & & \\ E & E & E \\ E & E & E \\ E & E & E\end{array}$




\begin{tabular}{llll} 
Level of care & III & II & I \\
\hline d. Storage: lockable cupboard (medication,...) & E & E & E \\
e. Separate pass through cupboard clean/dirty material & E & E & D
\end{tabular}

III.1.2. Visual observation of the patient

Patient line of vision

- nurse

- external window

E $\quad$ E $\quad E$

III.1.3. Services per patient area

III.1.3.1. Bedside layout

- priority of access to head and neck of patient

- sockets and service outlets with minimal hindrance to nursing care

$\begin{array}{lll}E & E & E \\ E & E & E\end{array}$

III. 1.3.2. Electric power source per bed

- 16-20 grounded sockets (minimal 12 for LOC I)

- 1 grounded socket for radiology equipment per 2 beds

E E D

III.1.3.3. Vacuum per bed

-3 outlets

-2 outlets

E E E

III.1.3.4. Oxygen per bed

-4 outlets

-3 outlets

- manual ventilation system

-airway maintenance material

III.1.3.5. Compressed air per bed..

-3 outlets

-2 outlets

III.1.3.6. Tubing for facultative gas

III.1.3.7.Water supply

2 sinks in each room

Hand disinfection facility per bed

Elbow/foot operated faucets

Hand-drying facility (disposable paper towels)

Self-sterilising heated traps

III.1.3.8. Radio and TV socket

III.1.3.9. Monitoring and computer equipment in patient areas

III.1.3.9.1. Monitoring

- modular systems

- trending capability

- visible and audible alarms

- unobstructed comfortable viewing

- simultaneous display and selectable digital values for

-EKG, arterial pressure, central venous pressure, temperature

D D O

E $\quad$ E $\quad D$

D D -

E $\quad$ D

E $\quad E \quad E$

E $\quad E \quad D$

E D O

E D

(central/cutaneous), pulse oxymetry, pressure control endotracheal cuff, non-invasive arterial pressure monitoring

- continuous monitoring of ventilation, alarm recording and hard copy, oxymetry of inspired gases

-pulmonary function, mixed venous saturation, arrhythmia detection

$\begin{array}{lll}\text { E } & \text { E } & \text { E } \\ \text { E } & \text { E } & \text { D } \\ \text { E } & \text { E } & \text { E } \\ \text { E } & \text { E } & \text { E } \\ & & \\ \text { E } & \text { E } & \text { E }\end{array}$

E $\quad$ E D

D D O 
III.1.3.9.2. Computer systems at bedside

1. trend analysis of on-line measured parameters

2. calculation of derived values

3. hard copy of visual display and trends

4. automatic reports of all directly measured and calculated parameters

5. communication with laboratory and diagnostic departments

6. drug dosage, adverse effects information

7. stock management of drugs, disposables

8. charging therapeutic acts

9. printing of laboratory labels

10. analysis and report of patient acuity data

III.2. Central nursing station

A spacious and commodious area containing

1. shelves for forms/library

2. satellite pharmacy (lockable drawers)

3. computer terminals

4. telephone, intercom and emergency call system

5. satellite storage sterile/non-sterile material

6. drug preparation area

7. visual display for incoming patient monitoring signals and alarm recording

8. air-conditioning, adequate lighting, clock, hand basin

III.3. Storage

- maximum $30 \mathrm{~m}$ distance from patient area

- separate entries from patient area and supply route

III.4. Utility

Clean utility room $(15 \mathrm{~m} 2)$

Dirty utility room $(25 \mathrm{~m} 2)$ with separate way out

III.5. Nurses' office (15 m2)

- clerical space

- telephone, intercom, notice boards, alarm system bedside calls

III.6. Medical office $(20 \mathrm{~m} 2)$

- one per full time ICU physician

- telephone-intercom-alarm registration

- computer terminal (access to patient monitoring data, laboratory and

diagnostic departments)

III.7. Secretariat (20 m2/8 ICU beds)

III.8. Staff lounge (24 m2/8 ICU beds)

III.9. Physician's bedroom (15 m2/8 ICU beds)

- adjacent to unit

- telephone, alarm code system, television

- toilet/shower

III.10. Laboratory (15 m2)

- emergency laboratory located in ICD

- refrigerator

- telephone intercom

\begin{tabular}{|c|c|}
\hline$E$ & $E$ \\
\hline$E$ & $\mathrm{E}$ \\
\hline $\mathrm{E}$ & $E$ \\
\hline $\mathrm{E}$ & $E$ \\
\hline$D$ & $D$ \\
\hline$D$ & $D$ \\
\hline $\mathrm{E}$ & $E$ \\
\hline$E$ & $\mathrm{E}$ \\
\hline$E$ & $E$ \\
\hline$D$ & $\mathrm{D}$ \\
\hline$E$ & $\mathrm{E}$ \\
\hline$E$ & $\mathrm{E}$ \\
\hline$E$ & $\mathrm{E}$ \\
\hline $\mathrm{E}$ & $\mathrm{E}$ \\
\hline $\mathrm{E}$ & $\mathrm{E}$ \\
\hline $\mathrm{E}$ & $\mathrm{E}$ \\
\hline$D$ & $D$ \\
\hline$E$ & $\mathrm{E}$ \\
\hline$E$ & $\mathrm{E}$ \\
\hline$E$ & $E$ \\
\hline$E$ & $\mathrm{E}$ \\
\hline$E$ & $E$ \\
\hline$E$ & $\mathrm{E}$ \\
\hline$E$ & $\mathrm{E}$ \\
\hline $\mathrm{E}$ & $\mathrm{E}$ \\
\hline $\mathrm{E}$ & $\mathrm{E}$ \\
\hline $\mathrm{E}$ & $\mathrm{E}$ \\
\hline$D$ & $\mathrm{D}$ \\
\hline
\end{tabular}

III.12. Kitchen ( $25 \mathrm{~m} 2)$ 
III.13. Reception area and relatives' rooms

$15 \mathrm{~m} 2 / 8$ ICU beds or 1.5-2 chairs/bed

III.14. Receptionist's office $(10 \mathrm{~m} 2)$

Position with access control to unit

Separate professional and visitor entrance

Telephone, intercom

III.15. Special procedures room/therapy room (35 m2)

Meets patient room standards

High intensity lighting

III.16. Seminar/conference room (40 m2)

III.17. Computer room ( $20 \mathrm{~m} 2)$

III.18. Cleaners' room (3-4 m2/8 beds)

III.19. Interview room (15 m2)

III.20. Corridors and elevators

Separated patient, professional and public corridors

Oversized elevators

\begin{tabular}{|c|c|c|}
\hline III & II & I \\
\hline$E$ & $E$ & $D$ \\
\hline$D$ & $D$ & D \\
\hline$E$ & $E$ & $D$ \\
\hline$E$ & $D$ & 0 \\
\hline$E$ & $E$ & 0 \\
\hline$E$ & $E$ & $D$ \\
\hline$D$ & D & 0 \\
\hline$E$ & $E$ & $\mathrm{E}$ \\
\hline$E$ & $D$ & 0 \\
\hline$E$ & $E$ & $D$ \\
\hline$D$ & $D$ & 0 \\
\hline$E$ & $E$ & $E$ \\
\hline$D$ & $D$ & $D$ \\
\hline$D$ & $D$ & 0 \\
\hline$E$ & $E$ & $E$ \\
\hline$E$ & $E$ & $E$ \\
\hline$E$ & $\mathrm{E}$ & $\mathrm{E}$ \\
\hline$E$ & $E$ & $E$ \\
\hline$E$ & $E$ & $E$ \\
\hline $\mathrm{E}$ & $E$ & $\mathrm{E}$ \\
\hline
\end{tabular}

IV.2. Floor plan on display: showing exits, fire hoses, control panels services hazard areas

V. Central services

Control switches, shut-off valves and monitoring located adjacent to ICD

VI. Communications

VI.1. Telephone

- two external lines/8 beds

- in-hospital line in each patient area

- in-hospital line in each architectural entity

- secretariat 2 internal/1 external line

- emergency phone bypassing hospital switchboard

VI.2. Intercom

- all ICD rooms

- with key departments (blood bank, pharmacy)

VI.3. Alarm call

- alarm call button per bed

- alarm call signal in nursing station, staff lounge, conference room, physician bedroom

- alarm call signal on staff location system

$\begin{array}{lll}E & E & E \\ E & E & E \\ E & E & E \\ E & E & E \\ E & D & D \\ & & \\ E & D & D \\ D & D & D \\ & & \\ E & E & E \\ E & E & E \\ E & E & E \\ D & D & O \\ E & E & E\end{array}$


VI.6. Personal call systems

Medical staff

E $\quad E \quad E$

Head nurse

E $\quad E \quad E$

Physiotherapist

D $\quad \mathrm{O} \quad \mathrm{O}$

Technician

D $\quad$ D $\quad$ D

Referring physician

D $\quad$ D $\quad D$

VII. Management of equipment

VII.1. Consumables: Stock control

E $\quad E \quad E$

VII.2. Durable equipment

VII.2.1. Continuous updated selection policy

$\begin{array}{lll}E & E & D \\ E & E & E \\ E & E & E \\ D & D & D\end{array}$

VII.2.2. Lockable storage facilities

VII.2.3. Equipment log cards

VII.2.4. Sterilisation in central hospital service

* In Spain a specific training in intensive care medicine exists without the requirements of a primary speciality.

** These requirements may be fulfilled by senior residents capable of handling emergency situations provided that an attending physician is on call and available within 20 min. 



\section{ANEXO II}

\section{Consentimiento Informado}



Nombre y apellidos:

MANIFIESTO:

1. Que he sido informado suficientemente de las pruebas y tratamientos que recibiré a consecuencia de la investigación que se realiza.

2. Que estoy de acuerdo y acepto libremente y voluntariamente que recibiré únicamente y exclusivamente este tratamiento y me comprometo a seguir las prescripciones y a formalizar los cuestionarios que me indiquen.

3. Que, en función de esta opción libre anteriormente dicha, puedo abandonar el tratamiento en el momento que quiera.

De la misma manera el terapeuta puede dar por finalizado el tratamiento si el solicitante no cumple un mínimo de pautas establecidas que posibilite un tratamiento adecuado.

4. Que, salvaguardando siempre mi derecho a la intimidad, acepto que los datos que se puedan derivar de dicho estudio de investigación puedan ser utilizados para la divulgación científica.

El interesado/a.

El/La investigador/a principal en el proyecto.

Castelló de la Plana, a d de 20 



\section{ANEXO III}

\section{A-Hoja de Registro Datos Pacientes B- Hoja de Registro Datos Familiares}



DATOS PACIENTES UCI

Fecha:

Fecha ingreso $\mathrm{UCl}$ :

№ $\mathrm{UCl}$ :

№ Historia Clínica:

Teléfono:

Apellidos:

Nombre:

Edad:

Año de nacimiento:

Sexo:

Estado civil:

Profesión:

Estudios:

Creencias religiosas:

Domicilio:

Código postal y Población:

Lugar donde se administra el cuestionario:

$\mathrm{UCl}$

PLANTA

.CASA

$>$ GRUPO DIAGNÓSTICO INGRESO

$\square \quad$ Paciente coronario

$\square \quad$ Paciente con enfermedad médica

$\square \quad$ Paciente neuroquirúrgico

$\square$ Paciente séptico

$\square$ Paciente respiratorio

$\square$ Paciente con traumatismos no operados

○ SNC

- $\operatorname{Sin} \mathrm{SNC}$

$\square$ Paciente con Traumatismo quirúrgico

- SNC

- $\operatorname{Sin} \mathrm{SNC}$

$>$ SUBTIPO

Cáncer

$\square \quad$ Sin Cáncer

TIPO PACIENTE

$\square$ Quirúrgico

○ Urgente

- $\quad \mathrm{RR}$ (Despertar)

- Programado

$\square \quad$ No quirúrgico

ANTECEDENTES

$\square$ Enfermedad anterior limitante

$\square \quad$ Enfermedad anterior no limitante

$\square \quad$ Sin enfermedad previa 

DATOS FAMILIARES UCI

Fecha: .....................................Fecha ingreso PACIENTE UCI:

Apellidos:

Nombre:

Teléfono:

Edad:

Año de nacimiento:

Sexo:

Estado civil: Número de hijos:

Profesión:

Estudios:

Creencias religiosas:

Domicilio:

Población: 



\section{ANEXO IV}

Escala de Ansiedad y Depresión

(HADS) 



\section{ESCALA DE ANSIEDAD Y DEPRESIÓN (HADS)}

\section{Zigmond y Snaith (1983)}

Lea cada frase y marque la respuesta que más se ajusta a como se sintió usted durante la semana pasada. No piense mucho las respuestas. Lo más seguro es que si apunta deprisa sus respuestas se ajustarán mucho más a cómo se sintió la última semana.

\begin{tabular}{|c|c|c|c|c|}
\hline $\begin{array}{l}\text { 1. Me siento tenso o } \\
\text { nervioso. }\end{array}$ & Todos los días & Muchas veces & A veces & Nunca \\
\hline $\begin{array}{l}\text { 2. Todavía disfruto con lo } \\
\text { que antes me gustaba. }\end{array}$ & Como siempre & $\begin{array}{c}\text { No lo } \\
\text { bastante }\end{array}$ & Sólo un poco & Nada \\
\hline $\begin{array}{l}\text { 3. Tengo una sensación de } \\
\text { miedo, como si algo horrible } \\
\text { me fuera a suceder. }\end{array}$ & $\begin{array}{l}\text { Definitivamente } \\
\text { y es muy fuerte }\end{array}$ & $\begin{array}{l}\text { Sí, pero no es } \\
\text { muy fuerte }\end{array}$ & $\begin{array}{l}\text { Un poco, pero } \\
\text { no me } \\
\text { preocupa }\end{array}$ & Nada \\
\hline $\begin{array}{l}\text { 4. Puedo reírme y ver el lado } \\
\text { divertido de las cosas. }\end{array}$ & $\begin{array}{c}\text { Al igual que } \\
\text { siempre lo hice }\end{array}$ & $\begin{array}{c}\text { No tanto } \\
\text { ahora }\end{array}$ & Casi nunca & Nunca \\
\hline $\begin{array}{l}\text { 5. Tengo mi mente llena de } \\
\text { preocupaciones. }\end{array}$ & $\begin{array}{l}\text { La mayoría de } \\
\text { las veces }\end{array}$ & $\begin{array}{l}\text { Con bastante } \\
\text { frecuencia }\end{array}$ & $\begin{array}{l}\text { A veces, } \\
\text { aunque no } \\
\text { muy a } \\
\text { menudo }\end{array}$ & $\begin{array}{l}\text { Sólo en } \\
\text { ocasiones }\end{array}$ \\
\hline 6. Me siento alegre. & Nunca & $\begin{array}{l}\text { No muy a } \\
\text { menudo }\end{array}$ & A veces & $\begin{array}{c}\text { Casi } \\
\text { siempre }\end{array}$ \\
\hline $\begin{array}{l}\text { 7. Puedo estar sentado } \\
\text { tranquilamente y sentirme } \\
\text { relajado. }\end{array}$ & Siempre & Por lo general & $\begin{array}{l}\text { No muy a } \\
\text { menudo }\end{array}$ & Nunca \\
\hline $\begin{array}{l}\text { 8. Me siento como si cada } \\
\text { día estuviera más lento. }\end{array}$ & $\begin{array}{c}\text { Por lo general } \\
\text { en todo } \\
\text { momento } \\
\end{array}$ & $\begin{array}{l}\text { Muy a } \\
\text { menudo }\end{array}$ & A veces & Nunca \\
\hline $\begin{array}{l}\text { 9. Tengo una sensación } \\
\text { extraña, como de "aleteo" } \\
\text { en el estómago. }\end{array}$ & Nunca & $\begin{array}{l}\text { En ciertas } \\
\text { ocasiones }\end{array}$ & $\begin{array}{l}\text { Con bastante } \\
\text { frecuencia }\end{array}$ & $\begin{array}{l}\text { Muy a } \\
\text { menudo }\end{array}$ \\
\hline $\begin{array}{l}\text { 10. He perdido el interés en } \\
\text { mi aspecto personal. }\end{array}$ & Totalmente & $\begin{array}{l}\text { No me } \\
\text { preocupo } \\
\text { tanto como } \\
\text { debiera }\end{array}$ & $\begin{array}{l}\text { Podría tener } \\
\text { un poco más } \\
\text { de cuidado }\end{array}$ & $\begin{array}{l}\text { Me } \\
\text { preocupo } \\
\text { igual que } \\
\text { siempre }\end{array}$ \\
\hline $\begin{array}{l}\text { 11. Me siento inquieto, } \\
\text { como si no pudiera parar de } \\
\text { moverme. }\end{array}$ & Mucho & Bastante & No mucho & Nada \\
\hline $\begin{array}{l}\text { 12. Me siento optimista } \\
\text { respecto a futuro. }\end{array}$ & $\begin{array}{l}\text { Igual que } \\
\text { siempre }\end{array}$ & $\begin{array}{l}\text { Menos de lo } \\
\text { que } \\
\text { acostumbraba }\end{array}$ & $\begin{array}{l}\text { Mucho menos } \\
\text { de lo que } \\
\text { acostumbraba }\end{array}$ & Nada \\
\hline $\begin{array}{l}\text { 13. Me asaltan sentimientos } \\
\text { repentinos de pánico. }\end{array}$ & $\begin{array}{c}\text { Muy } \\
\text { frecuentemente }\end{array}$ & $\begin{array}{c}\text { Bastante a } \\
\text { menudo }\end{array}$ & $\begin{array}{l}\text { No muy a } \\
\text { menudo }\end{array}$ & Nada \\
\hline $\begin{array}{l}\text { 14. Me divierto con un buen } \\
\text { libro, la radio o un programa } \\
\text { de televisión. }\end{array}$ & A menudo & A veces & $\begin{array}{l}\text { No muy a } \\
\text { menudo }\end{array}$ & Rara vez \\
\hline
\end{tabular}





\section{ANEXO V}

Cuestionario de Ansiedad

Estado/Rasgo (STAI) 



\section{CUESTIONARIO DE ANSIEDAD ESTADO/ RASGO (STAI).}

\section{STAI-E}

Instrucciones:

A continuación encontrarás unas frases que se utilizan corrientemente para describirse uno a sí mismo. Lee cada frase y señala la puntuación de 0 a 3 que indique mejor CÓMO TE SIENTES AHORA MISMO, en este momento. No hay respuestas buenas ni malas. No emplees demasiado tiempo en cada frase y contesta señalando la respuesta que mejor describa tu situación presente.

\begin{tabular}{|c|c|c|c|c|}
\hline & $\begin{array}{l}\frac{\pi}{8} \\
\frac{\pi}{2}\end{array}$ & $\stackrel{\circ}{\frac{\circ}{\alpha}}$ & 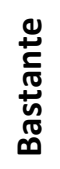 & $\begin{array}{l}\stackrel{\circ}{\mathrm{C}} \\
\stackrel{\mathrm{S}}{\mathrm{z}}\end{array}$ \\
\hline 1. Me siento calmado. & 0 & 1 & 2 & 3 \\
\hline 2. Me siento seguro. & 0 & 1 & 2 & 3 \\
\hline 3. Estoy tenso. & 0 & 1 & 2 & 3 \\
\hline 4. Estoy contrariado. & 0 & 1 & 2 & 3 \\
\hline 5. Me siento cómodo (estoy a gusto). & 0 & 1 & 2 & 3 \\
\hline 6. Me siento alterado. & 0 & 1 & 2 & 3 \\
\hline 7. Estoy preocupado ahora por posibles desgracias futuras. & 0 & 1 & 2 & 3 \\
\hline 8. Me siento descansado. & 0 & 1 & 2 & 3 \\
\hline 9. Me siento angustiado. & 0 & 1 & 2 & 3 \\
\hline 10. Me siento confortable. & 0 & 1 & 2 & 3 \\
\hline 11. Tengo confianza en mí mismo. & 0 & 1 & 2 & 3 \\
\hline 12. Me siento nervioso. & 0 & 1 & 2 & 3 \\
\hline 13. Estoy desasosegado (intranquilo). & 0 & 1 & 2 & 3 \\
\hline 14. Me siento muy "atado" (como oprimido). & 0 & 1 & 2 & 3 \\
\hline 15. Estoy relajado. & 0 & 1 & 2 & 3 \\
\hline 16. Me siento satisfecho. & 0 & 1 & 2 & 3 \\
\hline 17. Estoy preocupado. & 0 & 1 & 2 & 3 \\
\hline 18. Me siento aturdido y sobreexcitado. & 0 & 1 & 2 & 3 \\
\hline 19. Me siento alegre. & 0 & 1 & 2 & 3 \\
\hline 20. En este momento me siento bien. & 0 & 1 & 2 & 3 \\
\hline
\end{tabular}





\section{STAI-R}

\section{Instrucciones:}

A continuación encontrarás unas frases que se utilizan corrientemente para describirse uno a sí mismo. Lee cada frase y señala la puntuación de 0 a 3 que indique mejor CÓMO TE SIENTES EN GENERAL, en la mayoría de las ocasiones. No hay respuestas buenas ni malas. No emplees demasiado tiempo en cada frase y contesta señalando la respuesta que mejor describa cómo te sientes tú generalmente.

\begin{tabular}{|c|c|c|c|c|}
\hline & $\begin{array}{l}\frac{\pi}{0} \\
\frac{\pi}{2}\end{array}$ & $\stackrel{\circ}{\frac{0}{\alpha}}$ & 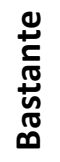 & $\frac{\circ}{\frac{\rho}{5}}$ \\
\hline 1. Me siento bien. & 0 & 1 & 2 & 3 \\
\hline 2. Me canso rápidamente. & 0 & 1 & 2 & 3 \\
\hline 3. Siento ganas de llorar. & 0 & 1 & 2 & 3 \\
\hline 4. Me gustaría ser tan feliz como otros. & 0 & 1 & 2 & 3 \\
\hline 5. Pierdo oportunidades por no decidirme pronto. & 0 & 1 & 2 & 3 \\
\hline 6. Me siento descansado. & 0 & 1 & 2 & 3 \\
\hline 7. Soy una persona tranquila, serena y sosegada. & 0 & 1 & 2 & 3 \\
\hline 8. Veo que las dificultades se amontonan y no puedo con ellas. & 0 & 1 & 2 & 3 \\
\hline 9. Me preocupo demasiado por cosas sin importancia. & 0 & 1 & 2 & 3 \\
\hline 10. Soy feliz. & 0 & 1 & 2 & 3 \\
\hline 11. Suelo tomar las cosas demasiado seriamente. & 0 & 1 & 2 & 3 \\
\hline 12. Me falta confianza en mí mismo. & 0 & 1 & 2 & 3 \\
\hline 13. Me siento seguro. & 0 & 1 & 2 & 3 \\
\hline 14. No puedo afrontar las crisis o dificultades. & 0 & 1 & 2 & 3 \\
\hline 15. Me siento triste (melancólico). & 0 & 1 & 2 & 3 \\
\hline 16. Estoy satisfecho. & 0 & 1 & 2 & 3 \\
\hline 17. Me rondan y molestan pensamientos sin importancia. & 0 & 1 & 2 & 3 \\
\hline 18. Me afectan tanto los engaños, que no puedo olvidarlos. & 0 & 1 & 2 & 3 \\
\hline 19. Soy una persona estable. & 0 & 1 & 2 & 3 \\
\hline $\begin{array}{l}\text { 20. Cuando pienso sobre asuntos y preocupaciones actuales, me } \\
\text { pongo tenso y agitado. }\end{array}$ & 0 & 1 & 2 & 3 \\
\hline
\end{tabular}





\section{ANEXO VI \\ Inventario de Depresión De Beck (BDI)}





\section{INVENTARIO DE DEPRESIÓN DE BECK (BDI).}

\section{Instrucciones:}

En este cuestionario aparecen varios grupos de afirmaciones. Por favor, lee con atención cada uno de ellos.

A continuación, señala la afirmación de cada grupo que describa mejor tus sentimientos durante la ÚLTIMA SEMANA, INCLUÍDO EL DÍA DE HOY. Rodea con un círculo el número que esté a la izquierda de la afirmación que hayas elegido.

Asegúrate de haber leído todas las afirmaciones dentro de cada grupo antes de hacer la elección.

(1) $\quad 0$ No me siento triste.

1 Me siento triste.

2 Me siento triste continuamente y no puedo dejar de estarlo.

3 Me siento tan triste o tan desgraciado/a que no puedo soportarlo.

(2) 0 No me siento especialmente desanimado/a de cara al futuro.

1 Me siento desanimado/a de cara al futuro.

2 Siento que no hay nada por lo que luchar.

3 El futuro es desesperanzador y las cosas no mejorarán.

(3) 0 No me siento como un fracasado/a.

1 He fracasado más que la mayoría de las personas.

2 Cuando miro hacia atrás, lo único que veo es un fracaso tras otro.

3 Soy un fracaso total como persona.

(4) 0 Las cosas me satisfacen tanto como antes.

1 No disfruto tanto de las cosas como antes.

2 Ya no tengo la misma satisfacción de las cosas.

3 Estoy insatisfecho/a o aburrido/a con respecto a todo.

(5) 0 No me siento especialmente culpable.

1 Me siento culpable en bastantes ocasiones.

2 Me siento culpable en la mayoría de las ocasiones.

3 Me siento culpable constantemente.

(6) 0 No creo que esté siendo castigado/a.

1 Siento que quizás esté siendo castigado/a.

2 Espero ser castigado/a.

3 Siento que estoy siendo castigado/a.

(7) 0 No estoy descontento/a de mí mismo/a.

1 Estoy descontento/a de mí mismo/a.

2 Estoy a disgusto conmigo mismo/a.

3 Me detesto. 
(8) $\quad 0$ No me considero peor que cualquier otro/a.

1 Me autocritico por mi debilidad o por mis errores.

2 Continuamente me culpo por mis faltas.

3 Me culpo por todo lo malo que sucede.

(9) 0 No tengo ningún pensamiento de suicidio.

1 A veces pienso en suicidarme, pero no lo haré.

2 Desearía poner fin a mi vida.

3 Me suicidaría si tuviese oportunidad.

(10) 0 No lloro más de lo normal.

1 Ahora lloro más que antes.

2 Lloro continuamente.

3 No puedo dejar de llorar aunque me lo proponga

(11) 0 No estoy especialmente irritado/a.

1 Me molesto o irrito más fácilmente que antes.

2 Me siento irritado/a continuamente.

3 Ahora ya no me irrita lo que antes me irritaba.

(12) 0 No he perdido el interés por los demás.

1 Estoy menos interesado/a en los demás que antes.

2 He perdido gran parte del interés por los demás.

3 He perdido todo interés por los demás.

(13) 0 Tomo mis propias decisiones igual que antes.

1 Evito tomar decisiones más que antes.

2 Tomar decisiones me resulta mucho más difícil que antes.

3 Me es imposible tomar decisiones.

(14) 0 No creo tener peor aspecto que antes.

1 Estoy preocupado/a porque parezco envejecido/a y poco atractivo/a.

2 Noto cambios constantes en mi aspecto físico que me hacen parecer poco atractivo/a.

3 Creo que tengo un aspecto horrible.

(15) 0 Trabajo igual que antes.

1 Me cuesta más esfuerzo de lo habitual comenzar a hacer algo.

2 Tengo que obligarme a mí mismo/a para hacer algo.

3 Soy incapaz de llevar a cabo ninguna tarea.

(16) 0 Duermo tan bien como siempre.

1 No duermo tan bien como antes.

2 Me despierto una o dos horas antes de lo habitual y me cuesta volverme a dormir.

3 Me despierto varias horas antes de lo habitual y ya no puedo volverme a dormir. 
(17) 0 No me siento más cansado/a de lo habitual.

1 Me canso más que antes.

2 Me canso en cuanto hago cualquier cosa.

3 Estoy demasiado cansado/a para hacer nada.

(18) $0 \mathrm{Mi}$ apetito no ha disminuido.

1 No tengo tan buen apetito como antes.

2 Ahora tengo mucho menos apetito.

3 He perdido completamente el apetito.

(19) 0 No he perdido peso últimamente.

1 He perdido más de dos quilos.

2 He perdido más de cuatro quilos.

3 He perdido más de siete quilos.

(20) 0 No estoy preocupado/a por mi salud.

1 Me preocupan los problemas físicos como dolores, malestar de estomago o los catarros.

2 Me preocupan las enfermedades y me resulta difícil pensar en otras cosas.

3 Estoy tan preocupado/a por las enfermedades que soy incapaz de pensar en otra cosa.

(21) 0 No he observado ningún cambio en mi interés por el sexo.

1 La relación sexual me atrae menos que antes.

2 Estoy mucho menos interesado/a por el sexo que antes.

3 He perdido totalmente el interés sexual. 

ANEXO VII

Escala de Estado de Ánimo 



\section{ESCALA DE ESTADO DE ÁNIMO}

(Ballester et al., 2005)

Código:

Por favor, indique en una escala de 0 a 10, hasta qué punto usted presenta ahora mismo:

\section{Malestar general}

\begin{tabular}{|l|l|l|l|l|l|l|l|l|l|l|}
\hline & & & & & & & & & & \\
\hline 0 & 1 & 2 & 3 & 4 & 5 & 6 & 7 & 8 & 9 & 10 \\
\hline
\end{tabular}

Nada

Muchísimo

Ansiedad y nerviosismo

\begin{tabular}{|l|l|l|l|l|l|l|l|l|l|l|}
\hline & & & & & & & & & & \\
\hline 0 & 1 & 2 & 3 & 4 & 5 & 6 & 7 & 8 & 9 & 10 \\
\hline
\end{tabular}

Nada

Muchísimo

Estado de ánimo deprimido

\begin{tabular}{|l|l|l|l|l|l|l|l|l|l|l|}
\hline & & & & & & & & & & \\
\hline 0 & 1 & 2 & 3 & 4 & 5 & 6 & 7 & 8 & 9 & 10 \\
\hline
\end{tabular}

Nada

Muchísimo 

ANEXO VIII

Valoración de la Estancia en UCI 



\section{CUESTIONARIO DE VALORACIÓN DE LA ESTANCIA EN UCI}

\section{VERSIÓN PARA EL PACIENTE}

(Ballester et al., 2005)

$\mathrm{N}^{\circ} \mathrm{H}^{\mathrm{a}}$ Clínica:

¿En que grado diría que su estancia en la UCl está siendo o ha sido agradable o desagradable, sin considerar los problemas derivados de su situación médica?

\begin{tabular}{|c|c|c|c|c|c|}
\hline $\begin{array}{c}\text { Muy } \\
\text { desagradable }\end{array}$ & $\begin{array}{c}\text { Bastante } \\
\text { desagradable }\end{array}$ & $\begin{array}{c}\text { Algo } \\
\text { desagradable }\end{array}$ & $\begin{array}{c}\text { Algo } \\
\text { agradable }\end{array}$ & $\begin{array}{c}\text { Bastante } \\
\text { agradable }\end{array}$ & $\begin{array}{c}\text { Muy } \\
\text { agradable }\end{array}$ \\
\hline & & & & & \\
\hline
\end{tabular}

¿Podría indicar cómo valora los siguientes aspectos de su estancia en la UCI?

\begin{tabular}{|c|c|c|c|c|c|c|}
\hline & $\begin{array}{l}\text { Muy } \\
\text { mal }\end{array}$ & $\begin{array}{c}\text { Bastante } \\
\text { mal }\end{array}$ & $\begin{array}{l}\text { Algo } \\
\text { mal }\end{array}$ & $\begin{array}{l}\text { Algo } \\
\text { bien }\end{array}$ & $\begin{array}{c}\text { Bastante } \\
\text { bien }\end{array}$ & $\begin{array}{l}\text { Muy } \\
\text { bien }\end{array}$ \\
\hline Los cuidados médicos & & & & & & \\
\hline La atención de los médicos & & & & & & \\
\hline La atención de los enfermeros/as & & & & & & \\
\hline $\begin{array}{l}\text { La atención de los/las auxiliares de } \\
\text { enfermería }\end{array}$ & & & & & & \\
\hline $\begin{array}{l}\text { La claridad de la información } \\
\text { recibida }\end{array}$ & & & & & & \\
\hline $\begin{array}{l}\text { La cantidad de la información } \\
\text { recibida }\end{array}$ & & & & & & \\
\hline $\begin{array}{l}\text { El trato por parte del personal de } \\
\text { enfermería }\end{array}$ & & & & & & \\
\hline $\begin{array}{l}\text { El afecto/apoyo emocional recibido } \\
\text { del personal de enfermería }\end{array}$ & & & & & & \\
\hline El respeto a la intimidad & & & & & & \\
\hline La atención a los familiares & & & & & & \\
\hline $\begin{array}{l}\text { La atención a las necesidades } \\
\text { psicológicas del paciente y familia }\end{array}$ & & & & & & \\
\hline $\begin{array}{l}\text { La calidad (comodidad, higiene...) } \\
\text { de las instalaciones }\end{array}$ & & & & & & \\
\hline Las posibilidades de distraerse & & & & & & \\
\hline El silencio o tranquilidad en la sala & & & & & & \\
\hline El régimen de visitas & & & & & & \\
\hline
\end{tabular}

Si desea hacer algún comentario o sugerencia que nos pueda ayudar a mejorar nuestra Unidad, por favor escríbalo a continuación: 



\title{
CUESTIONARIO DE VALORACIÓN DE LA ESTANCIA EN UCI
}

\author{
VERSIÓN PARA FAMILIARES
}

(Ballester et al., 2005)

$\mathrm{N}^{\circ} \mathrm{H}^{\mathrm{a}}$ Clínica:

Parentesco:

¿En que grado diría que la estancia de su familiar en la UCl está siendo o ha sido agradable o desagradable, sin considerar los problemas derivados de su situación médica?

\begin{tabular}{|c|c|c|c|c|c|}
\hline $\begin{array}{c}\text { Muy } \\
\text { desagradable }\end{array}$ & $\begin{array}{c}\text { Bastante } \\
\text { desagradable }\end{array}$ & $\begin{array}{c}\text { Algo } \\
\text { desagradable }\end{array}$ & $\begin{array}{c}\text { Algo } \\
\text { agradable }\end{array}$ & $\begin{array}{c}\text { Bastante } \\
\text { agradable }\end{array}$ & $\begin{array}{c}\text { Muy } \\
\text { agradable }\end{array}$ \\
\hline & & & & & \\
\hline
\end{tabular}

¿Podría indicar cómo valora los siguientes aspectos de la estancia de su familiar en la $\mathrm{UCl}$ ?

\begin{tabular}{|c|c|c|c|c|c|c|}
\hline & $\begin{array}{l}\text { Muy } \\
\text { mal }\end{array}$ & $\begin{array}{c}\text { Bastante } \\
\text { mal }\end{array}$ & $\begin{array}{l}\text { Algo } \\
\text { mal }\end{array}$ & $\begin{array}{l}\text { Algo } \\
\text { bien }\end{array}$ & $\begin{array}{c}\text { Bastante } \\
\text { bien }\end{array}$ & $\begin{array}{l}\text { Muy } \\
\text { bien }\end{array}$ \\
\hline \multicolumn{7}{|l|}{ Los cuidados médicos } \\
\hline \multicolumn{7}{|l|}{ La atención de los médicos } \\
\hline \multicolumn{7}{|l|}{ La atención de los enfermeros/as } \\
\hline \multicolumn{7}{|l|}{$\begin{array}{l}\text { La atención de los/las auxiliares de } \\
\text { enfermería }\end{array}$} \\
\hline \multicolumn{7}{|l|}{$\begin{array}{l}\text { La claridad de la información } \\
\text { recibida }\end{array}$} \\
\hline \multicolumn{7}{|l|}{$\begin{array}{l}\text { La cantidad de la información } \\
\text { recibida }\end{array}$} \\
\hline \multicolumn{7}{|l|}{$\begin{array}{l}\text { El trato por parte del personal de } \\
\text { enfermería }\end{array}$} \\
\hline \multicolumn{7}{|l|}{$\begin{array}{l}\text { El afecto/apoyo emocional recibido } \\
\text { del personal de enfermería }\end{array}$} \\
\hline \multicolumn{7}{|l|}{ El respeto a la intimidad } \\
\hline \multicolumn{7}{|l|}{ La atención a los familiares } \\
\hline \multicolumn{7}{|l|}{$\begin{array}{l}\text { La atención a las necesidades } \\
\text { psicológicas del paciente y familia }\end{array}$} \\
\hline \multicolumn{7}{|l|}{$\begin{array}{l}\text { La calidad (comodidad, higiene...) } \\
\text { de las instalaciones }\end{array}$} \\
\hline \multicolumn{7}{|l|}{ Las posibilidades de distraerse } \\
\hline \multicolumn{7}{|l|}{ El silencio o tranquilidad en la sala } \\
\hline El régimen de visitas & & & & & & \\
\hline
\end{tabular}

Si desea hacer algún comentario o sugerencia que nos pueda ayudar a mejorar nuestra Unidad, por favor escríbalo a continuación: 



\section{ANEXO IX-A}

Escala sobre Factores Estresantes en Pacientes Ingresados en UCI 



\section{ESCALA SOBRE FACTORES ESTRESANTES EN PACIENTES INGRESADOS EN UCI.}

(Adaptado por Ballester et al., 2005)

Código:

Indique con una cruz $(\mathrm{X})$ qué grado de estrés le producen cada una de los factores que a continuación se describen, teniendo en cuenta que todos ellos están relacionados con su ingreso en esta unidad de cuidados intensivos. Por favor, responda a todas las preguntas. Sólo deje sin contestar aquellas que hagan referencia a situaciones que durante su ingreso no haya vivido.

Gracias por su colaboración.

1.- No disponer de baño en el box para hacer sus necesidades con intimidad

\begin{tabular}{|l|l|l|l|l|}
\hline Nada & Algo & Bastante & Mucho & Muchísimo \\
\hline & & & & \\
\hline
\end{tabular}

2.- Tener que estar en la cama o en el sillón todo el día

\begin{tabular}{|l|l|l|l|l|}
\hline Nada & Algo & Bastante & Mucho & Muchísimo \\
\hline & & & & \\
\hline
\end{tabular}

3.- Estar hospitalizado lejos de casa

\begin{tabular}{|l|l|l|l|l|}
\hline Nada & Algo & Bastante & Mucho & Muchísimo \\
\hline & & & & \\
\hline
\end{tabular}

4.- Tener que dormir en una cama que no es la suya

\begin{tabular}{|l|l|l|l|l|}
\hline Nada & Algo & Bastante & Mucho & Muchísimo \\
\hline & & & & \\
\hline
\end{tabular}

5.- Tener que utilizar la cuña de cama

\begin{tabular}{|l|l|l|l|l|}
\hline Nada & Algo & Bastante & Mucho & Muchísimo \\
\hline & & & & \\
\hline
\end{tabular}

6.- Que no respondan al timbre de aviso

\begin{tabular}{|l|l|l|l|l|}
\hline Nada & Algo & Bastante & Mucho & Muchísimo \\
\hline & & & & \\
\hline
\end{tabular}

7.- Tener que dormir junto a otros enfermos con los que comparte la unidad

\begin{tabular}{|l|l|l|l|l|}
\hline Nada & Algo & Bastante & Mucho & Muchísimo \\
\hline & & & & \\
\hline
\end{tabular}

8.- Tener que ser ayudado para ir al baño

\begin{tabular}{|l|l|l|l|l|}
\hline Nada & Algo & Bastante & Mucho & Muchísimo \\
\hline & & & & \\
\hline
\end{tabular}


9.- Tener que comer en la cama en una postura incómoda

\begin{tabular}{|l|l|l|l|l|}
\hline Nada & Algo & Bastante & Mucho & Muchísimo \\
\hline & & & & \\
\hline
\end{tabular}

10.- Tener que estar ingresado en la unidad junto a otras personas gravemente enfermas

\begin{tabular}{|l|l|l|l|l|}
\hline Nada & Algo & Bastante & Mucho & Muchísimo \\
\hline & & & & \\
\hline
\end{tabular}

11.- Estar al cuidado de médicos, enfermeras y auxiliares que le son desconocidos

\begin{tabular}{|l|l|l|l|l|}
\hline Nada & Algo & Bastante & Mucho & Muchísimo \\
\hline & & & & \\
\hline
\end{tabular}

12.- Tener demasiadas visitas

\begin{tabular}{|l|l|l|l|l|}
\hline Nada & Algo & Bastante & Mucho & Muchísimo \\
\hline & & & & \\
\hline
\end{tabular}

13.- Tener que estar todo el tiempo desnudo, únicamente cubierto por una sábana

\begin{tabular}{|l|l|l|l|l|}
\hline Nada & Algo & Bastante & Mucho & Muchísimo \\
\hline & & & & \\
\hline
\end{tabular}

14.- Necesitar ayuda para comer

\begin{tabular}{|l|l|l|l|l|}
\hline Nada & Algo & Bastante & Mucho & Muchísimo \\
\hline & & & & \\
\hline
\end{tabular}

15.-No poder ver la TV, la radio o leer periódicos cuando uno quiere

\begin{tabular}{|l|l|l|l|l|}
\hline Nada & Algo & Bastante & Mucho & Muchísimo \\
\hline & & & & \\
\hline
\end{tabular}

16.- Escuchar ruidos de máquinas o de gente hablar constantemente

\begin{tabular}{|l|l|l|l|l|}
\hline Nada & Algo & Bastante & Mucho & Muchísimo \\
\hline & & & & \\
\hline
\end{tabular}

17.- Estar las luces todo el día encendidas

\begin{tabular}{|l|l|l|l|l|}
\hline Nada & Algo & Bastante & Mucho & Muchísimo \\
\hline & & & & \\
\hline
\end{tabular}

18.- No tener a los familiares y amigos acompañándole a lo largo del día

\begin{tabular}{|l|l|l|l|l|}
\hline Nada & Algo & Bastante & Mucho & Muchísimo \\
\hline & & & & \\
\hline
\end{tabular}

19.- Estar aislado en la habitación por prescripción médica

\begin{tabular}{|l|l|l|l|l|}
\hline Nada & Algo & Bastante & Mucho & Muchísimo \\
\hline & & & & \\
\hline
\end{tabular}


20.- Tener dolor

\begin{tabular}{|l|l|l|l|l|}
\hline Nada & Algo & Bastante & Mucho & Muchísimo \\
\hline & & & & \\
\hline
\end{tabular}

21.- No saber con seguridad o no entender en que consiste la enfermedad

\begin{tabular}{|l|l|l|l|l|}
\hline Nada & Algo & Bastante & Mucho & Muchísimo \\
\hline & & & & \\
\hline
\end{tabular}

22.- Pensar que le puede ocurrir algo grave

\begin{tabular}{|l|l|l|l|l|}
\hline Nada & Algo & Bastante & Mucho & Muchísimo \\
\hline & & & & \\
\hline
\end{tabular}

23.- Pensar si podrá volver a su vida normal después de salir del hospital

\begin{tabular}{|l|l|l|l|l|}
\hline Nada & Algo & Bastante & Mucho & Muchísimo \\
\hline & & & & \\
\hline
\end{tabular}

24.- No poder ocuparse de la familia como hasta ahora venía haciendo

\begin{tabular}{|l|l|l|l|l|}
\hline Nada & Algo & Bastante & Mucho & Muchísimo \\
\hline & & & & \\
\hline
\end{tabular}

25.- No saber con seguridad cómo se quedara después de la operación

\begin{tabular}{|l|l|l|l|l|}
\hline Nada & Algo & Bastante & Mucho & Muchísimo \\
\hline & & & & \\
\hline
\end{tabular}

26.- Estar separado de sus familiares más cercanos

\begin{tabular}{|l|l|l|l|l|}
\hline Nada & Algo & Bastante & Mucho & Muchísimo \\
\hline & & & & \\
\hline
\end{tabular}

27.- No saber cuando le darán el alta de la unidad de cuidados intensivos

\begin{tabular}{|l|l|l|l|l|}
\hline Nada & Algo & Bastante & Mucho & Muchísimo \\
\hline & & & & \\
\hline
\end{tabular}

28.- Haber sido hospitalizado de repente, sin esperarlo

\begin{tabular}{|l|l|l|l|l|}
\hline Nada & Algo & Bastante & Mucho & Muchísimo \\
\hline & & & & \\
\hline
\end{tabular}

29.- No saber los resultados o las razones de los tratamientos que le dan o de los análisis y pruebas que le hacen

\begin{tabular}{|l|l|l|l|l|}
\hline Nada & Algo & Bastante & Mucho & Muchísimo \\
\hline & & & & \\
\hline
\end{tabular}

30.-Pensar que puede tener dolor a causa de la operación, los análisis o las pruebas.

\begin{tabular}{|l|l|l|l|l|}
\hline Nada & Algo & Bastante & Mucho & Muchísimo \\
\hline & & & & \\
\hline
\end{tabular}


31.- No saber cuando van a hacerle cosas a uno

\begin{tabular}{|l|l|l|l|l|}
\hline Nada & Algo & Bastante & Mucho & Muchísimo \\
\hline & & & & \\
\hline
\end{tabular}

32.- No obtener alivio para el dolor aún tomando medicamentos para quitarlo

\begin{tabular}{|l|l|l|l|l|}
\hline Nada & Algo & Bastante & Mucho & Muchísimo \\
\hline & & & & \\
\hline
\end{tabular}

33.- Ver que el personal del hospital tiene prisa

\begin{tabular}{|l|l|l|l|l|}
\hline Nada & Algo & Bastante & Mucho & Muchísimo \\
\hline & & & & \\
\hline
\end{tabular}

34.- Que los médicos y las enfermeras hablen deprisa o usen palabras que no puede entender

\begin{tabular}{|l|l|l|l|l|}
\hline Nada & Algo & Bastante & Mucho & Muchísimo \\
\hline & & & & \\
\hline
\end{tabular}

35.- Que el personal sanitario no conteste a sus preguntas

\begin{tabular}{|l|l|l|l|l|}
\hline Nada & Algo & Bastante & Mucho & Muchísimo \\
\hline & & & & \\
\hline
\end{tabular}

36.- Que no le den la medicación para el dolor cuando lo necesita

\begin{tabular}{|l|l|l|l|l|}
\hline Nada & Algo & Bastante & Mucho & Muchísimo \\
\hline & & & & \\
\hline
\end{tabular}

37.- Pensar en la posible pérdida de dinero a causa de la enfermedad

\begin{tabular}{|l|l|l|l|l|}
\hline Nada & Algo & Bastante & Mucho & Muchísimo \\
\hline & & & & \\
\hline
\end{tabular}

38.- Sentir olores extraños en el hospital

\begin{tabular}{|l|l|l|l|l|}
\hline Nada & Algo & Bastante & Mucho & Muchísimo \\
\hline & & & & \\
\hline
\end{tabular}

39.- Tener que comer a horas diferentes de las habituales

\begin{tabular}{|l|l|l|l|l|}
\hline Nada & Algo & Bastante & Mucho & Muchísimo \\
\hline & & & & \\
\hline
\end{tabular}

40.- Su nivel de estrés en general durante el ingreso en la unidad de cuidados intensivos lo calificaría como de:

\begin{tabular}{|l|l|l|l|l|}
\hline Nada & Algo & Bastante & Mucho & Muchísimo \\
\hline & & & & \\
\hline
\end{tabular}




\section{ANEXO IX-B}

Escala sobre Factores Estresantes en los Familiares de Pacientes de UCI 



\section{ESCALA SOBRE FACTORES ESTRESANTES EN LOS FAMILIARES DE PACIENTES DE UCI}

(Adaptado por Ballester et al., 2005)

Código:

Indique con una cruz $(X)$ qué grado de estrés le produce cada uno de los factores que a continuación se describen, teniendo en cuenta que todos ellos están relacionados con el ingreso de su familiar en esta unidad de cuidados intensivos. Por favor, responda a todas las preguntas. Sólo deje sin contestar aquellas que hagan referencia a factores que en su caso no se hayan presentado.

Gracias por su colaboración.

1.-Que el enfermo pueda tener dolor

\begin{tabular}{|l|l|l|l|l|}
\hline Nada & Algo & Bastante & Mucho & Muchísimo \\
\hline & & & & \\
\hline
\end{tabular}

2.- No saber con seguridad o no entender en qué consiste su enfermedad

\begin{tabular}{|l|l|l|l|l|}
\hline Nada & Algo & Bastante & Mucho & Muchísimo \\
\hline & & & & \\
\hline
\end{tabular}

3.- Pensar que le puede ocurrir algo grave

\begin{tabular}{|l|l|l|l|l|}
\hline Nada & Algo & Bastante & Mucho & Muchísimo \\
\hline & & & & \\
\hline
\end{tabular}

4.- Pensar si podrá volver a su vida normal después de salir del hospital

\begin{tabular}{|l|l|l|l|l|}
\hline Nada & Algo & Bastante & Mucho & Muchísimo \\
\hline & & & & \\
\hline
\end{tabular}

5.- No poder ocuparse usted de la familia como hasta ahora venía haciendo

\begin{tabular}{|l|l|l|l|l|}
\hline Nada & Algo & Bastante & Mucho & Muchísimo \\
\hline & & & & \\
\hline
\end{tabular}

6.- No saber con seguridad cómo quedará después de la operación

\begin{tabular}{|l|l|l|l|l|}
\hline Nada & Algo & Bastante & Mucho & Muchísimo \\
\hline & & & & \\
\hline
\end{tabular}

7.- Estar separado del enfermo

\begin{tabular}{|l|l|l|l|l|}
\hline Nada & Algo & Bastante & Mucho & Muchísimo \\
\hline & & & & \\
\hline
\end{tabular}

8.- No saber cuándo le van a dar el alta de la unidad de cuidados intensivos

\begin{tabular}{|l|l|l|l|l|}
\hline Nada & Algo & Bastante & Mucho & Muchísimo \\
\hline & & & & \\
\hline
\end{tabular}

9.- Haber sido hospitalizado en esta unidad de repente, sin esperarlo

\begin{tabular}{|l|l|l|l|l|}
\hline Nada & Algo & Bastante & Mucho & Muchísimo \\
\hline & & & & \\
\hline
\end{tabular}


10.- No saber los resultados /razones de los tratamientos que le dan, o de las pruebas y análisis que le hacen

\begin{tabular}{|l|l|l|l|l|}
\hline Nada & Algo & Bastante & Mucho & Muchísimo \\
\hline & & & & \\
\hline
\end{tabular}

11.- Tener que organizarse para poder acudir a las visitas

\begin{tabular}{|l|l|l|l|l|}
\hline Nada & Algo & Bastante & Mucho & Muchísimo \\
\hline & & & & \\
\hline
\end{tabular}

12.- Pensar que puede tener dolor a causa de la operación o análisis

\begin{tabular}{|l|l|l|l|l|}
\hline Nada & Algo & Bastante & Mucho & Muchísimo \\
\hline & & & & \\
\hline
\end{tabular}

13.- No saber cuándo van a hacerle cosas al enfermo

\begin{tabular}{|l|l|l|l|l|}
\hline Nada & Algo & Bastante & Mucho & Muchísimo \\
\hline & & & & \\
\hline
\end{tabular}

14.- Pensar que el paciente pueda no obtener alivio para el dolor aún tomando medicamentos

\begin{tabular}{|l|l|l|l|l|}
\hline Nada & Algo & Bastante & Mucho & Muchísimo \\
\hline & & & & \\
\hline
\end{tabular}

15.- Ver que el personal del hospital tiene prisa

\begin{tabular}{|l|l|l|l|l|}
\hline Nada & Algo & Bastante & Mucho & Muchísimo \\
\hline & & & & \\
\hline
\end{tabular}

16.- El hospital en que está ingresado el paciente se encuentra lejos del domicilio familiar

\begin{tabular}{|l|l|l|l|l|}
\hline Nada & Algo & Bastante & Mucho & Muchísimo \\
\hline & & & & \\
\hline
\end{tabular}

17.- Que los médicos y enfermeras hablen deprisa o que usen palabras que no se pueden entender

\begin{tabular}{|l|l|l|l|l|}
\hline Nada & Algo & Bastante & Mucho & Muchísimo \\
\hline & & & & \\
\hline
\end{tabular}

18.- Que el personal sanitario no conteste a sus preguntas

\begin{tabular}{|l|l|l|l|l|}
\hline Nada & Algo & Bastante & Mucho & Muchísimo \\
\hline & & & & \\
\hline
\end{tabular}

19.- Tener que dormir fuera del domicilio habitual (p.e. en sala de estar para familiares en el hospital)

\begin{tabular}{|l|l|l|l|l|}
\hline Nada & Algo & Bastante & Mucho & Muchísimo \\
\hline & & & & \\
\hline
\end{tabular}

20.- Preocupación por que no le den la medicación para el dolor cuando la necesita

\begin{tabular}{|l|l|l|l|l|}
\hline Nada & Algo & Bastante & Mucho & Muchísimo \\
\hline & & & & \\
\hline
\end{tabular}


21.- Pensar en la posible pérdida de dinero a causa de la enfermedad

\begin{tabular}{|l|l|l|l|l|}
\hline Nada & Algo & Bastante & Mucho & Muchísimo \\
\hline & & & & \\
\hline
\end{tabular}

22.- Sentir olores extraños en el hospital

\begin{tabular}{|l|l|l|l|l|}
\hline Nada & Algo & Bastante & Mucho & Muchísimo \\
\hline & & & & \\
\hline
\end{tabular}

23.- Tener que comer a horas diferentes de las habituales para poder ir a las visitas

\begin{tabular}{|l|l|l|l|l|}
\hline Nada & Algo & Bastante & Mucho & Muchísimo \\
\hline & & & & \\
\hline
\end{tabular}

24.- No poder llamar al paciente por teléfono

\begin{tabular}{|l|l|l|l|l|}
\hline Nada & Algo & Bastante & Mucho & Muchísimo \\
\hline & & & & \\
\hline
\end{tabular}

25.- Que el enfermo esté al cuidado de médicos y personal de enfermería desconocido

\begin{tabular}{|l|l|l|l|l|}
\hline Nada & Algo & Bastante & Mucho & Muchísimo \\
\hline & & & & \\
\hline
\end{tabular}

26.- Tener demasiados horarios de visitas

\begin{tabular}{|l|l|l|l|l|}
\hline Nada & Algo & Bastante & Mucho & Muchísimo \\
\hline & & & & \\
\hline
\end{tabular}

27.- Tener que ver en la sala durante las visitas a otros enfermos muy graves

\begin{tabular}{|c|c|c|c|c|}
\hline Nada & Algo & Bastante & Mucho & Muchísimo \\
\hline & & & & \\
\hline
\end{tabular}

28.- Miedo a que el paciente pueda morir

\begin{tabular}{|l|l|l|l|l|}
\hline Nada & Algo & Bastante & Mucho & Muchísimo \\
\hline & & & & \\
\hline
\end{tabular}

29.- Que el paciente sea atendido por diferentes médicos durante su ingreso

\begin{tabular}{|l|l|l|l|l|}
\hline Nada & Algo & Bastante & Mucho & Muchísimo \\
\hline & & & & \\
\hline
\end{tabular}

30.- Que los familiares sean informados por diferentes médicos durante la estància del paciente en la unidad

\begin{tabular}{|l|l|l|l|l|}
\hline Nada & Algo & Bastante & Mucho & Muchísimo \\
\hline & & & & \\
\hline
\end{tabular}

31.- Esperar para entrar a las diferentes horas de visita

\begin{tabular}{|l|l|l|l|l|}
\hline Nada & Algo & Bastante & Mucho & Muchísimo \\
\hline & & & & \\
\hline
\end{tabular}


32.- No poder estar junto al enfermo todo el tiempo, al estar restringida la permanencia en la unidad al horario de las visitas

\begin{tabular}{|l|l|l|l|l|}
\hline Nada & Algo & Bastante & Mucho & Muchísimo \\
\hline & & & & \\
\hline
\end{tabular}

33.- Tener que desplazarse a diario para visitar al enfermo en las 4 horas de visitas que hay establecidas

\begin{tabular}{|l|l|l|l|l|}
\hline Nada & Algo & Bastante & Mucho & Muchísimo \\
\hline & & & & \\
\hline
\end{tabular}

34.- Los horarios en que están concertadas las visitas al enfermo en la unidad

\begin{tabular}{|l|l|l|l|l|}
\hline Nada & Algo & Bastante & Mucho & Muchísimo \\
\hline & & & & \\
\hline
\end{tabular}

35.- Que el enfermo permanezca solo durante todo el día junto a otros pacientes que están graves

\begin{tabular}{|l|l|l|l|l|}
\hline Nada & Algo & Bastante & Mucho & Muchísimo \\
\hline & & & & \\
\hline
\end{tabular}

36.- Que el paciente no descanse adecuadamente por el ruido de los aparatos, las horas de visita, o el ritmo de trabajo de la unidad

\begin{tabular}{|l|l|l|l|l|}
\hline Nada & Algo & Bastante & Mucho & Muchísimo \\
\hline & & & & \\
\hline
\end{tabular}

37.- Que el paciente manifieste temor

\begin{tabular}{|l|l|l|l|l|}
\hline Nada & Algo & Bastante & Mucho & Muchísimo \\
\hline & & & & \\
\hline
\end{tabular}

38.- Que el paciente tenga que permanecer aislado por prescripción médica

\begin{tabular}{|l|l|l|l|l|}
\hline Nada & Algo & Bastante & Mucho & Muchísimo \\
\hline & & & & \\
\hline
\end{tabular}

39.- Pensar que el tiempo de información para los familiares resulta insuficiente para la cantidad de dudas y preguntas que se plantean sobre el enfermo

\begin{tabular}{|l|l|l|l|l|}
\hline Nada & Algo & Bastante & Mucho & Muchísimo \\
\hline & & & & \\
\hline
\end{tabular}

40.- Su nivel de estrés en general durante el ingreso en la unidad de cuidados intensives lo calificaría como de:

\begin{tabular}{|l|l|l|l|l|}
\hline Nada & Algo & Bastante & Mucho & Muchísimo \\
\hline & & & & \\
\hline
\end{tabular}




\section{ANEXO X}

Cuestionario de Ayuda a Morir en paz (CAMP) 



\section{CUESTIONARIO DE AYUDA A MORIR EN PAZ (CAMP)}

(Bayés et al., 2000)

Edad:
Sexo:
V (varón)
$M$ (mujer)

La persona que responde este cuestionario es:

$\square$ Paciente

Familiar de un paciente ingresado

$\square$ Personal sanitario

Categoría profesional: $\square$ Médico

$\square$ Enfermera/o

$\square$ Aux. enfermería

$\square$ Personal no sanitario (secretaria, celadores y limpieza)

Por favor responda señalando con una cruz (X), a cada una de las siguientes preguntas:

En el caso de que se estuviera muriendo realmente ¿̇en qué medida cree que los siguientes aspectos podrían ayudarle a morir en paz?

A. Pensar que los médicos pueden controlar mi dolor y otros síntomas generadores de malestar

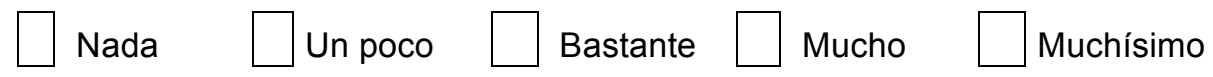

B. Pensar que mi proceso de morir, si me produce sufrimiento, será corto

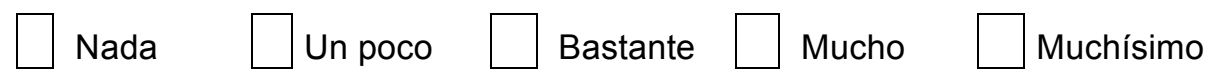

C. Pensar que podré controlar hasta el final mis pensamientos y funciones fisiológicas

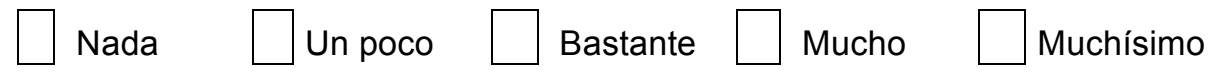

D. Pensar que mi muerte o mi desaparición no supondrán una carga insoportable (económica, afectiva o de otro tipo) para mis personas queridas

$\square$ Nada $\square$ Un poco $\square$ Bastante $\square$ Mucho $\square$ Muchísimo

E. Poder sentirme cerca, comunicarme y estrechar los vínculos afectivos con mis personas queridas

$\square$ Nada $\square$ Un poco $\square$ Bastante $\square$ Mucho $\square$ Muchísimo 
F. Pensar que, si no tengo una esperanza real de recuperación, no se prolongará artificialmente mi vida en una unidad de cuidados intensivos

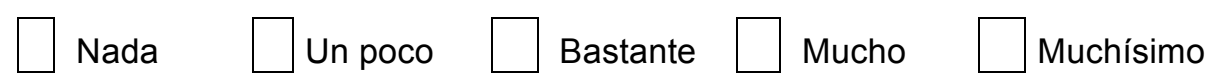

G. Pensar que mi vida ha tenido algún sentido

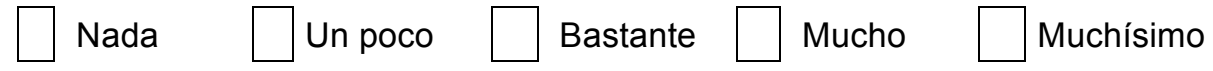

H. Creer en otra vida después de la muerte

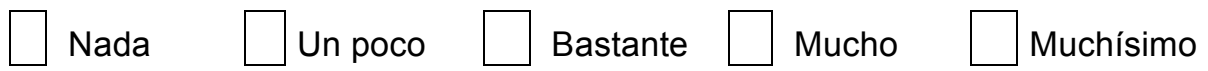

I. No sentirse culpable (o sentirme perdonado) por conflictos personales del pasado

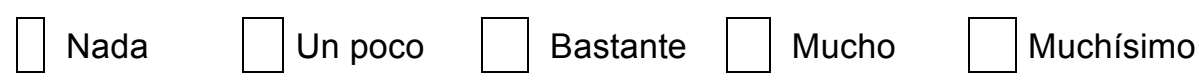

J. Pensar que si la situación se me hace insoportable podré disponer de ayuda para morir con rapidez

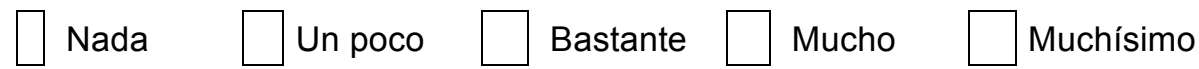

K. Pensar que podré morir en mi casa

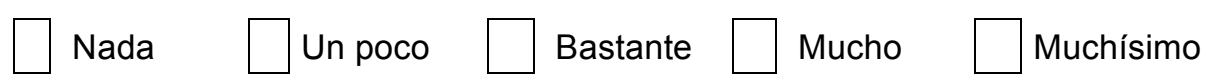

2) Si de los aspectos mencionados tuviera que elegir los dos que considera más importantes para ayudarle a morir en paz, ¿cuáles elegiría? Rodee, por favor, con un círculo las letras correspondientes a sólo dos de ellos:
A $B$
C
D E
F
G $\quad H$
K 


\section{ANEXO XI}

Cuestionario de Valoración del Proceso de Información y Toma de Decisiones (CITD) 



\section{CIDT}

\section{Cuestionario de Valoración del proceso de Información y toma de Decisiones en el ámbito hospitalario}

(Ballester et al., 2005)

Por favor, indíquenos en qué grado está de acuerdo con las siguientes afirmaciones y no deje ninguna sin contestar:

\begin{tabular}{|c|c|c|c|c|}
\hline & Nada & Algo & Bastante & Totalmente \\
\hline $\begin{array}{l}\text { 1. Los familiares deben ser informados } \\
\text { acerca de todo lo que se refiere al estado, } \\
\text { tratamiento y pronóstico del enfermo. }\end{array}$ & & & & \\
\hline $\begin{array}{l}\text { 2. Los enfermos deben ser informados } \\
\text { acerca de todo lo que se refiere al estado, } \\
\text { tratamiento y pronóstico de su enfermedad. }\end{array}$ & & & & \\
\hline $\begin{array}{l}\text { 3. Los familiares deben recibir información } \\
\text { antes que el mismo enfermo. }\end{array}$ & & & & \\
\hline $\begin{array}{l}\text { 4. Los enfermos deben recibir información } \\
\text { antes que los familiares. }\end{array}$ & & & & \\
\hline $\begin{array}{l}\text { 5. Los familiares y el enfermo deben recibir } \\
\text { información al mismo tiempo. }\end{array}$ & & & & \\
\hline $\begin{array}{l}\text { 6. Cuando las noticias son negativas, es la } \\
\text { familia la que debe transmitir la información } \\
\text { al enfermo y no el médico. }\end{array}$ & & & & \\
\hline $\begin{array}{l}\text { 7. Creo que he recibido suficiente } \\
\text { información acerca del estado, tratamiento } \\
\text { y pronóstico de la enfermedad. }\end{array}$ & & & & \\
\hline $\begin{array}{l}\text { 8. Los médicos me han dado la oportunidad } \\
\text { de aclarar todas mis dudas sobre el estado, } \\
\text { tratamiento y pronóstico del enfermo. }\end{array}$ & & & & \\
\hline $\begin{array}{l}\text { 9. En cuanto al estilo del médico a la hora de } \\
\text { informar, prefiero que éste sea directo y me } \\
\text { anticipe las posibles sospechas en relación a } \\
\text { la enfermedad. }\end{array}$ & & & & \\
\hline $\begin{array}{l}\text { 10. En cuanto al estilo del médico a la hora } \\
\text { de informar, prefiero que éste se guarde lo } \\
\text { que aún no es seguro. }\end{array}$ & & & & \\
\hline $\begin{array}{l}\text { 11. Los familiares deben tener la posibilidad } \\
\text { de participar en las decisiones médicas } \\
\text { respecto al tratamiento del paciente. }\end{array}$ & & & & \\
\hline $\begin{array}{l}\text { 12. Los enfermos deben tener la posibilidad } \\
\text { de participar en las decisiones médicas } \\
\text { respecto al tratamiento de su enfermedad. }\end{array}$ & & & & \\
\hline
\end{tabular}




\begin{tabular}{|c|c|c|c|c|}
\hline & Nada & Algo & Bastante & Totalmente \\
\hline \multicolumn{5}{|l|}{$\begin{array}{l}\text { 13. Me siento capacitado para participar en } \\
\text { la toma de decisiones que afecten a la salud } \\
\text { del enfermo. }\end{array}$} \\
\hline \multicolumn{5}{|l|}{$\begin{array}{l}\text { 14. En el caso de tener que tomar una } \\
\text { decisión relevante, me gustaría que el } \\
\text { médico pidiera su opinión al enfermo, es } \\
\text { decir, le hiciera participar en la decisión. }\end{array}$} \\
\hline \multicolumn{5}{|l|}{$\begin{array}{l}\text { 15. En el caso de tener que tomar una } \\
\text { decisión relevante, me gustaría que el } \\
\text { médico preguntara a los familiares, es decir, } \\
\text { les hiciera participar en la decisión. }\end{array}$} \\
\hline \multicolumn{5}{|l|}{$\begin{array}{l}\text { 16. Creo que la última palabra en la toma de } \\
\text { decisiones respecto al enfermo la debe } \\
\text { tener la familia. }\end{array}$} \\
\hline \multicolumn{5}{|l|}{$\begin{array}{l}\text { 17. Creo que la última palabra en la toma de } \\
\text { decisiones respecto al enfermo la debe } \\
\text { tener el mismo paciente. }\end{array}$} \\
\hline \multicolumn{5}{|l|}{$\begin{array}{l}\text { 18. Creo que la última palabra en la toma de } \\
\text { decisiones respecto al enfermo la debe } \\
\text { tener el médico. }\end{array}$} \\
\hline \multicolumn{5}{|l|}{$\begin{array}{l}\text { 19. En el caso de que las noticias fueran } \\
\text { negativas, también me gustaría saberlas. }\end{array}$} \\
\hline \multicolumn{5}{|l|}{$\begin{array}{l}\text { 20. En el caso de que las noticias fueran } \\
\text { negativas, se deberían ocultar al enfermo. }\end{array}$} \\
\hline \multicolumn{5}{|l|}{$\begin{array}{l}\text { 21. En el caso de que las noticias fueran } \\
\text { negativas, se deberían ocultar a la familia. }\end{array}$} \\
\hline \multicolumn{5}{|l|}{$\begin{array}{l}\text { 22. Para mí, poder participar en una } \\
\text { decisión médica sería más una carga que un } \\
\text { privilegio. }\end{array}$} \\
\hline \multicolumn{5}{|l|}{$\begin{array}{l}\text { 23. Si fuera a morir, me gustaría que me lo } \\
\text { dijeran con antelación. }\end{array}$} \\
\hline \multicolumn{5}{|l|}{$\begin{array}{l}\text { 24. Si fuera a morir, preferiría que me lo } \\
\text { dijera el médico. }\end{array}$} \\
\hline \multicolumn{5}{|l|}{$\begin{array}{l}\text { 25. Si fuera a morir, preferiría que me lo } \\
\text { dijera mi familia. }\end{array}$} \\
\hline $\begin{array}{l}\text { 26. Me ayudaría poder contar con la ayuda } \\
\text { de un psicólogo a la hora de afrontar una } \\
\text { mala noticia o tener que tomar una decisión } \\
\text { relevante. }\end{array}$ & & & & \\
\hline
\end{tabular}


ANEXO XII

Adaptación del Euro-Qol-5D 



\section{CUESTIONARIO DE CALIDAD DE VIDA RELACIONADA CON LA \\ SALUD: ADAPTACIÓN DEL EUROQOL-5D}

(García, Peres, De Cubber \& Vincent, 2003)

Código:

A) Señale con una cruz $(X)$ la situación que mejor describa su estado un mes antes de haber sido ingresado en el hospital, y la actual.

Antes

Ahora

Movilidad (M)

1. No tengo problemas para caminar

2. Tengo algunos problemas para caminar

3. Estoy encamado

Cuidado personal/Autonomía (A)

1. No tengo problemas para mis cuidados. Soy completamente autónomo

2. Tengo problemas para lavarme o vestirme por mi mismo

3. No puedo lavarme ni vestirme por mi mismo

Actividades habituales $(\mathrm{AH})$

1. No tengo problemas para llevar a cabo mis actividades habituales (por ejemplo trabajar, estudiar, hacer las tareas de casa...)

2. Tengo algunos problemas para llevar a cabo mis actividades habituales

3. No tengo posibilidad de llevar a cabo mis actividades habituales

Dolor/ malestar (DM)

1. No tengo dolor ni malestar

2. Tengo dolor o malestar moderado

3. Tengo dolor o malestar extremo

Ansiedad/ depresión (AD)

1. No estoy ansioso ni deprimido

2. Estoy moderadamente ansioso y deprimido

3. Estoy extremadamente ansioso y deprimido

Comparando mi nivel de salud en general un mes antes de ser hospitalizado, mi estado hoy es:

1. Mejor

2. Igual

3. Peor

B) Respecto a su situación laboral, señale con una cruz (X) su estado actual, y el estado anterior al ingreso en la Unidad de Cuidados Intensivos.

Previo al ingreso Actual

a. Retirado o incapacitado permanentemente

b. Temporalmente incapacitado

c. Trabajador a. Retirado o incapacitado permanentemente

b. Temporalmente incapacitado

c. Trabajador 



\section{ANEXO XIII}

\section{Escala de Inadaptación}





\section{ESCALA DE INADAPTACIÓN}

(E. Echeburúa y P. de Corral, 1987)

Nombre:

Fecha:

\section{TRABAJO}

A causa de mis problemas actuales, mi funcionamiento en el trabajo se ha visto afectado:

\begin{tabular}{|c|c|c|c|c|c|}
\hline 0 & 1 & 2 & 3 & 4 & 5 \\
\hline Nada & Casi nada & Poco & Bastante & Mucho & Muchísimo \\
\hline
\end{tabular}

\section{VIDA SOCIAL}

A causa de mis problemas actuales, mi vida habitual (relaciones de amistad con otras personas) se ha visto afectada:

\begin{tabular}{|c|c|c|c|c|c|}
\hline 0 & 1 & 2 & 3 & 4 & 5 \\
\hline Nada & Casi nada & Poco & Bastante & Mucho & Muchísimo \\
\hline
\end{tabular}

\section{TIEMPO LIBRE}

A causa de mis problemas actuales, mis actividades habituales en los ratos libres (salidas, cenas, excursiones, viajes, práctica deportiva...) se han visto afectadas:

\begin{tabular}{|c|c|c|c|c|c|}
\hline 0 & 1 & 2 & 3 & 4 & 5 \\
\hline Nada & Casi nada & Poco & Bastante & Mucho & Muchísimo \\
\hline
\end{tabular}

\section{RELACIÓN DE PAREJA}

A causa de mis problemas actuales, mi relación de pareja se ha visto afectada:

\begin{tabular}{|c|c|c|c|c|c|}
\hline 0 & 1 & 2 & 3 & 4 & 5 \\
\hline Nada & Casi nada & Poco & Bastante & Mucho & Muchísimo \\
\hline
\end{tabular}

\section{VIDA FAMILIAR}

A causa de mis problemas actuales, mi relación familiar en general se ha visto afectada:

\begin{tabular}{|c|c|c|c|c|c|}
\hline 0 & 1 & 2 & 3 & 4 & 5 \\
\hline Nada & Casi nada & Poco & Bastante & Mucho & Muchísimo \\
\hline
\end{tabular}

\section{ESCALA GLOBAL}

A causa de mis problemas actuales, mi vida normal en general se ha visto afectada:

\begin{tabular}{|c|c|c|c|c|c|}
\hline 0 & 1 & 2 & 3 & 4 & 5 \\
\hline Nada & Casi nada & Poco & Bastante & Mucho & Muchísimo \\
\hline
\end{tabular}





\section{ANEXO XIV}

\section{Cuestionario de Necesidades de los}

familiares de pacientes de cuidados intensivos (CCFNI): versión breve 



\section{CUESTIONARIO DE NECESIDADES DE LOS FAMILIARES DE PACIENTES DE CUIDADOS INTENSIVOS \\ (CCFNI) VERSIÓN BREVE \\ (Gómez, Ballester \& Gil, 2011)}

En el siguiente cuestionario se le van a hacer una serie de preguntas relacionadas con necesidades que puede presentar usted como familiar de un paciente ingresado en la Unidad de Cuidados Intensivos.

Para responder al cuestionario debe rodear con un círculo el número que se corresponda con la respuesta que usted daría a esa pregunta. Por favor, recuerde responder a todas las preguntas.

Gracias por su colaboración.

1.- ¿Usted siente que se le están dando los mejores cuidados posibles al paciente?
1. Casi todas las veces
2. La mayoría de veces
3. Sólo algunas veces
4. Nunca

2.- ¿Usted siente que el personal del hospital se preocupa por el paciente?
1. Casi todas las veces
2. La mayoría de veces
3. Sólo algunas veces
4. Nunca

3.- ¿Le dan explicaciones sobre el estado del paciente en términos que usted pueda comprender?
1. Casi todas las veces
2. La mayoría de veces
3. Sólo algunas veces
4. Nunca

4.- ¿Usted siente que le están dando información sincera respecto al estado y progreso del paciente?
1. Casi todas las veces
2. La mayoría de veces
3. Sólo algunas veces
4. Nunca

5.- ¿Usted comprende lo que le está sucediendo al paciente y por qué motivos le están haciendo cosas (pruebas, técnicas)?
1. Casi todas las veces
2. La mayoría de veces
3. Sólo algunas veces
4. Nunca

6.- ¿Están siendo los miembros del equipo atentos con usted?
1. Casi todas las veces
2. La mayoría de veces
3. Sólo algunas veces
4. Nunca

\section{7.- ¿Muestra algún miembro del equipo interés en cómo está usted?}
1. Casi todas las veces
2. La mayoría de veces
3. Sólo algunas veces
4. Nunca

8.- ¿ Le ha explicado el personal del hospital el equipamiento que está utilizándose?
1. Casi todas las veces
2. La mayoría de veces
3. Sólo algunas veces
4. Nunca

9.- Yo estoy muy satisfecho con las atenciones médicas recibidas por el paciente
1. Casi todas las veces
2. La mayoría de veces
3. Sólo algunas veces
4. Nunca

10.- ¿Usted se siente solo y aislado en la sala de espera?
1. Casi todas las veces
2. La mayoría de veces
3. Sólo algunas veces
4. Nunca

11.- ¿Hay algunas cosas respecto a los cuidados médicos recibidos por el paciente que podrían ser mejoradas?
1. Casi todas las veces
2. La mayoría de veces
3. Sólo algunas veces
4. Nunca 



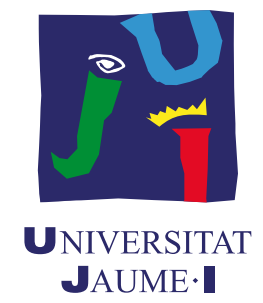

Facultad de Ciencias de la Salud Departamento de Psicología Básica, Clínica y Psicobiología 